Al treball "Rigat, M., Gras, A., Vallès, J. \& Garnatje, T. 2017. Estudis etnobotànics a la comarca del Ripollès (Pirineu, Catalunya, península Ibèrica). Collectanea Botanica 36: e003. https://doi.org/10.3989/ collectbot.2017.v36.003", els autors ens han fet notar que l'índex d'etnobotanicitat (IE) que hi donen per a la comarca del Ripollès és incorrecte. El valor correcte ha de ser 28,56\%, no 35,01\%. 


\title{
Estudis etnobotànics a la comarca del Ripollès (Pirineu, Catalunya, península Ibèrica)
}

\author{
M. RIGAT ${ }^{1, *}$, A. GRAS ${ }^{1, *}$, J. VALLÈS ${ }^{1} \&$ T. GARNATJE ${ }^{2}$ \\ ${ }^{1}$ Laboratori de Botànica - Unitat Associada CSIC, Facultat de Farmàcia i Ciències de l'Alimentació, Universitat de Barcelona, \\ av. Joan XXIII, s/n, ES-08028 Barcelona, Catalunya, Espanya \\ ${ }^{2}$ Institut Botànic de Barcelona (IBB-CSIC-ICUB), pg. del Migdia, s/n, Parc de Montjuïc, ES-08038 Barcelona, Catalunya, Espanya \\ *Les dues autores han contribuït per igual a la realització d'aquest treball
}

ORCID iD. M. RIGAT: http://orcid.org/0000-0001-8039-1889, A. GRAS: http://orcid.org/0000-0002-2256-3256, J. VALLÈS: http://orcid.org/0000-0002-1309-3942, T. GARNATJE: http://orcid.org/0000-0001-6295-6217

Autor per a correspondència: T. Garnatje (tgarnatje@ibb.csic.es)

Editor: J. López-Pujol

Rebut 29 desembre 2015; acceptat 28 juliol 2016; publicat on line 22 desembre 2017

\begin{abstract}
Ethnobotanical studies in the Ripollès district (Pyrenees, Catalonia, Iberian Peninsula). - This paper presents a synthesis of the ethnobotanical prospection performed in the Ripollès district between 2004 and 2013. Through semistructured interviews with 163 informants born between 1915 and 1988, we obtained information on popular names and uses of 457 taxa (including species, subspecies and varieties), 15 of which have only been determined at the genus level. About these plants, the informants have produced 7192 use reports. In this article we provide general comments on the different uses (medicinal, food and others) and we present, in two appendices, the complete catalogue of the district's ethnoflora.
\end{abstract}

Key words: ethnobotany; ethnoflora; plant names; plant uses; Pyrenees; Ripollès.

\section{Resumen}

Estudios etnobotánicos en la comarca del Ripollès (Pirineos, Cataluña, península ibérica).- Este trabajo presenta una síntesis de la prospección etnobotánica llevada a cabo en la comarca del Ripollès entre los años 2004 y 2013. Mediante entrevistas semiestructuradas con 163 informantes nacidos entre 1915 y 1988, hemos obtenido información sobre nombres y usos populares de 457 táxones (incluyendo especies, subespecies y variedades), 15 de los cuales solamente han sido determinados hasta el nivel de género. Sobre estas plantas, los informantes han referido 7192 reportes de uso. En este artículo incluimos comentarios generales sobre diversos usos (medicinales, alimentarios y de otro tipo) y presentamos, en dos apéndices, el catálogo completo de la etnoflora comarcal.

Palabras clave: etnobotánica; etnoflora; nombres de las plantas; Pirineos; Ripollès; usos de plantas.

\section{Resum}

Estudis etnobotànics a la comarca del Ripollès (Pirineu, Catalunya, Península Ibèrica).- Aquest treball presenta una síntesi de la prospecció etnobotànica duta a terme a la comarca del Ripollès entre els anys 2004 i 2013. A través d'entrevistes semiestructurades amb 163 informants nascuts entre 1915 i 1988, hem obtingut informació sobre noms i usos populars de 457 tàxons (comptant-hi espècies, subespècies i varietats), 15 dels quals només han estat determinats fins al nivell de gènere. Sobre aquestes plantes, els informants han fet 7192 reports d'ús. En aquest article fem comentaris generals sobre els diversos usos (medicinals, alimentaris i d'altra mena) i presentem, en dos apèndixs, el catàleg complet de l'etnoflora comarcal.

Paraules clau: etnobotànica; etnoflora; noms de plantes; Pirineu; Ripollès; usos de plantes. 
Cómo citar este artículo / Citation

Rigat, M., Gras, A., Vallès, J. \& Garnatje, T. 2017. Estudis etnobotànics a la comarca del Ripollès (Pirineu, Catalunya, península Ibèrica). Collectanea Botanica 36: e003. doi: http://dx.doi.org/10.3989/collectbot.2017.v36.003

\section{Copyright}

(C) 2017 CSIC. Este es un artículo de acceso abierto distribuido bajo los términos de la licencia Creative Commons Attribution License (CC BY) Spain 3.0.

\section{INTRODUCCIÓ}

\section{Territori estudiat}

La comarca del Ripollès és situada al vessant sud del Pirineu oriental i té una extensió de 956,6 km². Limita al nord amb les comarques de la Cerdanya, el Vallespir i el Conflent, i al sud amb les d'Osona, la Garrotxa i el Berguedà. Inclou 19 municipis (Fig. 1) amb un total de 25.700 habitants i una densitat de 26,9 hab. $/ \mathrm{km}^{2}$ (IDESCAT, 2014). Les modalitats de poblament comprenen tant viles grans (com ara Ripoll, Sant Joan de les Abadesses, Campdevànol i Camprodon) com pobles petits, sense negligir l'existència de masos aillats. Els municipis de la comarca tenen 113 nuclis poblacionals, alguns dels quals avui en dia gairebé o totalment despoblats (Taula 1).

La comarca s'estructura en tres àrees geogràfiques, que poden ser considerades subcomarques:
l'Alta Vall del Ter (anomenada també Vall de Camprodon), l'Alta Vall del Freser (també coneguda com a Vall de Ribes) i el Baix Ripollès. La part nord de la comarca és una àrea d'alta muntanya formada per les dues primeres àrees, les valls del Ter i del Freser, i la part sud és ocupada per la tercera, que significa la confluència de les valls dels rius abans esmentats en una zona més plana $\mathrm{i}$ de menor altitud. Aquests dos rius marquen el relleu de la comarca, que es troba formada per les seves dues grans valls i els seus nombrosos afluents, que conformen una xarxa hidrogràfica molt rica i intensa. Les capçaleres estan formades pels cims pirinencs que atenyen gairebé 3000 metres, marquen la separació entre les comarques de Catalunya sud i nord i formen part del Pirineu axial (ICGC, 2015). L'altitud de les muntanyes va disminuint cap al sud, on els cims són més baixos i formen les serralades prepirinenques. Aquesta orografia dóna lloc a valls profundes i històricament mal comunicades entre

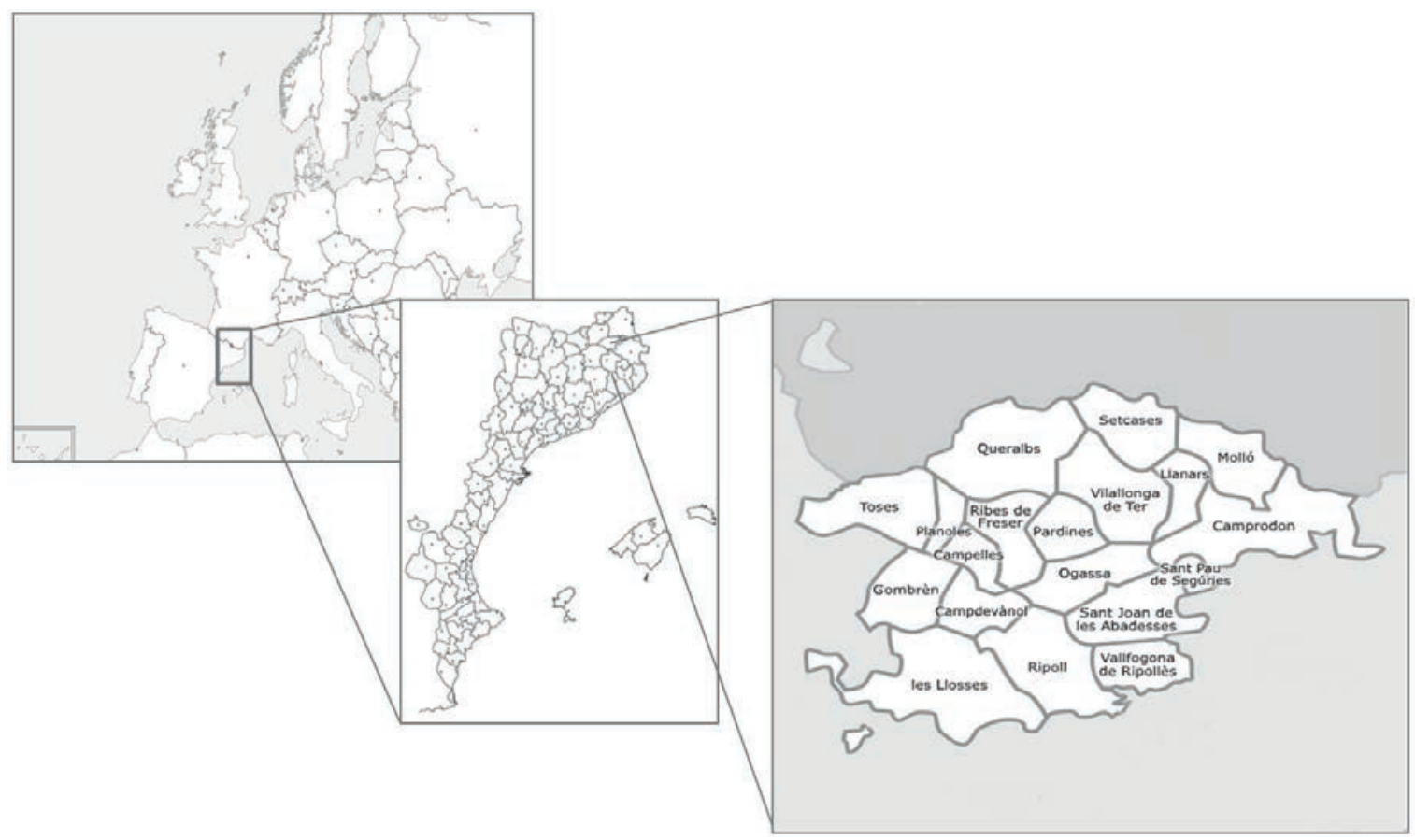

Figura 1. Situació geogràfica de la comarca del Ripollès a Catalunya i a la península Ibèrica. 
Taula 1. Nom dels municipis estudiats, superfície, població, altitud (IDESCAT, 2014) i nuclis poblacionals que els componen.

\begin{tabular}{|c|c|c|c|c|}
\hline Municipi & Superfície $\left(\mathrm{km}^{2}\right)$ & Població & Altitud (m) & Nuclis poblacionals $^{1}$ \\
\hline Campdevànol & 32,6 & 3395 & 738 & $\begin{array}{l}\text { La Creu, l'Herand, Sant Cristòfol, Sant Llorenç de } \\
\text { Campdevànol, Sant Martí d'Armàncies, Sant Pere } \\
\text { d'Aüira, Sant Quintí de Puigrodon }\end{array}$ \\
\hline Campelles & 18,6 & 132 & 1303 & El Baell \\
\hline Camprodon & 103,4 & 2359 & 947 & $\begin{array}{l}\text { Bolòs, Cavallera, la Colònia Estebanell, Creixenturri, } \\
\text { Freixenet, Beget, Bestrecà, el Riberal, Rocabruna, Salarça }\end{array}$ \\
\hline Gombrèn & 43,3 & 195 & 919 & Aranyonet, el Cortal, Montgrony \\
\hline Llanars & 24,7 & 509 & 983 & $\begin{array}{l}\text { Espinalba, Feitús, el Llanarès, el Riberal de Feitús, les } \\
\text { Planes de Llanars }\end{array}$ \\
\hline Les Llosses & 114 & 211 & 1000 & $\begin{array}{l}\text { La Farga de Bebiè, Sant Esteve de Vallespirans, Sant } \\
\text { Martí de Vinyoles, Sant Sadurní de Sovelles, Santa Maria } \\
\text { de Matamala, Viladonja, Palmerola }\end{array}$ \\
\hline Molló & 43,1 & 339 & 1182 & $\begin{array}{l}\text { Can Solà, Espinavell, Favars, Fabert, Ginestosa, Grells, } \\
\text { Moixons, el Riberal }\end{array}$ \\
\hline Ogassa & 45,2 & 245 & 951 & $\begin{array}{l}\text { Sant Julià de Saltor, Sant Martí d'Ogassa, Sant Martí de } \\
\text { Surroca, Ca l'Enric, les Costes, Prat del Pinter, el Taller }\end{array}$ \\
\hline Pardines & 31 & 155 & 1226 & Llavanera, l'Orri, Puigsac, Pujalt, Vilaró \\
\hline Planoles & 18,8 & 300 & 1136 & $\begin{array}{l}\text { Aspre, les Casetes, Can Fosses, Can Croells i el Serrat, el } \\
\text { Molí, Planès, el Puig }\end{array}$ \\
\hline Queralbs & 93,5 & 182 & 1236 & La Farga, Fustanyà, Núria, Rialb, Serrat, Vilamanya \\
\hline Ribes de Freser & 41,9 & 1859 & 912 & Armàncies, Batet, Bruguera, Ribesaltes, el Solà i Ventolà \\
\hline Ripoll & 73,7 & 10751 & 691 & $\begin{array}{l}\text { Els Brucs, la Colònia de Santa Maria, Llaés, Ordina, } \\
\text { Rama, el Remei, Rocafiguera, Sant Antoni, Sant } \\
\text { Bartomeu, Sant Bernabé de les Tenes, Sant Roc }\end{array}$ \\
\hline $\begin{array}{l}\text { Sant Joan de les } \\
\text { Abadesses }\end{array}$ & 53,7 & 3413 & 773 & $\begin{array}{l}\text { Baga Amunt, Baga Avall, Can Martí Toralles, la Colònia } \\
\text { Jordana, la Colònia Llaudet, Comafreda, Solei Amunt, } \\
\text { Solei Avall }\end{array}$ \\
\hline Sant Pau de Segúries & 8,7 & 674 & 867 & La Ral \\
\hline Setcases & 49,1 & 195 & 1265 & Pastuira, Pla dels Hospitalets \\
\hline Toses & 57,9 & 150 & 1444 & Dòrria, Espinosa, Fornells de la Muntanya, Nevà \\
\hline $\begin{array}{l}\text { Vallfogona de } \\
\text { Ripollès }\end{array}$ & 39,2 & 215 & 956 & $\begin{array}{l}\text { La Baga Avall, les Domes, Puigsec, Solana Amunt, } \\
\text { Solana Avall, la Taverna }\end{array}$ \\
\hline Vilallonga de Ter & 64,2 & 421 & 1067 & $\begin{array}{l}\text { Abella, el Catllar, el Cros, Llebro, la Roca, Tregurà de } \\
\text { Baix, Tregurà de Dalt, veïnat de Vallvigil, veïnat del } \\
\text { Comalet }\end{array}$ \\
\hline
\end{tabular}

${ }^{1} \operatorname{IDESCAT}(2011)$

elles, fet que ha dotat els seus habitants d'una manera de ser, una personalitat i uns costums propis, deguts a l'aïllament geogràfic relatiu, sens dubte trencat amb fenòmens com la transhumància o el comerç ambulant de les trementinaires, entre d'altres.

Malgrat que el clima de la comarca s'inclogui dins de l'anomenat mediterrani, la influència directa del mar es va perdent a mesura que es va guanyant altitud i el clima propi de la muntanya mitjana dóna pas a un d'alta muntanya pròpiament dit. Les zones baixes, especialment les que limiten amb la Garrotxa, reben les masses d'aire humit procedents del mar, que suavitzen la continentalitat del clima. Els valors de precipitació es distribueixen de manera irregular a la comarca, tant pel que fa a les diferents zones com pel que fa a les èpoques de l'any. En les parts més altes, la precipitació mitjana anual és de l'ordre de $1200 \mathrm{~mm}$, mentre que a les zones baixes, vora de la capital de la comarca, no superen 
els $1000 \mathrm{~mm}$, a causa d'un fenomen conegut com ombra pluviomètrica (els cims que voregen una vall impedeixen l'entrada de les masses d'aire humit). La zona més plujosa és la més oriental i la quantitat de precipitació disminueix cap al sud. Pel que fa a les temperatures, també observem diferències importants entre les parts altes i baixes de la comarca, però cal remarcar que a tot el territori els hiverns són freds i els estius temperats, malgrat que les temperatures diürnes puguin ser elevades.

El Ripollès presenta una gran variació altitudinal, des dels $400 \mathrm{~m}$ de la riera de Beget fins als gairebé $3000 \mathrm{~m}$ del Puigmal (Ortiz, 2004). Aquesta gran diferència d'altituds comporta que la comarca presenti diversos estatges de vegetació. De dalt a baix, hi trobem l'estatge alpí, que baixa fins els $2300 \mathrm{~m}$ aproximadament $\mathrm{i}$ que es caracteritza fonamentalment per una vegetació herbàcia que constitueix els prats alpins. En general són formacions dominades per espècies perennes i de cicle curt. A més d'aquests prats, en aquest estatge hi trobem la vegetació típica de pedruscalls i tarteres, sovint relacionada amb zones de forta innivació. Per sota dels $2300 \mathrm{~m}$ i fins als $1600 \mathrm{~m}$ hi trobem l'estatge subalpí, caracteritzat a la comarca del Ripollès per les pinedes de pi negre [Pinus mugo Turra subsp. uncinata (Ramond ex DC. in Lam. et DC.) Domin] amb neret (Rhododendron ferrugineum L.) i les avetoses d'Abies alba Mill. ocupant les obagues i sovint acompanyat d'alguns caducifolis com el faig (Fagus sylvatica L.) i el bedoll (Betula pendula Roth).

L'estatge montà ocupa una franja per sota de l'estatge subalpí i s'estén entre els 1600 i els $400 \mathrm{~m}$. Hi sovintegen les pinedes de pi roig (Pinus sylvestris L.), les fagedes i les rouredes. El pi roig forma, en alguns indrets, un bosc ben constituït mentre que en altres zones forma masses forestals secundàries. La fageda es desenvolupa en indrets humits, fondalades $i$ algunes torrenteres. La roureda de roure pènol (Quercus robur L.) colonitza els vessants humits, mentre que la roureda de roure de fulla gran [Quercus petraea (Matt.) Liebl.] és de caire més atlàntic i la roureda de roure martinenc (Quercus pubescens Willd.) ocupa els solells de zones d'hivern fred. Podem destacar també, en aquest estatge, el bosc de ribera, format per verns [Alnus glutinosa (L.) Gaertn.], pollancres (Populus spp.) i salzes (Salix spp.).

En referència al paisatge vegetal, cal mencionar que, com altres àrees de muntanya, el Ripollès ha sofert un progressiu abandó de les terres conreades, a causa de la dificultat d'accés, de l'elevat cost de la mecanització i del relativament baix rendiment, a més de la necessitat de disposició de sòl urbanitzable. Això ha fet que antigues terres agrícoles hagin esdevingut pastures o, sovint, hagin estat recolonitzades per boscs, naturals o amb l'ajut de reforestació (Pla Comarcal de Muntanya, 1995-1999). Els paisatges que hem descrit succintament són poblats per una flora que, segons estimacions del botànic $\mathrm{J}$. Vigo (com. pers.), consta d'uns 700-1800 tàxons.

\section{Activitat econòmica}

El sector primari és molt important a la comarca del Ripollès. A causa de l'orografia del terreny, poc apte per a l'agricultura, la ramaderia, sovint transhumant, constitueix un element clau de l'activitat econòmica. L'agricultura queda reduïda a petites explotacions, sovint destinades al consum familiar. En aquest sentit, hem de destacar la importància, no tant econòmica com tradicional, dels horts familiars, malgrat que constitueixin una part molt reduïda de l'economia del sector (Rigat et al., 2009). La major part del sòl agrícola — i no només d'aquest - es destina a les pastures.

Pel que fa a la indústria, cal destacar l'explotació de recursos del subsòl, històricament important, però actualment inexistent. Durant molts anys la indústria metal·lúrgica ha estat una de les més importants, juntament amb la indústria tèxtil, totes dues molt presents al Baix Ripollès. Actualment, les indústries d'aquesta mena han estat substituïdes per d'altres de caire agroalimentari.

Malgrat les formes de producció esmentades, a hores d'ara, en tot cas, el principal motor econòmic de la comarca és el turisme, bàsicament atret pels paisatges de muntanya, tant en èpoques hivernals per l'esquí i altres activitats vinculades a la neu com durant la resta de l'any per l'excursionisme, turisme rural, cultural i gastronòmic.

\section{Treballs etnobotànics previs i objectius}

La comarca del Ripollès és una de les zones de Catalunya - i del Pirineu - amb un volum més important d'informació florística (Aymerich et al., 2010-2011). Pel que fa als estudis etnobotànics, l'activitat ha estat força més escassa. A part dels treballs parcials (des d'un punt de vista geogràfic) 
o sectorials (sobre tipus d'usos concrets) fets en el marc de les recerques que sintetitzem aquí (vegeu Rigat, 2005; Rigat et al., 2006, 2007, 2009, 2013a, $b, 2015,2016$; Carrió et al., 2012), podem mencionar, de temps antics, que la flòrula de la Vall de Núria (Vayreda, 1881) conté algunes informacions sobre noms populars i també sobre l'ús d'algunes de les plantes que cita. A part d'això, els treballs d'ampli abast de caire etnobotànic que comprenguin el Ripollès es redueixen a una recerca etnobotànica de la veïna Alta Garrotxa, que inclou alguns informants del Ripollès (Llongarriu \& Sala, 2005) i a l'obra de M. D. Escalé i Parramon Herbes remeieres de Queralbs i de Núria (Escalé, 2013), que recull les receptes de la seva mare, resident a Queralbs però originària de la Vansa (Alt Urgell). A la seva Flora de la Vall de Ribes, l'esmentat J. Vigo, originari d'aquest territori, recull alguns noms populars de plantes (Vigo, 1983). Altres treballs, no pas menys importants, però d'abast més reduït, que contenen recerques etnobotàniques dutes a terme al territori considerat són els de Serna \& Vila (2007), Díaz (2009) i Pastoret (2009).

Els escassos antecedents indicaven que una prospecció etnobotànica completa de la comarca era per fer i tenia interès. A més, l'estudi d'aquesta comarca completava el coneixement, ja força avançat en treballs anteriors, del Pirineu català (llevat a la part on s'hi parla occità, la Vall d'Aran, on només hi ha encara un coneixement incipient) (Vallès et al., 2007, 2015).

En conseqüència amb això, els objectius d'aquest treball han estat els següents: (1) recollir dades sobre els noms, els usos, el maneig i coneixements populars de les plantes a la comarca del Ripollès; (2) elaborar un catàleg etnoflorístic de la comarca; (3) analitzar i discutir les dades per a poder valorar la rellevància i la pervivència del coneixement tradicional a la zona i poder avaluar l'interès de les dades obtingudes, sobretot en els usos medicinals i alimentaris de les plantes i (4) analitzar i avaluar la quantitat de dades generades en aquesta comarca, en relació a d'altres territoris similars.

\section{MATERIAL I MÈTODES}

\section{Municipis estudiats}

Es varen fer entrevistes a tots els municipis de la comarca, intentant tenir-hi representat el màxim nombre possible de nuclis poblacionals, de manera que es cobrís tot el territori comarcal. Les característiques d'aquests municipis es troben a la Taula 1. Alguns nuclis poblacionals no es varen mostrejar a causa de la manca de població estable o del perfil dels seus habitants, sovint nouvinguts o de segones residències.

\section{Entrevista etnobotànica}

El mètode utilitzat es basa en l'entrevista etnobotànica semiestructurada (Pujadas et al., 2004; Vallès et al., 2007) individual o col-lectiva i l'elecció dels informants es va dur a terme pel mètode de bola de neu (Goodman, 1961; Bernard, 1998). Per a l'obtenció de la informació sobre el coneixement popular de les plantes hem conversat amb 163 persones durant 104 entrevistes, algunes de les quals col-lectives, dutes a terme a tots els municipis. La Taula 2 recull els municipis prospectats, el nombre d'entrevistes que s'hi van realitzar i el nombre d'informants que hi van participar.

El treball de camp va respectar els principis ètics de la Societat Internacional d'Etnobiologia (International Society of Ethnobiology, 2008) i va comptar amb el consentiment informat previ dels informants (Rosenthal, 2006). Les entrevistes varen ser enregistrades, igualment amb el corresponent permís. Després van ser transcrites i totes les informacions obtingudes es van entrar a la base de dades del nostre grup de recerca (http://www.etnobotanica.cat); més tard van ser analitzades amb els programes Excel (Microsoft Excel 2007) i XLSTAT (v2007.5, Addinsoft SARL).

\section{Material vegetal}

De totes les mostres que ho han permès s'han preparat plecs d'herbari que, un cop convenientment etiquetats, han estat dipositats a l'herbari BCN, del Centre de Documentació de Biodiversitat Vegetal de la Universitat de Barcelona o a l'herbari $\mathrm{BC}$, de l'Institut Botànic de Barcelona (IBB-CSIC-ICUB). La majoria de materials que no han pogut ser transformats en plecs d'herbari (mostres de plantes trossejades, objectes elaborats amb plantes...) han estat dipositats al primer dels dos herbaris esmentats, en el qual es va crear recentment una subcol-lecció (BCN-E) per a aquesta mena de mostres. Al catàleg etnoflorístic que constitueix l'Apèndix $1 \mathrm{~s}$ 'indiquen els codis i números de plec d'herbari de cada tàxon, que no es repeteixen al catàleg de barreges que conforma l'Apèndix 2. 
Taula 2. Municipis estudiats, nombre d'entrevistes i nombre de persones entrevistades per municipi.

\begin{tabular}{|l|c|c|}
\hline Municipi & Nombre d'entrevistes realitzades & Nombre de persones entrevistades \\
\hline Campdevànol & 4 & 4 \\
\hline Campelles & 1 & 2 \\
\hline Camprodon & 26 & 1 \\
\hline Gombrèn & 1 & 13 \\
\hline Llanars & 8 & 7 \\
\hline Les Llosses & 4 & 8 \\
\hline Molló & 5 & 3 \\
\hline Ogassa & 2 & 9 \\
\hline Pardines & 3 & 2 \\
\hline Planoles & 1 & 8 \\
\hline Queralbs & 5 & 16 \\
\hline Ribes de Freser & 8 & 4 \\
\hline Ripoll & 2 & 18 \\
\hline Sant Joan de les Abadesses & 10 & 6 \\
\hline Sant Pau de Segúries & 5 & \\
\hline Setcases & 5 & 7 \\
\hline Toses & 5 & 8 \\
\hline Vallfogona de Ripollès & 2 & 3 \\
\hline Vilallonga de Ter & 7 & \\
\hline & & \\
\hline
\end{tabular}

Els tàxons de plantes s'han identificat i determinat bàsicament amb la Flora Manual dels $\mathrm{Pa}$ ïsos Catalans (Bolòs et al., 2005), la taxonomia i la nomenclatura de la qual s'ha seguit de manera regular. Per a plantes no contingudes en aquesta flora (sobretot ornamentals i alguna d'altra mena), s'ha seguit Kindersley $(1999,2003)$ i Burnie et al. (2003). No obstant, l'assignació de cada tàxon a una família botànica s'ha fet seguint els criteris del Grup de Filogènia de les Angiospermes (APG III, 2009).

\section{Etnobotànica quantitativa}

Per a l'anàlisi de les dades obtingudes, hem dut a terme alguns càlculs per tal de poder quantificar alguns aspectes, des del nombre de tàxons, reports d'ús i noms populars recollits, fins a les proporcions de parts de plantes usades i els modes de preparació del material vegetal per al seu ús.

Hem obtingut el valor de l'índex d'etnobotanicitat (Portères, 1970), que consisteix en la relació entre el nombre d'espècies usades en un territori i el nombre total d'espècies que en constitueixen la flora, expressat en percentatge, i que indica la proporció de tàxons existents en un territori sobre els quals es té algun coneixement popular. De manera similar, hem obtingut també l'índex d'etnofitonímia (Bonet et al., 1999), dividint el nombre de plantes d'un territori per a les quals s'ha localitzat algun fitònim pel nombre d'espècies de la seva flora (i multiplicant la xifra obtinguda per 100 per a donar el resultat en percentatge) per a expressar la proporció de plantes de la flora d'un indret que reben nom popular. Encara en el camp fitonímic, hem buscat un segon valor, el de l'índex de diversitat lingüística en la fitonímia, dividint el nombre de fitònims pel de tàxons referits pels informants, $\mathrm{i}$ que expressa la riquesa lingüística en les denominacions dels vegetals d'una zona, independentment de la grandària de la seva flora.

A més, hem calculat alguns índexs que permeten considerar el grau de coherència dels usos reportats pels nostres informants i, doncs, llur fiabilitat. En primer lloc, hem identificat i comptat els tàxons amb tres o més reports d'ús; aquests són, segons Le Grand \& Wondergem (1987) i Johns et al. (1990), els que podrien ser més prometedors de cares a emprendre recerques encaminades a la producció i la possible comercialització de nous productes 
(medicinals, alimentaris o d'altra mena) d'interès general. Segonament, hem calculat (en general i per a plantes medicinals i alimentàries en particular) el factor de consens d'informants $\left(F_{\text {IC }}\right.$; Trotter \& Logan, 1986). Aquest índex, consistent en el quocient entre el nombre de reports d'ús menys el nombre de tàxons als quals aquestes reports pertanyen i el nombre de reports d'ús menys 1 , es considera un bon indicador de la coincidència o coherència dels informants d'una àrea determinada respecte del maneig de la biodiversitat (vegetal en aquest cas), la qual cosa, al seu torn, dóna idea de la fiabilitat d'aquestes dades. Com més s'acosti aquest índex a la unitat, és a dir com més els informants coincideixin a referir un mateix determinat ús per a una mateixa determinada planta, més coherent i fiable serà el corpus de coneixement que refereixin.

\section{RESULTATS I DISCUSSIÓ}

\section{Població entrevistada: els informants}

Els informants d'aquest treball van néixer entre 1915 i 1988. Entre ells, hi ha 68 homes (42\%) i 95 dones $(58 \%)$. Aquesta prevalença del gènere femení és força comuna en els estudis etnobotànics duts a terme a Catalunya (Parada, 2007 i referències que conté), mentre que en algunes altres zones ibèriques (p. ex. a Andalusia) la situació s'inverteix (Fernández-Ocaña, 2000 i referències que conté). El predomini de les dones ha estat considerat lògic per alguns autors (Hardy, 2000), car, en general, elles s'ocupen de la casa, de la cuina, de l'hort i de moltes activitats en els quals les plantes hi juguen un paper preponderant. Un dels punts que poden explicar el predomini d'homes com a informants a Andalusia, segons la investigadora citada, és el rol dominant de l'home a la família que, fins i tot, en algun cas pot arribar a eclipsar un xic la dona durant l'entrevista o abans que aquesta es dugui a terme.

Els informants són nascuts molt majoritàriament a la mateixa comarca del Ripollès, $i$ els que no (representen només un $5,52 \%$ ) hi han viscut una part molt significativa de la seva vida.

Pel que fa a les professions (i tenint en compte que algunes persones n'han exercit més d'una al llarg de la vida) de les persones entrevistades, hi predominen les lligades al medi rural. Entre les dones trobem un $49 \%$ de pageses, un $25 \%$ de mestresses de casa i un $10 \%$ de treballadores en fäbriques. Entre els homes, el 48\% són pagesos (única professió de les principals en la qual el percentatge és quasi idèntic al de les dones) $i$ un $21 \%$ pastors $i$ ramaders.

\section{Nombre de plantes conegudes i reports d'ús}

El nombre total de tàxons sobre els quals s'ha obtingut informació (noms o usos populars) és de 457 (comptant-hi espècies, subespècies i varietats), 15 dels quals només han estat determinats fins al nivell de gènere. Sobre aquestes plantes, els informants han fet 7192 reports d'ús, entenent per tal cada menció d'un ús d'una part o de la planta sencera per un informant (és a dir que si dos informants diuen que la camamilla és digestiva, això es compta dues vegades; com veurem més endavant, aquest concepte és important per a càlculs d'etnobotànica quantitativa).

\section{Famílies botàniques}

Les plantes citades pertanyen a 99 famílies botàniques. A l'Apèndix 3 recollim els nombres i percentatges de reports d'ús de cada família i de tàxons que hi pertanyen.

La família més citada $\mathrm{i}$ amb més espècies és la de les compostes o asteràcies. Això no és pas gens d'estranyar, ja que és la família de plantes vasculars amb més diversitat de tàxons (uns 25.000), té una àrea de distribució cosmopolita i és ben present a la regió mediterrània (Funk et al., 2009). A part d'això, les famílies que ocupen els llocs destacats pel que fa a nombre de tàxons $\mathrm{i}$ citacions coincideixen (les 10 primeres i, amb alguna variació en l'ordre, ben bé cinc més) amb les de la resta de territoris catalans $i$, en general, mediterranis, prospectats (Parada, 2007; Carrió, 2013, i referències que contenen). En general es tracta, com en el cas de les compostes, de famílies força diverses i esteses.

\section{Nombre de plantes per superfície, habitant i informant}

Una primera manera de valorar la rellevància de la xifra corresponent al nombre de tàxons vegetals coneguts a la comarca és calcular el nombre de plantes per superfície, per habitant i per informant. 
Si només tenim en compte les plantes reportades com a medicinals (que són 282, com veurem més endavant), per tal de poder comparar amb estudis previs, que feien el càlcul només amb aquesta mena de plantes, els valors són de 0,30 tàxons $/ \mathrm{km}^{2}, 0,01$ tàxons per habitant i 1,73 tàxons per informant. $\mathrm{A}$ la Taula 3 hi ha reflectits els resultats d'aquests valors només per a les plantes medicinals, així com

Taula 3. Comparació dels resultats de diversos estudis etnobotànics duts a terme a la regió mediterrània. Les dades relatives al present treball es presenten en negreta. Flora: nombre aproximat d'espècies de plantes vasculars de la flora del territori; PM: nombre de plantes medicinals reportades; NI: nombre d'informants; PM/I: nombre de plantes medicinals reportades per informant; IE: índex d'etnobotanicitat (Portères, 1970: nombre d'espècies utilitzades $\times 100 /$ nombre d'espècies de la flora).

\begin{tabular}{|c|c|c|c|c|c|c|c|c|c|}
\hline Territori & $\begin{array}{c}\text { Extensió } \\
\left(\mathbf{k m}^{2}\right)\end{array}$ & Població & Flora & $\mathbf{P M}$ & $\mathbf{P M} / \mathbf{k m}^{2}$ & $\begin{array}{c}\text { PM/ } \\
\text { Habitant }\end{array}$ & NI & $\mathbf{P M} / \mathbf{I}$ & IE \\
\hline Alta Vall del Tera & 294 & 4526 & 1600 & 220 & 0,75 & $4,87 \times 10^{-2}$ & 60 & 3,67 & 16,2 \\
\hline $\begin{array}{l}\text { Alt Empordà (plana } \\
\text { interior) })^{b}\end{array}$ & 178 & 41.300 & 1650 & 149 & 0,84 & $3,61 \times 10^{-3}$ & 46 & 3,24 & 11 \\
\hline $\begin{array}{l}\text { Alt Empordà } \\
(\text { comarca sencera })^{c}\end{array}$ & 1358 & 118.718 & 1650 & 334 & 0,25 & $2,80 \times 10^{-3}$ & 178 & 1,87 & 25,9 \\
\hline Cabo de Gata ${ }^{\mathrm{d}}$ & 800 & 20.000 & 1000 & 253 & 0,32 & $1,26 \times 10^{-2}$ & 153 & 1,65 & 25,3 \\
\hline $\begin{array}{l}\text { Campoo - Los } \\
\text { Valles }\end{array}$ & 1012,12 & 23.027 & 1500 & 166 & 0,16 & $7,20 \times 10^{-3}$ & 107 & 1,55 & 23 \\
\hline Capcir $^{\mathrm{f}}$ & 177,1 & 1752 & 550 & 94 & 0,53 & $5,40 \times 10^{-3}$ & 28 & 3,48 & 17,09 \\
\hline Castellóg $^{g}$ & 6679 & 385.823 & 2128 & 365 & 0,06 & $9,46 \times 10^{-4}$ & 150 & 2,34 & 17,2 \\
\hline Caurel $^{\mathrm{h}}$ & 260 & 2400 & 800 & 223 & 0,86 & $9,29 \times 10^{-2}$ & 45 & 4,96 & 27,9 \\
\hline Cerdanya $^{\mathrm{i}}$ & 1086 & 23.000 & 1600 & 234 & 0,22 & $1,02 \times 10^{-2}$ & 155 & 1,53 & 15 \\
\hline Cerdanya $^{\mathrm{j}}$ & 1139,9 & 26.250 & 1500 & 146 & 0,13 & $5,60 \times 10^{-3}$ & 83 & 4,56 & 9,7 \\
\hline Conflent $^{\mathrm{k}}$ & 882,6 & 16.554 & 1500 & 170 & 0,19 & $10,27 \times 10^{-3}$ & 60 & 2,88 & 11,33 \\
\hline Córdoba $^{1}$ & 13.718 & 724.000 & 1641 & 145 & 0,01 & $2,00 \times 10^{-4}$ & 106 & 1,37 & 8,8 \\
\hline Granada $^{\mathrm{m}}$ & 12.531 & 761.734 & - & 241 & 0,02 & $3,16 \times 10^{-4}$ & - & - & - \\
\hline Guilleries $^{\mathrm{n}}$ & 594 & 27.298 & 1100 & 158 & 0,27 & $5,80 \times 10^{-3}$ & 27 & 5,85 & 20 \\
\hline Huesca $^{\circ}$ & 15.671 & 222.000 & 2500 & 553 & 0,04 & $2,48 \times 10^{-3}$ & - & - & 22 \\
\hline Israel-Palestina $^{\mathrm{p}}$ & 20.700 & 4.486 .600 & - & 150 & 0,007 & $3,34 \times 10^{-5}$ & 100 & 1,5 & - \\
\hline $\begin{array}{l}\text { Los Villares - } \\
\text { Valdepeñas }^{\mathrm{q}}\end{array}$ & 271 & 9508 & 906 & 158 & 0,58 & $1,66 \times 10^{-2}$ & 100 & 1,58 & 51,1 \\
\hline Mallorca $^{r}$ & 3622,54 & 873.414 & 1500 & 255 & 0,07 & $2,90 \times 10^{-4}$ & 235 & 1,09 & 29,2 \\
\hline Montseny & 826 & 79.373 & 1500 & 351 & 0,43 & $4,43 \times 10^{-3}$ & 172 & 2,05 & 25 \\
\hline Pallars $^{t}$ & 2530 & 18.880 & 1500 & 437 & 0,17 & $2,32 \times 10^{-2}$ & 264 & 1,66 & 29,1 \\
\hline
\end{tabular}


Taula 3 (cont.). Comparació dels resultats de diversos estudis etnobotànics duts a terme a la regió mediterrània. Les dades relatives al present treball es presenten en negreta. Flora: nombre aproximat d'espècies de plantes vasculars de la flora del territori; PM: nombre de plantes medicinals reportades; NI: nombre d'informants; PM/I: nombre de plantes medicinals reportades per informant; IE: índex d'etnobotanicitat (Portères, 1970: nombre d'espècies utilitzades $\times 100 /$ nombre d'espècies de la flora).

\begin{tabular}{|l|c|c|c|c|c|c|c|c|c|}
\hline Territori & $\begin{array}{c}\text { Extensió } \\
\left(\mathbf{k m}^{2}\right)\end{array}$ & Població & Flora & $\mathbf{P M}$ & $\mathbf{P M} / \mathbf{k m}^{\mathbf{2}}$ & $\begin{array}{c}\mathbf{P M} / \\
\text { Habitant }\end{array}$ & NI & PM/I & IE \\
\hline $\begin{array}{l}\text { Parque Natural de } \\
\text { Montesinhou }^{u}\end{array}$ & 734 & 7427 & 1271 & 166 & 0,23 & $2,24 \times 10^{-2}$ & 100 & 1,66 & 24,7 \\
\hline Ripollèsv $^{\mathrm{v}}$ & $\mathbf{9 5 6 , 6}$ & $\mathbf{2 5 . 7 0 0}$ & $\mathbf{1 6 0 0}$ & $\mathbf{2 8 2}$ & $\mathbf{0 , 3 0}$ & $\mathbf{1 , 1 0 \times \mathbf { 1 0 } ^ { - 2 }}$ & $\mathbf{1 6 3}$ & $\mathbf{1 , 7 3}$ & $\mathbf{3 5 , 0 1}$ \\
\hline Segarraw $^{\mathrm{w}}$ & 646 & 17.040 & - & 92 & 0,14 & $5,39 \times 10^{-3}$ & 29 & 3,17 & - \\
\hline $\begin{array}{l}\text { Serra de São } \\
\text { Mamede }^{\mathrm{x}}\end{array}$ & 400 & 35.770 & - & 150 & 0,38 & $4,19 \times 10^{-3}$ & 45 & 3,33 & - \\
\hline Tunísia $^{\mathrm{y}}$ & 154.520 & 7.900 .000 & 2000 & 553 & 0,004 & $7,00 \times 10^{-5}$ & 130 & 0,43 & 27,7 \\
\hline Vall del Tenes $^{\mathrm{z}}$ & 260 & 17.969 & - & 150 & 0,58 & $8,35 \times 10^{-3}$ & 28 & 5,40 & - \\
\hline Xipre $^{\text {aa }}$ & 9251 & 639.000 & 1900 & 379 & 0,04 & $5,93 \times 10^{-4}$ & - & - & - \\
\hline
\end{tabular}

\begin{abstract}
a Rigat (2005) — es tracta de l'estudi preliminar d'una part de la comarca que ara hem estudiat en tota la seva extensió-; b Parada (1997); ${ }^{\mathrm{c}}$ Parada (2007); ${ }^{\mathrm{d}}$ Martínez (1993); ${ }^{\mathrm{e}}$ Pardo de Santayana (2003); ${ }^{\mathrm{f}}$ Muntané (2005); ${ }^{\mathrm{g}}$ Mulet

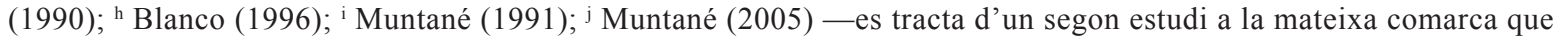
l'anterior fet uns quants anys després del primer i de menor abast pel que fa a informants—; ${ }^{\mathrm{k}}$ Muntané $(2005) ;{ }^{1} \mathrm{Ca}-$ sana (1993), Galán (1993); ${ }^{\mathrm{m}}$ González-Tejero (1989); ${ }^{\mathrm{n}}$ Selga (1998); ${ }^{\circ}$ Villar et al. (1992); ${ }^{\mathrm{p}}$ Friedman et al. (1986), Palevitch et al. (1986); ${ }^{\mathrm{q}}$ Ortuño (2003); ${ }^{\mathrm{r}}$ Carrió (2013); ${ }^{\mathrm{s}}$ Bonet (2001); ${ }^{\mathrm{t}}$ Agelet (1999); ${ }^{\mathrm{u}}$ Carvalho (2005); ${ }^{\mathrm{v}}$ Dades del present treball; ${ }^{w}$ Raja (1995); ${ }^{x}$ Rodrigues (2001); y Le Floc'h (1983), Boukef (1986); ${ }^{\text {z } ~ B o n e t ~(1991) ; ~ a a ~ A r n o l d-~}$ Apostolides (1991).
\end{abstract}

els dels altres estudis previs. Si comparem aquestes xifres amb algunes altres que s'han trobat en diverses zones mediterrànies prospectades etnobotànicament, veiem que, pel que fa a plantes medicinals per $\mathrm{km}^{2}$, el valor del Ripollès és superior als de 0,25 a 1'Alt Empordà (Parada, 2007), 0,25 a la Cerdanya (Muntané, 1991, 2005) i 0,27 a les Guilleries (Selga, 1998) i inferior als del Montseny $(0,43$, Bonet, 2001) i la Vall del Tenes $(0,58$, Bonet, 1991); aquest fet és causat en bona part per les extensions prou diverses que ocupa cada territori. El nombre de plantes medicinals per habitant és força més alt que el que es troba en territoris molt més poblats, com ara l'Alt Empordà (Parada, 2007), que és gairebé 10 cops inferior. Finalment, el nombre de plantes medicinals per informant té un valor semblant que els que s'han trobat a la Serra de Cazorla, al Montseny i a l'Alt Empordà (1,9, 2,05 i 1,9, respectivament; Fernández-Ocaña, 2000; Bonet, 2001; Parada, 2007).

\section{Índex d'etnbotanicitat}

Aquest índex (Portères, 1970) expressa el percentatge de la flora d'un territori que és objecte d'algun coneixement popular. Tenint en compte que tal com s'ha dit la flora del Ripollès és constituïda per uns 1600 tàxons, podem deduir que l'índex d'etnobotanicitat és d'aproximadament 35,01\%.

De totes maneres, podem afirmar que un terç de les plantes del Ripollès és conegut $i$, en general, usat, pels informants de la comarca. Aquest valor se situa entre els més alts (de fet, és el més elevat) que s'han obtingut en estudis similars duts a terme en altres territoris situats del tot o en bona part a l'àrea lingüística catalana: 25,9 a l'Alt Empordà (Parada, 2007), 23,2 al Montseny (Bonet, 2001), 20 a les Guilleries (Selga, 1998), 17,2 a la província de Castelló (Mulet, 1990), 15 (Muntané, 1991) o 9,73 (Muntané, 2005) a la Cerdanya, 29,1 al Pallars (Agelet, 1999), 17,09 al Capcir (Muntané, 2005), 
11,33 al Conflent (Muntané, 2005) i 29,81 a Mallorca (Carrió, 2013).

\section{Tradició i fiabilitat de les dades: freqüència d'ús de les plantes i factor de consens d'informants}

Un dels punts rellevants d'una prospecció etnobotànica, a part d'avaluar — com hem fet més amunt - el nombre i la importància relativa de les plantes conegudes i usades en una àrea geogràfica, és calibrar la coherència de les dades, la qual cosa pot menar a considerar-les útils de cares a futures recerques encaminades, posem per cas, al descobriment $i$ la possible posada en el mercat de productes útils derivats de plantes.

Per a fer aquesta valoració, en primer lloc hem quantificat els tàxons amb tres o més reports d'ús, que són, segons els criteris àmpliament seguits de Le Grand \& Wondergem (1987) i Johns et al. (1990), aquells amb un grau de fiabilitat més alta. En el nostre cas, dels 457 tàxons reportats, 332 (és a dir, el 72,65\%) acompleixen aquest requisit. Això vol dir que gairebé les tres quartes parts de les espècies vegetals conegudes i majoritàriament usades al Ripollès ho són amb una freqüència de citació que supera el mínim acceptable per a considerar-les com a objecte de consens en el territori.

En segon 1loc, el factor de consens d'informants $\left(F_{\text {IC }}\right.$, Trotter \& Logan, 1986) permet valorar de manera encara més precisa la fiabilitat de les dades, car dóna idea de la seva coherència, és a dir, de fins a quin punt els diferents informants es refereixen a les mateixes plantes per als mateixos usos. En definitiva, es tracta d'apreciar si hi ha una tradició comuna en el coneixement sobre les plantes en una àrea geogràfica o si cada informant va pel seu cantó. El $F_{\text {IC }}$ es pot calcular de manera general (per a totes les plantes i tots els usos) o per a cada mena d'ús (plantes medicinals, plantes alimentàries, plantes per a un o un altre ús medicinal concret...).

El $F_{\text {IC }}$ general al Ripollès és de 0,94 . Això (essent la unitat el valor màxim d'aquest índex) indica una coherència molt alta entre els usos que tots els informants reporten per a les plantes a la comarca. Son dades amb un grau elevat de fiabilitat que les fa potencialment utilitzables en futurs estudis de desenvolupament de medicaments $\mathrm{o}$ altres productes a base de plantes. Novament, el valor que hem trobat és entre els més alts dels territoris de llengua catalana prospectats, igualat només pel 0,94 reportat a Mallorca (Carrió, 2013), amb un grau d'aïllament comparable al de les valls de muntanya, i seguit per 0,91 al Montseny i a l'Alt Empordà (Bonet, 2001; Parada, 2007) i 0,87 als Pallars (Agelet, 1999).

Ultra el $F_{\text {IC }}$ general hem calculat alguns $F_{\text {IC }}$ parcials que hem considerat interessants. Així, el $F_{\text {IC }}$ per a plantes medicinals a l'Alta Vall del Ter és de 0,87 (Rigat et al., 2006, 2007), similar als d'altres territoris del domini lingüístic català (Carrió, 2013 i referències que conté) i superior als trobats en altres àrees ben distants $i$ on el saber popular és molt arrelat, com ara diverses zones de Mèxic (Heinrich et al., 1998; Leonti et al., 2001) i l'Índia (Ragupathy et al., 2008).

En resum, tant les freqüències de citació de plantes i usos com els factors de consens d'informants general i parcials mostren un elevat grau de coincidència a l'hora d'utilitzar les plantes per a diverses finalitats a l'àrea estudiada, la qual cosa permet afirmar que existeix una tradició fonamentada en el saber popular ripollès sobre les plantes i que les dades obtingudes són fiables $i$ en gran part poden ser usades amb profit en futurs estudis de tipus bàsic o aplicat.

\section{Anàlisi dels catàlegs etnobotànics}

El catàleg de tàxons (Apèndix 1) conté totes les dades sobre usos, ja siguin medicinals, alimentaris o d'altra mena, així com sobre noms populars, a més de dades d'altres tipus (observacions ecològiques, dites, creences...). Ara bé, per als comentaris següents hem separat els diversos temes: plantes medicinals, plantes alimentàries, plantes tòxiques o nocives, plantes amb altres usos i noms populars.

En canvi, el catàleg de barreges (Apèndix 2), comprèn únicament les mescles de plantes amb finalitat medicinal. És per això que aquest segon catàleg només és objecte de comentaris en l'apartat de plantes medicinals.

\section{Plantes medicinals}

El nombre de plantes amb algun ús medicinal esmentat pels informants és de 282 tàxons, pertanyents a 81 famílies. Hi corresponen 6515 reports d'ús. Això fa de les aplicacions lligades a l'àmbit 
medicinal les més importants, en termes de nombre de tàxons i de freqüència d'ús, de totes les utilitzacions de les plantes al territori considerat.

La immensa majoria dels usos medicinals són destinats a medicina humana. De totes maneres, el $6 \%$ de plantes amb usos adreçats a medicina veterinària (5\% únicament i $1 \%$ compartit amb la medicina humana) és prou significatiu. Es tracta de 49 espècies de plantes que mantenen una vigència d'ús prou alta, tot $i$ que els avenços de la veterinària han fet disminuir els tractaments populars arreu de les societats industrialitzades (Carrió et al., 2012).

\section{Espècies més citades i usades}

Al subapartat d'etnobotànica quantitativa hem esmentat que una gran majoria de les plantes citades pels nostres informants ho havien estat almenys tres vegades. Algunes, però, depassen $\mathrm{i}$ de molt aquesta xifra. Els 10 tàxons amb més reports d'ús en comprenen, tots junts, uns 2100 , és a dir, aproximadament un $30 \%$ dels gairebé 7200 totals.

Alguns d'aquests tàxons (com ara Sambucus nigra L., Thymus vulgaris L., Tilia platyphyllos Scop. i Santolina chamaecyparissus L.) es compten entre els que solen estar en els primers llocs del rànquing en molts dels territoris catalans - $\mathrm{i}$ en molts d'altres de mediterranis - prèviament prospectats (Parada, 2007; Carrió, 2013 i referències que contenen). La primera espècie de la llista, amb més de 400 reports d'ús, és, certament, una de les plantes més conegudes i utilitzades en moltes zones, una de les que té usos més diversos i una de les quals s'usen més parts; a més, el sabuc és una de les plantes per les quals els informants solen mostrar una predilecció i un afecte especials (Vallès et al., 2004a i referències que conté).

Alguns tàxons, en canvi, són força específics de la zona estudiada i donen testimoni del seu caràcter d'alta muntanya. Són clars exemples d'això l'àrnica (Arnica montana L. subsp. montana) i la camamilla [Achillea ptarmica L. subsp. pyrenaica (Godr.) Heimerl]. D'altres plantes anomenades àrnica i camamilla s'usen per a les mateixes respectives funcions en molts territoris (i fins $i$ tot al Ripollès mateix), però aquí les que ho són per excel·lència són dues espècies rares o inexistents en altres zones, però, en canvi, molt a l'abast en aquest. Això és coherent amb la idea que moltes de les plantes usades en medicina popular són obtingudes de llocs propers a aquells on viuen els usuaris (vegeu-ne un exemple, en una cultura ben diferent de la nostra, a Giday, 2001). Ara bé, en el cas que tractem, la proximitat pot implicar una bona caminada i superar un desnivell d'altituds considerable.

\section{Parts de planta usades}

Les parts més aparents dels vegetals sumen un percentatge molt important (69\% entre part aèria flori$\mathrm{da}$, inflorescència, part aèria, fulla i flor), tot $\mathrm{i}$ que el $6 \%$ de l'arrel no és pas menyspreable pel que fa al seu ús.

Aquests resultats són també bàsicament concordants amb els que s'han publicat a d'altres zones de l'àrea mediterrània (Parada, 2007; Carrió, 2013 i referències que contenen).

\section{Alteracions tractades $i$ usos medicinals}

A la Fig. 2 es recullen els grans tipus de trastorns de la salut que són tractats popularment amb plantes al Ripollès, en molts casos agrupats per sistemes orgànics. Podem veure que cinc grups de problemes són àmpliament dominants: traumatismes, inflamacions, trastorns dels sistemes digestiu, respiratori $\mathrm{i}$ genitourinari.

Complementàriament, presentem a la Fig. 3 els 17 tipus d'ús medicinal de les plantes més estesos segons els informants. Conseqüentment amb els trastorns més tractats, el usos antiinflamatori intestinal (corresponent a inflamacions $\mathrm{i}$ a afeccions del sistema digestiu), anticatarral (sistema respiratori) i antihipertensiu (sistema circulatori) ocupen els primers llocs.

La majoria dels usos medicinals de les plantes reportats pels informants $i$ els principals pel que fa a la freqüència de citació van en la idea que se sol difondre que la fitoteràpia (ja sigui popular $\mathrm{o}$ industrial) s'ocupa de malalties lleus o no gaire greus i d'afeccions cròniques. De totes maneres, cal dir que, com s'ha vist també en altres casos, algunes de les propietats medicinals que els informants atribueixen a les plantes són ben definides i per a malalties que cal qualificar d'importants $i$ greus. 


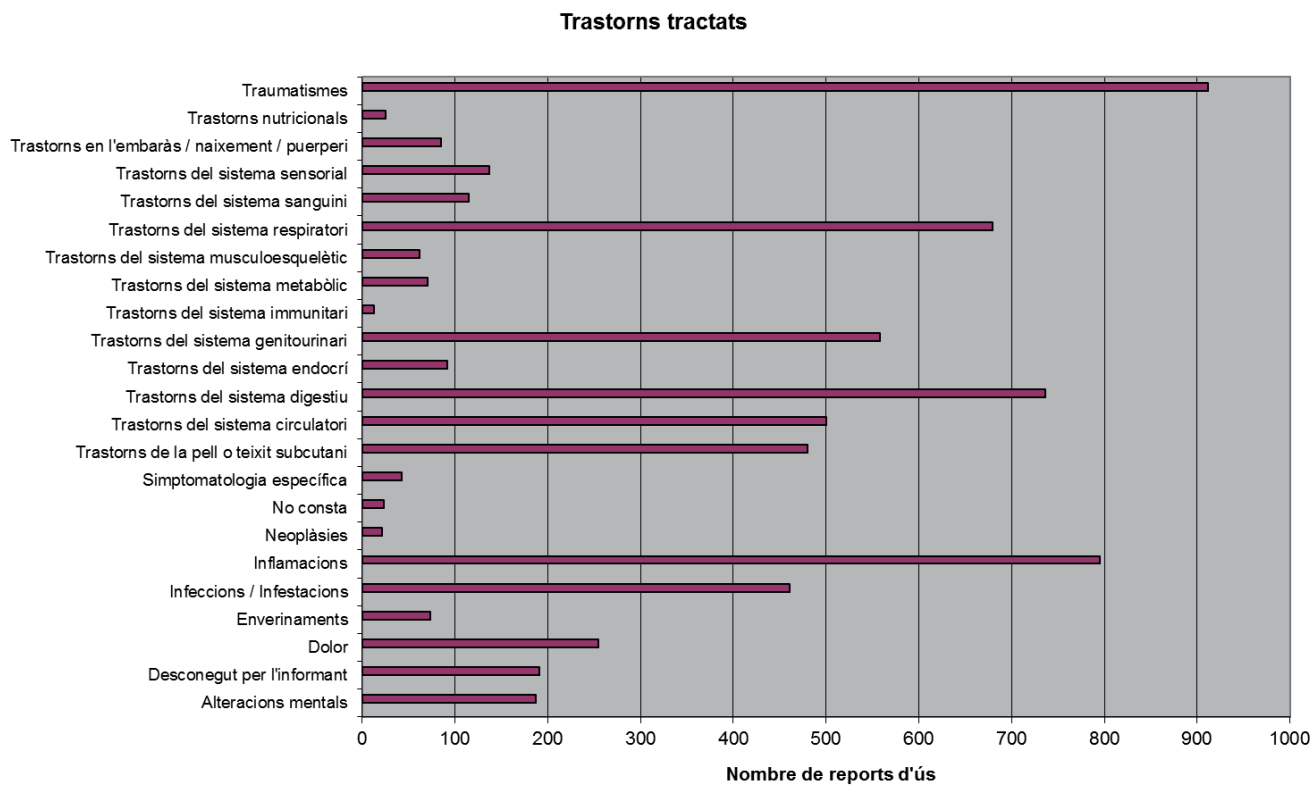

Figura 2. Tipologia i reports d'ús dels trastorns tractats al Ripollès.

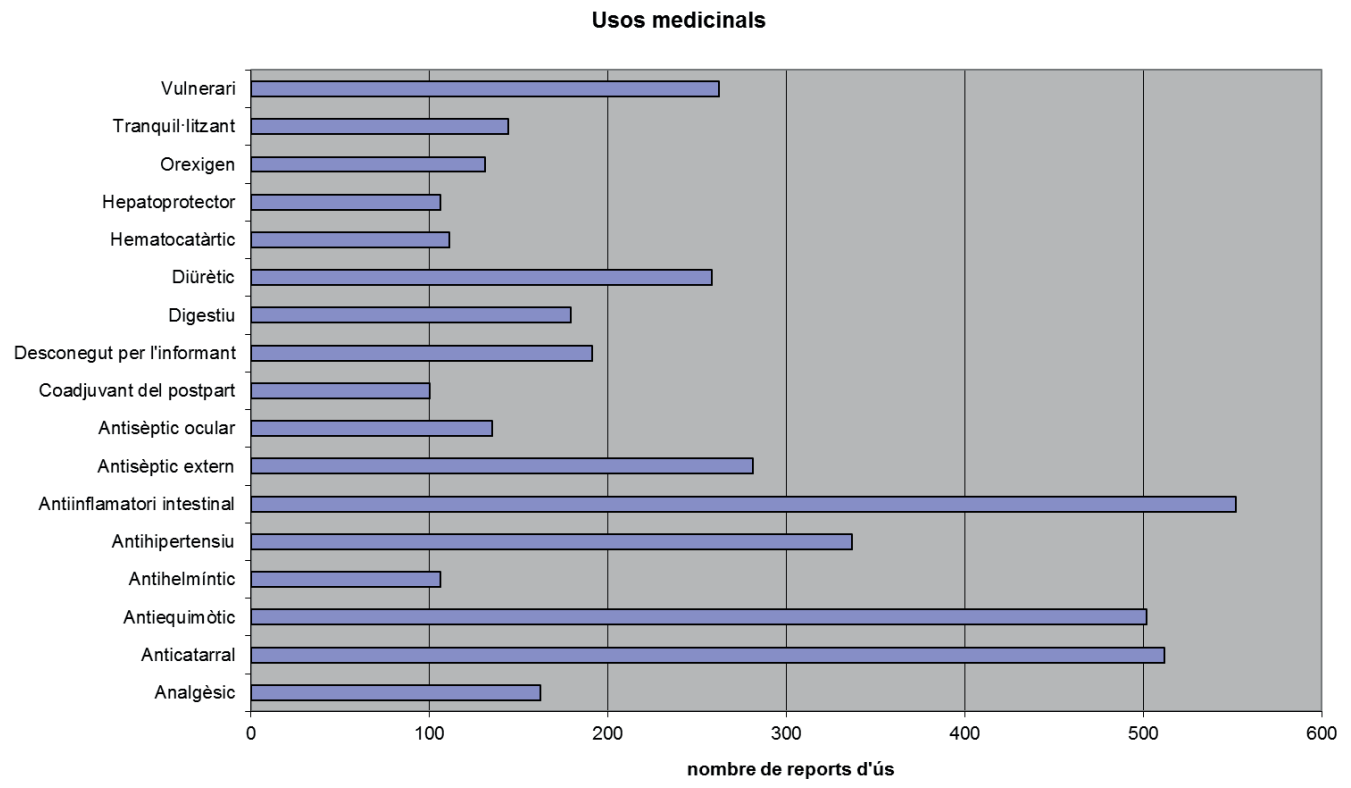

Figura 3. Tipologia i reports d'ús de les principals aplicacions medicinals al Ripollès.

\section{Formes de preparació $i$ administració}

En general, els tractaments que s'apliquen a les plantes usades en medicina popular no són pas gaire complexos. La decocció o la infusió solen predominar sobre altres modes de preparació, i sovint hom parla més aviat de tisana com a forma d'administració, car la diferència entre infusió i decocció és fina i a vegades poc clara en boca dels informants, com ja assenyalava Mulet (1990) en un treball sobre la província de Castelló. En els resultats del present treball veiem reflectida aquesta mateixa pauta, car la tisana domina com a forma d'aplicació dels remeis populars amb un $51 \%$.

Aquesta senzillesa aparent, però, no ens ha de fer creure que la fitoteràpia o la medicina populars no 
tinguin mecanismes que es poden titllar de complexos o sofisticats. N'és un exemple, en l'etnobotànica ripollesa, el procés de destil·lació seca que es duu a terme per a obtenir els anomenats esperits (de fet, essències) de sabuc (Sambucus nigra) i d'àrnica (Arnica montana subsp. montana). En ambdós casos les inflorescències són sotmeses a calor seca perquè vagin donant el producte desitjat, en un procés que cal preparar i controlar minuciosament (vegeu Rigat et al., 2007 i Vallès et al., 2010). La destil·lació del sabuc és comuna a altres territoris (Vallès et al., 2010), mentre que la d'àrnica, planta típicament d'alta muntanya, no l'hem trobada reportada; a l'Alt Empordà, un procés similar es duu a terme per a obtenir essència de donzell (Artemisia absinthium L.; Parada et al., 2009). Altres preparacions poc o molt elaborades detectades són xarops, ungüents o melits, per exemple.

\section{Barreges medicinals}

Les plantes medicinals són usades sovint (i això tant de manera popular com industrial) en barreges, algunes de les quals es consideren, a més, sinèrgiques (Gilbert \& Alves, 2003). Els nostres resultats ho reafirmen: al llarg de les entrevistes realitzades hem pogut inventariar 180 barreges medicinals a base de plantes, les quals impliquen 135 tàxons i tenen 1015 reports d'ús. La mitjana per barreja és de 2,78 tàxons, amb un mínim de dues i un màxim de vuit plantes. Les espècies més citades en barreges (amb 44 reports d'ús cadascuna) són Hypericum perforatum L. i Rosmarinus officinalis $\mathrm{L}$.

Els principals usos de les barreges medicinals són l'anticatarral, l'analgèsic, l'antiequimòtic, l'antisèptic extern i el coadjuvant del postpart per aquest ordre. En general, s'inscriuen en la mateixa tendència d'usos preferents que les plantes aïllades (vegeu més amunt la secció sobre afeccions tractades i usos medicinals).

\section{Plantes tòxiques o nocives}

Com que la manera de consolidar els usos populars de les plantes és la d'assaig i error, és normal que, en treballs etnobotànics, es detecti la presència de plantes nocives o tòxiques. Alguns ho són de manera associada a l'ús medicinal o fins i tot alimentari, com a efectes secundaris no desitjats, i d'altres de manera directa. Els informants han proporcionat dades sobre 48 tàxons d'aquesta mena, pertanyents a 23 famílies, dels quals s'han fet 252 reports. Les sis espècies que tenen 10 o més reports d'ús són les següents: Aconitum napellus L., Helleborus viridis L., Ranunculus bulbosus L., Veratrum album L., Conium maculatum L. i Saxifraga longifolia Lapeyr.

Aquestes sis espècies són ben conegudes entre les tòxiques. Aconitum napellus, la tora blava, és una de les plantes considerades més tòxiques, almenys de la flora europea (Lin et al., 2004). Algunes d'elles són també usades com a medicinals (vegeu els catàlegs, Apèndixs 1 i 2).

\section{Plantes alimentàries}

Després dels medicinals, els alimentaris (incloent les plantes comestibles, les usades per a elaborar begudes, les condimentàries i les utilitzades en alimentació animal), són els usos més citats en treballs etnobotànics en general, i també en aquest. Hem obtingut dades sobre 180 tàxons d'aquest àmbit, que pertanyen a 55 famílies i dels quals s'han fet 1662 reports d'ús, dels quals el $76 \%$ estan destinats a alimentació humana, el 23\% a animal i 1'1\% restant no consta. El predomini de l'alimentació humana és molt important, però no és tan gran com la diferència entre medicina humana $i$ animal. Això vol dir que la medicina veterinària té menys força que l'alimentació animal, és a dir, que aquest últim és un dels usos populars de les plantes que es mantenen més en àrees rurals.

Les famílies de les compostes o asteràcies, labiades o lamiàcies, rosàcies i umbel·líferes o apiàcies destaquen força sobre les altres. Com hem esmentat més amunt en el cas de les plantes medicinals, es tracta de famílies grans i cosmopolites i, a més, contenen plantes alimentàries molt típiques.

\section{Espècies més citades}

Presentem a la Fig. 4 les 33 plantes d'ús alimentari que tenen més de 15 reports d'ús. Aquesta llista en comprèn de silvestres i de conreades. Entre aquestes darreres n'hi ha de ben típiques i generalment usades, com ara la pomera (Pyrus malus L.), la perera (Pyrus communis L.) o el julivert [Petroselinum crispum (Mill.) Fuss]. No obstant, hi predominen les plantes silvestres o els conreus anomenats menors. La planta de lluny més citada, 


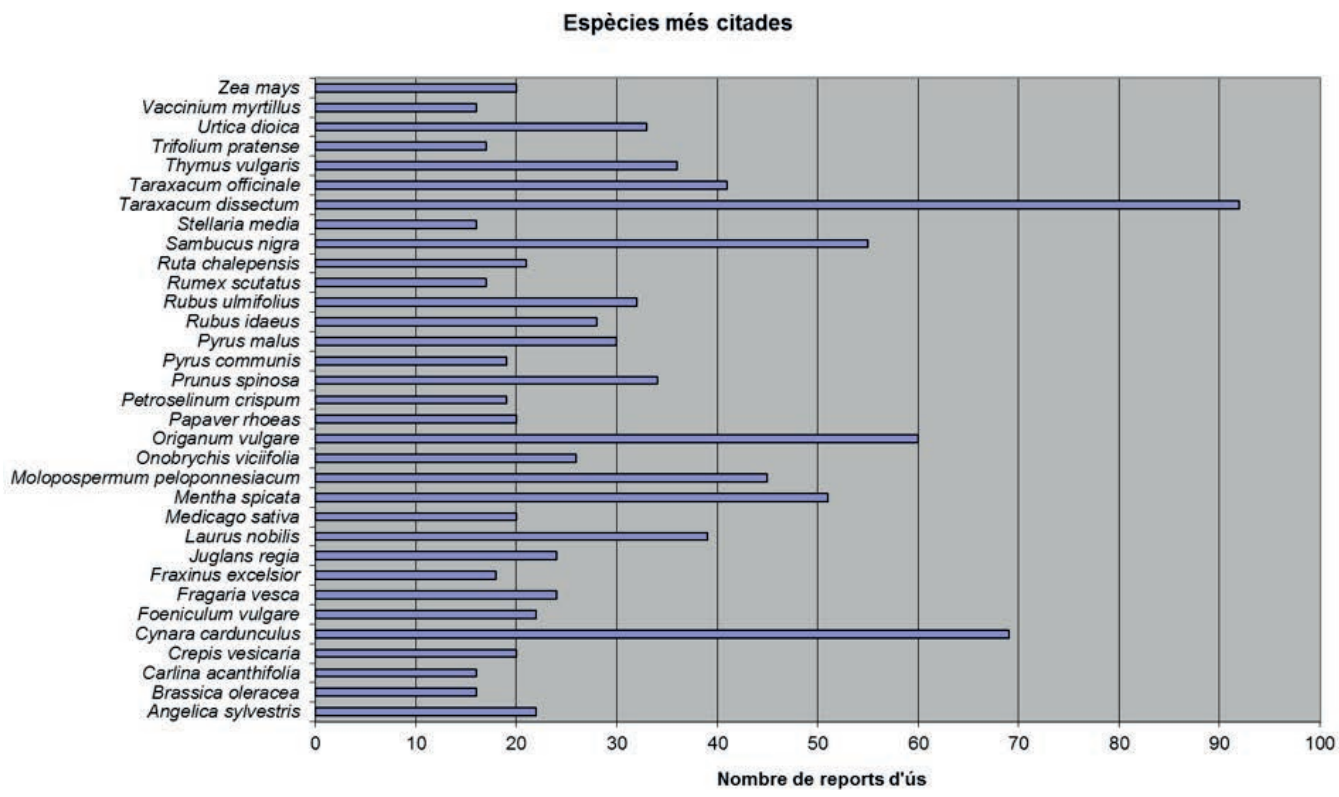

Figura 4. Plantes alimentàries més citades i reports d'ús de cadascuna al Ripollès.

la xicoina [Taraxacum dissectum (Ledeb.) Ledeb.] és una espècie típica d'alta muntanya usada, fora del Ripollès, en ben pocs altres territoris, com ara la Cerdanya (Muntané, 1991), tot i que espècies properes, normalment esmentades sota el nom de T. officinale L., són d'ús bastant general (Pardo de Santayana et al., 2014). A continuació hi trobem una planta conreada a petita escala, l'herbacol (Cynara cardunculus L.), molt usada per a quallar la llet i obtenir formatge casolà. En tercer lloc, hi trobem l'orenga (Origanum vulgare L.), planta que presenta la particularitat de tenir usos tradicionals antics, però també recents; de fet és una de les més conegudes del jovent, ja que s'usa per a condimentar la pizza. Destaca finalment el sabuc (Sambucus nigra), del qual ja hem destacat la rellevància com a planta medicinal.

\section{Parts de planta}

Hom pot trobar a la Fig. 5 les diverses parts de les plantes que són objecte de consum alimentari. Novament, de manera similar a les plantes medicinals, les parts més evidents - les aèries - de les plantes són les que més es fan servir. És remarcable que entre la part aèria i la fulla es cobreix gairebé la meitat dels reports, proporció que ateny els dos terços si hi afegim la part aèria florida, el fruit i la infructescència. A diferència de l'alimentació general (compres per a menjar i conreus majors), la popular fa poc cas de les parts subterrànies: les arrels i els tubercles junts no arriben al 2,5\% dels reports d'ús.

\section{Categories d'usos}

La ingestió de la planta crua (molt sovint en amanides) és, de llarg, el mode de consumició més estès, amb més de la meitat dels reports d'ús. A continuació hi trobem l'ús com a condiment o espècia $\mathrm{i}$ la ingestió de la planta cuita (majoritàriament en aigua, però també d'altres maneres), amb percentatges gairebé idèntics. Cal remarcar també que aproximadament un de cada 10 reports d'ús és referit a la preparació de begudes. Dins d'aquestes, la ratafia, un licor tradicional molt estès a Catalunya (Vallès et al., 2004b), hi ocupa un lloc preeminent (vegeu Rigat et al., 2009, 2016).

\section{Preparació}

Els procediments de preparació de les plantes alimentàries són variats. En podem trobar la diversitat a la Fig. 6. Gairebé la meitat dels reports d'ús indiquen que el tractament majoritari es limita a una neteja: en el $47 \%$ dels casos, la planta s'usa fresca, sense preparació. Això lligaria amb la pretesa senzillesa dels usos etnobotànics, que hem comentat més amunt, en parlar dels medicinals, però també hi ha elaboracions complexes, com ara confitures i melmelades o la preparació de begudes de menes 


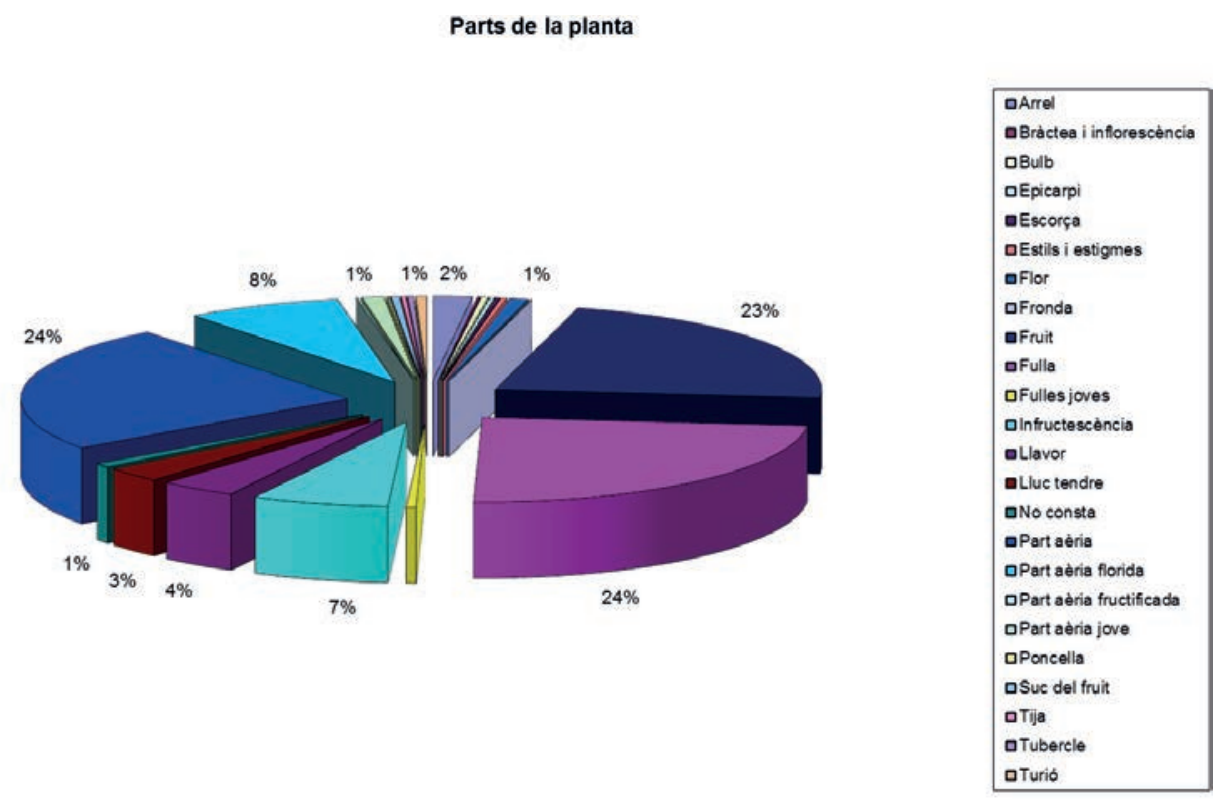

Figura 5. Parts de plantes usades en alimentació al Ripollès.
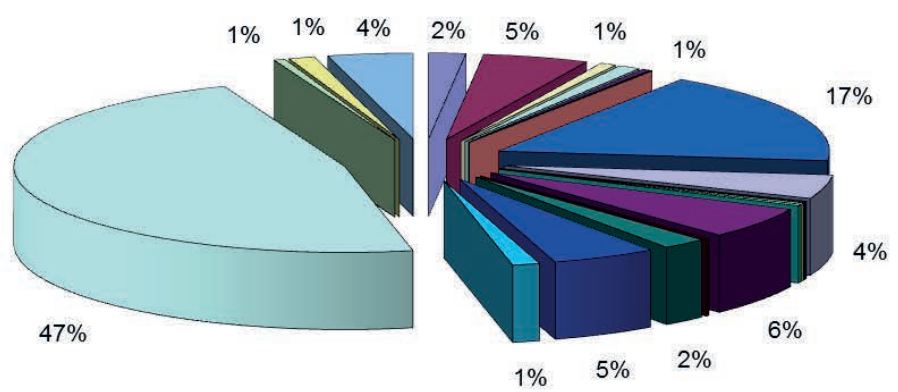

口Beguda preparada amb aigua
$\square$ Beguda preparada amb aiguardent
$\square$ Beguda preparada amb licor
$\square$ Beguda preparada amb sucre sense fermentació
$\square$ Beguda preparada amb vi
$\square$ Beguda preparada per fermentació
$\square$ Condiment
$\square$ Conservada dessecada a l'aire
$\square$ Conservada en oli
$\square$ Conservada en salmorra
$\square$ Conservada en vi
$\square$ Conservada en vinagre
$\square$ Cuita en aigua
$\square$ Cuita en llet
$\square$ Cuita en oli
$\square$ Cuita en sucre
$\square$ Cuita sense vehicle
$\square$ Fresca (sense preparació)
$\square$ Macerada en aigua
$\square$ No consta el mode de preparació
$\square$ Quall

-Beguda preparada amb aiguardent $\square$ Beguda preparada amb licor

Beguda preparada amb sucre sense fermentació

$\square$ Beguda preparada per fermentació

aCondiment

- Conservada en oli

aConservada en salmorra

aConservada en vi

$\square$ Cuita en aigua

-Cuita en llet

$\square$ Cuita sense vehicle

口Macerada en aigua

口Quall

Figura 6. Percentatges de les modalitats de preparació dels aliments vegetals d'ús popular al Ripollès.

diverses. A més, es pot destacar el $17 \%$ de reports d'ús com a condiment, ja que, en aquest cas, no es cerca tan sols l'obtenció d'un gust interessant, sinó també la millora de la digestibilitat del menjar i la seva conservació.

\section{Aliments funcionals populars}

En els darrers temps hi ha un interès important pels productes alimentaris que exerceixen alguna funció salutífera en l'organisme humà (Mariné \& Vidal, 2005 , i referències que conté). En etnobotànica, la interfície entre usos alimentaris i medicinals de les plantes és molt permeable, de manera que molts aliments curen i molts medicaments alimenten, i avui en dia es valoren més els productes etnobiològics (Etkin, 1996, 2006 i referències que contenen).

En un treball previ sobre plantes alimentàries, dedicat a una part del Ripollès (Rigat et al., 2009), vam proposar el concepte $\mathrm{i}$ el terme d'aliment 
funcional popular, sobre el qual insistim en un altre treball (Rigat et al., 2016), dedicat a tota la comarca. Aquesta mena d'aliments medicamentosos comprenen aquelles plantes (o fongs, animals $o$ altres organismes quan sigui aplicable) que tenen usos alimentaris populars $i$, al mateix temps, tenen propietats medicinals vinculades a la seva ingestió (és a dir, tenint en compte només els usos interns). En la present recerca hem trobat que el 62,5\% (50 de 80 ) de les plantes silvestres (sense considerar, en aquest cas, les conreades) amb usos alimentaris reportats tenen també usos medicinals per via interna. Aquest elevat percentatge confirma no només l'afirmació clàssica d'Hipòcrates que «el teu aliment serà la teva medicina» (Etkin, 2006), sinó també la riquesa de la regió estudiada en aquest tipus d'ús, la qual cosa col-loca els aliments funcionals populars del Ripollès en un bon lloc per a futures recerques sobre aquests productes d'avantguarda situats a la zona de contacte entre la nutrició i la salut.

\section{Altres usos}

Agrupem sota la denominació d'altres usos totes aquelles utilitzacions populars de les plantes al Ripollès que no són ni medicinals (incloent-hi al·lusions a toxicitat o d'altres efectes nocius) ni alimentàries. Hem recollit informació d'aquest tipus sobre
183 tàxons pertanyents a 60 famílies, amb un total de 681 reports d'ús (Gras et al., 2016).

A la Fig. 7 presentem les 11 espècies més citades en aquest àmbit, les que tenen 10 reports d'ús o més. En aquesta figura veiem que hi ha molt poques coincidències entre les plantes que ocupen els primers llocs pel que fa a altres usos i les medicinals i alimentàries (que sí que eren més coincidents entre elles, com ja hem dit). Això és degut al fet que aquests altres usos són força diferents dels que tenen a veure amb la salut en sentit ampli.

La Fig. 8 aplega les parts de planta que es fan servir per a propòsits altres que els alimentaris $\mathrm{i}$ els medicinals. En aquest àmbit d'usos, la predominança de les parts aèries, les més vistents de les plantes, és encara més clara que per als usos medicinals i alimentaris, en què ja es dóna prou. Gairebé un $60 \%$ dels reports d'ús corresponen a part aèria (florida o no), planta sencera i tija, mentre que l'arrel no arriba a representar un $2 \%$.

Tot i que no té un nombre de reports d'ús elevadíssim, sí que hi ha una gran variació de menes d'aprofitament en aquest camp que exclou la salut i la nutrició. Hom en pot veure el detall a la Fig. 9. Els usos d'aquest àmbit tenen a veure amb la vida rural o, si es vol, amb la vida en general. Hi dominen llargament les utilitzacions ornamentals (en jardineria $\mathrm{i}$ en elaboració de rams), seguides de els creences magicoreligioses i el que anomenem

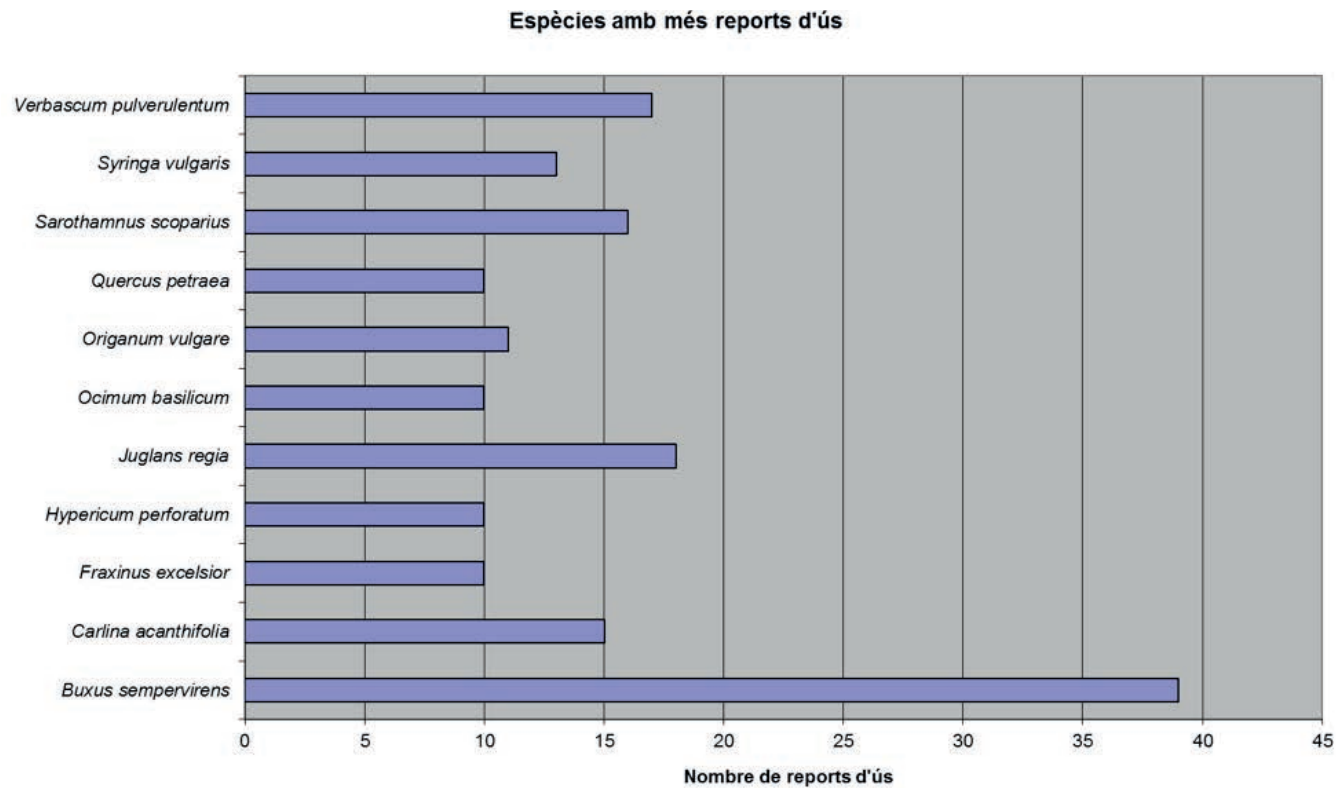

Figura 7. Espècies més citades amb altres usos (vegeu el text) i nombre de reports d'ús de cadascuna al Ripollès. 


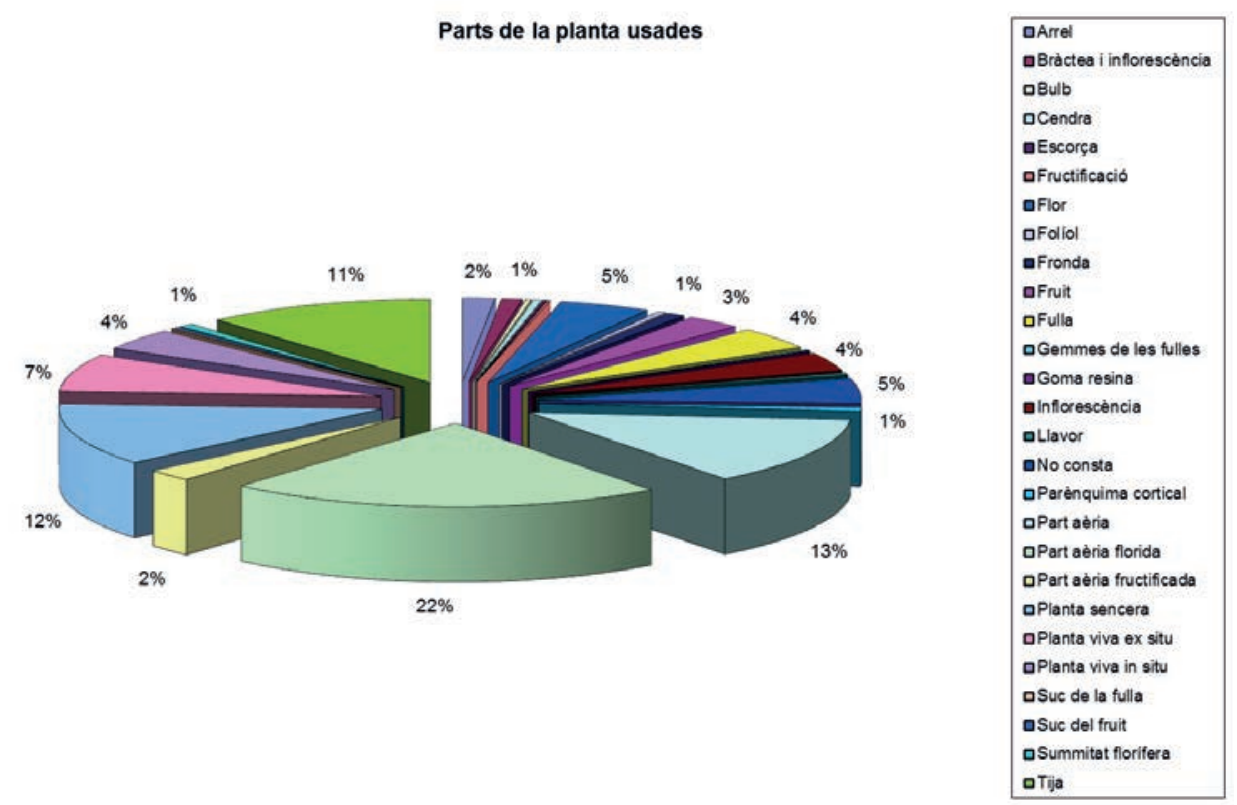

Figura 8. Parts de planta i derivats amb usos ni medicinals ni alimentaris al Ripollès.

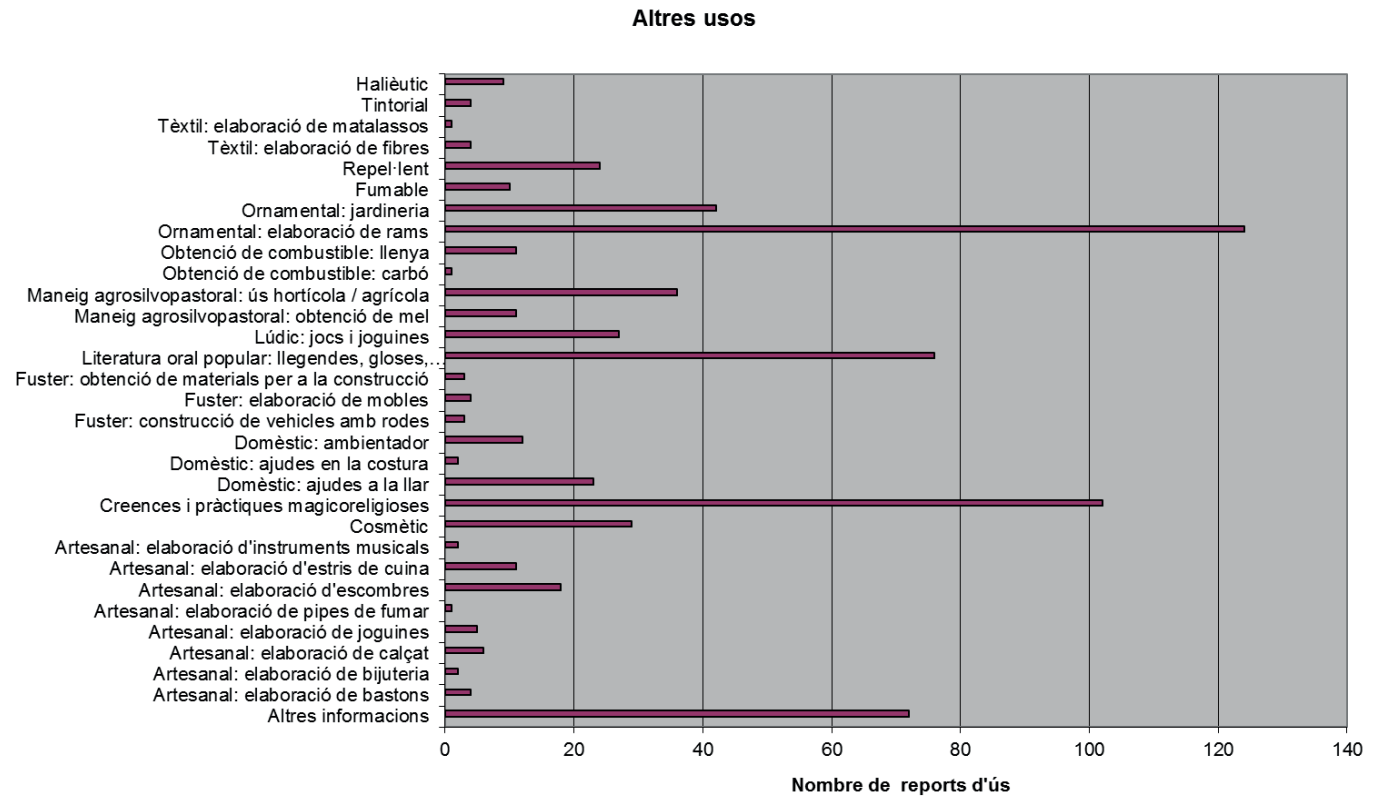

Figura 9. Tipologia dels usos de les plantes altres que els medicinals i els alimentaris al Ripollès.

literatura oral popular (dites, refranys, contes, llegendes...). Intuïm sense grans dificultats que alguns usos força restringits (com ara els fusters i artesanals, per exemple en elaboracions de mobles, vehicles, estris i similars) tenien valors prou més alts en temps passats, en què dins una comarca de muntanya com el Ripollès calia fer-s'ho gairebé tot.
Igualment, els usos lúdics (per a jugar o per a fer-se joguets) devien ser més vigents fa temps.

\section{Fitonímia popular al Ripollès}

Una de les primeres activitats humanes és la d'anomenar i classificar els objectes que les persones tenen 
al seu abast, i els objectes de la natura no en constitueixen pas cap excepció; a més, els noms populars (també anomenats comuns, vulgars o vernacles) de les plantes solen ser dels darrers elements que es perden en cas d'erosió dels sabers tradicionals (Berlin, 1992; Vallès et al., 2005).

En les entrevistes els informants han denominat les plantes que coneixen amb 804 noms (sense comptar-hi les nombroses variants fonètiques), dels quals han produït 7415 reports. Gairebé totes les plantes esmentades tenen alguna denominació popular: 451 tàxons dels 457 que constitueixen el catàleg etnoflorístic, és a dir el 98,8\%. Tots aquests noms populars figuren a l'Apèndix 1 . Només algun exemple de noms recollits al nostre territori figura a Vallès et al. (2005) i Vallès (2010). Articles d'abast més general sobre fitonímia i etnobotànica, i els que havíem recollit fins el 2010, aproximadament, s'han buidat a Vallès et al. (2014), un compendi d'uns 35.000 noms catalans per a uns 6500 tàxons de plantes.

Hem calculat l'índex d'etnofitonímia (Bonet et al., 1999), definit, en base a l'índex d'etnobotanicitat (Portères, 1970), com la relació, expressada en tant per cent, entre el nombre de plantes d'un territori per a les quals s'ha recollit algun fitònim i el nombre d'espècies de la seva flora. Al Ripollès aquest índex té un valor de $28,19 \%$, força proper al de l'índex d'etnobotanicitat (vegeu més amunt, el subapartat d'etnobotànica quantitativa), ja que, com hem dit, gairebé totes les plantes reportades pels informants ho han estat amb nom(s) popular(s). Aquest índex expressa la proporció de plantes de la flora que reben nom popular i té interès en dos camps prou diferents, tot i que de fet força relacionats: la lingüística, ja que és un testimoni de la de la vivor del dialecte de l'àrea considerada, i l'etnobotànica, perquè mostra la importància de la relació de la societat humana del territori amb les plantes.

Un altre índex que afecta els noms de plantes $\mathrm{i}$ que hem calculat és el de diversitat lingüística en la fitonímia (Bonet \& Vallès, 2006), dividint el nombre de fitònims pel de tàxons als quals donen nom. Al Ripollès hem trobat un valor d'1,78 per a aquest índex, que significa, en mitjana, gairebé dos noms populars per tàxon. Això expressa la riquesa lingüística en les denominacions dels vegetals de la zona, independentment de la magnitud de la flora. Els nombres mínim i màxim de noms populars per planta han estat d'un i 14, respectivament. Les dues espècies amb més noms comuns són Santolina chamaecyparissus (amb 14 denominacions) i Thymus serpyllum L. (10).

Els valors dels índexs d'etnobotanicitat i de diversitat lingüística en la fitonímia al territori estudiat són similars als d'altres llocs del domini lingüístic català, tot i que lleugerament més baixos que en diversos casos. Per exemple, a l'Alt Empordà, els valors d'aquests dos índexs són del 31,2\% i 1,94 (Parada, 2007). La diferència pot considerar-se insignificant, ja que en el cas present no hem comptat com a noms independents moltes de les variants fonètiques [per exemple, 'coscoi' enfront del normatiu coscoll per a Molopospermum peloponnesi$\operatorname{acum}(\mathrm{L}$.) W. D. J. Koch], mentre que altres treballs els han considerat separadament.

Els elevats nombre i grau de diversitat de noms populars de les plantes són, en definitiva, un indici més del bon nivell de conservació del saber tradicional lligat a la biodiversitat vegetal al Ripollès que hem pogut anar desgranant en aquesta anàlisi dels catàlegs etnobotànics elaborats a partir de les dades fornides pels informants.

\section{REMARQUES FINALS}

Els resultats obtinguts mostren una riquesa considerable de l'etnoflora ripollesa (Fig. 10). El nombre de tàxons amb noms i usos i el de reports d'ús són elevats i els índexs d'etnobotànica quantitativa mostren la coherència, la robustesa i la fiabilitat dels coneixements. Així, doncs, aquest conjunt de coneixements culturals relatius a un element de la natura (el vegetal) és sòlid al territori considerat.

Això no obstant, i com passa de manera general a les societats industrialitzades, hi ha força usos que són encara coneguts, però ja no posats en pràctica. Treballs com el present són, doncs, necessaris per a salvaguardar aquest patrimoni natural i cultural de cara a facilitar la seva transmissió a les generacions més joves i al seu possible ús per part d'altres investigadors adreçats a la recerca de nous elements per al benestar de la humanitat.

\section{AGRAÏMENTS}

Regraciem especialment els nostres informants, que han compartit amb nosaltres la seva saviesa, així com J. Vigo i P. Barnola, que ens han ajudat en la determinació d'alguns tàxons. Agraïm també al Dr. L. Villar i a un altre revisor anònim llurs 

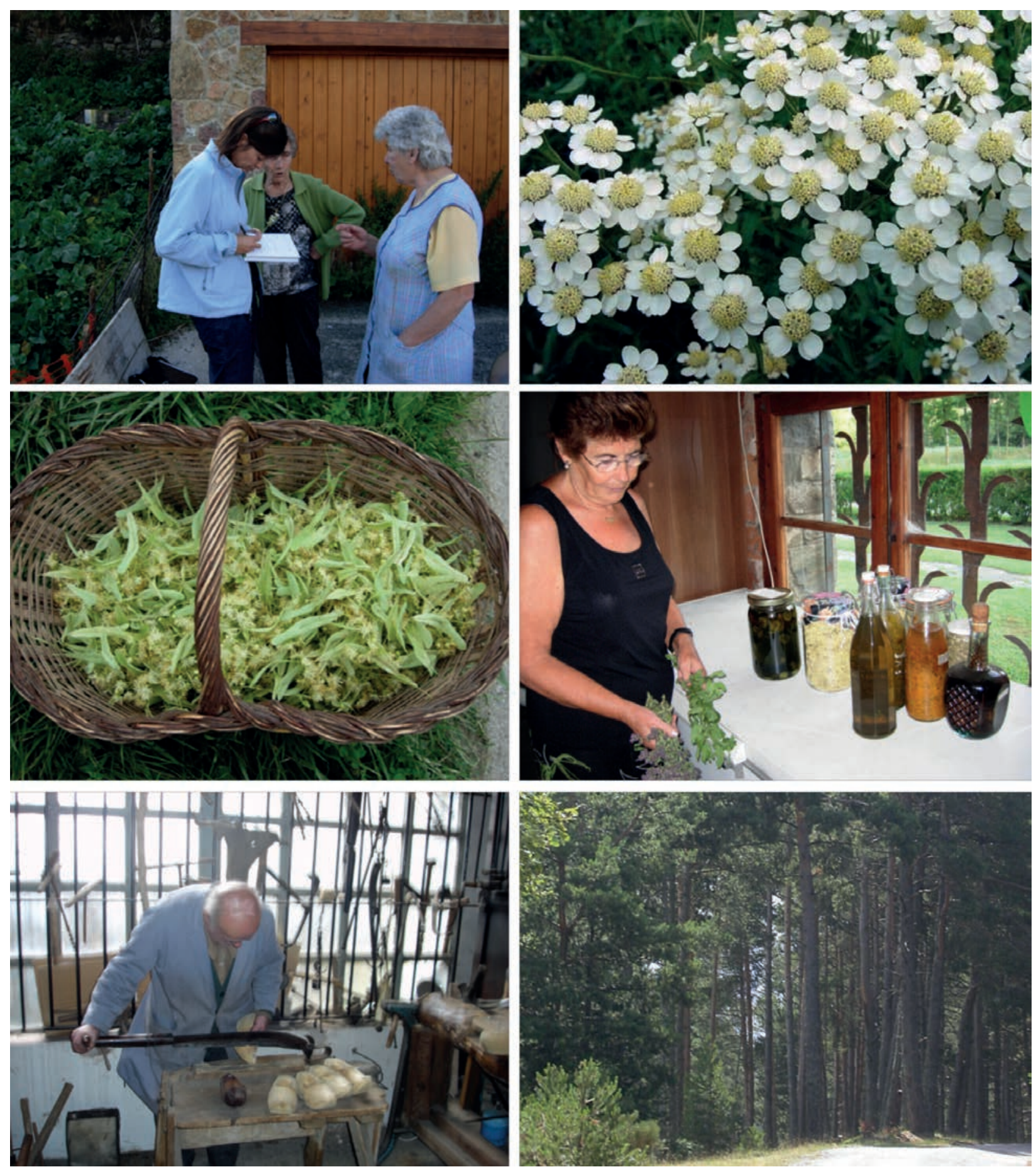

Figura 10. Plantes i informants del Ripollès.

suggeriments. Aquesta recerca s'ha dut a terme amb el suport dels següents ajuts: 2005ACOM00024 de l'Agència per a la Gestió dels Ajuts Universitaris i de Recerca (AGAUR), Generalitat de Catalunya, i Centre d'Estudis Comarcals del Ripollès), 2005SGR00344 (Departament d'Universitats, Recerca i Societat de la Informació, Generalitat de Catalunya), AP07/07 (Institut Ramon Muntaner - Fundació Privada dels Centres d'Estudis de Parla Catalana), SEJ2007-60873/SOCI (Dirección General de Investigación, Ministerio de Educación y Ciencia), 2009SGR439 (Departament d'Universitats, Recerca i Societat de la Informació, Generalitat de Catalunya), 2009ACOM00013 —novament Agència per a la Gestió dels Ajuts Universitaris i de Recerca (AGAUR), Generalitat de Catalunya-, i Centre d'Estudis Comarcals del Ripollès, CSO2011-27565 (Dirección General de Investigación, Ministerio de Ciencia e Innovación) i finalment 2014SGR514 (Departament d'Economia i Coneixement, Generalitat de Catalunya). 


\section{REFERÈNCIES BIBLIOGRÀFIQUES}

Agelet, A. 1999. Estudis d'etnobotànica farmacèutica al Pallars. Tesi Doctoral, Universitat de Barcelona, Barcelona.

APG III (Angiosperm Phylogeny Group) 2009. An update of the Angiosperm Phylogeny Group classification for the orders and families of flowering plants: APG III. Botanical Journal of the Linnean Society 161: 105-121. https://doi. org/10.1111/j.1095-8339.2009.00996.x

Arnold-Apostolides, N. 1991. Ethnobotanique et ethnopharmacologie de la flore de Chypre et de l'est méditerranéen. 6 vols. Centre régional de Phytosociologie, Bailleul.

Aymerich, P., Tenas, B. \& Vigo, J. 2010-2011. Notes florístiques del Ripollès (Pirineus orientals). Acta Botanica Barcinonensia 53: 11-26.

Berlin, B. 1992. Ethnobiological classification: principles of categorization of plants and animals in traditional societies. Princeton University Press, Princeton. https://doi. org/10.1515/9781400862597

Bernard, H. R. 1998. Handbook of methods in cultural anthropology. AltaMira Press, Walnut Creek.

Blanco, E. 1996. El Caurel, las plantas y sus habitantes. Estudio etnobotánico de la Sierra del Caurel (Lugo): la importancia de las plantas para nuestros antepasados. Fundación Caixa Galicia, A Coruña.

Bolòs, O. de, Vigo, J., Masalles, R. M. \& Ninot, J. M. 2005. Flora manual dels Països Catalans. 3a edició. Editorial Pòrtic, Barcelona.

Bonet, M. A. 1991. Estudis etnobotànics a la Vall del Tenes (Vallès Oriental). Tesi de Llicenciatura, Universitat de Barcelona, Barcelona.

Bonet, M. A. 2001. Estudi etnobotànic del Montseny. Tesi Doctoral, Universitat de Barcelona, Barcelona.

Bonet, M. A., Parada, M., Selga, A. \& Vallès, J. 1999. Studies on pharmaceutical ethnobotany in the regions of l'Alt Empordà and Les Guilleries (Catalonia, Iberian Peninsula). Journal of Ethnopharmacology 68: 145-168. https://doi. org/10.1016/S0378-8741(99)00083-5

Bonet, M. A. \& Vallès, J. 2006. Plantes, remeis i cultura popular del Montseny. Etnobotànica d'una reserva de la biosfera. Museu de Ciències Naturals de Granollers \& Brau Edicions, Granollers \& Figueres.

Boukef, M. K. 1986. Les plantes dans la médicine traditionelle tunisienne. Agence de Coopération Culturelle et Technique, Paris.

Burnie G., Forrester, S., Greig, D. et al. 2003. Botanica. Das Abc der Pflanzen. Könemann, Vienna.

Carrió, E. 2013. Contribució a l'etnobotànica de Mallorca. La biodiversitat vegetal i la seva gestió en una illa mediterrània. Tesi Doctoral, Universitat de Barcelona, Barcelona.

Carrió, E., Rigat, M., Garnatje, T., Mayans, M. Parada, M \& Vallès, J. 2012. Plant ethnoveterinary practices in two Pyrenean territories of Catalonia (Iberian Peninsula) and in two areas of the Balearic Islands, and comparison with ethnobotanical uses in human medicine. Evidence-Based Complementary and Alternative Medicine 2012: 896295. https:// doi.org/10.1155/2012/896295

Carvalho, A. M. P. 2005. Etnobotànica del Parque Natural de Montesinho. Plantas, tradición y saber popular en un territorio del noreste de Portugal. Tesi Doctoral, Universidad Autónoma de Madrid, Madrid.

Casana, E. 1993. Patrimonio etnobotánico de la provincia de Córdoba: Subbética, campiña y vega del Guadalquivir. Tesi
Doctoral, Escuela Técnica Superior de Ingeniería Agronómica, Universidad de Córdoba, Córdoba.

Díaz, E. 2009. Iniciació a la recerca etnobotànica. Estudi etnobotànic del Ripollès. Treball de curs de Botànica econòmica, Universitat de Barcelona, Barcelona.

Escalé, D. 2013. Herbes remeieres de Queralbs i de Núria: usos medicinals populars de la Lluïsa Parramon. L'Albí, Berga.

Etkin, N. L. 1996. Medicinal cuisines: diet and ethnopharmacology. International Journal of Pharmacognosy 34: 313326. https://doi.org/10.1076/phbi.34.5.313.13246

Etkin, N. L. 2006. Edible medicines: An ethnopharmacology of food. University of Arizona Press, Tucson.

Fernández-Ocaña, A. M. 2000. Estudios etnobotánicos en el parque natural de las Sierras de Segura, Cazorla y Las Villas. Investigación química de algunas especies interesantes. Tesi Doctoral, Universidad de Jaén, Jaén.

Friedman, J., Yaniu, Z., Dafni, A. \& Palevitch, D. 1986. A preliminary classification of the healing potential of medicinal plants, based on a rational analysis of an ethnopharmacological field survey among bedouins in the Negev desert, Israel. Journal of Ethnopharmacology 16: 275-287. https:// doi.org/10.1016/0378-8741(86)90094-2

Funk, V. A., Susanna, A., Stuessy, T. F. \& Bayer, R. J. (Eds.) 2009. Systematics, evolution and biogeography of Compositae. International Association for Plant Taxonomy, Viena.

Galán, R. 1993. Patrimonio etnobotánico de la provincia de Córdoba: Pedroches, Sierra Norte y vega del Guadalquivir. Tesi Doctoral, Escuela Técnica Superior de Ingeniería Agronómica, Universidad de Córdoba, Córdoba.

Giday, M. 2001. An ethnobotancial study of medicinal plants used by the Zay people in Ethiopia. CMB:s Skriftserie 3: 81-99.

Gilbert, B. \& Alves, L. 2003. Synergy in plant medicines. Current Medicinal Chemistry 10: 13-20. https://doi.org/ 10.2174/0929867033368583

González-Tejero, M. R. 1989. Investigaciones etnobotánicas en la provincia de Granada. Tesi Doctoral, Universidad de Granada, Granada.

Goodman, L. A. 1961. Snowball sampling. The Annals of Mathematical Statistics 32: 148-170. https://doi.org/10.1214/ aoms/1177705148

Gras, A., Garnatje, T., Bonet, M., Carrió, E., Mayans, M., Parada, M., Rigat, M. \& Vallès, J. 2016. Beyond food and medicine, but necessary for life, too. Other folk plant uses in several territories of Catalonia and the Balearic Islands. Journal of Ethnobiology and Ethnomedicine 12: 23. https:// doi.org/10.1186/s13002-016-0097-8

Hardy, M. L. 2000. Herbs of special interest to women. Journal of the American Pharmaceutical Association 40: 234-242. https://doi.org/10.1016/S1086-5802(16)31064-6

Heinrich, M., Ankli, A., Frei, B., Weimann, C. \& Sticher, O. 1998. Medicinal plants in Mexico: healers' consensus and cultural importance. Social Science \& Medicine 47: 18591871. https://doi.org/10.1016/S0277-9536(98)00181-6

ICGC (Institut Cartogràfic i Geològic de Catalunya) 2015. Consultat el 23 d'agost de 2015, a http://www.icc.cat/vissir3/

IDESCAT (Institut d'Estadística de Catalunya) 2011. Consultat el 14 de novembre de 2012, a http://www.idescat.cat

IDESCAT (Institut d'Estadística de Catalunya) 2014. Consultat el 14 d'agost de 2015, a http://www.idescat.cat

International Society of Ethnobiology 2008. International Society of Ethnobiology Code of Ethics (with 2008 additions). Consultat el 23 d'agost de 2015, a www.ethnobiology. net/ethics.php 
Johns, T., Kokwaro, J. O. \& Kimanani, E. K. 1990. Herbal remedies of the Luo of Siaya district, Kenya: establishing quantitative criteria for consensus. Economic Botany 44: 369-381. https://doi.org/10.1007/BF03183922

Kindersley, D. 1999. Nueva enciclopedia de plantas y flores. The Royal Horticultural Society, Grijalbo, Barcelona.

Kindersley, D. 2003. Todas las plantas del jardín. The Royal Horticultural Society, Blume, Barcelona.

Le Floc'h, E. 1983. Contribution à une étude Ethnobotanique de la flore Tunisienne. Imprimerie Officielle de la République Tunisienne, Tunis.

Le Grand, A. \& Wondergem, P. A. 1987. Les phytothérapies anti-infectieuses de la fôret-savane, Sénégal, Afrique Occidentale. Un inventaire. Journal of Ethnopharmacology 21: 109-125. https://doi.org/10.1016/0378-8741(87)90122-X

Leonti, M., Vibrans, H., Sticher, O. \& Heinrich, M. 2001. Ethnopharmacology of the Popoluca, Mexico: an evaluation. Journal of Pharmacy and Pharmacology 53: 1653-1659. https://doi.org/10.1211/0022357011778052

Lin, C. C., Chan, T. Y. \& Deng, J. F. 2004. Clinical features and management of herb-induced aconitine poisoning. Annals of Emergency Medicine 43: 574-579. https://doi. org/10.1016/j.annemergmed.2003.10.046

Llongarriu, M. \& Sala, S. 2005. Herbes remeieres de la Garrotxa: recull de medicina tradicional. Llibres de Batet, Olot.

Mariné, A. \& Vidal, M. C. 2005. Aliments funcionals. Escola Catalana 422: 12-14.

Martínez, M. J. 1993. Investigaciones etnobotánicas en el parque natural de Cabo de Gata-Nijar (Almería). Tesi de Licenciatura de Biología, Universidad de Granada, Granada.

Mulet, L. 1990. Aportaciones al conocimiento etnobotánico de la provincia de Castellón. Tesi Doctoral, Universitat de València, València.

Muntané, J. 1991. Aportació al coneixement de l'etnobotànica de Cerdanya. Tesi Doctoral, Universitat de Barcelona, Barcelona.

Muntané, J. 2005. Etnobotànica, etnofarmàcia i tradicions populars de la Catalunya septentrional (Capcir, Cerdanya $i$ Conflent). Tesi Doctoral, Universitat de Barcelona, Barcelona.

Ortiz, P. 2004. Aproximació als diversos ecosistemes del Ripollès. Annals del Centre d'Estudis Comarcals del Ripollès 2002-2003: 83-102.

Ortuño, I. 2003. Etnobotánica de Los Villares y Valdepeñas de Jaén (sur de la Península Ibérica). Tesi Doctoral, Universidad de Jaén, Jaén.

Palevitch, D., Yaniv, Z., Dafni, A. \& Friedman, J. 1986. Medicinal plants of Israel: an ethnobotanical survey. In: Craker \& J. E. Simon (Eds.), Herbs, spices, and medicinal plants: recent advances in Botany, Horticulture and Pharmacology 1. Oryx Press, Phoenix, 281-345.

Parada, M. 1997. Aportació al coneixement de l'etnoflora de l'Alt Empordà. Tesi de Llicenciatura, Universitat de Barcelona, Barcelona.

Parada, M. 2007. Estudi etnobotànic de l'Alt Empordà. Tesi Doctoral, Universitat de Barcelona, Barcelona.

Parada, M., Bonet, M. A., Carrió, E. \& Vallès, J. 2009. Ethnobotany of the Alt Empordà region (Catalonia, Iberian Peninsula). Plants used in human traditional medicine. Journal of Ethnopharmacology 124: 609-618. https://doi. org/10.1016/j.jep.2009.04.050

Pardo de Santayana, M. 2003. Las plantas en la cultura tradicional de la Antigua Merindad de Campoo. Tesi Doctoral, Universidad Autónoma de Madrid, Madrid.
Pardo de Santayana, M., Morales, R., Aceituno, L. \& Molina, M. (Eds.) 2014. Inventario español de los conocimientos tradicionales relativos a la biodiversidad. Ministerio de Agricultura, Alimentación y Medio Ambiente. Madrid: 149-152.

Pastoret, L. 2009. Què cultivaven els nostres avis? Els conreus tradicionals del poble de Molló. Annals del Centre d'Estudis Comarcals del Ripollès 2007-2008: 255-273.

Pla Comarcal de Muntanya 1995-1999. El Ripollès. Generalitat de Catalunya, Departament de Política Territorial i Obres Públiques, Barcelona.

Portères, R. 1970. Cours d'ethno-botanique et ethno-zoologie (1969-1970) 1: Ethnobotanique générale. Muséum National d'Histoire Naturelle (Laboratoire d'Ethno-botanique et Ethno-zoologie), Faculté des Lettres (Institut d'Ethnologie), Paris.

Pujadas, J. J., Comas, D. \& Roca, J. 2004. Etnografia. Universitat Oberta de Catalunya, Barcelona.

Ragupathy, S., Steven, N. G., Maruthakkutti, M., Velusamy, B. \& Ul-Huda, M. M. 2008. Consensus of the 'Malasars' traditional aboriginal knowledge of medicinal plants in the Velliangiri holy hills, India. Journal of Ethnobiology and Ethnomedicine. 4: 8. https://doi.org/10.1186/17464269-4-8

Raja, D. 1995. Estudis etnobotànics a la comarca de la Segarra. Tesi de Llicenciatura, Universitat de Barcelona, Barcelona.

Rigat, M. 2005. Estudi etnobotànic de la Vall de Camprodon (Alta Vall del Ter, Pirineus). Màster experimental, Universitat de Barcelona, Barcelona.

Rigat, M., Bonet, M. A., Garcia, S., Garnatje, T. \& Vallès, J. 2006. Ethnobotanical studies in the high river Ter valley (Pyrenees, Catalonia, Iberian Peninsula). In: Ertug, F. Z. (Ed.), Ethnobotany: at the junction of the continents and the disciplines: Proceedings of the IVth International Congress of Ethnobotany (ICEB 2005). Istanbul, Turkey, 21-21 August 2005. Yayinlari, Istanbul: 523-526.

Rigat, M., Bonet, M. A., Garcia, S., Garnatje, T. \& Vallès, J. 2007. Studies on pharmaceutical ethnobotany in the high river Ter valley (Pyrenees, Catalonia, Iberian Peninsula). Journal of Ethnopharmacology 113: 267-277. https://doi. org/10.1016/j.jep.2007.06.004

Rigat, M., Bonet, M. A., Garcia, S., Garnatje, T. \& Vallès, J. 2009. Ethnobotanical studies in the high river Ter valley (Pyrenees, Catalonia, Iberian Peninsula). Non-crop food vascular plants and crop food plants with medicinal properties. Ecology of Food and Nutrition 48: 303-326. https:// doi.org/10.1080/03670240903022320

Rigat, M., D’Ambrosio, U., Garnatje, T., Gras, A., Parada, M. \& Vallès, J. 2016. Wild food plants and minor crops in the Ripollès district (Catalonia, Iberian Peninsula): potentialities for developing a local production, consumption and exchange program. Journal of Ethnobiology and Ethnomedicine 12: 49. https://doi.org/10.1186/s13002-016-0122-y

Rigat, M., Garnatje, T., Moré, E. \& Vallès, J. 2013a. Un receptari medicinal del Ripollès de principis del segle XX. Facsímil, edició crítica i comentaris. Annals del Centre d'Estudis Comarcals del Ripollès 2011-2012: 73-128.

Rigat, M., Vallès, J., D’Ambrosio, U., Gras, A. Iglésias, J. \& Garnatje, T. 2015. Plants with topical uses in the Ripollès district (Pyrenees, Catalonia, Iberian Peninsula): ethnobotanical survey and pharmacological validation in the literature. Journal of Ethnopharmacology 164: 162-179. https:// doi.org/10.1016/j.jep.2015.01.055

Rigat, M., Vallès, J., Iglésias, J. \& Garnatje, T. 2013b. Traditional and alternative natural therapeutic products used in the 
treatment of respiratory tract infectious diseases in the eastern Catalan Pyrenees (Iberian Peninsula). Journal of Ethnopharmacology 148: 411-422. https://doi.org/10.1016/j. jep.2013.04.022

Rodrigues, J. S. C. 2001. Contributo para o estudo etnobotânico das plantas medicinais e aromáticas no parque natural da Serra de S. Mamede. Tesi de Màster, Universidade de Lisboa, Lisboa.

Rosenthal, J. P. 2006. Politics, culture and governance in the development of prior informed consent in indigenous communities. Current Anthropology 47:119-142. https://doi. org $/ 10.1086 / 497670$

Selga, A. 1998. Estudis etnobotànics a les Guilleries. Tesi de Llicenciatura, Universitat de Barcelona, Barcelona.

Serna, E. \& Vila, P. 2007. Un receptari de manescalia i de remeis casolans de la casa Bruel de Molló. Annals del Centre d'Estudis Comarcals del Ripollès 2005-2006: 203-229.

Trotter, R. T. \& Logan, M. H. 1986. Informant consensus: a new approach for identifying potentially effective medicinal plants. In: Etkin, N. L. (Ed.), Plants in indigenous medicine and diet, behavioural approaches. Redgrave Publishing Company, Bredford Hills: 91-112.

Vallès, J. 2010. Variació geolingüística en la comunicació especialitzada. El cas dels noms de les plantes. In: Fargas, F. X. (Ed.), Espais Terminologics 2009. Terminologia $i$ variació geolingüística. Eumo Editorial - Termcat, Barcelona: 129-149.

Vallès, J. (amb la col·laboració d'A. Agelet, M. A. Bonet, E. Carrió, T. Egea, T. Garnatje, J. Muntané, M. Parada, M. Puig, D. Raja, M. Rigat, M. Santamaria \& A. Selga). 2007. La recerca en etnobotànica a Catalunya: objectius, mètodes, zones estudiades i alguns resultats i comentaris generals. RIDEC (Recerca i Difusió de l'Etnologia Catalana) 2007: $1-10$.

Vallès, J., Agelet, A., Bonet, M. A. et al. 2005. Algunes qüestions entorn de la fitonímia i els aspectes lingüístics de l'etnobotànica. In: Massot, J. (Coord.), Estudis de llengua i literatura catalanes (Miscel·lània Joan Veny, 5). Publicacions de l'Abadia de Montserrat, Barcelona: 273-293.

Vallès, J., Bonet, M. A. \& Agelet, A. 2004a. Ethnobotany of Sambucus nigra L.: the integral exploitation of a natural resource in mountain regions of Catalonia (Iberian Peninsula). Economic Botany 58: 456-469. https://doi.org/10.1663/0013-0001(2004)058[0456:EOSNLI]2.0.CO;2

Vallès, J., Bonet, M. A., Agelet, A. \& Selga, A. 2004b. 'Quaranta dies en alcohol a sol i serena"... y el sabor embotellado: la "ratafia", licor catalán de plantas aromáticas. In: Garrido, A. (Ed.), El sabor del sabor: hierbas aromáticas, condimentos y especias. Publicaciones de la Universidad de Córdoba, Córdoba: 255-276.

Vallès, J., Bonet, M. A., Garnatje, T., Muntané, J., Parada, M. \& Rigat, M. 2010. Sambucus nigra L. in Catalonia (Iberian Peninsula): popular knowledge and holistic exploitation of an underutilized natural resource. In: Peter, K. V. (Ed.), Underutilized and Underexploited Horticultural Crops 5. Publishing Agency, New Delhi: 393-424.

Vallès, J., D'Ambrosio, U., Gras, A., Parada, M., Serrasolses, G. \& Garnatje, T. 2015. Una denominació recent per a una ciència antiga. Algunes consideracions sobre l'etnobotànica i la seva situació a Catalunya. Revista de Girona 290: 80-83.

Vallès, J. (Dir.), Veny, J., Vigo, J., Bonet, M. A., Julià, M. A. \& Villalonga, J. C. 2014. Noms de plantes. Corpus de fitonímia catalana. Termcat - Centre de Terminologia \& Universitat de Barcelona, Barcelona.

Vayreda, E. 1881. Catàlech de la flora de la vall de Núria. Associació d'Excursions Catalana, Barcelona.

Vigo, J. 1983. El poblament vegetal de la Vall de Ribes. Generalitats i catàleg florístic. Acta Botanica Barcinonensia 35: 1-793.

Villar, L., Palacín, J. M., Calvo, C., Gómez, D. \& Montserrat, G. 1992. Plantas medicinales del Pirineo Aragonés y demás tierras oscenses (2 $2^{\mathrm{a}}$ ed.). Diputación de Huesca, Huesca. 


\section{Abies alba Mill. (pinàcies) \\ BCN 24699}

\section{NOMS POPULARS}

Avet $(538,546,547,548,549,559,565,566,578,579,581,1321)$

Avet de Setcases $(753,754,755)$

\section{USOS MEDICINALS}

\section{Fructificació}

Antiasmàtic

FONT 1321. DESCRIPCIÓ DE L'ÚS FETA PER L'INFORMANT. Per a l'asma i l'ofegament. FORMA FARMACĖUTICA I ÚS. Tisana (ús intern). DESTINACIÓ. Medicina humana.

Anticatarral

FONTS 538, 565, 566, 578, 579, 581, 753, 754, 755. DESCRIPCIÓ DE L'ÚS FETA PELS INFORMANTS. Va bé per als refredats $(538,581)$. Va bé per als constipats i la tos $(565$ 566). Per als refredats $(753,754,755)$. Per als constipats $(578,579)$. FORMA FARMACĖUTICA I ÚS. Xarop (ús intern). PREPARACIÓ. Pinyes tendres amb sucre, se'n fa un xarop $(538,565,566)$. Les pinyes aixafades i amb sucre, es deixen degotar i se'n fa xarop $(753,754,755)$. Amb les pinyes d'avet i sucre es feia xarop $(578,579)$. Les pinyes amb sucre, se'n fa un xarop (581). DESTINACIO. Medicina humana.

Antitussigen

FONTS 547, 548, 565, 566. DESCRIPCIÓ DE L'ÚS FETA PELS INFORMANTS. Va molt be per a la tos $(547,548)$. Va bé per als constipats i la tos $(565,566)$. FORMA FARMACĖUTICA I ÚS. Xarop (ús intern). PREPARACIÓ. Es fa un xarop amb sucre roig, per a anar bé han de ser les pinyes de dalt de tot que són més joves i esqueixar-les, no tallar-les perquè així fan més suc $(547,548)$. Pinyes tendres amb sucre, se'n fa un xarop $(565,566)$. DESTINACIÓ Medicina humana.

\section{Resina}

Antineoplàstic

FONT 546. DESCRIPCIÓ DE L'ÚS FETA PER L'INFORMANT. L'oli diuen que cura el càncer FORMA FARMACĖUTICA I ÚS. Sense forma farmacèutica (ús directe, ús intern). PREPARACIÓ. La gent abans anava a la muntanya a fer-ne, es feia al mes de juliol, quan fa calor. Duien una esquella ben llimada d'un cantó a la qual havien tret el batall; s'havien d'enfilar a l'avet i punxar-li les berrugues on hi ha l'oli. S'hi estaven tot el dia per a fer-ne un quart de litre. A casa es colava amb un drap per tal de treure-li les impureses i quedava un ol espès i ben clar que es guardava en ampolles. DESTINACIÓ. Medicina humana.

\section{Antitífic}

FONT 549. DESCRIPCIÓ DE L'ÚS FETA PER L'INFORMANT. Per a la gent que havia tingut tifus, però no recordo si se'l preneien o els untaven. FORMA FARMACĖUTICA I ÚS
Desconegut per l'informant. PREPARACIÓ. Sempre teníem oli d'avet. Els avets joves en tenen més bossetes. El pare agafava una llauneta i feia com una canal, s'enfilava a l'avet i punxava la bosseta i amb molta estona anava agafant I'oli. DESTINACIÓ. Medicina humana.

Desconegut per l'informant

FONTS 559, 571. FORMA FARMACĖUTICA I ÚS. Desconegut per l'informant PREPARACIÓ. S'agafa I'oli (559). DESTINACIÓ. Medicina humana. OBSERVACIONS. N'haviem anat a fer a Campelles. No recordo per a què el feien servir (571).

Per a trastorns del sistema musculoesquelètic

FONT 549. DESCRIPCIÓ DE L'ÚS FETA PER L'INFORMANT. El posàvem a les potes del bestiar quan hi tenien mal. FORMA FARMACÈUTICA I ÚS. Sense forma farmacèutica (ús directe, ús extern). PREPARACIÓ. Oli. DESTINACIÓ. Medicina veterinària.

\section{ALTRES OBSERVACIONS}

FONT 549. DESCRIPCIÓ FETA PER L'INFORMANT. L'agafava a Prats, a sota la Cubil.

\section{Acer campestre L. (aceràcies)}

BCN 29613

\section{NOMS POPULARS}

Auró $(520,521)$

\section{ALTRES USOS}

Tija

Fuster: elaboració de mobles

FONTS 520, 521. DESCRIPCIÓ DE L'ÚS FETA PELS INFORMANTS. Dels brots de l'auró en feien els llitets del nen Jesús.

Acer opalus Mill. subsp. opalus (aceràcies)

BCN 29615

\section{NOMS POPULARS}

Blada $(586,587)$

\section{ALTRES OBSERVACIONS}

FONTS 586, 587. DESCRIPCIÓ FETA PELS INFORMANTS. M'he fixat aquest any que és el primer arbre que treu la fulla. 
Acer rubrum L. (aceràcies)

BC 134650

\section{NOMS POPULARS}

Arce $(520,521)$

\section{ALTRES OBSERVACIONS}

FONTS 520, 521. DESCRIPCIÓ FETA PELS INFORMANTS. Va venir amb un test del Canadà. És el símbol del Canadà.

\section{Aconitum anthora L. (ranunculàcies)}

BCN 27297

\section{NOMS POPULARS}

Tora blanca $(546,556,557,559,586,587)$

Tora groga $(569,570,1321)$

\section{ACCIONS NOCIVES O TÒXIQUES}

\section{Planta sencera}

FONTS 546, 556, 557, 559,569,570,586,587, 1321. DESCRIPCIÓ DE L'ACCIÓ NOCIVA O TÒXICA FETA PELS INFORMANTS. Tòxica $(546,559,569,570)$. Molt tòxica $(556,557)$. Molt verinosa (1321). GRAU DE TOXICITAT. Letal (1321). TOXICITAT EN ANIMALS. Sí (1321).

\section{ALTRES OBSERVACIONS}

FONTS 569, 570, 586, 587, 1321. DESCRIPCIÓ FETA PELS INFORMANTS. N'hi ha menys però també n'hi ha $(569,570)$. N'he vist en algun lloc, em sembla que és darrere Puigestela allà als Tarters, penjada al bac $(586,587)$. Diuen que és igual que la tora blava (Aconitum napellus) (1321)

\section{Aconitum napellus L. subsp. vulgare Rouy et Fouc.} (ranunculàcies)

BCN 24702

\section{NOMS POPULARS}

Tora $(511,512,513,514,515,516,528,532,538,539,540,545,547,548,553,569,570$, $571,572,573,574,575,576,577,753,754,755,1213,1214,1322,1328,1329,1332,1333$ $1334,1337,1338,1341,1342,1353,1354)$

Tora blava $(556,557,559,586,587,1321)$

Tora lilada (546)

\section{USOS MEDICINALS}

\section{Arrel}

Antiartrític

FONTS 1213, 1214. DESCRIPCIÓ DE L'ÚS FETA PELS INFORMANTS. Per al dolor d'artritis. FORMA FARMACĖUTICA I ÚS. Desconegut per l'informant. DESTINACIÓ Medicina humana. OBSERVACIONS. No la fa servir.

Desconegut per l'informant

FONT 571. FORMA FARMACĖUTICA I ÚS. Desconegut per l'informant. OBSERVACIONS Se l'enduien per a farmàcies, diuen que és bona la rel.

\section{No consta}

Antireumàtic

FONT 532. DESCRIPCIÓ DE L'ÚS FETA PER L'INFORMANT. Es feia servir per a fer fregues a la gent que tenia reuma. FORMA FARMACEUTICA I ÚS. Ungüent (ús extern). PREPARACIÓ. Es feia un ungüent amb greix. DESTINACIÓ. Medicina humana. OBSERVACIONS. Diuen que de la tora se n'extreia el cloroform, el meu home n'anava a buscar per a vendre.

\section{ALTRES USOS}

\section{Planta sencera}

Altres informacions

FONTS 538, 1337, 1338, 1341, 1342. DESCRIPCIÓ DE L'ÚS FETA PELS INFORMANTS. La gent la collia per vendre-la i es pagava molt bé (538). Recorden que els herbolaris en compraven i que usaven la rel $(1337,1338)$. Abans en compraven molta els herbolaris (1341, 1342)

\section{ACCIONS NOCIVES O TÒXIQUES}

\section{Arrel}

FONT 1321. DESCRIPCIÓ DE L'ACCIÓ NOCIVA O TÒXICA FETA PER L'INFORMANT. Molt verinosa. Una vegada vam bullir una rel de tora amb la llet de cabra per a matar rates, el gos s'ho va beure i va fer tres passes i va quedar mort. GRAU DE TOXICITAT. Letal. gos s'ho va beure i va fer tres
TOXICITAT EN ANIMALS. Sí. 
Fulla

FONT 532. DESCRIPCIÓ DE L'ACCIÓ NOCIVA O TÒXICA FETA PER L'INFORMANT. És una planta molt tòxica. Uns de la Cerdanya en van menjar amanida pensant que menjaven coscolls (Molopospermum peloponnesiacum) i van morir. GRAU DE TOXICITAT. Letal. VIA D'INTOXICACIÓ. Via interna. TOXICITAT LLIGADA A L'ÚS MEDICINAL. No.

\section{Part aèria}

FONTS 528, 553, 571, 574, 575, 576, 577, 753, 754, 755. DESCRIPCIÓ DE L'ACCIÓ NOCIVA O TOOXICA FETA PELS INFORMANTS. És molt dolent, pot matar el bestiar, si les cabres en mengen les mata (528). És molt tòxica. Si culls un ram la saba et pot entrar pels porus de la pell i provocar-te una aturada cardíaca (553). És tòxica. L'animal que en menja mor (571). A Fontlletera una vaca que va vedellar li va rodolar el vedell avall i va caure al mig d'una mata de tora, la vaca va llepar el vedell i l'endemà eren morts tots dos. A Queralbs un home va agafar xicoines (Taraxacum dissectum) i també va morir perquè les havia collit enmig d'unes mates de tora $(753,754,755)$. És tòxica, les cabres si en mengen es moren $(574,575,576,577)$. GRAU DE TOXICITAT Letal $(528,553,571,574,575,576,577,753$, $754,755)$. VIA D'INTOXICACIÓ. Via interna (528). Via interna i externa $(553,753,754,755)$ TOXICITAT EN ANIMALS. Sí $(528,574,575,576,577,753,754,755)$.

\section{Planta sencera}

FONTS $511,512,513,514,515,516,538,539,540,541,545,546,547,548,556,557,559$ $569,570,572,573,586,587,1322,1328,1329,1332,1333,1334,1337,1338,1341,1342$, 1353, 1354. DESCRIPCIÓ DE L'ACCIÓ NOCIVA O TOXXICA FETA PELS INFORMANTS. ÉS verinosa $(515,516)$. És molt verinosa $(511,512,513,514)$. Planta tòxica $(545)$. Un d'Andorra en diu l'herba de les viudes $(539,540)$. Tòxica i mortal $(546)$. Molt tòxica $(541,556,557)$. El bestiar no se la menja $(547,548)$. És tòxica $(559,572,573,1322)$. Tòxica $(569,570)$. És bestiar no se la menja $(547,548)$. Es toxica $(559,572,573,1322)$. Toxica $(569,570)$. Es
dolenta, les ovelles no la toquen gota; a les cabres, a vegades els fa gràcia i se'n mor alguna dolenta, les ovelles no la toquen gota; a les cabres, a vegades els fa gràcia i se'n mor alguna $(586,587)$. És tòxica, el bestiar no la toca $(1328,1329)$. Diu que és verinosa, però que segur que té una utilitat, encara que no la sap $(1332,1333,1334)$. Diuen que és molt verinosa $(1337,1338)$. És molt tòxica $(1341,1342)$. És molt dolenta, en Coma va estar a punt de morir perquè en va amanir pensant que eren coscolls $(1353,1354)$. GRAU DE TOXICITAT. Letal
(546, 1353, 1354). TOXICITAT LLIGADA A L'ÚS MEDICINAL. No (545). TOXICITAT EN ANIMALS. Sí $(547,548,586,587)$.

\section{Aconitum vulparia Reichenb. (ranunculàcies)}

BCN 48017

\section{NOMS POPULARS}

Tora $(748,749)$

\section{ACCIONS NOCIVES O TÒXIQUES}

Planta sencera
FONTS 748, 749. DESCRIPCIÓ DE L'ACCIÓ NOCIVA O TÒXICA FETA PELS INFORMANTS. És tòxica. No hi ha cap bestiar que se la mengi. La d'aquí a Sant Amand floreix blanc. TOXICITAT EN ANIMALS. Sí.

\section{Achillea millefolium L. (compostes)}

BCN 24700

\section{NOMS POPULARS}

Cent fulles (504)

Herba de cent fulles $(507,509,510,561,562,563)$

Herba de dall (525)

Herba de les cent fulles $(505,506,517,539,540,572,573)$

Herba de mil fulles $(520,521,583,584,585)$

Herba de tall $(526,538,553,590,591,592,753,754,755,1215,1293,1300,1310,1311$ $1312,1322,1327,1332,1333,1334,1335,1336,1339,1340,1345,1346,1347,1348,1349$, $1350,1351,1361,1362$

Herba dels conills $(1311,1312)$

Mil fulles (581)

\section{USOS MEDICINALS}

\section{Arrel}

Antihipertensiu

FONTS 1345, 1346. DESCRIPCIÓ DE L'ÚS FETA PELS INFORMANTS. Per a fer baixar la pressió. FORMA FARMACĖUTICA I ÚS. Tisana (ús intern). PREPARACIÓ. Decocció. Aigua de la rel. DESTINACIÓ. Medicina humana.

\section{Inflorescència}

Abortiu

FONTS 1350, 1351. DESCRIPCIÓ DE L'ÚS FETA PELS INFORMANTS. És abortiva FORMA FARMACEUUTICA I ÚS. Tisana (ús intern). DESTINACIÓ. Medicina humana.

Analgèsic

FONTS 1339, 1340. DESCRIPCIÓ DE L'ÚS FETA PELS INFORMANTS. Va bé per al dolor FORMA FARMACĖUTICA I ÚS. Tisana (ús intern). PREPARACIÓ. Decocció. DESTINACIÓ. Medicina humana.

Antidiarreic

FONTS 1339, 1340. DESCRIPCIÓ DE L'ÚS FETA PELS INFORMANTS. Per a la diarrea FORMA FARMACĖUTICA I ÚS. Tisana (ús intern). PREPARACIÓ. Decocció. DESTINACIÓ. Medicina humana. 


\section{Antihipertensiu}

FONTS 505, 506, 591, 592, 1293, 1327, 1335, 1361, 1362. DESCRIPCIÓ DE L'ÚS FETA PELS INFORMANTS. Per a rebaixar la sang $(505,506,591,592)$. Deien que anava bé per a la pressió, però no ho feien servir (1293). Per a fer baixar la pressió $(1327,1361,1362)$. Pe a regular la pressió (1335). FORMA FARMACĖUTICA I ÚS. Tisana (ús intern) PREPARACIÓ. Decocció $(505,506,591,592,1293,1327)$. Infusió (1335). Infusió de les flors (1361, 1362). DESTINACIÓ. Medicina humana. OBSERVACIONS. La venien als herbolaris (1293). La gent de fora se n'emportava molta (1335).

Antiinflamatori intestinal

FONTS 517, 1322. DESCRIPCIÓ DE L'ÚS FETA PELS INFORMANTS. Per al mal de ventre $(517,1322)$. FORMA FARMACĖUTICA I ÚS. Tisana (ús intern). PREPARACIÓ. Decocció (517, 1322). DESTINACIO. Medicina humana. OBSERVACIONS. Es fa servir com la camamilla (Achillea ptarmica subsp. pyrenaica) (1322).

Antisèptic extern

FONT 504. DESCRIPCIÓ DE L'ÚS FETA PER L'INFORMANT. Per a rentar mals desinfectar. FORMA FARMACÉUTICA I ÚS. Bany (ús extern). PREPARACIÓ. Decocció DESTINACIO. Medicina humana.

Cicatritzant

FONTS 1311, 1312. DESCRIPCIÓ DE L'ÚS FETA PELS INFORMANTS. Va bé per a les llagues, fa pellar molt. FORMA FARMACEUTICA I ÚS. Desconegut per l'informant. DESTINACIÓ. Medicina humana.

Desconegut per l'informant

FONT 1310. FORMA FARMACĖUTICA I ÚS. Desconegut per l'informant. OBSERVACIONS Ells no la utilitzaven com a medicinal, però n'anaven a buscar per a vendre.

Digestiu

FONT 504. DESCRIPCIÓ DE L'ÚS FETA PER L'INFORMANT. Per a pair. FORMA FARMACĖUTICA I ÚS. Tisana (ús intern). PREPARACIÓ. Decocció. DESTINACIÓ. Medicina humana.

Diürètic

FONTS 539, 540. DESCRIPCIÓ DE L'ÚS FETA PELS INFORMANTS. És com una camamilla, és estomacal i també diürètica. FORMA FARMACĖUTICA I ÚS. Tisana (ús intern). PREPARACIO. Decocció. DESTINACIO. Medicina humana.

Estomacal

FONTS 539, 540. DESCRIPCIÓ DE L'ÚS FETA PELS INFORMANTS. És com una camamilla, és estomacal i també diürètica. FORMA FARMACEUTICA I ÚS. Tisana (ús intern). PREPARACIÓ. Decocció. DESTINACIÓ. Medicina humana.

Hematocatàrtic

FONTS 1332, 1333, 1334. DESCRIPCIÓ DE L'ÚS FETA PELS INFORMANTS. Per a neteja la sang. FORMA FARMACĖUTICA I ÚS. Tisana (ús intern). PREPARACIÓ. En infusió. DESTINACIO. Medicina humana.
Hemostàtic intern

FONTS 1350, 1351. DESCRIPCIÓ DE L'ÚS FETA PELS INFORMANTS. Per a les hemorràgies. FORMA FARMACĖUTICA I ÚS. Tisana (ús intern). DESTINACIÓ. Medicina humana.

Vasotònic

FONTS 553, 1215, 1336. DESCRIPCIÓ DE L'ÚS FETA PELS INFORMANTS. La mare la prenia per a ajudar a circular la sang (553). Per a la circulació (1215). Anava bé per a la circulació (1336). FORMA FARMACEUTICA I USS. Tisana (ús intern). PREPARACIÓ. Decocció $(553,1215,1336)$. DESTINACIÓ. Medicina humana. OBSERVACIONS. La collien per a vendre. Una vegada la va prendre i no es va trobar bé, no l'ha provat més (1336).

Vulnerari

FONTS 1311, 1312, 1339, 1340. DESCRIPCIÓ DE L'ÚS FETA PELS INFORMANTS. Va bé per a les llagues, fa pellar molt $(1311,1312)$. Per a quan et fas un tall $(1339,1340)$. FORMA FARMACĖUTICA I ÚS. Desconegut per l'informant $(1311,1312)$. Emplastre (ús extern) $(1339,1340)$. PREPARACIÓ. En emplastres de cansalada quan et fas un tall $(1339,1340)$ DESTINACIÓ. Medicina humana.

\section{No consta}

Desconegut per l'informan

FONTS 507, 509, 510, 590. FORMA FARMACÈUTICA I ÚS. Desconegut per l'informant. OBSERVACIONS. No recordo l'ús, però la fèiem servir $(507,509,510)$. Abans la buscaven per a fer medicines (590).

\section{USOS ALIMENTARIS}

\section{Part aèria}

Ingestió de la part de la planta crua - Fresca (sense preparació)

FONTS 538, 561, 562, 563, 572, 573, 583, 584, 585, 590, 1347, 1348, 1349. DESCRIPCIÓ DE L'ÚS FETA PELS INFORMANTS. Per a menjar els conills $(538,561,562,563)$. Es donava als conills $(572,573,583,584,585,590)$. Per a menjar als conills $(1347,1348,1349)$. DESTINACIÓ. Alimentació animal $(538,561,562,563,572,573,583,584,585,590,1347$ 1348, 1349).

\section{ALTRES USOS}

\section{No consta}

Altres informacions

FONTS 525, 526, 527. DESCRIPCIÓ DE L'ÚS FETA PELS INFORMANTS. La compraven els herbolaris.

\section{BARREGES AMB AQUEST TÀXON}

Inflorescència 
FONTS 520, 521. Entrevista 56, barreja III (vegeu catàleg de barreges)

FONTS 753, 754, 755. Entrevista 67, barreja III (vegeu catàleg de barreges) FONTS 753, 754, 755. Entrevista 67, barreja VII (vegeu catàleg de barreges)

FONT 581. Entrevista 94, barreja III (vegeu catàleg de barreges)

\section{Achillea ptarmica L. subsp. pyrenaica (Sibth. ex Godr. in Gren. et Godr.) Rouy (compostes)}

BCN 24701

\section{NOMS POPULARS}

Camamilla (532, 538, 539, 540, 552, 559, 574, 575, 576, 577, 753, 754, 755, 1213, 1214 $1215,1317,1321,1341,1342,1350,1351$

Camamilla de muntanya $(525,526,527,538,541,542,543,544,545,547,548,556,557$ $558,574,575,576,577,588,590,591,592,1293,1294,1296,1297,1298,1300,1307$ $1308,1309,1310,1311,1312,1313,1314,1318,1319,1320,1322,1323,1325,1326,1327$ $1328,1329,1330,1335,1337,1338,1339,1340,1343,1344,1345,1346,1347,1348,1349$ $1353,1354,1361,1362)$

Camamilla de Núria $(511,512,513,514,528,533,534,538,541,545,546,549,553,569$, $570,571,572,573,580,748,749$ )

Camamilla de Rojà (1331)

\section{USOS MEDICINALS}

\section{Inflorescència}

Analgèsic

FONT 1330. DESCRIPCIO DE L'US FETA PER L'INFORMANT. Per al dolor. FORMA FARMACEUTICA I ÚS. Liniment (ús extern). PREPARACIÓ. Confitada en oli. DESTINACIO. Medicina humana.

Anticatarral

FONTS 538, 1317, 1321. DESCRIPCIÓ DE L'ÚS FETA PELS INFORMANTS. Per als refredats (538). Per als constipats (1317). Quan estàs refredat va bé perquè et fa sua (1321). FORMA FARMACËUTICA I ÚS. Tisana (ús intern). PREPARACIO. Decocció (538). DESTINACIO. Medicina humana.

Antidiarreic

FONTS 591, 592. DESCRIPCIÓ DE L'ÚS FETA PELS INFORMANTS. Per a quan els vedells tenen diarrea. FORMA FARMACEUTICA I ÚS. Tisana (ús intern). PREPARACIO. Decocció. DESTINACIÓ. Medicina veterinària.

Antiinflamatori gàstric
FONT 1327. DESCRIPCIÓ DE L'ÚS FETA PER L'INFORMANT. Per a quan tens cremor. Medicina humana.

Antiinflamatori intestinal

FONTS $511,512,513,514,528,532,533,534,542,543,544,545,546,547,548,558,559$ $569,570,571,572,573,574,575,576,577,580,588,590,591,592,748,749,753,754$ $755,1297,1298,1310,1314,1317,1318,1319,1322,1323,1325,1326,1330,1331,1335$ 755, $1339,138,130$ I INFORMANTS. Per al mal de panxa $(511,512,513,514,528,532,748,749,1297,1298$ 1317, 1319, 1330, 1335). Per al mal de ventre $(533,534,546,572,573,1310,1314,1322$ $1323,1325,1326,1331,1345,1346,1353,1354,1361,1362)$. Per a la panxa $(542,543$, $544,545,547,548,559,569,570,574,575,576,577,588,591,592,753,754,755,1339$ 1340). Per al mal de ventre i estómac (571). És bona per a la panxa (580). És la més bona per a la panxa (590). Per al mal de ventre del bestiar $(574,575,576,577)$. FORMA FARMACEUTICA I US. Tisana (ús intern). PREPARACIO. Decocció $(511,512,513,514$ $528,532,533,534,542,543,544,545,546,547,548,558,559,569,570,571,572,573$ $574,575,576,577,580,588,590,591,592,748,749,753,754,755,1298,1318,1319$ $1322,1325,1326,1330,1331,1335,1339,1340)$. La flor en infusió (1297). En infusió, també s'hi pot escaldar una cullerada d'aiguardent (1323). En infusió $(1345,1346,1361,1362)$. EFECTES SECUNDARIS. Sí. DESTINACIO Medicina EFECTES SECUNDARIS. SI. DESTINACIO. Medicina humana $(511,512,513,514,528$, $532,533,534,542,543,544,545,546,547,548,558,559,569,570,571,572,573,574$ $575,576,577,580,588,590,591,592,748,749,753,754,755,1297,1298,1310,1314$ $1317,1318,1319,1322,1323,1325,1326,1330,1331,1335,1339,1340,1345,1346,1353$ $1354,1361,1362)$. Medicina veterinària $(574,575,576,577)$. OBSERVACIONS. Si tens vòmits no va be de prendre'n perque et fa vomitar mes $(511,512,513,514)$. Es molt amarga la trobo molt de mal prendre (532). És amargant, però és molt bona per medicina (528). No la fem servir, és massa amarganta (558). És molt més forta (571). És molt forta $(569,570)$. No és tant amargant com la camamilla borda (Tanacetum parthenium) (580). És la veritable, és molt bona $(574,575,576,577)$. És la més amargant, però la més estimada (1310). La de muntanya és la més medicinal (1314). Abans la feia servir, ara no en té (1318). Li agrada més la del botó (Santolina chamaecyparissus) (1335).

Antinauseabund

FONTS 539, 540, 1307, 1308, 1309, 1310, 1311, 1312, 1313, 1325, 1326, 1327, 1331, 1353 , 1354. DESCRIPCIÓ DE L'ÚS FETA PELS INFORMANTS. Per al mareig (539, 540, 1307 , $1308,1309,1310,1311,1312,1313,1325,1326,1327,1331,1353,1354)$. FORMA FARMACEUTICA I ÚS. Tisana (ús intern). PREPARACIO. Decocció (539, 540, 1307, 1308, $1309,1311,1312,1325,1326,1327,1331)$. DESTINACIÓ. Medicina humana. OBSERVACIONS. És la més amargant, però la més estimada (1310). En tenen sempre $(1311,1312)$.

Antisèptic ocula

FONTS 545, 591, 592, 1314, 1317, 1319, 1337, 1338, 1339, 1340, 1347, 1348, 1349, 1350 1351. DESCRIPCIÓ DE L'ÚS FETA PELS INFORMANTS. Per als ulls $(545,1337,1338$ $1339,1340)$. Per a quan les vaques tenen mal als ulls $(591,592)$. Per a banyar els ulls $(1314$, $1319,1347,1348,1349,1350,1351)$. Per a rentar els ulls quan els tens malalts (1317). 
FORMA FARMACĖUTICA I ÚS. Bany (ús extern). PREPARACIÓ. Decocció (545, 591, 592 1319, 1337, 1338, 1339, 1340, 1347, 1348, 1349). Infusió (1317). DESTINACIÓ. Medicina humana $(545,1314,1317,1319,1337,1338,1339,1340,1347,1348,1349,1350,1351)$ Medicina veterinària $(591,592)$. OBSERVACIONS. Diu que la de muntanya és la més medicinal (1314).

Cardiotònic

FONT 1330. DESCRIPCIÓ DE L'ÚS FETA PER L'INFORMANT. Per al cor. FORMA FARMACĖUTICA I ÚS. Tisana (ús intern). PREPARACIÓ. Decocció. DESTINACIÓ. Medicina humana.

Digestiu

FONTS 532, 539, 540, 541, 549, 553, 1215, 1293, 1294, 1296, 1300, 1310, 1328, 1329 $1337,1338,1341,1342,1347,1348,1349,1353,1354$. DESCRIPCIÓ DE L'ÚS FETA PELS INFORMANTS. Per al bestiar si se'ls fa un nus a l'estómac i no poden pair, els fem aigua amb un bon grapat de camamilla (532). Digestiva $(539,540,553)$. Per a pair $(549,1215$, amb un bon grapat de camamilla (532). Digestiva $(539,540,553)$. Per a pair $(549,1215$, $1310,1328,1329,1341,1342,1347,1348,1349,1353,1354)$. Per a ajudar a fer la digestió
$(1337,1338)$. FORMA FARMACÉUTICA I ÚS. Tisana (ús intern). PREPARACIÓ. Decocció $(532,539,540,541,549,553,1215,1293,1294,1296,1300,1328,1329,1347,1348,1349)$ En infusió $(1337,1338,1341,1342)$. DESTINACIÓ. Medicina veterinària (532). Medicina humana $(539,540,541,549,553,1215,1293,1294,1296,1300,1310,1328,1329,1337$ $1338,1341,1342,1347,1348,1349,1353,1354)$. OBSERVACIONS. A mi no m'agrada gaire (549). Aquesta és la camamilla amarga (1215). La més estimada aquí dalt (1293). La troba molt forta (1294). Diuen que és millor, és més forta (1296). Diuen que és molt bona, però jo la trobo amargant (1300). Es la més amargant, però la més estimada (1310).

Estomacal

FONTS 571, 1335, 1343, 1344, 1350, 1351. DESCRIPCIÓ DE L'ÚS FETA PELS INFORMANTS. Per al mal de ventre i estómac (571). Per al mal d'estómac $(1335,1343$ $1344,1350,1351)$. FORMA FARMACĖUTICA I ÚS. Tisana (ús intern). PREPARACIÓ. Decocció $(571,1335,1343,1344)$. DESTINACIÓ Medicina humana. OBSERVACIONS. És molt més forta (571). Li agrada més la del botó (Santolina chamaecyparissus) (1335).

Laxan

FONT 1362. DESCRIPCIÓ DE L'ÚS FETA PER L'INFORMANT. Per a quan les vaques queden botides, els fa diarrea. FORMA FARMACËUTICA I ÚS. Tisana (ús intern). PREPARACIÓ. Aigua de camamilla amb bicarbonat i un raig d'oli. DESTINACIÓ. Medicina veterinària.

Restauratiu

FONTS 1328, 1329. DESCRIPCIÓ DE L'ÚS FETA PELS INFORMANTS. Tenen un vedell setmesó i li donen cada dia aigua de camamilla. FORMA FARMACĖUTICA I ÚS. Tisana (ús intern). PREPARACIÓ. Decocció. DESTINACIÓ. Medicina veterinària.

Tranquil·litzant

FONTS 1339, 1340. DESCRIPCIÓ DE L'ÚS FETA PELS INFORMANTS. Per als nervis. FORMA FARMACĖUTICA I ÚS. Tisana (ús intern). PREPARACIÓ. Decocció. DESTINACIÓ. Medicina humana.

\section{No consta}

Desconegut per l'informant

FONTS 525, 526, 527, 552. FORMA FARMACĖUTICA I ÚS. Desconegut per l'informant DESTINACIÓ. Medicina humana. OBSERVACIONS. És més forta que les altres, però també és bona $(525,526,527)$. No la fem servir (552).

No consta

FONT 1361. DESCRIPCIÓ DE L'ÚS FETA PER L'INFORMANT. Per a quan les vaques queden botides, els fa diarrea. FORMA FARMACĖUTICA I ÚS. Desconegut per l'informant. PREPARACIÓ. Aigua de camamilla amb bicarbonat i un raig d'oli.

\section{USOS ALIMENTARIS}

\section{Inflorescència}

Preparació de begudes - Beguda preparada amb aiguarden

FONTS 1341, 1342. DESCRIPCIÓ DE L'ÚS FETA PELS INFORMANTS. Per a fer ratafia, es confita llor (Laurus nobilis), romaní (Rosmarinus officinalis), nous (Juglans regia), granes de ginebró (Juniperus communis), camamilla (Achillea ptarmica subsp. pyrenaica), ortigues ginebró (Juniperus communis), camamilla (Achillea ptarmica subsp. pyrenaica), ortigues
(Urtica dioica), pela de taronja (Citrus sinensis), pela de llimona (Citrus limon), canyella (Urtica dioica), pela de taronja (Citrus sinensis), pela de llimona (Citrus limon), canyella
(Cinnamomum zeylanicum), marialluïsa (Lippia triphylla), poniol (Satureja calamintha subsp. ascendens), rosa de bosc (Rosa tomentosa) i malva (Malva sylvestris) en aiguardent i es deixa 40 dies a sol i a serena, llavors es cola i ja es pot beure. DESTINACIÓ. Alimentació humana.

\section{ALTRES USOS}

\section{Inflorescència}

Cosmètic

FONT 1330. DESCRIPCIÓ DE L'ÚS FETA PER L'INFORMANT. Aigua per a aclarir el cabell.

\section{ALTRES OBSERVACIONS}

FONTS 542, 543, 544, 559, 753, 754, 755, 1215. DESCRIPCIÓ FETA PELS INFORMANTS. En teníem a l'hort però ara se'ns ha perdut $(542,543,544)$. Ara ja no es pot agafar $(559)$. L'anem a buscar a Fontlletera $(753,754,755)$. Aquesta és la camamilla amarga $(1215)$

\section{BARREGES AMB AQUEST TAXXN}

Inflorescència

FONTS 1213, 1214. Entrevista 102, barreja I (vegeu catàleg de barreges) FONTS 1213, 1214. Entrevista 102, barreja V (vegeu catàleg de barreges) FONTS 1213, 1214. Entrevista 102, barreja VI (vegeu catàleg de barreges) FONTS 1339, 1340. Entrevista 22, barreja II (vegeu catàleg de barreges) 
FONT 1330. Entrevista 32, barreja V (vegeu catàleg de barreges) FONT 1320. Entrevista 34, barreja II (vegeu catàleg de barreges) FONT 528. Entrevista 61, barreja I (vegeu catàleg de barreges)

FONT 538. Entrevista 68, barreja II (vegeu catàleg de barreges)

FONT 1310. Entrevista 9 (vegeu catàleg de barreges)

\section{Aesculus hippocastanum L. (hipocastanàcies)}

BCN 24703

\section{NOMS POPULARS}

Castanya borda (llavor) $(518,519,1210)$

Castanyer $(1353,1354)$

Morronyer (1352)

\section{USOS MEDICINALS}

Fruit

Antihemorroïdal

FONTS 518, 519, 1210. DESCRIPCIÓ DE L'ÚS FETA PELS INFORMANTS. Portar tres castanyes bordes (sempre senars) a la butxaca per a les morenes $(518,519)$. Per a les morenes (1210). FORMA FARMACEUTICA I ÚS. Sense forma farmacèutica (ús directe, ús extern) $(518,519,1210)$. Decocció (ús extern) (1210). Bany (ús extern) (1210). PREPARACIÓ. Bullir les castanyes en aigua. Un cop bullides i pelades, es feia una pasta que s'aplicava com una crema localment i l'aigua resultant es posava en una ampolla de vidre fosc a sol i serena uns quants dies i llavors s'utilitzava ben freda per a fer banys (1210). Bullir les castanyes en aigua. Un cop bullides i pelades, es feia una pasta que s'aplicava com una crema localment i l'aigua resultant es posava en una ampolla de vidre fosc a sol i serena uns quants dies i llavors s'utilitzava ben freda per a fer banys. T'havies d'eixugar amb un drap uns quants dies i lavors s'utilitzava ben freda per a fer banys. Thavies d'eixugar amb un drap
de fil (1210). Cal portar una castanya a la butxaca (1210). MODE de fil (1210). Cal portar una castanya a la butxaca (1210). MODE
D'UTILITZACIÓ/POSOLOGIA. Nou dies i nou de repòs i llavors si calia nou dies més (1210). DESTINACIÓ. Medicina humana. OBSERVACIONS. Li ho va dir la Maria Sagué (1210).

\section{ALTRES USOS}

Fruit

Creences i pràctiques magicoreligioses

FONTS 1353, 1354. DESCRIPCIÓ DE L'ÚS FETA PELS INFORMANTS. Si portes tres castanyes bordes a la butxaca no et falten diners de tot l'any.

Lúdic: jocs i joguines
FONT 1352. DESCRIPCIÓ DE L'ÚS FETA PER L'INFORMANT. Les castanyes per a jugar.

\section{Aethusa cynapium L. (umbel·líferes)}

BCN 47731

\section{NOMS POPULARS}

Julivertassa $(528,541,553,582,583,584,585)$

\section{ACCIONS NOCIVES O TÒXIQUES}

No consta

FONTS 528, 553. DESCRIPCIÓ DE L'ACCIÓ NOCIVA O TÒXICA FETA PELS INFORMANTS. No es tocava (553). És una herba dolenta per a les persones, però el bestiar moltes vegades se la menja (528). TOXICITAT EN ANIMALS. No (528).

\section{ALTRES OBSERVACIONS}

FONTS 541, 583, 584, 585. DESCRIPCIÓ FETA PELS INFORMANTS Surt curiosament a costat del julivert (Petroselinum crispum) (541). Són una nosa per als prats $(583,584,585)$ S'assembla a la cicuta (Conium maculatum), n'hi ha pels voltants de casa (583). S'assembla a la cicuta, n'hi ha pels voltants de casa $(584,585)$

\section{Agave americana L. (asparagàcies)}

BCN 46860

\section{NOMS POPULARS}

Atzavara $(1213,1214)$

\section{BARREGES AMB AQUEST TÀXON}

Suc de la fulla

FONTS 1213, 1214. Entrevista 102, barreja IV (vegeu catàleg de barreges)

Agrimonia eupatoria L. (rosàcies)

BCN 24704

\section{NOMS POPULARS}

Agafallosa $(583,584,585)$ 
Herba brotònica $(520,521)$

Herba cuquera $(518,519,528,553,1293,1325,1326,1327,1336)$

\section{USOS MEDICINALS}

\section{No consta}

Desconegut per l'informant

FONTS 518, 519. FORMA FARMACĖUTICA I ÚS. Desconegut per l'informant. DESTINACIÓ Medicina humana. OBSERVACIONS. No recordo l'ús.

Part aèria

Anticatarral

FONTS 520, 521. DESCRIPCIÓ DE L'ÚS FETA PELS INFORMANTS. Per a la tos i els constipats. FORMA FARMACĖUTICA I ÚS. Tisana (ús intern). PREPARACIÓ. Decocció. DESTINACIÓ. Medicina humana.

Antihelmíntic

FONTS 528, 553, 1293, 1325, 1326, 1327, 1336. DESCRIPCIÓ DE L'ÚS FETA PELS INFORMANTS. Per als porcs quan tenien cucs (528). Per als cucs $(553,1293,1325,1326)$. Per als cucs de la mainada (1327). Per a treure els cucs de la mainada (1336). FORMA FARMACĖUTICA I ÚS. Desconegut per l'informant (528). Tisana (ús intern) $(553,1293$ $1325,1326,1327,1336)$. PREPARACIÓ. Decocció (553, 1293, 1325, 1326, 1327, 1336). DESTINACIÓ. Medicina veterinària (528). Medicina humana (553, 1293, 1325, 1326, 1327 1336).

Antitussigen

FONTS 520, 521. DESCRIPCIÓ DE L'ÚS FETA PELS INFORMANTS. Per a la tos i els constipats. FORMA FARMACĖUTICA I ÚS. Tisana (ús intern). PREPARACIÓ. Decocció. DESTINACIÓ. Medicina humana.

\section{ALTRES USOS}

Fruit

Lúdic: jocs i joguines

FONTS 583, 584, 585. DESCRIPCIÓ DE L'ÚS FETA PELS INFORMANTS. Quan érem petits hi jugàvem.

\section{ALTRES OBSERVACIONS}

FONTS 518, 519. DESCRIPCIÓ FETA PELS INFORMANTS. Fa la flor groga i com uns ganxos i té la fulla peluda.

\section{BARREGES AMB AQUEST TÀXON}

Part aèria
FONTS 520, 521. Entrevista 56, barreja III (vegeu catàleg de barreges)

\section{Agrostemma githago L. (cariofil·làcies)}

BCN 27268

\section{NOMS POPULARS}

Blauet $(569,570)$

Clavell de blat (1352)

\section{ALTRES USOS}

Part aèria florida

Ornamental: elaboració de rams

FONT 1352. DESCRIPCIÓ DE L'ÚS FETA PER L'INFORMANT. Per a fer rams.

\section{ALTRES OBSERVACIONS}

FONTS 569, 570. DESCRIPCIÓ FETA PELS INFORMANTS. Surten als camps de blat.

\section{Alchemilla alpina L. (rosàcies)}

BCN 24705

\section{NOMS POPULARS}

Herba de les cinc fulles (1322)

Herba del peucrist (1327)

Herba Sant Crist $(1347,1348,1349)$

Peu de rei $(1341,1342)$

Peucrist $(1213,1214,1322,1332,1333,1334)$

\section{USOS MEDICINALS}

\section{No consta}

Desconegut per l'informant

FONTS 1332, 1333, 1334. FORMA FARMACĖUTICA I ÚS. Desconegut per l'informant DESTINACIO. Medicina humana. OBSERVACIONS. Sap que és bona, però no en recorda l'ús.

Part aèria 
Antiinflamatori intestinal

FONTS 1341, 1342. DESCRIPCIÓ DE L'ÚS FETA PELS INFORMANTS. Per al mal de ventre. FORMA FARMACĖUTICA I ÚS. Tisana (ús intern). PREPARACIÓ. Decocció DESTINACIÓ. Medicina humana.

Antiulcerós (per a úlceres gàstriques)

FONT 1327. DESCRIPCIÓ DE L'ÚS FETA PER L'INFORMANT. Per a les llagues d'estómac. FORMA FARMACĖUTICA I ÚS. Tisana (ús intern). PREPARACIÓ. Decocció. DESTINACIÓ. Medicina humana.

Litotríptic renal

FONTS 1347, 1348, 1349. DESCRIPCIÓ DE L'ÚS FETA PELS INFORMANTS. Per a les pedres al ronyó. FORMA FARMACĖUTICA I ÚS. Tisana (ús intern). PREPARACIÓ. Decocció. DESTINACIÓ. Medicina humana.

\section{Alchemilla saxatilis Buser (rosàcies)}

BCN 15412

\section{NOMS POPULARS}

Peucrist $(541,553)$

\section{USOS MEDICINALS}

\section{Part aèria}

Antidiarreic

FONT 553. DESCRIPCIÓ DE L'ÚS FETA PER L'INFORMANT. Per a la diarrea. FORMA FARMACĖUTICA I ÚS. Tisana (ús intern). PREPARACIÓ. Decocció. DESTINACIÓ. Medicina humana.

Resolutic

FONT 553. DESCRIPCIÓ DE L'ÚS FETA PER L'INFORMANT. Per a tancar llagues. FORMA FARMACĖUTICA I ÚS. Bany (ús extern). PREPARACIÓ. Decocció. Per a fer banys amb aigua, com la farigola. DESTINACIÓ. Medicina humana.

\section{Alkanna tinctoria Tausch (boraginàcies)}

BCN 24706

\section{NOMS POPULARS}

Herba de peu de colom (1335)
Peu de colom $(554,555,1336)$

Pota de colom $(518,519,753,754,755)$

\section{USOS MEDICINALS}

Arrel

Anticolític

FONT 1335. DESCRIPCIÓ DE L'ÚS FETA PER L'INFORMANT. És molt bona per a la colitis (com unes llagues als budells) que dóna molta diarrea. FORMA FARMACĖUTICA I ÚS Pomada (ús extern). PREPARACIO. Un quilo de greix de budells grossos de porc, una o dues pomes sense pelar tallades a monjos, mig quilo de sucre $\mathrm{i}$ un grapadet d'arrel de peu de colom. En un recipient de terra nou, es fa escalfar el greix fins que es fon i es treuen els greixons, s'hi afegeix les pomes i el sucre, es fa bullir fins que el sucre queda caramel (groc, però no cremat), l'herba és vermella, el sucre junt amb la rel es queda al cul de la cassola, es cola i es deixa refredar. Aquest greix vermell es guarda al congelador. MODE D'UTILITZACIÓ/POSOLOGIA Se'n pren una cullerada al matí i una al vespre. DESTINACIÓ. Dedicina humana. OBSERVACIONS. A l'Angeleta li havien diagnosticat colitis i va prenclo. durant un any peu de colom i mai més no he tingut problemes. Diu que la rel només trendre durant un any peu de colom i mai mess no ha tingut problemes. Diu que la rel només treu suc vermell bullit en oli, si ho bulls en aigua no el treu.

Antiinflamatori intestinal

FONTS 518, 519. DESCRIPCIÓ DE L'ÚS FETA PELS INFORMANTS. Va bé per al mal de ventre. FORMA FARMACĖUTICA I ÚS. Desconegut per l'informant. PREPARACIÓ. Es fa un greix vermell de la rel. DESTINACIÓ. Medicina humana.

\section{ALTRES USOS}

\section{Arre}

Cosmètic

FONTS 518, 519, 1336. DESCRIPCIÓ DE L'ÚS FETA PELS INFORMANTS. Les nenes de la Coma s'hi pintaven els llavis i quan arribaven a estudi la mestra deia: Carme, Carme.. (518, 519). Recorda que feia un suc vermell i que les noies de la Vall del Bac la feien servir per a pintar-se els llavis (1336).

\section{BARREGES AMB AQUEST TÀXON}

Arrel

FONTS 753, 754, 755. Entrevista 67, barreja I (vegeu catàleg de barreges) FONTS 554, 555. Entrevista 78, barreja IV (vegeu catàleg de barreges)

Alnus glutinosa (L.) Gaertn. (betulàcies) BCN 97496 
Apèndix 1. Catàleg de tàxons.

\section{NOMS POPULARS}

Vern $(564,568,1215,1352)$

\section{ALTRES USOS}

\section{Part aèria}

Creences i pràctiques magicoreligioses

FONT 564. DESCRIPCIÓ DE L'ÚS FETA PER L'INFORMANT. Per a fer l'altar el dia de Corpus.

\section{Planta sencera}

Literatura oral popular: llegendes, gloses, contes, dites, refranys, poemes, cançons

FONTS 1215, 1352. DESCRIPCIÓ DE L'ÚS FETA PELS INFORMANTS. Va deixar morir la mare de fred. No crema bé (1215). A vegades també es cremava però és una fusta que no escalfa i deien "el vern va deixar morir el seu pare de fred" (1352). Assemblar-se com el boix (Buxus sempervirens) i el vern (no assemblar-se de res) (1352).

Tija

Artesanal: elaboració de calçat

FONT 568. DESCRIPCIÓ DE L'ÚS FETA PER L'INFORMANT. Per a fer esclops.

\section{Aloe vera (L.) Burm.f. (xantorreàcies)}

\section{BCN 27242}

\section{NOMS POPULARS}

Aloe $(1361,1362)$

Cactus (588)

\section{USOS MEDICINALS}

\section{Suc de la fulla}

Antipiròtic

FONTS 588, 1361, 1362. DESCRIPCIÓ DE L'ÚS FETA PELS INFORMANTS. Per a les cremades (588). Et poses la fulla a sobre les cremades $(1361,1362)$. FORMA FARMACĖUTICA I ÚS. Sense forma farmacèutica (ús directe, ús extern). DESTINACIÓ. Medicina humana.

\section{Althaea officinalis L. (malvàcies)}

BCN 24709

\section{NOMS POPULARS}

Arrel de malví (578)

Malvesí $(522,523)$

Malví $(505,506,507,509,510,524,525,526,527,564,565,566,572,573,579,583,584$ $585,588,746,1210,1213,1214,1215,1294,1300,1314,1318,1319,1327,1330,1335$ $1339,1340,1341,1342,1343,1344,1345,1346,1353,1354,1352,1361,1362)$

\section{USOS MEDICINALS}

\section{Arre}

Antibronquític

FONT 1327. DESCRIPCIÓ DE L'ÚS FETA PER L'INFORMANT. Per a les bronquitis. FORMA FARMACĖUTICA I ÚS. Tisana (ús intern). PREPARACIÓ. Decocció de l'arrel. DESTINACIÓ. Medicina humana.

Anticatarral

FONTS 522, 523, 524, 525, 526, 527, 578, 579, 588, 1210, 1215, 1318, 1319, 1330, 1341 , 1342, 1343, 1344, 1345, 1346, 1352, 1353, 1354. DESCRIPCIÓ DE L'ÚS FETA PELS INFORMANTS. Per als constipats (522, 523, 1319, 1341, 1342). Per als refredats $(524,525$, $526,527,578,579,1210,1215,1343,1344,1345,1346,1352,1353,1354)$. És molt bona per als constipats (588). Per a estovar els constipats (1318). Per a destapar quan estàs constipat (1330). FORMA FARMACÉUTICA I ÚS. Tisana (ús intern) $(522,523,524,525,526$, constipat (1330). FoRMA $578,579,588,1210,1318,1319,1330,1341,1342,1345,1346,1352,1353,1354)$. Desconegut per l'informant (1215). Xarop (ús intern) $(1343,1344)$. PREPARACIÓ. Decocció. Aigua de la rel $(522,523,1318,1319,1330)$. Decocció $(524,578,579)$. Decocció. L'arrel fa Aigua de la rel $(522,523,1318,1319,1330)$. Decocció $(524,578,579)$. Decocció. L'arrel fa una aigua llefiscosa $(525,526,527)$. Decocció. L'arrel bullida (588). Infusions d'arrels de malví $(1210)$. L'arrel bullida tres minuts $(1341,1342)$. Arrel de malví bullida i afegir-hi sucre
fins que es redueix a la meitat $(1343,1344)$. L'arrel bullida $(1345,1346)$. Aigua de la re (1352). L'arrel en infusió $(1353,1354)$. DESTINACIÓ. Medicina humana. OBSERVACIONS. Li han dit que la flor també va bé per als refredats, però no ho ha provat mai $(1345,1346)$.

\section{Antiinflamatori faring}

FONTS 505, 506, 1345, 1346. DESCRIPCIÓ DE L'ÚS FETA PELS INFORMANTS. És una aigua molt llefiscosa que va molt bé per al mal de coll $(505,506)$. Per al mal de coll $(1345$ 1346). FORMA FARMACEUUTICA I US. Desconegut per l'informant $(505,506)$. Tisana (ús intern) $(1345,1346)$. PREPARACIÓ. L'arrel bullida $(1345,1346)$. DESTINACIÓ. Medicina humana.

Antipneumònic

FONT 1319. DESCRIPCIÓ DE L'ÚS FETA PER L'INFORMANT. Per a pulmonies. FORMA FARMACĖUTICA I ÚS. Tisana (ús intern). PREPARACIÓ. Decocció. Aigua de la rel. DESTINACIÓ. Medicina humana.

Desconegut per l'informant 
FONT 564. FORMA FARMACĖUTICA I ÚS. Desconegut per l'informant. DESTINACIÓ. Medicina humana. OBSERVACIONS. Es feia servir la rel, però no recordo per a què.

Expectorant

FONT 1330. DESCRIPCIÓ DE L'ÚS FETA PER L'INFORMANT. Per a destapar quan estàs constipat. FORMA FARMACĖUTICA I ÚS. Tisana (ús intern). PREPARACIÓ. Decocció. Aigua de la rel. DESTINACIÓ. Medicina humana.

Tranquil·litzant

FONTS 1361, 1362. DESCRIPCIÓ DE L'ÚS FETA PELS INFORMANTS. Per als nervis. FORMA FARMACĖUTICA I ÚS. Tisana (ús intern). PREPARACIÓ. Decocció. DESTINACIÓ. Medicina humana.

\section{No consta}

Desconegut per l'informant

FONTS 1339, 1340. FORMA FARMACĖUTICA I ÚS. Desconegut per l'informant DESTINACIÓ. Medicina humana. OBSERVACIONS. No recorda l'ús.

\section{ALTRES OBSERVACIONS}

FONTS 522, 523, 583, 584, 585, 1215. DESCRIPCIÓ FETA PELS INFORMANTS. L'arrel és ben dolça, fa una flor alta com una malva $(522,523)$. N'hi havia a Montgrony $(583,584,585)$ En tenia una mata (1215)

\section{BARREGES AMB AQUEST TÀXON}

\section{Arrel}

FONTS 1213, 1214. Entrevista 102, barreja IV (vegeu catàleg de barreges)

FONTS 1213, 1214. Entrevista 102, barreja V (vegeu catàleg de barreges)

FONT 1327. Entrevista 14, barreja $\vee$ (vegeu catàleg de barreges)

FONT 1335. Entrevista 15, barreja II (vegeu catàleg de barreges)

FONT 1314. Entrevista 17, barreja I (vegeu catàleg de barreges)

FONT 746. Entrevista 45, barreja II (vegeu catàleg de barreges)

FONTS 507, 509, 510. Entrevista 46 (vegeu catàleg de barreges)

FONTS 505, 506. Entrevista 47, barreja II (vegeu catàleg de barreges)

FONT 524. Entrevista 58 (vegeu catàleg de barreges)

FONT 1294. Entrevista 6, barreja I (vegeu catàleg de barreges)

FONT 1300. Entrevista 8, barreja II (vegeu catàleg de barreges)

FONTS 565, 566. Entrevista 85 (vegeu catàleg de barreges)

FONTS 572, 573. Entrevista 90, barreja III (vegeu catàleg de barreges)

\section{Althaea rosea (L.) Cav. (malvàcies)}

BCN 6469

\section{NOMS POPULARS}

Malva reial $(583,584,585)$

\section{ALTRES USOS}

\section{Planta viva ex situ}

Ornamental: jardineria

FONTS 583, 584, 585. DESCRIPCIÓ DE L'ÚS FETA PELS INFORMANTS. És per a fer bonic.

\section{Allium cepa L. (amaril·lidàcies)}

\section{BCN 27279}

\section{NOMS POPULARS}

Ceba $(505,506,518,519,520,521,529,530,531,545,549,565,566,572,573,583,584$ $585,746,751,1213,1214,1313,1323,1327,1330,1352)$

\section{USOS MEDICINALS}

Bulb

Anticatarral

FONTS 520, 521, 1323. DESCRIPCIÓ DE L'ÚS FETA PELS INFORMANTS. Per als constipats i per a la tos $(520,521)$. Per als constipats (1323). FORMA FARMACĖUTICA I ÚS Melit (ús intern) $(520,521)$. Tisana (ús intern) (1323). PREPARACIÓ. Decocció. El caldo de fer bullir cebes junt amb mel $(520,521)$. Infusió de ceba bullida (1323). DESTINACIÓ. Medicina humana.

Antigripal

FONTS 520, 521. DESCRIPCIÓ DE L'ÚS FETA PELS INFORMANTS. Per a prevenir-se del grip. FORMA FARMACEUTICA I ÚS. Tisana (ús intern). PREPARACIÓ. La ceba cuita. DESTINACIÓ. Medicina humana.

Antiinflamatori intestinal

FONT 549. DESCRIPCIÓ DE L'ÚS FETA PER L'INFORMANT. Per al mal de ventre. FORMA FARMACEUTICA I ÚS. Emplastre (ús extern). PREPARACIO. Ceba cuita entre dos draps. DESTINACIO. Medicina humana.

Antitussigen 
FONTS 520, 521, 565, 566. DESCRIPCIÓ DE L'ÚS FETA PELS INFORMANTS. Per als constipats i per a la tos $(520,521)$. Va bé per a la tos $(565,566)$. FORMA FARMACĖUTICA I Ús. Melit (ús intern) $(520,521)$. Aerosol (ús intern) $(565,566)$. PREPARACIÓ. Decocció. EI caldo de fer bullir cebes junt amb mel $(520,521)$. Tallada i a sota el llit $(565,566)$ DESTINACIÓ. Medicina humana.

Cardiotònic

FONTS 572, 573. DESCRIPCIÓ DE L'ÚS FETA PELS INFORMANTS. Va bé per al cor. FORMA FARMACĖUTICA I ÚS. Sense forma farmacèutica (ús directe, ús intern). PREPARACIÓ. Has de menjar ceba crua. MODE D'UTILITZACIÓ/POSOLOGIA. Cada dia. DESTINACIÓ. Medicina humana. OBSERVACIONS. Un metge li va dir a un home de Gombrèn "si menges ceba crua cada dia et trec el medicament".

Diürètic

FONT 1352. DESCRIPCIÓ DE L'ÚS FETA PER L'INFORMANT. Per a fer orinar. FORMA FARMACĖUTICA I ÚS. Tisana (ús intern). PREPARACIÓ. Beure aigua de ceba. DESTINACIÓ. Medicina humana.

Litotríptic renal

FONT 1313. DESCRIPCIÓ DE L'ÚS FETA PER L'INFORMANT. Per a les pedres dels ronyons, perquè és lleficosa. FORMA FARMACĖUTICA I ÚS. Tisana (ús intern). PREPARACIÓ. Decocció. DESTINACIÓ. Medicina humana.

Per a les picades

FONTS 572, 573. DESCRIPCIÓ DE L'ÚS FETA PELS INFORMANTS. És un contraverí [dit "contravereno"]. Una vegada quan la meva mare quan era petita empipaven un galàpet $i$ els va llençar el verí [dit "vereno"], els va quedar la cara inflada i la ceba els va treure el verí. FORMA FARMACĖUTICA I ÚS. Emplastre (ús extern). PREPARACIÓ. Trompes de ceba aixafades. DESTINACIÓ. Medicina humana.

Per al panadís

FONT 1323. DESCRIPCIÓ DE L'ÚS FETA PER L'INFORMANT. Per als voltadits. FORMA FARMACĖUTICA I ÚS. Decocció (ús extern). PREPARACIÓ. Ceba cuita i llavors s'embenava. DESTINACIÓ. Medicina humana.

Resolutiu

FONTS 518, 519. DESCRIPCIÓ DE L'ÚS FETA PELS INFORMANTS. Per a fer madurar grans i furóncols. FORMA FARMACĖUTICA I ÚS. Ungüent (ús extern). PREPARACIÓ. Ceba escalivada i barrejada amb greix de porc. DESTINACIÓ. Medicina humana.

Restauratiu

FONTS 505, 506. DESCRIPCIÓ DE L'ÚS FETA PELS INFORMANTS. Per a les gallines quan estan malaltes. FORMA FARMACĖUTICA I ÚS. Sense forma farmacèutica (ús directe, ús intern). PREPARACIÓ. Ceba trinxada. DESTINACIÓ. Medicina veterinària.

Vulnerari

FONT 751. DESCRIPCIÓ DE L'ÚS FETA PER L'INFORMANT. Quan t'has fet una ferida i tens aquell foc a dins, va molt bé posar-t'hi una ceba cuita. FORMA FARMACĖUTICA I ÚS. Emplastre (ús extern). PREPARACIÓ. Ceba cuita. DESTINACIÓ. Medicina humana.

\section{ALTRES USOS}

Bulb

Cosmètic

FONTS 1213, 1214. DESCRIPCIÓ DE L'ÚS FETA PELS INFORMANTS. Si ho passes per la pell, queda fina.

\section{BARREGES AMB AQUEST TÀXON}

Bulb

FONT 1327. Entrevista 14, barreja III (vegeu catàleg de barreges)

FONT 1330. Entrevista 32, barreja III (vegeu catàleg de barreges)

FONT 746. Entrevista 45, barreja III (vegeu catàleg de barreges)

FONTS 529, 530, 531. Entrevista 53, barreja VIII (vegeu catàleg de barreges)

FONTS 520, 521. Entrevista 56, barreja I (vegeu catàleg de barreges)

FONT 545. Entrevista 72, barreja III (vegeu catàleg de barreges)

FONT 553. Entrevista 77, barreja I (vegeu catàleg de barreges)

FONTS 583, 584, 585. Entrevista 96, barreja III (vegeu catàleg de barreges)

\section{Allium porrum L. (amaril·lidàcies)}

BCN 24707

\section{NOMS POPULARS}

All porro $(1328,1329)$

Porro $(532,580,1322)$

\section{USOS MEDICINALS}

Bulb

Antihipertensiu

FONT 1329. DESCRIPCIÓ DE L'ÚS FETA PER L'INFORMANT. Per a fer baixar la pressió FORMA FARMACĖUTICA I ÚS. Tisana (ús intern). PREPARACIÓ. Decocció. MODE D'UTILITZACIÓ/POSOLOGIA. Un got cada matí en dejú. DESTINACIÓ. Medicina humana.

Hipoglucemiant

FONTS 1322, 1328. DESCRIPCIÓ DE L'ÚS FETA PELS INFORMANTS. Per a fer baixar el sucre $(1322,1328)$ FORMA FARMACĖUTICA I ÚS Tisana (ús intern). PREPARACIÓ Decoció $(1322,1328)$. MODE D'UTILITZACIO/POSOLOGIA. S'na de prendre un cop a 
Hipolipemiant

FONT 532. DESCRIPCIÓ DE L'ÚS FETA PER L'INFORMANT. Va bé per al colesterol. FORMA FARMACĖUTICA I ÚS. Tisana (ús intern). PREPARACIÓ. Decocció. DESTINACIÓ. Medicina humana. OBSERVACIONS. Però també el poso al caldo.

\section{USOS ALIMENTARIS}

Bulb

Ingestió de la part de la planta cuita - Cuita en aigua

FONTS 532, 580. DESCRIPCIÓ DE L'ÚS FETA PELS INFORMANTS. El poso al caldo (532) Per al caldo (580). DESTINACIÓ. Alimentació humana $(532,580)$.

\section{Allium sativum L. (amaril·lidàcies)}

\section{BCN 24708}

\section{NOMS POPULARS}

All $(503,505,506,507,509,510,511,512,513,514,520,521,525,526,527,528,532,546$ $547,548,553,561,562,563,571,574,575,576,577,581,583,584,585,586,587,747$ $1210,1297,1300,1314,1318,1319,1320,1322,1324,1330,1332,1333,1334,1347,1348$ $1349,1350,1351,1353,1354,1361,1362$

\section{USOS MEDICINALS}

Bulb

Analgèsic

FONT 546. DESCRIPCIÓ DE L'ÚS FETA PER L'INFORMANT. Per a treure el dolor. Hi ha gent que en menja quan tenen molt dolor. FORMA FARMACĖUTICA I ÚS. Sense forma farmacèutica (ús directe, ús intern). DESTINACIÓ. Medicina humana.

Antibronquític

FONT 1210. DESCRIPCIÓ DE L'ÚS FETA PER L'INFORMANT. Per a les bronquitis. FORMA FARMACĖUTICA I ÚS. Tintura alcohòlica (ús intern). PREPARACIÓ. Una cabeça d'alls amb un litre d'esperit de vi de $96^{\circ}$. Sol i serena. MODE D'UTILITZACIÓ/POSOLOGIA. Cada dia beure'n un got al matí, durant cinc o sis dies. DESTINACIÓ. Medicina humana.

Antieczematós

FONT 1322. DESCRIPCIÓ DE L'ÚS FETA PER L'INFORMANT. Aquest remei el va fer amb un nen que tenia la cara plena de crostes que no se li curaven. FORMA FARMACE்UTICA I Ús. Sense forma farmacèutica (ús directe, ús extern). PREPARACIÓ. Un drap de fil moll amb oli i cremat; les gotes han de caure a sobre uns grans d'all, i llavors amb aquestes gotes et fregues el mal. DESTINACIÓ. Medicina humana.

Antifúngic
FONTS 586, 587. DESCRIPCIÓ DE L'ÚS FETA PELS INFORMANTS. Quan tens brians diu que va bé fregar-te'ls amb alls. FORMA FARMACĖUTICA I ÚS. Sense forma farmacèutica (ús directe, ús extern). DESTINACIÓ. Medicina humana.

Antihelmíntic

FONTS 1332, 1333, 1334. DESCRIPCIÓ DE L'ÚS FETA PELS INFORMANTS. Per als cucs. FORMA FARMACĖUTICA I ÚS. Sense forma farmacèutica (ús directe, ús intern). MODE D'UTILITZACIÓ/POSOLOGIA. En dejú. DESTINACIÓ. Medicina humana.

Antiinflamatori intestinal

FONTS 547, 548. DESCRIPCIÓ DE L'ÚS FETA PELS INFORMANTS. Quan sembla que estàs empatxat o tens mal de panxa. FORMA FARMACĖUTICA I ÚS. Suspensió (ús intern). PREPARACIÓ. Sopa d'alls bullida. Un parell de grans, un raget d'oli i ben bullida amb pa. DESTINACIÓ. Medicina humana.

Antiotàlgic

FONTS 505, 506, 507, 509, 510, 511, 512, 513, 514, 547, 548, 747, 1297, 1300, 1319, 1353 1354. DESCRIPCIÓ DE L'ÚS FETA PELS INFORMANTS. Per al mal d'orelles $(505,506$, $507,509,510,511,512,513,514,547,548,747,1300,1353,1354)$. Treu el mal (1297). Es posa a l'orella quan et fa mal (1319). FORMA FARMACÉUTICA I ÚS. Embrocació (ús extern) $(505,506,507,509,510)$. Sense forma farmacèutica (ús directe, ús extern) $(511,512,513$, $514,547,548,747,1319)$. Sense forma farmacèutica (ús directe, ús intern) $(1297,1300)$ $514,547,548,747,1319)$. Sense forma farmaceutica (us directe, ús intern) $(1297,1300$ ). Decoccio (ús extern) $(1353,1354)$. PREPARACIÓ. Es maceren en oli $(507,509,510)$. Tallat en oli $(505,506)$. Escaldat amb oli ben calent $(511,512,513,514)$. Rescaldejat al caliu $(747)$ S'ha de fregir l'all amb oli i llavors posar a l'orella $(547,548)$. Escalivat al foc i posat a l'orella amb una mica d'oli (1297). Gra d'all escalivat al foc (1300). Un gra d'all escalivat (1319). Un all escalivat $(1353,1354)$. DESTINACIO. Medicina humana.

Antisèptic extern

FONTS 507, 509, 510. DESCRIPCIÓ DE L'ÚS FETA PELS INFORMANTS. Per a les ferides. FORMA FARMACĖUTICA I ÚS. Embrocació (ús extern). PREPARACIÓ. Es maceren els alls en oli. DESTINACIO. Medicina humana.

Cardiotònic

FONTS 1320, 1330. DESCRIPCIÓ DE L'ÚS FETA PELS INFORMANTS. Per al cor (1320). Va bé per al cor (1330). FORMA FARMACEUUTICA I US. Sense forma farmacèutica (ús directe, ús intern). MODE D'UTILITZACIO/POSOLOGIA. En dejú (1320, 1330) DESTINACIO. Medicina humana.

Digestiu

FONTS 547, 548. DESCRIPCIÓ DE L'ÚS FETA PELS INFORMANTS. Quan sembla que estàs empatxat o tens mal de panxa. FORMA FARMACEUTICA I US. Suspensió (ús intern). PREPARACIO. Sopa d'alls bullida. Un parell de grans, un raget d'oli i ben bullida amb pa. DESTINACIO. Medicina humana.

Hematocatàrtic 
FONT 1320. DESCRIPCIÓ DE L'ÚS FETA PER L'INFORMANT. Per a depurar la sang FORMA FARMACĖUTICA I ÚS. Sense forma farmacèutica (ús directe, ús intern). MODE D'UTILITZACIÓ/POSOLOGIA. En dejú. DESTINACIÓ. Medicina humana.

Hipolipemiant

FONTS 1361, 1362. DESCRIPCIÓ DE L'ÚS FETA PELS INFORMANTS. Per al colesterol. FORMA FARMACĖUTICA I ÚS. Sense forma farmacèutica (ús directe, ús intern). MODE D'UTILITZACIÓ/POSOLOGIA Cada matí. DESTINACIÓ Medicina humana.

Per a les picades

FONTS 525, 526, 527. DESCRIPCIÓ DE L'ÚS FETA PELS INFORMANTS. Per a les pessigades de vespes o d'abelles. FORMA FARMACĖUTICA I ÚS. Sense forma farmacèutica (ús directe, ús extern). PREPARACIÓ. Et fregues amb un gra d'all i et treu el verí [dit "vereno"]. DESTINACIÓ. Medicina humana.

Per als penellons

FONTS 1347, 1348, 1349. DESCRIPCIÓ DE L'ÚS FETA PELS INFORMANTS. Fregar els penellons amb alls. FORMA FARMACĖUTICA I ÚS. Sense forma farmacèutica (ús directe, ús extern). DESTINACIÓ. Medicina humana.

Vasotònic

FONT 1324. DESCRIPCIÓ DE L'ÚS FETA PER L'INFORMANT. Per a la circulació. FORMA FARMACĖUTICA I ÚS. Tintura alcohòlica (ús intern). PREPARACIÓ. Alls en aiguardent. DESTINACIÓ. Medicina humana.

Vulnerari

FONTS 520, 521. DESCRIPCIÓ DE L'ÚS FETA PELS INFORMANTS. Per als mals i pelats, per a les esgarrapades dels conills, que són molt verinoses. FORMA FARMACĖUTICA I ÚS Embrocació (ús extern). PREPARACIÓ. Alls bullits en oli, s'han de posar els alls senars. DESTINACIÓ. Medicina humana i veterinària. OBSERVACIONS. També l'usem per al bestiar.

\section{USOS ALIMENTARIS}

\section{Bulb}

No consta el tipus d'ingesta - No consta el mode de preparació

FONT 503. DESCRIPCIÓ DE L'ÚS FETA PER L'INFORMANT. Els alls són molt bons i saludables. DESTINACIÓ. Alimentació humana.

\section{BARREGES AMB AQUEST TÀXON}

Bulb

FONT 1314. Entrevista 17, barreja I (vegeu catàleg de barreges)

FONT 1322. Entrevista 28, barreja I (vegeu catàleg de barreges)

FONT 1318. Entrevista 31, barreja IV (vegeu catàleg de barreges)

FONT 1330. Entrevista 32, barreja III (vegeu catàleg de barreges)
FONT 1330. Entrevista 32, barreja VII (vegeu catàleg de barreges) FONTS 1350, 1351. Entrevista 39, barreja II (vegeu catàleg de barreges) FONT 528. Entrevista 61, barreja I (vegeu catàleg de barreges) FONT 528. Entrevista 61, barreja II (vegeu catàleg de barreges) FONT 532. Entrevista 63, barreja I (vegeu catàleg de barreges) FONT 1300. Entrevista 8, barreja II (vegeu catàleg de barreges) FONTS 561, 562, 563. Entrevista 83 (vegeu catàleg de barreges) FONT 571. Entrevista 89, barreja II (vegeu catàleg de barreges) FONT 571. Entrevista 89, barreja III (vegeu catàleg de barreges) FONTS 574, 575, 576, 577. Entrevista 91, barreja II (vegeu catàleg de barreges) FONT 581. Entrevista 94, barreja II (vegeu catàleg de barreges)

FONTS 583, 584, 585. Entrevista 96, barreja II (vegeu catàleg de barreges)

FONTS 583, 584, 585. Entrevista 96, barreja III (vegeu catàleg de barreges)

\section{Allium schoenoprasum L. (amaril·lidàcies)}

BCN 28815

\section{NOMS POPULARS}

Cibulet (582)

\section{USOS ALIMENTARIS}

Bulb

Ingestió de la part de la planta cuita - Cuita en oli

FONT 582. DESCRIPCIÓ DE L'ÚS FETA PER L'INFORMANT. Per a fer truites és molt bo. DESTINACIÓ. Alimentació humana.

\section{Alyssum maritimum (L.) Lam. (crucíferes)}

BCN 24710

\section{NOMS POPULARS}

Caps blancs $(569,570)$

USOS ALIMENTARIS

Part aèria 
Apèndix 1. Catàleg de tàxons.

Ingestió de la part de la planta crua - Fresca (sense preparació)

FONTS 569, 570. DESCRIPCIÓ DE L'ÚS FETA PELS INFORMANTS. Per als conills. DESTINACIÓ. Alimentació animal.

\section{Amaranthus retroflexus L. (amarantàcies)}

BCN 47548

\section{NOMS POPULARS}

Blet $(529,530,531,583,584,585,586,587)$

\section{USOS ALIMENTARIS}

Part aèria

Ingestió de la part de la planta crua - Fresca (sense preparació)

FONTS 529, 530, 531, 583, 584, 585, 586, 587. DESCRIPCIÓ DE L'ÚS FETA PELS INFORMANTS. Per a menjar les vaques $(529,530,531)$. El bestiar se'ls menja $(583,584$ 585). A les ovelles els agraden, però si en mengen gaire els fa mal $(586,587)$ OBSERVACIONS. Els blets vermells són els bons i els altres són dolents, els que fan la pota més gruixuda, creixen més alts que jo i en Pere diu que aquests no són bons $(529,530,531)$. DESTINACIÓ. Alimentació animal $(529,530,531,583,584,585,586,587)$.

\section{Amelanchier ovalis Medic. (rosàcies)}

BCN 16410

\section{NOMS POPULARS}

Cornier $(511,512,513,514,532,539,540,546,554,555,569,570,581)$

Corniera $(572,573,583,584,585)$

\section{USOS MEDICINALS}

Flor

Anticatarral

FONTS 539, 540. DESCRIPCIÓ DE L'ÚS FETA PELS INFORMANTS. Per a fer baixar la pressió, per a les sangs i per als refredats. FORMA FARMACĖUTICA I ÚS. Tisana (ús intern). PREPARACIO. Decocció. DESTINACIO. Medicina humana.

Antihipertensiu

FONTS $511,512,513,514,539,540,546,554,555,572,573$. DESCRIPCIÓ DE L'ÚS FETA PELS INFORMANTS. Per a fer baixar la pressió $(511,512,513,514,546,572,573)$. Per a fer baixar la pressió, per a les sangs i per als refredats $(539,540)$. Per a rebaixar la sang $(511,512,513,514,539,540,546,554,555,572$, Hematocatàrtic

FONTS 539, 540. DESCRIPCIÓ DE L'ÚS FETA PELS INFORMANTS. Per a fer baixar la pressió, per a les sangs i per als refredats. FORMA FARMACĖUTICA I ÚS. Tisana (ús intern). PREPARACIÓ. Decocció. DESTINACIÓ. Medicina humana.

Hipoglucemiant

FONT 581. DESCRIPCIÓ DE L'ÚS FETA PER L'INFORMANT. Per als diabètics. FORMA FARMACĖUTICA I ÚS. Tisana (ús intern). PREPARACIÓ. Decocció. DESTINACIÓ. Medicina humana.

\section{No consta}

Antiespasmòdic

FONT 532. DESCRIPCIÓ DE L'ÚS FETA PER L'INFORMANT. Per a nervis que s'encallaven FORMA FARMACĖUTICA I ÚS. Emplastre (ús extern). PREPARACIÓ. Es fa un emplastre amb oli o amb llet. DESTINACIÓ. Medicina humana.

\section{Part aèria jove}

Antihipertensiu

FONTS 583, 584, 585. DESCRIPCIÓ DE L'ÚS FETA PELS INFORMANTS. Per a rebaixar la sang. FORMA FARMACĖUTICA I ÚS. Tisana (ús intern). PREPARACIÓ. Decocció. DESTINACIÓ. Medicina humana. OBSERVACIONS. S'ha de vigiliar perquè rebaixa molt.

\section{ALTRES USOS}

Part aèria florida

Ornamental: elaboració de rams

FONTS 546, 569, 570. DESCRIPCIÓ DE L'ÚS FETA PELS INFORMANTS. Per a fer rams, quan és florit és molt maco (546).

\section{ALTRES OBSERVACIONS}

FONTS $511,512,513,514,572,573$. DESCRIPCIÓ FETA PELS INFORMANTS. Arbust de flor blanca semblant a l'arç (Crataegus monogyna subsp. monogyna) $(511,512,513,514)$. És un arbust que fa les flors blanques $(572,573)$.

\section{Anemone hepatica L. (ranunculàcies)}

BCN 27247

\section{NOMS POPULARS}


Herba fetgera $(505,506,507,509,510,515,516,517,520,521,522,523,529,530,531$, $538,542,543,544,553,554,555,561,562,563,564,568,571,572,573,578,579,583$ $584,585,746,747,748,749,753,754,755,1215,1293,1298,1299,1300,1311,1312$ $1313,1314,1317,1322,1327,1328,1329,1330,1335,1336,1339,1340,1345,1346,1347$ $1348,1349,1350,1351,1353,1354,1352,1361,1362)$

Viola de llop $(536,537,541,564)$

\section{USOS MEDICINALS}

Flor

Hepatoprotector

FONT 1300. DESCRIPCIÓ DE L'ÚS FETA PER L'INFORMANT. La flor va bé per al fetge FORMA FARMACEUTICA I ÚS. Tisana (ús intern). PREPARACIÓ. Decocció. DESTINACIO. Medicina humana.

Fulla

Antiictèric

FONTS 561, 562, 563. DESCRIPCIÓ DE L'ÚS FETA PELS INFORMANTS. Per al fetge i per al fel. FORMA FARMACĖUTICA I ÚS. Tisana (ús intern). PREPARACIÓ. Decocció. al fel. FORMA FARMACEUTICA

Antiinflamatori intestinal

FONT 1322. DESCRIPCIÓ DE L'ÚS FETA PER L'INFORMANT. Quan alguna cosa t'ha fet mal. FORMA FARMACĖUTICA I ÚS. Tisana (ús intern). PREPARACIÓ. Decocció. DESTINACIÓ. Medicina humana.

Hepatoprotector

FONTS $505,506,507,509,510,511,512,513,514,515,516,517,520,521,522,523,529$ $530,531,538,542,543,544,553,554,555,561,562,563,571,572,573,578,579,583$, $584,585,746,747,748,749,753,754,755,1215,1293,1298,1299,1311,1312,1313$ $1314,1317,1330,1335,1336,1339,1340,1345,1346,1347,1348,1349,1350,1351,1352$ 1353, 1354. DESCRIPCIO DE L'US FETA PELS INFORMANTS. Per al fetge $(505,506,507$ $509,510,511,512,513,514,515,516,517,520,521,522,523,529,530,531,538,542$ $543,544,553,554,555,571,572,573,578,579,583,584,585,746,747,748,749,753$ $754,755,1298,1313,1314,1317,1330,1335,1336,1339,1340,1345,1346,1347,1348$ $1349,1350,1351,1352,1353,1354)$. Per al fetge i per al fel $(561,562,563)$. És bona per a fetge (1215). Per a la gent delicada del fetge (1293). Va bé per al fetge $(1299,1311,1312$. FORMA FARMACEUTICA I US. Tisana (ús intern) $(505,506,507,509,510,511,512,513$ $514,515,516,517,520,521,522,523,529,530,531,538,542,543,544,553,554,555$ $561,562,563,571,572,573,578,579,583,584,585,746,747,748,749,753,754,755$ $1215,1293,1298,1311,1312,1313,1314,1317,1330,1335,1336,1339,1340,1345,1346$, $1347,1348,1349,1350,1351,1352,1353,1354)$. PREPARACIÓ. De 135ió $(505,506,507,509,510,511,512,513,514,515,516,517,520$ $521,522,523,529,530,531,538,542,543,544,553,554,555,561,562,563,571,572$ $573,578,579,583,584,585,746,748,749,753,754,755,1293,1298,1311,1312,1314$,
1317, 1330, 1335, 1339, 1340, 1345, 1346, 1347, 1348, 1349). Decocció. Aigua de les fulles (747). Aigua en infusió (1215). Les fulles en remull tota la nit i l'endemà et beus l'aigua (1299). Infusió de les fullos (1336). DESTINACIÓ. Medina humana. OBSERVACIONS (1299). Infusió de les fulles (1336). DESTINACIÓ. Medicina humana. OBSERVACIONS. La bona es la que es morada. En té un pot amb fulles $(1311,1312)$. Abans en compraven molta $(1345,1346,1347,1348$ 1349)

Vulnerari

FONTS 536, 537, 564. DESCRIPCIÓ DE L'ÚS FETA PELS INFORMANTS. Per a curar ferides $(536,537)$. Per a les ferides (564). FORMA FARMACĖUTICA I ÚS. Sense forma farmacèutica (ús directe, ús extern). PREPARACIÓ. Les fulles per un costat estiren i per farmacèutica (ús directe, ús extern). PREPARACIO. Les fulles per un costat estiren i per DESTINACIÓ. Medicina humana.

\section{Part aèria}

Hepatoprotector

FONTS 1328, 1329, 1361, 1362. DESCRIPCIÓ DE L'ÚS FETA PELS INFORMANTS. Per al fetge, quan tens amargantor de boca $(1328,1329)$. Per al fetge $(1361,1362)$. FORMA FARMACĖUTICA I ÚS. Tisana (ús intern). PREPARACIÓ. Decocció $(1328,1329)$. En infusió $(1361,1362)$. DESTINACIÓ. Medicina humana.

\section{ALTRES OBSERVACIONS}

FONTS 520, 521, 568. DESCRIPCIÓ FETA PELS INFORMANTS. La fulla s'assembla al fetge $(520,521)$. Es fa a les ombres dels freixes $(568)$.

\section{Anemone pulsatilla L. (ranunculàcies)}

BCN 24711

\section{NOMS POPULARS}

Flor de Sant Pere (1321)

ALTRES OBSERVACIONS

FONT 1321. DESCRIPCIÓ FETA PER L'INFORMANT. N'hi ha molta allà a la vora del xalet.

\section{Angelica sylvestris L. (umbel·líferes)}

\section{BCN 24712}

\section{NOMS POPULARS}

Angèlica $(539,540,553,572,573,583,584,585,1324)$ 
Apèndix 1. Catàleg de tàxons.

Greixa $(505,506,517,529,530,531,554,555,586,587,591,592,748,749,1313,1321)$ Greixen $(556,557)$

\section{USOS MEDICINALS}

\section{Arrel}

Diürètic

FONT 528. DESCRIPCIÓ DE L'ÚS FETA PER L'INFORMANT. La rel és bona per a fer orinar. FORMA FARMACĖUTICA I ÚS. Tisana (ús intern). PREPARACIÓ. Decocció DESTINACIÓ. Medicina humana.

Tranquil.litzant

FONT 1324. DESCRIPCIÓ DE L'ÚS FETA PER L'INFORMANT. Va bé per als nervis FORMA FARMACĖUTICA I ÚS. Tisana (ús intern). PREPARACIÓ. L'arrel bullida. DESTINACIÓ. Medicina humana.

\section{Fulla}

Anticefalàlgic

FONTS 539, 540. DESCRIPCIÓ DE L'ÚS FETA PELS INFORMANTS. Van bé per al mal de cap. FORMA FARMACĖUTICA I ÚS. Tisana (ús intern). PREPARACIÓ. Les fulles en infusió. DESTINACIÓ. Medicina humana.

\section{Antipirètic}

FONT 517. DESCRIPCIÓ DE L'ÚS FETA PER L'INFORMANT. Per a les febres. FORMA FARMACÉUTICA I ÚS. Tisana (ús intern). PREPARACIÓ. Decocció. Aigua de greixes. DESTINACIÓ. Medicina humana.

\section{Hematocatàrtic}

FONTS 554, 555. DESCRIPCIÓ DE L'ÚS FETA PELS INFORMANTS. Es mengen la sang dolenta. FORMA FARMACĖUTICA I ÚS. Sense forma farmacèutica (ús directe, ús intern). PREPARACIÓ. Amanides. DESTINACIÓ. Medicina humana.

\section{USOS ALIMENTARIS}

Fulla

Ingestió de la part de la planta crua - Fresca (sense preparació)

FONTS 505, 506, 528, 529, 530, 531, 554, 555, 556, 557, 586, 587, 591, 592, 748, 749 DESCRIPCIÓ DE L'ÚS FETA PELS INFORMANTS. Per a amanir, la mare era de Vilallonga i sempre em parlava de les greixes amanides $(505,506)$. Per a menjar amanit $(748,749)$. Per a amanir $(528,529,530,531,556,557,591,592)$. Amanides, es mengen la sang dolenta $(554,555)$. Per a amanir quan són tendres $(586,587)$. CONSUMICIÓ. Entrant - Amanida (556). DESTINACIÓ. Alimentació humana $(505,506,528,529,530,531,554,555,556,557$, 586, 587, 591, 592, 748, 749).

\section{Part aèria}

Ingestió de la part de la planta crua - Fresca (sense preparació)
FONTS 553, 572, 573, 1313, 1321. DESCRIPCIÓ DE L'ÚS FETA PELS INFORMANTS. Es donava per a menjar als porcs, quan no hi havia ni cols ni res (553). Es donaven als porcs $(572,573)$. Per a menjar els porcs (1313). En donen als porcs (1321). DESTINACIÓ Alimentació animal $(553,572,573,1313,1321)$.

Ingestió de la part de la planta cuita - Cuita en aigua

FONTS 539, 540. DESCRIPCIÓ DE L'ÚS FETA PELS INFORMANTS. Bullides, se'n feia perola per a donar al bestiar. DESTINACIÓ. Alimentació animal.

\section{ALTRES OBSERVACIONS}

FONTS 517, 528, 586, 587. DESCRIPCIÓ FETA PELS INFORMANTS. Es fa a les vores de l'aigua (517). Es fa a les molleres (528). Es fan a les molleres $(586,587)$.

\section{Antennaria dioica (L.) Gaertn. (compostes)}

BCN 62399

\section{NOMS POPULARS}

Pota de gat $(753,754,755)$

\section{BARREGES AMB AQUEST TÀXON}

\section{No consta}

FONTS $753,754,755$. Entrevista 67 , barreja VIII (vegeu catàleg de barreges)

\section{Anthemis arvensis L. (compostes)}

BCN 31630

\section{NOMS POPULARS}

Bòlig (529, 530, 531)

Sistorna $(529,530,531)$

\section{ALTRES USOS}

\section{Part aèria florida}

Ornamental: elaboració de rams

FONTS 529, 530, 531. DESCRIPCIÓ DE L'ÚS FETA PELS INFORMANTS. Per a fer rams. Es una camamilla borda i fa pudor quan la culls. 


\section{BARREGES AMB AQUEST TÀXON}

Inflorescència

FONTS 529, 530, 531. Entrevista 53, barreja VI (vegeu catàleg de barreges)

\section{Anthyllis vulneraria L. subsp. forondae (Senn.)}

Cullen (papilionàcies)

BCN 24713

\section{NOMS POPULARS}

Vulnerària (1324)

\section{USOS MEDICINALS}

Part aèria

Antihipertensiu

FONT 1324. DESCRIPCIÓ DE L'ÚS FETA PER L'INFORMANT. Per a fer baixar la pressió FORMA FARMACĖUTICA I ÚS. Tisana (ús intern). PREPARACIÓ. Decocció. DESTINACIÓ Medicina humana.

Antisèptic extern

FONT 1324. DESCRIPCIÓ DE L'ÚS FETA PER L'INFORMANT. Per a desinfectar ferides FORMA FARMACĖUTICA I ÚS. Bany (ús extern). PREPARACIÓ. Decocció. DESTINACIÓ. Medicina humana.

\section{Antirrhinum asarina L. (escrofulariàcies)}

BCN 58376

\section{NOMS POPULARS}

Descadellagossos $(507,509,510)$

\section{ACCIONS NOCIVES O TÒXIQUES}

No consta

FONTS 507, 509, 510. DESCRIPCIÓ DE L'ACCIÓ NOCIVA O TÒXICA FETA PELS INFORMANTS. Deien que era abortiva. És una planta petita amb la flor groga.

Antirrhinum majus L. subsp. majus (escrofulariàcies) BCN 27271

\section{NOMS POPULARS}

Cadells (517)

Gossets $(541,553,580)$

Gossos $(547,548,552)$

\section{USOS ALIMENTARIS}

\section{Inflorescència}

Ingestió de la part de la planta crua - Fresca (sense preparació)

FONT 517. DESCRIPCIÓ DE L'ÚS FETA PER L'INFORMANT. Si la xucles és dolça. DESTINACIO. Alimentació humana.

\section{ALTRES USOS}

Inflorescència

Artesanal: elaboració de joguines

FONT 541. DESCRIPCIÓ DE L'ÚS FETA PER L'INFORMANT. S'usaven per a jugar.

Ornamental: elaboració de rams

FONTS 548, 552, 553, 580. DESCRIPCIÓ DE L'ÚS FETA PELS INFORMANTS. Per a fer rams $(548,553)$. Per a guarnir l'església per Sant Joan (552).

\section{Aphyllanthes monspeliensis L. (liliàcies)}

\section{BCN 54567}

\section{NOMS POPULARS}

Jonça $(518,519,578,579)$

Junça $(529,530,531)$

\section{USOS ALIMENTARIS}

Flor

Ingestió de la part de la planta crua - Fresca (sense preparació)

FONTS 518, 519, 529, 530, 531, 578, 579. DESCRIPCIÓ DE L'ÚS FETA PELS NFORMANTS. És dolça, te la pots menjar $(578,579)$. Nosaltres ens menjàvem la flor, és bona, dolça $(529,530,531)$. El bestiar se la menja, la flor és dolça $(518,519)$. DESTINACIÓ Alimentació humana $(529,530,531,578,579)$. Alimentació animal $(518,519)$. 


\section{Apium graveolens L. (umbel·líferes)}

BCN 24714

\section{NOMS POPULARS}

Api $(580,1330)$

Àpit $(503,558)$

\section{USOS ALIMENTARIS}

Fulla

Ingestió de la part de la planta crua - Fresca (sense preparació)

FONTS 503, 558. DESCRIPCIÓ DE L'ÚS FETA PELS INFORMANTS. Amanit (503). Per a amanir (558). OBSERVACIONS. Encara me'n recordo quan la mare va portar per primera vegada una planteta d'àpit per plantar i va explicar que li havien dit que era tan bo (503). DESTINACIÓ. Alimentació humana $(503,558)$.

Ingestió de la part de la planta cuita - Cuita en aigua

FONT 580. DESCRIPCIÓ DE L'ÚS FETA PER L'INFORMANT. Per a posar al caldo. DESTINACIO. Alimentació humana.

\section{BARREGES AMB AQUEST TÀXON}

Part aèria

FONT 1330. Entrevista 32, barreja III (vegeu catàleg de barreges)

\section{Apium nodiflorum (L.) Lag. subsp. nodiflorum}

(umbel·líferes)

BCN 27277

\section{NOMS POPULARS}

Api bord $(529,530,531,1347,1348,1349,1352)$

Àpit (552)

Àpit bord $(528,533,534,553,572,573,588)$

\section{USOS ALIMENTARIS}

Part aèria jove

Ingestió de la part de la planta crua - Fresca (sense preparació)
FONTS 528, 529, 530, 531, 533, 534, 552, 553, 572, 573, 588, 1347, 1348, 1349, 1352 DESCRIPCIÓ DE L'ÚS FETA PELS INFORMANTS. Per a amanir $(528,529,530,531,533$ $534,572,573,588,1347,1348,1349)$. Amanit $(552,553)$. Per a menjar amanit (1352). $534,572,573,588,1347,1348,1349)$. Amanit $(552,553)$. Per a menjar amanit (1352). OBSERVACIONS. La meva mare en deia àpit. Una vegada ens va fer mal de ventre. Deu ser un apit bord (552). El meu pare en menjava quan no hi havia res a l'hort (553). DESTINACIO. Alimentació humana $(528,529,530,531,533,534,552,553,572,573,588,1347,1348$ $1349,1352)$

\section{ALTRES OBSERVACIONS}

FONTS 552, 553. DESCRIPCIÓ FETA PELS INFORMANTS. Es fa en els rierols (552). Es fa en llocs molt humits (553).

\section{Aquilegia vulgaris L. (ranunculàcies)}

\section{BCN 27253}

\section{NOMS POPULARS}

Campana $(1353,1354)$

\section{ALTRES USOS}

\section{Part aèria florida}

Ornamental: elaboració de rams

FONTS 1353, 1354. DESCRIPCIÓ DE L'ÚS FETA PELS INFORMANTS. Per a fer rams al mes de maig (1353). Floreixen al maig i surten a l'hort, fa un all (1354).

\section{Arctium minus Bernh. (compostes)}

BCN 24715

\section{NOMS POPULARS}

Enganxadones $(1215,1352)$

Gossos $(586,587)$

Repalassa $(518,519,520,521,553,561,562,563,568,583,584,585,586,587,750,1299$ $1324,1327)$

\section{USOS MEDICINALS}

Arrel

Desconegut per l'informan 
FONTS 518, 519, 583, 584, 585, 1299. FORMA FARMACĖUTICA I ÚS. Desconegut per l'informant. DESTINACIÓ. Medicina humana. OBSERVACIONS. Les rels són medicinals, però no recordo per a què $(518,519)$. Em sembla que la rel era medicinal $(583,584,585)$ S'utilitzava l'arrel, però no recordo per a què (1299).

Hematocatàrtic

FONTS 520, 521. DESCRIPCIÓ DE L'ÚS FETA PELS INFORMANTS. L'arrel per a purificar la sang, et prevé que no et surtin furóncols. FORMA FARMACĖUTICA I ÚS. Tisana (ús intern). PREPARACIÓ. Decocció. MODE D'UTILITZACIÓ/POSOLOGIA. S'ha de fer una novena a la primavera o a la tardor. DESTINACIÓ. Medicina humana.

Hepatoprotector

FONT 1324. DESCRIPCIÓ DE L'ÚS FETA PER L'INFORMANT. Per al fetge. FORMA FARMACĖUTICA I ÚS. Tisana (ús intern). PREPARACIÓ. Decocció. DESTINACIÓ. Medicina humana.

Litotríptic renal

FONTS 561, 562, 563. DESCRIPCIÓ DE L'ÚS FETA PELS INFORMANTS. L'arrel per a les pedres del ronyó. FORMA FARMACĖUTICA I ÚS. Tisana (ús intern). PREPARACIÓ. Decocció. DESTINACIÓ. Medicina humana.

Vasotònic

FONT 1324. DESCRIPCIÓ DE L'ÚS FETA PER L'INFORMANT. Per a la mala circulació FORMA FARMACĖUTICA I ÚS. Tisana (ús intern). PREPARACIÓ. Decocció. DESTINACIÓ. Medicina humana.

\section{Part aèria}

Hipouricemiant

FONT 750. DESCRIPCIÓ DE L'ÚS FETA PER L'INFORMANT. Per al dolor de gota. FORMA FARMACĖUTICA I ÚS. Tisana (ús intern). PREPARACIÓ. Decocció. Aigua de la planta DESTINACIÓ. Medicina humana.

Litotríptic renal

FONT 1327. DESCRIPCIÓ DE L'ÚS FETA PER L'INFORMANT. Ajuda a fer les pedres dels ronyons. FORMA FARMACEUUTICA I ÚS. Tisana (ús intern). PREPARACIÓ. En infusió. DESTINACIÓ. Medicina humana.

\section{USOS ALIMENTARIS}

\section{Part aèria}

No consta el tipus d'ingesta - No consta el mode de preparació

FONT 568. DESCRIPCIÓ DE L'ÚS FETA PER L'INFORMANT. Per als porcs. DESTINACIÓ. Alimentació animal.

\section{ALTRES USOS}

Inflorescència
Altres informacions

FONT 1215. DESCRIPCIÓ DE L'ÚS FETA PER L'INFORMANT. En fèiem nius i els posàvem per a veure si els ocells hi anaven.

Lúdic: jocs i joguines

FONT 1352. DESCRIPCIÓ DE L'ÚS FETA PER L'INFORMANT. Per a fer paneretes i corones també per a enganxar als cabells d'altres nens.

\section{ALTRES OBSERVACIONS}

FONTS 586, 587. DESCRIPCIÓ FETA PELS INFORMANTS. S'enganxen molt quan són secs.

\section{BARREGES AMB AQUEST TÀXON}

Arrel

FONT 1324. Entrevista 5, barreja III (vegeu catàleg de barreges)

Arctostaphylos uva-ursi (L.) Spreng. (ericàcies)

BCN 101094

\section{NOMS POPULARS}

Boixerola $(583,584,585)$

ALTRES OBSERVACIONS

FONTS 583, 584, 585. DESCRIPCIÓ FETA PELS INFORMANTS. A Montgrony n'hi havia.

Aristolochia rotunda L. (aristoloquiàcies)

BCN 44558

\section{NOMS POPULARS}

Herba felera (517)

\section{USOS MEDICINALS}

Part aèria

Antiictèric 
FONT 517. DESCRIPCIÓ DE L'ÚS FETA PER L'INFORMANT. Per al fel. FORMA FARMACĖUTICA I ÚS. Tisana (ús intern). PREPARACIÓ. Decocció. Es fa aigua de tota la planta encara que és millor les boles. DESTINACIÓ. Medicina humana.

\section{ALTRES OBSERVACIONS}

FONT 517. DESCRIPCIÓ FETA PER L'INFORMANT. És una planta que s'estén com les corretjoles (Convolvulus arvensis) i a la tardor fa unes boles verdes.

\section{Arnica montana L. subsp. montana (compostes)}

\section{BCN 24716}

\section{NOMS POPULARS}

Àrnica $(504,505,506,507,509,510,511,512,513,514,515,516,517,518,519,520,521$ $522,523,525,526,527,528,529,530,531,532,533,534,538,541,542,543,544,545$ $546,547,548,549,552,554,555,556,557,558,559,561,562,563,565,566,567,569$ $570,571,572,573,574,575,576,577,578,579,580,581,583,584,585,586,587,588$ $589,590,591,592,746,748,749,750,751,753,754,755,1213,1214,1215,1293,1294$ 1296, 1297, 1298, 1299, 1300, 1301, 1307, 1308, 1309, 1310, 1313, 1314, 1315, 1316, 1317 $1318,1319,1320,1321,1322,1323,1324,1325,1326,1327,1328,1329,1330,1331,1332$ $1333,1334,1335,1336,1337,1338,1339,1340,1341,1342,1343,1344,1345,1346,1347$ $1348,1349,1350,1351,1353,1354,1361,1362)$

Flor de tabaco (castellà) $(541,574,575,576,577,1310,1337,1338,1347,1348,1349)$ Tabac de muntanya $(1213,1214)$

Tabaco (castellà) (532)

\section{USOS MEDICINALS}

\section{Inflorescència}

Analgèsic

FONTS 517, 529, 530, 531, 561, 562, 563, 572, 573, 586, 587, 746, 753, 754, 755, 1296 $1297,1298,1301,1315,1316,1317,1318,1319,1320,1322,1323,1324,1328,1329,1330$ $1331,1332,1333,1334,1335,1336,1343,1344,1345,1346,1347,1348,1349,1350,1351$ $1353,1354,1361,1362$. DESCRIPCIÓ DE L'ÚS FETA PELS INFORMANTS. Per a quan e fas un truc i per al dolor (746). Per al dolor i per als trucs (517). Per al dolor (529, 530, 531, $561,562,563,1296,1297,1298,1301,1315,1316,1317,1318,1319,1320,1323,1324$ $1328,1329,1330,1331,1332,1333,1334,1335,1336,1343,1344,1345,1346,1347,1348$ $1349,1350,1351,1353,1354)$. Per als cops i per al dolor $(572,573,753,754,755)$. Per a fer fregues per als trucs, per al dolor $(586,587)$. Per a fer fregues quan tens dolor quan estès fres (1322). Per als trucs i per al dolor $(1361,1362)$. FORMA FARMACE் quan estas cansat (1322). Per $(517,561,562,563,572,573,586,587,746,1296,1297,1301,1317$ $1318,1319,1320,1322,1323,1330,1332,1333,1334,1345,1346,1350,1351,1353,1354$
1361, 1362). Vinagre medicinal (ús extern) $(746,1301,1324,1328,1329)$. Loció (ús extern) $(517,529,530,531,561,562,563,572,573,586,587,746,753,754,755,1296,1297$, $1298,1301,1315,1316,1318,1319,1320,1322,1323,1330,1331,1332,1333,1334,1336$ $1343,1344,1345,1346,1350,1351,1353,1354,1361,1362)$. Essència (ús extern) (1335, $1347,1348,1349,1361,1362$ ). Pomada (ús extern) (1335). PREPARACIÓ. Es posa en esperit de vi, en oli o vinagre (746). En oli o esperit de vi (517). En esperit de vi $(529,530$, esperit de vi, en oli o vinagre (746). En oli o esperit de vi (517). En esperit de vi $(529,530$,
$531,561,562,563,572,573,586,587,1296,1298,1315,1316,1318,1319,1320,1323$, $1353,1354,1361,1362)$. En oli $(561,562,563,572,573,586,587,1296,1317,1318,1319$, $1322,1323,1353,1354,1361,1362)$. En esperit de vi per a fer fregues $(753,754,755)$. La flor en oli (1297). La flor en esperit de vi (1297). Confitada en oli (1301, 1320, 1330, 1345, $1346,1350,1351)$. Confitada en esperit de vi $(1301,1330,1336,1343,1344,1345,1346$, 1350, 1351). Confitada en vinagre (1301). En esperit de vi o colònia (1322). En vinagre $(1324,1328,1329)$. En esperit (1331). Confitat en esperit de vi $(1332,1333,1334)$. Confitat en oli $(1332,1333,1334)$. L'usen en essència (1335). També n'ha fet pomada. Les flors de l'àrnica bullides en oli al bany maria, llavors es treuen les flors i s'hi posa cera d'abella perquè li doni consistència de crema (1335). En essència $(1347,1348,1349)$. DESTINACIÓ . Medicina humana. OBSERVACIONS. No es pot fer servir quan tens ferida (1320). Diu que la que va més bé, és la de colònia (1322). A en Jaume li sortien grans i el metge els va dir que era una al·èrgia a l'àrnica, i no l'han usat més (1344). És millor que l'alcohol perquè no resseca tant $(1347,1348,1349)$.

Anticatarral

FONTS 529, 530, 531, 581, 586, 587, 753, 754, 755. DESCRIPCIÓ DE L'ÚS FETA PELS INFORMANTS. Per als refredats $(529,530,531,586,587)$. Per a quan estàs refredat de pit i
no pots arrencar les reumes $(753,754,755)$. Per als constipats (581). FORMA no pots arrencar les reumes (753, 754, 755). Per als constipats (581). FORMA
FARMACÉUTICA I ÚS. Tintura alcohòlica (ús intern). PREPARACIÓ. En aiguardent (529, $530,531)$. En aiguardent de bóta, hi poso 40 flors, s'ha de prendre amb mesura $(753,754$ 755). En aiguardent, en un litre d'anís set o vuit flors perquè s'ha de prendre i no sigui massa fort (581). Es posa en aiguardent $(586,587)$. MODE D'UTILITZACIÓ/POSOLOGIA. Te n'has de prendre un parell de cullerades $(529,530,531)$. S'ha de prendre una cullerada (581). DESTINACIÓ. Medicina humana. OBSERVACIONS. S'ha de vigilar perquè és molt forta $(586,587)$.

Anticefalàlgic

FONT 1331. DESCRIPCIÓ DE L'ÚS FETA PER L'INFORMANT. Per al mal de cap. FORMA FARMACĖUTICA I ÚS. Vinagre medicinal (ús extern). PREPARACIÓ. En vinagre. DESTINACIO. Medicina humana.

Antieczematós

FONTS 1328, 1329. DESCRIPCIÓ DE L'ÚS FETA PELS INFORMANTS. Per a curar les crostes. FORMA FARMACĖUTICA I ÚS. Embrocació (ús extern). PREPARACIÓ. En oli. DESTINACIÓ. Medicina humana.

Antiequimòtic

FONTS 504, 505, 506, 507, 509, 510, 511, 512, 513, 514, 515, 516, 517, 518, 519, 520, 521 , $522,523,525,526,527,528,532,533,534,538,542,543,544,546,547,548,549,554$ $555,556,557,558,559,565,566,567,569,570,571,572,573,574,575,576,577,578$, 
$579,580,583,584,585,586,587,588,589,590,591,592,746,748,749,750,751,753$, $754,755,1213,1214,1215,1293,1294,1296,1297,1298,1299,1300,1301,1307,1308$ $1309,1310,1313,1314,1315,1316,1317,1318,1319,1320,1321,1322,1323,1324,1325$, $1326,1328,1329,1330,1331,1335,1336,1337,1338,1341,1342,1345,1346,1347,1348$ $1349,1350,1351,1353,1354,1361,1362$. DESCRIPCIÓ DE L'ÚS FETA PELS INFORMANTS. Per als cops $(504,511,512,513,514,520,521,533,534,547,548,549$, $556,557,565,566,571,583,584,585,588,1215)$. Per a quan et fas un truc i per al dolor (746). Es fa servir com l'oli de cop. Per als trucs $(507,509,510)$. Per als trucs $(505,506,515$ $516,518,519,522,523,525,526,527,528,538,542,543,544,569,570,574,575,576$ $577,578,579,580,589,591,592,748,749,750,1293,1294,1297,1298,1300,1301,1310$ $1314,1315,1316,1317,1318,1319,1320,1321,1322,1323,1324,1325,1326,1328,1329$ 1330, 1331, 1335, 1336, 1337, 1338, 1341, 1342, 1345, 1346, 1347, 1348, 1349, 1350, 1351 $1353,1354)$. Per al dolor i per als trucs (517). Per als trucs i cops (751). Per als cops i per a dolor $(532,572,573,753,754,755)$. Per a quan et fas un cop fort (546). Per a trucs, patacades i dolor (559). Per als trucs i el dolor (558). Per als cops i dolor (567). Per a fer sortir els morats $(554,555)$. Per a fer sortir els morats (555). Per a posar als trucs (500). Per (1) Per fres (1296). Per a fer fregues $(1213,1214)$. Per al dolor o quan et fas un truc $(1296)$. Per al dolor (1296). Per a fer fregues per als trucs (1299). La Palmira va caure i va curar fent-se fregues d'arnica $(1307,1308,1309)$. Quan et feies un truc (1313). Quan tenies una llaga (1313). Va molt bé per a fer marxar els blaus quan t'has fet un truc (1328, 1329). Per als trucs i per al dolor $(1361,1362)$. FORMA FARMACĖUTICA I ÚS. Loció (ús extern) $(504,505,506,511,512,513,514,516,517,518,519,520,521,522,523,525,526$ $527,528,532,533,534,538,542,543,544,546,547,548,549,554,555,556,557,558$ $559,565,566,567,569,570,571,572,573,578,579,580,583,584,585,586,587,588$ $589,590,591,592,746,748,749,750,751,753,754,755,1213,1214,1293,1296,1297$ $1298,1299,1300,1301,1310,1313,1314,1315,1316,1317,1318,1319,1320,1321,1322$ $1323,1325,1326,1328,1329,1330,1331,1336,1337,1338,1341,1342,1345,1346,1347$ $1348,1349,1350,1351,1353,1354,1361,1362)$ Vinagre medicinal (ús extern) $(516,746$ 1301). Liniment (ús extern) $(507,509,510,511,512,513,514,515,516,517,520,521,525$ $526,527,528,533,534,538,547,548,554,555,558,550,565,566,567,560,570,571$, $526,527,528,533,534,538,547,548,554,555,558,559,565,566,567,569,570,571$ 132, $1320,1322,1323,1325,1326,1330,1337,1338,1341,1342,1345,1346,1347,1348,1349$ 1350, 1351, 1353, 1354, 1361, 1362). Desconegut per l'informant (574, 575, 576, 577, 1307 $1308,1309)$. Essència (ús extern) (1294, 1328, 1329, 1335, 1361, 1362). Embrocació (ús extern) (1313). Pomada (ús extern) $(1320,1324,1335)$. PREPARACIÓ. Posada en esperit de vi $(504,518,519)$. Es posa en esperit de vi, en oli o vinagre (746). Es macera en oli (507, $509,510)$. Confitada en esperit de vi $(505,506,1299,1301,1314,1321,1325,1330,1336$ $1337,1338,1341,1345,1346,1350,1351)$. En oli $(511,512,513,514,528,547,548,558$ $567,569,570,572,573,580,586,587,1215,1296,1318,1319,1322,1323,1347,1348$ $1349,1353,1354,1361,1362)$. En esperit de vi $(511,512,513,514,528,542,543,544,547$ $548,549,556,557,558,567,569,570,572,573,578,579,580,583,584,585,586,587$ $588,589,590,748,749,1296,1298,1315,1316,1317,1318,1319,1320,1323,1347,1348$ $1349,1353,1354,1361,1362)$. En esperit de vi, oli o vinagre $(515,516)$. Es posa en esperit 134 vi $(522,523,571,591,592,750,751)$. En oli o esperit devi $(517,533,534)$. En en esperit vi o oli $(525,526,527,533,534)$. Per als cops amb mig litre d'esperit de vi i 30 flors (532). La flor en esperit de vi o oli $(520,521,538)$. Alcohol amb flors d'àrnica (546). Posada en oli (559). Posada en alcohol (559). Es posa en oli $(571)$. Posat en oli $(565,566)$. Posat en esperit de vi $(565,566)$. En esperit de vi, nou dies a sol i serena $(554,555)$. En esperit de vi per a fer fregues $(753,754,755)$. En alcohol. Es fan fregues amb una gasa o un cotó xopat per a fer fregues $(753,754,755)$. En alcohol. Es fan fregues amb una gasa o un coto xopat d'alcohol en la zona adolorida $(1213,1214)$. Es pot fer en oli o esperit de vi (1293). La flor en oli (1297). La flor en esperit de vi (1297). Es confita la flor en oli $(1300,1310)$. Es confita en esperit de vi $(1300,1310)$. Confitada en oli $(1301,1320,1325,1326,1330,1337,1338,1341$, $1345,1346,1350,1351)$. Confitada en vinagre (1301). Confitada en anís o alcohol. Et posaven una flor confitada i ben embolicat (1313). Confitada en oli. Et posaven una flor confitada i ben embolicat (1313). En esperit de vi o colònia (1322). Una pomada amb flors d'àrnica, oli i cera natural. La flor d'àrnica s'ha de bullir en oli, es cola i s'hi posa la cera (1324). Cofitada en esperit de vi (1326). En alcohol $(1328,1329)$. En essència $(1328,1329)$. En esperit (1331). L'usen en essència (1335). També n'ha fet pomada. Les flors de l'àrnica bullides en oli al bany maria, llavors es treuen les flors i s'hi posa cera d'abella perquè li doni consistència de crema (1335). Confitat en oli (1342). Confitat en esperit de vi (1342) DESTINACIÓ. Medicina humana. OBSERVACIONS. No la fem servir $(507,509,510)$. Ara . Cora tambe lhe fet L'alcohol no es pot aplicar a la pell si hi ha ferida $(1213,1214)$. Una veina els en porta (1307, 1308, 1309). No es pot fer servir quan th colònia (1322). Amb l'àrnica s'ha d'anar amb compte perquè diuen que és una droga (1325, 1326)

\section{Antihipertensiu}

FONTS 554, 555. DESCRIPCIÓ DE L'ÚS FETA PELS INFORMANTS. Per a la gent que té la pressió alta. Abans se'n prenien gotes de l'esperit de vi sobretot la gent que té la pressió alta (554). Per a la gent que té la pressió alta. Abans se'n prenien gotes de la d'esperit de vi sobretot la gent que té la pressió alta (555). FORMA FARMACĖUTICA I ÚS. Tintura alcohòlica (ús intern). PREPARACIÓ. En esperit de vi, nou dies a sol i serena $(554,555)$. DESTINACIÓ. Medicina humana.

Antiinflamatori

FONT 1331. DESCRIPCIÓ DE L'ÚS FETA PER L'INFORMANT. Per a fer fregues a les cervicals. FORMA FARMACĖUTICA I ÚS. Loció (ús extern). PREPARACIÓ. En esperit de vi. DESTINACIÓ. Medicina humana.

Antiinflamatori intestinal

FONT 1314. DESCRIPCIÓ DE L'ÚS FETA PER L'INFORMANT. Quan tenies mal de ventre FORMA FARMACĖUTICA I ÚS. Essència (ús intern). DESTINACIÓ. Medicina humana.

Antipiròtic

FONTS 529, 530, 531. DESCRIPCIÓ DE L'ÚS FETA PELS INFORMANTS. Va molt bé per a les cremades. FORMA FARMACĖUTICA I ÚS. Embrocació (ús extern). PREPARACIÓ. En oli. DESTINACIÓ. Medicina humana.

Antisèptic ocular

FONT 581. DESCRIPCIÓ DE L'ÚS FETA PER L'INFORMANT. Va molt bé per als ulls. FORMA FARMACĖUTICA I ÚS. Col-liri (ús extern). PREPARACIÓ. També se'n treu essència 
i es posa una gota a l'ull. DESTINACIÓ. Medicina humana. OBSERVACIONS. Això ho deia en Pipes de Ripoll.

Antitussigen

FONTS 1325, 1326. DESCRIPCIÓ DE L'ÚS FETA PELS INFORMANTS. Va bé per a quan tens tos. FORMA FARMACĖUTICA I ÚS. Xarop (ús intern). PREPARACIÓ. Fan un xarop amb 12 flors i 1 litre d'aiguardent. MODE D'UTILITZACIÓ/POSOLOGIA. Només una cullerada. DESTINACIÓ. Medicina humana. OBSERVACIONS. Amb l'àrnica s'ha d'anar amb compte perquè diuen que és una droga.

Cardiotònic

FONT 545. DESCRIPCIÓ DE L'ÚS FETA PER L'INFORMANT. A mi em fa por, ataca el cor.Per al cor. FORMA FARMACĖUTICA I ÚS. Tintura alcohòlica (ús intern). Essència (ús intern). PREPARACIÓ. Només s'hi pot posar tres flors per un quart de litre d'esperit de vi.En intern). PREPARACIO. Nomes s'hi pot posar tres flors per un quart
fancia i pren en gotes. DESTINACIÓ. Medicina humana.

Desconegut per l'informant

FONTS 1310, 1323. FORMA FARMACĖUTICA I ÚS. Essència (ús intern) (1310). Tintura alcohòlica (ús intern) (1323). PREPARACIÓ. Se'n feia essència (1310). Confitada en anís (1323). DESTINACIÓ. Medicina humana. OBSERVACIONS. Hi ha gent que se la pren, ella no ho ha provat mai (1323).

Hematocatàrtic

FONTS 1299, 1319. DESCRIPCIÓ DE L'ÚS FETA PELS INFORMANTS. Va bé per a la circulació de la sang (1299). Per a netejar el cos (1319). FORMA FARMACĖUTICA I ÚS Loció (ús extern) (1299). Essència (ús intern) (1319). PREPARACIÓ. Confitada en esperit de vi (1299). DESTINACIÓ. Medicina humana. OBSERVACIONS. No se'n pot prendre gaire (1319).

\section{No consta}

FONT 581. DESCRIPCIÓ DE L'ÚS FETA PER L'INFORMANT. Les vaques agafen una malaltia que en diem reprís que els ve de menjar molta lleguminosa, queden com contretes els ataca el braguer i les cames, en diem cop de sang. FORMA FARMACĖUTICA I ÚS. Liniment (ús extern). PREPARACIÓ. Els faig un massatge d'àrnica en oli perquè l'ol amoroseix molt. DESTINACIÓ. Medicina veterinària.

Per a l'ictus apoplèctic/cerebral

FONTS 532, 554, 555, 1328, 1329, 1339, 1340. DESCRIPCIÓ DE L'ÚS FETA PELS INFORMANTS. Per a prevenir les feridures $(532,554)$. Per a prevenir de les feridures (555). Per a prevenir la feridura $(1328,1329)$. Per a evitar tenir una feridura $(1339,1340)$. FORMA FARMACĖUTICA I ÚS. Tintura alcohòlica (ús intern) $(532,554,555,1339,1340)$. Essència (ús intern) $(1328,1329)$. PREPARACIÓ. En alcohol de $30^{\circ}$ i posar-hi menys de 30 flors (532) En esperit de vi, nou dies a sol i serena $(554,555)$. Essència (1328). En essència (1329). MODE D'UTILITZACIÓ/POSOLOGIA. Es solia prendre en forma de novena (532). En novenes $(1328,1329)$. Unes gotes d'esperit d'àrnica cada matí $(1339,1340)$. DESTINACIÓ Medicina humana.

Per a les picades
FONTS 581, 746. DESCRIPCIÓ DE L'ÚS FETA PELS INFORMANTS. La de vinagre va molt bé, també, per a les picades de mosquits (746). Per a les picades de mosquit (581). FORMA FARMACĖUTICA I ÚS. Vinagre medicinal (ús extern). PREPARACIÓ. En vinagre (581). DESTINACIÓ. Medicina humana.

Per a les punxades

FONT 1318. DESCRIPCIÓ DE L'ÚS FETA PER L'INFORMANT. Per a les punxades. FORMA FARMACĖUTICA I ÚS. Liniment (ús extern). Loció (ús extern). PREPARACIÓ. En oli.En esperit de vi. DESTINACIÓ. Medicina humana.

Per a trastorns del sistema respiratori

FONTS 591, 592. DESCRIPCIÓ DE L'ÚS FETA PELS INFORMANTS. És bona per a I'ofegament. FORMA FARMACĖUTICA I ÚS. Tintura alcohòlica (ús intern). PREPARACIÓ. Esperit d'àrnica. MODE D'UTILITZACIÓ/POSOLOGIA. Es pren una cullerada cada dia. Esperit d'àrnica. MODE D'UTILITZ
DESTINACIÓ. Medicina humana.

Per als esquinços

FONT 751. DESCRIPCIÓ DE L'ÚS FETA PER L'INFORMANT. Carnesqueixats. FORMA FARMACĖUTICA I ÚS. Loció (ús extern). PREPARACIÓ. En esperit de vi. Ben fregat i estar quiet 4 dies per esperar que la carn es torni a agafar a l'ós. DESTINACIÓ. Medicina humana.
quand quiet 4 dies
Vasotònic

FONTS 511, 512, 513, 514, 1324, 1327. DESCRIPCIÓ DE L'ÚS FETA PELS INFORMANTS. Hi ha gent que la fa servir per a fer fregues per a la circulació $(511,512,513,514)$. Per a la mala circulació de les cames (1324). Per a fer-se fregues a les cames per a la mala circulació (1327). FORMA FARMACĖUTICA I ÚS. Liniment (ús extern) $(511,512,513,514)$. Loció (ús (1327). FORMA FARMACEUTICA I U. Liniment (ús extern) $(511,512,513,514)$. Loció (ús extern) $(511,512,513,514)$. Vinagre medicinal (ús extern) $(1324,1327)$. PREPARACIO. En
oli $(511,512,513,514)$. En esperit de vi $(511,512,513,514)$. En vinagre (1324). Confitada en vinagre (1327). DESTINACIÓ. Medicina humana.

Vulnerari

FONTS 590, 1213, 1214, 1313, 1328, 1329, 1331, 1341, 1342. DESCRIPCIÓ DE L'ÚS FETA PELS INFORMANTS. Per als talls $(590,1341,1342)$. Per a les ferides $(1213,1214)$. Quan tenies una llaga (1313). Per als talls (encara que pica una mica) $(1328,1329)$. Per a les ferides que tenen sang (1331). FORMA FARMACĖUTICA I ÚS. Loció (ús extern) (590, 1313, $1328,1329)$. Liniment (ús extern) $(1213,1214)$. Embrocació (ús extern) (1331). Essència (ús extern) $(1341,1342)$. PREPARACIÓ. En esperit de vi $(590)$. En oli $(1213,1214,1331)$. Confitada en anís o alcohol. Et posaven una flor confitada i ben embolicat (1313). En alcohol $(1328,1329)$. Essència $(1341,1342)$. DESTINACIÓ. Medicina humana.

\section{No consta}

Desconegut per l'informant

FONT 552. FORMA FARMACĖUTICA I ÚS. Desconegut per l'informant. DESTINACIÓ. Medicina humana. OBSERVACIONS. No la fem servir.

\section{ALTRES OBSERVACIONS}


FONTS 507, 509, 510, 517, 520, 521, 522, 523, 552, 583, 584, 585, 750, 751. DESCRIPCIÓ FETA PELS INFORMANTS. Aquí no n'hi ha $(507,509,510,552)$. L'anàvem a buscar al Pla d'Anyella o a Núria (750). A nosaltres ens la baixen de la muntanya (517). Jo n'havia collit a la muntanya $(522,523)$. És una planta que fa unes punxes i la flor groga $(751)$. Aquí no n'hi ha, l'anem a buscar al Taga $(520,521)$. Aquí se'n fa, allà a Gombrèn no n'hi havia pas ( 583 $584,585)$.

\section{BARREGES AMB AQUEST TÀXON}

\section{Inflorescència}

FONTS 1332, 1333, 1334. Entrevista 11, barreja I (vegeu catàleg de barreges)

FONTS 1332, 1333, 1334. Entrevista 11, barreja II (vegeu catàleg de barreges)

FONTS 529, 530, 531. Entrevista 53, barreja III (vegeu catàleg de barreges)

FONTS 518, 519. Entrevista 54, barreja II (vegeu catàleg de barreges)

FONTS 753, 754, 755. Entrevista 67, barreja IV (vegeu catàleg de barreges)

FONT 546. Entrevista 74, barreja I (vegeu catàleg de barreges)

FONTS 574, 575, 576, 577. Entrevista 91, barreja I (vegeu catàleg de barreges)

FONT 581. Entrevista 94, barreja I (vegeu catàleg de barreges)

FONTS 586, 587. Entrevista 97 (vegeu catàleg de barreges)

\section{Artemisia absinthium L. (compostes)}

\section{BCN 24717}

\section{NOMS POPULARS}

Donzell $(505,506,507,509,510,511,512,513,514,518,519,520,521,525,526,527,528$ $539,540,541,542,543,544,549,553,556,557,558,561,562,563,568,569,570,572$ $573,581,583,584,585,586,587,588,590,591,592,746,748,749,1296,1299,1301$, $1311,1312,1313,1314,1327,1332,1333,1334,1335,1337,1338,1341,1342,1343,1344$ $1353,1354,1352,1361,1362)$

Herba cuquera (1301)

\section{USOS MEDICINALS}

\section{Fulla}

Antihelmíntic

FONT 541. DESCRIPCIÓ DE L'ÚS FETA PER L'INFORMANT. Per a expulsar els cucs. FORMA FARMACĖUTICA I ÚS. Sense forma farmacèutica (ús directe, ús intern) PREPARACIÓ. Mastegar alguna fulla. DESTINACIÓ. Medicina humana.

No consta
Desconegut per l'informant

FONTS 586, 587, 588. FORMA FARMACĖUTICA I ÚS. Desconegut per l'informant DESTINACIÓ. Medicina humana. OBSERVACIONS. Es feia servir molt abans (588). No recorda l'ús $(586,587)$.

\section{Part aèria}

Antihelmíntic

FONTS 505, 506, 507, 509, 510, 511, 512, 513, 514, 518, 519, 520, 521, 539, 540, 542, 543 $544,556,557,558,561,562,563,568,569,570,572,573,581,583,584,585,590,591$ $592,746,748,749,1296,1301,1311,1312,1313,1314,1327,1332,1333,1334,1335$ $1337,1338,1341,1342,1343,1344,1352,1353,1354,1361,1362$. DESCRIPCIÓ DE L'ÚS FETA PELS INFORMANTS. Va bé per als cucs (746). Per a la mainada quan tenien cucs, es prenia a cullerades $(507,509,510)$. Per als cucs de la canalla $(505,506,590,591,592$, prenia a cullerades $(507,509,510)$. Per als cucs de la canalla $(505,506,590,591,592$,
$1353)$. Per als cucs $(511,512,513,514,518,519,542,543,544,569,570,581,583,584$ $585,748,749,1311,1312,1327,1335)$. Treia els cucs $(542,543,544)$. Feia sortir els cucs $585,748,749,1311,1312,1327,1335)$. Treia els cucs $(542,543,544)$. Feia sortir els cucs
$(539,540)$. Quan tenien cucs i mel al cul $(520,521)$. Per als cucs. Era molt amargant, al final sortien els cucs per la caca $(556,557)$. Aigua de donzell per a descucar $(568)$. Per a quan tenien cucs (558). Es penjava al coll dels nens quan tenien cucs $(561,562,563)$. Te'n posaven un ramet al coll quan tenies cucs $(572,573)$. Per als cucs de la mainada $(1296$, 1332, 1333, 1334, 1354). Es penjava a la mainada al coll quan tenien cucs (1301). Per als atacs de cucs (1313). De petita li posaven un ramet al pit perquè deien que en olorar-lo es morien els cucs (1314). Per a fer marxar els cucs $(1337,1338,1341,1342)$. Se'n posava al llombrígol de la mainada quan tenien cucs $(1343,1344)$. Un ramet penjat al coll de la mainada que tenia cucs (1352). Se'n penjava un ramet al coll dels nens que tenien cucs (1361, 1362). FORMA FARMACËUTICA I Ús. Macerat en medicinal (ús in medicinal (us intern) $(507,509,510,556,557)$. Sense forma farmaceutica (ús directe, ús extern) $(505,506,520,521,558,561,562,563,569,570,572,573,748,749,1296,1301$ $1313,1314,1337,1338,1352,1361,1362)$. Emplastre (us extern) (511, 512, 513, 514, 539, $540,542,543,544,1341,1342,1343,1344)$. Tisana (ús intern) $(518,519,542,543,544$, $568,581,583,584,585,590,1327,1332,1333,1335,1353,1354)$. Decocció (ús intern) $(591,592,1311,1312)$. Essència (ús intern) (1334). PREPARACIÓ. S'ha de posar el donzell tota la nit en aigua i l'endemà t'has de beure aquesta aigua (746). Es macerava la planta amb vi i sucre, se'n deia vi amargant $(507,509,510)$. Et penjaven un ramet de donzell al coll $(505$, 506). Barrejat amb llevat, te'l posaven al llombrígol i deien que els cucs sortien $(511,512$, $513,514)$. Se'n posava un ramet al coll de la mainada $(748,749)$. Decocció $(518,519,542$, $543,544,568,581,583,584,585,590,1327,1335)$. L'emplastre es posava a la panxa (542, $543,544)$. S'aixafava i se'n feia un emplastre a sobre el melic $(539,540)$. Es posava un ramet al coll de la canalla $(520,521)$. Es posava en vi dolç i te'l prenies uns quants dies $(556,557)$. Se'ls hi posava un ramet al coll als nens (558). Es posava al coll dels nens $(560,570)$. Es Sels hi posava un rame posava a la xocola perquè una bossa amb 1312). Es penjava un ramet de donzell $(1311,1312)$. Es penjava un ramet de donzell al coll (1313). Decocció. Se' $n$ feia aigua de les fulles $(1332,1333)$. Una cullerada d'essència de donzell (1334). Es penjava un grapadet de donzell al coll de la mainada $(1337,1338)$. Es feien emplastres que es posaven a la panxa $(1341,1342)$. MODE D'UTILITZACIÓ/POSOLOGIA. En dejú (1334). 
Apèndix 1. Catàleg de tàxons.

DESTINACIÓ. Medicina humana. OBSERVACIONS. El primer divendres de març, es feia prendre a la canalla una tassa d'aquesta xocolata perquè deien que així no tindrien cucs $(1311,1312)$. Es prenia amb sucre, perquè és molt amargant $(1332,1333)$. També te'n posaven amb un drapet al coll perquè ho anessis olorant, deien que això els matava (1341, 1342).

Hipoglucemiant

FONT 746. DESCRIPCIÓ DE L'ÚS FETA PER L'INFORMANT. Va bé per a fer baixar el sucre. FORMA FARMACĖUTICA I ÚS. Macerat en aigua (ús intern). PREPARACIÓ. S'ha de posar el donzell tota la nit en aigua i l'endemà t'has de beure aquesta aigua. DESTINACIÓ. posar el donzell tota.

Laxant

FONTS 525, 526, 527. DESCRIPCIÓ DE L'ÚS FETA PELS INFORMANTS. Per a quan els vedells s'empatxen. FORMA FARMACĖUTICA I ÚS. Tisana (ús intern). DESTINACIÓ. Medicina veterinària.

\section{ALTRES USOS}

\section{Part aèria}

Altres informacions

FONTS 528, 1332, 1333. DESCRIPCIÓ DE L'ÚS FETA PELS INFORMANTS. Si menges cargols i aquests han menjat donzell són ben amargants i no es poden menjar (528). Abans en recollien molt per vendre'n $(1332,1333)$

Domèstic: ambientador

FONT 528. DESCRIPCIÓ DE L'ÚS FETA PER L'INFORMANT. És amargant com un dimoni. A les cases quan s'anava a portar un mort et posaves un brot a la boca per no sentir la pudor.

\section{ACCIONS NOCIVES O TÒXIQUES}

\section{Part aèria}

FONT 1299. DESCRIPCIÓ DE L'ACCIÓ NOCIVA O TÒXICA FETA PER L'INFORMANT. La consideren molt perillosa, diu que si li fas aigua a una criatura per als cucs $\mathrm{i}$ li'n fas prendre per força, la criatura pot quedar trastocada. VIA D'INTOXICACIÓ. Via interna. TOXICITA LLIGADA A L'ÚS MEDICINAL. Si.

\section{ALTRES OBSERVACIONS}

FONTS 549, 571, 586, 587. DESCRIPCIÓ FETA PELS INFORMANTS. A casa n'hi havia, fa molta pudor (549). Fa una olor molt forta i les ovelles no en volen (571). Abans per aquí vora la casa n'hi havia $(586,587)$

\section{BARREGES AMB AQUEST TÀXON}

\section{Llavor}

FONT 1327. Entrevista 14, barreja III (vegeu catàleg de barreges)

Part aèria

FONTS 1343, 1344. Entrevista 23, barreja I (vegeu catàleg de barreges)

FONTS 586, 587. Entrevista 97 (vegeu catàleg de barreges)

\section{Artemisia alba Turra (compostes)}

\section{BCN 24718}

\section{NOMS POPULARS}

Herba de la xocolata $(517)$

Herba menuda $(520,521,524,561,562,563,565,566,591,592,1293,1294,1301,1311$, $1312,1361,1362)$

\section{USOS MEDICINALS}

\section{Part aèria}

Antiinflamatori intestinal

FONTS 591, 592, 1293, 1301, 1311, 1312. DESCRIPCIÓ DE L'ÚS FETA PELS INFORMANTS. Es prenia per a la panxa $(591,592)$. Quan tenies mal de ventre (1293). Per a mal de ventre (1301). Per a la panxa $(1311,1312)$. FORMA FARMACĖUTICA I ÚS. Tisana (ús intern) (591, 592, 1301). Decocció (ús intern) (591, 592, 1293, 1311, 1312) PREPARACIÓ. Decocció $(591,592,1301)$. Es prenia barrejat amb xocolata $(591,592,1311$, 1312). Es posava a la xocolata (1293). DESTINACIÓ. Medicina humana.

Digestiu

FONTS 1294, 1361, 1362. DESCRIPCIÓ DE L'ÚS FETA PELS INFORMANTS. És digestiva (1294). Per a pair $(1361,1362)$. FORMA FARMACĖUTICA I ÚS. Tisana (ús intern). PREPARACIÓ. Decocció (1294). En infusió $(1361,1362)$. DESTINACIÓ. Medicina humana.

Tranquil·litzant

FONTS 524, 561, 562, 563. DESCRIPCIÓ DE L'ÚS FETA PELS INFORMANTS. Va bé per als nervis (524). Deien que anava bé per als nervis (561, 562, 563). FORMA FARMACEUUTICAIUS. Decocció (ús intern). PREPARACIO. Es prenia barrejat amb xocolata desfeta $(524,561,562,563)$. DESTINACIO. Medicina humana.

\section{USOS ALIMENTARIS}

Part aèria

Condiment 
Apèndix 1. Catàleg de tàxons.

FONTS 517, 520, 521, 1301. DESCRIPCIÓ DE L'ÚS FETA PELS INFORMANTS. Per a posar a la xocolata $(520,521)$. Es posava per a donar gust a la xocolata $(517)$. Per a donar gust a la xocolata (1301). DESTINACIÓ. Alimentació humana $(517,520,521,1301)$.

\section{ALTRES OBSERVACIONS}

FONT 517. DESCRIPCIÓ FETA PER L'INFORMANT. Fa una matarrada, és molt aromàtica i té la fulla com la camamilla (Matricaria chamomilla).

\section{Artemisia vulgaris L. (compostes)}

BCN 24719

\section{NOMS POPULARS}

Altimira $(517,583,584,585)$

Altimiri $(511,512,513,514,528,532,538,553,556,557,558,574,575,576,577,580$ $1293,1325,1326,1327)$

Altimiris $(1361,1362)$

Artemisa (568)

\section{USOS MEDICINALS}

No consta

Desconegut per l'informant

FONTS 556, 557. FORMA FARMACĖUTICA I ÚS. Fumigació (ús extern). PREPARACIÓ.

Se'n feien perfums.

\section{Part aèria}

Antihipertensiu

FONTS 511, 512, 513, 514, 528. DESCRIPCIÓ DE L'ÚS FETA PELS INFORMANTS. Per a fer baixar la pressió. FORMA FARMACÉUTICA I ÚS. Tisana (ús intern). PREPARACIÓ. Decocció. DESTINACIÓ. Medicina humana.

Hipolipemiant

FONTS 517, 532, 580, 1293, 1327, 1361, 1362. DESCRIPCIÓ DE L'ÚS FETA PELS INFORMANTS. Per al colesterol $(517,532,580,1293)$. Per a fer baixar el colesterol (1327 1361, 1362). FORMA FARMACĖUTICA I ÚS. Tisana (ús intern). PREPARACIÓ. Decocció $(517,532,580,1293,1327,1361,1362)$. DESTINACIÓ. Medicina humana.

\section{USOS ALIMENTARIS}

\section{Part aèria}

Ingestió de la part de la planta crua - Fresca (sense preparació)
FONTS 538, 574, 575, 576, 577, 1293, 1325, 1326. DESCRIPCIÓ DE L'ÚS FETA PELS INFORMANTS. Es donava per a menjar als conills $(538,574,575,576,577,1325,1326)$. Els agrada molt als conills (1293). DESTINACIÓ. Alimentació animal $(538,574,575,576,577$, $1293,1325,1326)$

\section{ALTRES USOS}

\section{Part aèria}

Maneig agrosilvopastoral: ús hortícola/agrícola

FONT 558. DESCRIPCIÓ DE L'ÚS FETA PER L'INFORMANT. En fèiem feixets i ens les compraven.

\section{Arum italicum Mill. subsp. italicum (aràcies)}

BCN 32358

\section{NOMS POPULARS}

Fulles de cremat $(1213,1214)$

\section{USOS MEDICINALS}

Fulla

Antieritematós

FONTS 1213, 1214. DESCRIPCIÓ DE L'ÚS FETA PELS INFORMANTS. Per als escaldats FORMA FARMACĖUTICA I ÚS. Sense forma farmacèutica (ús directe, ús extern). PREPARACIO. Passar la fulla per la paella amb oli roent i posar la fulla cremada i pansida a sobre de la ferida. DESTINACIO. Medicina humana.

\section{Arundo donax L. (gramínies)}

\section{BCN 24720}

\section{NOMS POPULARS}

Canya $(503,518,519,541,1325,1326)$

Canya americana (564)

\section{USOS MEDICINALS}

Arre

Desconegut per l'informant 
FONTS 1325, 1326. FORMA FARMACĖUTICA I ÚS. Desconegut per l'informant. DESTINACIÓ. Medicina veterinària. OBSERVACIONS. Es feia aigua per al bestiar, però no recorda per a què.

\section{ALTRES USOS}

Tija

Maneig agrosilvopastoral: ús hortícola/agrícola

FONT 541. DESCRIPCIÓ DE L'ÚS FETA PER L'INFORMANT. Per a fer aspres, però no s'utilitzaven gaire, només en algun lloc que en tenien plantades en un sota torrent Normalment es feien els aspres amb branques d'altres plantes.

Ús halièutic

FONT 564. DESCRIPCIÓ DE L'ÚS FETA PER L'INFORMANT. Abans no n'hi havia, algú li deu haver plantat. Es feien servir canyes per anar a pescar.

\section{BARREGES AMB AQUEST TÀXON}

Arrel

FONT 503. Entrevista 43 (vegeu catàleg de barreges)

Fulla

FONTS 518, 519. Entrevista 54, barreja I (vegeu catàleg de barreges)

\section{Asparagus acutifolius L. (asparagàcies)}

BCN 29976

\section{NOMS POPULARS}

Espàrrec (turió) (1335)

Esparreguera silvestre (564)

\section{USOS ALIMENTARIS}

Turió

Ingestió de la part de la planta cuita - Cuita en oli

FONTS 564, 1335. DESCRIPCIÓ DE L'ÚS FETA PELS INFORMANTS. Els espàrrecs són bons en truita (564). Per a menjar (1335). DESTINACIÓ. Alimentació humana $(564,1335)$.

\section{ALTRES OBSERVACIONS}

FONT 1335. DESCRIPCIÓ FETA PER L'INFORMANT. En tenen a l'hort.

\section{Asparagus officinalis L. (asparagàcies)}

BCN 24721

\section{NOMS POPULARS}

Espàrrec verd (turió) $(574,575,576,577)$

Esparreguera (582)

\section{USOS ALIMENTARIS}

Turió

Ingestió de la part de la planta crua - Fresca (sense preparació)

FONTS 574, 575, 576, 577, 582. DESCRIPCIÓ DE L'ÚS FETA PELS INFORMANTS. Per a menjar. DESTINACIO. Alimentació humana.

\section{Asperula cynanchica L. (rubiàcies)}

\section{BCN 24722}

\section{NOMS POPULARS}

Herba prima $(503,504,507,509,510,511,512,513,514,515,516,517,518,519,520,521$ $522,523,528,529,530,531,541,542,543,544,556,557,560,561,562,563,565,566$ $567,569,570,572,573,590,747,748,749,750,752,1215,1293,1298,1299,1301,1311$ $1312,1313,1314,1321,1324,1327,1330,1332,1333,1334,1336,1337,1338,1339,1340$ $1343,1344,1345,1346,1347,1348,1349,1350,1351,1362)$

\section{USOS MEDICINALS}

\section{Part aèria florida}

Antihipertensiu

FONT 528. DESCRIPCIÓ DE L'ÚS FETA PER L'INFORMANT. Per a fer baixar la pressió. FORMA FARMACĖUTICA I ÚS. Tisana (ús intern). PREPARACIÓ. Decocció. DESTINACIÓ Medicina humana.

Antiinflamatori intestinal

FONTS 1311, 1312. DESCRIPCIÓ DE L'ÚS FETA PELS INFORMANTS. Va bé per al ventre. FORMA FARMACĖUTICA I ÚS. Tisana (ús intern). PREPARACIÓ. Decocció. DESTINACIÓ. Medicina humana.

\section{Antiprostatític}

FONTS 748, 749. DESCRIPCIÓ DE L'ÚS FETA PELS INFORMANTS. Per a la pròstata FORMA FARMACĖUTICA I ÚS. Tisana (ús intern). PREPARACIÓ. Decocció. DESTINACIÓ. Medicina humana. 
Antisèptic urinari

FONTS 515, 516, 520, 521, 556, 557, 1324. DESCRIPCIÓ DE L'ÚS FETA PELS INFORMANTS. Per a les infeccions als ronyons $(515,516)$. Per a fer orinar $\mathrm{i}$ infeccions d'orina $(520,521)$. Per a infeccions d'orina $(556,557)$. Per a les infeccions d'orina, cistitis (1324). FORMA FARMACĖUTICA I ÚS. Tisana (ús intern). PREPARACIÓ. Decocció (515, $516,520,521,556,557,1324)$. DESTINACIÓ. Medicina humana.

Diürètic

FONTS 503, 504, 507, 509, 510, 511, 512, 513, 514, 517, 518, 519, 520, 521, 522, 523, 528 $529,530,531,541,542,543,544,560,561,562,563,565,566,567,569,570,572,573$ $590,747,752,1293,1299,1301,1313,1314,1321,1327,1332,1333,1334,1336,1337$ 1338, 1339, 1340, 1343, 1344, 1345, 1346, 1347, 1348, 1349, 1361, 1362. DESCRIPCIÓ DE L'US FETA PELS INFORMANTS. Per a fer orinar $(504,511,512,513,514,517,518,519$ $528,529,530,531,541,560,561,562,563,567,569,570,572,573,590,747,1301,1314$ $1321,1327,1332,1333,1334,1336,1337,1338,1339,1340,1343,1344,1345,1346,1347$ $1348,1349)$. Diürètica $(507,509,510)$. Per a problemes d'orina $(522,523)$. És diürètica $(752$ 1299). Per a netejar [dit "llempiar"] $(542,543,544)$. Per a fer orinar i infeccions d'orina (520, 521). Per a ajudar a orinar $(565,566)$. Va bé per a orinar (1293). És diürètica. Fa orinar 521). Per a ajudar a orinar $(565,566)$. Va be per a orinar (1293). És diưretica. Fa orinar molt (1313). Per a orinar (1361, 1362). FORMA FARMACENCA Us. Tisana (ús intern) PREPARACIO. Decocio $(503,504,507,509,510,511,512,513,514,517,518,519,520$ $521,522,523,528,529,530,531,541,542,543,544,560,561,562,563,565,566,567$ $569,570,572,573,590,747,752,1301,1314,1321,1332,1333,1334,1336,1337,1338$ $1339,1340,1343,1344,1345,1346)$. Infusió de tota la planta (1293). En infusió (1327, 1347 1348, 1349, 1361, 1362). MODE D'UTILITZACIÓ/POSOLOGIA. Una tassa d'aigua cada dia (503). Una infusió al matí (1313). DESTINACIO. Medicina humana.

Emmenagog

FONTS 1337, 1338. DESCRIPCIÓ DE L'ÚS FETA PELS INFORMANTS. Per a regular la regla $(1337,1338)$. FORMA FARMACÉUTICA I ÚS. Tisana (ús intern). PREPARACIÓ Decocció (1338). Decocció (1337). DESTINACIO. Medicina humana.

Protector renal

FONTS 1330, 1350, 1351. DESCRIPCIÓ DE L'ÚS FETA PELS INFORMANTS. Per als ronyons $(1330,1350,1351)$. FORMA FARMACĖUTICA I ÚS. Tisana (ús intern) PREPARACIÓ. Decocció (1330). DESTINACIÓ. Medicina humana.

Restauratiu

FONT 1298. DESCRIPCIÓ DE L'ÚS FETA PER L'INFORMANT. Per a quan no et trobaves gaire bé. FORMA FARMACEUTICA I ÚS. Tisana (ús intern). PREPARACIÓ. Decocció DESTINACIÓ. Medicina humana.

\section{ALTRES OBSERVACIONS}

FONTS 543, 544, 560, 590, 1311, 1312, 1321. DESCRIPCIO FETA PELS INFORMANTS. Aquí no n'hi ha gaire s'ha d'anar cap a Olot $(543,544)$. Tothom en tenia plantada als horts (560). A les parets i cap aú amunt n'hi ha (590). A Cavallera n'hi havia molta, aquí

\section{BARREGES AMB AQUEST TÀXON}

\section{Part aèria florida}

FONTS 1343, 1344. Entrevista 23, barreja II (vegeu catàleg de barreges)

FONT 1301. Entrevista 36 (vegeu catàleg de barreges)

FONT 750. Entrevista 50, barreja I (vegeu catàleg de barreges)

Asplenium septentrionale (L.) Hoffm. (polipodiàcies) BCN 44184

\section{NOMS POPULARS}

Herba prima $(538,553,588,1215)$

Herba prima de paret $(572,573)$

\section{USOS MEDICINALS}

\section{Fronda}

Diürètic

FONTS 538, 553, 572, 573, 588. DESCRIPCIÓ DE L'ÚS FETA PELS INFORMANTS. Va bé per a fer orinar i dissoldre les pedres (553). Per a fer orinar $(538,572,573,588)$. FORMA FARMACEUTICA I ÚS. Tisana (ús intern). PREPARACIO. Decocció (538, 553, 572, 573, 588). DESTINACIO. Medicina humana.

Litotríptic renal

FONT 553. DESCRIPCIÓ DE L'ÚS FETA PER L'INFORMANT. Va bé per a fer orinar dissoldre les pedres. FORMA FARMACEUTICA I ÚS. Tisana (ús intern). PREPARACIÓ. Decocció. DESTINACIO. Medicina humana.

\section{ALTRES OBSERVACIONS}

FONTS 538, 553, 572, 573, 588, 1215. DESCRIPCIÓ FETA PELS INFORMANTS. Es fa a les roques (553). Es fa a les parets velles (588). Es fa a les parets $(572,573)$. Es fa serrat a les parets (538). A la Mare de la Font n'hi ha d'aquestes falgueres (1215).

\section{Asplenium trichomanes L. (polipodiàcies)}

BCN 24723

\section{NOMS POPULARS}

Auradelleta (1324) 
Costelles de paret (1335)

Falguereta de paret $(511,512,513,514)$

Herba del cordó (553)

\section{USOS MEDICINALS}

\section{Fronda}

Antihipertensiu

FONTS 511, 512, 513, 514. DESCRIPCIÓ DE L'ÚS FETA PELS INFORMANTS. Per a fer baixar la pressió. FORMA FARMACĖUTICA I ÚS. Tisana (ús intern). PREPARACIÓ. Decocció. DESTINACIÓ. Medicina humana.

Antitussigen

FONT 1324. DESCRIPCIÓ DE L'ÚS FETA PER L'INFORMANT. Per a calmar la tos. FORMA FARMACĖUTICA I ÚS. Tisana (ús intern). PREPARACIÓ. Decocció. DESTINACIÓ. Medicina humana.

\section{ALTRES USOS}

Fronda

Cosmètic

FONT 1335. DESCRIPCIÓ DE L'ÚS FETA PER L'INFORMANT. L'aigua es feia servir per a rentar els cabells. OBSERVACIONS. Si els treus les fulletes queda com un cabell.

\section{Atropa belladonna L. (solanàcies)}

BCN 19513

\section{NOMS POPULARS}

Belladona $(520,521)$

\section{ALTRES OBSERVACIONS}

FONTS 520, 521. DESCRIPCIÓ FETA PELS INFORMANTS. Aquí en va néixer una planta casualment.

\section{Avena sativa L. (gramínies)}

BCN-E 3

\section{NOMS POPULARS}

Civada $(571,586,587)$

\section{USOS ALIMENTARIS}

Llavor

Ingestió de la part de la planta crua - Conservada dessecada a l'aire

FONT 571. DESCRIPCIÓ DE L'ÚS FETA PER L'INFORMANT. El gra el donàvem a les gallines i als conills. DESTINACIÓ. Alimentació animal.

\section{ALTRES USOS}

\section{No consta}

Maneig agrosilvopastoral: ús hortícola/agrícola

FONTS 586, 587. DESCRIPCIÓ DE L'ÚS FETA PELS INFORMANTS. D'això n'ha vingut grana en descarregar alguna bala de palla.

\section{Ballota nigra L. subsp. foetida (Vis.) Hayek (labiades)}

BCN 27275

\section{NOMS POPULARS}

Malroig $(583,585,588,590)$

\section{ACCIONS NOCIVES O TÒXIQUES}

\section{No consta}

FONTS 583, 584, 585, 588, 590. DESCRIPCIÓ DE L'ACCIÓ NOCIVA O TÒXICA FETA PELS INFORMANTS. Mata els conills (588). Els havíem de separar de les ortigues perquè GRAU DE TOXICITAT. Letal (588). TOXICITAT EN ANIMALS. Sí $(588,590)$

\section{Bellis perennis L. (compostes)}

BCN 31264

\section{NOMS POPULARS}

Margarideta (582)

Margarita (564)

\section{ALTRES USOS}




\section{Inflorescència}

Creences i pràctiques magicoreligioses

FONT 564. DESCRIPCIÓ DE L'ÚS FETA PER L'INFORMANT. Per a fer les catifes [dit "alfombres"] de Corpus.

\section{BARREGES AMB AQUEST TÀXON}

Inflorescència

FONT 582. Entrevista 95 (vegeu catàleg de barreges)

Berberis vulgaris L. (berberidàcies)

BCN 27274

\section{ALTRES USOS}

Fruit

Lúdic: jocs i joguines

FONT 1352. DESCRIPCIÓ DE L'ÚS FETA PER L'INFORMANT. Els fruits eren el dinar de les nines.

\section{Bergenia sp. (saxifragàcies)}

\section{NOMS POPULARS}

Hortènsia d'hivern $(569,570)$

Viola d'hivern $(525,526,527)$

\section{ALTRES USOS}

Planta viva ex situ

Ornamental: jardineria

FONTS 569, 570. DESCRIPCIÓ DE L'ÚS FETA PELS INFORMANTS. Plantades al jardí.

\section{ALTRES OBSERVACIONS}

FONTS 525, 526, 527. DESCRIPCIÓ FETA PELS INFORMANTS. Floreixen molt aviat a la primavera.

\section{BARREGES AMB AQUEST TÀXON}

Fulla
FONTS 1347, 1348, 1349. Entrevista 27 (vegeu catàleg de barreges)

FONT 1318. Entrevista 31, barreja I (vegeu catàleg de barreges)

FONT 1330. Entrevista 32, barreja II (vegeu catàleg de barreges)

Beta vulgaris L. subsp. vulgaris var. crassa (Alef.) Helm (quenopodiàcies)

BCN 50761

\section{NOMS POPULARS}

Remolatxa $(525,526,527,565,566)$

\section{USOS ALIMENTARIS}

\section{Arrel}

Ingestió de la part de la planta crua - Macerada en aigua

FONTS 565, 566. DESCRIPCIÓ DE L'ÚS FETA PELS INFORMANTS. La polpa estovada els va molt bé, a les vaques, és tot energia i les ajuda a remugar. DESTINACIÓ. Alimentació animal.

Fulla

Ingestió de la part de la planta crua - Fresca (sense preparació)

FONTS 525, 526, 527. DESCRIPCIÓ DE L'ÚS FETA PELS INFORMANTS. Per a menjar amanit. DESTINACIÓ. Alimentació humana.

\section{Beta vulgaris L. subsp. vulgaris var. vulgaris}

(quenopodiàcies)

BCN 24724

\section{NOMS POPULARS}

Bleda $(515,516,1318,1330,1347,1348,1349)$

\section{USOS ALIMENTARIS}

Fulla

Ingestió de la part de la planta cuita - Cuita en aigua

FONTS 515, 516. DESCRIPCIÓ DE L'ÚS FETA PELS INFORMANTS. Per a menjar. DESTINACIÓ. Alimentació humana. 


\section{Betula pendula Roth (betulàcies)}

BCN 27263

\section{NOMS POPULARS}

Arbre blanc $(535,539,540)$

Beç $(539,540,541,553,560,574,575,576,577,1213,1214,1324,1352)$

Bedoll $(541,1210)$

\section{USOS MEDICINALS}

\section{Escorça}

Hipouricemiant

FONTS 574, 575, 576, 577. DESCRIPCIÓ DE L'ÚS FETA PELS INFORMANTS. Va bé per a l'àcid úric. FORMA FARMACĖUTICA I ÚS. Tisana (ús intern). PREPARACIÓ. Decocció DESTINACIO. Medicina humana.

Fulla

Antibacterià

FONTS 539, 540. DESCRIPCIÓ DE L'ÚS FETA PELS INFORMANTS. Les fulles són un antibiòtic. FORMA FARMACĖUTICA I ÚS. Desconegut per l'informant. DESTINACIÓ. Medicina humana.

\section{Diürètic}

FONTS 553, 1210. DESCRIPCIÓ DE L'ÚS FETA PELS INFORMANTS. Les fulles fan orinar molt (553). Per a desinflar i aprimar (1210). FORMA FARMACĖUTICA I ÚS. Tisana (ús intern). PREPARACIÓ. Decocció (553). Infusions de les fulles de bedoll (1210). MODE D'UTILITZACIÓ/POSOLOGIA. Beure'n cada dia un got al matí a setmanes alternes (1210). DESTINACIÓ. Medicina humana. OBSERVACIONS. A la seva mare li va treure l'edema pulmonar (553). Li ho va dir la Maria Sagué (1210).

Reforçant ossi

FONT 1324. DESCRIPCIÓ DE L'ÚS FETA PER L'INFORMANT. Per a la descalcificació dels ossos. FORMA FARMACĖUTICA I ÚS. Tisana (ús intern). PREPARACIÓ. Les fulles en infusió. DESTINACIÓ. Medicina humana.

Vasotònic

FONT 535. DESCRIPCIÓ DE L'ÚS FETA PER L'INFORMANT. Va bé per a la circulació. FORMA FARMACĖUTICA I ÚS. Tisana (ús intern). PREPARACIÓ. Decocció. DESTINACIÓ. Medicina humana.

Saba

Salutífer
FONTS 1213, 1214. DESCRIPCIO DE L'ÚS FETA PELS INFORMANTS. Es prenia a la primavera per a eliminar les toxines de l'hivern. FORMA FARMACĖUTICA I ÚS. Desconegut per l'informant. DESTINACIÓ. Medicina humana.

\section{ALTRES USOS}

\section{Fulla}

Cosmètic

FONTS 539, 540. DESCRIPCIÓ DE L'ÚS FETA PELS INFORMANTS. També posades en esperit de vi són bones per al cabell.

Creences i pràctiques magicoreligioses

FONT 560. DESCRIPCIÓ DE L'ÚS FETA PER L'INFORMANT. Es posaven les fulles a les catifes [dit "alfombres"] de Corpus.

\section{No consta}

Cosmètic

FONTS 1213, 1214. DESCRIPCIÓ DE L'ÚS FETA PELS INFORMANTS. Crema per a la cara.

\section{Part aèria}

Artesanal: elaboració d'escombres

FONT 1352. DESCRIPCIÓ DE L'ÚS FETA PER L'INFORMANT. Per a fer escombres.

\section{Borago officinalis L. (boraginàcies)}

BCN 68582

\section{NOMS POPULARS}

Borratja $(582,1324,1335)$

Borratxa (1210)

\section{USOS MEDICINALS}

\section{No consta}

Antidepressiu

FONT 1210. DESCRIPCIÓ DE L'ÚS FETA PER L'INFORMANT. Per a la gent que té ganes de plorar. FORMA FARMACĖUTICA I ÚS. Tisana (ús intern). PREPARACIÓ. Decocció. MODE D'UTILITZACIÓ/POSOLOGIA. S'ha de beure una tassa d'aquesta herba al matí i una al vespre. DESTINACIÓ. Medicina humana.

\section{USOS ALIMENTARIS}


Fulla

Ingestió de la part de la planta cuita - Cuita en aigua

FONTS 582, 1324, 1335. DESCRIPCIÓ DE L'ÚS FETA PELS INFORMANTS. Són per a menjar (582). Per a menjar (1324). Es menja com a verdura (1335). DESTINACIÓ.

Alimentació humana $(582,1324,1335)$.

\section{Botrychium Iunaria (L.) Swartz (ofioglossàcies)}

BCN 24726

\section{NOMS POPULARS}

Herba de les llunetes $(1328,1329,1339,1340)$

\section{USOS MEDICINALS}

\section{Part aèria}

Antisèptic ocular

FONTS 1328, 1329, 1339, 1340. DESCRIPCIÓ DE L'ÚS FETA PELS INFORMANTS. Per a rentar els ulls $(1328,1329)$. Per als ulls $(1339,1340)$. FORMA FARMACĖUTICA I ÚS. Bany (ús extern). PREPARACIÓ. Decocció $(1328,1329)$. En infusió $(1339,1340)$. DESTINACIÓ Medicina humana.

\section{Brachypodium phoenicoides (L.) Roem. et Schultes} (gramínies)

BCN 32182

\section{NOMS POPULARS}

Fenàs (541)

Brassica napus L. (crucíferes)

BCN 24727

\section{NOMS POPULARS}

Nap (541)

USOS MEDICINALS

\section{Bulb}

Antireumàtic

FONT 541. DESCRIPCIÓ DE L'ÚS FETA PER L'INFORMANT. Deien que dur un nap a la butxaca anava bé per al reuma. FORMA FARMACĖUTICA I ÚS. Sense forma farmacèutica (ús directe, ús extern). DESTINACIÓ. Medicina humana.

\section{USOS ALIMENTARIS}

Bulb

Condiment

FONT 541. DESCRIPCIÓ DE L'ÚS FETA PER L'INFORMANT. Per a menjar. DESTINACIÓ. Alimentació humana.

\section{Brassica nigra (L.) Koch in Roehl (crucíferes)}

BCN-E 4

\section{NOMS POPULARS}

Mostassa $(518,519)$

\section{BARREGES AMB AQUEST TÀXON}

Llavor

FONTS 518, 519. Entrevista 54, barreja IV (vegeu catàleg de barreges)

\section{Brassica oleracea L. (crucíferes)}

BCN 24728

\section{NOMS POPULARS}

Col $(503,515,516,517,518,519,529,530,531,532,539,540,545,565,566,567,571$ $574,575,576,577,588,589,591,592,746,1336,1345,1346,1350,1351,1352)$

Col blanca (1215)

\section{USOS MEDICINALS}

Fulla

Analgèsic

FONTS 591, 592. DESCRIPCIÓ DE L'ÚS FETA PELS INFORMANTS. Per a quan et fa mal el genoll. FORMA FARMACĖUTICA I ÚS. Sense forma farmacèutica (ús directe, ús extern). 
Apèndix 1. Catàleg de tàxons.

PREPARACIÓ. Posada directament sobre el genoll i embolicar-ho amb benes. DESTINACIÓ. Medicina humana. OBSERVACIONS. Quan t'ho treus, la col surt com si estigués cuita.

Hipolipemiant

FONT 532. DESCRIPCIÓ DE L'ÚS FETA PER L'INFORMANT. També és bo per al colesterol. FORMA FARMACĖUTICA I ÚS. Tisana (ús intern). PREPARACIÓ. Decocció. DESTINACIÓ. Medicina humana.

Litotríptic renal

FONTS 539, 540. DESCRIPCIÓ DE L'ÚS FETA PELS INFORMANTS. Per a aplacar l'atac de pedra. FORMA FARMACEUTICA I ÚS. Emplastre (ús extern). PREPARACIÓ. Una fulla de col ben calenta amb la planxa de planxar, a sobre els ronyons i a sobre una baieta de lana fregant per a aplacar l'atac de pedra. DESTINACIO. Medicina humana.

Per a trastorns del sistema musculoesquelètic

FONTS 1350, 1351. DESCRIPCIÓ DE L'ÚS FETA PELS INFORMANTS. Per a malformacions dels ossos. FORMA FARMACĖUTICA I ÚS. Emplastre (ús extern). PREPARACIÓ. Per a fer emplastres de la fulla ben trinxada i, aprofitant el suc. DESTINACIÓ. Medicina humana.

Vulnerari

FONTS 517, 529, 530, 531. DESCRIPCIÓ DE L'ÚS FETA PELS INFORMANTS. Per a tapar mals, calma (517). Es posava a sobre de les ferides, neteja molt, treu tota la brutícia (529, 530,531 ). FORMA FARMACĖUTICA I ÚS. Sense forma farmacèutica (ús directe, ús extern) DESTINACIÓ. Medicina humana.

\section{Llavor}

Analgèsic

FONT 1336. DESCRIPCIÓ DE L'ÚS FETA PER L'INFORMANT. Per al lloc on et fa mal. FORMA FARMACĖUTICA I ÚS. Emplastre (ús extern). PREPARACIÓ. Emplastres amb Ia grana de col picada barrejada amb oli entremig dels draps. DESTINACIÓ. Medicina humana. Anticefalàlgic

FONT 588. DESCRIPCIÓ DE L'ÚS FETA PER L'INFORMANT. Aquest remei es feia quan tenies mal de cap. FORMA FARMACĖUTICA I ÚS. Emplastre (ús extern). PREPARACIÓ. Es feien el que en dèiem mostasses. Grana de col picada amb el morter, es posava en un tup amb vinagre i es feia bullir una mica. Llavors es posava al mig de dos draps blancs de cotó es col-locava als peus. DESTINACIO. Medicina humana.

Antihelmíntic

FONT 1336. DESCRIPCIÓ DE L'ÚS FETA PER L'INFORMANT. Per als cucs de la mainada FORMA FARMACĖUTICA I ÚS. Tisana (ús intern). PREPARACIÓ. Grana de col bullida DESTINACIO. Medicina humana.

Suc de la fulla

Antiulcerós (per a úlceres gàstriques)
FONT 1352. DESCRIPCIÓ DE L'ÚS FETA PER L'INFORMANT. Per a curar les llagues de l'estómac. FORMA FARMACĖUTICA I ÚS. Sense forma farmacèutica (ús directe, ús intern). PREPARACIÓ. La fulla ben trinxada i aprofitant tot el suc. DESTINACIÓ. Medicina humana

\section{USOS ALIMENTARIS}

Fulla

Ingestió de la part de la planta crua - Conservada en vinagre

FONT 503. DESCRIPCIÓ DE L'ÚS FETA PER L'INFORMANT. Abans a casa sempre teníem col confitada. DESTINACIÓ. Alimentació humana.

Ingestió de la part de la planta crua - Fresca (sense preparació)

FONTS 565, 566, 567, 574, 575, 576, 577. DESCRIPCIÓ DE L'ÚS FETA PELS INFORMANTS. Per als conills (567). Els animals que engreixàvem que havien menjat cols, pomes (Pyrus malus subsp. mitis), blat de moro (Zea mays)... eren molt més bons que els que ara venen, la carn tenia un altre gust. I són més bones les femelles que no hagin parit (la polla, la truja...), que els mascles $(565,566)$. Per a les gallines $(574,575,576,577)$ DESTINACIÓ. Alimentació animal $(565,566,567,574,575,576,577)$

Ingestió de la part de la planta cuita - Cuita en aigua

FONTS 503, 515, 516, 589, 746. DESCRIPCIÓ DE L'ÚS FETA PELS INFORMANTS. També en menjàvem a l'hivern (746). Per a fer col i patata, a l'hivern és molt bona (503). Per a menjar $(515,516)$. DESTINACIÓ. Alimentació humana $(503,515,516,589,746)$.

No consta el tipus d'ingesta - No consta el mode de preparació

FONT 571. DESCRIPCIÓ DE L'ÚS FETA PER L'INFORMANT. Per a les gallines, els donàvem cols de l'hort. DESTINACIÓ. Alimentació animal.

\section{Part aèria}

Ingestió de la part de la planta crua - Conservada en vinagre FONT 1352. DESCRIPCIÓ DE L'ÚS FETA PER L'INFORMANT. Cols confitades en vinagre per a menjar a I'hivern. DESTINACIÓ. Alimentació humana.

\section{Part aèria jove}

Ingestió de la part de la planta crua - Conservada en vinagre

FONT 1215. DESCRIPCIÓ DE L'ÚS FETA PER L'INFORMANT. Confitada amb pebrots i vinagre. DESTINACIÓ. Alimentació humana.

\section{BARREGES AMB AQUEST TÀXON}

Fulla

FONT 545. Entrevista 72, barreja II (vegeu catàleg de barreges)

Llavor

FONTS 1345, 1346. Entrevista 25 (vegeu catàleg de barreges)

FONTS 518, 519. Entrevista 54, barreja IV (vegeu catàleg de barreges) 


\section{Brassica rapa L. (crucíferes)}

BCN 24729

\section{NOMS POPULARS}

Nap de bou $(1313,1353,1354)$

\section{USOS ALIMENTARIS}

Arrel

Ingestió de la part de la planta crua - Fresca (sense preparació)

FONTS 1313, 1353, 1354. DESCRIPCIÓ DE L'ÚS FETA PELS INFORMANTS. Per a donar al bestiar (1313). Són com els naps que mengem, però més grossos i es donaven al bestiar $(1353,1354)$. DESTINACIÓ. Alimentació animal $(1313,1353,1354)$.

Ingestió de la part de la planta cuita - Cuita en aigua

FONTS 1353, 1354. DESTINACIÓ. Alimentació humana.

\section{Briza media L. (gramínies)}

BCN 29650

\section{NOMS POPULARS}

Bellugadís $(529,530,531)$

Belluguets (569)

Puces $(520,521)$

\section{ALTRES USOS}

\section{Part aèria fructificada}

Ornamental: elaboració de rams

FONTS 520, 521, 529, 530, 531, 569, 570. DESCRIPCIÓ DE L'ÚS FETA PELS INFORMANTS. Per a fer rams $(520,521)$. És bonic per a fer rams $(529,530,531)$.

\section{Bryonia cretica L. subsp. dioica (Jacq.) Tutin (cucurbitàcies) BCN 24730}

\section{NOMS POPULARS}

Carabassí (1317)

Carabassina $(1300,1318,1323,1332,1333,1334,1350,1351)$

Carbassina $(511,512,513,514,520,521,539,540,553,565,566,580,582,583,584,585$ $746,753,754,755)$

\section{USOS MEDICINALS}

Arrel

Analgèsic

FONTS $520,521,753,754,755,1332,1333,1334$. DESCRIPCIÓ DE L'ÚS FETA PELS INFORMANTS. Deien que anaven bé per al dolor $(520,521)$. Per al dolor $(753,754,755$, $1332,1333,1334)$. FORMA FARMACÈUTICA I ÚS. Emplastre (ús extern) (520, 521) Liniment (ús extern) $(753,754,755)$. Loció (ús extern) $(1332,1333,1334)$. PREPARACIÓ De la rel en feien emplastres $(520,521)$. L'arrel bullida en oli $(753,754,755)$. La rel en esperit de vi 45 dies a sol i serena $(1332,1333,1334)$. DESTINACIÓ. Medicina humana.

Anticatarral

FONT 553. DESCRIPCIÓ DE L'ÚS FETA PER L'INFORMANT. Per als refredats. FORMA FARMACĖUTICA I ÚS. Tisana (ús intern). PREPARACIÓ. Decocció. DESTINACIÓ. Medicina FARMACE

Antiinflamatori faringi

FONTS 553, 583, 584, 585. DESCRIPCIÓ DE L'ÚS FETA PELS INFORMANTS. Per al coll (553). Per al mal de coll de les eugues i també per a la gent $(583,584,585)$. FORMA FARMACĖUTICA I ÚS. Tisana (ús intern). PREPARACIÓ. Decocció $(553,583,584,585)$ DESTINACIÓ. Medicina humana (553). Medicina humana i veterinària $(583,584,585)$.

Antipleurític

FONT 553. DESCRIPCIÓ DE L'ÚS FETA PER L'INFORMANT. Per a la pleura. FORMA FARMACĖUTICA I ÚS. Tisana (ús intern). PREPARACIÓ. Decocció. DESTINACIÓ. Medicina humana.

Antisèptic extern

FONTS 511, 512, 513, 514. DESCRIPCIÓ DE L'ÚS FETA PELS INFORMANTS. Per a desinfectar ferides. FORMA FARMACĖUTICA I ÚS. Fumigació (ús extern). PREPARACIÓ. Amb les arrels se'n feien perfums. DESTINACIÓ. Medicina humana.

Desconegut per l'informant

FONTS 553, 582, 1317. DESCRIPCIÓ DE L'ÚS FETA PELS INFORMANTS. Per al peu gros de les vaques (1317). FORMA FARMACĖUTICA I ÚS. Emplastre (ús extern) $(553,1317)$ Desconegut per l'informant (582). PREPARACIÓ. També en emplastres (553). Aixafada barrejada amb oli, en emplastre (1317). DESTINACIÓ. Medicina humana. OBSERVACIONS Es feia un oli de la rel, però no recordo l'ús (582)

Per a la sarna 
Apèndix 1. Catàleg de tàxons.

FONT 1317. DESCRIPCIÓ DE L'ÚS FETA PER L'INFORMANT. Per a quan tenien ronya. FORMA FARMACĖUTICA I ÚS. Bany (ús extern). PREPARACIÓ. Decocció. Aigua de la re per a fregar les ovelles. DESTINACIÓ. Medicina humana.

Per a trastorns de la pell o del teixit subcutan

FONTS 1350, 1351. DESCRIPCIÓ DE L'ÚS FETA PELS INFORMANTS. Per a podridures de dit. FORMA FARMACĖUTICA I ÚS. Ungüent (ús extern). PREPARACIÓ. Bullida amb greix de gallina DESTINACIÓ. Medicina humana.

Resolutiu

FONTS 539, 540. DESCRIPCIÓ DE L'ÚS FETA PELS INFORMANTS. Quan el bestiar tenia bonys o furóncols. FORMA FARMACĖUTICA I ÚS. Emplastre (ús extern). PREPARACIÓ. Es picava l'arrel i es feia un emplastre per a fer sortir el pus cap enfora. DESTINACIÓ. Medicina veterinària.

\section{BARREGES AMB AQUEST TÀXON}

\section{Arrel}

FONT 1323. Entrevista 24 (vegeu catàleg de barreges)

FONT 1318. Entrevista 31, barreja IV (vegeu catàleg de barreges)

FONT 746. Entrevista 45, barreja III (vegeu catàleg de barreges)

FONT 1300. Entrevista 8, barreja II (vegeu catàleg de barreges)

\section{Buxus sempervirens L. (buxàcies)}

BCN 24731

\section{NOMS POPULARS}

Boix $(504,515,516,517,528,539,540,546,553,554,555,558,560,564,565,566,569$ $570,583,584,585,586,587,589,590,1213,1214,1215,1295,1299,1324,1332,1333$ $1334,1334,1347,1348,1349,1353,1354,1352)$

Boix vermell $(554,555)$

Olleta (541)

\section{USOS MEDICINALS}

\section{Arrel}

Per als penellons

FONTS 1347, 1348, 1349. DESCRIPCIÓ DE L'ÚS FETA PELS INFORMANTS. Per als penellons. FORMA FARMACÉUTICA I ÚS. Bany (ús extern). PREPARACIÓ. Decocció. Aigua de la rel. DESTINACIÓ. Medicina humana.

Fulla

\section{Antihelmíntic}

FONTS 554, 555. DESCRIPCIÓ DE L'ÚS FETA PELS INFORMANTS. Per als cucs dels porcs. FORMA FARMACĖUTICA I ÚS. Tisana (ús intern). PREPARACIÓ. Decocció. Aigua bullida amb boix vermell. DESTINACIÓ. Medicina veterinària.

Antireumàtic

FONTS 1213, 1214. DESCRIPCIÓ DE L'ÚS FETA PELS INFORMANTS. Alleuja el dolo reumàtic. FORMA FARMACĖUTICA I ÚS. Tisana (ús intern). PREPARACIÓ. Aigua feta amb les fulles. DESTINACIÓ. Medicina humana.

Antisèptic urinari

FONT 1214. DESCRIPCIÓ DE L'ÚS FETA PER L'INFORMANT. Per a les infeccions d'orina FORMA FARMACĖUTICA I ÚS. Tisana (ús intern). PREPARACIÓ. Aigua feta de les fulles. MODE D'UTILITZACIÓ/POSOLOGIA. Una tasseta de cafè. DESTINACIÓ. Medicina humana. Estomacal

FONT 1299. DESCRIPCIÓ DE L'ÚS FETA PER L'INFORMANT. Va bé per a treure la cremor d'estómac. FORMA FARMACĖUTICA I ÚS. Sense forma farmacèutica (ús directe, ús intern) PREPARACIÓ. Et poses un parell de fulles a la boca i les vas mastegant. DESTINACIÓ Medicina humana.

Laxant

FONTS 1213, 1214. DESCRIPCIÓ DE L'ÚS FETA PELS INFORMANTS. Per al restrenyiment. FORMA FARMACÈUTICA I ÚS. Tisana (ús intern). PREPARACIÓ. Aigua feta amb les fulles. DESTINACIÓ. Medicina humana.

Per a inflamacions del sistema genitourinari

FONT 1213. DESCRIPCIÓ DE L'ÚS FETA PER L'INFORMANT. Per a les inflamacions d'orina. FORMA FARMACĖUTICA I ÚS. Tisana (ús intern). PREPARACIÓ. Aigua feta de les fulles. MODE D'UTILITZACIÓ/POSOLOGIA. Una tasseta de cafè. DESTINACIÓ. Medicina humana.

Per a l'afonia

FONT 517. DESCRIPCIÓ DE L'ÚS FETA PER L'INFORMANT. Per a l'enregull. FORMA FARMACĖUTICA I ÚS. Tisana (ús intern). PREPARACIÓ. Decocció. Aigua de fulles de boixos vermells. DESTINACIÓ. Medicina humana.

Per a la melsa

FONTS 515, 516. DESCRIPCIÓ DE L'ÚS FETA PELS INFORMANTS. Per al flato, mal de melsa. FORMA FARMACĖUTICA I ÚS. Sense forma farmacèutica (ús directe, ús intern). PREPARACIÓ. Rosegar una fulla de boix. DESTINACIÓ. Medicina humana.

\section{ALTRES USOS}

Fruit

Artesanal: elaboració de bijuteria 
FONT 504. DESCRIPCIÓ DE L'ÚS FETA PER L'INFORMANT. Aglans que són penjolls i clauers.

Lúdic: jocs i joguines

FONT 541. DESCRIPCIÓ DE L'ÚS FETA PER L'INFORMANT. De petits hi jugaven posantlos drets i fent-los caure tirant-los una bola i en general, remenant-los.

\section{Fulla}

Creences i pràctiques magicoreligioses

FONTS 560, 564, 1332, 1333, 1334. DESCRIPCIÓ DE L'ÚS FETA PELS INFORMANTS. Es posaven les fulles a les catifes [dit "alfombres"] de Corpus (560). Esmicolats per a fer la part verda de les catifes [dit "alfombres"] de Corpus (564). Diuen que va bé agafar fulles de boix tantes com berrugues tens, i amagar-les al bosc en un lloc on no es puguin mullar; si ho aconsegueixes et desapareixen les berrugues $(1332,1333,1334)$.

\section{Part aèria}

Artesanal: elaboració d'escombres

FONTS 517, 558, 589, 1215, 1324. DESCRIPCIÓ DE L'ÚS FETA PELS INFORMANTS. Per a fer escombres $(1215,1324)$

Creences i pràctiques magicoreligioses

FONTS 586, 587, 590, 1352. DESCRIPCIÓ DE L'ÚS FETA PELS INFORMANTS. Per a dur a l'església $(586,587)$. Es duia boix a l'església per a fer bonic, quan vaig fer la comunió n'h van posar (590). Es feien cordes de boix que guarnien l'altar de l'església per a les festes més assenyalades (1352)

Lúdic: jocs i joguines

FONT 1352. DESCRIPCIÓ DE L'ÚS FETA PER L'INFORMANT. Per a jugar a canibòlit. Es feia una cana (pal llarg) i un bòlit (pal curt) i amb la cana es disparava el bòlit, llavors es mesurava on havia caigut el bòlit amb la cana.

Ornamental: elaboració de rams

FONTS 546, 569. DESCRIPCIÓ DE L'ÚS FETA PELS INFORMANTS. Per a fer rams (546)

\section{Planta sencera}

Literatura oral popular: llegendes, gloses, contes, dites, refranys, poemes, cançons

FONT 1352. DESCRIPCIÓ DE L'ÚS FETA PER L'INFORMANT. Assemblar-se com el boix el vern (Alnus glutinosa) (no assemblar-se de res).

\section{Planta viva in situ}

Maneig agrosilvopastoral: ús hortícola/agrícola

FONT 589. DESCRIPCIÓ DE L'ÚS FETA PER L'INFORMANT. Aquí n'hi ha molts i ens van bé perquè ens tapen el mal temps.

Tija

Altres informacions
FONTS 539, 540, 1295. DESCRIPCIO DE L'ÚS FETA PELS INFORMANTS. Per a fer cadenes i culleres $(539,540)$. Se'n feien botons $(1295)$.

Artesanal: elaboració d'escombres

FONT 1352. DESCRIPCIÓ DE L'ÚS FETA PER L'INFORMANT. Per a fer escombres.

Artesanal: elaboració d'estris de cuina

FONTS 504, 528, 539, 540, 583, 584, 585, 1215, 1295, 1353, 1354. DESCRIPCIÓ DE L'ÚS FETA PELS INFORMANTS. Se'n feien culleres i altres estris (504). La seva fusta és molt bona per a fer culleres i altres eines (528). Per a fer cadenes i culleres $(539,540)$. Per a fer culleres i estris de cuina $(583,584,585)$. Per a fer culleres (1215). Se'n feien culleres, en general coses de torneria (1295). Per a fer culleres i cusses, mai malbé, el meu padrí en feia i encara les fem servir $(1353,1354)$.

Artesanal: elaboració de joguines

FONT 504. DESCRIPCIÓ DE L'ÚS FETA PER L'INFORMANT. Per a fer jocs per a nens.

Domèstic: ajudes en la costura

FONT 1352. DESCRIPCIÓ DE L'ÚS FETA PER L'INFORMANT. Per a fer els boixets de fer punta de coixí.

\section{ACCIONS NOCIVES O TÒXIQUES}

\section{No consta}

FONTS 553, 565, 566, 1213, 1214. DESCRIPCIÓ DE L'ACCIÓ NOCIVA O TÒXICA FETA PELS INFORMANTS. És tòxica (553). Una vegada va venir un pastor andalús, molt professional, en sabia moltíssim. Aquell dia feia sol era ben serè i al vespre quan anàvem a tancar les ovelles al corral no hi havia manera de poder-les fer entrar. El pastor va dir que les deixéssim un moment i les ovelles van tornar a tirar muntanya amunt i menjaven boix. El boix no el toquen mai, és tòxic. El pastor va dir que faria mal temps i efectivament l'endemà va fer una nevada d'aquelles fortes. Això ho vaig parlar amb molta gent, veterinaris i d'altres i entre tots vam pensar que en mengen perquè se's hi quedi l'estómac adormit i així estan dos tols vestan do 0 tres dies que no remuguen. Va ser una cosa molt curiosa, no ho he vist mai mes $(565,566)$ Es recomana fer servir el boix de bosc, l no se'n pot abusar perquè és lleugerament tòxic (1213, 1214). TOXICITAT LLIGADA A L'ÚS MEDICINAL. Sí $(1213,1214)$. TOXICITAT EN
ANIMALS. Sí $(565,566)$.

\section{BARREGES AMB AQUEST TÀXON}

\section{Fulla}

FONTS 554, 555. Entrevista 78, barreja III (vegeu catàleg de barreges)

\section{Calendula arvensis L. (compostes)}

\section{BCN 32863}




\section{NOMS POPULARS}

Gojat $(520,521)$

Lligamans (553)

\section{USOS MEDICINALS}

Inflorescència

Antiequimòtic

FONTS 520, 521. DESCRIPCIÓ DE L'ÚS FETA PELS INFORMANTS. Per als trucs, semblant a l'àrnica. FORMA FARMACĖUTICA I ÚS. Liniment (ús extern). PREPARACIÓ. La flor en oli. DESTINACIÓ. Medicina humana.

\section{Calendula officinalis L. (compostes)}

BCN 24732

\section{NOMS POPULARS}

Boixac $(539,540,572,573)$

Bojac $(545,561,562,563)$

Calèndula $(1324,1335)$

Jaumet (560)

Lligamans (580)

\section{USOS MEDICINALS}

Inflorescència

Antidismenorreic

FONT 1324. DESCRIPCIÓ DE L'ÚS FETA PER L'INFORMANT. Per a regles doloroses. FORMA FARMACĖUTICA I ÚS. Tisana (ús intern). PREPARACIÓ. En infusió. DESTINACIÓ. Medicina humana.

Antiequimòtic

FONT 1335. DESCRIPCIÓ DE L'ÚS FETA PER L'INFORMANT. Per als trucs. FORMA FARMACĖUTICA I ÚS. Pomada (ús extern). PREPARACIÓ. Se'n fa una pomada. DESTINACIÓ. Medicina humana.

Antiinflamatori faringi

FONTS 539, 540. DESCRIPCIÓ DE L'ÚS FETA PELS INFORMANTS. Per al mal de coll fent gargarismes. FORMA FARMACĖUTICA I ÚS. Gargarisme (ús extern). PREPARACIÓ. Decocció. DESTINACIÓ. Medicina humana.

Antipsoriàsic
FONT 545. DESCRIPCIÓ DE L'ÚS FETA PER L'INFORMANT. Untar-te per a la psoriasi. FORMA FARMACĖUTICA I ÚS. Liniment (ús extern). PREPARACIÓ. Fer bullir els bojacs en oli. DESTINACIÓ. Medicina humana. OBSERVACIONS. Les flors s'han d'agafar just abans de florir, és quan tenen més força.

Antisèptic ocular

FONTS 539, 540. DESCRIPCIÓ DE L'ÚS FETA PELS INFORMANTS. Per a banyar els ulls quan els tens malalts. FORMA FARMACĖUTICA I ÚS. Bany (ús extern). PREPARACIÓ. Decocció. Aigua de les flors. DESTINACIÓ. Medicina humana.

Per a les picades

FONT 1324. DESCRIPCIÓ DE L'ÚS FETA PER L'INFORMANT. Per a pessigades. FORMA FARMACĖUTICA I ÚS. Essència (ús extern). DESTINACIÓ. Medicina humana i veterinària.

Per a trastorns de la pell o del teixit subcutani

FONT 1335. DESCRIPCIÓ DE L'ÚS FETA PER L'INFORMANT. Per a les durícies, amoroseix la pell. FORMA FARMACĖUTICA I ÚS. Pomada (ús extern). PREPARACIÓ. Se'n fa una pomada. DESTINACIÓ. Medicina humana.

\section{ALTRES USOS}

Part aèria florida

Ornamental: elaboració de rams

FONTS 560, 561, 562, 563. DESCRIPCIÓ DE L'ÚS FETA PELS INFORMANTS. Per a fer bonic (560). Les flors fan bonic $(561,562,563)$.

Planta viva ex situ

Ornamental: jardineria

FONTS 572, 573, 580. DESCRIPCIÓ DE L'ÚS FETA PELS INFORMANTS. En tenim flors a fora $(572,573)$. Per a fer bonic (580).

\section{BARREGES AMB AQUEST TÀXON}

Inflorescència

FONT 545. Entrevista 72, barreja I (vegeu catàleg de barreges)

Callistephus chinensis (L.) Nees (compostes)

BCN-E249

\section{NOMS POPULARS}

Coronado (castellà) (590)

ALTRES USOS 
Planta viva ex situ

Ornamental: jardineria

FONT 590. DESCRIPCIÓ DE L'ÚS FETA PER L'INFORMANT. Per a fer bonic.

\section{Calluna vulgaris (L.) Hull (ericàcies)}

BCN 24733

\section{NOMS POPULARS}

Brossa $(541,553,569,1321)$

\section{USOS MEDICINALS}

Part aèria florida

Diürètic

FONT 553. DESCRIPCIÓ DE L'ÚS FETA PER L'INFORMANT. Neteja, és depurativa i fa orinar. FORMA FARMACĖUTICA I ÚS. Tisana (ús intern). PREPARACIÓ. Decocció. DESTINACIÓ. Medicina humana.

\section{ALTRES USOS}

\section{Part aèria florida}

Ornamental: elaboració de rams

FONTS 569,570

\section{ACCIONS NOCIVES O TÒXIQUES}

\section{No consta}

FONT 1321. DESCRIPCIÓ DE L'ACCIÓ NOCIVA O TÒXICA FETA PER L'INFORMANT. E bestiar no se la menja. TOXICITAT EN ANIMALS. Si.

\section{Campanula rotundifolia $\mathrm{L}$. (campanulàcies)}

BCN 24748

\section{NOMS POPULARS}

Campaneta blava $(1328,1329)$

\section{USOS MEDICINALS}

No consta
Desconegut per l'informant

FONTS 1328, 1329. FORMA FARMACĖUTICA I ÚS. Desconegut per l'informant DESTINACIÓ. Medicina humana. OBSERVACIONS. Li sembla que en feien oli, però no sap per a què servia.

\section{Campanula trachelium $\mathrm{L}$. (campanulàcies)}

BCN 24734

\section{NOMS POPULARS}

Ortiga morta (1299)

\section{USOS MEDICINALS}

\section{Part aèria}

Diürètic

FONT 1299. DESCRIPCIÓ DE L'ÚS FETA PER L'INFORMANT. És diürètica. FORMA FARMACĖUTICA I ÚS. Tisana (ús intern). DESTINACIÓ. Medicina humana.

Vasotònic

FONT 1299. DESCRIPCIÓ DE L'ÚS FETA PER L'INFORMANT. Per a la circulació de la sang. FORMA FARMACĖUTICA I ÚS. Tisana (ús intern). DESTINACIÓ. Medicina humana.

\section{Cannabis sativa L. (cannabàcies)}

\section{BCN 24735}

\section{NOMS POPULARS}

Cànem $(753,754,755,1213,1214,1215,1335)$

\section{USOS MEDICINALS}

\section{No consta}

Analgèsic

FONTS 1213, 1214. DESCRIPCIÓ DE L'ÚS FETA PELS INFORMANTS. Per al dolor FORMA FARMACEUTICA I US. Tisana (ús intern) PREPARACIÓ Decocció - MODE D'UTILITZACIÓ/POSOLOGIA. DBSERVACIONS. NO I FIA. Novenes. DESTINACIÓ. Medicina humana.

\section{ALTRES USOS}

Part aèria 
Tèxtil: elaboració de fibres

FONT 1335. DESCRIPCIÓ DE L'ÚS FETA PER L'INFORMANT. Abans en feien cordes i llençols, no havien sabut mai que era droga. Es deixava assecar, llavors es picava amb un pal perquè es trenqués i quedaven uns fils que es pentinaven amb unes pues i així saltaven les pellofes, aquests fils els anaven retorcent per a anar fent les cordes. OBSERVACIONS. Els molins on es molia el blat era el lloc on es feien els fils. A cal Pentinado de Molló tenien el teler per a fer els llençols. Quedaven uns llençols grollers, costaven molt de rentar, eren un mata dones. S'utilitza lleixiu de cendra (es posa la cendra a bullir i l'aigua que fa és blanquejador i no fa malbé la roba) i els llençols s'anaven tornant blancs. L'avi de la casa només volia aquests llençols deia que a l'hivern són calents i a l'estiu frescos.

Tija

Tèxtil: elaboració de fibres

FONT 1215. DESCRIPCIÓ DE L'ÚS FETA PER L'INFORMANT. Se'n feien vànoves.

\section{BARREGES AMB AQUEST TÀXON}

\section{No consta}

FONTS 753, 754, 755. Entrevista 67, barreja IV (vegeu catàleg de barreges)

\section{Capparis spinosa L. (capparàcies)}

BCN 52998

\section{NOMS POPULARS}

Tàpera (poncella) (1352)

\section{USOS ALIMENTARIS}

Fruit

Condiment

FONT 1352. DESCRIPCIÓ DE L'ÚS FETA PER L'INFORMANT. La meva padrina la usava per a cuinar. OBSERVACIONS. Els seus menjars eren molt especiats i molt bons. DESTINACIO. Alimentació humana.

\section{Capsella bursa-pastoris (L.) Medic. (crucíferes)}

BCN 24736

\section{NOMS POPULARS}

Bossa de pastor $(583,584,585,1324)$
Caps blancs $(572,573,1313,1352)$

\section{USOS MEDICINALS}

Part aèria florida

Antihipertensiu

FONT 1324. DESCRIPCIÓ DE L'ÚS FETA PER L'INFORMANT. Per a la pressió alta. FORMA FARMACĖUTICA I ÚS. Tisana (ús intern). PREPARACIÓ. En infusió. DESTINACIÓ. Medicina humana.

Hemostàtic extern

FONT 1324. DESCRIPCIÓ DE L'ÚS FETA PER L'INFORMANT. Per a les hemorràgies. Una vaca va vedellar i no se li parava l'hemorràgia i li va anar molt bé. FORMA FARMACĖUTICA ÚS. Tisana (ús intern). PREPARACIÓ. En infusió. DESTINACIÓ. Medicina veterinària.

\section{USOS ALIMENTARIS}

\section{Part aèria}

Ingestió de la part de la planta crua - Fresca (sense preparació)

FONTS 572, 573, 1313, 1352. DESCRIPCIÓ DE L'ÚS FETA PELS INFORMANTS. Les ovelles se'ls mengen per força, no els agrada gaire $(572,573)$. Se'n donava als conills (1313). Per a menjar els conills (1352). DESTINACIÓ. Alimentació animal (572, 573, 1313 1352)

\section{Capsicum annuum L. (solanàcies)}

\section{BCN 24737}

\section{NOMS POPULARS}

Cirereta (fruit) (751)

Pebrotera $(1353,1354)$

\section{USOS ALIMENTARIS}

Fruit

Ingestió de la part de la planta crua - Conservada en salmorra

FONTS 1353, 1354. DESCRIPCIÓ DE L'ÚS FETA PELS INFORMANTS. Per a fer conserves per a l'hivern. DESTINACIÓ. Alimentació humana.

Ingestió de la part de la planta crua - Fresca (sense preparació)

FONT 751. DESCRIPCIÓ DE L'ÚS FETA PER L'INFORMANT. En menjo i tan tranquil. DESTINACIÓ. Alimentació humana. 


\section{Cardamine heptaphylla (Vill.) O.E.Schulz (crucíferes) BCN 1050}

\section{NOMS POPULARS}

Canoguera $(748,749)$

Herba canoguera $(517,520,521)$

\section{USOS MEDICINALS}

Arrel

Antipirètic

FONTS 520, 521, 748, 749. DESCRIPCIÓ DE L'ÚS FETA PELS INFORMANTS. Les arrels per a fer baixar la febre $(748,749)$. Per a fer baixar la febre $(520,521)$. FORMA FARMACĖUTICA I ÚS. Tisana (ús intern). PREPARACIÓ. Decocció $(748,749)$. Decocció. Cada nus indica els graus de febre, si per exemple estaves a $40^{\circ}$ de febre, havies de posar a I'hora de fer aigua quatre nusos (de $36^{\circ}$ a $\left.40^{\circ}\right)(520,521)$. DESTINACIÓ. Medicina humana.

\section{Part aèria florida}

Antipirètic

FONT 517. DESCRIPCIÓ DE L'ÚS FETA PER L'INFORMANT. Per a fer baixar la febre. FORMA FARMACĖUTICA I ÚS. Tisana (ús intern). PREPARACIÓ. Decocció. DESTINACIÓ. Medicina humana.

\section{ALTRES OBSERVACIONS}

FONTS 520, 521, 748, 749. DESCRIPCIÓ FETA PELS INFORMANTS. Quan és petita, la fulla s'assembla a la tora (Aconitum napellus subsp. vulgare) i les arrels són molt arrugades $(748,749)$. Puja un espigó i fa la flor lila, la rel fa uns nusos. Les fulles semblants a les de noguer (Juglans regia) i la flor blanca o rosa $(520,521)$.

\section{Carduncellus monspelliensium All. (compostes)}

BCN 872140

\section{NOMS POPULARS}

Herba dels erístols $(529,530,531)$

\section{USOS MEDICINALS}

No consta
Per al panadís

FONTS 529, 530, 531. DESCRIPCIÓ DE L'ÚS FETA PELS INFORMANTS. Per als erístols Aquesta no fa gats. FORMA FARMACĖUTICA I ÚS. Bany (ús extern). PREPARACIÓ. Es feia aigua. Es posava en una cassola i hi posaves el dit per a saber si tenies o no un erístol. DESTINACIÓ. Medicina humana.

\section{Carlina acanthifolia All. subsp. cynara (Pourr. ex Duby)}

Arcang. (compostes)

BCN 24738

\section{NOMS POPULARS}

Carlina $(541,549,553,559,561,562,563,564,586,587,590,591,592,1215,1298,1313$, $1321,1337,1338,1352$

Carolina (560)

Escarlina (547)

\section{USOS ALIMENTARIS}

\section{Inflorescència}

Ingestió de la part de la planta crua - Conservada en vinagre

FONT 553. DESCRIPCIÓ DE L'ÚS FETA PER L'INFORMANT. Es menja quan és tendra. DESTINACIÓ. Alimentació humana.

Ingestió de la part de la planta crua - Fresca (sense preparació)

FONTS 547, 548, 549, 559, 561, 562, 563, 586, 587, 590, 591, 592, 1215, 1298, 1313. DESCRIPCIÓ DE L'ÚS FETA PELS INFORMANTS. Quan és tendre es menjava $(547,548)$ Es menja tendra (559). Es pot menjar, però no té pas gust de res $(586,587)$. La part de dins és bona per a menjar (590). Quan són tendres són bones per a menjar $(591,592)$. Quan són tendres es mengen i n'hi ha molt dolces (549). Es pelaven com les escarxofes i es menjaven quan eren tendres $(561,562,563)$. Es menjava la part interna quan eren tendres, eren molt bones (1215). Es treu tota la part de fora espinuda i es menja la part de sota que és blanca, té gust dolç (1298). Quan és tendra s'obre i es menja una cosa blanca de dins (1313). DESTINACIO. Alimentació humana (547, 548, 549, 559, 561, 562, 563, 586, 587, 590, 591 $592,1215,1298,1313)$.

Ingestió de la part de la planta cuita - Cuita en llet

FONT 1321. DESCRIPCIÓ DE L'ÚS FETA PER L'INFORMANT. Es menja allò blanc de dins, és dolç. Abans els pastors se les menjaven bullides amb llet. DESTINACIO. Alimentació humana.

\section{ALTRES USOS}




\section{Inflorescència}

Altres informacions

FONT 1215. DESCRIPCIÓ DE L'ÚS FETA PER L'INFORMANT. Les buidaven i s'utilitzaven per a beure aigua.

Creences i pràctiques magicoreligioses

FONTS 1337, 1338. DESCRIPCIÓ DE L'ÚS FETA PELS INFORMANTS. Les carlines es penjaven a la porta per a indicar el temps. Si s'obren vol dir que farà bo, i si es tanquen indica mal temps.

\section{Part aèria florida}

Altres informacions

FONTS 591, 592. DESCRIPCIÓ DE L'ÚS FETA PELS INFORMANTS. Abans també es venien, les posàvem a sobre brimes de ginesta (Sarothamnus scoparius) per a no punxarnos.

Creences i pràctiques magicoreligioses

FONTS 541, 553, 560, 1352. DESCRIPCIÓ DE L'ÚS FETA PELS INFORMANTS. Hi havia alguna cosa que deien que també protegia dels mals esperits (541). A les portes de les cases se n'hi posaven, em sembla que era per a protegir de les bruixes (553). Es posaven a les portes de les cases per a protegir de les bruixes. Abans a totes les cases deien que hi havia bruixes. A la Maçana s'hi anava a buscar les carolines (560). Es penjava una carlina a la porta d'entrada a les cases per a fer fora els mals esperits (1352).

Maneig agrosilvopastoral: ús hortícola/agrícola

FONTS $541,564,586,587,590$. DESCRIPCIÓ DE L'ÚS FETA PELS INFORMANTS. S'obre i es tanca segons la humitat (541). Es penjaven a les portes de les cases perquè indicaven el canvi de temps, quan fa bo s'obren i quan fa humitat es tenquen (564). Es posava a la porta per veure el temps, quan s'obre és que fa sol i quan es tenca plou $(586,587)$. Es posaven a la porta i senyalaven el temps. Quan es tanquen designen pluja (590).

Ornamental: elaboració de rams

FONT 559. DESCRIPCIÓ DE L'ÚS FETA PER L'INFORMANT. Es posava per a adornar les cases.

\section{ALTRES OBSERVACIONS}

FONTS 547, 548, 1215. DESCRIPCIÓ FETA PELS INFORMANTS. Quan fa sol s'obre i quan plou es tanca $(547,548)$. Se'n trobaven a la Mare de la Font $(1215)$

\section{Carum carvi L. (umbel·líferes)}

BCN 24739

\section{NOMS POPULARS}

Comí $(511,512,513,514,520,521,525,526,527,528,529,530,531,536,537,549,553$ $585,588,591,592,748,749,1293,1296,1297,1299,1300,1310,1313,1314,1317,1318$ 1319, 1321, 1323, 1325, 1326, 1328, 1329, 1330, 1332, 1333, 1334, 1335, 1347, 1348, 1318 $1319,1321,1323,1325,1326$ $1353,1354,1352)$

Herba de comí $(547,548,572,573)$

\section{USOS MEDICINALS}

\section{Llavor}

Antidiarreic

FONT 1296. DESCRIPCIÓ DE L'ÚS FETA PER L'INFORMANT. Per a la diarrea. FORMA FARMACĖUTICA I ÚS. Tisana (ús intern). PREPARACIÓ. Decocció. DESTINACIÓ. Medicina humana.

Antiinflamatori intestinal

FONTS 511, 512, 513, 514, 525, 526, 527, 529, 530, 531, 553, 554, 555, 560, 561, 562, 563 $567,574,575,576,577,588,591,592,748,749,1297,1299,1313,1317,1318,1319,1321$ $1323,1325,1326,1328,1329,1330,1332,1333,1334,1335,1347,1348,1349,1352$ DESCRIPCIÓ DE L'US FETA PELS INFORMANTS, Per al mal de panxa, sobretot, de canalla $(511,512,513,514)$. Per al mal de panxa $(574,575,576,577,748,749,1297)$. Pe cant al mal de ventre, es molt refrescint (529, 530,531$)$. Per al mal de ventre $(525,526,527,529$, $530,531,554,555,560,1317,1318)$. Per a la panxa $(553,561,562,563)$. Per a la panxa, sobretot, de la mainada (567). Per al mal de panxa de les criatures $(588)$. Es una aigua molt bona per a la panxa i té molt bon gust, per aixo es donava tant a la canalla $(591,592)$. Per a mal de ventre del bestiar $(574,575,576,577)$. Per al mal de ventre de la mainada (1299, $1313,1325,1326,1332,1333,1334,1335)$. Per al mal de panxa de la mainada $(1319,1352)$ Per al mal de ventre de la canalla $(1321,1323,1328,1329,1330,1347,1348,1349)$. FORMA FARMACĖUTICA I ÚS. Tisana (ús intern). PREPARACIÓ. Decocció $(511,512,513$ $514,529,530,531,553,554,555,560,561,562,563,567,574,575,576,577,588,591$, $592,748,749,1297,1299,1317,1319,1321,1323,1325,1326,1328,1329,1330,1347$, 1348, 1349). Decocció. Fer aigua de comí i barrejar-hi una mica de greix de teixó i beure-ho $(529,530)$. Decocció. Fer aigua de comí i barrejar-hi una mica de greix de teixó i beure-ho (531). Décoció. Es fa aigua de la grana ( $525,526,527)$. Les granes en infusió (1313). Aigua Aigua de les granes (1352). DESTINACIO. Medicina humana $(511,512,513,514,525,526$, $527,529,530,531,553,554,555,560,561,562,563,567,574,575,576,577,588,591$ $592,748,749,1297,1299,1313,1317,1318,1319,1321,1323,1325,1326,1328,1329$ $1330,1332,1333,1334,1335,1347,1348,1349,1352)$. Medicina veterinària $(574,575,576$, 577). OBSERVACIONS. Sobretot se'n donava als nens perquè té molt bon gust (1297). Agafaven la planta, es deixava assecar i llavors s'espolsaven les granes sobre un drap (1313). La seva germana se la prenia bullida amb la llet (1335).

Carminatiu 
FONTS 520, 521, 528, 547, 548, 569, 570, 583, 584, 585, 1314, 1353, 1354. DESCRIPCIÓ DE L'ÚS FETA PELS INFORMANTS. Per als gasos, se'n donava molt als nens petits (520, 521). Per als gasos dels nens. Es donava amb els biberons $(547,548)$. Per a les criatures quan tenien gasos $(569,570)$. Per a la panxa, ajuda a fer petar, anava bé per a la canalla $(583,584,585)$. Per a treure els gasos de la mainada (1314). Per als gasos de la panxa (1353). Quan tens gasos a la panxa (1354). FORMA FARMACËUTICA I ÚS. Tisana (ús intern) $(520,521,528,547,548,569,570,583,584,585,1314)$. Macerat en aigua (ús intern) intern) $(520,521,528,547,548,569,570,583,584,585,1314)$. Macerat en aigua (ús intern)
(1353, 1354). PREPARACIÓ. Decocció $(520,521,528,547,548,569,570,583,584,585$ 1314). La grana estovada en aigua $(1353,1354)$. DESTINACIÓ. Medicina humana OBSERVACIONS. Es feia aigua per a la canalla petits (528). Quan estaves embarassada ja en collies per a tenir-ne quan naixés la criatura $(547,548)$.

Digestiu

FONTS 536, 537. DESCRIPCIÓ DE L'ÚS FETA PELS INFORMANTS. Per a fer pair, era la medicina de la mainada cada dia en prenien. FORMA FARMACĖUTICA I ÚS. Tisana (ús intern). PREPARACIO. Decocció. DESTINACIO. Medicina humana.

Laxant

FONTS 561, 562, 563, 574, 575, 576, 577. DESCRIPCIÓ DE L'ÚS FETA PELS INFORMANTS. Per a quan els nens no poden anar de ventre $(561,562,563)$. Per a anar de ventre $(574,575,576,577)$. FORMA FARMACĖUTICA I ÚS. Tisana (ús intern). PREPARACIO. Decocció $(561,562,563,574,575,576,577)$. DESTINACIO. Medicina humana.

Salutífer

FONTS 572, 573. DESCRIPCIÓ DE L'ÚS FETA PELS INFORMANTS. És un refrescant de la canalla, als nadons se'ls donava. FORMA FARMACEUTICA I ÚS. Tisana (ús intern). PREPARACIÓ. Decocció. DESTINACIO. Medicina humana.

Tònic

FONTS 556, 557. DESCRIPCIO DE L'ÚS FETA PELS INFORMANTS. Va bé per a quan estàs cansat a l'estiu. FORMA FARMACEUTICA I ÚS. Tisana (ús intern). PREPARACIO. La grana es posava en aigua fresca. DESTINACIO. Medicina humana.

\section{Part aèria fructificada}

Digestiu

FONT 1310. DESCRIPCIÓ DE L'ÚS FETA PER L'INFORMANT. Per a fer pair. FORMA FARMACĖUTICA I ÚS. Tisana (ús intern). DESTINACIÓ. Medicina humana.

\section{USOS ALIMENTARIS}

\section{Llavor}

Condiment

FONTS 558, 572, 573. DESCRIPCIÓ DE L'ÚS FETA PELS INFORMANTS. En posàvem a les coques que fèiem a casa i quedaven boníssimes $(558)$. Es posa als guisats $(572,573)$. DESTINACIÓ. Alimentació humana $(558,572,573)$.
Ingestió de la part de la planta crua - Fresca (sense preparació)

FONTS 567, 1310. DESCRIPCIÓ DE L'ÚS FETA PELS INFORMANTS. Quan era petit em posava les granes a la boca, eren molt bones, tenien aquell gustet d'anís (567). Abans quan es dallava l'herba anaves menjant grans de comí que trobaves pel camp (1310). DESTINACIÓ. Alimentació humana $(567,1310)$.

Ingestió de la part de la planta cuita - Cuita en oli

FONTS 1347, 1348, 1349. DESCRIPCIÓ DE L'ÚS FETA PELS INFORMANTS. Per a fer bunyols. DESTINACIÓ. Alimentació humana.

Preparació de begudes - Beguda preparada amb aigua

FONTS 558, 1300. DESCRIPCIÓ DE L'ÚS FETA PELS INFORMANTS. Es posava a l'aigua i li donava una mica de gustet d'anís, anava bé per espassar la set (558). N'utilitza les granes en infusió per a refrescar, no com a medicina (1300). OBSERVACIONS. Temps enrera venia un home de Lleida que s'enduia comí i els portava boixerola, no recordo per a què la feien servir (1300). DESTINACIÓ. Alimentació humana $(558,1300)$.

\section{ALTRES OBSERVACIONS}

FONTS 560, 1296, 1300, 1321. DESCRIPCIÓ FETA PELS INFORMANTS. Aquí no se'n feia, a Camprodon sí que se'n feia (560). S'ha perdut una mica, abans n'hi havia més (1296) Abans n'hi havia, ara costa de trobar (1300). Ara costa de trobar-ne (1321).

\section{BARREGES AMB AQUEST TÀXON}

\section{Llavor}

FONT 1293. Entrevista 2, barreja II (vegeu catàleg de barreges)

FONT 1330. Entrevista 32, barreja III (vegeu catàleg de barreges)

FONT 1296. Entrevista 7, barreja I (vegeu catàleg de barreges)

\section{Castanea sativa Mill. (fagàcies)}

\section{BCN 24740}

\section{NOMS POPULARS}

Castanya (fruit) $(1353,1354)$

Castanyer $(1347,1348,1349,1352)$

\section{USOS MEDICINALS}

Fruit

Per als penellons 
Apèndix 1. Catàleg de tàxons.

FONTS 1347, 1348, 1349. DESCRIPCIÓ DE L'ÚS FETA PELS INFORMANTS. Per als penellons. FORMA FARMACĖUTICA I ÚS. Bany (ús extern). PREPARACIÓ. Decocció Aigua de les cloves de les castanyes. L'aigua ha de ser molt calenta, tant com ho puguis aguantar. DESTINACIÓ. Medicina humana.

\section{USOS ALIMENTARIS}

Fruit

Ingestió de la part de la planta cuita - Cuita sense vehicle

FONTS 1353, 1354. DESCRIPCIÓ DE L'ÚS FETA PELS INFORMANTS. En mengem per Tot Sants. DESTINACIÓ. Alimentació humana.

\section{ALTRES USOS}

Tija

Maneig agrosilvopastoral: ús hortícola/agrícola

FONT 1352. DESCRIPCIÓ DE L'ÚS FETA PER L'INFORMANT. Se'n feien les forquetes

\section{Catananche caerulea L. (compostes)}

BCN 29645

\section{NOMS POPULARS}

Pell de serp $(529,530,531)$

\section{ALTRES USOS}

Part aèria florida

Ornamental: elaboració de rams

FONTS 529, 530, 531. DESCRIPCIÓ DE L'ÚS FETA PELS INFORMANTS. La vinc a buscar per a fer rams. És preciosa.

\section{Celtis australis L. (cannabàcies)}

\section{BCN 2474}

\section{NOMS POPULARS}

Lledoner $(517,532,561,562,563,747,753,754,755,1307,1308,1309,1313,1323,1336$ $1350,1351,1353,1354,1361,1362)$

\section{USOS MEDICINALS}

Fruit

Antihipertensiu

FONT 517. DESCRIPCIÓ DE L'ÚS FETA PER L'INFORMANT. Per a les sangs i el colesterol. FORMA FARMACĖUTICA I ÚS. Tisana (ús intern). PREPARACIÓ. No es pot bullir, s'ha de deixar estovar. DESTINACIÓ. Medicina humana. OBSERVACIONS. És millor fer aigua de les boles, però quan no n'hi ha, ja van bé les fulles.

Hipolipemiant

FONT 517. DESCRIPCIÓ DE L'ÚS FETA PER L'INFORMANT. Per a les sangs i el colesterol. FORMA FARMACĖUTICA I ÚS. Tisana (ús intern). PREPARACIÓ. No es pot bullir, s'ha de deixar estovar. DESTINACIÓ. Medicina humana. OBSERVACIONS. És millor fer aigua de les boles, però quan no n'hi ha, ja van bé les fulles.

Fulla

Antihipertensiu

FONT 517. DESCRIPCIÓ DE L'ÚS FETA PER L'INFORMANT. Per a les sangs i el colesterol. FORMA FARMACĖUTICA I US. Tisana (ús intern). PREPARACIÓ. Aigua de les fulles. No es pot bullir s'ha de deixar estovar. DESTINACIO. Medicina humana. OBSERVACIONS. És millor fer aigua de les boles, però quan no n'hi ha ja van bé les fulles.

Desconegut per l'informant

FONTS 1361, 1362. FORMA FARMACĖUTICA I ÚS. Macerat en aigua (ús intern) PREPARACIÓ. Deixant-la en remull la nit abans i llavors només escaldar-la MODE D'UTILITZACIO/POSOLOGIA. Fer una novena d'aigua, començant per una fulla i fins a nou. DESTINACIÓ Medicina humana.

Hipolipemiant

FONTS 517, 532, 561, 562, 563, 747, 753, 754, 755, 1307, 1308, 1309, 1313, 1323, 1336 $1350,1351,1353,1354$. DESCRIPCIÓ DE L'ÚS FETA PELS INFORMANTS. Per a les sangs i el colesterol (517). Per a fer baixar el colesterol $(747,753,754,755,1323,1336,1350$, $1351,1353,1354)$. Per al colesterol $(532,562,563,1307,1308,1309,1313)$. Per al colesterol (561). FORMA FARMACĖUTICA I ÚS. Tisana (ús intern). PREPARACIÓ. Aigua de les fulles. No es pot bullir, s'ha de deixar estovar (517). Decocció. Aigua de les fulles (747) Decocció $(532,561,562,563,753,754,755,1307,1308,1309,1313,1336)$. En infusió (1323). Bullit tres minuts $(1350,1351)$. DESTINACIÓ. Medicina humana. OBSERVACIONS. És millor fer aigua de les boles, però quan no n'hi ha, ja van bé les fulles (517). Això ho sap És millor fer aigua de les boles, pero
d'ara, abans no ho feien pas (1313).

\section{Centaurea calcitrapa L. (compostes)}

BCN 24742

NOMS POPULARS 
Floravia $(529,530,531,583,584,585)$

Herba espitllera $(505,506,507,509,510,518,519,528,541,1327,1335,1352)$

\section{USOS MEDICINALS}

\section{Inflorescència}

Antisèptic extern

FONTS 583, 584, 585. DESCRIPCIÓ DE L'ÚS FETA PELS INFORMANTS. Per a desinfecta i rentar mals. FORMA FARMACÈUTICA I ÚS. Bany (ús extern). PREPARACIÓ. Decocció DESTINACIÓ. Medicina humana.

Desconegut per l'informant

FONTS 518, 519. FORMA FARMACĖUTICA I ÚS. Desconegut per l'informant. DESTINACIÓ Medicina humana. OBSERVACIONS. Hi havia una iaia en una casa que deia "em moriré porteu-me aigua d'herba espitllera".

Per al panadís

FONTS 505, 506, 507, 509, 510, 528. DESCRIPCIÓ DE L'ÚS FETA PELS INFORMANTS. Per a curar les espitlles $(507,509,510)$. Per a les espitlles $(505,506)$. Es feia servir per curar les espitlles del bestiar (528). FORMA FARMACEUTICA I ÚS. Bany (ús extern) PREPARACIÓ. Decocció $(507,509,510,528)$. Decocció. T'has de rentar l'espitlla $(505,506)$. DESTINACIO. Medicina humana $(505,506,507,509,510)$. Medicina veterinària (528)

\section{Part aèria}

Antiinflamatori

FONTS 529, 530, 531. DESCRIPCIÓ DE L'ÚS FETA PELS INFORMANTS. Aigua per a les inflamacions de les vaques. FORMA FARMACĖUTICA I ÚS. Bany (ús extern). PREPARACIÓ. Es fan banys de tota la planta, les espines també. DESTINACIÓ. Medicina veterinària.

Per al panadís

FONTS 1327, 1335, 1352. DESCRIPCIÓ DE L'ÚS FETA PELS INFORMANTS. Per a curar les espitlles (1327). Per a tractar les espitlles (fístula d'os, que es consumeix) (1335). Per a les espitlles (1352). FORMA FARMACĖUTICA I ÚS. Liniment (ús extern) (1327). Embrocació (ús extern) (1335). Sense forma farmacèutica (ús directe, ús extern) (1352). PREPARACIÓ La planta ben picada posada en oli i et fregaves l'espitlla (1327). Se'n fa oli (1335). Se'n feia La planta ben picada posada en oli i et fregaves l'espitlla (1327). Se'n fa oli (1335). Se'n feia
aigua i es posava en una cassola, s'hi trabucava un tupí i es posaven set dobles de drap de fil a sobre el tupí; llavors havies de posar la ma de l'espitlla en contacte amb el drap. S realment tenies una espitlla, l'aigua pujava a dins del tupí (1352). DESTINACIÓ. Medicina humana.

\section{ALTRES USOS}

\section{Planta sencera}

Literatura oral popular: llegendes, gloses, contes, dites, refranys, poemes, cançons
FONTS 583, 584, 585. DESCRIPCIÓ DE L'ÚS FETA PELS INFORMANTS. La floravia tant es troba de nit com de dia.

\section{ALTRES OBSERVACIONS}

FONTS 528, 529, 530, 531, 1335. DESCRIPCIÓ FETA PELS INFORMANTS. És una planta que punxa, puja rodona i fa la flor fúcsia o lila $(529,530,531)$. És una planta que fa punxes (528). Per darrera la casa li sembla que n'hi ha (1335).

\section{BARREGES AMB AQUEST TÀXON}

Inflorescència

FONTS 583, 584, 585. Entrevista 96, barreja III (vegeu catàleg de barreges)

\section{Centaurea cyanus L. (compostes)}

BCN 27257

\section{NOMS POPULARS}

Clavell de blat (1352)

\section{ALTRES USOS}

\section{Part aèria florida}

Ornamental: elaboració de rams

FONT 1352. DESCRIPCIÓ DE L'ÚS FETA PER L'INFORMANT. Per a fer rams.

\section{Centaurea jacea L. (compostes)}

BCN 21907

\section{NOMS POPULARS}

Caps de burro bord (1324)

\section{USOS MEDICINALS}

\section{Inflorescència}

Hipoglucemiant

FONT 1324. DESCRIPCIÓ DE L'ÚS FETA PER L'INFORMANT. Per a fer baixar el sucre. FORMA FARMACĖUTICA I ÚS. Tisana (ús intern). PREPARACIÓ. Decocció. Aigua de les flors. DESTINACIÓ. Medicina humana. 


\section{Centaurea nigra L. (compostes)}

BCN 24744

\section{NOMS POPULARS}

Caps de burro $(511,512,513,514,518,519,520,521,535,553,569,570,572,573,591$ $592,1293,1294,1296,1300,1307,1308,1309,1310,1318,1322,1324,1327,1328,1329$ $1330,1339,1340,1341,1342,1345,1346,1362$

\section{USOS MEDICINALS}

\section{Inflorescència}

Antidiarreic

FONTS 520, 521. DESCRIPCIÓ DE L'ÚS FETA PELS INFORMANTS. Per a la diarrea. FORMA FARMACĖUTICA I ÚS. Tisana (ús intern). PREPARACIÓ. Decocció. DESTINACIÓ. Medicina humana.

Antihipertensiu

FONT 535. DESCRIPCIÓ DE L'ÚS FETA PER L'INFORMANT. Per a fer baixar la pressió. FORMA FARMACEUTICA I ÚS. Tisana (ús intern). PREPARACIÓ. Decocció. DESTINACIÓ. Medicina humana.

Cardiotònic

FONTS 1339, 1340. DESCRIPCIÓ DE L'ÚS FETA PELS INFORMANTS. Per al cor. FORMA FARMACEUUTICA I ÚS. Tisana (ús intern). PREPARACIÓ. Decocció. DESTINACIÓ. Medicina humana.

Desconegut per l'informant

FONT 553. FORMA FARMACĖUTICA I ÚS. Tisana (ús intern). PREPARACIÓ. Decocció DESTINACIO. Medicina humana. OBSERVACIONS. La mare en feia aigua, però no recordo perquè ho utilitzava.

Hipoglucemiant

FONTS 511, 512, 513, 514, 518, 519, 569, 570, 572, 573, 591, 592, 1293, 1294, 1296, 1300 1307, 1308, 1309, 1310, 1318, 1322, 1324, 1327, 1328, 1329, 1330, 1341, 1342, 1345, 1346 DESCRIPCIO DE L'ÚS FETA PELS INFORMANTS. Per a fer baixar el sucre $(511,512,513$ $514,591,592,1293,1294,1307,1308,1309,1310,1318,1322,1324,1327,1328,1329$ $1330,1341,1342,1345,1346)$. Per al sucre $(518,519,569,570,572,573,1300)$. Per a

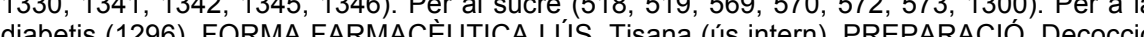
(511,512,513,514,518,519,569,570,572,573,591,592,1296,1307,1308, 1309, 1318, 1322, 1328,1329, 1345, 1346). Decocí́. Aigua de $1322,1328,1329,1345,1346)$. Decocció. Algua de les fors (1293, 1324, 1327). Infusió de la flor (1294). Decocció. Fer bulir la flor (1300). Infusió de les flors (1310). En infusió (1330) 1341, 1342). MODE D'UTILITZACIÓ/POSOLOGIA. S'ha de prendre en novenes (1318)
DESTINACIÓ. Medicina humana. OBSERVACIONS. Té un gust amarg igual que la flor de xicoina $(1307,1308,1309)$

Hipolipemiant

FONTS 511, 512, 513, 514, 1300. DESCRIPCIÓ DE L'ÚS FETA PELS INFORMANTS. Per a colesterol $(511,512,513,514,1300)$. FORMA FARMACE்UTICA I ÚS. Tisana (ús intern). PREPARACIÓ. Decocció $(511,512$, DESTINACIÓ. Medicina humana.

Vasotònic

FONTS 1361, 1362. DESCRIPCIÓ DE L'ÚS FETA PELS INFORMANTS. Per a la circulació FORMA FARMACĖUTICA I ÚS. Tisana (ús intern). PREPARACIÓ. Decocció. DESTINACIÓ. Medicina humana.

\section{ALTRES OBSERVACIONS}

FONTS 518, 519. DESCRIPCIÓ FETA PELS INFORMANTS. N'hi ha de dues classes, uns més grossos que els altres.

\section{Centaurea scabiosa L. (compostes)}

BCN 24745

\section{NOMS POPULARS}

Escabiosa (1324)

\section{USOS MEDICINALS}

Inflorescència

Antigripal

FONT 1324. DESCRIPCIO DE L'US FETA PER L'INFORMANT. Per a quan tens grip. FORMA FARMACĖUTICA I ÚS. Tisana (ús intern). PREPARACIÓ. En infusió. DESTINACIÓ. Medicina humana.

Per a trastorns del sistema immunitari

FONT 1324. DESCRIPCIÓ DE L'ÚS FETA PER L'INFORMANT. Per a fer sortir els grans de la rosa. FORMA FARMACEUTICA I ÚS. Tisana (ús intern). PREPARACIÓ. En infusió DESTINACIO. Medicina humana.

Centaurium erythraea Rafn subsp. majus (Hoffms. et Link) Laínz (gencianàcies)

BCN 24746 


\section{NOMS POPULARS}

Centaura $(520,521,583,584,585)$

Fel de la terra $(1320)$

Flor de centaura $(517,529,530,531,581,750)$

Herba centaura $(533,534,542,543,1353,1354)$

Herba de centaura $(511,512,513,514,522,523,538,539,540,541,544,549,568,572$ $573,751)$

Herba de Santa Margarida $(505,506,542,543,544,560,578,579,747,752,753,754,755$ $1210,1293,1294,1296,1298,1300,1307,1308,1309,1310,1318,1320,1324,1335,1336$ $1339,1340,1345,1346)$

Santa Margarida $(507,509,510,518,519,1327,1361,1362)$

\section{USOS MEDICINALS}

Flor

Hipoglucemiant

FONTS 583, 584, 585. DESCRIPCIÓ DE L'ÚS FETA PELS INFORMANTS. Aigua per a fer baixar el sucre $(583)$. Per a fer baixar el sucre $(584,585)$. FORMA FARMACEUTICA I ÚS. Macerat en aigua (ús intern). PREPARACIÓ. La flor es macerava perquè és molt amargan $(583,584,585)$. DESTINACIÓ. Medicina humana.

Orexigen

FONTS 572, 573, 1324. DESCRIPCIÓ DE L'ÚS FETA PELS INFORMANTS. Per a fer agafar gana $(572,573,1324)$. FORMA FARMACEUTICA I ÚS. Tisana (ús intern). PREPARACIO Decocció $(572,573)$. S'utilitza la flor en infusió (1324). DESTINACIO. Medicina humana. OBSERVACIONS. És molt de mal prendre, perquè és amargant (1324).

\section{Part aèria florida}

Antibacterià

FONT 1327. DESCRIPCIÓ DE L'ÚS FETA PER L'INFORMANT. És un antibiòtic. FORMA FARMACĖUTICA I ÚS. Tisana (ús intern). PREPARACIÓ. Decocció. DESTINACIÓ. Medicina humana.

Antidiarreic

FONT 1327. DESCRIPCIÓ DE L'ÚS FETA PER L'INFORMANT. Per a les diarrees. FORMA FARMACĖUTICA I ÚS. Tisana (ús intern). PREPARACIÓ. Decocció. DESTINACIÓ. Medicina humana.

Antiinflamatori intestinal

FONTS $751,1298,1339,1340$. DESCRIPCIÓ DE L'ÚS FETA PELS INFORMANTS. Mals de ventre (751). Per al ventre (1298). Per al mal de ventre $(1339,1340)$. FORMA FARMACĖUTICA I ÚS. Tisana (ús intern). PREPARACIÓ. Decocció $(751,1298,1339,1340)$ DESTINACIÓ. Medicina humana. OBSERVACIONS. La seva iaia se'n prenia sempre una tassa en dejú. Diu que tota la seva família sempre ha tingut molta fe en aquesta herba (1298)

Antinauseabund

FONTS 1298, 1310. DESCRIPCIÓ DE L'ÚS FETA PELS INFORMANTS. Per al mareig (1298, 1310). FORMA FARMACĖUTICA I ÚS. Tisana (ús intern). PREPARACIÓ Decocció (1298). S'usava tota la planta en infusió (1310). DESTINACIO. Medicina humana. OBSERVACIONS. La seva iaia se'n prenia sempre una tassa en dejú. Diu que tota la seva família sempre ha tingut molta fe en aquesta herba (1298).

Antipirètic

FONTS 1293, 1320, 1335, 1336. DESCRIPCIÓ DE L'ÚS FETA PELS INFORMANTS. Per a matar la febre petita (es donava a la canalla quan tenia febre) (1293). Per a fer baixar la febre (1320). Fa baixar la febre $(1335,1336)$. FORMA FARMACEUTICA I Ús. Tisana (ús intern) $(1293,1320,1336)$. Macerat en aigua (ús intern) (1335). PREPARACIÓ. Decocció (1293). Escaldada (1320). Es posa a estovar la planta tota la nit en aigua i l'endemà et prens l'aigua Escaldada (1320). Es posa a estovar la planta tota la nit en aigua i l'endemà et prens l'aigua També és pot prendre només remullada tota la nit, sense bullir (1320). Si la bulls quasi no es pot prendre de tan amarga com és (1335).

Digestiu

FONTS 1296, 1310, 1345, 1346. DESCRIPCIÓ DE L'ÚS FETA PELS INFORMANTS. Va bé per a pair (1296). Per a pair (1310). Per a ajudar a pair $(1345,1346)$. FORMA FARMACĖUTICA I ÚS. Tisana (ús intern). PREPARACIÓ. Decocció $(1296,1345,1346)$. S'usava tota la planta en infusió (1310). DESTINACIÓ. Medicina humana.

Hematocatàrtic

FONTS 520, 521. DESCRIPCIÓ DE L'ÚS FETA PELS INFORMANTS. Purificant de la sang FORMA FARMACĖUTICA I ÚS. Tisana (ús intern). PREPARACIÓ. Decocció. DESTINACIÓ. Medicina humana.

Hepatoprotector

FONT 1320. DESCRIPCIÓ DE L'ÚS FETA PER L'INFORMANT. Per al fetge. FORMA FARMACĖUTICA I ÚS. Tisana (ús intern). PREPARACIÓ. Escaldada. DESTINACIÓ. Medicina humana. OBSERVACIONS. També és pot prendre només remullada tota la nit, sense bullir.

Hipoglucemiant

FONTS 1293, 1294, 1335. DESCRIPCIÓ DE L'ÚS FETA PELS INFORMANTS. Per a fer baixar el sucre (1293). Fa baixar molt el sucre (1294). Va bé per al sucre (1335). FORMA FARMACEUTICA I US. Tisana (ús intern) (1293, 1294). Macerat en aigua (ús intern) (1335). PREPARACIO. Decocció $(1293,1294)$. Es posa a estovar la planta tota la nit en aigua I'endemà et prens l'aigua (1335). EFECTES SECUNDARIS. Sí. DESTINACIO. Medicina humana. OBSERVACIONS. S'ha de vigilar perquè és molt forta (1294). Si la bulls quasi no es pot prendre de tan amarga com és (1335).

Orexigen 
FONTS 505, 506, 507, 509, 510, 511, 512, 513, 514, 517, 518, 519, 520, 521, 522, 523, 529, $530,531,533,534,538,539,540,542,543,544,549,560,568,578,579,581,747,750$ $752,753,754,755,1210,1293,1296,1300,1307,1308,1309,1310,1318,1320,1335$ $1345,1346,1353,1354,1361,1362$. DESCRIPCIÓ DE L'ÚS FETA PELS INFORMANTS. Per a fer agafar gana $(505,506,507,509,510,511,512,513,514,518,519,520,521,522$, $523,529,530,531,542,543,544,747,1335,1353,1354,1361,1362)$. Per a fer venir gana $523,529,530,531,542,543,544,747,1335,1353,1354,1361,1362)$. Per a fer venir gana
$(517,533,534,549,560,568,750,752,1296,1307,1308,1309,1310,1320)$. Per a fer venir gana a la canalla $(538,539,540)$. És molt amargant, es prenia per a fer agafar gana (753, $754,755)$. Es donava a la canalla quan no tenien gana $(578,579)$. Es feia servir per a fer venir gana (581). Per a fer venir gana als nens (1210). Per a posar gana $(1293,1318,1345$ 1346). Per a fer venir la gana (1300). FORMA FARMACEUTICA I ÚS. Macerat en aigua (ús intern) $(505,506,507,509,510,1335,1353,1354)$. Tisana (ús intern) $(511,512,513,514$ $517,518,519,520,521,522,523,529,530,531,533,534,538,539,540,542,543,544$ $549,560,568,578,579,581,747,750,752,753,754,755,1210,1293,1296,1300,1307$ $1308,1309,1310,1318,1320,1345,1346,1361,1362)$. PREPARACIÓ. És molt amargant, no es deixa bullir, es posa a estovar $(507,509,510)$. Es prenia estovada perquè és molt amant $752,753,754,755,1210,1293,1296,1300,1318,1345,1346)$. $752,753,754,755,1210,1293,1296,1300,1318,1345,1346)$. Decoccio. Aigua de la planta (750). Nomes s'ha d'escaldar, és molt amargant $(529,530,531)$. S usava tota la planta en infusió (1310). Escaldada (1320). Es posa a estovar la planta tota la nit en aigua i l'endemà e prens l'aigua (1335). Estovada al dia abans $(1353,1354)$. En infusió $(1361,1362)$. MODE D'UTILITZACIÓ/POSOLOGIA. Cada dia 10 minuts abans dels àpats beure'n un gotet (1210). DESTINACIÓ. Medicina humana. OBSERVACIONS. És molt amargant $(511,512,513,514$ $578,579,750,1300)$. També és pot prendre només remullada tota la nit, sense bullir (1320) Si la bulls quasi no es pot prendre de tan amarga com és (1335).

\section{ALTRES OBSERVACIONS}

FONTS 520, 521, 541, 542, 543, 544. DESCRIPCIÓ FETA PELS INFORMANTS. Aquí n'h ha molt poca $(542,543,544)$ La centaura a vegades fa la flor blanca, rosa clar o rosa fosc això són les abelles que ho barregen $(520,521)$. Em sembla que n'havia anat a collir $(541)$.

\section{BARREGES AMB AQUEST TÀXON}

\section{Part aèria florida}

FONT 1318. Entrevista 31, barreja II (vegeu catàleg de barreges)

Cerastium tomentosum $\mathrm{L}$. (cariofil-làcies)

BCN 47710

\section{NOMS POPULARS}

Nevada herba $(520,521)$

\section{ALTRES USOS}

Planta viva ex situ

Ornamental: jardineria

FONTS 520, 521. DESCRIPCIÓ DE L'ÚS FETA PELS INFORMANTS. En tenim de plantada.

\section{Ceratonia siliqua L. (papilionàcies)}

\section{BCN 32177}

\section{NOMS POPULARS}

Garrofa (fruit) $(565,566)$

\section{USOS ALIMENTARIS}

Fruit

Ingestió de la part de la planta crua - Fresca (sense preparació)

FONTS 565, 566. DESCRIPCIÓ DE L'ÚS FETA PELS INFORMANTS. En donàvem a les vaques. Només les trencàvem, sense estovar. DESTINACIÓ. Alimentació animal.

\section{Ceterach officinarum DC. in Lam. et DC. (polipodiàcies)}

\section{BCN 29850}

\section{NOMS POPULARS}

Dauradella $(507,509,510,518,519,524,528,553,574,575,576,577,582,753,754,755$ $1313,1314,1324,1335)$

Herba daurada $(574,575,576,577)$

Herba dauradella (535)

\section{USOS MEDICINALS}

Fronda

Abortiu

FONT 1314. DESCRIPCIÓ DE L'ÚS FETA PER L'INFORMANT. És abortiva. FORMA FARMACĖUTICA I ÚS. Tisana (ús intern). PREPARACIÓ. Decocció. DESTINACIÓ. Medicina humana.

Antiamenorreic 
FONT 582. DESCRIPCIÓ DE L'ÚS FETA PER L'INFORMANT. Quan es para la regla beus aigua dauradella i et torna. Va molt bé per a les sangs. FORMA FARMACĖUTICA I ÚS. Tisana (ús intern). PREPARACIÓ. Decocció. DESTINACIÓ. Medicina humana.

Anticatarral

FONT 524. DESCRIPCIÓ DE L'ÚS FETA PER L'INFORMANT. Per als constipats. FORMA FARMACĖUTICA I ÚS. Tisana (ús intern). PREPARACIÓ. Decocció. DESTINACIÓ. Medicina humana.

Antihipertensiu

FONTS 507, 509, 510, 518, 519, 528, 553, 574, 575, 576, 577, 753, 754, 755, 1313, 1324 1335. DESCRIPCIÓ DE L'ÚS FETA PELS INFORMANTS. Per a fer baixar la pressió (507, $509,510,518,519,528,574,575,576,577,753,754,755,1335)$. Per a rebaixar la sang (553). Per a la pressió $(1313,1324)$. FORMA FARMACĖUTICA I ÚS. Tisana (ús intern).

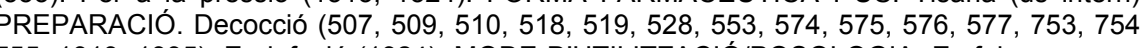
755, 1313, 1335). En infusió (1324). MODE D'UTILITZACIÓ/POSOLOGIA. Es feien novenes $(574,575,576,577)$. EFECTES SECUNDARIS. Sí. DESTINACIÓ. Medicina humana OBSERVACIONS. S'ha de vigilar perquè és molt forta $(518,519)$. Deien que atacava la vista (1324)

Coadjuvant del postpart

FONT 535. DESCRIPCIÓ DE L'ÚS FETA PER L'INFORMANT. Per a quan les cabres no poden fer les despulles. FORMA FARMACĖUTICA I ÚS. Tisana (ús intern). PREPARACIÓ Decocció. DESTINACIÓ. Medicina veterinària.

\section{BARREGES AMB AQUEST TÀXON}

Fronda

FONTS 518, 519. Entrevista 54, barreja I (vegeu catàleg de barreges)

\section{Chaenomeles japonica (Thunb.) Lindl. (rosàcies)}

BCN 47664

\section{NOMS POPULARS}

Arç de Sant Josep (524)

Cedònia (524)

\section{ALTRES USOS}

\section{Planta viva ex situ}

Ornamental: jardineria

FONT 524. DESCRIPCIÓ DE L'ÚS FETA PER L'INFORMANT. Fa bonic davant de la casa.

\section{Chamaespartium sagittale (L.) P.Gibbs (papilionàcies)}

BCN 24749

\section{NOMS POPULARS}

laiol (541)

ljol $(1339,1340,1352)$

Jajol $(586,587)$

Ujol (541)

\section{USOS MEDICINALS}

\section{Part aèria}

Analgèsic

FONTS 1339, 1340. DESCRIPCIO DE L'ÚS FETA PELS INFORMANTS. Per al dolor FORMA FARMACĖUTICA I ÚS. Tisana (ús intern). PREPARACIÓ. Decocció. DESTINACIÓ. Medicina humana.

\section{ALTRES USOS}

\section{Part aèria}

Altres informacions

FONT 1352. DESCRIPCIÓ DE L'ÚS FETA PER L'INFORMANT. Diu el meu pare que les llebres es freguen amb l'ijol.

\section{ALTRES OBSERVACIONS}

FONTS 586, 587. DESCRIPCIÓ FETA PELS INFORMANTS. No val res, al bestiar no li agrada.

\section{Chelidonium majus L. (papaveràcies)}

\author{
BCN 24750
}

\section{NOMS POPULARS}

Celdoni $(554,555)$

Herba berruguera $(539,540,542,543,544,554,555)$

Herba de Santa Teresa $(1361,1362)$

Herba dels fics (541)

Llet de Santa Teresa $(1347,1348,1349,1349)$ 
Lletdeteresa $(560,564,572,573,1215,1332,1333,1334,1334,1352)$ Lleteresa (1300)

\section{USOS MEDICINALS}

Làtex

Antiberrugós

FONTS 539, 540, 541, 542, 543, 544, 560, 564, 1215, 1300, 1332, 1333, 1334, 1347, 1348 $1349,1352,1361,1362$. DESCRIPCIÓ DE L'ÚS FETA PELS INFORMANTS. Per a curar les berrugues $(542,543,564)$. Per a les berrugues $(539,540,560,1215,1361,1362)$. El làtex va bé per als fics (541). La llet es feia servir per a les berrugues i aquestes venien negres (1300). Per a les berrugues, les va cremant fins que desapareixen $(1332,1333,1334)$. Per a cremar berrugues $(1347,1348,1349)$. Per a les berrugues, aquestes desapareixen perque les crema (1352). FORMA FARMACÉUTICA I ÚS. Sense forma farmacèutica (ús directe ús extern) PREPARACIÓ. Per a curar les berrugues (544). S'ha d'escapcar la berruga i posar llet a dins (560). El suc de la tija aplicat directament (1332). El suc de la tija directament (1334). Suc de la tija directament (1333). DESTINACIÓ. Medicina humana.

\section{ACCIONS NOCIVES O TÒXIQUES}

\section{No consta}

FONTS 572, 573. DESCRIPCIÓ DE L'ACCIÓ NOCIVA O TÒXICA FETA PELS INFORMANTS. És tòxica, el bestiar no se la menja. TOXICITAT EN ANIMALS. Sí.

\section{BARREGES AMB AQUEST TÀXON}

\section{Part aèria}

FONTS 554, 555. Entrevista 78, barreja III (vegeu catàleg de barreges)

\section{Chenopodium album L. (quenopodiàcies)}

\section{BCN 24751}

\section{NOMS POPULARS}

Blet $(529,530,531,583,584,585,586,587,1324)$

\section{USOS ALIMENTARIS}

\section{Part aèria}

Ingestió de la part de la planta crua - Fresca (sense preparació)

FONTS 529, 530, 531, 583, 584, 585, 586, 587. DESCRIPCIÓ DE L'ÚS FETA PELS INFORMANTS. Els animals se'ls mengen però no els agrada tant com els altres (529, 530,
531). El bestiar se'Is menja $(583,584,585)$. En mengen les ovelles $(586,587)$. DESTINACIÓ. Alimentació animal $(529,530,531,583,584,585,586,587)$.

Ingestió de la part de la planta cuita - Cuita en aigua

FONT 1324. DESCRIPCIÓ DE L'ÚS FETA PER L'INFORMANT. Es menja bullit, com verdura. DESTINACIÓ. Alimentació humana.

\section{Chenopodium ambrosioides L. (quenopodiàcies)}

BCN 27282

\section{NOMS POPULARS}

Te $(522,523,572,573,1345,1346)$

\section{USOS MEDICINALS}

Fulla

Antiinflamatori intestinal

FONTS 522, 523. DESCRIPCIÓ DE L'ÚS FETA PELS INFORMANTS. És bona per a la panxa. FORMA FARMACĖUTICA I ÚS. Tisana (ús intern). PREPARACIÓ. Decocció. DESTINACIÓ. Medicina humana.

\section{USOS ALIMENTARIS}

Fulla

Preparació de begudes - Beguda preparada amb aigua

FONTS 572, 573, 1345, 1346. DESCRIPCIÓ DE L'ÚS FETA PELS INFORMANTS. Per a fer aigua per a beure $(572,573)$. La meva mare en bevia perquè era diabètica i sempre tenia molta set $(1345,1346)$. DESTINACIÓ. Alimentació humana $(572,573,1345,1346)$.

\section{ALTRES OBSERVACIONS}

FONTS 522, 523, 572, 573. DESCRIPCIÓ FETA PELS INFORMANTS. Fa molta olor i la flor és com un granet, és molt alta $(522,523)$. En teniem a l'hort $(572,573)$.

\section{Chenopodium bonus-henricus L. (quenopodiàcies)}

\section{BCN 27272}

\section{NOMS POPULARS}

Espinac bord (1321)

Sarronets $(554,555,571)$ 
Sarrons $(533,534,541,1321)$

\section{USOS ALIMENTARIS}

Fulla

Ingestió de la part de la planta crua - Fresca (sense preparació)

FONTS 533, 534, 541, 571. DESCRIPCIÓ DE L'ÚS FETA PELS INFORMANTS. Per a amanir $(533,534)$. Se'n feien sopes o no sé si els amanien (541). S'amania (571). amanir $(533,534)$. Se'n feien sopes o no sé si els
DESTINACIÓ. Alimentació humana $(533,534,541,571)$.

Ingestió de la part de la planta cuita - Cuita en aigua

FONTS 541, 554, 555. DESCRIPCIÓ DE L'ÚS FETA PELS INFORMANTS. Se'n feien sopes o no sé si els amanien $(541)$. Per a verdura $(554,555)$. DESTINACIÓ. Alimentació humana $(541,554,555)$.

Ingestió de la part de la planta cuita - Cuita en llet

FONT 1321. DESCRIPCIÓ DE L'ÚS FETA PER L'INFORMANT. Els pastors en menjaven bullits amb llet. DESTINACIÓ. Alimentació humana.

\section{ALTRES OBSERVACIONS}

FONT 571. DESCRIPCIÓ FETA PER L'INFORMANT. Es fan a les jaces del bestiar.

\section{Cicer arietinum L. (papilionàcies)}

BCN 29659

\section{NOMS POPULARS}

Cigró (llavor) (517)

\section{USOS MEDICINALS}

Llavor

Litotríptic renal

FONT 517. DESCRIPCIÓ DE L'ÚS FETA PER L'INFORMANT. Va bé per a la gent que té pedres. FORMA FARMACĖUTICA I ÚS. Macerat en aigua (ús intern). PREPARACIÓ. Agafes cigrons en nombre senar i els poses a estovar tota la nit i l'endemà et beus l'aigua. DESTINACIO. Medicina humana.

\section{Cichorium endivia L. (compostes)}

BCN 46854

\section{NOMS POPULARS}

Endívia (1335)

Escarola $(505,506,746)$

\section{USOS MEDICINALS}

Fulla

Hipoglucemiant

FONT 1335. DESCRIPCIÓ DE L'ÚS FETA PER L'INFORMANT. Per a fer baixar el sucre. FORMA FARMACĖUTICA I ÚS. Tisana (ús intern). PREPARACIÓ. Decocció. Aigua de les fulles. DESTINACIÓ. Medicina humana.

\section{USOS ALIMENTARIS}

Fulla

Ingestió de la part de la planta crua - Fresca (sense preparació)

FONTS 505, 506, 746. DESCRIPCIÓ DE L'ÚS FETA PELS INFORMANTS. En menjàvem tot l'any, les tapàvem amb la rama de les mongeteres perquè no es glacessin (746). Per a amanir $(505,506)$. DESTINACIÓ. Alimentació humana $(505,506,746)$.

\section{Cichorium intybus L. (compostes)}

BCN 29660

\section{NOMS POPULARS}

Endívia $(525,526,527)$

Raditxa $(572,573)$

Xicoia $(520,521)$

\section{USOS ALIMENTARIS}

Fulla

Ingestió de la part de la planta crua - Fresca (sense preparació)

FONTS 520, 521, 525, 526, 527, 572, 573. DESCRIPCIÓ DE L'ÚS FETA PELS INFORMANTS. Per a amanir $(525,526,527,572,573)$. Les fulles es menjaven amanides $(520,521)$. OBSERVACIONS. Un noi que va venir de turisme rural, ens ho va dir, això, que es menjaven amanides, no ho sabiem pas nosaltres $(520,521)$. DESTINACIÓ. Alimentació humana $(520,521,525,526,527,572,573)$.

\section{ALTRES OBSERVACIONS}


FONTS 520, 521, 572, 573. DESCRIPCIÓ FETA PELS INFORMANTS. Van venir amb la sorra, abans no n'hi havia $(520,521)$. Es fan en llocs on s'havia sembrat blat per segar i fa una flor blava, sembla com una escarola espigada. És semblant a la xicoia però la fulla més estreta $(572,573)$.

\section{Cinnamomum zeylanicum Nees (lauràcies)}

BCN-E 62

\section{NOMS POPULARS}

Canyella $(524,1341,1342)$

\section{USOS ALIMENTARIS}

\section{Escorça}

Preparació de begudes - Beguda preparada amb aiguardent

FONTS 524, 1341, 1342. DESCRIPCIÓ DE L'ÚS FETA PELS INFORMANTS. Per a fer ratafia, es confita llor (Laurus nobilis), romaní (Rosmarinus officinalis), nous (Juglans regia) granes de ginebró (Juniperus communis), camamilla (Achillea ptarmica subsp. pyrenaica) ortigues (Urtica dioica), pela de taronja (Citrus sinensis), pela de llimona (Citrus limon), canyella (Cinnamomum zeylanicum), marialluïsa (Lippia triphylla), poniol (Satureja calamintha subsp. ascendens), rosa de bosc (Rosa tomentosa) i malva (Malva sylvestris) en aiguardent es deixa 40 dies a sol i a serena, llavors es cola i ja es pot beure $(1341,1342)$. Amb les nous verdes, la mare feia alguna vegada ratafia. Recepta de ratafia: per un litre d'aiguardent $h$ posava tres nous (Juglans regia), una branca de canyella (Cinnamomum zeylanicum), una nou moscada (Myristica fragrans), tarongina (Melissa officinalis), algunes herbes més que no nou amb una garafa de vidre i es deixava a la finesta a sol i verena uns quants dies, no recova amb una garrafa de vidre ies deixava (524). DESTINACIÓ. Alimentació humana $(524,1341$ 1342).

\section{Cirsium arvense (L.) Scop. (compostes)}

BCN 27256

\section{NOMS POPULARS}

Calcida $(503,520,521,571,583,584,585,1353,1354)$

Card $(542,543,544)$

\section{USOS MEDICINALS}

No consta
Antihelmíntic

FONTS 542, 543, 544. DESCRIPCIÓ DE L'ÚS FETA PELS INFORMANTS. Per a matar els cucs. FORMA FARMACĖUTICA I ÚS. Tisana (ús intern). PREPARACIÓ. Decocció. DESTINACIÓ. Medicina humana.

\section{USOS ALIMENTARIS}

\section{Part aèria}

No consta el tipus d'ingesta - No consta el mode de preparació

FONTS 583, 584, 585. DESCRIPCIÓ DE L'ÚS FETA PELS INFORMANTS. Es donaven als porcs. DESTINACIÓ. Alimentació animal.

\section{ALTRES OBSERVACIONS}

FONTS 503, 520, 521, 542, 543, 544, 571, 1353, 1354. DESCRIPCIÓ FETA PELS INFORMANTS. Quan segàvem amb volant et deixaven les mans fetes malbé (571). Sempre $n$ 'hi ha a l'hort i s'han de treure perquè punxen molt (503). Aquells petits que es fan els camps, que són verds $(542,543,544)$. Les havíem d'arrencar del mig del blat $(520,521)$. Són males herbes que surten a l'hort $(1353,1354)$.

\section{Citrus limon (L.) Burm. (rutàcies)}

BCN 27241

\section{NOMS POPULARS}

Llimona (fruit) $(505,506,507,509,510,517,536,537,539,540,545,547,548,1213,1214$, $1320,1324,1327,1330,1335,1336,1341,1342,1353,1354,1352,1361,1362)$

\section{USOS MEDICINALS}

\section{Fruit}

Analgèsic

FONT 517. DESCRIPCIÓ DE L'ÚS FETA PER L'INFORMANT. Calma el dolor quan tens mal d'ossos. FORMA FARMACĖUTICA I ÚS. Sense forma farmacèutica (ús directe, ús extern). PREPARACIÓ. Fregar-se amb una llimona i tot aquell suc que s'empapi. S'ha de fer al sol o a la vora del foc. DESTINACIO. Medicina humana.

Suc del fruit

Antiberrugós

FONT 1320. DESCRIPCIÓ DE L'ÚS FETA PER L'INFORMANT. Suc de llimona per a banyar les berrugues. FORMA FARMACĖUTICA I ÚS. Sense forma farmacèutica (ús directe, ús extern). DESTINACIÓ. Medicina humana. 


\section{Anticatarral}

FONTS 547, 548. DESCRIPCIÓ DE L'ÚS FETA PELS INFORMANTS. Va bé per als constipats de pit. FORMA FARMACĖUTICA I ÚS. Xarop (ús intern). PREPARACIÓ. Faig un xarop de sucre cremat, suc de llimona i conyac cremat. MODE D'UTILITZACIÓ/POSOLOGIA. Ho prenc 3 o 4 dies. DESTINACIÓ. Medicina humana.

Antihelmíntic

FONT 1327. DESCRIPCIÓ DE L'ÚS FETA PER L'INFORMANT. Per als cucs. FORMA FARMACĖUTICA I ÚS. Sense forma farmacèutica (ús directe, ús intern). PREPARACIÓ. Una cullerada de llimona amb sucre i mel. DESTINACIÓ. Medicina humana.

Antiinflamatori faringi

FONTS 547, 548, 1320, 1353, 1354. DESCRIPCIÓ DE L'ÚS FETA PELS INFORMANTS. Per al mal de coll $(547,548,1320,1353,1354)$. FORMA FARMACĖUTICA I ÚS. Gargarisme (ús extern) $(547,548)$. Melit (ús intern) $(1320,1353,1354)$. PREPARACIÓ. Fer gàrgares de suc de llimona i bicarbonat $(547,548)$. Llimona amb mel (1320). Suc de llimona amb mel (1353, 1354). DESTINACIO. Medicina humana.

Antitífic

FONTS 536, 537. DESCRIPCIÓ DE L'ÚS FETA PELS INFORMANTS. Beure aigua amb llimona per a un atac de tifus. FORMA FARMACĖUTICA I ÚS. Desconegut per l'informant. DESTINACIÓ. Medicina humana.

Antitussigen

FONT 1327. DESCRIPCIÓ DE L'ÚS FETA PER L'INFORMANT. Per a quan es té tos FORMA FARMACĖUTICA I ÚS. Sense forma farmacèutica (ús directe, ús intern). PREPARACIÓ. Una cullerada de llimona amb sucre i mel. DESTINACIÓ. Medicina humana.

Hematocatàrtic

FONT 1352. DESCRIPCIÓ DE L'ÚS FETA PER L'INFORMANT. Per a rebaixar la sang FORMA FARMACĖUTICA I ÚS. Sense forma farmacèutica (ús directe, ús intern). MODE D'UTILITZACIÓ/POSOLOGIA. En dejú. EFECTES SECUNDARIS. Sí. DESTINACIÓ. Medicina humana. OBSERVACIONS. No se'n pot abusar perquè debilita.

Hipouricemiant

FONT 1330. DESCRIPCIÓ DE L'ÚS FETA PER L'INFORMANT. Per a l'àcid úric. FORMA FARMACĖUTICA I ÚS. Sense forma farmacèutica (ús directe, ús intern). PREPARACIÓ. Es barreja mitja llimona amb un got d'aigua gros amb mitja cullerada de bicarbonat i sucre. MODE D'UTILITZACIO/POSOLOGIA. Cada dia en dejú. DESTINACIÓ. Medicina humana.

\section{USOS ALIMENTARIS}

Epicarpi

Preparació de begudes - Beguda preparada amb aiguardent

FONTS 1341, 1342. DESCRIPCIÓ DE L'ÚS FETA PELS INFORMANTS. Per a fer ratafia, es confita llor (Laurus nobilis), romaní (Rosmarinus officinalis), nous (Juglans regia), granes de ginebró (Juniperus communis), camamilla (Achillea ptarmica subsp. pyrenaica), ortigues
(Urtica dioica), pela de taronja (Citrus sinensis), pela de llimona (Citrus limon), canyella (Cinnamomum zeylanicum), marialluïsa (Lippia triphylla), poniol (Satureja calamintha subsp. ascendens), rosa de bosc (Rosa tomentosa) i malva (Malva sylvestris) en aiguardent i es deixa 40 dies a sol i a serena, llavors es cola i ja es pot beure. DESTINACIÓ. Alimentació humana.

Fruit

Condiment

FONTS 1353, 1354. DESCRIPCIÓ DE L'ÚS FETA PELS INFORMANTS. Per a posar a la crema. DESTINACIÓ. Alimentació humana.

\section{Suc del fruit}

Condiment

FONTS 505, 506. DESCRIPCIÓ DE L'ÚS FETA PELS INFORMANTS. Per a fer formatges. Per dos litres de llet, el suc de dues llimones. DESTINACIÓ. Alimentació humana.

\section{BARREGES AMB AQUEST TÀXON}

Epicarpi

FONT 1335. Entrevista 15, barreja II (vegeu catàleg de barreges)

FONT 1330. Entrevista 32, barreja I (vegeu catàleg de barreges)

Fruit

FONT 1330. Entrevista 32, barreja III (vegeu catàleg de barreges)

FONTS 507, 509, 510. Entrevista 46 (vegeu catàleg de barreges)

FONTS 539, 540. Entrevista 69 (vegeu catàleg de barreges)

\section{Suc del fruit}

FONTS 1213, 1214. Entrevista 102, barreja III (vegeu catàleg de barreges)

FONT 1336. Entrevista 16, barreja IV (vegeu catàleg de barreges)

FONTS 1361, 1362. Entrevista 29, barreja I (vegeu catàleg de barreges)

FONT 1320. Entrevista 34, barreja I (vegeu catàleg de barreges)

FONT 1320. Entrevista 34, barreja II (vegeu catàleg de barreges)

FONT 1324. Entrevista 5, barreja I (vegeu catàleg de barreges)

FONT 545. Entrevista 72, barreja III (vegeu catàleg de barreges)

\section{Citrus sinensis (L.) Osbeck (rutàcies)}

BCN 24752

\section{NOMS POPULARS}

Taronja (fruit) $(536,537,1320,1335,1341,1342,1361,1362)$ 


\section{USOS MEDICINALS}

Fulla

Cardiotònic

FONT 1335. DESCRIPCIÓ DE L'ÚS FETA PER L'INFORMANT. Diuen que va bé per al cor. FORMA FARMACĖUTICA I ÚS. Tisana (ús intern). PREPARACIÓ. Decocció. Aigua de les fulles. DESTINACIO. Medicina humana. OBSERVACIONS. No l'utilitza.

\section{USOS ALIMENTARIS}

Epicarpi

Preparació de begudes - Beguda preparada amb aiguardent

FONTS 1341, 1342. DESCRIPCIÓ DE L'ÚS FETA PELS INFORMANTS. Per a fer ratafia, es confita llor (Laurus nobilis), romaní (Rosmarinus officinalis), nous (Juglans regia), granes de ginebró (Juniperus communis), camamilla (Achillea ptarmica subsp. pyrenaica), ortigues (Urtica dioica), pela de taronja (Citrus sinensis), pela de llimona (Citrus limon), canyella (Cinnamomum zeylanicum), marialluïsa (Lippia triphylla), poniol (Satureja calamintha subsp. ascendens), rosa de bosc (Rosa tomentosa) i malva (Malva sylvestris) en aiguardent i es deixa 40 dies a sol i a serena, llavors es cola i ja es pot beure. DESTINACIÓ. Alimentació humana.

Fruit

Ingestió de la part de la planta cuita - Cuita sense vehicle

FONTS 536, 537. DESCRIPCIÓ DE L'ÚS FETA PELS INFORMANTS. Es couen taronges amb pela el dia de matar el porc i es mengen amb l'amanida. DESTINACIO. Alimentació humana.

\section{BARREGES AMB AQUEST TÀXON}

Epicarpi

FONT 1335. Entrevista 15, barreja II (vegeu catàleg de barreges)

Suc del fruit

FONTS 1361, 1362. Entrevista 29, barreja I (vegeu catàleg de barreges)

FONT 1320. Entrevista 34, barreja I (vegeu catàleg de barreges)

Clematis flammula L. (ranunculàcies)

BCN 29856

\section{NOMS POPULARS}

Ridorta $(539,540)$

\section{USOS MEDICINALS}

\section{No consta}

Antipirètic

FONTS 539, 540. DESCRIPCIÓ DE L'ÚS FETA PELS INFORMANTS. Fa suar i fa baixar la febre. FORMA FARMACÉUTICA I ÚS. Tisana (ús intern). PREPARACIÓ. Decocció. DESTINACIO. Medicina humana.

\section{Clematis vitalba L. (ranunculàcies)}

\section{BCN 109187}

\section{NOMS POPULARS}

Ridorta $(511,512,513,514,528,541,553,564,565,566,574,575,576,577,583,584,585$ 590)

\section{USOS MEDICINALS}

Flor

Desconegut per l'informan

FONTS 511, 512, 513, 514. FORMA FARMACĖUTICA I ÚS. Desconegut per l'informant. OBSERVACIONS. La flor és bona, però no recordo perquè.

\section{USOS ALIMENTARIS}

\section{Part aèria}

Ingestió de la part de la planta crua - Fresca (sense preparació)

FONTS 565, 566, 574, 575, 576, 577, 590. DESCRIPCIÓ DE L'ÚS FETA PELS INFORMANTS. La donàvem als xais per a engreixar-los, els anava molt bé $(565,566)$. Es
donaven als conills $(590)$. Per als conills $(574,575,576,577)$. DESTINACIÓ. Alimentació donaven als conills $(590)$. Per als conills
animal $(565,566,574,575,576,577,590)$

\section{ALTRES USOS}

Tija

Planta fumable

FONTS 528, 541, 583, 584, 585. DESCRIPCIÓ DE L'ÚS FETA PELS INFORMANTS. Es fumava el tronc (528). Abans es fumava el tronc sec $(583,584,585)$.

Coffea arabica L. (rubiàcies) 
Apèndix 1. Catàleg de tàxons.

BCN-E 65

\section{NOMS POPULARS}

Cafè (llavor) $(536,537,547,548,1353,1354)$

\section{USOS MEDICINALS}

\section{Llavo}

Antiodontàlgic

FONTS 536, 537. DESCRIPCIÓ DE L'ÚS FETA PELS INFORMANTS. Per al mal de queixals. FORMA FARMACĖUTICA I ÚS. Fumigació (ús extern). PREPARACIÓ. Perfums de cafè al foc. DESTINACIÓ. Medicina humana.

Tònic

FONTS 1353, 1354. DESCRIPCIÓ DE L'ÚS FETA PELS INFORMANTS. Quan érem petits estàvem decaiguts, sense gana, ens donaven un "bullon". FORMA FARMACĖUTICA I ÚS Sense forma farmacèutica (ús directe, ús intern). PREPARACIÓ. Rovell d'ou amb sucre cafè. DESTINACIÓ. Medicina humana.

\section{USOS ALIMENTARIS}

Llavor

Preparació de begudes - Beguda preparada amb aigua

FONTS 547, 548. DESCRIPCIÓ DE L'ÚS FETA PELS INFORMANTS. Per a fer passar la set: cafè i vi o cafè i gasosa [dit "graciosa"]. La mare en deia un soldat, de la gasosa amb cafe. DESTINACIO. Alimentació humana.

\section{Conium maculatum L. (umbel·líferes)}

BCN 32171

\section{NOMS POPULARS}

Cicuta $(507,509,510,522,523,525,526,527,542,543,544,568,569,570,583,584,585$ $591,592,748,749,1324)$

Julivertassa $(1310,1324)$

\section{USOS MEDICINALS}

\section{Arrel}

Resolutiu
FONTS 583, 584, 585. DESCRIPCIÓ DE L'ÚS FETA PELS INFORMANTS. Per a rebentar grans dolents. FORMA FARMACĖUTICA I ÚS. Embrocació (ús extern). PREPARACIÓ. Es feia un oli de la rel. DESTINACIÓ. Medicina veterinària.

\section{Fulla}

Resolutiu

FONTS 583, 584, 585. DESCRIPCIÓ DE L'ÚS FETA PELS INFORMANTS. Per a rebentar grans dolents. FORMA FARMACĖUTICA I ÚS. Emplastre (ús extern). PREPARACIÓ. Amb les fulles es feien emplastres. DESTINACIÓ. Medicina veterinària.

\section{Part aèria}

Antiequimòtic

FONTS 522, 523, 591, 592, 748, 749. DESCRIPCIÓ DE L'ÚS FETA PELS INFORMANTS. La va fer servir per a un truc que tenia en un genoll $(748,749)$. Per als trucs $(522,523)$. Es feia servir per als trucs $(591,592)$. FORMA FARMACEUTICA I US. Emplastre (ús extern) $(522$ $523,748,749)$. Liniment (ús extern) $(591,592)$. PREPARACIO. Emplastres per a trucs, ben Q planta en oli $(591,592)$. DESTINACIO. Medicina humana.

Antiofídic

FONTS 591, 592. DESCRIPCIÓ DE L'ÚS FETA PELS INFORMANTS. Es feia servir quan et pessigava un escurçó. FORMA FARMACĖUTICA I ÚS. Embrocació (ús extern) PREPARACIÓ. Es posava la planta en oli. DESTINACIÓ. Medicina humana

Resolutiu

FONTS 507, 509, 510. DESCRIPCIÓ DE L'ÚS FETA PELS INFORMANTS. Es posava als bultos $\mathrm{i}$ als mals que no tinguessin ferida. FORMA FARMACĖUTICA I ÚS. Liniment (ús extern). PREPARACIÓ. Se'n feia oli. DESTINACIÓ. Medicina humana.

\section{USOS ALIMENTARIS}

Part aèria

Ingestió de la part de la planta crua - Fresca (sense preparació)

FONTS 507, 509, 510. DESCRIPCIÓ DE L'ÚS FETA PELS INFORMANTS. Les vaques se la mengen, això que diuen que és tòxica. DESTINACIÓ. Alimentació animal.

\section{ACCIONS NOCIVES O TÒXIQUES}

\section{No consta}

FONTS $507,509,510,525,526,527,542,543,544,568,569, \quad 570,1310,1324$ DESCRIPCIÓ DE L'ACCIÓ NOCIVA O TOOXICA FETA PELS INFORMANTS. Diuen que és tòxica, però les vaques en menjaven i no els hi feia res $(507,509,510)$. És verinosa $(525$, $526,527)$. El bestiar no se la menja $(542,543,544)$. És tòxica. De tota manera no ho deu ser molt perquè en vaig fer aigua per un gos malalt que volia que es morís i no li va passar res molt perque en vaig fer aigua per un gos malalt que volia que es moris i no li va passar res
(568). És toxica $(569,570,1324)$. Quan es donava herbes als porcs es procurava que no n'hi hagués cap (1310). TOXICITAT LLIGADA A L'ÚS MEDICINAL. No $(507,509,510)$. Sí $(542$, 
543, 544). TOXICITAT EN ANIMALS. No $(507,509,510)$. Sí (568). OBSERVACIONS. Però se'n feia medicina $(542,543,544)$. Sap que hi ha gent que en fa pomada, però ella no ho faria, té molt de respecte per a les plantes tòxiques (1324).

\section{ALTRES OBSERVACIONS}

FONTS 507, 509, 510, 522, 523, 748, 749. DESCRIPCIÓ FETA PELS INFORMANTS. Es feia a les vores de l'hort, aquí a casa n'hi havia i ara no n'hi ha. A la Ginebrosa diu que n'hi ha $(507,509,510)$. Té la grana molt semblant al fonoll (Foeniculum vulgare) $(507,509,510)$. És una planta semblant a la julivertassa (Aethusa cynapium) $(748,749)$. És com una julivertassa (Aethusa cynapium), però més grossa $(522,523)$.

\section{Convolvulus arvensis L. (convolvulàcies) BCN 24753}

\section{NOMS POPULARS}

Corretjola $(520,521,528,541,553,564,569,570,582,583,584,585,586,587,588,1324)$

\section{USOS MEDICINALS}

\section{Part aèria}

Purgant

FONT 553. DESCRIPCIÓ DE L'ÚS FETA PER L'INFORMANT. Per a fer una purga. FORMA FARMACĖUTICA I ÚS. Tisana (ús intern). PREPARACIÓ. Decocció. DESTINACIÓ. Medicina humana.

\section{USOS ALIMENTARIS}

Part aèria

Ingestió de la part de la planta crua - Fresca (sense preparació)

FONTS 520, 521, 528, 541, 564, 569, 570, 583, 584, 585, 588, 1324. DESCRIPCIÓ DE L'ÚS FETA PELS INFORMANTS. Per a donar als conills (528). Es donaven als conills (541). Ens ho feien collir per a donar als conills $(520,521)$. Per als conills $(564,569,570,588)$. Es cullen $i$ es donen als conills $(583,584,585)$. Són bones per a menjar (1324). DESTINACIÓ Alimentació animal $(520,521,528,541,564,569,570,583,584,585,588)$. Alimentació humana (1324)

\section{ALTRES OBSERVACIONS}

FONTS 582, 586, 587. DESCRIPCIÓ FETA PELS INFORMANTS. S'enfilen a les patates de l'hort (582). Surten a l'hort i als marges $(586,587)$.

\section{Coriaria myrtifolia L. (coriariàcies)}

BCN 24754

\section{NOMS POPULARS}

Emborratxacabres $(520,521,1324)$

Roldor $(520,521,564,578,579,1324)$

\section{USOS ALIMENTARIS}

Fruit

Ingestió de la part de la planta crua - Fresca (sense preparació)

FONTS 520, 521. DESCRIPCIÓ DE L'ÚS FETA PELS INFORMANTS. Les cabres en menjaven i quedaven emborratxades. DESTINACIO. Alimentació animal.

\section{ALTRES USOS}

\section{Folíol}

Creences i pràctiques magicoreligioses

FONT 564. DESCRIPCIÓ DE L'ÚS FETA PER L'INFORMANT. Esmicolats per a fer la part verda de les catifes [dit "alfombres"] de Corpus.

\section{ACCIONS NOCIVES O TÒXIQUES}

Fruit

FONTS 520, 521. DESCRIPCIÓ DE L'ACCIÓ NOCIVA O TÒXICA FETA PELS INFORMANTS. És molt tòxica (520). És tòxica (521). VIA D'INTOXICACIÓ. Via interna (520 521). TOXICITAT EN ANIMALS. Sí (520, 521). OBSERVACIONS. Les cabres en menjaven quedaven emborratxades $(520,521)$.

No consta

FONTS 578, 579. DESCRIPCIÓ DE L'ACCIÓ NOCIVA O TÒXICA FETA PELS INFORMANTS. És tòxic, si les cabres en mengen queden emborratxades. VIA D'INTOXICACIO. Via interna. TOXICITAT EN ANIMALS. Si.

\section{Corylus avellana L. (betulàcies)}

\section{BCN 24755}

\section{NOMS POPULARS}

Avellaner (564, 567, 583, 584, 585, 589, 1215, 1321, 1324) 


\section{USOS MEDICINALS}

\section{Inflorescència}

Antipirètic

FONT 1324. DESCRIPCIÓ DE L'ÚS FETA PER L'INFORMANT. Les arracades són bones per a la febre. FORMA FARMACĖUTICA I ÚS. Tisana (ús intern). PREPARACIÓ. Decocció. DESTINACIÓ. Medicina humana.

\section{USOS ALIMENTARIS}

\section{Fruit}

Ingestió de la part de la planta cuita - Cuita sense vehicle

FONTS 564, 567. DESCRIPCIÓ DE L'ÚS FETA PELS INFORMANTS. Ens mengem les avellanes (564). DESTINACIÓ. Alimentació humana $(564,567)$.

\section{Part aèria}

Ingestió de la part de la planta crua - Fresca (sense preparació)

FONTS 583, 584, 585. DESCRIPCIÓ DE L'ÚS FETA PELS INFORMANTS. La rama també es donava a les cabres i als cabrits, però diuen que no és tan saludable. DESTINACIÓ. Alimentació animal.

\section{ALTRES USOS}

Tija

Maneig agrosilvopastoral: ús hortícola/agrícola

FONT 1215. DESCRIPCIÓ DE L'ÚS FETA PER L'INFORMANT. Per als aspres de les mongeteres.

\section{ALTRES OBSERVACIONS}

FONTS 567, 1321. DESCRIPCIÓ FETA PELS INFORMANTS. N'hi havia (567). A cada Mare de Déu fa unes arracades (1321)

\section{Crataegus monogyna Jacq. subsp. monogyna (rosàcies)}

BCN 24756

\section{NOMS POPULARS}

Arç $(504,517,542,543,544,581,589,747,1300)$

Arç blanc $(507,509,510,515,516,520,521,525,526,527,529,530,531,532,535,539$ $540,541,545,549,553,554,555,559,561,562,563,564,578,579,590,591,592,746$ $753,754,755,1215,1293,1294,1296,1297,1299,1313,1314,1315,1316,1320,1325$,
$1326,1327,1330,1332,1333,1334,1335,1336,1341,1342,1343,1344,1347,1348,1349$, 1361,1362

Arç broaller $(574,575,576,577)$

Badull (564)

Cirereta de pastor (fruit) $(541,574,575,576,577)$

\section{USOS MEDICINALS}

\section{Flor}

Antihipertensiu

FONTS 520, 521, 529, 530, 531, 554, 555, 564, 578, 579, 591, 592, 746, 747, 1293, 1296 1297, 1299, 1300, 1315, 1316, 1325, 1326, 1327, 1330, 1332, 1333, 1334, 1335, 1361, 1362 DESCRIPCIÓ DE L'ÚS FETA PELS INFORMANTS. Per a fer baixar la pressió $(520,521$ $578,579,591,592,746,747,1300,1315,1316,1327,1335,1361,1362)$. La flor per al cor $\mathrm{i}$ per a la pressió $(529,530,531)$. Per a la sang, rebaixa la sang, l'aclareix $(554,555)$. Per a regular la pressió $(564,1296,1325,1326)$. Per a la pressió $(1293,1297)$. Quan tens la pressió descompensada (1299). Equilibra la pressió (1330). Per a regular la sang (1332 $1333,1334)$. FORMA FARMACĖUTICA I ÚS. Tisana (ús intern) $(520,521,529,530,531$ $554,555,578,579,591,592,746,747,1293,1296,1297,1299,1300,1315,1316,1325$ $1326,1327,1330,1332,1333,1334,1335,1361,1362)$ Tintura alcohòlica (ús intern) (564). PREPARACIÓ. Decció $(520,521,529,530,531,578,579,591,592,746,747,1293$ $1297,1315,1316,1325,1326,1330)$. Decocció Aigua de la flor, ha de $592,746,747,1293$, $1297,1315,1316,1325,1326,1330)$. Decoccio. Algua de la flor, ha de ser just abans que la flor exploti $(554,555)$. En faig esperit (564). Infusio de for d'arç (1296). Decocció. Aigua de les flors (1299). La flor en infusió $(1300,1332,1333,1334,1335)$. Decocció. Aigua de la flor (1327). Infusió de les flors $(1361,1362)$. DESTINACIÓ. Medicina humana.

Antiinflamatori faring

FONT 1313. DESCRIPCIÓ DE L'ÚS FETA PER L'INFORMANT. Per al mal de coll. FORMA FARMACĖUTICA I ÚS. Tisana (ús intern). DESTINACIÓ. Medicina humana.

Antiinflamatori hepàtic

FONTS 515, 516. DESCRIPCIÓ DE L'ÚS FETA PELS INFORMANTS. Les boles (fruit) i les flors van bé per a les infeccions al fetge. FORMA FARMACĖUTICA I ÚS. Tisana (ús intern). PREPARACIÓ. Decocció. DESTINACIÓ. Medicina humana.

Cardiotònic

FONTS 504, 507, 509, 510, 529, 530, 531, 532, 545, 553, 581, 753, 754, 755, 1330, 1336 1341,1342 . DESCRIPCIÓ DE L'ÚS FETA PELS INFORMANTS. Va bé per al cor $(504,545$, $753,754,755,1330,1336,1341,1342)$. Aigua de les flors per al cor $(507,509,510)$. La flor per al cor i per a la pressió $(529,530,531)$. És molt bo per al cor (532) Per a prevenir l'angina de pit (553). És bona per al cor (581). FORMA FARMACĖUTICA I ÚS. Tisana (ús intern). PREPARACIÓ. Decocció $(504,507,509,510,529,530,531,553,1330)$. Decocció Tant la flor com la cirereta de pastor (532). Decocció. Aigua de flors i fulles (545). Decocció Aigua de les flors $(753,754,755)$. La flor en infusió $(581,1336)$. Decocció. Aigua de la flor 
Apèndix 1. Catàleg de tàxons.

(1341, 1342). MODE D'UTILITZACIÓ/POSOLOGIA. Només novenes, perquè és forta (545). DESTINACIÓ. Medicina humana.

Desconegut per l'informant

FONTS 525, 526, 527. FORMA FARMACĖUTICA I ÚS. Desconegut per l'informant. OBSERVACIONS. La flor és medicinal.

Hematocatàrtic

FONTS 517, 539, 540, 559. DESCRIPCIÓ DE L'ÚS FETA PELS INFORMANTS. Per a netejar les sangs (517). Va bé per a depurar la sang. Li costa molt de fer efecte, però quan en fa, en fa molt $(539,540)$. La flor és purificant de la sang (559). FORMA FARMACEUUTICA ÚS. Tisana (ús intern). PREPARACIÓ. Decocció $(517,539,540,559)$. DESTINACIÓ. Medicina humana.

Hipnòtic

FONTS 1294, 1335. DESCRIPCIÓ DE L'ÚS FETA PELS INFORMANTS. L'ajuda a dormir (1294). Va bé per a dormir quan estàs nerviós (1335). FORMA FARMACE்UTICA I ÚS. Tisana (ús intern). PREPARACIÓ. Utilitza la flor en infusió (1294) La flor en infusió (1335). pot abusar gaire perquè fa baixar molt la pressió (1294).

Hipolipemiant

FONTS 590, 1320. DESCRIPCIÓ DE L'ÚS FETA PELS INFORMANTS. Va molt bé per al colesterol (590). Per a fer baixar el colesterol (1320). FORMA FARMACĖUTICA I ÚS. Tisana (ús intern). PREPARACIÓ. Decocció (590). Decocció. Aigua de les flors (1320). DESTINACIÓ. Medicina humana.

Tranquil·litzant

FONT 504. DESCRIPCIÓ DE L'ÚS FETA PER L'INFORMANT. Per a relaxar. FORMA FARMACĖUTICA I ÚS. Tisana (ús intern). PREPARACIÓ. Decocció.

Vasotònic

FONTS 535, 561, 562, 563, 574, 575, 576, 577. DESCRIPCIÓ DE L'ÚS FETA PELS INFORMANTS. Va bé per a la circulació $(535)$. La flor és bona per a la circulació $(561,562)$. Per a la circulació (563). És bona per a la circulació $(574,575,576,577)$. FORMA FARMACĖUTICA I ÚS. Tisana (ús intern). PREPARACIÓ. Decocció (535, 561, 562, 563, $574,575,576,577)$. DESTINACIÓ. Medicina humana. OBSERVACIONS. Les punxes són $574,575,576,577)$. DESTINACIO.
molt dolentes $(574,575,576,577)$.

Fruit

Antihipertensiu

FONTS 542, 543, 544. DESCRIPCIÓ DE L'ÚS FETA PELS INFORMANTS. Fa aquelles cireretes de pastor que van bé per a fer baixar la pressió. FORMA FARMACEUTICA I ÚS. Tisana (ús intern). PREPARACIO. Decocció. DESTINACIO. Medicina humana.

Antiinflamatori hepàtic

FONTS 515, 516, 529, 530, 531, 1293, 1327. DESCRIPCIÓ DE L'ÚS FETA PELS INFORMANTS. Les boles (fruit) i les flors van bé per a les infeccions al fetge $(515,516)$. Les cireretes van bé per a l'hepatitis $(529,530,531)$. Amb la grana, que se'n diu pa de pastor, la ont abans s'hi currava les espitlles (1203). Per a Amb litis (1327). FORMA FARMACEUTICA

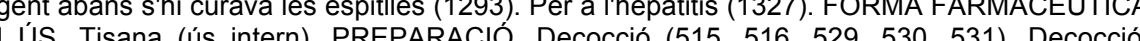
IUS. Tisana (ús intern). PREPARACIO. Decocció (515, Aquesta grana es posa a bullir en aigua i es va bevent (1293). Decocció de les granes (1327). DESTINACIÓ. Medicina humana.

Cardiotònic

FONT 532. DESCRIPCIÓ DE L'ÚS FETA PER L'INFORMANT. És molt bo per al cor FORMA FARMACĖUTICA I ÚS. Tisana (ús intern). PREPARACIÓ. Decocció. Tant la flor com la cirereta de pastor. DESTINACIÓ. Medicina humana.

Hepatoprotector

FONTS 507, 509, 510, 564. DESCRIPCIÓ DE L'ÚS FETA PELS INFORMANTS. Aiqua de la grana per al fetge $(507,509,510)$. Per al fetge i segons quina hepatitis te la pots curar (564). GORMA FARMACÉUTICA I Ús. Tisana (ús intern) $(507,509,510)$. Tintura alcohòlica (ús intern) (564). PREPARACIÓ. Decocció $(507,509,510)$. Dels "balduis" (boletes vermelles) de l'arç també en faig esperit (564). DESTINACIÓ. Medicina humana.

Fulla

Cardiotònic

FONT 545. DESCRIPCIÓ DE L'ÚS FETA PER L'INFORMANT. Va bé per al cor. FORMA FARMACĖUTICA I ÚS. Tisana (ús intern). PREPARACIÓ. Decocció. Aigua de flors i fulles MODE D'UTILITZACIO/POSOLOGIA. Només novenes, perquè és forta. DESTINACIÓ. Medicina humana.

\section{No consta}

Desconegut per l'informant

FONTS 1343, 1344. FORMA FARMACĖUTICA I ÚS. Desconegut per l'informant. DESTINACIÓ. Medicina humana. OBSERVACIONS. L'utilitzava amb altres herbes, però no ho recorda.

\section{Part aèria}

Antiofídic

FONTS 1347, 1348, 1349. DESCRIPCIÓ DE L'ÚS FETA PELS INFORMANTS. Si et pessiga un escurçó, t'has de punxar amb punxes de l'arç, és un contraverí. FORMA FARMACEUUTICA I ÚS. Sense forma farmacèutica (ús directe, ús extern). DESTINACIÓ. Medicina humana.

\section{USOS ALIMENTARIS}

Fruit

Ingestió de la part de la planta crua - Fresca (sense preparació)

FONT 532. DESCRIPCIÓ DE L'ÚS FETA PER L'INFORMANT. La cirereta de pastor es menja, quan érem canalla sempre en buscàvem. DESTINACIÓ. Alimentació humana.

No consta

No consta el tipus d'ingesta - No consta el mode de preparació 
FONT 564. DESCRIPCIÓ DE L'ÚS FETA PER L'INFORMANT. Els porcs se'Is menjaven molt bé, i tots els animals. DESTINACIÓ. Alimentació animal.

\section{ALTRES USOS}

Cendra

Domèstic: ajudes a la llar

FONT 1215. DESCRIPCIÓ DE L'ÚS FETA PER L'INFORMANT. Per a fer lleixiu. Es feia bullir les cendres blanques d'alzina, arç blanc o fins i tot olivera $i$ aquesta aigua es colava mantinguda calenta s'anava abocant en un cossi ple de roba que duia un forat el fons per on s'anava escolant l'aigua més freda del fons. Per a evitar impureses es posava un llençol de fil al damunt de la roba.

\section{Part aèria florida}

Ornamental: elaboració de rams

FONT 549. DESCRIPCIÓ DE L'ÚS FETA PER L'INFORMANT. Per l'olor que fan a vegades en fèiem rams, però punxa molt.

\section{ALTRES OBSERVACIONS}

FONT 589. DESCRIPCIÓ FETA PER L'INFORMANT. Aquí n'hi ha molts.

\section{BARREGES AMB AQUEST TÀXON}

Flor

FONT 1314. Entrevista 17, barreja II (vegeu catàleg de barreges)

FONTS 1343, 1344. Entrevista 23, barreja III (vegeu catàleg de barreges)

\section{Crepis vesicaria L. (compostes)}

BCN 29719

\section{NOMS POPULARS}

Raditxa $(511,512,513,514,528,529,530,531,554,555,559,574,575,576,577,583,584$ $585,748,749)$

\section{USOS ALIMENTARIS}

\section{Fulla}

Ingestió de la part de la planta crua - Fresca (sense preparació)

FONTS 511, 512, 513, 514, 528, 529, 530, 531, 554, 555, 559, 574, 575, 576, 577, 583, 584 $585,748,749$. DESCRIPCIÓ DE L'ÚS FETA PELS INFORMANTS. Es menjava amanit (528).
Per a amanir $(559,583,584,585)$. Amanides $(554,555)$. Es mengen amanides $(511,512$, $513,514)$. Es menjaven amanits a la primavera $(529,530,531)$. Són bones amanides $(574$ $575,576,577)$. CONSUMICIÓ. Entrant - Amanida (555). DESTINACIÓ. Alimentació humana $(511,512,513,514,528,529,530,531,554,555,559,574,575,576,577,583,584,585$, $(511,512$,
$748,749)$.

\section{ALTRES OBSERVACIONS}

FONTS 511, 512, 513, 514, 528, 529, 530, 531, 554, 555, 559, 574, 575, 576, 577, 583, 584, $585,748,749$. DESCRIPCIÓ FETA PELS INFORMANTS. Surten pels camps sembrats de blat, es mengen amanides, això era boníssim. Es un símil de les xicoies (Taraxacum dissectum), però puja alta i s'espiga, seria com un enciam que s'espiga $(748,749)$. Es feia en els camps de blat i és un simil a la xicoia (Taraxacum dissectum), però s'espiga (528). Es fan en els camps de blat (559). Es feien al mig dels camps de blat $(554,555)$. Es fan als camps de blat i són semblants a les xicoines (Taraxacum dissectum), però les fulles més amarronad $(511,512,513,514)$. Es feien als camps de blat ( del blat $(583,584,585)$. Es fan al blat $(574,575,576,577)$.

\section{Crocus sativus L. (iridàcies)}

BCN 32170

\section{NOMS POPULARS}

Safrà $(561,562,563,580,1352)$

\section{USOS ALIMENTARIS}

\section{Estils i estigmes}

Condiment

FONTS 561, 562, 563, 580, 1352. DESCRIPCIÓ DE L'ÚS FETA PELS INFORMANTS. Per a posar a l'arròs $(561,562,563)$. Per a guisar $(580)$. La meva padrina l'usava per a cuinar, els seus menjars eren molt especiats i molt bons (1352). DESTINACIÓ. Alimentació humana $(561,562,563,580,1352)$

\section{ALTRES OBSERVACIONS}

FONTS 561, 562, 563, 580. DESCRIPCIÓ FETA PELS INFORMANTS. A Can Puntí n'hi tenien $(561,562,563)$. Fa la flor a la tardor $(580)$.

\section{Cucumis sativus L. (cucurbitàcies)}

BCN 46850 


\section{NOMS POPULARS}

Pepino (castellà) (fruit) $(746,1321,1353,1354)$

\section{USOS ALIMENTARIS}

\section{Fruit}

Ingestió de la part de la planta crua - Fresca (sense preparació)

FONTS 1353, 1354. DESCRIPCIÓ DE L'ÚS FETA PELS INFORMANTS. En té a l'hort i es menja amanit. DESTINACIÓ. Alimentació humana.

\section{No consta}

Preparació de begudes - Beguda preparada amb licor

FONT 1321. DESCRIPCIÓ DE L'ÚS FETA PER L'INFORMANT. Es posa el brot on ha de sortir el cogombre [dit "pepino"] a dintre una ampolla amb aigua i aquest va creixent, llavors s'emplena d'anís i es pren com a licor. DESTINACIÓ. Alimentació humana.

\section{BARREGES AMB AQUEST TÀXON}

Fruit

FONT 746. Entrevista 45, barreja III (vegeu catàleg de barreges)

\section{Cucurbita ficifolia C.D.Bouché in Verh. (cucurbitàcies)} BCN 29980

\section{NOMS POPULARS}

Carabassa de cabell d'àngel (fruit) $(525,526,527)$

Carbassa (564)

Pastega (fruit) $(525,526,527)$

\section{USOS ALIMENTARIS}

Fruit

Ingestió de la part de la planta cuita - Cuita en sucre

FONTS 525, 526, 527, 564. DESCRIPCIÓ DE L'ÚS FETA PELS INFORMANTS. Carabasses de cabell d'àngel $(525,526,527)$. En faig confitures i quan ja quasi està feta hi tiro sucre cremat i menta (564). DESTINACIÓ. Alimentació humana $(525,526,527,564)$.

\section{Cucurbita pepo L. var. pepo (cucurbitàcies)} BCN 24757

\section{NOMS POPULARS}

Carabassa $(1210,1315,1316,1318,1320,1324,1335)$

Carabassera (1307)

Carbassa $(504,505,506,507,509,510,515,516,518,519,590,1293)$

\section{USOS MEDICINALS}

\section{Endocarpi}

Antisèptic extern

FONT 1318. DESCRIPCIÓ DE L'ÚS FETA PER L'INFORMANT. Serveix per a desinfectar ferides. FORMA FARMACĖUTICA I ÚS. Pomada (ús extern). PREPARACIÓ. La tripa de la carabassa sense granes, bullida amb greix de porc, queda com una pomada. DESTINACIÓ. Medicina humana.

\section{Flor}

\section{Antieczematós}

FONT 1307. DESCRIPCIÓ DE L'ÚS FETA PER L'INFORMANT. Per a l'al-lèrgia que li fan les mitges. FORMA FARMACĖUTICA I ÚS. Pomada (ús extern). DESTINACIÓ. Medicina humana. OBSERVACIONS. Una amiga els dóna aquesta pomada que fa amb la flor de la carabassera i que li va molt bé a la Palmira. No saben com la fa exactament.

Antiequimòtic

FONT 1335. DESCRIPCIÓ DE L'ÚS FETA PER L'INFORMANT. Per als trucs. FORMA FARMACÉUTICA I ÚS. Pomada (ús extern). PREPARACIÓ. Se'n fa una pomada. FARMACEUTICA I ÚS. Pomada

Antihemorroïdal

FONT 1320. DESCRIPCIÓ DE L'ÚS FETA PER L'INFORMANT. Va bé per a tot, per a les morenes. FORMA FARMACÉUTICA I ÚS. Pomada (ús extern). PREPARACIÓ. Es fa bullir en una cassola de terra amb greix de porc, es cola i s'hi afegeix cera verge perquè quedi més compacte. DESTINACIÓ. Medicina humana.

Antiinflamatori intestinal

FONTS 590, 1320. DESCRIPCIÓ DE L'ÚS FETA PELS INFORMANTS. Serveix per a untar mals. La meva tia ho va fer servir per a untar el budell culà d'un nen que li feia molt mal per a anar de ventre (590). Va bé per a tot, per al mal de ventre (t'untes la panxa) (1320). FORMA FARMACĖUTICA I ÚS. Ungüent (ús extern) (590). Pomada (ús extern) (1320). PREPARACIÓ. Els badocs de les carabasses sofregits amb greix (590). Es fa bullir en una cassola de terra amb greix de porc, es cola i s'hi afegeix cera verge perquè quedi més compacte (1320). DESTINACIO. Medicina humana.

Antiofídic

FONT 1324. DESCRIPCIÓ DE L'ÚS FETA PER L'INFORMANT. Per a les pessigades d'escurçó. FORMA FARMACĖUTICA I ÚS. Pomada (ús extern). PREPARACIÓ. Una pomada 
amb greix de porc i cera. DESTINACIÓ. Medicina humana. OBSERVACIONS. Una vegada que la va pessigar un escurçó se n'hi va posar de seguida, li va baixar molt el dolor i també la inflor.

Antipiròtic

FONTS 518, 519, 1315, 1316, 1320. DESCRIPCIÓ DE L'ÚS FETA PELS INFORMANTS. Per a grans, cremades i ferides $(518,519)$. Per a cremades $(1315,1316)$. Va bé per a tot, per a cremades (1320). FORMA FARMACĖUTICA I ÚS. Ungüent (ús extern) $(518,519)$. Pomada (ús extern) $(1315,1316,1320)$. PREPARACIÓ. Es fa un ungüent amb els badocs de les carabasses $(518,519)$. Es fa bullir en una cassola de terra amb greix de porc, es cola i s'hi

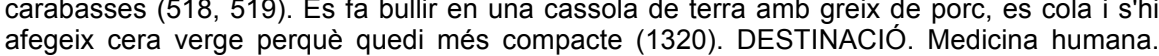
OBSERVACIONS. Tenen una pomada que els ha donat la Paquita $(1315,1316)$.

Per a la mastitis

FONT 590. DESCRIPCIÓ DE L'ÚS FETA PER L'INFORMANT. Serveix per a untar mals. Les vaques quan els feien mal les metes. FORMA FARMACĖUTICA I ÚS. Ungüent (ús extern). PREPARACIÓ. Els badocs de les carabasses sofregits amb greix. DESTINACIÓ. Medicina humana.

Per a les picades

FONTS 1315, 1316, 1320. DESCRIPCIÓ DE L'ÚS FETA PELS INFORMANTS. Per a les picades $(1315,1316)$. Va bé per a tot, per a picades $(1320)$. FORMA FARMACĖUTICA I ÚS Pomada (ús extern). PREPARACIÓ. Es fa bullir en una cassola de terra amb greix de porc es cola i s'hi afegeix cera verge perquè quedi més compacte (1320). DESTINACIÓ. Medicin humana. OBSERVACIONS. Tenen una pomada que els ha donat la Paquita $(1315,1316)$.

Resolutiu

FONTS 518, 519, 1315, 1316, 1320. DESCRIPCIÓ DE L'ÚS FETA PELS INFORMANTS. Per a grans, cremades i ferides $(518,519)$. Per als grans $(1315,1316)$. Va bé per a tot, per als grans de la cara (1320). FORMA FARMACĖUTICA I ÚS. Ungüent (ús extern) $(518,519)$. Pomada (ús extern) $(1315,1316,1320)$. PREPARACIO. Es fa un ungüent amb els badocs de les carabasses $(518,519)$. Es fa bullir en una cassola de terra amb greix de porc, es cola s'hi afegeix cera verge perquè quedi més compacte (1320). DESTINACIO. Medicina humana. OBSERVACIONS. Tenen una pomada que els ha donat la Paquita $(1315,1316)$

Vulnerari

FONTS 518, 519, 1320, 1324. DESCRIPCIÓ DE L'ÚS FETA PELS INFORMANTS. Per a grans, cremades i ferides $(518,519)$. Va bé per a tot, per a talls $(1320)$. Com a desinfectant per a les clivelles [dit "esquebraies"] i per als talls (1324). FORMA FARMACEUTICA I US. Ungüent (ús extern) $(518,519)$. Pomada (ús extern) $(1320,1324)$. PREPARACIO Es fa un ungüent amb els badocs de les carabasses $(518,519)$. Es fa bullir en una cas amb greix de porc es cola i s'hi a pomada amb greix de porc i cera (1324). DESTINACIÓ. Medicina humana.

\section{Llavor}

Antihelmíntic
FONT 1210. DESCRIPCIÓ DE L'ÚS FETA PER L'INFORMANT. Per als cucs dels nens. FORMA FARMACĖUTICA I ÚS. Tisana (ús intern). PREPARACIÓ. Decocció. Cal bullir granes de carabassa seques i prendre l'aigua. MODE D'UTILITZACIÓ/POSOLOGIA. S'ha de granes de carabassa seques i prendre l'aigua. MODE DU DESTINACIÓ. Medicina humana. OBSERVACIONS. Li va dir la Maria del Mas Ventós. Antiprostatític

FONTS 507, 509, 510. DESCRIPCIÓ DE L'ÚS FETA PELS INFORMANTS. Les granes en aigua van bé per a la pròstata. FORMA FARMACĖUTICA I ÚS. Tisana (ús intern). PREPARACIÓ. Decocció. DESTINACIÓ. Medicina humana.

\section{USOS ALIMENTARIS}

Fruit

Ingestió de la part de la planta cuita - Cuita en aigua

FONTS 504, 515, 516. DESCRIPCIÓ DE L'ÚS FETA PELS INFORMANTS. Per a fer caldo (504). Per a menjar $(515,516)$. DESTINACIÓ. Alimentació humana $(504,515,516)$.

\section{BARREGES AMB AQUEST TÀXON}

\section{Flor}

FONT 1293. Entrevista 2, barreja I (vegeu catàleg de barreges)

Fruit

FONTS 505, 506. Entrevista 47, barreja I (vegeu catàleg de barreges)

\section{Cucurbita pepo L. var. oblonga Link (cucurbitàcies)}

\section{BCN 29859}

\section{NOMS POPULARS}

Carabassó (1215)

Carbassó $(565,566,582,746)$

\section{USOS ALIMENTARIS}

Flor

Ingestió de la part de la planta cuita - Cuita en oli

FONTS 565, 566. DESCRIPCIÓ DE L'ÚS FETA PELS INFORMANTS. Els badocs, la flor mascle, la que no fa carabassó, arrebossat amb ou i farina i una mica de llimona ratllada, llavors una mica de sucre o mel i són unes postres delicioses. Si ho vols fer per a acompanyar carn ho fas igual, pero amb sal. DESTINACIO. Alimentació humana. 


\section{ALTRES USOS}

Flor

Cosmètic

FONT 582. DESCRIPCIÓ DE L'ÚS FETA PER L'INFORMANT. La flor bullida en oli va molt bé per a la pell.

\section{ALTRES OBSERVACIONS}

FONT 1215. DESCRIPCIÓ FETA PER L'INFORMANT. Els xucladors de carabassons són lladres, són els que no fan carabassons.

\section{BARREGES AMB AQUEST TÀXON}

Fruit

FONT 746. Entrevista 45, barreja III (vegeu catàleg de barreges)

\section{Cupressus sempervirens L. (cupressàcies)}

BCN 35770

\section{NOMS POPULARS}

Xiprer (560)

\section{ALTRES USOS}

\section{Planta viva ex situ}

Creences i pràctiques magicoreligioses

FONT 560. DESCRIPCIÓ DE L'ÚS FETA PER L'INFORMANT. En plantaven en els cementiris. A les cases no n'hi havia. A can Batlle si que n'hi ha un, no sé perquè es plantava. En el cementiri vell n'hi havia dos o tres de molt grossos, però els van tallar quan ho van arreglar.

\section{Cuscuta epithymum (L.) L. (convolvulàcies)}

\section{BCN 112569}

\section{NOMS POPULARS}

Tinya (553)

\section{ALTRES USOS}

\section{Planta sencera}

Literatura oral popular: llegendes, gloses, contes, dites, refranys, poemes, cançons

FONT 553. DESCRIPCIÓ DE L'ÚS FETA PER L'INFORMANT. "És més dolent que la tinya".

\section{ALTRES OBSERVACIONS}

FONT 553. DESCRIPCIÓ FETA PER L'INFORMANT. La tinya es posa als camps i no deixa créixer res més.

\section{Cydonia oblonga Mill. (rosàcies)}

\section{BCN 24758}

\section{NOMS POPULARS}

Codony (fruit) $(561,562,563,589,1327,1353,1354,1352)$

Codonyer $(560,572,573)$

\section{USOS MEDICINALS}

\section{Fruit}

Antinauseabund

FONT 1327. DESCRIPCIÓ DE L'ÚS FETA PER L'INFORMANT. Per al mareig. FORMA FARMACĖUTICA I ÚS. Tintura alcohòlica (ús intern). PREPARACIÓ. Confitat en aiguardent. DESTINACIO. Medicina humana.

\section{USOS ALIMENTARIS}

Fruit

Ingestió de la part de la planta cuita - Cuita en sucre

FONTS 560, 561, 562, 563, 589, 1327, 1352, 1353, 1354. DESCRIPCIÓ DE L'ÚS FETA PELS INFORMANTS. Per a fer codonyat $(561,562,563)$. Per a fer codonyat. Els escaldo trec la pela i les granes. Després els poso en una cassola i els faig bullir amb sucre fins que és ben fet, després es posa en una capsa i es talla (560). La majordoma de mossèn Tussell en feia codonyat, nosaltres els dúiem els codonys (589). En fa melmelada (1327). Per a fer confitura (1352). Per a fer melmelades $(1353,1354)$. DESTINACIÓ. Alimentació humana $(560,561,562,563,589,1327,1352,1353,1354)$

No consta el tipus d'ingesta - No consta el mode de preparació

FONTS 572, 573. DESCRIPCIÓ DE L'ÚS FETA PELS INFORMANTS. Es feia allioli de codony s'hi posava un parell de pomes (Pyrus malus subsp. mitis) i una mica de patata (Solanum tuberosum), un gra d'all (Allium sativum) i rovell d'ou. Era boníssim, amb el codony tenia molt bon gust. DESTINACIÓ. Alimentació humana. 


\section{ALTRES USOS}

Fruit

Domèstic: ambientador

FONT 1352. DESCRIPCIÓ DE L'ÚS FETA PER L'INFORMANT. Per a perfumar la roba, es posaven a dins dels armaris.

\section{Cynara cardunculus L. (compostes)}

\section{BCN 24759}

\section{NOMS POPULARS}

Flor d'empresorar $(525,526,527,564,589,747,1314,1318,1345,1346,1347,1348,1349)$ Flor per a fer formatges $(1337,1338)$

Herba d'empresorar $(1297,1311,1312,1336)$

Herba preonera $(1307,1308,1309)$

Herba presonera $(515,516,524,535,1215,1307,1308,1309)$

Herbacol $(505,506,515,516,535,541,556,557,558,560,561,562,563,564,565,566$ $568,569,570,571,572,573,574,575,576,577,578,579,583,584,585,586,587,1296$ $1300,1301,1311,1312,1324$

\section{USOS ALIMENTARIS}

\section{Inflorescència}

Quall

FONTS $505,506,515,516,524,525,526,527,535,541,556,557,558,560,561,562,563$ $564,565,566,568,569,570,571,572,573,574,575,576,577,578,579,583,584,585$ $586,587,589,747,1215,1296,1297,1300,1301,1307,1308,1309,1311,1312,1314$ $1318,1324,1336,1337,1338,1345,1346,1347,1348,1349$. DESCRIPCIÓ DE L'ÚS FETA PELS INFORMANTS. Per a fer formatges $(505,506,515,516,525,526,527,556,557,558$ $560,564,568,574,575,576,577,578,579,583,584,585,586,587,589,747,1296,1297$ $1301,1314,1324,1345,1346,1347,1348,1349)$. Per a fer formatges. Treien le flors quan havia ben florit la planta, les deixaves assecar i quan eren ben somalles es posaven a estovar i es posava a la llet perquè s'empresorés. N'havia tingut però s'ha perdut (524). Per a fer formatges amb la llet de les cabres (535). Per a empresorar la llet (541). La flor es posava a estovar el dia abans i l'endemà ho tiraves a la llet per a fer formatges (571). Per a fer formatges i mató $(561,562,563)$. Per a fer formatges i matons $(565,566)$. Per a quallar la llet $(569,570)$. Per a fer formatges. Has de posar la flor a estovar amb un got. L'endemà es fa bullir la llet i quan era tèbia i tirànem l'aigua de la flor que haviem ben picat i la llet que bulli la llet i quan era cabra, de les cabres que teníem a Bolòs (1215). La feien servir per a fer els formatges
(1300). Per a fer mató i formatges $(1307,1308,1309)$. Per a fer formatges. Els filets de la flor es posen a estovar en aigua, llavors es pica ben picada, ho tornes a barrejar amb aigua i ho es posen a estovar coles amb un dre des lo picada en remull la nit abans lende foc perque s'empresorés més ràpid (1318). Per a fer formatges. Es posava la llet a bullir amb la flor a sobre amb una mica d'aigua que s'estovés. Quan la llet era tèbia s'hi tirava l'aigua i la llet al cap de poc ja s'empresorava i llavors ja es podia fer el formatge (1336). La flor s'assecava i s'usava per a empresorar la llet $(1337,1338)$. OBSERVACIONS. Aquí a Vallfogona encara fan formatges amb flor a l'Orri (747). La llet de cabra al cap de deu minuts ja s'amatona, a la llet de vaca li costa una mica més $(1311,1312)$. DESTINACIÓ. Alimentació humana $(505,506,515,516,524,525,526,527,535,541,556,557,558,560,561,562$, $563,564,565,566,568,569,570,571,572,573,574,575,576,577,578,579,583,584$, $585,586,587,589,747,1215,1296,1297,1300,1301,1307,1308,1309,1311,1312,1314$ $1318,1324,1336,1337,1338,1345,1346,1347,1348,1349)$.

\section{ALTRES OBSERVACIONS}

FONTS 525, 526, 527, 556, 557, 558, 564, 1296, 1300, 1307, 1308, 1309, 1314. DESCRIPCIÓ FETA PELS INFORMANTS. A casa sempre n'havíem tingut $(525,526,527)$. A l'hort n'hi havia $(556,557,558,564,1314)$. En té a l'hort (1296). En tenen de plantada a l'hort (1300). A totes les cases de pagès n'hi havia una mata $(1307,1308,1309)$.

\section{Cynara scolymus L. (compostes)}

BCN 46848

\section{NOMS POPULARS}

Carxofa (inflorescència) $(572,573,1327,1330,1335)$

Escarxofa $(1361,1362)$

Escarxofa (inflorescència) $(520,521)$

Escarxofera $(547,548)$

\section{USOS MEDICINALS}

Fulla

Hepatoprotector

FONTS 520, 521. DESCRIPCIÓ DE L'ÚS FETA PELS INFORMANTS. Per al colesterol, els ronyons $\mathrm{i}$ el fetge. FORMA FARMACĖUTICA I ÚS. Tisana (ús intern). PREPARACIÓ. Decocció. L'aigua de les fulles i també de les escarxofes. DESTINACIÓ. Medicina humana.

Hipoglucemiant

FONTS 520, 521, 1361, 1362. DESCRIPCIÓ DE L'ÚS FETA PELS INFORMANTS. Per als diabètics $(520,521)$. Per a fer baixar el sucre $(1361,1362)$. FORMA FARMACĖUTICA I ÚS. 
Tisana (ús intern). PREPARACIÓ. Decocció. L'aigua de les fulles i també de les escarxofes $(520,521)$. Decocció $(1361,1362)$. DESTINACIÓ. Medicina humana.

Hipolipemiant

FONTS 520, 521. DESCRIPCIÓ DE L'ÚS FETA PELS INFORMANTS. Per al colesterol, els ronyons i el fetge. FORMA FARMACĖUTICA I ÚS. Tisana (ús intern). PREPARACIÓ. Decocció. L'aigua de les fulles i també de les escarxofes. DESTINACIÓ. Medicina humana.

\section{Protector renal}

FONTS 520, 521. DESCRIPCIÓ DE L'ÚS FETA PELS INFORMANTS. Per al colesterol, els ronyons i el fetge. FORMA FARMACĖUTICA I ÚS. Tisana (ús intern). PREPARACIÓ. Decocció. L'aigua de les fulles i també de les escarxofes. DESTINACIÓ. Medicina humana.

\section{Inflorescència}

Antiinflamatori hepàtic

FONT 1327. DESCRIPCIÓ DE L'ÚS FETA PER L'INFORMANT. Va bé per a l'hepatitis. FORMA FARMACĖUTICA I ÚS. Tisana (ús intern). PREPARACIÓ. Decocció. Aigua de fulles de carxofes. DESTINACIÓ. Medicina humana.

Hematocatàrtic

FONT 1330. DESCRIPCIÓ DE L'ÚS FETA PER L'INFORMANT. Va bé per a depurar la sang. FORMA FARMACĖUTICA I ÚS. Tisana (ús intern). PREPARACIÓ. Aigua de fer bullir les carxofes. DESTINACIÓ. Medicina humana.

Hepatoprotector

FONTS 520, 521, 572, 573. DESCRIPCIÓ DE L'ÚS FETA PELS INFORMANTS. Per al colesterol, els ronyons $\mathrm{i}$ el fetge $(520,521)$. Per al fetge $(572,573)$. FORMA FARMACEUTICA I US. Tisana (ús intern). PREF també de les escarxofes $(520,521)$. Decocció. Aigua de fer bullir les carxofes $(572,573)$. DESTINACIÓ. Medicina humana.

Hipoglucemiant

FONTS 520, 521, 547, 548, 1330, 1335. DESCRIPCIÓ DE L'ÚS FETA PELS INFORMANTS. Per als diabètics $(520,521)$. Per al sucre $(547,548)$. Per a fer baixar el sucre $(1330,1335)$ FORMA FARMACĖUTICA I ÚS. Tisana (ús intern). PREPARACIÓ. Decocció. L'aigua de les fulles i també de les escarxofes $(520,521)$. Decocció $(547,548,1335)$. Aigua de fer bullir carxofes (1330). DESTINACIO. Medicina humana.

Hipolipemiant

FONTS 520, 521, 547, 548. DESCRIPCIÓ DE L'ÚS FETA PELS INFORMANTS. Per a colesterol, els ronyons $\mathrm{i}$ el fetge $(520,521)$. Per al colesterol $(547,548)$. FORMA FARMACEUTICA I US. Tisana (ús intern). PREPARACIO. Decocció. L'aigua de les fulles també de les escarxofes $(520,521)$. Decocció $(547,548)$. DESTINACIO. Medicina humana.

Protector renal

FONTS 520, 521. DESCRIPCIÓ DE L'ÚS FETA PELS INFORMANTS. Per al colesterol, els ronyons $\mathrm{i}$ el fetge. FORMA FARMACEUTICA I US. Tisana (ús intern). PREPARACIO. Decocció. L'aigua de les fulles i també de les escarxofes. DESTINACIO. Medicina humana.

\section{Cynodon dactylon (L.) Pers (gramínies)}

BCN 29686

\section{NOMS POPULARS}

Gram $(511,512,513,514,586,587)$

Gram blanc (1324)

Gram d'hort $(520,521)$

\section{USOS MEDICINALS}

\section{Part aèria}

Protector renal

FONTS 511, 512, 513, 514. DESCRIPCIO DE L'ÚS FETA PELS INFORMANTS. Serveix per al ronyó. FORMA FARMACEUTICA I ÚS. Tisana (ús intern). PREPARACIÓ. Decocció. DESTINACIO. Medicina humana.

\section{ALTRES USOS}

\section{Part aèria}

Creences i pràctiques magicoreligioses

FONTS 586, 587. DESCRIPCIÓ DE L'ÚS FETA PELS INFORMANTS. Si un home malalt es posa en aigua de gram i ordi (Hordeum vulgare), diuen que es cura.

\section{Planta sencera}

Literatura oral popular: llegendes, gloses, contes, dites, refranys, poemes, cançons

FONT 1324. DESCRIPCIÓ DE L'ÚS FETA PER L'INFORMANT. Als homes, els farem aigua de gram i ja curaran si a Déu plau.

\section{ALTRES OBSERVACIONS}

FONTS 511, 512, 513, 514, 520, 521. DESCRIPCIÓ FETA PELS INFORMANTS. Semblant a una pota de gallina, fa una flor marronosa $(511,512,513,514)$. És una mala herba. Va envaint, fa com les maduixeres $(520,521)$

\section{Dahlia sp. (compostes)}

\section{NOMS POPULARS}

Dàlia $(549,590)$ 


\section{ALTRES USOS}

Planta viva ex situ

Ornamental: jardineria

FONTS 549, 590. DESCRIPCIÓ DE L'ÚS FETA PELS INFORMANTS. Per a fer bonic, en teníem a l'hort (549). Per a fer bonic (590)

\section{Daphne laureola L. (timeleàcies)}

\section{BCN 24762}

\section{NOMS POPULARS}

Senet $(581,590)$

Senet bord (1324)

\section{USOS MEDICINALS}

\section{Fulla}

Antifúngic

FONT 581. DESCRIPCIÓ DE L'ÚS FETA PER L'INFORMANT. Amb un pinzell es pinten els brians. És oli en un llum per als brians. FORMA FARMACĖUTICA I ÚS. Embrocació (ús extern). PREPARACIÓ. Es bull en oli la fulla. DESTINACIÓ. Medicina humana.

Laxant

FONT 1324. DESCRIPCIÓ DE L'ÚS FETA PER L'INFORMANT. És laxant. FORMA FARMACĖUTICA I ÚS. Tisana (ús intern). PREPARACIÓ. Decocció. DESTINACIÓ. Medicina humana. OBSERVACIONS. Cal llençar-ne la primera aigua.

Purgant

FONT 590. DESCRIPCIÓ DE L'ÚS FETA PER L'INFORMANT. Les fulles són un purgant. FORMA FARMACĖUTICA I ÚS. Tisana (ús intern). PREPARACIÓ. Decocció. DESTINACIÓ. Medicina humana.

\section{Daphne mezereum L. (timeleàcies)}

BCN 50758

\section{NOMS POPULARS}

Senet $(583,584,585,588)$

Senet de pagesos (541)

\section{USOS MEDICINALS}

Fulla

Purgant

FONTS 583, 584, 585, 588. DESCRIPCIÓ DE L'ÚS FETA PELS INFORMANTS. Són una purga (588). Es purgant $(583,584,585)$. FORMA FARMACEUTICA I US. Tisana (ús intern). PREPARACIO. Decocció. Les fulles bullides (588). Decocció. Es una aigua de mal prendre $(583,584,585)$. DESTINACIÓ. Medicina humana.

No consta

Desconegut per l'informant

FONTS 583, 584, 585. FORMA FARMACÈUTICA | ÚS. Desconegut per l'informant DESTINACIÓ. Medicina humana. OBSERVACIONS. Es feia un oli i no recordo per a què el fèiem servir.

\section{Datura stramonium L. (solanàcies)}

BCN 29688

\section{NOMS POPULARS}

Estramoni $(569,570,581)$

Herba queixalera $(1213,1214)$

Herba talpera $(581,583,584,585)$

Matatalps $(586,587)$

\section{USOS MEDICINALS}

\section{No consta}

Antiodontàlgic

FONTS 1213, 1214. DESCRIPCIÓ DE L'ÚS FETA PELS INFORMANTS. Es passava el suc amb un fil. FORMA FARMACËUTICA I US. Desconegut per l'informant. EFECTES SECUNDARIS. Sí. DESTINACIÓ. Medicina humana. OBSERVACIONS. S'havia de vigilar perquè podia provocar intoxicació.

\section{ALTRES USOS}

Planta viva ex situ

Repel·lents

FONTS 581, 583,584, 585,586,587,1213, 1214. DESCRIPCIÓ DE L'ÚS FETA PELS INFORMANTS. Els talps [dit "taups"] no s'hi acosten si la tens a l'hort, fa pudor i els talps no hi van $(583,584,585)$. Per a fer marxar els talps [dit "taups"] de l'hort $(586,587)$. Es planta en 
els horts perquè fa mala olor i evita que els talps hi vagin (581). Per a foragitar els talps [dit "taups"] (1214). Per a foragitar els talps [dit "taups"] (1213).

\section{ACCIONS NOCIVES O TÒXIQUES}

No consta

FONTS 569, 570, 1213, 1214. DESCRIPCIÓ DE L'ACCIÓ NOCIVA O TÒXICA FETA PELS INFORMANTS. És una herba dolenta $(569,570)$. Es feia servir per al mal de queixal, però s'havia de vigilar perquè podia provocar intoxicació $(1213,1214)$. TOXICITAT LLIGADA A L'ÚS MEDICINAL. Sí $(1213,1214)$

Daucus carota L. subsp. sativus (Hoffm.) Arcang.

(umbel·líferes)

BCN 46847

\section{NOMS POPULARS}

Pastanaga $(507,509,510,1352)$

\section{USOS MEDICINALS}

Arrel

Antidiarreic

FONTS 507, 509, 510. DESCRIPCIÓ DE L'ÚS FETA PELS INFORMANTS. Per a la diarrea. FORMA FARMACĖUTICA I ÚS. Tisana (ús intern). DESTINACIÓ. Medicina humana.

\section{BARREGES AMB AQUEST TÀXON}

Arrel

FONT 1352. Entrevista 41 (vegeu catàleg de barreges)

Daucus carota L. subsp. carota (umbel-líferes) BCN 48714

\section{NOMS POPULARS}

Caps blancs $(586,587)$

Pastanaga $(529,530,531,583,584,585)$

\section{ALTRES OBSERVACIONS}

FONTS 586, 587. DESCRIPCIÓ FETA PELS INFORMANTS. En surten per aquí.

Dianthus caryophyllus L. (cariofil·làcies)

BCN 27258

\section{NOMS POPULARS}

Clavell blanc (1352)

\section{ALTRES USOS}

Part aèria florida

Creences i pràctiques magicoreligioses

FONT 1352. DESCRIPCIÓ DE L'ÚS FETA PER L'INFORMANT. A totes les cases n'hi havia i se'n feien rams per Corpus, que feien molta olor. Quan anaves a missa et marejaves.

\section{Dianthus hyssopifolius L. subsp. hyssopifolius}

(cariofil·làcies)

BCN 27299

\section{NOMS POPULARS}

Clavell (1321)

\section{ALTRES USOS}

Flor

Cosmètic

FONT 1321. DESCRIPCIÓ DE L'ÚS FETA PER L'INFORMANT. Fan molt bona olor, no hi ha cap colònia tan bona.

Dianthus seguieri Vill. (cariofil·làcies)

BCN 24763

\section{NOMS POPULARS}

Clavell de muntanya $(552,1332,1333,1334,1339,1340)$

USOS MEDICINALS 
Flor

Antidiarreic

FONTS 1332, 1333, 1334. DESCRIPCIÓ DE L'ÚS FETA PELS INFORMANTS. Per a trencar la diarrea. FORMA FARMACEUTICA I ÚS. Tisana (ús intern). PREPARACIÓ. Decocció. Aigua de les flors. DESTINACIÓ. Medicina humana.

Laxant

FONTS 1339, 1340. DESCRIPCIÓ DE L'ÚS FETA PELS INFORMANTS. Per al restrenyiment. FORMA FARMACĖUTICA I ÚS. Tisana (ús intern). PREPARACIÓ. Decocció. Aigua de les flors. DESTINACIÓ. Medicina humana.

\section{ALTRES USOS}

Flor

Creences i pràctiques magicoreligioses

FONT 552. DESCRIPCIÓ DE L'ÚS FETA PER L'INFORMANT. Per a guarnir l'església per Sant Joan.

\section{Dianthus sp. (cariofil làcies)}

\section{NOMS POPULARS}

Clavell de bosc $(520,521)$

Clavell de Sant Jaume (553)

\section{USOS MEDICINALS}

Flor

Antidiarreic

FONTS 520, 521. DESCRIPCIÓ DE L'ÚS FETA PELS INFORMANTS. Per a la diarrea FORMA FARMACĖUTICA I ÚS. Tisana (ús intern). PREPARACIÓ. Decocció. DESTINACIÓ. Medicina humana.

\section{ALTRES USOS}

Flor

Ornamental: elaboració de rams

FONT 553. DESCRIPCIÓ DE L'ÚS FETA PER L'INFORMANT. Per a fer bonic

\section{Dicentra spectabilis (L.) Fukuhara (papaveràcies)}

BCN 59805

\section{NOMS POPULARS}

Cors d'àngel (541)

\section{ALTRES USOS}

Planta viva ex situ

Ornamental: jardineria

FONT 541. DESCRIPCIÓ DE L'ÚS FETA PER L'INFORMANT. Li ho va dir una senyora d'Ogassa fa uns 20 anys.

Dipsacus fullonum L. (dipsacàcies)

BCN 27266

\section{NOMS POPULARS}

Card (1352)

\section{ALTRES USOS}

Inflorescència

Ornamental: elaboració de rams

FONT 1352. DESCRIPCIÓ DE L'ÚS FETA PER L'INFORMANT. Quan eren seques les pintàvem amb purpurina.

Dorycnium hirsutum (L.) Ser. in DC. (papilionàcies)

BCN 37553

\section{NOMS POPULARS}

Peu de gat $(520,521)$

\section{USOS MEDICINALS}

\section{Part aèria}

Antihemorroïdal

FONTS 520, 521. DESCRIPCIÓ DE L'ÚS FETA PELS INFORMANTS. S'ha de beure per a les morenes. FORMA FARMACĖUTICA I ÚS. Tisana (ús intern). PREPARACIÓ. Decocció. DESTINACIÓ. Medicina humana. 


\section{Dorycnium pentaphyllum Scop. (papilionàcies)}

BCN 24764

\section{NOMS POPULARS}

Farigola blanca (1335)

Farigoleta (1324)

Herba conillera (1324)

\section{USOS MEDICINALS}

Part aèria

Antidiarreic

FONTS 1324, 1335. DESCRIPCIÓ DE L'ÚS FETA PELS INFORMANTS. La utilitza quan té diarrea (1324). Va bé per a les diarrees (1335). FORMA FARMACĖUTICA I ÚS. Tisana (ús intern). PREPARACIÓ. En infusió (1324). Decocció (1335). DESTINACIÓ. Medicina humana.

\section{ALTRES OBSERVACIONS}

FONT 1324. DESCRIPCIÓ FETA PER L'INFORMANT. Ha vist que n'hi ha al cantó de la carena del castell que és Garrotxa i al cantó Ripollès, no.

\section{Dracunculus vulgaris Schott. (aràcies)}

\section{BCN 24765}

\section{NOMS POPULARS}

Herba escurçonera $(525,526,527,554,555,572,573,1324,1345,1346,1352)$

\section{USOS MEDICINALS}

Bulb

\section{Antiequimòtic}

FONTS 554, 555. DESCRIPCIÓ DE L'ÚS FETA PELS INFORMANTS. Per a fer sortir els cops, ajuda a fer sortir el morat. FORMA FARMACEUTICA I ÚS. Ungüent (ús extern). PREPARACIÓ. Les arrels, que fan com unes patates, aixafades amb llard. DESTINACIÓ. Medicina humana.

Antiofídic

FONTS 525, 526, 527, 572, 573, 1324, 1345, 1346. DESCRIPCIÓ DE L'ÚS FETA PELS INFORMANTS. Servia de contraverí [dit "contravereno"] quan et pessigava un escurçó (525, 526, 527). Si et pica un escurçó és un contraverí [dit "contravereno"] $(572,573)$. Per a les pessigades dels escurçons (1324). Quan et pessigava un escurçó (1345, 1346). FORMA FARMACEUUICA I ÚS. Ungüent (ús extern) $(525,526,527)$. Desconegut per l'informant (572 573). Embrón (ús (ús) (1324). Empl, (ús extern) (1345,1346). (5REPARACIÓ . PREPARACIÓ. Es fela un ungüent (525, 526, 527). Amb el bulb se'n fela un oli (1324). En emplastre $(1345,1346)$. DESTINACIO. Medicina humana. OBSERVACIONS. No ho recorda bé $(1345,1346)$

Flor

Antiofídic

FONT 1352. DESCRIPCIÓ DE L'ÚS FETA PER L'INFORMANT. Per a les pessigades d'escurçó. FORMA FARMACEUTICA I US. Sense forma farmacèutica (ús directe, ús extern). PREPARACIO. La flor té la forma del cap de l'escurçó, es posava directament a sobre la pessigada i deien que estirava el verí. DESTINACIÓ. Medicina humana.

\section{Echinochloa crus-galli (L.) Beauv. (gramínies)}

\section{BCN 26091}

\section{NOMS POPULARS}

Pota de gall $(572,573)$

\section{USOS ALIMENTARIS}

Part aèria

Ingestió de la part de la planta crua - Fresca (sense preparació)

FONTS 572, 573. DESCRIPCIÓ DE L'ÚS FETA PELS INFORMANTS. Es donava als conills. DESTINACIÓ. Alimentació animal.

\section{Echium vulgare L. (boraginàcies)}

\section{BCN 24766}

\section{NOMS POPULARS}

Borrenga (1293)

Cua de porc $(520,521,553,583,584,585)$

\section{USOS MEDICINALS}

\section{Part aèria}

Anticatarral 
FONT 1293. DESCRIPCIÓ DE L'ÚS FETA PER L'INFORMANT. Per al constipat. FORMA FARMACEUUTICA I ÚS. Tisana (ús intern). DESTINACIÓ. Medicina humana.

Antiofídic

FONT 553. DESCRIPCIÓ DE L'ÚS FETA PER L'INFORMANT. Per a picades d'escurçons. FORMA FARMACĖUTICA I ÚS. Desconegut per l'informant. DESTINACIÓ. Medicina humana.

\section{Equisetum arvense L. (equisetàcies)}

BCN 24767

\section{NOMS POPULARS}

Cua de cavall $(504,507,509,510,511,512,513,514,518,519,520,521,522,523,524$ $525,526,527,529,530,531,532,541,549,553,556,557,561,562,563,564,565,566$ $567,568,574,575,576,577,583,584,585,586,587,590,591,592,747,752,753,754$, $755,1294,1301,1313,1320,1322,1323,1330,1331,1332,1333,1334,1335,1336,1341$ $1342,1343,1344,1350,1351,1352,1361,1362)$

Sangnua (532)

\section{USOS MEDICINALS}

\section{Part aèria estèril}

Antihemorroïdal

FONT 1320. DESCRIPCIÓ DE L'ÚS FETA PER L'INFORMANT. Va bé per a rentar les morenes. FORMA FARMACEUUTICA I ÚS. Bany (ús extern). PREPARACIÓ. Decocció DESTINACIÓ. Medicina humana.

\section{Antihipertensiu}

FONTS 518, 519, 524, 529, 530, 531, 574, 575, 576, 577. DESCRIPCIÓ DE L'ÚS FETA PELS INFORMANTS. Per a la pressió $(529,530,531)$. Per a les sangs $(524)$. Per a les sangs i per a la pressió $(518,519)$. Per a fer baixar la pressió $(574,575,576,577)$. FORMA FARMACĖUTICA I ÚS. Tisana (ús intern). PREPARACIÓ. Decocció $(518,519,524,529$, $530,531,574,575,576,577)$. DESTINACIÓ. Medicina humana.

Antiinflamatori intestinal

FONTS 520, 521. DESCRIPCIÓ DE L'ÚS FETA PELS INFORMANTS. Per al ventre. FORMA FARMACĖUTICA I ÚS. Tisana (ús intern). PREPARACIÓ. Decocció. DESTINACIÓ. Medicina humana.

Antiprostatític

FONTS 1332, 1333 1334. DESCRIPCIÓ DE L'ÚS FETA PELS INFORMANTS. Va molt bé per a la pròstata. FORMA FARMACĖUTICA I ÚS. Tisana (ús intern). PREPARACIÓ. S'usa la planta bullida. DESTINACIÓ. Medicina humana.

\section{Antisèptic ocular}

FONT 564. DESCRIPCIÓ DE L'ÚS FETA PER L'INFORMANT. Va bé per als ulls quan t'h has fet mal, t'has clavat alguna cosa. FORMA FARMACĖUTICA I ÚS. Bany (ús extern) PREPARACIÓ. Decocció. DESTINACIÓ. Medicina humana.

Antisèptic urinari

FONT 1294. DESCRIPCIÓ DE L'ÚS FETA PER L'INFORMANT. Per a les infeccions d'orina FORMA FARMACĖUTICA I ÚS. Tisana (ús intern). PREPARACIÓ. Decocció. DESTINACIÓ. Medicina humana. OBSERVACIONS. Tota la planta quan és tendra.

Diürètic

FONTS 504, 507, 509, 510, 511, 512, 513, 514, 520, 521, 522, 523, 525, 526, 527, 529, 530 $531,553,556,557,564,565,566,567,568,590,747,752,753,754,755,1301,1322,1323$ 1330, 1341, 1342, 1352. DESCRIPCIÓ DE L'ÚS FETA PELS INFORMANTS. Per a fer orina $(504,522,523,529,530,531,553,556,557,565,566,567,568,747,753,754,755,1301$ $1322,1323,1330,1341,1342,1352)$. És diürètic $(507,509,510,752)$. Per a ajudar a orinar $(511,512,513,514)$. Per a fer orinar. Jo no orinava i estava molt espantat, prenc aquesta aigua i em va molt bé $(525,526,527)$. Es un purificant $(520,521)$. Va bé per als ronyons i per a orinar (564). Per a les infeccions d'orina (590). FORMA FARMACĖUTICA I ÚS. Tisana (ús intern) $(504,507,509,510,511,512,513,514,520,521,522,523,525,526,527,529,530$ $531,553,556,557,565,566,567,568,590,747,752,753,754,755,1301,1322,1323$ $1330,1341,1342,1352)$. Tintura alcohòlica (ús intern) (564). PREPARACIÓ. Decocció (504, 1330, 1341, 1542, 1552). Tintura alcohoolica (ús intern) (564). PREPARACIO. Decocció (504 $507,509,510,511,512,513,514,520,521,522,523,525,526,527,529,530,531,553$, $556,557,565,566,567,568,590,747,752,753,754,755,1301,1322)$. En esperit (564). En

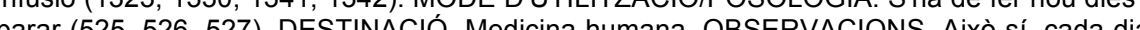
parar $(525,526,527)$. DESTINACIO. Medicina humana. OBSERVACIONS. Això sí, cada dia s'ha de fer nova i s'ha de vigilar perquè l'aigua aixorranca els camins $(525,526,527)$.

Litotríptic biliar

FONT 1313. DESCRIPCIÓ DE L'ÚS FETA PER L'INFORMANT. Per a les pedres. Es pot pendre sola o barrejada. FORMA FARMACĖUTICA I ÚS. Tisana (ús intern). PREPARACIÓ. Decocció. DESTINACIÓ. Medicina humana.

Litotríptic renal

FONT 1320. DESCRIPCIÓ DE L'ÚS FETA PER L'INFORMANT. Per a desfer les pedres de ronyó. FORMA FARMACĖUTICA I ÚS. Tisana (ús intern). PREPARACIÓ. Decocció. MODE D'UTILITZACIÓ/POSOLOGIA. Una tassa al matí i una tassa al vespre. DESTINACIÓ Medicina humana.

Protector renal

FONTS 532, 564, 591, 592, 1294, 1313, 1335, 1336, 1350, 1351. DESCRIPCIÓ DE L'ÚS FETA PELS INFORMANTS. Per a una euga que pixava sang. És bona per als ronyons (532). Va bé per als ronyons i per a orinar (564). Per als ronyons $(591,592,1335,1350,1351)$. És molt bona per als ronyons (1294). Per als ronyons. Es pot prendre sola o barrejada (1313). És molt bona per al mal de ronyons (1336). FORMA FARMACĖUTICA I ÚS. Tisana (ús intern) $(532,591,592,1294,1313,1335,1336,1350,1351)$. Tintura alcohòlica (ús intern) (564). PREPARACIO. Decocció $(532,591,592,1294,1313,1335)$. En esperit (564). En 
infusió (1336). DESTINACIÓ. Medicina veterinària (532). Medicina humana (564, 591, 592 , $1294,1313,1335,1336,1350,1351)$. OBSERVACIONS. Tota la planta quan és tendra (1294)

Reforçant ossi

FONTS 586, 587, 1331. DESCRIPCIÓ DE L'ÚS FETA PELS INFORMANTS. Em sembla que en fan aigua per als ossos $(586,587)$. Per als ossos de la gent gran (1331). FORMA FARMACĖUTICA I ÚS. Tisana (ús intern). PREPARACIÓ. Decocció $(586,587,1331$ ). DESTINACIÓ. Medicina humana.

Vasotònic

FONTS 561, 562, 563, 565, 566, 574, 575, 576, 577, 1361, 1362. DESCRIPCIÓ DE L'ÚS FETA PELS INFORMANTS. Per a la circulació $(561,562,563,574,575,576,577,1361$, 1362). És bona per a la circulació $(565,566)$. FORMA FARMACĖUTICA I ÚS. Tisana (ús intern). PREPARACIÓ. Decocció $(561,562,563,565,566,574,575,576,577,1361,1362)$. DESTINACIÓ. Medicina humana.

\section{ALTRES OBSERVACIONS}

FONTS 564, 586, 587. DESCRIPCIÓ FETA PELS INFORMANTS. La vaig a buscar a Olot, perquè aquí no n'hi ha gaire $(564)$. A la Jonquerassa n'és ple $(586,587)$

\section{BARREGES AMB AQUEST TÀXON}

\section{Part aèria estèril}

FONTS 1343, 1344. Entrevista 23, barreja II (vegeu catàleg de barreges)

FONT 1301. Entrevista 36 (vegeu catàleg de barreges)

FONT 1313. Entrevista 4, barreja II (vegeu catàleg de barreges)

\section{Erica arborea L. (ericàcies)}

BCN 24768

\section{NOMS POPULARS}

Bruc $(1321,1343,1344)$

\section{USOS MEDICINALS}

\section{Part aèria}

Diürètic

FONTS 1343, 1344. DESCRIPCIÓ DE L'ÚS FETA PELS INFORMANTS. Per a fer orinar. FORMA FARMACĖUTICA I ÚS. Tisana (ús intern). PREPARACIÓ. Decocció. DESTINACIÓ Medicina humana

\section{ALTRES USOS}

\section{Part aèria}

Artesanal: elaboració d'escombres

FONT 1321. DESCRIPCIÓ DE L'ÚS FETA PER L'INFORMANT. Per a fer escombres.

\section{ALTRES OBSERVACIONS}

FONTS 1343, 1344. DESCRIPCIÓ FETA PELS INFORMANTS. Els en duien de per avall.

\section{Eryngium bourgatii Gouan (umbel·líferes)}

BCN 24881

\section{NOMS POPULARS}

Espinacal $(586,587,1332,1333,1334)$

Espinacal blau $(553,559,564,569,570)$

\section{USOS MEDICINALS}

\section{Arrel}

Hematocatàrtic

FONTS 1332, 1333, 1334. DESCRIPCIÓ DE L'ÚS FETA PELS INFORMANTS. Per a netejar la sang. FORMA FARMACĖUTICA I ÚS. Tisana (ús intern). PREPARACIÓ. Decocció. DESTINACIÓ. Medicina humana.

\section{Part aèria}

Antiofídic

FONTS 564, 586, 587. DESCRIPCIÓ DE L'ÚS FETA PELS INFORMANTS. Per a mossegades d'escurcó $(564,586,587)$. FORMA FARMACĖUTICA I ÚS. Sense forma (5) úc extern) $(564,587)$. Liniment (ús extern) $(586,587)$. Sense forma directe, ús intern) (586). PREPARAĆÓ. Es fela un picar per a fer sortir el verí $(586,587)$. DESTINACIO. Medina veternaria (564). Medicina humana $(586,587)$. OBSERVACIONS. Són millor que els espinacals (Eryngium campestre), però, és clar, no pots pas anar a dalt del Comanegra (564).

\section{USOS ALIMENTARIS}

\section{Inflorescència}

Ingestió de la part de la planta crua - Fresca (sense preparació) 
FONTS 586, 587. DESCRIPCIÓ DE L'ÚS FETA PELS INFORMANTS. Les ovelles es mengen la capsa d'ara fins al 15 d'agost llavors quan s'asseca ja no la volen. DESTINACIÓ. Alimentació animal.

\section{ALTRES USOS}

\section{Part aèria florida}

Ornamental: elaboració de rams

FONT 559. DESCRIPCIÓ DE L'ÚS FETA PER L'INFORMANT. Per a fer rams.

\section{ALTRES OBSERVACIONS}

FONTS 564, 569, 570. DESCRIPCIÓ FETA PELS INFORMANTS. Es fan a la muntanya $(569,570)$. Es fan a dalt del Comanegra (564).

\section{BARREGES AMB AQUEST TÀXON}

Arrel

FONTS 1213, 1214. Entrevista 102, barreja VI (vegeu catàleg de barreges)

FONTS 1332, 1333, 1334. Entrevista 11, barreja III (vegeu catàleg de barreges)

\section{Eryngium campestre L. (umbel·líferes)}

\section{BCN 24882}

\section{NOMS POPULARS}

Espinacal $(505,506,507,509,510,511,512,513,514,515,516,517,518,520,521,525$ $526,527,529,530,531,541,553,556,557,564,569,570,586,587,589,1313,1323,1327$

\section{USOS MEDICINALS}

\section{Arrel}

Antihemorroïdal

FONTS 529, 530, 531. DESCRIPCIÓ DE L'ÚS FETA PELS INFORMANTS. Va bé per a les morenes. FORMA FARMACĖUTICA I ÚS. Embrocació (ús extern). PREPARACIÓ. L'arrel en oli. DESTINACIÓ. Medicina humana.

Antihipertensiu

FONTS 505, 506. DESCRIPCIÓ DE L'ÚS FETA PELS INFORMANTS. La rel per a rebaixar les sangs. FORMA FARMACĖUTICA I ÚS. Tisana (ús intern). PREPARACIÓ. Decocció. DESTINACIÓ. Medicina humana.

\section{Antiodontàlgic}

FONTS 556, 557. DESCRIPCIÓ DE L'ÚS FETA PELS INFORMANTS. Per al mal de queixal. FORMA FARMACĖUTICA I ÚS. Embrocació (ús extern). PREPARACIÓ. Oli de la rel. T'ho posaven amb una ploma de gallina. DESTINACIÓ. Medicina humana.

Antiofídic

FONTS 511, 512, 513, 514, 1313. DESCRIPCIÓ DE L'ÚS FETA PELS INFORMANTS. Per a untar-te quan et pessiga un escurçó $(511,512,513,514)$. Es frega la zona afectada per a la picada d'escurçó (1313). FORMA FARMACĖUTICA I ÚS. Liniment (ús extern). PREPARACIÓ. Les arrels bullides en oli $(511,512,513,514)$. Es prepara un oli en l'arrel (una mica calent) (1313). DESTINACIÓ. Medicina humana.

Per a les picades

FONTS 515, 516, 518, 519, 1327. DESCRIPCIÓ DE L'ÚS FETA PELS INFORMANTS. Per si et pessiga una feram $(515,516)$. És un contraverí [dit "contravereno"] per a quan et pessiga alguna feram $(518,519)$. Posada allà on tens la pessigada (1327). FORMA FARMACEUTICA I ÚS. Embrocació (ús extern). PREPARACIÓ. Les arrels bullides en oli $(515,516)$. La rel en oli $(518,519)$. Arrel en oli $(1327)$. DESTINACIÓ. Medicina humana $(515,516,518,519)$. Medicina humana i veterinària (1327)

Vulnerari

FONTS 529, 530, 531. DESCRIPCIÓ DE L'ÚS FETA PELS INFORMANTS. Va bé per a les ferides. FORMA FARMACĖUTICA I ÚS. Embrocació (ús extern). PREPARACIÓ. L'arrel en oli. DESTINACIÓ. Medicina humana.

\section{No consta}

Desconegut per l'informant

FONT 589. FORMA FARMACĖUTICA I ÚS. Desconegut per l'informant. OBSERVACIONS. Diuen que va bé per a fer medicina.

\section{Part aèria}

Antieritematós

FONTS 520, 521. DESCRIPCIÓ DE L'ÚS FETA PELS INFORMANTS. Per a la urticària. E meu germà en va tenir i en posava a sobre el llit i s'hi estirava a sobre, hi trobava alleujamen [dit "alivio"]. FORMA FARMACĖUTICA I ÚS. Sense forma farmacèutica (ús directe, ús extern). MODE D'UTILITZACIÓ/POSOLOGIA. T'has de punxar amb la planta. DESTINACIÓ. Medicina humana.

Antiinflamatori

FONTS 529, 530, 531. DESCRIPCIÓ DE L'ÚS FETA PELS INFORMANTS. Per a rentar el braguer de les vaques quan el tenien inflamat. FORMA FARMACEUTICA I US. Tisana (ús intern). PREPARACIÓ. Decocció. Aigua de tota la planta. DESTINACIÓ. Medicina veterinària.

Antiofídic

FONTS 505, 506, 515, 516, 518, 519, 525, 526, 527, 564, 1313, 1327, 1335. DESCRIPCIO DE L'US FETA PELS INFORMANTS. Treu el verí [dit "vereno"] de les pessigades dels 
escurçons $(505,506)$. Per a pessigades $(515,516)$. Si et pessiga un escurçó t'has de picar amb espinacals $(518,519)$. Per a pessigades d'escurçó $(525,526,527)$. Per a les mossegades d'escurçó (564). L'utilitzen per a picades d'escurçons als gossos. Es punxa el gos fins que surt sang. Per a fer sortir el verí (1313). Quan et pessiga un escurçó (1327). gos fins que surt sang. Per a fer sortir el verí (1313). Quan et pessiga un escurçó (1327). verí (1335). FORMA FARMACÉUTICA I Ús. Sense forma farmacèutica (ús directe, ús veri (1335). FORMA extern). PREPARACIO. Thas de punxar $(505,506)$. Punxar-te amb la planta $(515,516)$ T'has de fregar amb espinacals fins que surti la sang $(525,526,527)$. Punxar-lo ben punxat (564). Punxar-te ràpidament $\mathrm{amb}$ espinacal i fert-te sortir sang (1327). DESTINACIÓ Medicina humana $(505,506,515,516,518,519,525,526,527,1313,1327)$. Medicina veterinària $(564,1335)$. OBSERVACIONS. Una vegada hi havia un escurçó i una mustela que es barallaven i el padrí s'ho aguaitava [dit "agoitava"], cada vegada que l'escurçó pessigava la mustela s'anava a fregar amb la planta d'espinacals $(518,519)$. Mossegades d'escurçó: una vegada a la gossa la va mossegar un escurçó, el primer que vaig fer va ser punxar-li ben punxat amb espinacals, després vaig fer un pipí en un mocador i li ho vaig pressionar una estona, quan vaig arribar a casa li vaig fer perfums de flor de sabuc (Sambucus nigra) i els alt (Sap de 48 hores ja menjava (564).

Antireumàtic

FONTS 507, 509, 510. DESCRIPCIÓ DE L'ÚS FETA PELS INFORMANTS. Fregar-se amb espinacals per al dolor. FORMA FARMACĖUTICA I ÚS. Sense forma farmacèutica (ús directe, ús extern). DESTINACIÓ. Medicina humana.

Per a la rampa

FONTS 515, 516. DESCRIPCIÓ DE L'ÚS FETA PELS INFORMANTS. Per a la rampa FORMA FARMACĖUTICA I ÚS. Sense forma farmacèutica (ús directe, ús extern). PREPARACIÓ. Punxar-te amb la planta. DESTINACIÓ. Medicina humana.

Vasotònic

FONTS 569, 570. DESCRIPCIÓ DE L'ÚS FETA PELS INFORMANTS. Per a la mala circulació, la meva mare es punxava les cames. FORMA FARMACĖUTICA I ÚS. Sense forma farmacèutica (ús directe, ús extern). DESTINACIÓ. Medicina humana.

\section{ALTRES USOS}

Arrel

Creences i pràctiques magicoreligioses

FONTS 517, 518, 519. DESCRIPCIÓ DE L'ÚS FETA PELS INFORMANTS. S'ha de portar sempre una arrel a la butxaca, per a la rampa (517). Si portes una rel d'espinacal a la butxaca no tens grateres $(518,519)$

\section{BARREGES AMB AQUEST TÀXON}

\section{Arrel}

FONT 1323. Entrevista 24 (vegeu catàleg de barreges)
FONTS 529, 530, 531. Entrevista 53, barreja IX (vegeu catàleg de barreges)

\section{Eucalyptus globulus Labill. (mirtàcies)}

\section{BCN 24883}

\section{NOMS POPULARS}

Eucalipto $(1361,1362)$

Eucaliptus $(507,509,510,511,512,513,514,553,556,557,558,565,566,590,746,747$ $753,754,755,1298,1330,1353,1354)$

\section{USOS MEDICINALS}

Fulla

Anticatarral

FONTS 507, 509, 510, 511, 512, 513, 514, 556, 557, 558, 590, 746, 747, 753, 754, 755, 1330, 1361, 1362. DESCRIPCIO DE L'ÚS FETA PELS INFORMANTS. Per als refredats $(511,512,513,514,746,747)$. Per als refredats de pit $(507,509,510)$. Quan estàs refredat, també és desinfectant $(556,557)$. Quan estàs refredat $(558,753,754,755)$. Per als refredats de nas (590). Per al constipat (1330). Per als constipats (1361, 1362). FORMA FARMACEUTICA I ÚS. Aerosol (ús intern) $(556,557,558,59$ $1330,1361,1362)$. Tisana (ús intern) $(507,509,510,1330)$. Desconegut per l'informant (511, $512,513,514)$. PREPARACIÓ. Decocció $(507,509,510,1330)$. El comprem $(511,512,513$, $514)$. Per a fer bafs $(556,557,558)$. Decocció. Per a fer bafs $(753,754,755)$. Decocció. Fèiem bafs $(590)$. Bafs $(1330,1361,1362)$. DESTINACIÓ. Medicina humana.

Antipneumònic

FONT 1298. DESCRIPCIÓ DE L'ÚS FETA PER L'INFORMANT. Ho feia servir el seu pare quan va tenir pulmonia. FORMA FARMACĖUTICA I ÚS. Aerosol (ús intern). PREPARACIÓ. Vapors de fulles d'eucaliptus. DESTINACIÓ. Medicina humana. OBSERVACIONS. EI compraven perquè aquí no n'hi ha.

Expectorant

FONTS 565, 566, 1353, 1354. DESCRIPCIÓ DE L'ÚS FETA PELS INFORMANTS. Va bé per a expectorar i per als pulmons $(565,566)$. Quan estàs tapat de pit $(1353)$. Quan estàs tapat del pit (1354). FORMA FARMACĖUTICA I ÚS. Tintura alcohòlica (ús intern) $(565,566)$ Aerosol (ús intern) $(1353,1354)$. PREPARACIÓ. Posar mig litre d'aiguardent, un quart de me i eucaliptus, deixar-ho nou dies a sol i serena $(565,566)$. Per a fer bafs $(1353,1354)$. MODE D'UTILITZACIÓ/POSOLOGIA. S'ha de prendre el matí $(565,566)$. DESTINACIÓ. Medicina humana.

Mucolític 
Apèndix 1. Catàleg de tàxons.

FONTS 565, 566. DESCRIPCIÓ DE L'ÚS FETA PELS INFORMANTS. Per a la sinusitis. FORMA FARMACĖUTICA I ÚS. Aerosol (ús intern). PREPARACIÓ. Bafs d'eucaliptus. DESTINACIÓ. Medicina humana.

\section{ALTRES OBSERVACIONS}

FONTS 556, 557, 1298. DESCRIPCIÓ FETA PELS INFORMANTS. Ens en duien $(556,557)$ Aquí no n'hi ha (1298).

\section{BARREGES AMB AQUEST TÀXON}

Fruit

FONT 553. Entrevista 77, barreja II (vegeu catàleg de barreges)

Fulla

FONTS 565, 566. Entrevista 85 (vegeu catàleg de barreges)

\section{Euphorbia lathyris L. (euforbiàcies)}

BCN 24884

\section{NOMS POPULARS}

Herba talpera $(541,1328,1329)$

Herba talpinera $(529,530,531)$

\section{ALTRES USOS}

Planta viva in situ

Repel·lents

FONTS 529, 530, 531, 541, 1298, 1328, 1329. DESCRIPCIÓ DE L'ÚS FETA PELS INFORMANTS. Als taups no els agrada $(529,530,531)$. No vénen els talps a l'hort (541) Explica que allà on hi planten aquesta planta, els talps ja no hi talpinen [dit "tupinen"] més (1298). Si la tens a l'hort, no tens talps, és repel-lent dels taups $(1328,1329)$. OBSERVACIONS. No sap quina planta és (1298)

\section{Euphorbia marginata Pursh (euforbiàcies)}

\section{BCN 54463}

\section{NOMS POPULARS}

Flor de la núvia (504)

Flor de núvia (564)

\section{ALTRES USOS}

Part aèria florida

Ornamental: elaboració de rams

FONT 504. DESCRIPCIÓ DE L'ÚS FETA PER L'INFORMANT. Per a fer rams.

Planta viva ex situ

Ornamental: jardineria

FONT 564. DESCRIPCIÓ DE L'ÚS FETA PER L'INFORMANT. En tinc a l'hort, per a fer bonic.

\section{Euphorbia sp. (euforbiàcies)}

\section{NOMS POPULARS}

Lleteresa $(507,509,510,529,530,531,1352)$

Lletona (590)

\section{USOS MEDICINALS}

Làtex

Antiberrugós

FONT 590. DESCRIPCIÓ DE L'ÚS FETA PER L'INFORMANT. Per a les berrugues. FORMA FARMACĖUTICA I ÚS. Sense forma farmacèutica (ús directe, ús extern). PREPARACIÓ. S'utilitza la llet blanca. DESTINACIÓ. Medicina humana.

\section{ACCIONS NOCIVES O TÒXIQUES}

Làtex

FONTS 507, 509, 510, 1352. DESCRIPCIÓ DE L'ACCIÓ NOCIVA O TÒXICA FETA PELS INFORMANTS. Són irritants $(507,509,510)$. A un meu oncle li varen dir que la llet d'aquesta planta augmentava la potència sexual, ho va voler provar i se li van inflamar i irritar els testicles, va haver de pujar el metge a Setcases (1352). VIA D'INTOXICACIO. Via externa $(507,509,510)$.

No consta

FONTS 529, 530, 531. DESCRIPCIÓ DE L'ACCIÓ NOCIVA O TÒXICA FETA PELS INFORMANTS. Són verinoses, hi ha gent que s'hi cura les berrugues, però per mi són dolentes.

Euphrasia stricta D.Wolff ex J.F.Lehm. (escrofulariàcies) 
BCN 24885

\section{NOMS POPULARS}

Eufràsia $(507,509,510,581,1324)$

\section{USOS MEDICINALS}

\section{Part aèria florida}

Antisèptic ocular

FONTS 507, 509, 510, 581, 1324. DESCRIPCIÓ DE L'ÚS FETA PELS INFORMANTS. Per a rentar els ulls $(507,509,510)$. Va bé per als ulls (581). Per a rentar els ulls inflamats (1324) FORMA FARMACĖUTICA I ÚS. Bany (ús extern). PREPARACIÓ. Decocció (507, 509, 510 $581,1324)$. DESTINACIÓ. Medicina humana. OBSERVACIONS. Me la va ensenyar la Marta (581).

\section{Fagopyrum esculentum Moench (poligonàcies)}

\section{BCN 24886}

\section{NOMS POPULARS}

Fajol $(525,526,527,541,565,566,589,1324)$

\section{USOS ALIMENTARIS}

Llavor

Ingestió de la part de la planta cuita - Cuita en aigua

FONTS 525, 526, 527, 541, 565, 566, 589, 1324. DESCRIPCIÓ DE L'ÚS FETA PELS INFORMANTS. Se'n feien farinetes. La grana també es donava als polls. En el temps de la misèria la farina es barrejava amb la farina de blat per a fer el pa. La farina és grisosa i molt gustosa. Les farinetes també es menjaven amb mel $(525,526,527)$. Abans se'n feia per a menjar (541). Per a fer farinetes. S'ha de bullir la farina amb aigua, s'ha de vigilar perquè s'espesseeix molt. Després te'n posaves una llossada i es menjava calent amb una mica de mel o sucre. Però eren més bones l'endemà, quedaven ben preses i les havies de tallar amb ganivet, les fregies amb una mica de greix i hi posaves un xic de sucre o mel $(565,566)$. En fèiem farinetes, eren prou bones (589). Les farinetes són molt bones (1324). DESTINACIÓ. Alimentació humana $(525,526,527,541,565,566,589,1324)$.

No consta el tipus d'ingesta - No consta el mode de preparació

FONTS 525, 526, 527. DESCRIPCIÓ DE L'ÚS FETA PELS INFORMANTS. La grana també es donava als polls. DESTINACIÓ. Alimentació animal.
Fagus sylvatica L. (fagàcies)

BCN 27269

\section{NOMS POPULARS}

Faig $(586,587,1353,1354)$

\section{ALTRES USOS}

\section{Planta viva in situ}

Maneig agrosilvopastoral: ús hortícola/agrícola

FONTS 586, 587. DESCRIPCIÓ DE L'ÚS FETA PELS INFORMANTS. Quan el faig fa rama, és el temps de fer el blat de moro.

Tija

Fuster: elaboració de mobles

FONTS 1353, 1354. DESCRIPCIÓ DE L'ÚS FETA PELS INFORMANTS. La fusta es fa servir per a fer mobles.

Festuca eskia Ramond ex DC. in Lam. et DC. (gramínies) BCN 44800

\section{NOMS POPULARS}

Llispet (541)

\section{ALTRES OBSERVACIONS}

FONT 541. DESCRIPCIÓ FETA PER L'INFORMANT. Es coneixia molt perquè és una gramínia molt corrent que està per molts llocs i fa relliscar.

\section{Ficus carica L. (moràcies)}

BCN 24887

\section{NOMS POPULARS}

Figa (fruit) $(1215,1294)$

Figa borda (fruit) $(547,548)$

Figuera $(560,564,583,584,585,589,590,1335)$ 


\section{USOS MEDICINALS}

\section{Infructescència}

Anticatarral

FONT 1335. DESCRIPCIÓ DE L'ÚS FETA PER L'INFORMANT. Per als constipats. FORMA FARMACĖUTICA I ÚS. Tisana (ús intern). PREPARACIÓ. Les figues seques i bullides. DESTINACIÓ. Medicina humana.

Làtex

Antiberrugós

FONTS 547, 548, 590. DESCRIPCIÓ DE L'ÚS FETA PELS INFORMANTS. La llet per a les berrugues $(547,548)$. El suc de les figues va bé per a les berrugues (590). FORMA FARMACEUTICA I US. Sense forma farmacèutica (ús directe, ús extern). DESTINACIÓ. Medicina humana.

\section{Part aèria}

Galactòfug

FONTS 583, 584, 585. DESCRIPCIÓ DE L'ÚS FETA PELS INFORMANTS. Per a la gossa que vols que perdi la llet. FORMA FARMACĖUTICA I ÚS. Sense forma farmacèutica (ús directe, ús extern). PREPARACIÓ. Fer un collar de la planta de figuera. DESTINACIÓ. Medicina veterinària.

\section{USOS ALIMENTARIS}

Fruit

Ingestió de la part de la planta crua - Fresca (sense preparació)

FONT 1215. DESCRIPCIÓ DE L'ÚS FETA PER L'INFORMANT. Per a menjar i també per a engreixar els porcs. DESTINACIÓ. Alimentació animal.

Ingestió de la part de la planta crua - Fresca (sense preparació)

FONTS 564, 589. DESCRIPCIÓ DE L'ÚS FETA PELS INFORMANTS. Hi havia figues a punta pala. En el temps de les figues tots els animals s'engreixaven, també els gossos que en aquell temps passaven molta gana (564). Al Noassar hi havia figues, aquí no n'hi ha, pero com que érem amics ens en donaven (589). DESTINACIÓ. Alimentació animal (564). Alimentació humana $(564,589)$.

Ingestió de la part de la planta cuita - Cuita en sucre

FONT 560. DESCRIPCIÓ DE L'ÚS FETA PER L'INFORMANT. Es feia prunat (prunes figues) es coïa [dit "covia"] amb sucre i llavors es colava, quedava com una confitura. DESTINACIÓ. Alimentació humana.

\section{ALTRES OBSERVACIONS}

FONTS 560, 564. DESCRIPCIÓ FETA PELS INFORMANTS. N'hi havia als horts (560). L'any 1956 va fer molt fred i les va matar (564)

\section{BARREGES AMB AQUEST TÀXON}

Fruit

FONT 1294. Entrevista 6, barreja I (vegeu catàleg de barreges)

Filipendula ulmaria (L.) Maxim. (rosàcies)

BCN 120451

\section{NOMS POPULARS}

Ulmària (581)

\section{USOS MEDICINALS}

\section{No consta}

Analgèsic

FONT 581. FORMA FARMACĖUTICA I ÚS. Desconegut per l'informant. DESTINACIÓ. Medicina humana. OBSERVACIONS. L'aspirina, la van treure d'aquesta planta, ho vaig llegir a l'enciclopèdia. L'he conegut de fa poc. La flor fa una olor molt forta semblant a la de sabuc, pero ofen una mica de tant forta com és.

\section{ALTRES OBSERVACIONS}

FONT 581. DESCRIPCIÓ FETA PER L'INFORMANT. Floreix a finals d'estiu i es fa a les molleres.

Foeniculum vulgare Mill. (umbel·líferes)

BCN 24888

\section{NOMS POPULARS}

Fonoll $(504,507,509,510,515,516,520,521,528,529,530,531,554,555,561,562,563$ $564,569,570,572,573,574,575,576,577,580,581,748,749,1313,1327,1330,1331$ )

\section{USOS MEDICINALS}

Fruit

Antiinflamatori intestina

FONTS 507, 509, 510, 561, 562, 563. DESCRIPCIÓ DE L'ÚS FETA PELS INFORMANTS Per al mal de ventre $(507,509,510)$. Per a la panxa de les criatures $(561,562,563)$. FORMA 
FARMACĖUTICA I ÚS. Tisana (ús intern). PREPARACIÓ. Decocció (507, 509, 510, 561, 562, 563). DESTINACIÓ. Medicina humana.

Carminatiu

FONTS 520, 521. DESCRIPCIÓ DE L'ÚS FETA PELS INFORMANTS. Per als gasos. FORMA FARMACĖUTICA I ÚS. Tisana (ús intern). PREPARACIÓ. Decocció. DESTINACIÓ. Medicina humana.

Galactogen

FONTS 515, 516. DESCRIPCIÓ DE L'ÚS FETA PELS INFORMANTS. Aigua de fonoll per a fer pujar la llet a les dones. FORMA FARMACĖUTICA I ÚS. Tisana (ús intern). PREPARACIÓ. Decocció. DESTINACIÓ. Medicina humana.

Per a trastorns del sistema respiratori

FONT 580. DESCRIPCIÓ DE L'ÚS FETA PER L'INFORMANT. Va bé per als que s'afoguen. FORMA FARMACĖUTICA I ÚS. Tisana (ús intern). PREPARACIÓ. Decocció. Fa una aigua molt bona amb gust d'anís. DESTINACIÓ. Medicina humana.

Protector renal

FONTS 554, 555. DESCRIPCIÓ DE L'ÚS FETA PELS INFORMANTS. La grana és molt bona per als ronyons. FORMA FARMACĖUTICA I ÚS. Tisana (ús intern). PREPARACIÓ. Decocció. DESTINACIÓ. Medicina humana.

\section{USOS ALIMENTARIS}

Fruit

Condiment

FONTS 572, 573. DESCRIPCIÓ DE L'ÚS FETA PELS INFORMANTS. La grana per a cuinar, per a fer sarsueles de peix, per a posar a les olives. DESTINACIÓ. Alimentació humana.

\section{Part aèria}

Condiment

FONTS 504, 569, 570, 574, 575, 576, 577, 1313, 1327. DESCRIPCIÓ DE L'ÚS FETA PELS INFORMANTS. Per a condimentar els cuinats (504). Per a menjar, a vegades amb el peix però no gaire, no el fem servir $(569,570)$. Es posava a la xocolata desfeta $(574,575,576$ 577). Per a fer fumet de peix (1313). Per a cuinar (1327). DESTINACIÓ. Alimentació humana $(504,569,570,574,575,576,577,1313,1327)$.

Ingestió de la part de la planta crua - Fresca (sense preparació)

FONTS 564, 569, 570, 581. DESCRIPCIÓ DE L'ÚS FETA PELS INFORMANTS. Hi ha gent que se'l menja amanit $(569,570)$. Hi ha gent que s'ho menja amanit (581). Per als conills (564). DESTINACIO. Alimentació humana $(569,570,581)$. Alimentació animal (564).

Ingestió de la part de la planta cuita - Cuita en aigua

FONTS 529, 530, 531, 748, 749. DESCRIPCIÓ DE L'ÚS FETA PELS INFORMANTS. Es poden menjar bullits. En no sé qui en va menjar i li varen fer mal $(748,749)$. Per a fer sopes (529, 530, 531). DESTINACIÓ. Alimentació humana (529, 530, 531, 748, 749).
Ingestió de la part de la planta cuita - Cuita en ol

FONT 528. DESCRIPCIÓ DE L'ÚS FETA PER L'INFORMANT. En truita és bo DESTINACIÓ. Alimentació humana.

Preparació de begudes - Beguda preparada amb aigua

FONT 1331. DESCRIPCIÓ DE L'ÚS FETA PER L'INFORMANT. Per a beure, perquè és bo DESTINACIÓ. Alimentació humana.

\section{BARREGES AMB AQUEST TÀXON}

\section{Part aèria}

FONT 1330. Entrevista 32, barreja III (vegeu catàleg de barreges)

\section{Forsythia suspensa Vahl (oleàcies)}

BCN 47708

\section{NOMS POPULARS}

Ginesta de jardí (564)

\section{USOS ALIMENTARIS}

\section{Poncella}

Ingestió de la part de la planta crua - Fresca (sense preparació)

FONT 564. DESCRIPCIÓ DE L'ÚS FETA PER L'INFORMANT. Els ocelles es mengen les poncelles. DESTINACIÓ. Alimentació animal.

\section{ALTRES OBSERVACIONS}

FONT 564. DESCRIPCIÓ FETA PER L'INFORMANT. Hi ha anys que quasi no pot flori perquè els ocelles es mengen les poncelles.

\section{Fragaria vesca L. (rosàcies)}

\section{BCN 24889}

\section{NOMS POPULARS}

Maduixa (fruit) $(524,549,553,561,562,563,564,571,572,573,580,583,584,585,1313$ $1321,1324,1353,1354)$

Maduixa de bosc (fruit) (560)

Maduixera $(511,512,513,514,590)$ 


\section{USOS MEDICINALS}

Fruit

Hipouricemiant

FONT 553. DESCRIPCIÓ DE L'ÚS FETA PER L'INFORMANT. Diuen que si en menges quantitat va bé per a la gota. FORMA FARMACĖUTICA I ÚS. Sense forma farmacèutica (ús directe, ús intern). DESTINACIO. Medicina humana.

\section{USOS ALIMENTARIS}

\section{Fruit}

Ingestió de la part de la planta crua - Conservada en vi

FONTS 583, 584, 585, 590. DESCRIPCIÓ DE L'ÚS FETA PELS INFORMANTS. Les maduixes de bosc són bones amb sucre i vi dolç (590). Ens les menjàvem amb vi i sucre $(583,584,585)$. DESTINACIÓ. Alimentació humana $(583,584,585,590)$.

Ingestió de la part de la planta crua - Fresca (sense preparació)

FONTS 511, 512, 513, 514, 524, 549, 560, 561, 562, 563, 571, 572, 573, 580, 1313, 1321 1324, 1353, 1354. DESCRIPCIÓ DE L'ÚS FETA PELS INFORMANTS. El fruit per a menjar $(511,512,513,514)$. Per a menjar $(524,571,572,573,1313,1353,1354)$. N'anàvem a buscar per a menjar $(549,560)$. Ens les mengem (580). Són bones per a menjar (1324). Per a menjar cru (1321). OBSERVACIONS. N'anàvem a buscar $(561,562,563)$. DESTINACIÓ. Alimentació humana $(511,512,513,514,524,549,560,561,562,563,571,572,573,580$ $1313,1321,1324,1353,1354)$

Ingestió de la part de la planta cuita - Cuita en sucre

FONT 560. DESCRIPCIÓ DE L'ÚS FETA PER L'INFORMANT. Per a fer confitures. DESTINACIÓ. Alimentació humana.

\section{ALTRES USOS}

Fruit

Altres informacions

FONTS 560, 564. DESCRIPCIÓ DE L'ÚS FETA PELS INFORMANTS. Hi havia gent que les anava a buscar i després se les venien (560). S'anaven a buscar i es venien als senyors de Camprodon (564)

\section{Fraxinus excelsior L. (oleàcies)}

BCN 24890

\section{NOMS POPULARS}

Freixe $(505,506,507,509,510,520,521,522,523,529,530,531,535,539,540,541,547$ (13) $1361,1362)$

\section{USOS MEDICINALS}

\section{Flor}

Hepatoprotector

FONTS 507, 509, 510. DESCRIPCIÓ DE L'ÚS FETA PELS INFORMANTS. Aigua de la flor del freixe per al fetge. FORMA FARMACÉUTICA I ÚS. Tisana (ús intern). PREPARACIÓ. Decocció. DESTINACIÓ. Medicina humana.

Fruit

Analgèsic

FONTS 1314, 1361, 1362. DESCRIPCIÓ DE L'ÚS FETA PELS INFORMANTS. Va bé per al dolor (1314). Per al dolor (1361, 1362). FORMA FARMACĖUTICA I ÚS. Tisana (ús intern) PREPARACIÓ. Decocció. Aigua de les granes (1314). Decocció $(1361,1362)$. DESTINACIÓ. Medicina humana.

Hipolipemiant

FONT 1331. DESCRIPCIÓ DE L'ÚS FETA PER L'INFORMANT. Per a fer baixar el colesterol. FORMA FARMACĖUTICA I ÚS. Tisana (ús intern). PREPARACIÓ. Decocció. Les granes en aigua. DESTINACIÓ. Medicina humana.

Laxant

FONT 1299. DESCRIPCIÓ DE L'ÚS FETA PER L'INFORMANT. Per al restrenyiment. FORMA FARMACĖUTICA I ÚS. Tisana (ús intern). PREPARACIÓ. Decocció. Es fa aigua de les fulles i també de les granes. MODE D'UTILITZACIO/POSOLOGIA. Una tassa al matí una al vespre durant tres o quatre dies. DESTINACIÓ. Medicina humana.

Fulla

Antidiarreic

FONTS 505, 506. DESCRIPCIÓ DE L'ÚS FETA PELS INFORMANTS. Per a la diarrea del bestiar. FORMA FARMACĖUTICA I ÚS. Tisana (ús intern). PREPARACIÓ. Decocció. Aigua de les fulles. DESTINACIÓ. Medicina veterinària.

Antireumàtic

FONTS 539, 540, 1213, 1214. DESCRIPCIÓ DE L'ÚS FETA PELS INFORMANTS. Per al reuma $(539,540)$. Alleuja tot tipus de dolor reumàtic $(1213,1214)$. FORMA FARMACĖUTICA I ÚS. Tisana (ús intern). PREPARACIÓ. Infusió de 30 grams de fulles, aproximadament, per un litre d'aigua (1214). Prepareu una infusió de 30 grams de fulles, aproximadament, per un litre d'aigua (1213). MODE D'UTILITZACIÓ/POSOLOGIA. Tres cops al dia $(1213,1214)$ DESTINACIÓ. Medicina humana.

Antisèptic extern 
FONTS 529, 530, 531. DESCRIPCIÓ DE L'ÚS FETA PELS INFORMANTS. Les fulles de freixe són molt desinfectants. FORMA FARMACĖUTICA I Ús. Bany (ús extern). PREPARACIÓ. Decocció. DESTINACIÓ. Medicina humana.

Antisèptic ocular

FONT 535. DESCRIPCIÓ DE L'ÚS FETA PER L'INFORMANT. Per a rentar els ulls. FORMA FARMACĖUTICA I ÚS. Bany (ús extern). PREPARACIÓ. Decocció. Aigua de les fulles. DESTINACIÓ. Medicina humana.

Laxant

FONTS 1299, 1330. DESCRIPCIÓ DE L'ÚS FETA PELS INFORMANTS. Per al restrenyiment (1299). És laxant (1330). FORMA FARMACĖUTICA I ÚS. Tisana (ús intern). PREPARACIÓ. Decocció. Es fa aigua de les fulles i també de les granes (1299). Decocció (1330). MODE D'UTILITZACIÓ/POSOLOGIA. Una tassa al matí i una al vespre durant tres o quatre dies (1299). DESTINACIÓ. Medicina humana.

Restauratiu

FONTS 505, 506. DESCRIPCIÓ DE L'ÚS FETA PELS INFORMANTS. Quan les gallines s'emmalaltien. FORMA FARMACĖUTICA I ÚS. Macerat en aigua (ús intern). PREPARACIÓ. S'els posava brocs de freixe a l'aigua que bevien. DESTINACIÓ. Medicina veterinària.

\section{Gemmes de les fulles}

Antidiarreic

FONTS 1332, 1333, 1334. DESCRIPCIÓ DE L'ÚS FETA PELS INFORMANTS. Per a la diarrea. FORMA FARMACĖUTICA I ÚS. Tisana (ús intern). PREPARACIÓ. Decocció. Aigua de caps de freixe. DESTINACIÓ. Medicina humana.

\section{Parènquima cortical}

\section{Antihipertensiu}

FONTS 507, 509, 510. DESCRIPCIÓ DE L'ÚS FETA PELS INFORMANTS. La segona pela per a fer baixar la pressió. FORMA FARMACĖUTICA I ÚS. Tisana (ús intern). PREPARACIÓ. Decocció.

Antiinflamatori faringi

FONTS 583, 584, 585. DESCRIPCIÓ DE L'ÚS FETA PELS INFORMANTS. El vell Coronetes es prenia aigua de la segona pell per al coll. FORMA FARMACĖUTICA I ÚS. Tisana (ús intern). PREPARACIÓ. Decocció. DESTINACIÓ. Medicina humana.

Antisèptic extern

FONTS 520, 521, 522, 523, 578, 579, 583, 584, 585, 590. DESCRIPCIÓ DE L'ÚS FETA PELS INFORMANTS. Per a botidures i encetats $(522,523)$. La pela és bona per a desinfectar ferides $(520,521)$. La pela per a desinfectar ferides, sobretot es feia servir per al bestiar $(578,579)$. La pela és bona per a desinfectar ferides del bestiar $(590)$. La segona pell és més suavitzant $i$ es fa servir per a banyar els mals $(583,584,585)$. FORMA FARMACĖUTICA I ÚS. Bany (ús extern). PREPARACIÓ. Decocció. Aigua de la pela i dels tronquets per a desinfectar $(522,523)$. Decocció $(520,521,578,579,583,584,585,590)$. DESTINACIÓ. Medicina humana $(520,521,522,523,583,584,585,590)$. Medicina veterinària $(578,579)$. OBSERVACIONS. La primera pell és contraverí [dit "contravereno"] $(583,584,585)$.

Vulnerari

FONTS 748, 749. FORMA FARMACĖUTICA I ÚS. Sense forma farmacèutica (ús directe, ús extern). PREPARACIÓ. La segona pela tallada com una llesca posada a sobre les ferides. DESTINACIÓ. Medicina humana.

\section{Part aèria}

Antidiarreic

FONTS 505, 506. DESCRIPCIÓ DE L'ÚS FETA PELS INFORMANTS. Per a la diarrea del bestiar se'ls donava rama per a menjar. FORMA FARMACĖUTICA I Ús. Sense forma farmacèutica (ús directe, ús extern). DESTINACIÓ. Medicina veterinària.

Antiestàtic ruminal

FONTS 572, 573. DESCRIPCIÓ DE L'ÚS FETA PELS INFORMANTS. Pel setembre anaves a fer branca de freixe i es donava a les vaques i ovelles; diu que els va bé per al remuc. FORMA FARMACĖUTICA I ÚS. Sense forma farmacèutica (ús directe, ús intern). DESTINACIÓ. Medicina veterinària.

\section{USOS ALIMENTARIS}

\section{Part aèria}

Ingestió de la part de la planta crua - Conservada dessecada a l'aire

FONTS 565, 566, 568, 572, 573, 583, 584, 585. DESCRIPCIÓ DE L'ÚS FETA PELS INFORMANTS. Es feia rama per a les vaques i també es donava als conills. Es feia al setembre i es deixava assecar a l'ombra (568). Per a engreixar els xais els donàvem rama de freixe verda. També en guardàvem de seca per a donar a les vaques en comptes d'userda $(565,566)$. S'assecava i se'n feien garbons, es donava als conills $(572,573)$. Es feia rama per a donar a les cabres i als cabrits $(583,584,585)$. DESTINACIÓ. Alimentació animal $(565$ $566,568,572,573,583,584,585)$.

Ingestió de la part de la planta crua - Fresca (sense preparació)

FONTS 541, 565, 566, 574, 575, 576, 577, 589, 1215. DESCRIPCIÓ DE L'ÚS FETA PELS INFORMANTS. La rama es donava als conills (541). Per a engreixar els xais els donàvem rama de freixe verda Tambe en guardàn de d'u $(565,566)$. La d'userda (565, 566). La rama Per als conills i els xais (1215). DESTINACIÓ. Alimentació animal $(541,565,566,574,575$,
$576,577,589,1215)$.

\section{ALTRES USOS}

\section{Parènquima cortical}

Artesanal: elaboració d'instruments musicals

FONT 541. DESCRIPCIÓ DE L'ÚS FETA PER L'INFORMANT. S'utilitzava el freixe per a musicar, perquè se'n va molt fàcilment la pela. 


\section{Planta sencera}

Creences i pràctiques magicoreligioses

FONTS 547, 548. DESCRIPCIÓ DE L'ÚS FETA PELS INFORMANTS. Quan un nen petit s'herniava, amb un tascó s'obria un freixe viu i hi feien passar el nen.

Literatura oral popular: llegendes, gloses, contes, dites, refranys, poemes, cançons

FONTS 1213, 1214. DESCRIPCIÓ DE L'ÚS FETA PELS INFORMANTS. Qui té dolor i pren freixe, el bastó al racó deixa.

Tija

Domèstic: ajudes a la llar

FONT 1352. DESCRIPCIÓ DE L'ÚS FETA PER L'INFORMANT. Per a fer les paletes per a rentar la roba.

Domèstic: ajudes en la costura

FONT 1215. DESCRIPCIÓ DE L'ÚS FETA PER L'INFORMANT. Per a fer botons.

Fuster: construcció de vehicles amb rodes

FONT 1215. DESCRIPCIÓ DE L'ÚS FETA PER L'INFORMANT. Per a fer les rodes de carro.

Els cèrcols i els radis es feien d'alzina i el botó de freixe.

Maneig agrosilvopastoral: ús hortícola/agrícola

FONTS 1215, 1352. DESCRIPCIÓ DE L'ÚS FETA PELS INFORMANTS. Per a fer els mànecs de l'aixada de fangar (1215). Per a fer les forques de remenar l'herba (1352).

\section{BARREGES AMB AQUEST TÀXON}

Fulla

FONTS 1213, 1214. Entrevista 102, barreja V (vegeu catàleg de barreges)

FONTS 529, 530, 531. Entrevista 53, barreja I (vegeu catàleg de barreges)

Parènquima cortical

FONT 1317. Entrevista 21, barreja III (vegeu catàleg de barreges)

FONT 1318. Entrevista 31, barreja IV (vegeu catàleg de barreges)

\section{Gagea fistulosa (Ram. ex DC.) Ker-Gawler (liliàcies)}

BC 639665

\section{NOMS POPULARS}

Xarvió (541)

USOS ALIMENTARIS
Bulb

Ingestió de la part de la planta cuita - Cuita en aigua

FONT 541. DESCRIPCIÓ DE L'ÚS FETA PER L'INFORMANT. Fa una patateta que es pot menjar. DESTINACIÓ. Alimentació humana.

\section{ALTRES OBSERVACIONS}

FONT 541. DESCRIPCIÓ FETA PER L'INFORMANT. Als camps de conreu n'hi ha.

\section{Galanthus nivalis L. (amaril·lidàcies)}

BCN 27249

\section{NOMS POPULARS}

Herba de neu $(542,543,544)$

Llàgrimes de Sant Josep $(1353,1354)$

Lliri de neu $(569,570)$

\section{ALTRES USOS}

Part aèria florida

Ornamental: elaboració de rams

FONTS 542, 543, 544, 1353, 1354. DESCRIPCIÓ DE L'ÚS FETA PELS INFORMANTS. En podem fer algun ramet $(542,543,544)$. Per a fer un ramet $(1353,1354)$

\section{ALTRES OBSERVACIONS}

FONTS 542, 543, 544, 569, 570, 1353, 1354. DESCRIPCIÓ FETA PELS INFORMANTS. Surt quan tot just se'n va la neu $(542,543,544)$. N'hi ha per les vores dels recs i floreixen a finals de gener i febrer. Abans no m'hi havia fixat que n'hi havia, deu ser que quan floreix encara fa molt fred, fa potser 10 anys que els veig $(569,570)$. Són les primeres flors que surten $(1353$ 1354).

Galium aparine L. (rubiàcies)

BSCN27293

\section{NOMS POPULARS}

Rèvola $(520,521,1324)$ 


\section{ALTRES OBSERVACIONS}

FONTS 520, 521, 1324. DESCRIPCIÓ FETA PELS INFORMANTS. Fa anar malament els cultius de blat $(520,521)$. Surt al mig dels camps de blat i si n'hi ha molta s'ha d'arrencar (1324)

\section{Galium maritimum L. (rubiàcies)}

BCN 24891

\section{NOMS POPULARS}

Herba espunyidera (1324)

\section{USOS ALIMENTARIS}

\section{Part aèria}

Ingestió de la part de la planta crua - Fresca (sense preparació)

FONT 1324. DESCRIPCIÓ DE L'ÚS FETA PER L'INFORMANT. Es donava per a menjar als conills. DESTINACIO. Alimentació animal.

\section{Galium verum L. (rubiàcies)}

BCN 39982

\section{NOMS POPULARS}

Herba de Sant Joan $(583,584,585)$

Santjoans $(529,530,531)$

\section{ALTRES USOS}

\section{Planta sencera}

Altres informacions

FONTS 529, 530, 531. DESCRIPCIÓ DE L'ÚS FETA PELS INFORMANTS. La Roser i jo n'agafàvem quan érem petites.

Genista balansae (Boiss.) Rouy subsp. europaea (G.López et Ch.E.Jarvis) O.Bolòs et J.Vigo (papilionàcies)

BCN 113229

\section{NOMS POPULARS}

Bàlec $(541,553)$

Genista scorpius (L.) DC. in Lam. et DC. subsp. scorpius (papilionàcies)

BCN 27292

\section{NOMS POPULARS}

Argelaga $(515,516,518,519,520,521,589,1215,1324)$

\section{USOS MEDICINALS}

\section{Flor}

Antipirètic

FONTS 515, 516. DESCRIPCIÓ DE L'ÚS FETA PELS INFORMANTS. Per a fer baixar la febre. FORMA FARMACĖUTICA I ÚS. Tisana (ús intern). PREPARACIÓ. Decocció DESTINACIÓ. Medicina humana.

\section{Part aèria}

Antipirètic

FONTS 518, 519, 520, 521, 1324. DESCRIPCIÓ DE L'ÚS FETA PELS INFORMANTS. Per a fer baixar la febre $(518,519,520,521,1324)$. FORMA FARMACĖUTICA I ÚS. Tisana (ús intern). PREPARACIÓ. Decocció. Aigua de la planta $(518,519)$. Decocció $(520,521,1324)$ DESTINACIÓ. Medicina humana.

\section{ALTRES USOS}

\section{Part aèria}

Obtenció de combustible: llenya

FONT 1215. DESCRIPCIÓ DE L'ÚS FETA PER L'INFORMANT. Per a cremar.

\section{ACCIONS NOCIVES O TÒXIQUES}

Fruit

FONT 1324. DESCRIPCIÓ DE L'ACCIÓ NOCIVA O TÒXICA FETA PER L'INFORMANT. Les tavelles són tòxiques, és per això que s'han de collir les flors abans que surtin els fruits.

\section{ALTRES OBSERVACIONS}

FONT 589. DESCRIPCIÓ FETA PER L'INFORMANT. Aquí n'hi ha i només serveixen per a embrutir el terme. 


\section{Gentiana acaulis L. (gencianàcies)}

BCN 24892

\section{NOMS POPULARS}

Campaneta (552)

Genciana (1321)

\section{ALTRES OBSERVACIONS}

FONT 552. DESCRIPCIÓ FETA PER L'INFORMANT. Són petites i es fan els marges, quan surten indiquen la primavera.

\section{Gentiana lutea L. (gencianàcies)}

BCN 24893

\section{NOMS POPULARS}

Genciana $(511,512,513,514,520,521,528,529,530,531,533,534,541,542,543,544$ $547,548,552,553,554,555,556,557,559,561,562,563,568,571,572,573,574,575$ $576,577,583,584,585,586,587,588,590,746,753,754,755,1293,1297,1310,1313$ $1314,1317,1318,1319,1321,1328,1329,1330,1332,1333,1334,1337,1338,1339,1340$ $1341,1342,1343,1344,1345,1346,1347,1348,1349,1350,1351)$

\section{USOS MEDICINALS}

\section{Arrel}

Antihipertensiu

FONTS 586, 587. DESCRIPCIÓ DE L'ÚS FETA PELS INFORMANTS. Per a la pressió FORMA FARMACĖUTICA I ÚS. Tisana (ús intern). PREPARACIÓ. Decocció. DESTINACIÓ. Medicina humana.

Antiinflamatori intestinal

FONT 1293. DESCRIPCIÓ DE L'ÚS FETA PER L'INFORMANT. Per a la panxa. FORMA FARMACEUTICA I US. Tisana (ús intern). PREPARACIÓ. Infusió de l'arrel. DESTINACIÓ. Medicina humana.

Cicatritzant

FONTS 1347, 1348, 1349. DESCRIPCIÓ DE L'ÚS FETA PELS INFORMANTS. Ajuda a pellar es ferides. FORMA FARMACEUTICA I US. Bany (ús extern). PREPARACIO. Decocció. Aigua de l'arrel. DESTINACIO. Medicina humana i veterinària.

Digestiu
FONT 1310. DESCRIPCIÓ DE L'ÚS FETA PER L'INFORMANT. Per a pair. FORMA FARMACĖUTICA I ÚS. Tisana (ús intern). PREPARACIÓ. Decocció. DESTINACIÓ. Medicina humana. OBSERVACIONS. L'aigua és molt amargant.

Hematocatàrtic

FONTS 753, 754, 755, 1332, 1333, 1334. DESCRIPCIÓ DE L'ÚS FETA PELS INFORMANTS. Per a agafar gana i ajudar a netejar [dit "llempiar"] les sangs $(753,754,755)$. $\checkmark a$ molt bé per a netejar la sang $(1332,1333,1334)$. FORMA FARMACĖUTICA I ÚS. Tisana (ús intern) $(753,754,755)$. Macerat en aigua (ús intern) $(1332,1333,1334)$. PREPARACIÓ (ús intern) $(753,754,755)$. La rel s'estova en aigua tota una nit i l'endemà t'ho prens (1332, Decocció $(753,754,755)$. La rel s'estova en aigua tota una nit i l'endemà t'ho prens (1332, novenes $(753,754,755)$. En dejú. Es pot fer una novena (nou dies), no més dies, perquè és novenes $(753,754,755)$. En dejú. Es pot fer una novena (nou dies), no mes dies, perquè és
molt forta i et podria fer mal $(1332,1333,1334)$. DESTINACIÓ. Medicina humana. molt forta i et podria fer mal $(1332,1333,1334)$
OBSERVACIONS. És molt amargant $(753,754,755)$.

Hipoglucemiant

FONTS 561, 562, 563, 586, 587, 1339. DESCRIPCIÓ DE L'ÚS FETA PELS INFORMANTS Per al sucre $(561,562,563)$. L'arrel és bona per a fer baixar el sucre $(586,587)$. Per a baixar el sucre (1339). FORMA FARMACĖUTICA I ÚS. Tisana (ús intern). PREPARACIÓ. Decocció $(561,562,563,586,587)$. Decocció. Aigua de la rel (1339). DESTINACIÓ. Medicina humana. Hipolipemiant

FONT 1340. DESCRIPCIÓ DE L'ÚS FETA PER L'INFORMANT. Per a baixar el sucre. FORMA FARMACĖUTICA I ÚS. Tisana (ús intern). PREPARACIÓ. Decocció. Aigua de la rel. DESTINACIÓ. Medicina humana.

Orexigen

FONTS $511,512,513,514,520,521,528,529,530,531,533,534,542,543,544,547,548$ $553,554,555,559,561,562,563,568,572,573,574,575,576,577,583,584,585,746$, $753,754,755,1293,1297,1310,1313,1314,1317,1318,1319,1321,1328,1329,1330$, 1337, 1338, 1339, 1340, 1341, 1342, 1343, 1344, 1345, 1346, 1347, 1348, 1349, 1350, 1351. DESCRIPCIÓ DE L'ÚS FETA PELS INFORMANTS. Per a fer venir la gana $(547,548,559$, $561,562,563,583,584,585)$. Per a fer agafar gana $(511,512,513,514,520,521,528,542$, $543,544,554,555,572,573,1310,1313,1314,1318,1337,1338,1339,1340,1343,1344$ $1345,1346,1347,1348,1349,1350)$. Per a fer venir la gana, es fa servir l'arrel $(746)$. La rel va bé per a agafar gana $(529,530,531)$. Per a fer venir gana $(533,534,553,574,575,576$ 577). "If). Li"] 1351). L' les sangs (753, 754, 755). Per a agafar gana (1293, 1317, 1321, 1328, 1329, 1351). Larrel per a fer agafar gana (1297). Deien que anava be per a agafar gana (1319). Per a posar gana (1330). Es molt bona per a agafar gana $(1341,1342)$. FORMA FARMACEUTCA US. Vi medicinal (ús intern) (559). Tisana (ús intern) $(511,512,513,514$ $520,521,528,529,530,531,533,534,542,543,544,553,554,555,561,562,563,568$, $572,573,574,575,576,577,746,753,754,755,1293,1297,1310,1313,1314,1317,1318$, $1319,1330,1337,1338,1339,1340,1343,1344,1345,1346,1347,1348,1349,1350$, 1351). Macerat en aigua (ús intern) $(547,548,583,584,585,1321,1328,1329,1341,1342)$. PREPARACIÓ. Diuen que en fan vermut (559). Decocció $(511,512,513,514,520,521,528$, $529,530,531,533,534,542,543,544,553,554,555,561,562,563,568,572,573,574$, 
$575,576,577,746,753,754,755,1297,1310,1313,1314,1317,1343,1344,1350,1351)$. Arrel estovada en aigua i te la bevies l'endemà $(547,548)$. En un porró es tallava la rel a rodanxes is ana Aigua de la rel $(1318,1319,1330,1337,1338,1339,1340,1345,1346)$. Cal macerar-la en aigua i l'endemà beure't aquesta aigua (1321). L'arrel estovada en aigua i beure't l'aigua $(1328,1329)$. Es posa a remull tota la nit, i lendemà et beus l'aigua $(1341,1342)$. Decocció Aigua de l'arrel $(1347,1348,1349)$. MODE DUTILITZACIO/POSOLOGIA. S'ha de prendre en dejú i s'han de fer novenes $(753,754,755)$. EFECTES SECUNDARIS. Sí. DESTINACIÓ Medicina humana. OBSERVACIONS. És amargant i se'n fa vermut $(533,534)$. És molt amargant $(547,548,753,754,755)$. L'aigua és molt amargant (1310). Un senyor que en va beure molta va canviar tota la pell $(1328,1329)$

Vasotònic

FONTS 586, 587. DESCRIPCIÓ DE L'ÚS FETA PELS INFORMANTS. Per a la circulació. FORMA FARMACĖUTICA I ÚS. Tisana (ús intern). PREPARACIÓ. Decocció. DESTINACIÓ. Medicina humana.

\section{USOS ALIMENTARIS}

Arrel

Preparació de begudes - Beguda preparada amb vi

FONTS 533, 534, 559, 1317, 1321. DESCRIPCIÓ DE L'ÚS FETA PELS INFORMANTS Diuen que en fan vermut $(559)$. Se'n fa vermut. Es amarganta $(533,534)$. Es posa arrel al vi per a fer vermut (1317). Diu que la posen al vermut (1321). DESTINACIÓ. Alimentació humana $(533,534,559,1317,1321)$.

\section{ALTRES USOS}

Arrel

Altres informacions

FONTS 542, 543, 544, 552, 571, 572, 573, 1310, 1317. DESCRIPCIÓ DE L'ÚS FETA PELS INFORMANTS. En recollien molta, per a les farmàcies (571). Els herbolaris n'agafaven molta (544). Els herbolaris n'agafaven molta $(542,543)$. Abans en compraven les arrels (552). Abans n'agafaven molta i la gent se la venia $(572,573)$. L'arrel es collia s'assecava i es venia, ell recorda que n'agafaven molta quantitat (1310). Abans la compraven molt, un any en va fe 400.000 pessetes (1317)

Ornamental: elaboració de rams

FONT 559. DESCRIPCIÓ DE L'ÚS FETA PER L'INFORMANT. Per a fer rams.

\section{ACCIONS NOCIVES O TÒXIQUES}

\section{No consta}

FONTS 547, 548. DESCRIPCIÓ DE L'ACCIO NOCIVA O TOXICA FETA PELS INFORMANTS. El bestiar no se la menja.

\section{Geranium robertianum L. (geraniàcies)}

BCN 24894

\section{NOMS POPULARS}

Cicuta $(520,521,525,526,527,528,532,549,556,557,571,572,573,574,575,576,577$ $582,1324,1325,1326,1327,1330,1335,1343,1344,1350,1351)$

Herba de Sant Robert (1324)

\section{USOS MEDICINALS}

\section{Part aèria}

Anticefalàlgic

FONTS 525, 526, 527. DESCRIPCIÓ DE L'ÚS FETA PELS INFORMANTS. Anava bé per al mal de cap. FORMA FARMACEUTICA I ÚS. Tintura alcohòlica (ús intern). PREPARACIÓ. Es feia esperit de tota la planta. DESTINACIÓ. Medicina humana.

Antiequimòtic

FONTS $556,557,574,575,576,577,1330,1343,1344,1350,1351$. DESCRIPCIÓ DE L'ÚS FETA PELS INFORMANTS. Per a untar els cops $(556,557)$. Per als cops $(574,575,576$, 577). Fa sortir els trucs (1330). Per a quan et fas un truc $(1343,1344)$. Per a fer sortir trucs enfora $(1350,1351)$. FORMA FARMACËUTICA I ÚS. Liniment (ús extern) $(556,557,574$ $575,576,577)$. Emplastre (ús extern) $(1330,1343,1344,1350,1351)$. PREPARACIÓ. Es feia un oli $(556,557)$. Es foia oli $(574,575,576,577)$. Picada amb sagí i tot escalfat a feia un oll $(556,557)$. Es feia oll $(574,575,576,577)$. Picada amb sagi tot escalfat a la paella per 1350, 1351)

Antihemorroïdal

FONT 1335. DESCRIPCIÓ DE L'ÚS FETA PER L'INFORMANT. Per a les morenes. FORMA FARMACĖUTICA I ÚS. Embrocació (ús extern). PREPARACIÓ. Fer bullir la planta amb oli. DESTINACIÓ. Medicina humana.

Antiherpètic

FONT 1335. DESCRIPCIÓ DE L'ÚS FETA PER L'INFORMANT. Per a les panses dels llavis. FORMA FARMACĖUTICA I ÚS. Embrocació (ús extern). PREPARACIÓ. Fer bullir la planta amb oli. DESTINACIÓ. Medicina humana.

Antihipertensiu

FONT 1335. DESCRIPCIÓ DE L'ÚS FETA PER L'INFORMANT. Per a fer baixar la pressió. FORMA FARMACĖUTICA I ÚS. Tisana (ús intern). PREPARACIÓ. En infusió. DESTINACIÓ. 
Medicina humana. OBSERVACIONS. S'ha d'anar amb compte perquè la pot fer baixar massa.

Antiinflamatori faringi

FONT 1324. DESCRIPCIÓ DE L'ÚS FETA PER L'INFORMANT. Per al mal de coll. FORMA FARMACĖUTICA I ÚS. Gargarisme (ús extern). PREPARACIÓ. Decocció. En fas gàrgares. DESTINACIÓ. Medicina humana.

Antineoplàstic

FONT 1324. DESCRIPCIÓ DE L'ÚS FETA PER L'INFORMANT. Anticancerigen. FORMA FARMACĖUTICA I ÚS. Tisana (ús intern). PREPARACIÓ. Decocció. DESTINACIÓ. Medicina humana.

Antiodontàlgic

FONT 1327. DESCRIPCIÓ DE L'ÚS FETA PER L'INFORMANT. Per al mal de queixal. FORMA FARMACĖUTICA I ÚS. Emplastre (ús extern). PREPARACIÓ. Picada amb vinagre posada a sobre un drap. DESTINACIÓ. Medicina humana.

Antipneumònic

FONTS 1325, 1326. DESCRIPCIÓ DE L'ÚS FETA PELS INFORMANTS. Trencava la pulmonia, quan la gent tenia mal de costat. FORMA FARMACĖUTICA I ÚS. Emplastre (ús extern). PREPARACIÓ. Es feien emplastres. DESTINACIÓ. Medicina humana.

Desconegut per l'informant

FONTS 520, 521. FORMA FARMACĖUTICA I ÚS. Ungüent (ús extern). PREPARACIÓ. En feien ungüents. DESTINACIO. Medicina humana.

Per a trastorns del sistema musculoesquelètic

FONTS 572, 573. DESCRIPCIÓ DE L'ÚS FETA PELS INFORMANTS. Per als tendrums [dit "tenrums"] que es fan amb trencadures d'ossos mal curats. FORMA FARMACĖUTICA I ÚS. Liniment (ús extern). PREPARACIÓ. Posada amb oli. DESTINACIÓ. Medicina humana.

\section{ACCIONS NOCIVES O TÒXIQUES}

No consta

FONTS 1350, 1351. DESCRIPCIÓ DE L'ACCIÓ NOCIVA O TÒXICA FETA PELS INFORMANTS. És verinosa.

\section{BARREGES AMB AQUEST TÀXON}

Part aèria

FONT 1324. Entrevista 5, barreja II (vegeu catàleg de barreges)

FONT 532. Entrevista 63, barreja I (vegeu catàleg de barreges)

FONT 549. Entrevista 75, barreja I (vegeu catàleg de barreges)

FONT 571. Entrevista 89, barreja III (vegeu catàleg de barreges)

FONTS 572, 573. Entrevista 90, barreja II (vegeu catàleg de barreges)
Part aèria jove

FONT 528. Entrevista 61, barreja I (vegeu catàleg de barreges)

Geum urbanum L. (rosàcies)

BCN 24895

\section{NOMS POPULARS}

Herba de Sant Benet (1324)

\section{USOS MEDICINALS}

\section{Part aèria}

Antidiarreic

FONT 1324. DESCRIPCIÓ DE L'ÚS FETA PER L'INFORMANT. Per a la diarrea. FORMA FARMACĖUTICA I ÚS. Tisana (ús intern). PREPARACIÓ. En infusió. DESTINACIÓ. Medicina humana.

\section{Ginkgo biloba L. (ginkgoàcies)}

\section{BCN 62881}

\section{NOMS POPULARS}

Ginkgo $(1213,1214)$

\section{USOS MEDICINALS}

Fulla

Reforçant cerebral

FONTS 1213, 1214. DESCRIPCIÓ DE L'ÚS FETA PELS INFORMANTS. Per a la memòria. FORMA FARMACĖUTICA I ÚS. Desconegut per l'informant. DESTINACIÓ. Medicina humana.

\section{Gladiolus italicus Mill. (iridàcies)}

\section{BCN 56421}

\section{NOMS POPULARS}

Gudiol (580) 


\section{ALTRES USOS}

\section{Planta viva ex situ}

Ornamental: jardineria

FONT 580. DESCRIPCIÓ DE L'ÚS FETA PER L'INFORMANT. Per a fer bonic.

\section{Glaucium flavum Crantz (papaveràcies)}

\section{BCN 31276}

\section{NOMS POPULARS}

Rosella $(518,519)$

\section{USOS ALIMENTARIS}

Flor

Ingestió de la part de la planta crua - Fresca (sense preparació)

FONTS 518, 519. DESCRIPCIÓ DE L'ÚS FETA PELS INFORMANTS. Les ovelles només corrien darrere la flor i no menjaven res més i s'aprimaven. DESTINACIÓ. Alimentació animal.

\section{ALTRES USOS}

Flor

Literatura oral popular: llegendes, gloses, contes, dites, refranys, poemes, cançons

FONTS 518, 519. DESCRIPCIÓ DE L'ÚS FETA PELS INFORMANTS. Quan la rosella floreix l'ovella pateix.

\section{ALTRES OBSERVACIONS}

FONTS 518, 519. DESCRIPCIÓ FETA PELS INFORMANTS. Herba fina i fa una cerilla groga.

Globularia alypum L. (globulariàcies)

BCN 29868

\section{NOMS POPULARS}

Botons de Nostro Senyor (1336)

\section{USOS MEDICINALS}

\section{Inflorescència}

Tònic

FONT 1336. DESCRIPCIÓ DE L'ÚS FETA PER L'INFORMANT. Per a la canalla quan estaven aflaqueïts. FORMA FARMACĖUTICA I ÚS. Tisana (ús intern). PREPARACIÓ Decocció. DESTINACIÓ. Medicina humana.

Globularia cordifolia L. (globulariàcies)

BCN 123403

\section{NOMS POPULARS}

Herba de la roca $(529,530,531)$

Lluquet (504)

\section{USOS MEDICINALS}

Part aèria florida

Antihemorroïdal

FONT 504. DESCRIPCIÓ DE L'ÚS FETA PER L'INFORMANT. Per a les morenes. FORMA FARMACĖUTICA I ÚS. Bany (ús extern). Embrocació (ús extern). PREPARACIÓ. Decocció En oli. DESTINACIÓ. Medicina humana.

Antihipertensiu

FONTS 529, 530, 531. DESCRIPCIÓ DE L'ÚS FETA PELS INFORMANTS. Per a rebaixar la sang. FORMA FARMACĖUTICA I ÚS. Tisana (ús intern). PREPARACIÓ. Decocció. DESTINACIÓ. Medicina humana.

\section{ALTRES OBSERVACIONS}

FONTS 529, 531. DESCRIPCIÓ FETA PELS INFORMANTS. Arrapada a la roca i va marxant ben plana, fa unes floretes blaves.

Globularia vulgaris L. (globulariàcies)

BCN 24896

\section{NOMS POPULARS}

Botons de la guerrera de Nostro Senyor $(518,519)$

Herba negra $(518,519)$ 


\section{USOS MEDICINALS}

\section{Inflorescència}

Per a la rampa

FONTS 518, 519. DESCRIPCIÓ DE L'ÚS FETA PELS INFORMANTS. Ara diu que li han dit que va bé per a la rampa i que es diu herba negra. FORMA FARMACĖUTICA I ÚS. Tisana (ús intern). PREPARACIÓ. Decocció. DESTINACIÓ. Medicina humana.

\section{ALTRES USOS}

\section{Inflorescència}

Altres informacions

FONTS 518, 519. DESCRIPCIÓ DE L'ÚS FETA PELS INFORMANTS. Abans la collien per a vendre.

\section{ALTRES OBSERVACIONS}

FONTS 518, 519. DESCRIPCIÓ FETA PELS INFORMANTS. Viu arrapada a terra i fa un botó negre.

\section{Gossypium sp. (malvàcies)}

\section{NOMS POPULARS}

Cotó $(565,566)$

\section{USOS ALIMENTARIS}

\section{No consta}

No consta el tipus d'ingesta - No consta el mode de preparació

FONTS 565, 566. DESCRIPCIÓ DE L'ÚS FETA PELS INFORMANTS. El cotó sobrant de les fàbriques tèxtils, el donàvem a les vaques. També la grana de cotó alimenta molt, els dóna fibra que aquí amb el que mengen no n'hi ha, els ajuda a regular el remuc. DESTINACIÓ Alimentació anima.

\section{ALTRES USOS}

No consta

Maneig agrosilvopastoral: ús hortícola/agrícola

FONTS 565, 566. DESCRIPCIÓ DE L'ÚS FETA PELS INFORMANTS. S'usava per a fer un jaç per a les vaques.

\section{Hedera helix L. (araliàcies)}

BCN 27262

\section{NOMS POPULARS}

Heura $(505,506,517,529,530,531,535,553,564,583,584,585,586,587,1213,1214$ $1353,1354)$

\section{USOS MEDICINALS}

Fruit

Antiasmàtic

FONT 517. DESCRIPCIÓ DE L'ÚS FETA PER L'INFORMANT. Per a l'asma. FORMA FARMACĖUTICA I ÚS. Tisana (ús intern). PREPARACIÓ. Decocció. DESTINACIÓ. Medicina humana.

\section{Fulla}

Litotríptic renal

FONTS 1213, 1214. DESCRIPCIÓ DE L'ÚS FETA PELS INFORMANTS. Va bé per als atacs de pedra. FORMA FARMACEUTICA I ÚS. Bany (ús extern). PREPARACIO. Decocció. DESTINACIÓ. Medicina humana.

Vulnerari

FONTS 529, 530, 531. DESCRIPCIÓ DE L'ÚS FETA PELS INFORMANTS. Per a netejar les ferides. FORMA FARMACEUTICA I US. Bany (ús extern). PREPARACIO. Decocció. Aigua de les fulles d'heura. Es renta amb un porró. DESTINACIO Medicina humana.

\section{No consta}

Anticefalàlgic

FONTS 583, 584, 585. DESCRIPCIÓ DE L'ÚS FETA PELS INFORMANTS. Per a rentar-se el cap quan et feia mal la closca. FORMA FARMACĖUTICA I ÚS. Bany (ús extern). DESTINACIÓ. Medicina humana.

\section{USOS ALIMENTARIS}

\section{Fruit}

Ingestió de la part de la planta crua - Fresca (sense preparació)

FONTS 583, 584, 585. DESCRIPCIÓ DE L'ÚS FETA PELS INFORMANTS. Les merles es mengen les boles, tot i que diuen que és tòxica. DESTINACIÓ. Alimentació animal.

\section{Part aèria}

Ingestió de la part de la planta crua - Fresca (sense preparació)

FONT 564. DESCRIPCIÓ DE L'ÚS FETA PER L'INFORMANT. Abans que brotés es donava als conills, al final de thivern. DESTINACIO. Alimentació animal. 


\section{ALTRES USOS}

Fulla

Domèstic: ajudes a la llar

FONTS 505, 506, 535, 583, 584, 585. DESCRIPCIÓ DE L'ÚS FETA PELS INFORMANTS Per a rentar roba (505). Per a treure taques de la roba va molt bé. Es fa aigua amb les fulles d'heura (535). La roba queda molt bé, es fa servir per a peces de roba delicades $(583,584$ 585). Per a rentar roba (506)

\section{ACCIONS NOCIVES O TÒXIQUES}

No consta

FONTS 553, 586, 587. DESCRIPCIÓ DE L'ACCIÓ NOCIVA O TÒXICA FETA PELS INFORMANTS. Tòxica (553). És abortiva, les vaques en mengen i les fa avortar $(586,587)$ TOXICITAT EN ANIMALS. Sí $(586,587)$.

\section{ALTRES OBSERVACIONS}

FONTS 1353, 1354. DESCRIPCIÓ FETA PELS INFORMANTS. En surten pertot arreu i les

has de treure, perquè ho envaeixen tot.

\section{BARREGES AMB AQUEST TÀXON}

No consta

FONTS 748, 749. Entrevista 49 (vegeu catàleg de barreges)

Helianthemum nummularium (L.) Mill. (cistàcies) BCN 27290

\section{NOMS POPULARS}

Morenella $(1337,1338)$

Helianthemum oelandicum (L.) DC. in Lam. et DC. (cistàcies)

BCN 24897

\section{NOMS POPULARS}

Herba del mal de coll $(590,1339,1340,1361,1362$

\section{USOS MEDICINALS}

\section{Part aèria}

Antiinflamatori faring

FONTS 590, 1339, 1340, 1361, 1362. DESCRIPCIÓ DE L'ÚS FETA PELS INFORMANTS. És molt bo per al mal de coll $(590)$. Per al mal de coll $(1339,1340,1361,1362)$. FORMA FARMACEUTICA I ÚS. Tisana (ús intern). PREPARACIÓ. Decocció $(590,1339,1340)$. En infusió $(1361,1362)$. DESTINACIO. Medicina humana.

\section{ALTRES OBSERVACIONS}

FONT 590. DESCRIPCIÓ FETA PER L'INFORMANT. Fa una floreta com una estrella.

\section{Helianthus tuberosus L. (compostes)}

BCN 24898

\section{NOMS POPULARS}

Nyama (tubercle) $(591,592)$

Trumfa nyama (tubercle) $(1307,1308,1309,1324,1353,1354)$

\section{USOS ALIMENTARIS}

Arrel

Ingestió de la part de la planta crua - Fresca (sense preparació)

FONTS 1324, 1353, 1354. DESCRIPCIÓ DE L'ÚS FETA PELS INFORMANTS. Per a menjar el bestiar (1324). Es donaven als porcs $(1353,1354)$. DESTINACIO. Alimentació animal $(1324,1353,1354)$.

Ingestió de la part de la planta cuita - Cuita en aigua

FONTS 1307, 1308, 1309, 1353, 1354. DESCRIPCIÓ DE L'ÚS FETA PELS INFORMANTS. Abans es menjaven. DESTINACIÓ. Alimentació humana.

Fulla

Ingestió de la part de la planta crua - Fresca (sense preparació)

FONTS 591, 592. DESCRIPCIÓ DE L'ÚS FETA PELS INFORMANTS. Per a amanir són bones, tenen gust dolç. DESTINACIÓ. Alimentació humana.

\section{ALTRES USOS}

Part aèria florida

Ornamental: elaboració de rams 
FONTS 1307, 1308, 1309, 1353, 1354. DESCRIPCIÓ DE L'ÚS FETA PELS INFORMANTS. Es fan servir per a fer rams $(1307,1308,1309)$. Moltes vegades en faig rams $(1353,1354)$.

\section{Helleborus foetidus L. (ranunculàcies)}

BCN 29705

\section{NOMS POPULARS}

Marxívol (568)

\section{ACCIONS NOCIVES O TÒXIQUES}

No consta

FONT 568. DESCRIPCIÓ DE L'ACCIÓ NOCIVA O TÒXICA FETA PER L'INFORMANT. És tòxica.

\section{ALTRES OBSERVACIONS}

FONT 1215. DESCRIPCIÓ FETA PER L'INFORMANT. Si tenia tres granes seria bon any de collita i si només en tenia dues, no.

\section{Helleborus viridis L. (ranunculàcies)}

BCN 24899

\section{NOMS POPULARS}

Marxívol (528, 529, 530, 531, 553, 559, 561, 562, 563, 569, 570, 571, 572, 573, 580, 581 $583,584,585,586,587,746,748,749)$

Mengívol (1296)

\section{USOS MEDICINALS}

\section{No consta}

Desconegut per l'informant

FONT 553. FORMA FARMACĖUTICA I ÚS. Cataplasma (ús extern). DESTINACIÓ. Medicina humana. OBSERVACIONS. Deien la gent: "Saps què has de fer si això no se't cura, una cataplasma de marxívols o et curarà o et matarà".

\section{No consta}

FONT 559. DESCRIPCIÓ DE L'ÚS FETA PER L'INFORMANT. Per a fer banys als peus dels animals quan els sortia mal. FORMA FARMACËUTICA I US. Bany (ús extern). PREPARACIÓ. Decocció. DESTINACIÓ. Medicina veterinària.

\section{Vulnerari}

FONT 580. DESCRIPCIÓ DE L'ÚS FETA PER L'INFORMANT. Va bé fer-ne aigua i rentar les ferides dels animals. FORMA FARMACĖUTICA I ÚS. Bany (ús extern). PREPARACIÓ. Decocció. EFECTES SECUNDARIS. Sí. DESTINACIÓ. Medicina veterinària OBSERVACIONS. Diuen que és verinós.

\section{Parènquima cortical}

Vulnerari

FONT 581. DESCRIPCIÓ DE L'ÚS FETA PER L'INFORMANT. El meu oncle el feia servir per als encetats del bestiar, aquelles cremades que queden a la pell perquè han estirat una corda FORMA FARMACEUTICA I ÚS. Bany (ús extern). PREPARACIÓ. Treia la primera pela i la segona pela la bullia en aigua i els hi banyava les ferides. DESTINACIÓ. Medicina veterinària.

\section{USOS ALIMENTARIS}

\section{No consta}

No consta el tipus d'ingesta - No consta el mode de preparació

FONT 553. DESCRIPCIÓ DE L'ÚS FETA PER L'INFORMANT. Per al bestiar. DESTINACIÓ. Alimentació animal.

\section{ALTRES USOS}

Fruit

Creences i pràctiques magicoreligioses

FONT 528. DESCRIPCIÓ DE L'ÚS FETA PER L'INFORMANT. Segons les granes que té deien que seria més bona o més dolenta l'anyada.

\section{Llavor}

Creences i pràctiques magicoreligioses

FONT 1296. DESCRIPCIÓ DE L'ÚS FETA PER L'INFORMANT. Les granes d'aquesta planta eren l'indicador de com seria la collita. Si tenia tres grans o més volia dir que seria molt bon any. Si en tenia menys volia dir que seria un any de poca collita.

\section{Part aèria fructificada}

Creences i pràctiques magicoreligioses

FONTS 569, 570. DESCRIPCIÓ DE L'ÚS FETA PELS INFORMANTS. Aquest any serà una bona anyada perquè els marxívols estan molt macos, molt plens.

\section{ACCIONS NOCIVES O TÒXIQUES}

\section{No consta}

FONTS 528, 529, 530, 531, 559, 561, 562, 563, 569, 570, 572, 573, 580, 583, 584, 585, 586 $587,748,749$. DESCRIPCIÓ DE L'ACCIÓ NOCIVA O TÒXICA FETA PELS INFORMANTS 
És tòxic $(528,569,570,572,573,583,584,585,586,587)$. És tòxic, fa molta pudor ( 561 , $562,563,748,749)$. Són verinosos $(529,530,531)$. És tòxic. Una cabra que en va menjar va morir (559). Diuen que és verinós (580). GRAU DE TOXICITAT. Letal (559). TOXICITAT EN ANIMALS. Sí (559).

\section{Part aèria}

FONTS 571, 746. DESCRIPCIÓ DE L'ACCIÓ NOCIVA O TÒXICA FETA PELS INFORMANTS. Abans deien que no es podia tocar (746). Són tòxics, quan els agafes deixen anar una bravada (571). VIA D'INTOXICACIÓ. Via externa $(571,746)$

\section{Heracleum sphondylium L. (umbel·líferes)}

BCN 24900

\section{NOMS POPULARS}

Pampa $(539,540,568)$

Pàmpola $(583,584,585,1313,1321)$

\section{USOS ALIMENTARIS}

Fulla

Ingestió de la part de la planta crua - Fresca (sense preparació)

FONTS 568, 1313, 1321. DESCRIPCIÓ DE L'ÚS FETA PELS INFORMANTS. Per als porcs. DESTINACIO. Alimentació animal.

Ingestió de la part de la planta cuita - Cuita en aigua

FONTS 539, 540. DESCRIPCIÓ DE L'ÚS FETA PELS INFORMANTS. Bullides per al bestiar. DESTINACIO. Alimentació animal.

\section{Herniaria glabra L. (cariofil·làcies)}

BCN 24901

\section{NOMS POPULARS}

Herba de les mil granes $(504,542,543,544,753,754,755,1300,1313,1328,1329,1331$ $1333,1340,1343,1344,1345,1346,1347,1348,1349,1352)$

Herba de mil granes $(1296,1297,1310,1327,1332,1334,1339)$

Herba de milgrà $(549)$

Herba de Noè $(511,512,513,514,529,530,531,538,541,542,543,544,546,547,548$ $549,553,554,555,556,557,558,559,567,568,569,570,572,573,591,592,748,749$ $753,754,755)$
Herba pedrera $(518,519)$

\section{USOS MEDICINALS}

\section{No consta}

Desconegut per l'informant

FONTS 1296, 1310. FORMA FARMACĖUTICA I ÚS. Desconegut per l'informant DESTINACIÓ Medicina humana OBSERVACIONS. No recorda per a què la feien servir (1296). No en recorden l'ús (1310).

\section{Part aèria}

Anticatarral

FONT 549. DESCRIPCIÓ DE L'ÚS FETA PER L'INFORMANT. Per a refredats. FORMA FARMACĖUTICA I ÚS. Tisana (ús intern). PREPARACIÓ. Decocció. DESTINACIÓ. Medicina humana.

Antidiarreic

FONTS 511, 512, 513, 514, 591, 592. DESCRIPCIÓ DE L'ÚS FETA PELS INFORMANTS Per a les diarrees $(511,512,513,514)$. És bona per a quan tens diarrea $(591,592)$. FORMA FARMACEUTICA I US. Tisana (ús intern). PREPARACIO. Decocció $(511,512,513,514$ 591, 592). DESTINACIÓ. Medicina humana.

Antidismenorreic

FONT 549. DESCRIPCIÓ DE L'ÚS FETA PER L'INFORMANT. Per a mals de ventre de la regla. FORMA FARMACEUTICA I ÚS. Tisana (ús intern). PREPARACIÓ. Decocció. DESTINACIO. Medicina humana.

Antiictèric

FONT 1327. DESCRIPCIÓ DE L'ÚS FETA PER L'INFORMANT. Per a quan les vaques tenien mal de fel. FORMA FARMACĖUTICA I ÚS. Tisana (ús intern). PREPARACIÓ. Decocció. DESTINACIO. Medicina veterinària.

Antiinflamatori intestinal

FONTS 511, 512, 513, 514, 538, 553, 554, 555, 558, 559, 568, 572, 573, 748, 749, 753, 754 755,1297 . DESCRIPCIÓ DE L'ÚS FETA PELS INFORMANTS. Per a les inflamacions dels budells $(511,512,513,514)$. Va bé per a la panxa $(748,749)$. Per al mal de ventre $(538,572$, $573)$. Per a mals de panxa $(553,559)$. Per a la panxa $(558,568,753,754,755)$. Per al ventre $(554,555)$. Va molt bé per a la panxa (1297). FORMA FARMACEUTICA I US. Tisana (ús intern). PREPARACIÓ. Decocció $(511,512,513,514,538,553,554,555,558,559,568$, $572, \quad 573,748,749,753,754,755,1297)$. DESTINACIÓ. Medicina humana. OBSERVACIONS. Empipa perquè sempre és bruta, l'has de rentar molt bé $(748,749)$. E meu pare hi tenia molta fe (553).

Antinauseabund

FONTS 529, 530, 531. DESCRIPCIÓ DE L'ÚS FETA PELS INFORMANTS. Per al mareig. FORMA FARMACĖUTICA I ÚS. Tisana (ús intern). PREPARACIÓ. Decocció. DESTINACIÓ. Medicina humana. 
Coadjuvant del postpart

FONT 538. DESCRIPCIÓ DE L'ÚS FETA PER L'INFORMANT. Es donava als animals quan no podien fer les despulles. FORMA FARMACĖUTICA I ÚS. Tisana (ús intern) PREPARACIÓ. Decocció. DESTINACIÓ. Medicina veterinària.

Digestiu

FONTS 546, 547, 548. DESCRIPCIÓ DE L'ÚS FETA PELS INFORMANTS. Per a pair (546). És digestiva $(547,548)$. FORMA FARMACĖUTICA I ÚS. Tisana (ús intern). PREPARACIÓ Decocció $(546,547,548)$. DESTINACIÓ. Medicina humana.

Diürètic

FONTS 529, 530, 531, 541, 567, 753, 754, 755, 1300, 1332, 1333, 1334, 1345, 1346 DESCRIPCIÓ DE L'ÚS FETA PELS INFORMANTS. Per a l'orina (529, 530, 531). Era diürètica (541). Va bé per a orinar (567). Fa orinar $(753,754,755)$. És molt bona per a fer orinar (1300). Va bé per a fer orinar $(1332,1333,1334)$. Per a fer orinar $(1345,1346)$ FORMA FARMACĖUTICA I ÚS. Tisana (ús intern). PREPARACIÓ. Decocció (529, 530, 531 $541,567,753,754,755,1332,1333,1334,1345,1346)$. Decocció. De la planta seca se'n fa aigua (1300). DESTINACIO. Medicina humana. OBSERVACIONS. Es un preventiu de pedres $(753,754,755)$

Estomacal

FONTS 556, 557, 1327. DESCRIPCIÓ DE L'ÚS FETA PELS INFORMANTS. Aigua per als ronyons, fetge, estómac $(556,557)$. Per a quan li fa mal l'estómac (1327). FORMA FARMACĖUTICA I ÚS. Tisana (ús intern). PREPARACIÓ. Decocció $(556,557)$. En infusió (1327). MODE D'UTILITZACIÓ/POSOLOGIA. En pren dos cops a la setmana (1327). DESTINACIÓ. Medicina humana.

Hepatoprotector

FONTS 556, 557. DESCRIPCIÓ DE L'ÚS FETA PELS INFORMANTS. Aigua per als ronyons, fetge, estómac. FORMA FARMACĖUTICA I ÚS. Tisana (ús intern). PREPARACIÓ. Decocció. DESTINACIÓ. Medicina humana.

Litotríptic renal

FONTS 518, 519, 1313, 1331, 1347, 1348, 1349, 1352. DESCRIPCIÓ DE L'ÚS FETA PELS INFORMANTS. Per al mal de pedra $(518,519)$. Va bé per a les pedres als ronyons, les fa desfer (1313). Per a les pedres al ronyó (1331). Per als ronyons $(1347,1348,1349)$. Per a les pedres del ronyó (1352). FORMA FARMACĖUTICA I ÚS. Tisana (ús intern). PREPARACIÓ Decocció $(518,519,1331,1347,1348,1349)$. DESTINACIÓ. Medicina humana. OBSERVACIONS. A ella no li va gaire bé, sempre utilitza la pedrera $(1347,1348,1349)$.

Protector renal

FONTS 504, 529, 530, 531, 542, 543, 544, 556, $557,569,570,1339,1340$. DESCRIPCIO DE L'ÚS FETA PELS INFORMANTS. Per als ronyons $(504,569,570)$. Per al ronyó (529, $530,531,542,543,544)$. Aigua per als ronyons, fetge, estómac $(556,557)$. Va bé per als ronyons $(1339,1340)$. FORMA FARMACĖUTICA I ÚS. Tisana (ús intern). PREPARACIÓ. Decocció $(504,529,530,531,542,543,544,556,557,569,570)$. En infusió $(1339,1340)$. Decocció $(504,529,530,531,542$,
DESTINACIÓ. Medicina humana.

\section{Part aèria florida}

Diürètic

FONTS 1343, 1344. DESCRIPCIÓ DE L'ÚS FETA PELS INFORMANTS. Per a fer orinar FORMA FARMACĖUTICA I ÚS. Tisana (ús intern). PREPARACIÓ. Decocció. DESTINACIÓ.

Medicina humana.

\section{USOS ALIMENTARIS}

Part aèria

Preparació de begudes - Beguda preparada amb aiguardent

FONT 553. DESCRIPCIÓ DE L'ÚS FETA PER L'INFORMANT. Ratafia. Posar totes les herbes en aiguardent, 21 dies a sol i serena. Es fa pels volts de Sant Joan. Sempre surt bona, però no surt mai igual. Les herbes utilitzades són: nous verdes (Juglans regia), herba de Noè (Herniaria glabra), tarongina (Melissa officinalis), camamilla borda (Tanacetum parthenium), marialluïsa (Lippia triphylla), menta (Mentha spicata), salsufràgia (Peucedanum parthenium), marialluïsa (Lippia triphylla), menta (Mentha spicata), salsufràgia (Peucedanum
ostruthium), til-la (Tilia platyphyllos), nou moscada (Myristica fragrans) i clau (Syzygium aromaticum). DESTINACIÓ. Alimentació humana.

\section{ALTRES OBSERVACIONS}

FONTS 591, 592. DESCRIPCIÓ FETA PELS INFORMANTS. A la nostra devesa n'hi havia.

\section{BARREGES AMB AQUEST TÀXON}

\section{Part aèria}

FONT 1313. Entrevista 4, barreja II (vegeu catàleg de barreges)

FONTS 529, 530, 531. Entrevista 53, barreja V (vegeu catàleg de barreges)

FONT 546. Entrevista 74, barreja II (vegeu catàleg de barreges)

\section{Hieracium pilosella L. (compostes)}

BCN 96531

\section{NOMS POPULARS}

Herba cancera $(505,506,518,519,520,521)$

Peludeta $(529,530,531)$

\section{USOS MEDICINALS}

Fulla

Per a la candidosi 
FONTS 505, 506, 518, 519, 520, 521. DESCRIPCIÓ DE L'ÚS FETA PELS INFORMANTS. Per als càncers (mal blanc) de la boca de la canalla. És una planta molt arrapada a terra, blanquinosa i peluda $(505,506)$. Per als càncers de la boca de la canalla $(518,519)$. Per als càncers de boca de la canalla $(520,521)$. FORMA FARMACĖUTICA I ÚS. Tisana (ús intern). PREPARACIÓ. Decocció $(505,506,518,519,520,521)$. DESTINACIÓ. Medicina humana. Per al xarampió

FONTS 529,530 531. DESCRIPCIÓ DE L'ÚS FETA PELS INFORMANTS. Per al xarampió FORMA FARMACĖUTICA I ÚS. Desconegut per l'informant. DESTINACIÓ. Medicina humana. OBSERVACIONS. Fulles rodones i curtes amb pèls blancs, la flor és blava o lila.

\section{ALTRES OBSERVACIONS}

FONTS 518, 519, 520, 521. DESCRIPCIÓ FETA PELS INFORMANTS. Planteta aixafada a terra, sota la fulla és blanquinosa i té la flor groga $(518,519)$. Fa les fulles per un costat verdes i per l'altre blanquinoses, semblant al plantatge però més petit $(520,521)$.

\section{BARREGES AMB AQUEST TÀXON}

Fulla

FONTS 518, 519. Entrevista 54, barreja III (vegeu catàleg de barreges)

FONTS 520, 521. Entrevista 56, barreja II (vegeu catàleg de barreges)

No consta

FONTS 529, 530, 531. Entrevista 53, barreja X (vegeu catàleg de barreges)

\section{Hordeum distichon L. (gramínies)}

BCN 24902

\section{NOMS POPULARS}

Ordi $(560,589,746,1319,1336)$

\section{USOS MEDICINALS}

\section{Llavor}

Salutifer

FONT 1319. DESCRIPCIÓ DE L'ÚS FETA PER L'INFORMANT. Per a donar als nadons, quan encara la llet de la mare no ha fet la puja. FORMA FARMACEUTICA I US. Tisana (ús intern). DESTINACIÓ. Medicina humana.

\section{USOS ALIMENTARIS}

Llavor
Ingestió de la part de la planta cuita - Cuita en aigua

FONT 1319. DESCRIPCIÓ DE L'ÚS FETA PER L'INFORMANT. Abans es menjava sopa d'ordi escairat. DESTINACIÓ. Alimentació humana.

Preparació de begudes - Beguda preparada amb aigua

FONT 1336. DESCRIPCIÓ DE L'ÚS FETA PER L'INFORMANT. Abans es feia el cafè d'ordi. Es torrava l'ordi amb una paella, es molia amb el molinet, llavors el bullies en un tupí i e colaves i era com un cafè no tan fort. DESTINACIÓ. Alimentació humana.

\section{Part aèria}

Ingestió de la part de la planta crua - Conservada dessecada a l'aire

FONTS 589, 746. DESCRIPCIÓ DE L'ÚS FETA PELS INFORMANTS. Per a alimentar el bestiar (746). Se'n feia una mica, s'utilitza com a farratge (589). DESTINACIÓ. Alimentació animal $(589,746)$

\section{ALTRES USOS}

Planta viva in situ

Maneig agrosilvopastoral: ús hortícola/agrícola

FONT 560. DESCRIPCIÓ DE L'ÚS FETA PER L'INFORMANT. Es plantava a Beget.

\section{Hordeum vulgare L. (gramínies)}

BCN 46843

\section{NOMS POPULARS}

Ordi $(586,587)$

\section{ALTRES USOS}

Part aèria

Creences i pràctiques magicoreligioses

FONTS 586, 587. DESCRIPCIÓ DE L'ÚS FETA PELS INFORMANTS. Si un home malalt es posa en aigua de gram (Cynodon dactylon) $\mathrm{i}$ ordi, diuen que es cura.

\section{Hydrangea sp. (hidrangeàcies)}

\section{NOMS POPULARS}

Hortènsia (564) 


\section{ALTRES USOS}

Planta viva ex situ

Ornamental: jardineria

FONT 564. DESCRIPCIÓ DE L'ÚS FETA PER L'INFORMANT. A les cases n'hi havia per a fer bonic.

\section{Hyoscyamus niger L. (solanàcies)}

BCN 24903

\section{NOMS POPULARS}

Herba queixalera $(518,519,522,523,524,542,543,544,1332,1333,1334,1335)$

\section{USOS MEDICINALS}

Fulla

Antiodontàlgic

FONTS 1332, 1333, 1334. DESCRIPCIÓ DE L'ÚS FETA PELS INFORMANTS. Te'I fumaves $i$ et calmava el mal de queixal. FORMA FARMACĖUTICA I ÚS. Cigarreta (ús intern). PREPARACIÓ. S'assecava, s'engrunava $i$ es feia un cigarret. DESTINACIÓ. Medicina humana.

Llavor

Antiodontàlgic

FONTS $518,519,522,523,524,542,543,544,1335$. DESCRIPCIÓ DE L'ÚS FETA PELS INFORMANTS. Per al mal de queixal $(518,519,522,523,524,1335)$. Et fa saltar els corcs dels queixals $(542,543,544)$. FORMA FARMACĖUTICA I ÚS. Aerosol (ús intern). PREPARACIÓ. Es feien bafs amb aquest vapor. Es posaven les granes al rescals del foc $i$ trabucaven un tupí que quedés impregnat d'aquest fum, llavor s'hi tirava aigua ben calenta (524). Per a fer bafs $(542,543,544)$. S'usava per a fer bafs (1335). DESTINACIÓ. Medicina humana. OBSERVACIONS. No es pot prendre, és droga (1335).

\section{Hypericum androsaemum L. (gutíferes)}

\section{BCN 24904}

\section{NOMS POPULARS}

Fulles de la Mare de Déu $(525,526,527,1307,1308$, 1309, 1324, 1325, 1326, 1345, 1346)

\section{USOS MEDICINALS}

Fulla

Cicatritzant

FONTS 1307, 1308, 1309. DESCRIPCIÓ DE L'ÚS FETA PELS INFORMANTS. Es feia servir per a fer cicatritzar talls. FORMA FARMACĖUTICA I ÚS. Sense forma farmacèutica (ús directe, ús extern). DESTINACIÓ. Medicina humana.

Vulnerari

FONTS 525, 526, 527, 1307, 1308, 1309, 1324, 1325, 1326, 1345, 1346. DESCRIPCIÓ DE L'ÚS FETA PELS INFORMANTS. Es posava a les ferides $(525,526,527)$. Va bé per a curar les llagues de les cames $(1307,1308,1309)$. La fulla sobre les llagues (1324). A sobre ferides i llagues $(1325,1326)$. Per a les ferides $(1345,1346)$. FORMA FARMACE்UTICA I ÚS. Sene forma farme (ús directe, ús extern) $(525,526,527,1307,1308,1309,1325$. $1326,1345,1346)$. 1326, 1345, 1346). Embrocacio (ús extern) (1324). PREPARACIO. Per un costat desinfecta per l'altre fa pellar $(525,526,527)$. Agava la fulla i la posava sobre de la llaga, no per la part dels nervis, sinó per la part de sobre; despres s'hi embolicava un drap de fil $(1307,1308$, 1309). Es posaven en oli (1324). Assecades i directament (1325, 1326). S'aplica directamen $(1345,1346)$. DESTINACIÓ. Medicina humana. OBSERVACIONS. Una veïna seva de Rocabruna tota la vida va tenir una llaga a la cama i sempre se la va anar curant amb aquesta fulla; no va anar mai a la farmàcia $(1307,1308,1309)$.

\section{ALTRES OBSERVACIONS}

FONT 1308. DESCRIPCIÓ FETA PER L'INFORMANT. Només es fa en fonts on l'aigua és molt bona.

\section{Hypericum perforatum L. (gutíferes)}

BCN 24905

\section{NOMS POPULARS}

Cop $(591,592,1345,1346)$

Flor de cop $(503,507,509,510,586,587,1297,1299,1301,1307,1308,1309,1310,1314$, $1328,1329,1341,1342)$

Herba de cop $(504,505,506,511,512,513,514,515,516,517,518,519,520,521,522$ $523,524,525,526,527,528,529,530,531,538,541,542,543,544,546,547,548,549$, $552,553,554,555,558,559,561,562,563,564,565,566,567,569,570,571,572,573$, $574,575,576,577,578,579,580,581,583,584,585,590,747,748,749,750,751,752$, $753,754,755,1210,1213,1214,1215,1293,1294,1296,1298,1300,1311,1312,1313$ $1315,1316,1317,1318,1319,1320,1321,1323,1324,1325,1326,1327,1330,1331,1335$, 1336, 1337, 1338, 1339, 1340, 1343, 1344, 1347, 1348, 1349, 1350, 1351, 1353, 1354, 1352, $1336,1337,1336$

Herba de la pulmonia (751)

Herba de Sant Joan $(545,556,557,1213,1214,1215,1293,1324,1332,1333,1334)$ 
Apèndix 1. Catàleg de tàxons.

Pericó $(541,1213,1214,1215)$

Trescalam $(529,530,531,554,555,556,557)$

Trescam $(1335,1347,1348,1349)$

\section{USOS MEDICINALS}

Antiequimòtic

FONT 504. DESCRIPCIÓ DE L'ÚS FETA PER L'INFORMANT. Per als cops. FORMA FARMACĖUTICA I ÚS. Liniment (ús extern). PREPARACIÓ. La flor en oli. DESTINACIÓ.

\section{Medicina humana.}

\section{Part aèria florida}

\section{Analgèsic}

FONTS $752,753,754,755,1213,1214,1320,1328,1329,1336,1341,1342$. DESCRIPCIÓ DE L'ÚS FETA PELS INFORMANTS. Per als cops i per al dolor (752). Per al dolor i els trucs $(753,754,755)$. Per a les ferides, els trucs, el dolor i les cremades $(1213,1214)$. Per al dolor $(1320,1328,1329,1336,1341,1342)$. FORMA FARMACĖUTICA I ÚS. Liniment (ús extern) PREPARACIÓ. En oli $(752,753,754,755,1336)$. Se'n preparen olis $(1213,1214)$. Confitada en oli i nou dies a sol i serena (1320). Confitada en oli $(1328,1329)$. En fan oli de cop (1341, 1342). DESTINACIÓ. Medicina humana.

Antiasmàtic

FONTS 1213, 1214. DESCRIPCIÓ DE L'ÚS FETA PELS INFORMANTS. Combat els constipats crònics i l'asma. FORMA FARMACĖUTICA I ÚS. Tisana (ús intern). DESTINACIÓ Medicina humana.

Anticefalàlgic

FONTS 1213, 1214. DESCRIPCIÓ DE L'ÚS FETA PELS INFORMANTS. Treu el mal de cap per fort que sigui. FORMA FARMACĖUTICA I ÚS. Tisana (ús intern). DESTINACIÓ Medicina humana.

Antidepressiu

FONTS 1213, 1214, 1299, 1324. DESCRIPCIÓ DE L'ÚS FETA PELS INFORMANTS. ÉS antidepressiva i tranquil litzant $(1213,1214)$. Va be per a les depressions (1299). Es antidepressiva (1324). FORMA FARMACĖUTICA I ÚS. Tisana (ús intern). PREPARACIÓ Una o dues flors en infusió (1299). Decocció (1324). DESTINACIO. Medicina humana. OBSERVACIONS. No es pot prendre si prens medicaments de farmàcia (1324).

Antiequimòtic

FONTS 503, 505, 506, 507, 509, 510, 511, 512, 513, 514, 515, 516, 517, 518, 519, 520, 521 $522,523,524,525,526,527,528,529,530,531,538,541,542,543,544,546,547,548$ $549,552,553,554,555,558,559,561,562,563,564,565,566,567,569,570,571,572$ $573,574,575,576,577,578,579,580,581,583,584,585,586,587,590,591,592,747$ $748,749,750,751,752,753,754,755,1210,1213,1214,1215,1294,1296,1297,1298$, $1299,1300,1301,1307,1308,1309,1311,1312,1313,1314,1315,1316,1317,1318,1319$
$1320,1321,1323,1324,1325,1326,1327,1330,1331,1335,1336,1337,1338,1339,1340$, $1341,1342,1343,1344,1345,1346,1347,1348,1349,1350,1351,1352,1353,1354,1361$ 1362. DESCRIPCIÓ DE L'ÚS FETA PELS INFORMANTS. Per als cops $(511,512,513,514$ $518,519,528,541,542,543,544,546,547,548,549,554,555,558,559,565,566,567$ $569,570,574,575,576,577,581,583,584,585,1215,1296,1323,1330,1352)$. Per als trucs $(503,505,506,507,509,510,517,520,521,522,523,525,526,527,529,530,531$ $553,561,562,563,564,578,579,580,586,587,590,591,592,747,748,749,750,751$ $1213,1214,1300,1301,1314,1315,1316,1317,1318,1319,1320,1321,1325,1326,1327$ $1331,1335,1336,1337,1338,1339,1340,1341,1342,1343,1344,1345,1346,1347,1348$ $1349,1350,1351,1361,1362)$. Per a quan et fas un cop $(515,516)$. Es fa servir per als trucs (524). Per als cops i per al dolor (752). Per a les trompades $(538,552)$. Per a trucs (571). Pe al dolor i els trucs $(753,754,755)$. Per als cops, per a trencadures d'ossos quan encara fan mal $(572,573)$. Per a contusions i cops (1210). Per a les ferides, els trucs, el dolor i les cremades $(1213,1214)$. S'usa quan es fa un truc $(1297)$. Per a fer-ne fregues per a fer sortir els morats (1298). És molt bo quan et fas un truc (1299). Serveix per a treure els cops (1313). És molt bona per als trucs (1324). Si et fas un truc fa sortir el blau $(1353,1354)$. FORMA Es molt bona per al FARMACEUTCA $514,515,516,517,518,519,520,521,522,523,524,525,526,527,528,529,530,531$ $538,541,542,543,544,546,547,548,549,552,553,554,555,558,559,561,562,563$ $564,565,566,567,569,570,571,572,573,574,575,576,577,578,579,580,581,583$ $584,585,586,587,590,591,592,747,748,749,750,751,752,753,754,755,1210,1213$ $1214,1215,1294,1296,1297,1298,1299,1300,1301,1307,1308,1309,1311,1312,1313$ $1314,1317,1318,1319,1320,1321,1323,1324,1325,1326,1327,1330,1331,1335,1336$, $1337,1338,1339,1340,1341,1342,1343,1344,1345,1346,1347,1348,1349,1350,1351$ $1352,1353,1354,1361,1362)$. Loció (ús extern) $(518,519,747,751,1213,1214,1315$, 1316, 1324, 1343, 1344). Vinagre medicinal (ús extern) $(518,519)$. PREPARACIÓ. En oli $(503,505,506,511,512,513,514,515,516,517,524,525,526,527,528,529,530,531$ $549,553,554,555,559,572,573,574,575,576,577,581,583,584,585,586,587,590$ $591,592,752,753,754,755,1215,1296,1297,1321,1330,1336,1339,1340,1345,1346$ $1361,1362)$. Es macera en oli $(507,509,510)$. S'ha de bullir l'oli només un moment (748, 749). Es posa la planta $(747,751)$. Per a fer oll de cop $(522,523)$. En oli, esperit de vi o vinagre $(518,519)$. Es fa l'ol de cop (538). Conftada en oll (542, 543, 544, 580, 1294, 1298, 1301, 1307, 1308, 1309, $1313,1317,1323,1324,1325,1326,1327,1331,1337,1338,1343,1344,1347,1348$ 1349). En oli i bullit (546). Macerat en oli $(520,521,1335)$. Se'n feia oli (541). Es fa oli (552, $565,566,578,579)$. Per a fer oli $(547,548)$. Se'n fa oli $(558)$. Per a fer oli de cop. Amb una ploma de gallina tho untaves $(571)$. Es feia oli $(564,567)$. Fer oli de cop $(561,562,563)$ Macerada en oli $(569,570)$. Les fulles bullides en oli $(1210)$. Se'n preparen olis $(1213,1214)$ En alcohol $(1213,1214)$. La flor posada en oli 45 dies a sol i serena (1299). S'ha de bullir la flor en oli (1300). Es confita en oli i encara que faci quatre o cinc anys té les mateixes propietats encara que l'oli queda negre $(1311,1312)$. La flor la bullen en oli $(1314)$. En esperit de vi $(1315,1316,1324)$. La flor confitada en oli $(1318)$. Confitada en oli i nou dies a sol serena $(1319,1320)$. En fan oli de cop $(1341,1342)$. Confitada en esperit de vi $(1343,1344)$ Bullida en oli (1350, 1351). Confitada en oli i 40 dies a sol i serena (1352). Confitat en $(1353$ 1354). DESTINACIO. Medicina humana. OBSERVACIONS. Abans només ferm sen aquesta, fa uns anys que anem a buscar àrnica (Arnica montana subsp. montana) (581). Li 
va dir la Maria Sagué (1210). Creuen que té unes propietats semblants a les de l'àrnica (Arnica montana subsp. montana), però ells l'utilitzen poc $(1307,1308,1309)$.

Antieritematós

FONT 1310. DESCRIPCIÓ DE L'ÚS FETA PER L'INFORMANT. Per a curar les escaldades. FORMA FARMACĖUTICA I ÚS. Liniment (ús extern). PREPARACIÓ. La flor confitada en oli. DESTINACIÓ. Medicina humana.

\section{Antipiròtic}

FONTS 529, 530, 531, 1213, 1214. DESCRIPCIÓ DE L'ÚS FETA PELS INFORMANTS. Cremades $(529,530,531)$. Per a les ferides, els trucs, el dolor i les cremades $(1213,1214)$ FORMA FARMACÈUTICA I ÚS. Embrocació (ús extern) $(529,530,531)$. Liniment (ús extern) $(1213,1214)$. PREPARACIÓ. En oli $(529,530,531)$. Se'n preparen olis $(1213,1214)$ DESTINACIO. Medicina humana.

Antipneumònic

FONT 751. DESCRIPCIÓ DE L'ÚS FETA PER L'INFORMANT. La gent que tenia pulmonia s'untava. FORMA FARMACĖUTICA I ÚS. Liniment (ús extern). PREPARACIÓ. Es posava en oli i es feia bullir. DESTINACIÓ. Medicina humana.

Desconegut per l'informant

FONTS 556, 557. FORMA FARMACĖUTICA I ÚS. Desconegut per l'informant PREPARACIÓ. Se'n feia oli (nou dies a sol i serena els dies que el sol és més fort). DESTINACIÓ. Medicina humana. OBSERVACIONS. Abans en dèiem trescalam, ara herba de Sant Joan.

Per a les picades

FONTS 529, 530, 531. DESCRIPCIÓ DE L'ÚS FETA PELS INFORMANTS. Per a picades d'abella. FORMA FARMACĖUTICA I ÚS. Embrocació (ús extern). PREPARACIÓ. En oli. DESTINACIÓ. Medicina humana.

Reforçant cerebral

FONTS 1330, 1339, 1340. DESCRIPCIÓ DE L'ÚS FETA PELS INFORMANTS. Per a reforçar la memòria (1330). Per a reforçar el cap $(1339,1340)$. FORMA FARMACĖUTICA I ÚS. Tisana (ús intern). PREPARACIÓ. Decocció $(1330,1339,1340)$. EFECTES SECUNDARIS. Sí. DESTINACIÓ. Medicina humana. OBSERVACIONS. S'ha d'anar en compte perquè fa pujar la pressió (1330)

Tranquil. litzant

FONTS 1213, 1214, 1293. DESCRIPCIÓ DE L'ÚS FETA PELS INFORMANTS. És antidepressiva i tranquil litzant $(1213,1214)$. Tranquil litzant (1293). FORMA FARMACĖUTICA I ÚS. Tisana (ús intern). DESTINACIÓ. Medicina humana.

Vasotònic

FONTS 554, 555. DESCRIPCIÓ DE L'ÚS FETA PELS INFORMANTS. Per a regular la sang. FORMA FARMACĖUTICA I ÚS. Tisana (ús intern). PREPARACIÓ. Decocció. DESTINACIÓ. Medicina humana.

Vulnerari
FONTS 1213, 1214, 1324. DESCRIPCIÓ DE L'ÚS FETA PELS INFORMANTS. Per a les ferides, els trucs, el dolor i les cremades $(1213,1214)$. Per a les ferides $(1324)$. FORMA FARMACĖUTICA I ÚS. Liniment (ús extern) $(1213,1214)$. Embrocació (ús extern) (1324) PREPARACIÓ. Se'n preparen olis $(1213,1214)$. Confitada en oli (1324). DESTINACIÓ. Medicina humana.

\section{ALTRES USOS}

\section{Part aèria florida}

Creences i pràctiques magicoreligioses

FONTS 554, 555. DESCRIPCIÓ DE L'ÚS FETA PELS INFORMANTS. Si se'n penjava un ram a la porta de l'església i hi havia una bruixa a dins no podia sortir fins que es treia el ram.

\section{Planta sencera}

Literatura oral popular: llegendes, gloses, contes, dites, refranys, poemes, cançons FONTS 1213, 1214. DESCRIPCIÓ DE L'ÚS FETA PELS INFORMANTS. Qui té oli de pericó, no li cal metge ni doctor.

\section{ALTRES OBSERVACIONS}

FONTS 751, 1293. DESCRIPCIÓ FETA PELS INFORMANTS. Sembla que floreix groc (751). N'hi ha per tot arreu (1293).

\section{BARREGES AMB AQUEST TÀXON}

\section{Part aèria florida}

FONTS 1213, 1214. Entrevista 102, barreja VI (vegeu catàleg de barreges)

FONT 1215. Entrevista 104, barreja I (vegeu catàleg de barreges)

FONTS 1332, 1333, 1334. Entrevista 11, barreja II (vegeu catàleg de barreges)

FONT 1324. Entrevista 5, barreja IV (vegeu catàleg de barreges)

FONTS 529, 530, 531. Entrevista 53, barreja III (vegeu catàleg de barreges) FONTS 529, 530, 531. Entrevista 53, barreja IV (vegeu catàleg de barreges) FONTS 520, 521. Entrevista 56, barreja I (vegeu catàleg de barreges) FONTS $753,754,755$. Entrevista 67, barreja IV (vegeu catàleg de barreges) FONTS $753,754,755$. Entrevista 67, barreja VII (vegeu catàleg de barreges) FONT 545. Entrevista 72, barreja I (vegeu catàleg de barreges) FONT 546. Entrevista 74, barreja I (vegeu catàleg de barreges) FONTS 561, 562, 563. Entrevista 83 (vegeu catàleg de barreges) FONT 581. Entrevista 94, barreja I (vegeu catàleg de barreges) 


\section{Hyssopus officinalis L. (labiades)}

BCN 24906

\section{NOMS POPULARS}

Hisop $(515,516,520,521,522,523,525,526,527,553,560,564,582,590,746,747,752$ $753,754,755,1213,1214,1293,1294,1296,1299,1301,1324,1328,1329,1335,1336$ $1345,1346,1347,1348,1349$ )

\section{USOS MEDICINALS}

\section{No consta}

Desconegut per l'informant

FONTS 1345, 1346. FORMA FARMACĖUTICA I ÚS. Desconegut per l'informant DESTINACIÓ. Medicina humana. OBSERVACIONS. No recorda l'ús.

\section{Part aèria florida}

Antibronquític

FONT 553. DESCRIPCIÓ DE L'ÚS FETA PER L'INFORMANT. Per a les bronquitis. FORMA FARMACĖUTICA I ÚS. Xarop (ús intern). PREPARACIÓ. Es feia xarop. DESTINACIÓ. Medicina humana.

Anticatarral

FONTS 520, 521, 522, 523, 525, 526, 527, 560, 564, 582, 590, 746, 747, 753, 754, 755, 1293, 1294, 1296, 1299, 1301, 1324, 1328, 1329, 1347, 1348, 1349. DESCRIPCIÓ DE L'ÚS FETA PELS INFORMANTS. Per als refredats $(520,521,560,564,582,746,747,753,754$ $755,1294,1328,1329)$. Per als constipats $(522,523,1293,1296,1301,1324)$. Per als refredats. Es pot prendre amb mel $(525,526,527)$. Per al refredat de sang perquè estova refred (590). Va bé per als contipats (1209). Per als . Per al molt (590). Va be per als constipats (1299). Per als constipats, quan estàs molt tapat (1348, 1349). Per als constipats, quan estàs tapat (1347). (us intern) $(520,521,522,523,525,526,527,560,564,582,590,746,747,753,754,755$, 1293, 1296, 1290, 1301, 1324, 1328, 1329, 1347, 1348, 1349). Melit (ús intern) (1294). PREPARACIO. Decoccio $(520,521,522,523,525,526,527,560,564,582,590,746,747$ $753,754,755,1293,1299,1324,1328,1329)$. Infusió de tota la planta amb mel (1294). Només s'ha d'escaldar (1301). En infusió (1347, 1348, 1349). DESTINACIÓ. Medicina humana.

Antigripal

FONTS 515, 516, 564. DESCRIPCIÓ DE L'ÚS FETA PELS INFORMANTS. Per al grip (515, 516). Per a quan tens grip (564). FORMA FARMACĖUTICA I ÚS. Tisana (ús intern) (515 516). Tintura alcohòlica (ús intern) (564). PREPARACIÓ. Decocció $(515,516)$. DESTINACIÓ Medicina humana.

Antinauseabund
FONT 564. DESCRIPCIÓ DE L'ÚS FETA PER L'INFORMANT. Si estàs marejat i tens vòmits. FORMA FARMACĖUTICA I ÚS. Tintura alcohòlica (ús intern). DESTINACIÓ. Medicina humana.

Antitussigen

FONTS 752, 1324. DESCRIPCIÓ DE L'ÚS FETA PELS INFORMANTS. Va bé per a treure la tos (752). Per a la tos (1324). FORMA FARMACĖUTICA I ÚS. Tisana (ús intern) PREPARACIÓ. Decocció $(752,1324)$. DESTINACIÓ. Medicina humana.

Coadjuvant del part

FONTS 1213, 1214. DESCRIPCIÓ DE L'ÚS FETA PELS INFORMANTS. A les parteres se'Is feia xocolata desfeta amb hisop. L'hisop posa la mare a lloc. FORMA FARMACËUTICA I ÚS. Decocció (ús intern). PREPARACIÓ. En xocolata. DESTINACIÓ. Medicina humana.

\section{Digestiu}

FONT 564. DESCRIPCIÓ DE L'ÚS FETA PER L'INFORMANT. Va bé per a tota la part digestiva. FORMA FARMACĖUTICA I ÚS. Tintura alcohòlica (ús intern). DESTINACIÓ. Medicina humana.

\section{USOS ALIMENTARIS}

\section{Part aèria florida}

Preparació de begudes - Beguda preparada amb aigua

FONT 1335. DESCRIPCIÓ DE L'ÚS FETA PER L'INFORMANT. La prenen perquè els agrada el gust, per a acompanyar altres herbes. OBSERVACIONS. No l'usen com a medicina DESTINACIÓ. Alimentació humana.

\section{ALTRES USOS}

\section{No consta}

Literatura oral popular: llegendes, gloses, contes, dites, refranys, poemes, cançons

FONT 520. DESCRIPCIÓ DE L'ÚS FETA PER L'INFORMANT. Abans deien: "I'hisop fa parir de cop".

\section{Planta sencera}

Literatura oral popular: llegendes, gloses, contes, dites, refranys, poemes, cançons FONT 521. DESCRIPCIÓ DE L'ÚS FETA PER L'INFORMANT. Abans deien: "I'hisop fa parir de cop".

\section{ALTRES OBSERVACIONS}

FONTS 515, 516, 522, 523, 590, 752, 1296, 1345, 1346. DESCRIPCIÓ FETA PELS INFORMANTS. Aquí no n'hi ha, a la banda de Monars se'n fa molt $(515,516)$. Es fa en els roquers $(522,523)$. Se'n fa molt a la Penya del Roquer de les Llosses $(752)$. L'anàvem a
ren buscar a la muntanya de can França (590). En va a buscar a Beget (1296). En tenia a l'hort $(1345,1346)$. 


\section{BARREGES AMB AQUEST TÀXON}

\section{Part aèria florida}

FONT 1294. Entrevista 6, barreja I (vegeu catàleg de barreges)

\section{Ilex aquifolium L. (aquifoliàcies)}

BCN 27248

\section{NOMS POPULARS}

Boix grèvol $(528,586,587)$

Grèvol (1352)

\section{ALTRES USOS}

\section{Goma resina}

Maneig agrosilvopastoral: ús hortícola/agrícola

FONT 528. DESCRIPCIÓ DE L'ÚS FETA PER L'INFORMANT. Abans el feien servir els ocellaires, agafaven el bresc de la soca i l'enganxaven a la creueta que havien fet amb dues brinetes d'om, llavors posaven aquesta creueta a les branques d'un arbre i esperaven que els passarells s'hi agafessin i així els capturaven.

\section{Parènquima cortical}

Maneig agrosilvopastoral: ús hortícola/agrícola

FONTS 586, 587. DESCRIPCIÓ DE L'ÚS FETA PELS INFORMANTS. Les peles de boix grèvol servien per a fer vesc, es posaven al femer, després es rentaven al safareig i llavors es rascava amb un ganivet i quedava el vesc.

\section{Part aèria fructificada}

Ornamental: elaboració de rams

FONTS 528, 1352. DESCRIPCIÓ DE L'ÚS FETA PELS INFORMANTS. Per a fer bonic (528) Per a fer rams per Nadal (1352).

\section{Iris germanica L. (iridàcies)}

BCN 31278

\section{NOMS POPULARS}

Lliri blau $(539,540,553,569,570,572,573,578,579)$

\section{USOS MEDICINALS}

Flor

Resolutiu

FONTS 539, 540. DESCRIPCIÓ DE L'ÚS FETA PELS INFORMANTS. Servien per a curar les llagues. FORMA FARMACĖUTICA I ÚS. Embrocació (ús extern). PREPARACIÓ. Les flors es posaven en oli. DESTINACIÓ. Medicina humana.

Vulnerari

FONTS 578, 579. DESCRIPCIÓ DE L'ÚS FETA PELS INFORMANTS. Es feia servir per als talls. FORMA FARMACĖUTICA I ÚS. Loció (ús extern). PREPARACIÓ. En aiguardent per a confitar. DESTINACIÓ. Medicina humana.

\section{ALTRES USOS}

\section{Inflorescència}

Ornamental: elaboració de rams

FONTS 572, 573.

\section{ALTRES OBSERVACIONS}

FONTS 539, 540, 569, 570. DESCRIPCIÓ FETA PELS INFORMANTS. Pels marges i a les vores de les cases sempre n'hi ha hagut $(569,570)$. Es tenien en els horts $(539,540)$.

\section{Jasonia saxatilis (Lam.) Guss. (compostes)}

BCN 24496

\section{NOMS POPULARS}

Te de roc (588)

Te de roca $(554,555,559,569,570,581)$

\section{USOS MEDICINALS}

\section{Part aèria}

Anticatarral

FONTS 554, 555, 581, 588. DESCRIPCIÓ DE L'ÚS FETA PELS INFORMANTS. Per als constipats $(554,555)$. Va bé per als constipats, te la prens a la nit i fa suar molt, però et deixa nou (581). Era molt bona per als refredats (588). FORMA FARMACĖUTICA I ÚS. Tisana (ús intern). PREPARACIÓ. Decocció $(554,555,581,588)$. DESTINACIÓ. Medicina humana OBSERVACIONS. Ho compràvem a les trementinaires (588). 


\section{USOS ALIMENTARIS}

\section{Part aèria}

Preparació de begudes - Beguda preparada amb aigua

FONT 559. DESCRIPCIÓ DE L'ÚS FETA PER L'INFORMANT. Per a beure, per a fer una infusió. DESTINACIÓ. Alimentació humana.

\section{ALTRES OBSERVACIONS}

FONT 581. DESCRIPCIÓ FETA PER L'INFORMANT. És una planta que fa una olor molt agradable, quan l'asseques no et queda la flor, et queda la llavor. Aquí al Ripollès n'hi ha poca, n'hi ha molta al Berguedà. Es una planta que vol sol, està a les cares sud de les muntanyes.

\section{Jasonia tuberosa (L.) DC. (compostes)}

BCN 24907

\section{NOMS POPULARS}

Herba del mal estrany $(504,541,746,753,754,755,1336)$

\section{USOS MEDICINALS}

Part aèria florida

Antigangrenós

FONTS $753,754,755$. DESCRIPCIÓ DE L'ÚS FETA PELS INFORMANTS. És bona per a la gangrena. FORMA FARMACĖUTICA I ÚS. Boira (ús extern). PREPARACIÓ. Decocció. Es fa aigua i es posa la ferida infectada a sobre del vapor que surt ben calent. DESTINACIÓ. Medicina humana.

Antisèptic extern

FONT 504. DESCRIPCIÓ DE L'ÚS FETA PER L'INFORMANT. Per als mals infectats. FORMA FARMACĖUTICA I ÚS. Fumigació (ús extern). PREPARACIÓ. Poses el vapor sobre el mal. DESTINACIÓ. Medicina humana.

Cardiotònic

FONTS 753, 754, 755. DESCRIPCIÓ DE L'ÚS FETA PELS INFORMANTS. Va bé per al cor. FORMA FARMACĖUTICA I ÚS. Tisana (ús intern). PREPARACIÓ. Decocció. DESTINACIÓ. Medicina humana.

\section{ALTRES OBSERVACIONS}

FONT 504. DESCRIPCIÓ FETA PER L'INFORMANT. És una planta que quan l'agafes és enganxosa.

\section{BARREGES AMB AQUEST TÀXON}

\section{Part aèria florida}

FONT 1336. Entrevista 16, barreja III (vegeu catàleg de barreges)

FONT 746. Entrevista 45, barreja IV (vegeu catàleg de barreges)

\section{Juglans regia L. (juglandàcies)}

\section{BCN 24908}

\section{NOMS POPULARS}

Noguer $(507,509,510,524,529,530,531,554,555,558,564,578,579,582,583,584,585$, $589,591,592,747,1210,1213,1214,1293,1313,1314,1332,1333,1334,1341,1342$ $1345,1346,1347,1348,1349)$

Noguera (532)

Nou (fruit/lavor) $(503,522,523,553,588,590,750,1307,1308,1309)$

Nou verda (fruit) (528)

Nouer $(1213,1214)$

\section{USOS MEDICINALS}

\section{Fruit}

Hipolipemiant

FONTS 1307, 1308, 1309. DESCRIPCIÓ DE L'ÚS FETA PELS INFORMANTS. Les nous van bé per a fer baixar el colesterol. FORMA FARMACĖUTICA I ÚS. Sense forma farmacèutica (ús directe, ús intern). DESTINACIO. Medicina humana.

Restauratiu

FONT 528. DESCRIPCIÓ DE L'ÚS FETA PER L'INFORMANT. Te'I prenies com a reforçant Moltes vegades primer et bevies un ou $i$ en el mateix foradet de la clova t'hi posaven aquest vi. No recordo què més hi posava. FORMA FARMACEUUTICA I ÚS. Vi medicinal (ús intern). PREPARACIO. Recordo que la mare feia un vi compost amb nous verdes. DESTINACIO. Medicina humana.

Fulla

Antidermatític per a la dermatitis de contacte

FONT 1293. DESCRIPCIÓ DE L'ÚS FETA PER L'INFORMANT. Per a rentar la cara quan et surten grans. FORMA FARMACĖUTICA I ÚS. Bany (ús extern). PREPARACIÓ. Decocció. DESTINACIÓ. Medicina humana.

Antihemorroïdal 
FONTS 1341, 1342. DESCRIPCIÓ DE L'ÚS FETA PELS INFORMANTS. Per a les morenes. FORMA FARMACĖUTICA I ÚS. Bany (ús extern). PREPARACIÓ. Decocció. Aigua de les fulles. DESTINACIÓ. Medicina humana.

Antiherpètic

FONT 564. DESCRIPCIÓ DE L'ÚS FETA PER L'INFORMANT. Per a les panses i els herpes.La meva [dit "meu"] mare s'hi va curar un herpes de l'anus, s'hi posava un drap moll. FORMA FARMACĖUTICA I ÚS. Bany (ús extern). Loció (ús extern). PREPARACIÓ. Decocció.En faig esperit. DESTINACIÓ. Medicina humana. OBSERVACIONS. Combinava noguer i aulina (Quercus ilex) però no barrejat, uns dies una planta i després una altra.

Antihipertensiu

FONTS $591,592,1213,1214,1314,1332,1333,1334$. DESCRIPCIÓ DE L'ÚS FETA PELS INFORMANTS. Per a fer baixar la pressió $(591,592,1332,1333,1334)$. L'aigua de les fulles INFORMANTS. Per a fer baixar la pressió (591, $522,1332,1333,1334)$. L'aigua de les fulles fa baixar la pressús. Tisana (ús in, 1214). Per a baixar la prossió (1314). FORMA FARMACEUTTCA IUS. Tisana (ús intern). PREPARACIÓ. Decocció. Aigua de les fulles (591 592). Decocció (1213, 1214, 1314). Decocció. De les fulles en fan aigua (1332, 1333, 1334) MODE D'UTILITZACIÓ/POSOLOGIA. Tres cops a la setmana $(1213,1214)$. DESTINACIÓ. Medicina humana

Antiinflamatori faringi

FONT 1313. DESCRIPCIÓ DE L'ÚS FETA PER L'INFORMANT. Per al mal de coll. FORMA FARMACĖUTICA I ÚS. Gargarisme (ús extern). PREPARACIÓ. Infusió de les fulles de noguer. Després s'hi afegeix una mica de bicarbonat [dit "carbonat"] i en fas gàrgares. DESTINACIÓ. Medicina humana. OBSERVACIONS. Recorda que quan era a Setcases li'n feien, però diu que devien portar les fulles de noguer de fora perquè a Setcases no hi ha noguers.

Antipiròtic

FONT 747. DESCRIPCIÓ DE L'ÚS FETA PER L'INFORMANT. Per a les cremades. FORMA FARMACĖUTICA I ÚS. Sense forma farmacèutica (ús directe, ús extern). PREPARACIÓ. La part llisa fa supurar i la part rústica fa assecar. DESTINACIO. Medicina humana.

Antisèptic extern

FONTS 583, 584, 585. DESCRIPCIÓ DE L'ÚS FETA PELS INFORMANTS. Per a desinfectar mals. FORMA FARMACĖUTICA I ÚS. Bany (ús extern). PREPARACIÓ. Decocció. Aigua de les fulles. DESTINACIO. Medicina veterinària.

Antisèptic intern

FONTS 1213, 1214. DESCRIPCIÓ DE L'ÚS FETA PELS INFORMANTS. És un desinfectan intern. FORMA FARMACĖUTICA I ÚS. Tisana (ús intern). PREPARACIÓ. Decocció. DESTINACIO. Medicina humana.

Desconegut per l'informant

FONTS 507, 509, 510. DESCRIPCIÓ DE L'ÚS FETA PELS INFORMANTS. No recordo I'ús, però la fèiem servir. FORMA FARMACĖUTICA I ÚS. Desconegut per l'informant.

Hematocatàrtic
FONTS 1345, 1346. DESCRIPCIÓ DE L'ÚS FETA PELS INFORMANTS. Va bé per a purificar la sang sobretot a la primavera. FORMA FARMACĖUTICA I ÚS. Tisana (ús intern). PREPARACIÓ. Decoció. DESTINACIO. Medicina humana. OBSERVACIONS. Les fulles PREPARACIO. Dococció DESTINACIO. Medicina humaCE. OBICA IÚS. Tisana (ús intern de efecte.

Hipoglucemiant

FONTS 554, 555. DESCRIPCIÓ DE L'ÚS FETA PELS INFORMANTS. Per a fer baixar el sucre FORMA FARMACÈUTICA I ÚS. Tisana (ús intern). PREPARACIÓ. Decocció. DESTINACIÓ. Medicina humana.

Per a la sarna

FONT 564. DESCRIPCIÓ DE L'ÚS FETA PER L'INFORMANT. Per a la sarna dels gossos i quan els cau el pèl. FORMA FARMACĖUTICA I ÚS. Bany (ús extern). PREPARACIÓ. Decocció. Aigua de les fulles de noguer. DESTINACIÓ. Medicina veterinària.

Per a les punxades

FONTS 1347, 1348, 1349. DESCRIPCIÓ DE L'ÚS FETA PELS INFORMANTS. Per punxades. FORMA FARMACĖUTICA I ÚS. Bany (ús extern). PREPARACIÓ. Decocció. DESTINACIÓ. Medicina humana.

Per als penellons

FONT 1210. DESCRIPCIÓ DE L'ÚS FETA PER L'INFORMANT. Aplicar aigua bullida amb fulles de noguer directament sobre mans i peus i si eren a les orelles compreses amb un drap
fil. FORMA FARMACĖUTICA I ÚS. Bany (ús extern). PREPARACIÓ. Decocció. DESTINACIÓ. Medicina humana. OBSERVACIONS. Li ho va dir la Maria Sagué.

Vulnerari

FONTS 529, 530, 531, 532, 1347, 1348, 1349. DESCRIPCIÓ DE L'ÚS FETA PELS INFORMANTS. Les fulles van bé per a rentar les ferides $(529,530,531)$. Les fulles són bones per a desinflamar i també per a desinfectar ferides (532). Per a banyar ferides (1347, 1348,1349 ). FORMA FARMACÉUTICA I ÚS. Bany (ús extern). PREPARACIÓ. Decocció $(529,530,531,532,1347,1348,1349)$. DESTINACIÓ. Medicina humana.

\section{Suc del fruit}

Antiberrugós

FONTS 1213, 1214. DESCRIPCIÓ DE L'ÚS FETA PELS INFORMANTS. El suc de les nous verdes fa marxar les berrugues. FORMA FARMACEUTICA I US. Sense forma farmacèutica (ús directe, ús extern). DESTINACIO. Medicina humana.

\section{USOS ALIMENTARIS}

\section{Fruit}

Ingestió de la part de la planta crua - Fresca (sense preparació)

FONTS 564, 578, 579, 582, 589. DESCRIPCIÓ DE L'ÚS FETA PELS INFORMANTS. Per a menjar les anous $(582,589)$. Les nous són bones (564). DESTINACIÓ. Alimentació humana $(564,578,579,582,589)$. 
Preparació de begudes - Beguda preparada amb aiguardent

FONTS 503, 522, 523, 524, 529, 530, 531, 553, 588, 590, 591, 592, 750, 1213, 1214, 1341 1342. DESCRIPCIÓ DE L'ÚS FETA PELS INFORMANTS. Amb les nous verdes, la mare feia alguna vegada ratafia. Recepta de ratafia: per un litre d'aiguardent hi posava tres nous (Juglans regia), una branca de canyella (Cinnamomum zeylanicum), una nou moscada (Myristica fragrans), tarongina (Melissa officinalis), algunes herbes més que no recordo, i tres cullerades de sucre. Deien que com més varietat d'herbes millor. Es posava amb una garrafa de vidre i es deixava a la finestra a sol i serena uns quants dies, no recordo quants. Es solia fer per Sant Pere (524). Per a fer ratafia (750). Les nous verdes es posen a la ratafia, nosaltres no $n$ 'hem pas fet mai $(529,530,531)$. Les nous verdes per a fer ratafia $(522,523$ $591,592)$. Les herbes utilitzades són: nous verdes (Juglans regia), herba de Noè (Herniaria glabra), tarongina (Mellssa officinalis), camamilla borda (Tanacetum parthenium), marialluïsa (Lippia triphylla), menta (Mentha spicata), salsufragia (Peucedanum ostruthium), til·la (Tilia platyphyllos), nou moscada (Myristica fragrans) i clau (Syzygium aromaticum) (553). Ratafia. Abans si que n'havia fet, hi posava 14015 herbes, no me'n recordo de totes. Nous verdes (Juglans regia), farigola (Thymus serpyllum), nou moscada (Myristica fragrans), marialluïsa (Lippia triphylla), menta (Mentha spicata), orenga (Origanum vulgare) i poniol (Satureja calamintha subsp. ascendens) (588). Amb les nous verdes es fa ratafia (590). Les nous verdes són un ingredient de la ratafia $(1213,1214)$. Per a fer ratafia, es confita llor (Laurus nobilis), romaní (Rosmarinus officinalis), nous (Juglans regia), granes de ginebró (Juniperus communis), camamilla (Achillea ptarmica subsp. pyrenaica), ortigues (Urtica dioica), pela de taronja (Citrus sinensis), pela de llimona (Citrus limon), canyella (Cinnamomum zeylanicum), marialluïsa (Lippia triphylla), poniol (Satureja calamintha subsp. ascendens), rosa de bosc (Rosa tomentosa) i malva (Malva sylvestris) en aiguardent i es deixa 40 dies a sol i a serena (Rosa tomentosa) i malva (Malva sylvestris) en aiguardent ies. lavors es colatia la guardava per quan venia convidar (503). No recorda quines plan). S'ês hi posava (750). Saben que es posen a la ratafia però no n'han fet mai $(522,523)$. S'utilitzen nous verdes, en número imparell (553). $(503,522,523,524,529,530,531,553,588,590,591,592,750,1213,1214,1341,1342)$.

\section{ALTRES USOS}

Fulla

Tintorial

FONTS 1213, 1214. DESCRIPCIÓ DE L'ÚS FETA PELS INFORMANTS. Antigament, l'aigua bullida amb les fulles es feia servir per a donar color a la roba negra.

\section{Planta sencera}

Literatura oral popular: llegendes, gloses, contes, dites, refranys, poemes, cançons FONTS 1213, 1214. DESCRIPCIÓ DE L'ÚS FETA PELS INFORMANTS. Diuen que fer la migdiada a sota d'un noguer provoca mal de cap.

\section{Planta viva in situ}

Creences i pràctiques magicoreligioses
FONTS 507, 509, 510, 524, 1332, 1333, 1334. DESCRIPCIÓ DE L'ÚS FETA PELS INFORMANTS. No et pots adormir sota un noguer, però si li trenques un brot ja no et fa res (524). Si fics. migdiada a l'ombra del noguer quedaves gamat. De fet l'ombra del noguer (524). Si feles migdiada a l'ombra del noguer quedaves gamat. De fet l'ombra del noguer és molt freda (507, 509,510$)$ L'omba del noguer es enganyosa, si tu hi vas a reposar et pot no et farà res $(1332,1333,1334)$ Tija

Altres informacions

FONTS 583, 584, 585. DESCRIPCIÓ DE L'ÚS FETA PELS INFORMANTS. Per a fer els collars dels gossos.

\section{ALTRES OBSERVACIONS}

FONTS 558, 578, 579. DESCRIPCIÓ FETA PELS INFORMANTS. A Nevà n'hi ha molts (558). Aquí a Perella n'hi ha molts $(578,579)$.

\section{BARREGES AMB AQUEST TÀXON}

Fulla

FONTS 748, 749. Entrevista 49 (vegeu catàleg de barreges)

\section{Juncus trifidus L. (juncàcies)}

\section{BCN 24909}

\section{NOMS POPULARS}

Herba prima de Rojà $(1347,1348,1349)$

\section{USOS MEDICINALS}

\section{Part aèria}

Diürètic

FONTS 1347, 1348, 1349. DESCRIPCIÓ DE L'ÚS FETA PELS INFORMANTS. Per a fer orinar. FORMA FARMACĖUTICA I ÚS. Tisana (ús intern). PREPARACIÓ. Decocció. DESTINACIÓ. Medicina humana.

\section{Juniperus communis L. (cupressàcies)}

BCN 24910

NOMS POPULARS 
Ginebre $(503,518,519,559,568,571,574,575,576,577,583,584,585,586,587,753$ $754,755,1215,1296)$

Ginebró $(553,556,557,1341,1342)$

Oli de ginebre (producte elaborat) $(517,572,573,748,749,1210,1313,1339,1340)$

\section{USOS MEDICINALS}

\section{Arrel}

Desconegut per l'informant

FONTS 586, 587. DESCRIPCIÓ DE L'ÚS FETA PELS INFORMANTS. Era medicinal. FORMA FARMACĖUTICA I ÚS. Desconegut per l'informant. PREPARACIÓ. Amb la rel es feia oli. S'agafava la rel es posava al femer que es podrís, després es feia bullir el que era bo de l'aigua, no ho recordo gaire bé, però era una cosa així. DESTINACIÓ. Medicina humana.

\section{Fructificació}

Analgèsic

FONT 1215. FORMA FARMACĖUTICA I ÚS. Desconegut per l'informant. DESTINACIÓ Medicina humana. OBSERVACIONS. L'anava a collir, però no recorda el molt bé el perquè Remenava la mata i feia caure les boles al paraigua.

Anticatarral

FONTS 556, 557. DESCRIPCIÓ DE L'ÚS FETA PELS INFORMANTS. Per als refredats de pit. FORMA FARMACĖUTICA I ÚS. Tisana (ús intern). PREPARACIÓ. Decocció. DESTINACIÓ. Medicina humana.

Antihelmíntic

FONTS 559, 568, 1296. DESCRIPCIÓ DE L'ÚS FETA PELS INFORMANTS. Anava bé per a quan tenies cucs (559). Anava bé per a descucar el cuc del budell (568). Deien que anaven bé per als cucs (1296). FORMA FARMACĖUTICA I ÚS. Macerat en oli (ús intern) $(559,568)$ Tisana (ús intern) (1296). PREPARACIÓ. Les granes es posaven en oli i després te'l feien prendre amb una mica de vi (559). Se'n feia oli de les boles (568). Les granes seques s'utilitzaven en infusió (1296). DESTINACIÓ. Medicina humana.

Desconegut per l'informant

FONTS 503, 553, 574, 575, 576, 577. DESCRIPCIÓ DE L'ÚS FETA PELS INFORMANTS De les granes madures del ginebre, la mare en feia alguna medicina (503). FORMA FARMACĖUTICA I ÚS. Desconegut per l'informant $(503,574,575,576,577)$. Xarop (ús intern) (553). PREPARACIÓ. Es feia xarop de les granes (553). DESTINACIO. Medicin humana. OBSERVACIONS. Les granes són medicinals $(574,575,576,577)$

Salutífer

FONTS 753, 754, 755. DESCRIPCIÓ DE L'ÚS FETA PELS INFORMANTS. Aigua de ginebre a la primavera i a la tardor per a agafar salut. FORMA FARMACĖUTICA I ÚS. Tisana (ús intern). PREPARACIÓ. Decocció. MODE D'UTILITZACIÓ/POSOLOGIA. A casa se'n feien novenes. DESTINACIÓ. Medicina humana.

Vulnerari
FONT 571. DESCRIPCIÓ DE L'ÚS FETA PER L'INFORMANT. Era la nostra cura si et feies un tall. FORMA FARMACĖUTICA I ÚS. Liniment (ús extern). PREPARACIÓ. El gra es fa servir per a fer l'oli. DESTINACIÓ. Medicina humana.

\section{No consta}

Antifúngic

FONT 1313. DESCRIPCIÓ DE L'ÚS FETA PER L'INFORMANT. Per a curar els brians FORMA FARMACĖUTICA I ÚS. Sense forma farmacèutica (ús directe, ús extern) DESTINACIÓ. Medicina humana.

Antiodontàlgic

FONTS 572, 573. DESCRIPCIÓ DE L'ÚS FETA PELS INFORMANTS. Anava bé per al mal de queixals (572). Va bé per al mal de queixals (573). FORMA FARMACĖUTICA I ÚS Desconegut per l'informant. PREPARACIÓ. Oli de ginebre (producte elaborat) $(572,573$ ) DESTINACIÓ. Medicina humana. OBSERVACIONS. Passaven les trementinaires de la Serra de Cadí $(572,573)$.

Antisèptic intern

FONTS 748, 749. DESCRIPCIÓ DE L'ÚS FETA PELS INFORMANTS. Es prenia a la primavera per a desinfectar. L'oli el duien les pegaires. FORMA FARMACĖUTICA I ÚS Desconegut per l'informant. PREPARACIÓ. Oli de ginebre (producte elaborat) barrejat amb flor de sofre i sucre. DESTINACIÓ. Medicina humana.

Resolutiu

FONT 517. DESCRIPCIÓ DE L'ÚS FETA PER L'INFORMANT. Es posa damunt dels furóncols i els fa madurar. FORMA FARMACĖUTICA I ÚS. Desconegut per l'informant PREPARACIÓ. Oli de ginebre (producte elaborat), barrejat amb rovell d'ou, meitat per meitat. DESTINACIÓ. Medicina humana. OBSERVACIONS. Tiba molt.

\section{Part aèria}

Antifúngic

FONTS 1339, 1340. DESCRIPCIÓ DE L'ÚS FETA PELS INFORMANTS. Per als brians FORMA FARMACĖUTICA I ÚS. Sense forma farmacèutica (ús directe, ús extern). PREPARACIÓ. Oli de ginebre amb sucre. DESTINACIÓ. Medicina humana. OBSERVACIONS. El compraven a les trementinaires.

\section{USOS ALIMENTARIS}

\section{Fructificació}

Preparació de begudes - Beguda preparada amb aiguardent

FONTS 1341, 1342. DESCRIPCIÓ DE L'ÚS FETA PELS INFORMANTS. Per a fer ratafia, es confita llor (Laurus nobilis), romaní (Rosmarinus officinalis), nous (Juglans regia), granes de ginebró (Juniperus communis), camamilla (Achillea ptarmica subsp. pyrenaica), ortigues (Urtica dioica), pela de taronja (Citrus sinensis), pela de llimona (Citrus limon), canyella (Cinnamomum zeylanicum), marialluïsa (Lippia triphylla), poniol (Satureja calamintha subsp. ascendens), rosa de bosc (Rosa tomentosa) i malva (Malva sylvestris) en aiguardent i es 
deixa 40 dies a sol i a serena, llavors es cola i ja es pot beure. DESTINACIÓ. Alimentació humana.

\section{ALTRES USOS}

Fructificació

Altres informacions

FONT 1296. DESCRIPCIÓ DE L'ÚS FETA PER L'INFORMANT. Les granes bullides servien per a netejar les bótes de vi que s'havien tornat agres, i com que aquestes granes són dolces, endolcien la bóta.

Maneig agrosilvopastoral: ús hortícola/agrícola

FONTS 518, 519. DESCRIPCIÓ DE L'ÚS FETA PELS INFORMANTS. Les granes les colliem per vendre.

Tija

Maneig agrosilvopastoral: ús hortícola/agrícola

FONTS 583, 584, 585. DESCRIPCIÓ DE L'ÚS FETA PELS INFORMANTS. Els brocs es feien servir per a fer andans (pals per al vailet).

\section{BARREGES AMB AQUEST TÀXON}

Fructificació

FONTS 753, 754, 755. Entrevista 67, barreja IV (vegeu catàleg de barreges)

Tija

FONT 1210. Entrevista 103 (vegeu catàleg de barreges)

\section{Lactuca sativa L. (compostes)}

BCN 46842

\section{NOMS POPULARS}

Enciam $(505,506,589,750,1352)$

\section{USOS MEDICINALS}

\section{Fulla}

Antisèptic urinari

FONT 1352. DESCRIPCIÓ DE L'ÚS FETA PER L'INFORMANT. Per a les infeccions d'orina. FORMA FARMACĖUTICA I ÚS. Bany (ús extern). PREPARACIÓ. Fer-ne banys de seient. DESTINACIÓ. Medicina humana.

\section{USOS ALIMENTARIS}

Fulla

Ingestió de la part de la planta crua - Fresca (sense preparació)

FONTS 505, 506, 589, 1352. DESCRIPCIÓ DE L'ÚS FETA PELS INFORMANTS. Per a amanir $(505,506)$. A I'hort (589). Per a menjar amanit (1352). DESTINACIÓ. Alimentació humana $(505,506,589,1352)$

\section{ACCIONS NOCIVES O TÒXIQUES}

\section{Part aèria}

FONT 1352. DESCRIPCIÓ DE L'ACCIÓ NOCIVA O TÒXICA FETA PER L'INFORMANT. EI meu avi deia que si en menjava se li posaven els ulls vermells. VIA D'INTOXICACIÓ. Via interna.

\section{BARREGES AMB AQUEST TÀXON}

Fulla

FONT 750. Entrevista 50, barreja IV (vegeu catàleg de barreges)

\section{Lactuca serriola L. (compostes)}

BCN 49232

\section{NOMS POPULARS}

Enciam bord (564)

\section{USOS ALIMENTARIS}

Fulla

Ingestió de la part de la planta crua - Fresca (sense preparació)

FONT 564. DESCRIPCIÓ DE L'ÚS FETA PER L'INFORMANT. Els en donàvem a les gallines. DESTINACIÓ. Alimentació animal.

\section{Lamium album L. (labiades)}

BCN 24911

\section{NOMS POPULARS}

Ortiga blanca $(511,512,513,514,532,542,543,544,559,1213,1214,1331)$ 


\section{USOS MEDICINALS}

\section{Part aèria}

Antihipertensiu

FONTS 511, 512, 513, 514, 1331. DESCRIPCIÓ DE L'ÚS FETA PELS INFORMANTS. Per a fer baixar la pressió. FORMA FARMACĖUTICA I ÚS. Tisana (ús intern). PREPARACIÓ. Decocció. DESTINACIÓ. Medicina humana.

Diürètic

FONTS 1213, 1214. DESCRIPCIÓ DE L'ÚS FETA PELS INFORMANTS. Va bé per a la bufeta de l'orina, fa pixar. FORMA FARMACĖUTICA I ÚS. Tisana (ús intern). PREPARACIÓ. Decocció. DESTINACIÓ. Medicina humana.

Hematocatàrtic

FONTS 532, 559. DESCRIPCIÓ DE L'ÚS FETA PELS INFORMANTS. Per a depurar (532) Per a purificar la sang (559). FORMA FARMACĖUTICA I ÚS. Tisana (ús intern). PREPARACIÓ. Decocció $(532,559)$. DESTINACIÓ. Medicina humana.

\section{Laurus nobilis L. (lauràcies)}

\section{BCN 24912}

\section{NOMS POPULARS}

Llaurer $(515,516,539,540,547,548,569,570,571,580)$

Llor $(507,509,510,546,564,1296,1297,1313,1314,1321,1325,1326,1327,1330,1331$ $1336,1337,1338,1341,1342,1352)$

Llorer $(511,512,513,514,558,560,561,562,563,565,566,586,587,590,1317,1320$, 1335)

\section{USOS MEDICINALS}

Fulla

Digestiu

FONT 1330. DESCRIPCIÓ DE L'ÚS FETA PER L'INFORMANT. És molt digestiu. FORMA FARMACĖUTICA I ÚS. Tisana (ús intern). PREPARACIÓ. Decocció. DESTINACIÓ. Medicina humana.

Diürètic

FONTS 539, 540. DESCRIPCIÓ DE L'ÚS FETA PELS INFORMANTS. Les fulles per a fer orinar. FORMA FARMACÈUTICA I ÚS. Tisana (ús intern). PREPARACIÓ. Decocció DESTINACIÓ. Medicina humana.

Laxant
FONT 580. DESCRIPCIO DE L'ÚS FETA PER L'INFORMANT. L'aigua de llorer ajuda a anar de ventre. FORMA FARMACÉUTICA I ÚS. Tisana (ús intern). PREPARACIÓ. Decocció. DESTINACIÓ. Medicina humana.

Litotríptic renal

FONT 1320. DESCRIPCIÓ DE L'ÚS FETA PER L'INFORMANT. Per a desfer les pedres del ronyó. FORMA FARMACĖUTICA I ÚS. Tisana (ús intern). PREPARACIÓ. Decocció. DESTINACIÓ. Medicina humana.

\section{USOS ALIMENTARIS}

Fulla

Condiment

FONTS $507,509,510,511,512,513,514,515,516,546,547,548,558,560,561,562,563$ $564,565,566,569,570,571,590,1296,1297,1313,1314,1317,1321,1327,1331,1335$, $1336,1337,1338,1352$. DESCRIPCIÓ DE L'ÚS FETA PELS INFORMANTS. Per a posar als estofats (560). Per a cuinar $(546,547,548,558,564,569,570,571,1296,1314,1317,1337$, 1338). Romaní (Rosmarinus officinalis), llorer (Laurus nobilis), farigola (Thymus vulgaris) i orenga (Origanum vulgare). Piquem les herbes juntes i ho fem servir per a fer guisats (590) Per a donar gust als cuinats $(507,509,510,511,512,513,514,515,516)$. Per l'estofat (561, $562,563)$. Per a l'estofat $(565,566)$. Per als rostits $(1297)$. Per a donar gust $(1313,1321$, 1327, 1331, 1336). Per a donar gust a l'estofat (1335). La meva padrina l'usava per a cuinar (1352). OBSERVACIONS. En compra $(1296,1297)$. Els seus menjars eren molt especiats molt bons (1352). DESTINACIÓ. Alimentació humana $(507,509,510,511,512,513,514$ $515,516,546,547,548,558,560,561,562,563,564,565,566,569,570,571,590,1296$ $1297,1313,1314,1317,1321,1327,1331,1335,1336,1337,1338,1352)$.

Preparació de begudes - Beguda preparada amb aiguardent

FONTS 1341, 1342. DESCRIPCIÓ DE L'ÚS FETA PELS INFORMANTS. Per a fer ratafia, es confita llor (Laurus nobilis), romaní (Rosmarinus officinalis), nous (Juglans regia), granes de ginebró (Juniperus communis), camamilla (Achillea ptarmica subsp. pyrenaica), ortigues (Urtica dioica), pela de taronja (Citrus sinensis), pela de llimona (Citrus limon), canyella (Cinnamomum zeylanicum), marialluïsa (Lippia triphylla), poniol (Satureja calamintha subsp. ascendens), rosa de bosc (Rosa tomentosa) i malva (Malva sylvestris) en aiguardent i es ascendens), rosa de bosc (Rosa tomentosa) i malva (Malva sylvestris) en aiguardent i es
deixa 40 dies a sol i a serena, llavors es cola i ja es pot beure. DESTINACIÓ. Alimentació humana.

\section{ALTRES USOS}

\section{Part aèria}

Creences i pràctiques magicoreligioses

FONTS 560, 564, 586, 587, 590, 1325, 1326. DESCRIPCIÓ DE L'ÚS FETA PELS INFORMANTS. Per a beneir pel Ram $(560,586,587)$. Es cremava el llor beneït quan feia una maltempsada o tronava (564). Es beneïa pel dia del Ram (590). A Beget i Rocabruna es 
beneïa un ram de llor (Laurus nobilis) i romaní (Rosmarius officinalis) guarnits amb galetes i rosaris de sucre el diumenge de rams $(1325,1326)$.

\section{ALTRES OBSERVACIONS}

FONTS 539, 540, 1296, 1297, 1337, 1338. DESCRIPCIÓ FETA PELS INFORMANTS. A l'hort $(539,540)$. Aquí no n'hi ha $(1296,1297)$. La portaven de l'Alt Empordà, ells feien la transhumància i passaven l'hivern a Vilajuïga $(1337,1338)$.

\section{BARREGES AMB AQUEST TÀXON}

Fulla

FONT 1335. Entrevista 15, barreja III (vegeu catàleg de barreges)

\section{Lavandula angustifolia Mill. (labiades)}

BCN 24913

\section{NOMS POPULARS}

Bargalló $(503,518,519,529,530,531,564,578,579,1313)$

Espígol $(507,509,510,529,530,531,539,540,545,553,554,555,560,569,570,581,746$ $753,754,755,1294,1327,1331,1332,1333,1334,1335)$

Lavanda (1323)

Vermelló $(542,543,544,1215,1336,1341,1342)$

\section{USOS MEDICINALS}

\section{No consta}

Desconegut per l'informant

FONT 1215. FORMA FARMACĖUTICA I ÚS. Desconegut per l'informant. PREPARACIÓ. En oli.

\section{Summitat florífera}

Analgèsic

FONT 1335. DESCRIPCIÓ DE L'ÚS FETA PER L'INFORMANT. Per al dolor. FORMA FARMACĖUTICA I ÚS. Essència (ús extern). DESTINACIÓ. Medicina humana.

Antiàcid

FONT 564. DESCRIPCIÓ DE L'ÚS FETA PER L'INFORMANT. Emplastres d'aigua de vermelló per a treure la cremor d'estómac. FORMA FARMACĖUTICA I ÚS. Emplastre (ús extern). PREPARACIO. Decocció. Et poses un drap moll de vermelló. DESTINACIO. Medicina humana.

\section{Anticatarral}

FONTS $507,509,510,545,578,579,746,1294,1313,1327,1335,1341,1342$ DESCRIPCIÓ DE L'ÚS FETA PELS INFORMANTS. Per a fer fregues per als constipats (746). Quan estàs refredat $(507,509,510)$. Per als constipats $(545,1327)$. Quan estaves refredat $(578,579)$. Per als constipats en respires l'essència i destapa molt (1294). Per als constipats te'n fas fregues (1313). Per als constipats de nas (1335). Per a quan estàs constipat $(1341,1342)$. FORMA FARMACĖUTICA I ÚS. Loció (ús extern) $(507,509,510$ $545,746,1313,1341,1342)$. Emplastre (ús extern) $(578,579)$. Essència (ús intern) (1294, 1335). Tisana (ús intern) (1327). PREPARACIÓ. Es posa la flor en esperit de vi (746). Es macera en esperit de vi i es fan fregues $(507,509,510)$. S'ha de posar en esperit de vi i quan queda una mica verdós ja es pot utilitzar (545). Es feien emplastres pel pit. La planta ben queda $(578,579)$. Les flors es confiten en esperit de vi una mica rebaixat amb aigu aixafada (578,579). Les fors (1327). Conften en esperit de vi una mica rebaixat amb aigua destil·lada (1313). Decocció (1327). Confitat en esperit de vi per a fer-se fregues al pit o

Antienurètic

FONT 564. DESCRIPCIÓ DE L'ÚS FETA PER L'INFORMANT. Es posava als peus dels nens quan eren grandassos i encara es feien pipí al llit. FORMA FARMACĖUTICA I ÚS. Sense forma farmacèutica (ús directe, ús extern). DESTINACIÓ. Medicina humana.

Antiequimòtic

FONT 1335. DESCRIPCIÓ DE L'ÚS FETA PER L'INFORMANT. Per als trucs. FORMA FARMACĖUTICA I ÚS. Essència (ús extern). DESTINACIÓ. Medicina humana.

Antiinflamatori

FONT 564. DESCRIPCIÓ DE L'ÚS FETA PER L'INFORMANT. Em vaig trencar el braç i m'hi vaig posar el drap moll de vermelló i va bé, fa com un antiinflamatori. FORMA FARMACËUTICA I ÚS. Emplastre (ús extern). PREPARACIÓ Decocció. DESTINACIÓ. Medicina humana.

Antinauseabund

FONT 545. DESCRIPCIÓ DE L'ÚS FETA PER L'INFORMANT. Per al mareig, quan es va en cotxe, olores un mocador empapat d'espígol. FORMA FARMACĖUTICA I ÚS. Loció (ús extern). PREPARACIÓ. S'ha de posar en esperit de vi i quan queda una mica verdós ja es pot utilitzar. DESTINACIÓ. Medicina humana.

Antiodontàlgic

FONTS 542, 543, 544. DESCRIPCIÓ DE L'ÚS FETA PELS INFORMANTS. Per al mal de queixals. FORMA FARMACĖUTICA I ÚS. Fumigació (ús extern). PREPARACIÓ. Per a fer perfums. DESTINACIÓ. Medicina humana.

Antisèptic extern

FONTS 542, 543, 544. DESCRIPCIÓ DE L'ÚS FETA PELS INFORMANTS. Treu les infeccions. FORMA FARMACĖUTICA I ÚS. Fumigació (ús extern). PREPARACIÓ. Per a fer perfums. DESTINACIÓ. Medicina humana.

No consta 
Apèndix 1. Catàleg de tàxons.

FONT 545. DESCRIPCIÓ DE L'ÚS FETA PER L'INFORMANT. Va bé per a la paràlisi. FORMA FARMACĖUTICA I ÚS. Loció (ús extern). PREPARACIÓ. S'ha de posar en esperit de vi i quan queda una mica verdós ja es pot utilitzar. DESTINACIÓ. Medicina humana.

Tranquil·litzant

FONTS 545, 1323. DESCRIPCIÓ DE L'ÚS FETA PELS INFORMANTS. Si no pots dormir te'n tires una mica al pit i olores (545). Tenir-ne un ram, relaxa (1323). FORMA FARMACĖUTICA I ÚS. Loció (ús extern) (545). Sense forma farmacèutica (ús directe, ús extern) (1323). PREPARACIÓ. S'ha de posar en esperit de vi i quan queda una mica verdós ja es pot utilitzar (545). DESTINACIÓ. Medicina humana.

\section{USOS ALIMENTARIS}

\section{Part aèria}

Condiment

FONT 1335. DESCRIPCIÓ DE L'ÚS FETA PER L'INFORMANT. Per a donar gust a l'estofat. DESTINACIÓ. Alimentació humana.

\section{ALTRES USOS}

Summitat florífera

Domèstic: ambientador

FONTS 503, 569, 570, 1313. DESCRIPCIÓ DE L'ÚS FETA PELS INFORMANTS. Fa molt bona olor $(569,570)$. Es posava entremig de la roba i feia molta olor $(503)$. Per a fer olor (1313).

Repel·lents

FONT 560. DESCRIPCIÓ DE L'ÚS FETA PER L'INFORMANT. Es penjava per la casa perquè deien que espantava els mosquits.

\section{ALTRES OBSERVACIONS}

FONTS 545, 1341, 1342. DESCRIPCIÓ FETA PELS INFORMANTS. S'ha de collir el juliol i assecar a l'ombra (545). En té de plantat a l'hort $(1341,1342)$.

\section{BARREGES AMB AQUEST TÀXON}

Summitat florífera

FONTS 1332, 1333, 1334. Entrevista 11, barreja II (vegeu catàleg de barreges)

FONT 1327. Entrevista 14, barreja IV (vegeu catàleg de barreges)

FONT 1335. Entrevista 15, barreja I (vegeu catàleg de barreges)

FONT 1335. Entrevista 15, barreja III (vegeu catàleg de barreges)

FONT 1336. Entrevista 16, barreja II (vegeu catàleg de barreges)
FONT 1331. Entrevista 30, barreja I (vegeu catàleg de barreges)

FONT 503. Entrevista 43 (vegeu catàleg de barreges)

FONTS 529, 530, 531. Entrevista 53, barreja II (vegeu catàleg de barreges)

FONTS 529, 530, 531. Entrevista 53, barreja VI (vegeu catàleg de barreges)

FONTS 518, 519. Entrevista 54, barreja II (vegeu catàleg de barreges)

FONTS 753, 754, 755. Entrevista 67, barreja IV (vegeu catàleg de barreges)

FONTS 539, 540. Entrevista 69 (vegeu catàleg de barreges)

FONT 553. Entrevista 77, barreja II (vegeu catàleg de barreges)

FONTS 554, 555. Entrevista 78, barreja II (vegeu catàleg de barreges)

FONT 581. Entrevista 94, barreja I (vegeu catàleg de barreges)

\section{Lavandula stoechas L. (labiades)}

\section{BCN 27278}

\section{NOMS POPULARS}

Timó $(753,754,755,1321)$

\section{USOS MEDICINALS}

\section{Summitat florífera}

Antiasmàtic

FONT 1321. DESCRIPCIÓ DE L'ÚS FETA PER L'INFORMANT. Per a l'ofegament. FORMA FARMACĖUTICA I ÚS. Tisana (ús intern). DESTINACIÓ. Medicina humana.

\section{Antihipertensiu}

FONTS 753, 754, 755. DESCRIPCIÓ DE L'ÚS FETA PELS INFORMANTS. És bona per a fer baixar la pressió. FORMA FARMACĖUTICA I ÚS. Tisana (ús intern). PREPARACIÓ. Decocció. DESTINACIÓ. Medicina humana.

\section{ALTRES OBSERVACIONS}

FONTS 753, 754, 755. DESCRIPCIÓ FETA PELS INFORMANTS. L'anem a buscar a Sant Climent.

Leontodon hispidus L. (compostes)

BCN 24914

\section{NOMS POPULARS}


Queixalets $(1321,1337,1338)$

\section{USOS ALIMENTARIS}

Fulla

Ingestió de la part de la planta crua - Fresca (sense preparació)

FONTS 1321, 1337, 1338. DESCRIPCIÓ DE L'ÚS FETA PELS INFORMANTS. Per a amanir. DESTINACIÓ. Alimentació humana.

\section{Lepidium latifolium L. subsp. latifolium (crucíferes)}

BCN 123785

\section{NOMS POPULARS}

Lepídium $(539,540)$

\section{USOS MEDICINALS}

\section{Part aèria florida}

Litotríptic renal

FONTS 539, 540. DESCRIPCIÓ DE L'ÚS FETA PELS INFORMANTS. Per a desfer les pedres del ronyó. FORMA FARMACĖUTICA I ÚS. Tisana (ús intern). PREPARACIÓ. Decocció. EFECTES SECUNDARIS. Sí. DESTINACIÓ. Medicina humana.

\section{ACCIONS NOCIVES O TÒXIQUES}

No consta

FONTS 539, 540. DESCRIPCIÓ DE L'ACCIÓ NOCIVA O TÒXICA FETA PELS INFORMANTS. És una mica tòxica. TOXICITAT LLIGADA A L'ÚS MEDICINAL. Sí.

\section{Leucanthemum vulgare Lam. (compostes)}

BCN 27294

\section{NOMS POPULARS}

Margarida $(1353,1354)$

\section{ALTRES USOS}

Part aèria florida

Ornamental: elaboració de rams
FONTS 1353, 1354. DESCRIPCIÓ DE L'ÚS FETA PELS INFORMANTS. Per a fer rams.

\section{Levisticum officinale Koch (umbel-líferes)}

BCN 63750

\section{USOS ALIMENTARIS}

Fulla

No consta el tipus d'ingesta - No consta el mode de preparació

FONT 504. DESCRIPCIÓ DE L'ÚS FETA PER L'INFORMANT. Planta semblant a l'api. Ha vingut de França i diuen que en fan les pastilles d'Avecrem. La té plantada a l'hort. DESTINACIÓ. Alimentació humana.

\section{Ligustrum vulgare L. (oleàcies)}

BCN 24915

\section{NOMS POPULARS}

Escanyacabres (1324)

Olivereta (1324)

\section{USOS MEDICINALS}

Fulla

Antiàlgic ciàtic

FONT 1324. DESCRIPCIÓ DE L'ÚS FETA PER L'INFORMANT. Per a la ciàtica. FORMA FARMACĖUTICA I ÚS. Liniment (ús extern). PREPARACIÓ. Les fulles bullides en oli. DESTINACIÓ. Medicina humana.

\section{ALTRES USOS}

\section{Part aèria}

Altres informacions

FONT 1324. DESCRIPCIÓ DE L'ÚS FETA PER L'INFORMANT. Abans el feien servir per a buscar aigua, quan la branca s'aixecava volia dir que a sota hi havia aigua.

Lilium candidum L. (liliàcies)

BCN 24916 


\section{NOMS POPULARS}

Lliri $(529,530,531,571,1300,1310)$

Lliri blanc $(505,506,511,512,513,514,525,526,527,528,532,536,537,539,540,542$, $543,544,549,553,554,555,556,557,558,560,571,572,573,574,575,576,577,580$ $582,583,584,585,591,592,748,749,750,1213,1214,1297,1313,1314,1327,1339$ $1340,1341,1342,1347,1348,1349,1361,1362)$

Lliri de flor blanca $(1311,1312,1325,1326,1330)$

Lliri de Sant Josep $(569,570,1345,1346)$

\section{USOS MEDICINALS}

Bulb

Per a trastorns de la pell o del teixit subcutan

FONTS 569, 570. DESCRIPCIÓ DE L'ÚS FETA PELS INFORMANTS. Anava bé per als ulls de poll.Posada directament a l'ull de poll. FORMA FARMACĖUTICA I ÚS. Embrocació (ús extern). Desconegut per l'informant. PREPARACIÓ. El bulb es posava en oli.Una fulla del bulb escalfada. DESTINACIÓ. Medicina humana.

Resolutiu

FONTS 532, 591, 592, 1341, 1342. DESCRIPCIÓ DE L'ÚS FETA PELS INFORMANTS. S'usaven per a fer sortir les infeccions cap enfora (532). Anava molt bé per a grans infectats $(591,592)$. Per a madurar grans $(1341,1342)$. FORMA FARMACĖUTICA I ÚS. Emplastre (ús extern) $(532,1341,1342)$. Pomada (ús extern) $(591,592)$. PREPARACIÓ. De les cebes se'n feien emplastres amb greix i pa (532). La ceba del lliri es bullia amb llet i es feia una pomada $(591,592)$. Amb la ceba que fa el lliri es fan emplastres amb llet $(1341,1342)$. DESTINACIÓ. Medicina humana.

Flor

Antiequimòtic

FONTS 529, 530, 531, 1327. DESCRIPCIÓ DE L'ÚS FETA PELS INFORMANTS. Per a les ferides, patacades i mals $(529,530,531)$. Per als trucs (1327). FORMA FARMACEUTICA ÚS. Tintura alcohòlica (ús extern) $(529,530,531)$. Loció (ús extern) (1327). PREPARACIÓ. Confitat en aiguardent $(529,530,531)$. Confitada en anís (1327). DESTINACIÓ. Medicina humana.

Antipiròtic

FONTS 569, 570, 1297. DESCRIPCIÓ DE L'ÚS FETA PELS INFORMANTS. Per a les cremades $(569,570)$. Per a cremades (1297). FORMA FARMACĖUTICA I ÚS. Embrocació (ús extern) $(569,570)$. Tintura alcohòlica (ús extern) $(569,570)$. Loció (ús extern) (1297). PREPARACIÓ. En oli $(569,570)$. En esperit de vi $(569,570)$. Les flors confitades en anís i es posa directament a la zona a tractar i s'embolica (1297). DESTINACIÓ. Medicina humana.

Antisèptic extern
FONT 1297. DESCRIPCIÓ DE L'ÚS FETA PER L'INFORMANT. Per a desinfectar talls. FORMA FARMACĖUTICA I ÚS. Loció (ús extern). PREPARACIÓ. Les flors confitades en anís i es posa directament a la zona a tractar i s'embolica. DESTINACIÓ. Medicina humana. Cicatritzant

FONT 553. DESCRIPCIÓ DE L'ÚS FETA PER L'INFORMANT. Per a les ferides, ajuden que es tanquin. FORMA FARMACĖUTICA I ÚS. Tintura alcohòlica (ús extern). Embrocació (ús extern). PREPARACIÓ. Es posen en aiguardent.En oli. DESTINACIÓ. Medicina humana.

Per a trastorns de la pell o del teixit subcutani

FONTS 1213, 1214. DESCRIPCIÓ DE L'ÚS FETA PELS INFORMANTS. Per a treure les taques de la pell produïdes pel sol o per l'edat. FORMA FARMACĖUTICA I ÚS. Liniment (ús extern). PREPARACIÓ. Se'n fa un oli. DESTINACIÓ. Medicina humana.

Resolutiu

FONTS 539, 540, 582, 1341, 1342, 1347, 1348, 1349. DESCRIPCIÓ DE L'ÚS FETA PELS INFORMANTS. Servien per a curar les llagues $(539,540)$. Va bé per a les llagues (582). Per a madurar grans $(1341,1342)$. Per a fer madurar els furóncols $(1347,1348,1349)$. FORMA FARMACĖUTICA I ÚS. Embrocació (ús extern) $(539,540,1347,1348,1349)$. Tintura alcohòlica (ús extern) (582). Loció (ús extern) (1341, 1342, 1347, 1348, 1349). PREPARACIÓ. Les flors es posaven en oli $(539,540)$. La flor en aiguardent (582). Confitats en esperit de vi (1341). Confitat en esperit de vi (1342). Confitat en oli $(1347,1348,1349)$. Confitat en aiguardent (1348). Confitat en anís (1347, 1349). DESTINACIÓ. Medicina humana.

Vulnerari

FONTS 505, 506, 511, 512, 513, 514, 525, 526, 527, 528, 529, 530, 531, 536, 537, 542, 543, $544,549,553,554,555,556,557,558,560,569,570,571,572,573,580,582,583,584$ $585,591,592,748,749,750,1310,1311,1312,1313,1314,1325,1326,1330,1339,1340$, $1341,1342,1345,1346,1361,1362$. DESCRIPCIÓ DE L'ÚS FETA PELS INFORMANTS. Anava bé per als talls (558). Per a les ferides $(511,512,513,514,528,536,537,556,557$, $569,570,571,750,1325,1326)$. Quan et feies un encetat t'hi posaves la flor (580). Per a posar sobre de les ferides $(505,506)$. Per a posar a les ferides $(748,749,1330)$. Per a les ferides, patacades i mals $(529,530,531)$. Per als talls $(542,543,544,560,1339,1340,1341$, 1342). En aiguardent per a curar mals $(525,526,527)$. Servien per a curar mals (549). Per a les ferides, ajuden que es tanquin (553). Va be per a curar mals (582).Va molt be per als talls les ferides, ajuden que es tanquin (553). Va be per a curar mals (582). Va molt be per als talls $(554,555)$. Per a curar talls $(572,573)$. Es posava sobre els talls $(583,584,585,591,592)$ Per als talls i les ferides (1310). Per a les llagues o per a talls infectats $(1311,1312)$. Va bé per a les llagues i els talls (1313). Van bé per a les ferides (1314). Per a posar sobre les ferides (1345, 1346). Per a posar sobre pelats i ferides (1361, 1362). FORMA FARMACEUTICA 1 US. Tintura alcohollica (ús extern) $(505,506,511,512,513,514,525$, $526,527,529,530,531,536,537,542,543,544,549,553,554,555,556,557,558,560$, $569,570,571,572,573,582,591,592,748,749,750,1310,1311,1312$ ). Embrocació (ús extern) $(511,512,513,514,528,536,537,549,553,569,570,580,583,584,585,1311$, $1312,1325,1326,1361,1362)$. Loció (ús extern) $(1313,1314,1330,1339,1340,1341,1342$. $1345,1346)$. PREPARACIÓ. Es posaven en aiguardent (558). Les flors en esperit de vi (571). La flor es posava en oli $(580)$. Confitats en aiguardent $(505,506,1314,1330)$. Es posen en 
aiguardent $\mathrm{o}$ en oli $(511,512,513,514)$. Confitada en aiguardent $(748,749)$. En aiguardent $(560,750)$. Confitat en aiguardent $(529,530,531,1339,1340,1345,1346)$. En anís o en oli $(536,537)$. Confitades les flors en aiguardent $(542,543,544)$. Confitat en oli $(528)$. Es posaven en aiguardent o en oli (549). Es posen en aiguardent (553). En oli (553, 569, 570 $583,584,585)$. En aiguardent, s'hi posa la flor directament $(556,557)$. En esperit de vi $(569$ 570 ). La flor en aiguardent (582). La flor es posa en esperit de vi $(554,555)$. Es posaven en $570)$. La flor en aiguardent (582). La flor es posa en esperit de vi $(554,555)$. Es posaven en
esperit de vi $(572,573)$. La flor es confitava en anís $(591,592)$. La flor confitada en aiguardent (1310). S'utilitza la flor i es confita en aiguardent $(1311,1312)$. S'utilitza la flor i es confita en oli $(1311,1312)$. La flor es posa a confitar en anís o alcohol (1313). Les flors confitades en oli $(1325,1326)$. Confitat en esperit de vi $(1341,1342)$. Confitada en oli $(1361$, 1362). DESTINACIO. Medicina humana.

\section{ALTRES USOS}

\section{Part aèria florida}

Ornamental: elaboració de rams

FONTS 558, 571, 580. DESCRIPCIÓ DE L'ÚS FETA PELS INFORMANTS. Per a fer rams, fan molta olor (558). Per a fer rams, els barrejava amb el lilà (Syringa vulgaris), els feia sortir pel mig i quedava com un campanar (571). Fan uns rams molt macos (580).

\section{ALTRES OBSERVACIONS}

FONTS 539, 540. DESCRIPCIÓ FETA PELS INFORMANTS. Es tenien en els horts.

\section{BARREGES AMB AQUEST TÀXON}

Flor

FONTS 574, 575, 576, 577. Entrevista 91, barreja I (vegeu catàleg de barreges)

\section{Lilium martagon L. (liliàcies)}

BCN 24917

\section{NOMS POPULARS}

Consolta $(539,540,546)$

Consolta vermella $(511,512,513,514,532,1321)$

Consolva $(520,521)$

Consolva vermella $(569,570)$

Marcòlic vermell (559)

\section{USOS MEDICINALS}

\section{Bulb}

Resolutiu

FONTS 539, 540. DESCRIPCIÓ DE L'ÚS FETA PELS INFORMANTS. Servia per a rebentar grans dolents. FORMA FARMACĖUTICA I ÚS. Emplastre (ús extern). PREPARACIÓ S'aixafava la cabeça i es feia un emplastre amb greix de porc o oli. DESTINACIÓ. Medicina humana.

\section{ALTRES USOS}

Part aèria florida

Ornamental: elaboració de rams

FONTS 546, 559. DESCRIPCIÓ DE L'ÚS FETA PELS INFORMANTS. Abans a les núvies se's en donava perquè la flor és molt maca (546). Per a fer bonic, però no el deixaven agafar (559).

\section{ALTRES OBSERVACIONS}

FONTS 520, 521, 532, 539, 540, 546, 569, 570, 1353, 1354. DESCRIPCIÓ FETA PELS INFORMANTS. En vaig baixar unes cebes de la muntanya i les vaig plantar al jardí. Són grosses i fan una flor lilada amb unes brinques que semblen safrà. Els agrada les altures, a Núria se'n fa molta (546). Són de la muntanya i en tenim aquí de plantats (521). Es fan als bacs $(532)$. A tots els horts n'hi havia $(539,540)$. Són de la muntanya i en tenim aquí de plantats $(520)$. N'hi ha al bosc $(569,570)$. Abans al bac de la vila n'hi havien, ara hi són comptats $(1353,1354)$.

\section{Lilium pyrenaicum Gouan (liliàcies)}

BCN 24918

\section{NOMS POPULARS}

Consolta $(541,549,1213,1214,1300,1318,1347,1348,1349,1350,1351)$

Consolta borda $(525,526,527)$

Consolta groga $(511,512,513,514,532,1321)$

Consolva groga $(569,570)$

Marcòlic groc (559)

\section{USOS MEDICINALS}

Arrel

Per a trastorns de la pell o del teixit subcutani 
FONT 1318. DESCRIPCIÓ DE L'ÚS FETA PER L'INFORMANT. Per a podridures de dits. FORMA FARMACĖUTICA I ÚS. Ungüent (ús extern). PREPARACIÓ. Es renta greix de porc amb aigua freda nou vegades $\mathrm{i}$ llavors es fa bullir amb llet la rel de la consolta junt amb aquest greix. DESTINACIÓ. Medicina humana.

Resolutiu

FONT 1318. DESCRIPCIÓ DE L'ÚS FETA PER L'INFORMANT. Aquest ungüent es feia servir per a rebentar grans. FORMA FARMACĖUTICA I ÚS. Ungüent (ús extern). PREPARACIÓ. Es renta greix de porc amb aigua freda nou vegades i llavors es fa bullir amb llet la rel de la consolta junt amb aquest greix. DESTINACIÓ. Medicina humana.

Bulb

Analgèsic

FONTS 1350, 1351. DESCRIPCIÓ DE L'ÚS FETA PELS INFORMANTS. Per a les hèrnies. FORMA FARMACĖUTICA I ÚS. Emplastre (ús extern). PREPARACIÓ. Per a fer emplastres. DESTINACIÓ. Medicina humana.

Resolutiu

FONTS 525, 526, 527, 1300. DESCRIPCIÓ DE L'ÚS FETA PELS INFORMANTS. Va bé per a madurar furóncols $(525,526,527)$. Si tenies un gra, primer ben rentat amb agua de farigola (Thymus vulgaris) i llavors emplastres de consoltes (1300). FORMA FARMACĖUTICA I ÚS. Emplastre (ús extern). PREPARACIÓ. Fan una ceba, aquesta s'aixafa i se'n fa un emplastre $(525,526,527)$. DESTINACIO. Medicina humana.

Flor

Desconegut per l'informant

FONT 549. FORMA FARMACĖUTICA I ÚS. Desconegut per l'informant. PREPARACIÓ. Se'n feia un oli. DESTINACIÓ. Medicina humana.

\section{ALTRES USOS}

\section{Part aèria florida}

Ornamental: elaboració de rams

FONT 559. DESCRIPCIÓ DE L'ÚS FETA PER L'INFORMANT. Per a fer bonic, però no el deixaven agafar.

\section{ACCIONS NOCIVES O TÒXIQUES}

\section{No consta}

FONTS 1347, 1348, 1349. DESCRIPCIÓ DE L'ACCIÓ NOCIVA O TÒXICA FETA PELS INFORMANTS. Diu que és tòxica, que el bestiar no la toca.

\section{ALTRES OBSERVACIONS}

FONTS 532, 570, 1321, 1347, 1348, 1349. DESCRIPCIÓ FETA PELS INFORMANTS. Es fan als solells. No recordo que se'n fessin remeis (532). N'hi ha cap a Núria (570). És privat d'agafar-les perquè n'hi ha molt poques (1321). Fan molta olor (1321). Abans n'hi havia moltes, ara quasi no en veu mai enlloc $(1347,1348,1349)$.

\section{BARREGES AMB AQUEST TÀXON}

Bulb

FONT 1300. Entrevista 8, barreja II (vegeu catàleg de barreges)

Linum perenne L. (linàcies)

BCN 25130

\section{NOMS POPULARS}

Herba ronyonera $(1324,1336,1341,1342)$

\section{USOS MEDICINALS}

\section{Part aèria}

Diürètic

FONT 1336. DESCRIPCIÓ DE L'ÚS FETA PER L'INFORMANT. Fa orinar. FORMA FARMACĖUTICA I ÚS. Tisana (ús intern). PREPARACIÓ. En infusió. DESTINACIÓ Medicina humana.

Protector renal

FONTS 1324, 1336, 1341, 1342. DESCRIPCIÓ DE L'ÚS FETA PELS INFORMANTS. Per al mal de ronyons $(1324,1336)$. Va bé per als ronyons $(1341,1342)$. FORMA FARMACĖUTICA I ÚS. Tisana (ús intern). PREPARACIÓ. Decocció (1324). En infusió $(1336,1341,1342$ ). DESTINACIÓ. Medicina humana.

\section{Linum tenuifolium L. subsp. suffruticosum (L.) Litard.}

(linàcies)

BCN 24919

\section{NOMS POPULARS}

Lli (1324)

\section{USOS MEDICINALS}

Llavor

Laxant 
Apèndix 1. Catàleg de tàxons.

FONT 1324. DESCRIPCIÓ DE L'ÚS FETA PER L'INFORMANT. Per a ajudar a anar de ventre. FORMA FARMACĖUTICA I ÚS. Tisana (ús intern). PREPARACIÓ. Infusió de les granes. DESTINACIÓ. Medicina humana.

\section{Linum usitatissimum L. subsp. usitatissimum (linàcies)}

BCN 24920

\section{NOMS POPULARS}

Farina de lli (producte elaborat) $(528,529,530,531,588)$

Lli $(520,521,541,574,575,576,577,1210,1213,1214,1215,1319,1335,1337,1338$ $1339,1340,1352,1361,1362$

\section{USOS MEDICINALS}

\section{Llavor}

Antiinflamatori faringi

FONT 1319. DESCRIPCIÓ DE L'ÚS FETA PER L'INFORMANT. Per al mal de coll. FORMA FARMACĖUTICA I ÚS. Emplastre (ús extern). PREPARACIÓ. Emplastres de farina de lli. DESTINACIÓ. Medicina humana.

Antiinflamatori intestinal

FONTS 529, 530, 531. DESCRIPCIÓ DE L'ÚS FETA PELS INFORMANTS. Per al mal de ventre. FORMA FARMACĖUTICA I ÚS. Emplastre (ús extern). PREPARACIÓ. Emplastre de farina de lli amb una clara d'ou ben debatuda. DESTINACIO. Medicina humana.

Antipneumònic

FONTS 1337, 1338. DESCRIPCIÓ DE L'ÚS FETA PELS INFORMANTS. Per a trencar pulmonies. FORMA FARMACËUTICA I ÚS. Emplastre (ús extern). PREPARACIO. Per a fer emplastres, hi barrejava més plantes. DESTINACIÓ Medicina humana OBSERVACIONS. Les dones que ho feien no ho volien explicar perquè no els prenguessin la feina.

Carminatiu

FONTS 574, 575, 576, 577. DESCRIPCIÓ DE L'ÚS FETA PELS INFORMANTS. Per a quan els vedells estan botits. FORMA FARMACĖUTICA I ÚS. Tisana (ús intern). PREPARACIÓ. Decocció. DESTINACIÓ. Medicina veterinària.

Desconegut per l'informant

FONTS 541, 1352. DESCRIPCIO DE L'ÚS FETA PELS INFORMANTS. En feien emplastres (541). Crec que era per a mals abdominals interns, però no n'estic segura (1352). FORMA FARMACĖUTICA I ÚS. Emplastre (ús extern). PREPARACIÓ. La farina la utilitzaven per a fer emplastres (1352). DESTINACIÓ. Medicina humana.

Laxant
FONTS 1335, 1361, 1362. DESCRIPCIÓ DE L'ÚS FETA PELS INFORMANTS. Per a laxar $(1335,1361,1362)$. FORMA FARMACÈUTICA I ÚS. Sense forma farmacèutica (ús directe, 132) PREPARACIÓ LOS ús intern) (1335). Tisana (ús intern) $(1361,1362)$. PREPARACIÓ. Les granes barrejades amb un iogurt (1335). Decocció $(1361,1362)$. DESTINACIO Medicina humana. OBSERVACIONS. Ho compren (1335).

Purgant

FONTS 520, 521, 1339, 1340. DESCRIPCIÓ DE L'ÚS FETA PELS INFORMANTS. És bona per a fer una purga $(520,521)$. Serveix com a purga $(1339,1340)$. FORMA FARMACĖUTICA I ÚS. Desconegut per l'informant $(520,521)$. Macerat en aigua (ús intern) $(1339,1340)$. PREPARACIÓ. La grana es posava a macerar (520). La grana es posa a macerar (521). PREPARACIO. La grana es posava a macerar $(520)$. La grana es posa a macerar (521).
Estovada i després se'n beu l'aigua $(1339,1340)$. DESTINACIÓ. Medicina humana. OBSERVACIONS. Es comprava (1339, 1340).

Resolutiu

FONTS $588,1213,1214,1215,1335,1361,1362$. DESCRIPCIÓ DE L'ÚS FETA PELS INFORMANTS. Per als furóncols (588). Farina de lli per a fer emplastres (1215). Es posava sobre els furóncols per a fer-los rebentar $(1213,1214)$. Per a fer madurar els furóncols (1335). La farina de lli per a fer madurar grans $(1361,1362)$. FORMA FARMACĖUTICA I ÚS. Emplastre (ús extern). PREPARACIÓ. Es desfeia amb una mica de llet (588). Es feia una massa amb llet $(1213,1214)$. Bullida i en emplastre (1335). DESTINACIÓ. Medicina humana. OBSERVACIONS. Ho compren (1335). Ho compràvem $(1361,1362)$.

\section{ALTRES USOS}

\section{Part aèria}

Tèxtil: elaboració de fibres

FONT 1335. DESCRIPCIÓ DE L'ÚS FETA PER L'INFORMANT. Se'n feia el veritable fil.

\section{ALTRES OBSERVACIONS}

FONT 1335. DESCRIPCIÓ FETA PER L'INFORMANT. En feien un clap a l'hort.

\section{BARREGES AMB AQUEST TẢXON}

Llavor

FONT 1210. Entrevista 103 (vegeu catàleg de barreges)

FONT 528. Entrevista 61, barreja III (vegeu catàleg de barreges)

FONTS $574,575,576,577$. Entrevista 91, barreja II (vegeu catàleg de barreges)

Lippia triphylla (L'Hér.) O.Kuntze (labiades) BCN 24921 


\section{NOMS POPULARS}

Marialluïsa $(504,507,509,510,511,512,513,514,520,521,522,523,549,553,554,555$ $558,560,561,562,563,569,570,572,573,574,575,576,577,588,590,591,592,746$ $752,1294,1300,1301,1318,1323,1325,1326,1330,1331,1335,1336,1341,1342,1343$ $1344,1347,1348,1349,1361,1362)$

\section{USOS MEDICINALS}

\section{Part aèria}

Anticatarral

FONT 1300. DESCRIPCIÓ DE L'ÚS FETA PER L'INFORMANT. Per als constipats. FORMA FARMACĖUTICA I ÚS. Tisana (ús intern). PREPARACIÓ. Decocció. DESTINACIÓ. Medicina humana.

Antidiarreic

FONTS 520, 521, 590. DESCRIPCIÓ DE L'ÚS FETA PELS INFORMANTS. Per a la diarrea $(520,521)$. Quan es té diarrea $(590)$. FORMA FARMACĖUTICA I ÚS. Tisana (ús intern) PREPARACIÓ. Decocció $(520,521,590)$. DESTINACIÓ. Medicina humana.

Antiinflamatori intestinal

FONTS 522, 523, 558, 561, 562, 563, 574, 575, 576, 577, 591, 592, 752, 1301, 1325, 1326 DESCRIPCIO DE L'US FETA PELS INFORMANTS. Per al mal de panxa $(522,523)$. Per a mals de panxa $(574,575,576,577,752)$. Mal de ventre $(558)$. Per a la panxa i el mareig (561, 562, 563). Per al mal de ventre $(591,592,1301,1325,1326)$. FORMA FARMACĖUTICA I ÚS. Tisana (ús intern). PREPARACIÓ. Decocció $(522,523,558,561$ $562,563,574,575,576,577,501,502,752,1301,1325,1326)$. DESTINACIO. Medicina humana. OBSERVACIONS. També per a barrejar amb altres herbes (1301).

Antinauseabund

FONTS 561, 562, 563, 1347, 1348, 1349. DESCRIPCIÓ DE L'ÚS FETA PELS INFORMANTS. Per a la panxa i I mareig $(561,562,563)$. Per al mareig (1348). Per a quan estàs marejat $(1347,1349)$. FORMA FARMACE்UTCA I ÚS Tisan (ús quan PREPARACIÓ. Decocció $(561,562,563)$. En infusió $(1347,1348,1349)$. DESTINACIÓ Medicina humana.

Digestiu

FONTS 504, 511, 512, 513, 514, 520, 521, 549, 554, 555, 572, 573, 574, 575, 576, 577, 746 1323, 1325, 1326, 1361, 1362. DESCRIPCIÓ DE L'ÚS FETA PELS INFORMANTS. Digestiva (746). Com a digestiva $(511,512,513,514,520,521)$. Per a pair $(549,572,573,574,575$, $576,577,1325,1326)$. Per a prendre és bona $(554,555)$. Ajuda a pair $(1323)$. És digestiva 576, 577, 1325, 1326). Per a prendre és bona $(554,555)$. Ajuda a pair (1323). És digestiva $(1361,1362)$. FORMA FARMACEUUTICA I ÚS. Tisana (ús intern). PREPARACIO. Decocció
$(504,511,512,513,514,520,521,549,554,555,572,573,574,575,576,577,746,1323$ $(504,511,512,513,514,520,521,549,554,555,572,573,574,575,576,577,746,1323$,
$1325,1326)$. En infusió (1361, 1362). DESTINACIÓ. Medicina humana. OBSERVACIONS. $1325,1326)$. En infusió $(1361,1362)$. DESTINACIÓ. Medicina humana. OBSERVACIONS
Aquí no se'n fa però la comprem $(511,512,513,514)$. A vegades es barreja amb altres herbes, sobretot camamilla (1323).

Estomacal
FONTS 560, 569, 570. DESCRIPCIÓ DE L'ÚS FETA PELS INFORMANTS. Per a l'estómac (560). Per a l'estómac i té un gust molt bo $(569,570)$. FORMA FARMACĖUTICA I ÚS. Tisana (ús intern). PREPARACIÓ. Decocció $(560,569,570)$. DESTINACIÓ. Medicina humana.

Salutífer

FONTS 507, 509, 510. DESCRIPCIÓ DE L'ÚS FETA PELS INFORMANTS. En faig aigua perquè és bona. FORMA FARMACĖUTICA I ÚS. Tisana (ús intern). PREPARACIÓ. Decocció. DESTINACIÓ. Medicina humana.

Sedant

FONT 746. DESCRIPCIÓ DE L'ÚS FETA PER L'INFORMANT. Va bé per a barrejar amb altres plantes perquè és una mica sedant. FORMA FARMACĖUTICA I ÚS. Tisana (ús intern). PREPARACIÓ. Decocció. DESTINACIÓ. Medicina humana.

Tranquil-litzant

FONTS 560, 588. DESCRIPCIÓ DE L'ÚS FETA PELS INFORMANTS. Per a relaxar (560) És com un relaxant (588). FORMA FARMACĖUTICA I ÚS. Tisana (ús intern). PREPARACIÓ. Decocció $(560,588)$. DESTINACIÓ. Medicina humana.

\section{USOS ALIMENTARIS}

\section{Part aèria}

Condiment

FONT 1294. DESCRIPCIÓ DE L'ÚS FETA PER L'INFORMANT. La fa servir per a donar aroma a altres herbes que no tenen gaire bon gust. No sap si és medicinal. DESTINACIÓ. Alimentació humana.

Preparació de begudes - Beguda preparada amb aigua

FONT 1335. DESCRIPCIÓ DE L'ÚS FETA PER L'INFORMANT. La prenen perquè els agrada el gust, per a acompanyar altres herbes. OBSERVACIONS. No I'usen com a medicina. DESTINACIÓ. Alimentació humana.

Preparació de begudes - Beguda preparada amb aiguardent

FONTS 553, 588, 1341, 1342. DESCRIPCIÓ DE L'ÚS FETA PELS INFORMANTS. Ratafia Posar totes les herbes en aiguardent 21 dies a sol i serena. Es fa pels volts de Sant Joan. Sempre surt bona però no surt mai igual. Les herbes utilitzades són: nous verdes (Juglans regia), herba de Noè (Herniaria glabra), tarongina (Melissa officinalis), camamilla borda (Tanacetum parthenium), marialluïsa (Lippia tryphylla), menta (Mentha spicata), salsufràgia (Peucedanum ostruthium), til·la (Tilia platyphyllos), nou moscada (Myristica fragrans) i clau (Syzygium aromaticum) (553). Ratafia. Abans si que n'havia fet, hi posava 14015 herbes, no me'n recordo de totes. Nous verdes (Juglans regia), farigola (Thymus serpyllum), nou moscada (Myristica fragrans), marialluïsa (Lippia triphylla), menta (Mentha spicata), orenga (Origanum vulgare) i poniol (Satureja calamintha subsp. ascendens) (588). Per a fer ratafia, es confita llor (Laurus nobilis), romaní (Rosmarinus officinalis), nous (Juglans regia), granes de ginebró (Juniperus communis), camamilla (Achillea ptarmica subsp. pyrenaica), ortigues (Urtica dioica), pela de taronja (Citrus sinensis), pela de llimon (Citrus limon), canyues (Cinnamomum zeylanicum), marialluïsa (Lippia triphylla), poniol (Satureja calamintha subsp. 
Apèndix 1. Catàleg de tàxons.

ascendens), rosa de bosc (Rosa tomentosa) i malva (Malva sylvestris) en aiguardent i es deixa 40 dies a sol i a serena, llavors es cola i ja es pot beure $(1341,1342)$. DESTINACIÓ. Alimentació humana $(553,588,1341,1342)$.

\section{ALTRES OBSERVACIONS}

FONTS 504, 507, 509, 510, 558, 572, 573, 590, 1294, 1325, 1326, 1335. DESCRIPCIÓ FETA PELS INFORMANTS. La tinc a la part de la paret de l'hort perquè en tenia una altra plantada fora del recer i el fred me la va matar (504). En tenim però els anys que glaça molt, es mor $(507,509,510)$. A Nevà el fred la mata (558). En tenim a l'hort (590). En planto, però es mor $(572,573)$. En té un test; a l'hivern s'ha d'abrigar, si no, es mor (1294). En tenen a I'hort de Rocabruna $(1325,1326)$. No aguanta les temperatures de l'hivern, s'ha de tenir un test i entrar-lo quan ve el fred (1335).

\section{BARREGES AMB AQUEST TÀXON}

\section{Part aèria}

FONT 1336. Entrevista 16, barreja I (vegeu catàleg de barreges)

FONTS 1343, 1344. Entrevista 23, barreja III (vegeu catàleg de barreges)

FONT 1331. Entrevista 30, barreja III (vegeu catàleg de barreges)

FONT 1318. Entrevista 31, barreja III (vegeu catàleg de barreges)

FONT 1330. Entrevista 32, barreja VI (vegeu catàleg de barreges)

FONT 746. Entrevista 45, barreja I (vegeu catàleg de barreges)

FONT 746. Entrevista 45, barreja III (vegeu catàleg de barreges)

FONT 1294. Entrevista 6, barreja II (vegeu catàleg de barreges)

\section{Lithospermum fruticosum $\mathrm{L}$. (boraginàcies)}

BCN 4238

\section{NOMS POPULARS}

Herba pedrera $(591,592)$

Mill del sol (1335)

Mill gruà $(591,592)$

\section{USOS MEDICINALS}

No consta

Protector renal
FONT 1335. DESCRIPCIÓ DE L'ÚS FETA PER L'INFORMANT. Per a infeccions de ronyó FORMA FARMACĖUTICA I ÚS. Tisana (ús intern). PREPARACIÓ. Decocció. DESTINACIÓ. Medicina humana.

\section{Part aèria fructificada}

Antisèptic urinari

FONT 1335. DESCRIPCIÓ DE L'ÚS FETA PER L'INFORMANT. Per a infeccions d'orina FORMA FARMACĖUTICA I ÚS. Tisana (ús intern). PREPARACIÓ. Decocció. DESTINACIÓ. Medicina humana. OBSERVACIONS. No és gaire bona, però és molt medicinal.

Diürètic

FONT 1335. DESCRIPCIÓ DE L'ÚS FETA PER L'INFORMANT. Fa orinar molt. FORMA FARMACĖUTICA I ÚS. Tisana (ús intern). PREPARACIÓ. Decocció. DESTINACIÓ. Medicina humana. OBSERVACIONS. No és gaire bona, però és molt medicinal.

Litotríptic rena

FONTS 591, 592. DESCRIPCIÓ DE L'ÚS FETA PELS INFORMANTS. Desfà les pedres del ronyó. FORMA FARMACĖUTICA I ÚS. Tisana (ús intern). PREPARACIÓ. Decocció DESTINACIÓ. Medicina humana.

\section{ALTRES OBSERVACIONS}

FONTS 591, 592. DESCRIPCIÓ FETA PELS INFORMANTS. Al mig de la fulla fa un cor i quan floreix en pengen unes pedretes.

\section{Lithospermum officinale L. (boraginàcies)}

BCN 24922

\section{NOMS POPULARS}

Herba pedrera $(515,516,518,519,1336)$

Mill $(554,555)$

Mill de sol $(1294,1299,1301,1344,1346)$

Mill del sol $(515,516,520,521,528,529,530,531,553,753,754,755,1330,1343,1345$ 1361, 1362)

Mill gruà $(505,506,507,509,510,517,520,521,750)$

Millruà $(561,562,563)$

Tabaco (castellà) (1299)

\section{USOS MEDICINALS}

Fulla

Litotríptic renal 
Apèndix 1. Catàleg de tàxons.

FONTS 515, 516. DESCRIPCIO DE L'ÚS FETA PELS INFORMANTS. Per a les pedres a ronyó. FORMA FARMACĖUTICA I ÚS. Tisana (ús intern). PREPARACIÓ. Decocció. Aigua de les fulles i de les granes. DESTINACIÓ. Medicina humana.

Llavor

Antiinflamatori intestinal

FONTS 507, 509, 510. DESCRIPCIÓ DE L'ÚS FETA PELS INFORMANTS. Per a la panxa. FORMA FARMACĖUTICA I ÚS. Tisana (ús intern). PREPARACIÓ. Decocció. Aigua de les granes o de la planta. DESTINACIÓ. Medicina humana.

Diürètic

FONTS 507, 509, 510. DESCRIPCIÓ DE L'ÚS FETA PELS INFORMANTS. Per a fer orinar. FORMA FARMACĖUTICA I ÚS. Tisana (ús intern). PREPARACIÓ. Decocció. Aigua de les granes o de la planta. DESTINACIÓ. Medicina humana.

Litotríptic renal

FONTS 515, 516. DESCRIPCIÓ DE L'ÚS FETA PELS INFORMANTS. Per a les pedres al ronyó. FORMA FARMACĖUTICA I ÚS. Tisana (ús intern). PREPARACIÓ. Decocció. Aigua de les fulles i de les granes. DESTINACIÓ. Medicina humana.

\section{Part aèria fructificada}

Anticatarral

FONT 528. DESCRIPCIÓ DE L'ÚS FETA PER L'INFORMANT. Per als constipats. FORMA FARMACĖUTICA I ÚS. Tisana (ús intern). PREPARACIÓ. Decocció. DESTINACIÓ. Medicina humana.

Antiinflamatori intestinal

FONTS 507, 509, 510. DESCRIPCIÓ DE L'ÚS FETA PELS INFORMANTS. Per a la panxa. FORMA FARMACÉUTICA I ÚS. Tisana (ús intern). PREPARACIÓ. Decocció. Aigua de les granes o de la planta. DESTINACIÓ. Medicina humana.

Antisèptic intern

FONTS 554, 555. DESCRIPCIÓ DE L'ÚS FETA PELS INFORMANTS. Infeccions de ventre FORMA FARMACĖUTICA I ÚS. Tisana (ús intern). PREPARACIÓ. Decocció. DESTINACIÓ. Medicina humana.

Antisèptic urinari

FONT 1294. DESCRIPCIÓ DE L'ÚS FETA PER L'INFORMANT. Per a infeccions d'orina FORMA FARMACĖUTICA I ÚS. Tisana (ús intern). PREPARACIÓ. Decocció. DESTINACIÓ Medicina humana. OBSERVACIONS. S'ha de collir quan és granada. És una aigua repel·lent.

Coadjuvant del postpart

FONTS 561, 562, 563, 1299. DESCRIPCIÓ DE L'ÚS FETA PELS INFORMANTS. Per a bestiar que no pot fer les despulles $(561,562,563)$. Per a ajudar a fer les despulles a les vaques quan han vedellat (1299). FORMA FARMACĖUTICA I ÚS. Tisana (ús intern). PREPARACIÓ. Decocció $(561,562,563,1299)$. DESTINACIÓ. Medicina veterinària.

Diürètic
FONTS 505, 506, 507, 509, 510, 517, 520, 521, 753, 754, 755, 1301, 1343, 1344, 1361 1362. DESCRIPCIO DE L'US FETA PELS INFORMANTS. Per a fer orinar $(505,506,507$, $509,510,517,520,521,753,754,755,1301,1343,1344)$. Per a orinar $(1301,1302)$ FORMA FARMACEUTICA I ÚS. Tisang (ús intem). PREPARACIÓ. Decoció. Aigua de) FORMA FARMACEUTICA IUUS. Tisana (ús intern). PREPARACIO, De (53, 754, 755, 1301, 1343, 1344) En infusió $(1361,1362)$. DESTINACIÓ. Medicina humana.

Hepatoprotector

FONT 1299. DESCRIPCIÓ DE L'ÚS FETA PER L'INFORMANT. És bona per al fetge. FORMA FARMACĖUTICA I ÚS. Tisana (ús intern). PREPARACIÓ. Decocció. DESTINACIÓ. Medicina humana.

Litotríptic renal

FONTS $518,519,529,530,531,553,750,1336,1345,1346$. DESCRIPCIÓ DE L'ÚS FETA PELS INFORMANTS. Per a les pedres $(750)$. Per a les pedres del ronyó $(529,530,531$ $1345,1346)$. Per al mal de pedra $(518,519,1336)$. Desfà les pedres del ronyó i de la bufeta (553). FORMA FARMACĖUTICA I ÚS. Tisana (ús intern). PREPARACIÓ. Decocció Aigua de tota la planta $(750)$. Decocció $(518,519,529,530,531,553)$. En infusió $(1336,1345,1346)$. DESTINACIÓ. Medicina humana.

Protector renal

FONTS 554, 555, 1299, 1330. DESCRIPCIÓ DE L'ÚS FETA PELS INFORMANTS. Per als ronyons $(554,555,1330)$. És bona per als ronyons $(1299)$. FORMA FARMACĖUTICA I ÚS. Tisana (ús intern). PREPARACIÓ. Decocció $(554,555,1299,1330)$. DESTINACIÓ. Medicina humana.

Vasotònic

FONTS 561, 562, 563. DESCRIPCIÓ DE L'ÚS FETA PELS INFORMANTS. Per a la sang i la circulació. FORMA FARMACĖUTICA I ÚS. Tisana (ús intern). PREPARACIÓ. Decocció. DESTINACIÓ. Medicina humana.

\section{ALTRES OBSERVACIONS}

FONT 1294. DESCRIPCIO FETA PER L'INFORMANT. Es fa en llocs on hi vagin els cavalls.

\section{BARREGES AMB AQUEST TÀXON}

\section{Part aèria fructificada}

FONT 1301. Entrevista 36 (vegeu catàleg de barreges)

\section{Loiseleuria procumbens (L.) Desv. (ericàcies)}

BCN 24923

NOMS POPULARS 
Herba pedrera $(1317,1347,1348,1349)$

\section{USOS MEDICINALS}

Part aèria

Litotríptic renal

FONTS 1317, 1347, 1348, 1349. DESCRIPCIÓ DE L'ÚS FETA PELS INFORMANTS. Per al mal de pedra (1317). Per a les pedres al ronyó $(1347,1348,1349)$. FORMA FARMACEUTICA I ÚS. Tisana (ús intern). PREPARACIÓ. Infusió (1347, 1348, 1349). DESTINACIÓ. Medicina humana.

\section{Lolium perenne L. (gramínies)}

BCN 58204

\section{NOMS POPULARS}

Margall $(564,588)$

Raigràs $(586,587)$

\section{USOS ALIMENTARIS}

\section{Part aèria}

Ingestió de la part de la planta crua - Conservada dessecada a l'aire

FONTS 586, 587. DESCRIPCIÓ DE L'ÚS FETA PELS INFORMANTS. És menjar per a les bèsties. Ho talles i en fas bales per a l'hivern, és molt bon menjar. DESTINACIÓ. Alimentació animal.

Ingestió de la part de la planta crua - Fresca (sense preparació)

FONTS 564, 588. DESCRIPCIÓ DE L'ÚS FETA PELS INFORMANTS. Es donava als conills (564). Per als conills (588). DESTINACIÓ. Alimentació animal $(564,588)$.

\section{ALTRES OBSERVACIONS}

FONT 564. DESCRIPCIÓ FETA PER L'INFORMANT. Es trobava pels horts a la primavera, és molt fineta i molt verda.

\section{Lonicera xylosteum L. (caprifoliàcies)}

BCN 45364

\section{NOMS POPULARS}

Boix moll (541)

\section{ALTRES USOS}

Planta viva in situ

Altres informacions

FONT 541. DESCRIPCIÓ DE L'ÚS FETA PER L'INFORMANT. Pujàvem uns pendents i una dona de Campelles em deia "no t'agafis al boix moll, que se't trencarà, afaga't al boix de veritat".

Lotus corniculatus L. (papilionàcies)

BCN 27291

\section{NOMS POPULARS}

Banya de cabra $(553,571,1321)$

\section{USOS ALIMENTARIS}

Part aèria

Ingestió de la part de la planta crua - Fresca (sense preparació)

FONTS 571, 1321. DESCRIPCIÓ DE L'ÚS FETA PELS INFORMANTS. Se la mengen les ovelles (571). El bestiar se la menja (1321). DESTINACIÓ. Alimentació animal $(571,1321)$.

\section{ALTRES OBSERVACIONS}

FONT 571. DESCRIPCIÓ FETA PER L'INFORMANT. És una planta que fa una tavella de fesols (Phaesolus vulgaris), però més fina.

\section{Lunaria annua L. subsp. annua (crucíferes)}

BCN 31287

\section{NOMS POPULARS}

Flor de plata $(520,521)$

Fulla de plata $(1213,1214)$

\section{ALTRES USOS}

Part aèria fructificada

Ornamental: elaboració de rams 
FONTS 520, 521, 572, 573, 1213, 1214. DESCRIPCIÓ DE L'ÚS FETA PELS INFORMANTS Per a fer bonic $(520,521)$. Fa com unes llànties que es pelen i se'n fan rams $(572,573)$.

\section{Lupinus albus L. (papilionàcies)}

BCN 64375

\section{NOMS POPULARS}

Llobí $(565,566)$

\section{USOS ALIMENTARIS}

Llavor

Ingestió de la part de la planta crua - Macerada en aigua

FONT 566. DESCRIPCIÓ DE L'ÚS FETA PER L'INFORMANT. En donàvem als porcs i a les vaques. És una lleguminosa, aquí no n'hi ha, es fa a la Plana de Vic. DESTINACIÓ. Alimentació animal.

No consta

Ingestió de la part de la planta crua - Macerada en aigua

FONT 565. DESCRIPCIÓ DE L'ÚS FETA PER L'INFORMANT. En donàvem als porcs i a les vaques. Es una lleguminosa, aquí no n'hi ha, es fa a la Plana de Vic. DESTINACIO. Alimentació anima

\section{Lycoperdon sp. (agaricàcies)}

\section{NOMS POPULARS}

Pet de llop $(511,512,513,514,529,530,531,554,555,572,573)$

\section{USOS MEDICINALS}

Espora

Hemostàtic extern

FONTS $511,512,513,514,529,530,531,554,555,572,573$. DESCRIPCIÓ DE L'ÚS FETA PELS INFORMANTS. Per a parar hemorràgies $(512,513,514)$. Per a parar les hemorràgies (511). Si et fas un tall t'hi poses la pols $i$ et para la sang $(529,530,531)$. Per a trencar hemorràgies $(554,555)$. La pols que fa tancar les hemorràgies. Quan et talles et poses la pols i et deixa de sortir sang $(572,573)$. FORMA FARMACE்UTICA I Ús. Sense forma farmacèutica (ús directe, ús extern). PREPARACIÓ. S'utilitza la pols que fan quan són secs $(511,512,513,514)$. Pols dels pets de llop $(554,555)$. DESTINACIÓ. Medicina humana.

\section{Malva sylvestris L. (malvàcies)}

BCN 24924

\section{NOMS POPULARS}

Malva $(507,509,510,520,521,522,523,529,530,531,539,540,547,548,564,565,566$ $571,572,573,574,575,576,577,578,579,580,581,583,584,585,586,587,590,1213$, $1214,1215,1294,1297,1300,1314,1317,1324,1327,1330,1335,1337,1338,1339,1339$, $1340,1341,1342,1343,1344,1350,1351,1353,1354,1361,1362)$

\section{USOS MEDICINALS}

\section{Flor}

Anticatarral

FONTS 1213, 1214, 1294, 1335. DESCRIPCIÓ DE L'ÚS FETA PELS INFORMANTS. Fa millorar els constipats $(1213,1214)$. Per als constipats $(1294,1335)$. FORMA FARMACEUTICA I US. Tisana (ús intern). PREPARACIÓ. Infusió de la flor (1294). Decocció (1335). DESTINACIO. Medicina humana. OBSERVACIONS. S'ha d'assecar en un lloc a l'ombra ben airejat (1294)

Antipruriginós

FONTS 529, 530, 531. DESCRIPCIÓ DE L'ÚS FETA PELS INFORMANTS. Per a les ortigades [dit "ortrigades"]. FORMA FARMACEUTICA I ÚS. Sense forma farmacèutica (ús directe, ús extern). PREPARACIO. Fregar-te amb les flors. DESTINACIO. Medicina humana. Antisèptic bucal

FONTS 520, 521. DESCRIPCIÓ DE L'ÚS FETA PELS INFORMANTS. Quan tens llagues a la boca. FORMA FARMACEUTICA I ÚS. Col-lutori (ús extern). PREPARACIÓ. Decocció. Les flors per a glopejar. DESTINACIO. Medicina humana.

Antisèptic intern

FONTS 529, 530, 531. DESCRIPCIO DE L'ÚS FETA PELS INFORMANTS. La flor és molt refrescant, es feia servir per a infeccions de panxa. FORMA FARMACEUTICA I ÚS. Tisana (ús intern). PREPARACIÓ. Decocció. DESTINACIÓ. Medicina humana.

Antisèptic ocular

FONTS 1337, 1338, 1343, 1344. DESCRIPCIÓ DE L'ÚS FETA PELS INFORMANTS. Per a rentar-se els ulls $(1337,1338)$. Per a rentar els ulls $(1343,1344)$. FORMA FARMACEUTICA US. Bany (ús extern). PREPARACIO. Decocció. Aigua de la flor $(1337,1338)$. Decocció $(1343,1344)$. DESTINACIO. Medicina humana.

Mucolític

FONTS 547, 548. DESCRIPCIÓ DE L'ÚS FETA PELS INFORMANTS. Va bé per a la mucositat. També per als nens que fessin més baves. FORMA FARMACEUTICA I ÚS. Tisana (ús intern). PREPARACIO. Decocció. Aigua de les flors. DESTINACIO. Medicina humana. 
Antiinflamatori gingival

FONT 1214. DESCRIPCIÓ DE L'ÚS FETA PER L'INFORMANT. Van bé per a les afeccions de la boca, les inflamacions de les genives, el mal de queixal. FORMA FARMACEUTICA ÚS. Col-lutori (ús extern). DESTINACIÓ. Medicina humana.

Antiodontàlgic

FONTS 1213, 1214. DESCRIPCIÓ DE L'ÚS FETA PELS INFORMANTS. Van bé per a les afeccions de la boca, les inflamacions de les genives, el mal de queixal. FORMA FARMACEUTICA I US. Col-lutori (ús extern). DESTINACIO. Medicina humana.

\section{Antipruriginós}

FONTS 520, 521, 572, 573. DESCRIPCIÓ DE L'ÚS FETA PELS INFORMANTS. Quan et fas una ortigada [dit "ortrigada"] $(572,573)$. Les fulles van bé per a les ortigades $(520,521)$. FORMA FARMACĖUTICA I ÚS. Sense forma farmacèutica (ús directe, ús extern). PREPARACIÓ. Et fregues amb les fulles de malva $(572,573)$. DESTINACIÓ. Medicina humana.

Antisèptic bucal

FONTS 1213, 1214. DESCRIPCIÓ DE L'ÚS FETA PELS INFORMANTS. Van bé per a les afeccions de la boca, les inflamacions de les genives, el mal de queixal. FORMA FARMACEUTICA I US. Col-lutori (ús extern). DESTINACIO. Medicina humana.

Antisèptic gingival

FONT 1213. DESCRIPCIÓ DE L'ÚS FETA PER L'INFORMANT. Van bé per a les afeccions de la boca, les inflamacions de les genives, el mal de queixal. FORMA FARMACËUTICA ÚS. Col-lutori (ús extern). DESTINACIÓ. Medicina humana.

Laxant

FONTS 1213, 1214. DESCRIPCIÓ DE L'ÚS FETA PELS INFORMANTS. És lleugerament laxant. FORMA FARMACĖUTICA I ÚS. Tisana (ús intern). DESTINACIÓ. Medicina humana.

Per a les picades

FONTS 507, 509, 510. DESCRIPCIÓ DE L'ÚS FETA PELS INFORMANTS. Quan et pica una abella t'has de fregar amb fulles de malva. FORMA FARMACEUTICA I ÚS. Sense forma farmacèutica (ús directe, ús extern). DESTINACIÓ. Medicina humana.

Per al panadís

FONTS 1213, 1214. DESCRIPCIÓ DE L'ÚS FETA PELS INFORMANTS. Per als voltadits FORMA FARMACEUTICA I ÚS. Cataplasma (ús extern). PREPARACIO. Cataplasma de malva i greix dolç. DESTINACIÓ. Medicina humana.

\section{Part aèria}

Antipruriginós

FONTS 583, 584, 585, 586, 587. DESCRIPCIÓ DE L'ÚS FETA PELS INFORMANTS. Fregarte amb malves quan et fas una ortigada $(583,584,585)$. Fregar-te per a les ortigades $(586$, 587). FORMA FARMACĖUTICA I ÚS. Sense forma farmacèutica (ús directe, ús extern). DESTINACIÓ. Medicina humana.

\section{Part aèria florida}

Anticatarral

FONT 1324. DESCRIPCIÓ DE L'ÚS FETA PER L'INFORMANT. Per als constipats. FORMA FARMACEUTICA I US. Tisana (ús intern). PREPARACIO. Decocció. DESTINACIO. Medicina humana.

Antisèptic intern

FONT 1300. DESCRIPCIÓ DE L'ÚS FETA PER L'INFORMANT. Per a les infeccions. FORMA FARMACĖUTICA I ÚS. Tisana (ús intern). PREPARACIÓ. Utilitza tota la planta seca en infusió. DESTINACIÓ. Medicina humana.

Coadjuvant del postpart

FONTS 522, 523, 581, 590. DESCRIPCIÓ DE L'ÚS FETA PELS INFORMANTS. Aigua per a les truges quan havien godallat, per a desinfectar-les $(522,523)$. Se'ls feia aigua de malves a les truges quan havien godallat (581). Es donava al bestiar per a ajudar a fer els llits (590) FORMA FARMACĖUTICA I ÚS. Tisana (ús intern). PREPARACIÓ. Decocció $(522,523,581$ $590)$. DESTINACIÓ. Medicina humana $(522,523,590)$. Medicina veterinària $(581)$.

Desconegut per l'informant

FONTS 578, 579. FORMA FARMACĖUTICA I ÚS. Emplastre (ús extern). PREPARACIÓ. Per a fer emplastres. DESTINACIÓ. Medicina humana.

Expectorant

FONT 1324. DESCRIPCIÓ DE L'ÚS FETA PER L'INFORMANT. És expectorant.Per a quan et fa mal el pit del refredat. FORMA FARMACĖUTICA I ÚS. Tisana (ús intern). Emplastre (ús extern). PREPARACIO. DeCOCció Bullida i amb emplastre al pit. DESTINACIO. Medicina humana.

Per a trastorns de la pell o del teixit subcutani

FONT 553. DESCRIPCIÓ DE L'ÚS FETA PER L'INFORMANT. Per als bonys i mals de la pell. FORMA FARMACĖUTICA I ÚS. Bany (ús extern). Cataplasma (ús extern). PREPARACIÓ. Decocció. DESTINACIÓ. Medicina humana.

Protector renal

FONT 571. DESCRIPCIÓ DE L'ÚS FETA PER L'INFORMANT. Se'n feia aigua per a netejar els ronyons. FORMA FARMACĖUTICA I ÚS. Tisana (ús intern). PREPARACIÓ. Decocció. DESTINACIÓ. Medicina humana.

Salutífer

FONTS 539, 540. DESCRIPCIÓ DE L'ÚS FETA PELS INFORMANTS. Infusions que es posen bé. FORMA FARMACĖUTICA I ÚS. Tisana (ús intern). DESTINACIÓ. Medicina humana.

\section{USOS ALIMENTARIS}

Fruit

Ingestió de la part de la planta crua - Fresca (sense preparació) 
Apèndix 1. Catàleg de tàxons.

FONTS 1337, 1338, 1341, 1342, 1353, 1354. DESCRIPCIÓ DE L'ÚS FETA PELS INFORMANTS. La grana de la malva, abans se la menjaven $(1337,1338)$. Quan és granada, en deien formatges i de petits se'ls menjaven $(1341,1342)$. De la grana en dèiem formatges i ens la menjàvem $(1353,1354)$. DESTINACIÓ Alimentació humana $(1337,1338,1341,1342$, 1353, 1354).

\section{Lluc tendre}

Ingestió de la part de la planta crua - Fresca (sense preparació)

FONTS 565, 566. DESCRIPCIÓ DE L'ÚS FETA PELS INFORMANTS. S'amania el brot de dalt. DESTINACIÓ. Alimentació humana.

\section{No consta}

Ingestió de la part de la planta crua - Fresca (sense preparació)

FONTS 564, 1213, 1214. DESCRIPCIÓ DE L'ÚS FETA PELS INFORMANTS. Quan érem petits ens la menjàvem (564). Les flors de malva a l'amanida verda, l'alegren $(1213,1214)$. DESTINACIÓ. Alimentació humana $(564,1213,1214)$.

\section{Part aèria florida}

Preparació de begudes - Beguda preparada amb aiguardent

FONTS 1341, 1342. DESCRIPCIÓ DE L'ÚS FETA PELS INFORMANTS. Per a fer ratafia, es confita llor (Laurus nobilis), romaní (Rosmarinus officinalis), nous (Juglans regia), granes de ginebró (Juniperus communis), camamilla (Achillea ptarmica subsp. pyrenaica), ortigues (Urtica dioica), pela de taronja (Citrus sinensis), pela de llimona (Citrus limon), canyella (Cinnamomum zeylanicum), marialluïsa (Lippia triphylla), poniol (Satureja calamintha subsp. ascendens), rosa de bosc (Rosa tomentosa) i malva (Malva sylvestris) en aiguardent i es deixa 40 dies a sol i a serena, llavors es cola i ja es pot beure. DESTINACIÓ. Alimentació humana.

\section{ALTRES USOS}

\section{Flor}

Creences i pràctiques magicoreligioses

FONT 564. DESCRIPCIÓ DE L'ÚS FETA PER L'INFORMANT. Per a l'elaboració de les catifes [dit "alfombres"] de Corpus.

\section{No consta}

Literatura oral popular: llegendes, gloses, contes, dites, refranys, poemes, cançons

FONTS 520, 521, 572, 573. DESCRIPCIÓ DE L'ÚS FETA PELS INFORMANTS. Aquest ja fa temps que cria malves, es diu quan una persona ja fa temps que és morta $(572,573)$. Ortiga, ortiga fuig d'aquí que la malva ja és aquí $(520,521)$.

\section{Planta sencera}

Literatura oral popular: llegendes, gloses, contes, dites, refranys, poemes, cançons

FONTS 1213, 1214. DESCRIPCIÓ DE L'ÚS FETA PELS INFORMANTS. La malva tot ho salva.

\section{BARREGES AMB AQUEST TÀXON}

Flor

FONT 1215. Entrevista 104, barreja I (vegeu catàleg de barreges)

FONT 1330. Entrevista 32, barreja IV (vegeu catàleg de barreges)

No consta

FONTS 529, 530, 531. Entrevista 53, barreja VIII (vegeu catàleg de barreges)

\section{Part aèria}

FONTS 1339, 1340. Entrevista 22, barreja I (vegeu catàleg de barreges)

FONTS 1361, 1362. Entrevista 29, barreja III (vegeu catàleg de barreges)

FONTS 1350, 1351. Entrevista 39, barreja I (vegeu catàleg de barreges)

\section{Part aèria florida}

FONT 1297. Entrevista 10 (vegeu catàleg de barreges)

FONT 1327. Entrevista 14, barreja I (vegeu catàleg de barreges)

FONT 1314. Entrevista 17, barreja III (vegeu catàleg de barreges)

FONT 1317. Entrevista 21, barreja II (vegeu catàleg de barreges)

FONT 1300. Entrevista 8, barreja I (vegeu catàleg de barreges)

FONTS 583, 584, 585. Entrevista 96, barreja III (vegeu catàleg de barreges)

FONTS 583, 584, 585. Entrevista 96, barreja IV (vegeu catàleg de barreges)

\section{Mantisalca salmantica (L.) Briq. et Cavill. (compostes)}

\section{BCN 24925}

\section{NOMS POPULARS}

Baleges (1324)

Cabassuda $(583,584,585)$

Granera $(583,584,585)$

\section{USOS MEDICINALS}

\section{Fruit}

Hipoglucemiant

FONT 1324. DESCRIPCIÓ DE L'ÚS FETA PER L'INFORMANT. Per a fer baixar el sucre FORMA FARMACEUUTICA I ÚS. Tisana (ús intern). PREPARACIÓ. Infusió de les càpsules. DESTINACIO. Medicina humana. 


\section{ALTRES USOS}

\section{Part aèria}

Artesanal: elaboració d'escombres

FONT 1324. DESCRIPCIÓ DE L'ÚS FETA PER L'INFORMANT. Per a fer escombres.

Domèstic: ajudes a la llar

FONTS 583, 584, 585. DESCRIPCIÓ DE L'ÚS FETA PELS INFORMANTS. Per a fer escombres. Si quan feies una escombra hi posaves un parell de croques quedaven més valentes.

\section{Matricaria chamomilla L. (compostes)}

BCN 24926

\section{NOMS POPULARS}

Camamilla $(504,524,541,546,552,554,555,556,557,558,561,562,563,567,568,569$, $570,571,581,582,583,584,585,1215)$

Camamilla bona $(554,555)$

Camamilla d'hort $(578,579)$

Camamilla de l'hort $(528)$

Camamilla de llei $(505,506)$

Camamilla dolça $(511,512,513,514,520,521,1293,1299,1301)$

\section{USOS MEDICINALS}

\section{Inflorescència}

Antiinflamatori intestinal

FONTS 505, 506, 511, 512, 513, 514, 528, 554, 555, 556, 557, 558, 561, 562, 563, 567, 568 $569,570,571,578,579,582,583,584,585,1299,1301$. DESCRIPCIÓ DE L'ÚS FETA PELS INFORMANTS. Per a la panxa $(511,512,513,514,528,556,557,558,561,562,563$ $568,569,570,571,578,579,582,583,584,585,1301)$. Per al mal de ventre $(505,506,554$ $555,567,1299)$. FORMA FARMACEUTICA I US. Tisana (ús intern) $(505,506,511,512,513$ $514,528,554,555,556,557,558,561,562,563,568,569,570,571,578,579,582$, 583, $584,585,1299,1301)$. Cataplasma (ús extern) (567). PREPARACIÓ. Decocció (505, 506, $511,512,513,514,528,554,555,556,557,558,561,562,563,568,569,570,571,578$ $511,512,513,514,528,554,555,556,557,558,561,562,563,568,569,570,571,578$ $579,582,583,584,585,1301)$. Decocció. Cataplasma daigua de camamilla (567) DESTINACIÓ. Medicina humana. OBSERVACIONS. És molt dolça $(528)$. És més bona que
la borda $(578,579)$.

Antiotàlgic

FONT 1299. DESCRIPCIÓ DE L'ÚS FETA PER L'INFORMANT. Recorda que el seu germà va tenir un mal d'orella molt fort i el metge els va dir que portessin camamilla dolça a la farmàcia per a fer un oli, quan l'hi van posar va reposar de seguida. FORMA FARMACĖUTICA I ÚS. Embrocació (ús extern). PREPARACIÓ. En oli. DESTINACIÓ. Medicina hum

Digestiu

FONTS 504, 520, 521, 541, 552, 1215, 1293, 1301. DESCRIPCIÓ DE L'ÚS FETA PELS INFORMANTS. Per al mal de ventre, per a pair (504). Per a pair $(520,521,1215,1301)$ FORMA FARMACÈUTICA I ÚS. Tisana (ús intern). PREPARACIÓ. D20 5́́ $(504,520,521$, $541,552,1215,1293,1301)$. DESTINACIÓ. Medicin huCIO. DOCCIÓ (504, 520, 521 541, 552, 1215, 1293, 1301). DEST1). La tenim de criada de la Cerdanya ens en dula (541). La tenim de cap ala la d'aquí, la camamila de Bolòs (Achillea ptarmica subsp. pyrenaica) (1215). La que dolceja (1293).

No consta

Desconegut per l'informant

FONT 524. FORMA FARMACĖUTICA I ÚS. Desconegut per l'informant. OBSERVACIONS Es la que m'agrada, és més dolça.

\section{ALTRES USOS}

\section{Part aèria florida}

Ornamental: elaboració de rams

FONT 528. DESCRIPCIÓ DE L'ÚS FETA PER L'INFORMANT. Per a fer bonic, jo no en prenc.

\section{ALTRES OBSERVACIONS}

FONTS 520, 521, 554, 555, 556, 557, 558. DESCRIPCIÓ FETA PELS INFORMANTS. La dels horts $(520,521)$. Cada any en sortia a l'hort $(556,557)$. A l'hort sempre en tenim (558). La teníem a l'hort $(554,555)$

\section{BARREGES AMB AQUEST TÀXON}

\section{Inflorescència}

FONT 546. Entrevista 74, barreja II (vegeu catàleg de barreges)

FONTS 554, 555. Entrevista 78, barreja V (vegeu catàleg de barreges)

FONT 558. Entrevista 80 (vegeu catàleg de barreges)

FONT 581. Entrevista 94, barreja IV (vegeu catàleg de barreges)

\section{Medicago sativa L. subsp. sativa (papilionàcies)}




\section{NOMS POPULARS}

Alfals $(507,509,510,511,512,513,514,520,521,529,530,531,561,562,563,581,746$ $748,749)$

Ufals $(532,533,534,546,556,557,560,567,571,574,575,576,577,583,584,585)$

Userda $(515,516,538,565,566,572,573,580,586,587,589,753,754,755,1215,1313$ $1314,1317,1330,1337,1338,1347,1348,1349,1350,1351,1352,1361,1362)$

Userda borda (564)

\section{USOS MEDICINALS}

\section{Part aèria}

Analgèsic

FONTS 567, 748, 749. DESCRIPCIÓ DE L'ÚS FETA PELS INFORMANTS. Per a treure el dolor quan et dónes un cop molt fort $(748,749)$. Per al dolor (567). FORMA FARMACĖUTICA I ÚS. Ungüent (ús extern) $(748,749)$. Emplastre (ús extern) (567). PREPARACIÓ. Aixafat amb cansalada, quedava com una pasterada i posat al mig de dos draps $(748,749)$. Picat amb cansalada i posat en emplastre (567). DESTINACIÓ. Medicina humana.

Antialopècic

FONTS 572, 573. DESCRIPCIÓ DE L'ÚS FETA PELS INFORMANTS. Rentar els cabells amb aigua d'userda diu que va bé per a quan et cau el cabell. FORMA FARMACĖUTICA I ÚS. Bany (ús extern). PREPARACIÓ. Decocció. DESTINACIÓ. Medicina humana.

Antiequimòtic

FONTS 511, 512, 513, 514, 529, 530, 531, 561, 562, 563, 1314, 1317, 1330, 1337, 1338 $1347,1348,1349,1350,1351,1352,1361,1362$. DESCRIPCIÓ DE L'ÚS FETA PELS INFORMANTS. Per a quan et fas un truc $(511,512,513,514)$. Per a les patacades $(529$ $530,531)$. Per als trucs $(561,562,563,1317)$. Per als trucs i per a fer sortir hematomes (1314). Per a fer sortir els trucs $(1330,1350,1351)$. Per a quan tenies un truc $(1337,1338)$

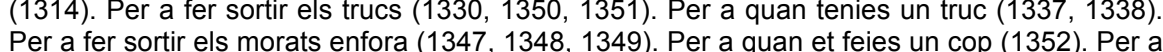
fer sortir els blaus $(1361,1362)$. FORMA FARMACĖUTICA I Ús. Ungüent (ús extern) (511, fer sortir els blaus $(1361,1362)$. FORMA FARMACĖUTICA I ÚS. Ungüent (ús extern) (511, $512,513,514,529,530,531)$. Emplastre (ús extern) $(561,562,563,1314,1317,1330,1337$
$1338,1347,1348,1349,1350,1351,1352,1361,1362)$. PREPARACIÓ. Alfals verd pica amb cansalada (511, 512, 513, 514). Picat amb cansalada (529, 530, 561, 562, 563, 1314 1337, 1338, 1347, 1348, 1349). Picat amb la cansalada (531). Emplastre d'userda amb cansalada (1317). Picada amb sagí per a fer emplastres (1330). Per a fer emplastres (1350 1351). Per a fer emplastres, picada amb cansalada i posada sobre d'un drap (1352). Picada amb cansalada $(1361,1362)$. DESTINACIÓ. Medicina humana.

Antiinflamatori

FONTS 572, 573, 583, 584, 585. DESCRIPCIÓ DE L'ÚS FETA PELS INFORMANTS. Quan tens una inflamació [dit "enflema"] $(572,573)$. Per a fer baixar la inflamació $(583,584,585)$. FORMA FARMACĖUTICA I ÚS. Emplastre (ús extern). PREPARACIÓ. Es feia servir per fer emplastres $(572,573)$. Es picava la cansalada i es feia un emplastre $(583,584,585)$. DESTINACIÓ. Medicina humana.
Antipirètic

FONTS 515, 516. DESCRIPCIÓ DE L'ÚS FETA PELS INFORMANTS. Per a fer baixar la febre. FORMA FARMACĖUTICA I ÚS. Emplastre (ús extern). PREPARACIÓ. Userda amb vinagre. Es posa a les plantes dels peus. DESTINACIÓ. Medicina humana.

Per als traumatismes

FONTS 507, 509, 510. DESCRIPCIÓ DE L'ÚS FETA PELS INFORMANTS. Per a quan et feies una torçada de peu o et queia un ferro a sobre. FORMA FARMACĖUTICA I ÚS. Ungüent (ús extern). PREPARACIÓ. Alfals tendre picat sol o amb cansalada. DESTINACIÓ. Medicina humana.

Resolutiu

FONTS 533, 534, 581. DESCRIPCIÓ DE L'ÚS FETA PELS INFORMANTS. Servia per a fer sortir mals cap enfora $(533,534)$. Fa sortir els mals enfora (581). FORMA FARMACĖUTICA I ÚS. Emplastre (ús extern). PREPARACIÓ. Rescaldejat al foc i barrejat amb cansalada, es feia un emplastre $(533,534)$. Es feien emplastres $(581)$. DESTINACIÓ. Medicina humana. OBSERVACIONS. Tiba molt (581).

\section{USOS ALIMENTARIS}

\section{Part aèria}

Ingestió de la part de la planta crua - Conservada dessecada a l'aire

FONTS 560, 561, 562, 563, 564, 565, 566, 567, 571, 574, 575, 576, 577, 580, 589, 746 DESCRIPCIÓ DE L'ÚS FETA PELS INFORMANTS. Per a alimentar el bestiar (746). Per als conills, els donàvem ufals sec, tendra no els va bé (571). Per als conills, els en donàvem sec (567). Per als conills, s'havia de vigilar perquè els podia fer mal $(561,562,563)$. Per donar (567). Per als con bestiar (conills, vaques, cavalls) (560). Per als conills $(564,565,566)$. Es dona al bestiar (580). Es feia per al bestiar (589). En menja el bestiar $(574,575,576,577)$. DESTINACIO Alimentació animal $(560,561,562,563,564,565,566,567,571,574,575,576,577,580$ $589,746)$.

Ingestió de la part de la planta crua - Fresca (sense preparació)

FONTS 565, 566, 586, 587. DESCRIPCIÓ DE L'ÚS FETA PELS INFORMANTS. Engegàvem els porcs a la userda $(565,566)$. Si se la mengen al mig de la calor, els fa mal i les boteix $(586,587)$. DESTINACIÓ. Alimentació animal $(565,566,586,587)$.

\section{ACCIONS NOCIVES O TÒXIQUES}

\section{Part aèria}

FONTS 507, 509, 510. DESCRIPCIÓ DE L'ACCIÓ NOCIVA O TÒXICA FETA PELS INFORMANTS. Quan es troba barrejat el fenc (Trifolium incarnatum) i l'ufals (Medicago sativa), fa un vapor perquè fermenta i no t'hi pots posar a sobre, és perillós, perquè et faria mal, et tapa i et fa estossegar. GRAU DE TOXICITAT. Elevat. VIA D'INTOXICACIÓ. Via interna.

Part aèria jove 
Apèndix 1. Catàleg de tàxons.

FONTS 556, 557. DESCRIPCIÓ DE L'ACCIÓ NOCIVA O TÒXICA FETA PELS INFORMANTS. Si és tendra i les vaques se'l mengen quan tenen molta gana, és perillós, els fa mal i les boteix. VIA D'INTOXICACIÓ. Via interna. TOXICITAT EN ANIMALS. Sí.

\section{BARREGES AMB AQUEST TÀXON}

\section{Part aèria}

FONT 1215. Entrevista 104, barreja II (vegeu catàleg de barreges)

FONT 1313. Entrevista 4, barreja I (vegeu catàleg de barreges)

FONTS 520, 521. Entrevista 56, barreja II (vegeu catàleg de barreges)

FONT 532. Entrevista 63, barreja II (vegeu catàleg de barreges)

FONTS $753,754,755$. Entrevista 67 , barreja $\vee$ (vegeu catàleg de barreges)

FONT 538. Entrevista 68, barreja I (vegeu catàleg de barreges)

FONT 546. Entrevista 74, barreja III (vegeu catàleg de barreges)

\section{Melilotus alba Medic. (papilionàcies)}

BCN 33328

\section{NOMS POPULARS}

Alfals bord $(529,530,531)$

\section{ALTRES OBSERVACIONS}

FONTS 529, 530, 531. DESCRIPCIÓ FETA PELS INFORMANTS. Fa la fulla igual que l'ufals però no ho és.

\section{Melissa officinalis L. (labiades)}

\section{BCN 24928}

\section{NOMS POPULARS}

Herba melissa (1293)

Melissa (1331)

Tarongina $(520,521,522,523,524,539,540,553,554,555,556,557,561,562,563,564$ $567,569,570,580,746,752,1213,1214,1324$

\section{USOS MEDICINALS}

Part aèria
Antihipertensiu

FONT 1293. DESCRIPCIÓ DE L'ÚS FETA PER L'INFORMANT. Va bé per a la pressió. FORMA FARMACĖUTICA I ÚS. Tisana (ús intern). PREPARACIÓ. Decocció. DESTINACIÓ. Medicina humana.

Antiinflamatori intestinal

FONT 752. DESCRIPCIÓ DE L'ÚS FETA PER L'INFORMANT. Per a la panxa. FORMA FARMACĖUTICA I ÚS. Tisana (ús intern). PREPARACIÓ. Decocció. DESTINACIÓ. Medicina humana.

Antinauseabund

FONTS 539, 540. DESCRIPCIÓ DE L'ÚS FETA PELS INFORMANTS. Si has de fer un viatge te'n prens una tassa abans de marxar i no et deixa marejar. FORMA FARMACĖUTICA I ÚS. Tisana (ús intern). PREPARACIÓ. Decocció. DESTINACIÓ. Medicina humana.

Digestiu

FONTS 520, 521, 554, 555. DESCRIPCIÓ DE L'ÚS FETA PELS INFORMANTS. Ajuda a pair $(520,521)$. FORMA FARMACĖUTICA I ÚS. Tisana (ús intern). PREPARACIÓ. Decocció $(520,521)$. Decocció. Se'n feien aigües $(554,555)$. DESTINACIÓ. Medicina humana.

Hematocatàrtic

FONTS 556, 557. DESCRIPCIÓ DE L'ÚS FETA PELS INFORMANTS. És depurativa. FORMA FARMACĖUTICA I ÚS. Tisana (ús intern). PREPARACIÓ. Decocció. DESTINACIÓ. Medicina humana.

Hipnòtic

FONT 580. DESCRIPCIÓ DE L'ÚS FETA PER L'INFORMANT. Per a fer dormir. FORMA FARMACĖUTICA I ÚS. Tisana (ús intern). PREPARACIÓ. Decocció. DESTINACIÓ. Medicina humana.

Tranquil·litzant

FONTS 1293, 1324, 1331. DESCRIPCIÓ DE L'ÚS FETA PELS INFORMANTS. Va bé per als nervis (1293). Per als nervis $(1324,1331)$. FORMA FARMACĖUTICA I ÚS. Tisana (ús intern). PREPARACIÓ. Decocció (1293). En infusió (1324, 1331). DESTINACIÓ. Medicina humana.

\section{USOS ALIMENTARIS}

\section{Part aèria}

Preparació de begudes - Beguda preparada amb aigua

FONTS 556, 557. DESCRIPCIÓ DE L'ÚS FETA PELS INFORMANTS. A l'estiu aigua per la canalla com a refrescant. DESTINACIO. Alimentació humana.

Preparació de begudes - Beguda preparada amb aiguardent

FONTS 522, 523, 524, 553. DESCRIPCIÓ DE L'ÚS FETA PELS INFORMANTS. Es posava a la ratafia $(522,523)$. Ratafia. Posar totes les herbes en aiguardent 21 dies a sol i serena. Es fa pels volts de Sant Joan. Sempre surt bona pero no surt mai igual. Les herbes utilitzades 
són: nous verdes (Juglans regia), herba de Noè (Herniaria glabra), tarongina (Melissa officinalis), camamilla borda (Tanacetum parthenium), marialluïsa (Lippia triphylla), menta (Mentha spicata), salsufràgia (Peucedanum ostruthium), til.la (Tilia platyphyllos), nou moscada (Myristica fragrans) i clau (Syzygium aromaticum) (553). Amb les nous verdes, la mare feia alguna vegada ratafia. Recepta de ratafia: per un litre d'aiguardent hi posava tres mare feia alguna vegada ratafia. Recepta de ratafia: per un litre d'aiguardent hi posava tres nous (Juglans regia), una branca de canyella (Cinnamomum zeylanicum), una nou moscada (Myristica fragrans), tarongina (Melissa officinalis), algunes herbes més que no recordo, i tre cullerades de sucre. Deien que com més varietat d'herbes millor. Es posava amb una garrafa de vidre i es deixava a la finestra a sol i serena uns quants dies, no recordo quants. Es solia fer per Sant Pere (524). DESTINACIÓ. Alimentació humana $(522,523,524,553)$.

\section{ALTRES USOS}

\section{Part aèria}

Maneig agrosilvopastoral: obtenció de mel

FONTS 561, 562, 563. DESCRIPCIÓ DE L'ÚS FETA PELS INFORMANTS. Quan es treia la mel a les abelles se'ls passava la tarongina i estaven contentes, perquè feia olor.

Planta sencera

Repel.lents

FONTS 520, 521. DESCRIPCIÓ DE L'ÚS FETA PELS INFORMANTS. Va bé perquè no entrin les mosques i els mosquits.

\section{ALTRES OBSERVACIONS}

FONTS 539, 540, 569, 570. DESCRIPCIÓ FETA PELS INFORMANTS. A l'hort $(539,540)$ En tenim a casa $(569,570)$.

\section{BARREGES AMB AQUEST TÀXON}

\section{Part aèria}

FONT 746. Entrevista 45, barreja III (vegeu catàleg de barreges) FONT 1324. Entrevista 5, barreja III (vegeu catàleg de barreges) FONT 1324. Entrevista 5, barreja IV (vegeu catàleg de barreges) FONT 564. Entrevista 84, barreja II (vegeu catàleg de barreges)

Mentha longifolia (L.) Huds. (labiades)

BCN 24929

\section{NOMS POPULARS}

Menta borda $(539,540)$
Menta de llop (1324)

\section{USOS MEDICINALS}

\section{Part aèria}

Antiinflamatori intestinal

FONTS 539, 540. DESCRIPCIÓ DE L'ÚS FETA PELS INFORMANTS. Per al mareig indigestions i mal de panxa. FORMA FARMACĖUTICA I ÚS. Tisana (ús intern). PREPARACIÓ. Decocció. DESTINACIÓ. Medicina humana.

Antinauseabund

FONTS 539, 540. DESCRIPCIÓ DE L'ÚS FETA PELS INFORMANTS. Per al mareig indigestions i mal de panxa. FORMA FARMACĖUTICA I ÚS. Tisana (ús intern). PREPARACIÓ. Decocció. DESTINACIÓ. Medicina humana.

Digestiu

FONTS 539, 540. DESCRIPCIÓ DE L'ÚS FETA PELS INFORMANTS. Per al mareig, indigestions i mal de panxa. FORMA FARMACĖUTICA I ÚS. Tisana (ús intern). PREPARACIÓ. Decocció. DESTINACIÓ. Medicina humana.

\section{Mentha xpiperita L. (labiades)}

BCN 113813

\section{NOMS POPULARS}

Aufàbrega romana $(525,526,527)$

Herbansana $(748,749)$

Menta (528)

Menta piperita $(539,540,569,570)$

Menta romana (1324)

\section{USOS MEDICINALS}

Fulla

Antiinflamatori intestinal

FONTS 748, 749. DESCRIPCIÓ DE L'ÚS FETA PELS INFORMANTS. Per al mal de panxa (749). Per al mal de panxa. Molt semblant a la menta, però és més blanquinosa (748). FORMA FARMACĖUTICA I ÚS. Suspensió (ús intern). PREPARACIÓ. Sopa de pa amb una fulla $(748,749)$. DESTINACIÓ. Medicina humana.

\section{Part aèria}

Antiinflamatori intestinal 
FONTS 539, 540. DESCRIPCIÓ DE L'ÚS FETA PELS INFORMANTS. Per al mareig, indigestions i mal de panxa. FORMA FARMACĖUTICA I ÚS. Tisana (ús intern). PREPARACIÓ. Decocció. DESTINACIÓ. Medicina humana.

Antinauseabund

FONTS 539, 540. DESCRIPCIÓ DE L'ÚS FETA PELS INFORMANTS. Per al mareig, indigestions i mal de panxa. FORMA FARMACĖUTICA I ÚS. Tisana (ús intern). PREPARACIÓ. Decocció. DESTINACIÓ. Medicina humana.

Digestiu

FONTS 539, 540. DESCRIPCIÓ DE L'ÚS FETA PELS INFORMANTS. Per al mareig, indigestions i mal de panxa. FORMA FARMACĖUTICA I ÚS. Tisana (ús intern). PREPARACIÓ. Decocció. DESTINACIÓ. Medicina humana.

\section{USOS ALIMENTARIS}

Fulla

Condiment

FONTS 525, 526, 527, 528, 748. DESCRIPCIÓ DE L'ÚS FETA PELS INFORMANTS. Per a cuinar les faves tendres (748). És molt més forta que l'altra i es posava a la xocolata (525, $526,527)$. Per a fer coure les faves (528). DESTINACIÓ. Alimentació humana $(525,526,527$ $528,748)$.

Part aèria

Condiment

FONT 1324. DESCRIPCIÓ DE L'ÚS FETA PER L'INFORMANT. Dóna molt bon gust a la llet. DESTINACIÓ. Alimentació humana.

\section{ALTRES OBSERVACIONS}

FONTS 569, 570. DESCRIPCIÓ FETA PELS INFORMANTS. En tenim a casa.

\section{Mentha pulegium L. (labiades)}

BCN 113598

\section{NOMS POPULARS}

Poliol $(520,521,561,562,563,572,573,752)$

Poniol $(504,554,555,569,570,578,579,580)$

\section{USOS MEDICINALS}

\section{No consta}

Desconegut per l'informant
FONTS 520, 521. FORMA FARMACĖUTICA I ÚS. Tisana (ús intern). OBSERVACIONS. És molt bona, l'aigua, no en recordo les propietats.

\section{Part aèria florida}

Anticatarral

FONT 504. DESCRIPCIÓ DE L'ÚS FETA PER L'INFORMANT. Per als constipats. FORMA FARMACĖUTICA I ÚS. Tisana (ús intern). PREPARACIÓ. Decocció. DESTINACIÓ. Medicina humana.

Antiinflamatori intestinal

FONTS 578, 579, 580, 752. DESCRIPCIÓ DE L'ÚS FETA PELS INFORMANTS. Per a la panxa $(578,579,752)$. Va bé per al ventre $(580)$. FORMA FARMACÉUTICA I ÚS. Tisana (ús intern). PREPARACIO. Decocció $(578,579,580,752)$. DESTINACIÓ. Medicina humana.

Digestiu

FONTS 504, 572, 573. DESCRIPCIÓ DE L'ÚS FETA PELS INFORMANTS. Va bé com a digestiva (504). Per a fer pair $(572,573)$. FORMA FARMACĖUTICA I ÚS. Tisana (ús intern). PREPARACIÓ. Decocció $(504,572,573)$. DESTINACIÓ. Medicina humana.

Estomacal

FONTS 569, 570. DESCRIPCIÓ DE L'ÚS FETA PELS INFORMANTS. Per a l'estómac FORMA FARMACĖUTICA I ÚS. Tisana (ús intern). PREPARACIÓ. Decocció. DESTINACIÓ Medicina humana.

\section{USOS ALIMENTARIS}

\section{Part aèria florida}

Preparació de begudes - Beguda preparada amb licor

FONTS 554, 555. DESCRIPCIÓ DE L'ÚS FETA PELS INFORMANTS. Se'n fa licor amb anís. DESTINACIÓ. Alimentació humana.

\section{BARREGES AMB AQUEST TÀXON}

\section{Part aèria florida}

FONTS 554, 555. Entrevista 78, barreja II (vegeu catàleg de barreges)

Mentha sp. (labiades)

\section{NOMS POPULARS}

Herba-sana $(583,584,585)$

Herbansana $(529,530,531)$

Meirastres $(583,584,585)$

Menta $(580,586,587,590,1215)$ 


\section{USOS MEDICINALS}

\section{Part aèria}

Antiinflamatori intestinal

FONTS 580, 590. DESCRIPCIÓ DE L'ÚS FETA PELS INFORMANTS. Per a la panxa (580) És bona per al ventre (590). FORMA FARMACĖUTICA I ÚS. Suspensió (ús intern) (580) Tisana (ús intern) (590). PREPARACIO. Sopes (580). Decocció (590). DESTINACIÓ. Medicina humana.

Antitussigen

FONTS 583, 584, 585. DESCRIPCIÓ DE L'ÚS FETA PELS INFORMANTS. Va bé per a la tos. FORMA FARMACĖUTICA I ÚS. Xarop (ús intern). PREPARACIÓ. Es picava la planta en feien xarop. DESTINACIÓ. Medicina humana.

Digestiu

FONTS 529, 530, 531. DESCRIPCIÓ DE L'ÚS FETA PELS INFORMANTS. Per a pair FORMA FARMACĖUTICA I ÚS. Tisana (ús intern). PREPARACIÓ. Decocció. DESTINACIÓ. Medicina humana.

\section{ALTRES USOS}

Planta sencera

Literatura oral popular: llegendes, gloses, contes, dites, refranys, poemes, cançons

FONTS 583, 584, 585, 1215. DESCRIPCIÓ DE L'ÚS FETA PELS INFORMANTS. Herbasana: Calla, calla que floriràs i no granaràs $(583,584,585)$. Menta traïdora floriràs i no granaràs (1215).

\section{ALTRES OBSERVACIONS}

FONTS 586, 587, 1215. DESCRIPCIÓ FETA PELS INFORMANTS. És grisosa, fa olor de menta, però em sembla que no es fa servir $(586,587)$. En teníem a l'hort $(1215)$.

\section{BARREGES AMB AQUEST TÀXON}

\section{Part aèria}

FONTS 529, 530, 531. Entrevista 53, barreja V (vegeu catàleg de barreges)

\section{Mentha spicata L. (labiades)}

BCN 24930

NOMS POPULARS
Menta $(505,506,507,509,510,511,512,513,514,517,520,521,522,523,524,532,535$ $573,574,575,576,577,578,579,581,588,746,752,1293,1294,1296,1299,1300,1301$ $1307,1308,1309,131$ $1353,1354,1361,1362)$

\section{USOS MEDICINALS}

\section{Part aèria}

Anticefalàlgic

FONTS 1343, 1344. DESCRIPCIÓ DE L'ÚS FETA PELS INFORMANTS. Per al mal de cap. FORMA FARMACĖUTICA I ÚS. Decocció (ús intern). PREPARACIÓ. Posaven un brot de menta a la xocolata desfeta. DESTINACIÓ. Medicina humana.

Antiemètic

FONT 1324. DESCRIPCIÓ DE L'ÚS FETA PER L'INFORMANT. Per als vòmits. FORMA FARMACÉUTICA I ÚS. Tisana (ús intern). PREPARACIÓ. En infusió. DESTINACIÓ. Medicina humana.

Antiinflamatori intestinal

FONTS 517, 522, 523, 554, 555, 558, 561, 562, 563, 567, 568, 572, 573, 578, 579, 752, 1299, 1301, 1307, 1308, 1309. DESCRIPCIÓ DE L'ÚS FETA PELS INFORMANTS. Per al mal de ventre $(517,522,523,578,579,1299,1307,1308,1309)$. Per a la panxa $(554,555$ $567,568,572,573,752,1301)$. Per al mal de panxa (558). Per als dolors de ventre $(561$ $562,563)$. FORMA FARMACĖUTICA I ÚS. Tisana (ús intern) $(517,522,523,554,555,558$, $561,562,563,568,572,573,578,579,752,1299,1301,1307,1308,1309$ ). Suspensió (ús intern) $(522,523,554,555,567,1307,1308,1309)$. PREPARACIÓ. Decocció $(517,522,523$, $554,555,558,561,562,563,568,572,573,578,579,752,1301)$. Sopa (522). Sopes (523). Amb sopa (567). Per a fer sopes $(554,555)$. Sopa de menta $(1307,1308,1309)$. DESTINACIÓ. Medicina humana.

Desconegut per l'informant

FONT 532. DESCRIPCIÓ DE L'ÚS FETA PER L'INFORMANT. Per a prendre, a vegades barrejada amb altres herbes. FORMA FARMACEUTICA I ÚS. Tisana (ús intern). PREPARACIÓ. Decocció. DESTINACIÓ. Medicina humana.

\section{Digestiu}

FONTS 505, 506, 507, 509, 510, 547, 548, 746, 1353, 1354, 1361, 1362. DESCRIPCIÓ DE L'ÚS FETA PELS INFORMANTS. Digestiva (746). Com a digestiva. La sopa de menta és bona quan tens la panxa malament $(507,509,510)$. Per a menjar quan tens la panxa malament $(505,506)$. Es digestiva $(547,548)$ malament (505, 506). (1353). QCATICA I ÚS. Tín (ús (505,500,507,509,510,547,548,1353,1354). PREPARACIÓ. D). Suspensió (ús intern) $(505,506,507,509,510,547,548,1353,1354)$. PREPARACIO. Decocció $(547,548,746)$ Sopa $(507,509,510)$. Sopa de pa amb menta $(505,506)$. Sopa $(547,548)$. Sopa de pa amb un brot de menta $(1353,1354)$. En infusió $(1361,1362)$. DESTINACIÓ. Medicina humana. 
Estomacal

FONTS 569, 570. DESCRIPCIÓ DE L'ÚS FETA PELS INFORMANTS. Per a l'estómac. FORMA FARMACÈUTICA I ÚS. Tisana (ús intern). PREPARACIÓ. Decocció. DESTINACIÓ Medicina humana.

Hepatoprotector

FONTS 1324, 1335, 1361, 1362. DESCRIPCIÓ DE L'ÚS FETA PELS INFORMANTS. Per al fetge $(1324,1361,1362)$. És bona per al fetge (1335). FORMA FARMACĖUTICA I ÚS Tisana (ús intern). PREPARACIÓ. En infusió $(1324,1361,1362)$. Decocció (1335) DESTINACIÓ. Medicina humana.

Tranquil.litzant

FONT 535. DESCRIPCIÓ DE L'ÚS FETA PER L'INFORMANT. Relaxa. FORMA FARMACĖUTICA I ÚS. Tisana (ús intern). PREPARACIÓ. Decocció. MODE D'UTILITZACIÓ/POSOLOGIA. Va bé una tassa abans d'anar a dormir. DESTINACIÓ. Medicina humana.

\section{USOS ALIMENTARIS}

\section{Fulla}

Condiment

FONTS 505, 506, 511, 512, 513, 514, 520, 521, 524, 554, 555, 565, 566, 574, 575, 576, 577 1293, 1294, 1296, 1300, 1310, 1313. DESCRIPCIÓ DE L'ÚS FETA PELS INFORMANTS. Quan faig sopa de pa, m'hi poso menta perquè m'agrada el gust que té $(505,506)$. Faves desgranades amb menta $(511,512,513,514)$. Per a fer sopa de pa i poses una mica de menta i li dóna aquell gust (524). Per a fer sopa amb ronyons de pa sec $(520,521)$. Per a posar a la xocolata $(520,521,574,575,576,577)$. En faig sopes de pa amb menta $(565$ $566)$. La poso als cargols $(565,566)$. Barrejat amb xocolata de pedra de l'Arumí $(554,555)$. Per a posar a les sopa $(575)$. Per a posar a les sopes $(574,576,577)$. Per a posar a la sopa de pa, li dóna molt bon gust (1293). Per a donar gust (1294). Per a cuinar (1296). Per a de pa, li dóna molt bon gust (1293). Per a donar gust (1294). Per a cuinar (1296). Per a
refrescar i per a donar gust a altres herbes no tan bones (1300). Per a posar a la sopa refrescar i per a donar gust a altres herbes no tan bones (1300). Per a posar a la sopa
(1310). S'usava per a acompanyar herbes que eren de mal prendre (1310). Sopa d'all amb una fulla de menta (1313). OBSERVACIONS. Per a adornar els plats (1313). DESTINACIÓ. Alimentació humana $(505,506,511,512,513,514,520,521,524,554,555,565,566,574$ $575,576,577,1293,1294,1296,1300,1310,1313)$

Ingestió de la part de la planta cuita - Cuita en aigua

FONTS 549, 553, 554, 555, 560, 569, 570, 571. DESCRIPCIÓ DE L'ÚS FETA PELS INFORMANTS. Per a fer sopes, és bona (549). Per a fer sopes, per als cuinats (553). Per fer sopes $(560,569,570,571)$. De sopes de menta, en mengem quasi cada dia, quan n'hi ha $(554,555)$. DESTINACIÓ. Alimentació humana $(549,553,554,555,560,569,570,571)$.

Preparació de begudes - Beguda preparada amb aiguardent

FONTS 553, 588. DESCRIPCIÓ DE L'ÚS FETA PELS INFORMANTS. Ratafia. Posar totes les herbes en aiguardent 21 dies a sol i serena. Es fa pels volts de Sant Joan. Sempre surt bona però no surt mai igual. Les herbes utilitzades son: nous verdes (Juglans regia), herba de Noè (Herniaria glabra), tarongina (Melissa officinalis), camamilla borda (Tanacetum parthenium), marialluïsa (Lippia triphylla), menta (Mentha spicata), salsufràgia (Peucedanum ostruthium), tilla (Tila platyphyllos), nou moscada (Myristica fragrans) i clau (Syzygium aromaticum) (553). Ratafla. Abans si que recordo de totes. Nous verdes (Juglans regia), farigola (Thymus serpyllum), nou muscada (Myristica fragrans), marialluïsa (Lippia triphylla), menta (Mentha spicata), orenga (Origanum vulgare) i poniol (Satureja calamintha subsp. ascendens) (588). DESTINACIÓ. Alimentació humana $(553,588)$

\section{Part aèria}

Condiment

FONTS 1319, 1341, 1342. DESCRIPCIÓ DE L'ÚS FETA PELS INFORMANTS. Sopa de pa amb un brot de menta $(1319)$. Per a posar a la sopa de pa $(1341,1342)$. DESTINACIÓ. Alimentació humana $(1319,1341,1342)$.

Ingestió de la part de la planta cuita - Cuita en aigua FONT 1320. DESCRIPCIÓ DE L'ÚS FETA PER L'INFORMANT. Per a fer sopa de menta. DESTINACIÓ. Alimentació humana.

Preparació de begudes - Beguda preparada amb aigua

FONTS 1327, 1335, 1336, 1341, 1342. DESCRIPCIÓ DE L'ÚS FETA PELS INFORMANTS En infusió per a beure i per a refrescar a l'estiu (1327). A l'aigua fresca hi poses un brot de menta i refresca més (1335). Aigua fresca amb menta per a refrescar (1336). En infusió per a beure com a refrescant $(1341,1342)$. DESTINACIÓ. Alimentació humana $(1327,1335,1336$ 1341, 1342).

Preparació de begudes - Beguda preparada amb aiguardent

FONT 1301. DESCRIPCIÓ DE L'ÚS FETA PER L'INFORMANT. Per a posar a la ratafia. DESTINACIO. Alimentació humana.

\section{ALTRES USOS}

\section{Part aèria}

Domèstic: ambientador

FONT 1296. DESCRIPCIÓ DE L'ÚS FETA PER L'INFORMANT. Per a fer olor.

\section{ALTRES OBSERVACIONS}

FONTS 538, 1296. DESCRIPCIÓ FETA PELS INFORMANTS. A l'hort tothom en tenia una mateta, però no recordo perquè es feia servir (538). En té a l'hort (1296).

\section{BARREGES AMB AQUEST TÀXON}

\section{Part aèria}

FONT 1330. Entrevista 32, barreja III (vegeu catàleg de barreges)

FONT 1330. Entrevista 32, barreja V (vegeu catàleg de barreges) 
FONT 558. Entrevista 80 (vegeu catàleg de barreges)

FONT 581. Entrevista 94, barreja IV (vegeu catàleg de barreges)

\section{Mercurialis annua L. (euforbiàcies)}

BCN 24932

\section{NOMS POPULARS}

Murcarola $(518,519,528,578,579,590,1336,1339,1340)$

\section{USOS MEDICINALS}

\section{Part aèria}

Antihipertensiu

FONTS 578, 579. DESCRIPCIÓ DE L'ÚS FETA PELS INFORMANTS. Per a fer baixar la pressió. FORMA FARMACĖUTICA I ÚS. Tisana (ús intern). PREPARACIÓ. Decocció DESTINACIÓ. Medicina humana.

Laxant

FONTS 518, 519, 1336. DESCRIPCIÓ DE L'ÚS FETA PELS INFORMANTS. Per a anar de ventre, quan estàs empatxat $(518,519)$. Per al restrenyiment (1336). FORMA FARMACEUTICA I ÚS. Tisana (ús intern). PREPARACIÓ. Decocció $(518,519,1336)$ DESTINACIO. Medicina humana.

\section{ACCIONS NOCIVES O TÒXIQUES}

\section{Part aèria}

FONTS 528, 1339, 1340. DESCRIPCIÓ DE L'ACCIÓ NOCIVA O TÒXICA FETA PELS INFORMANTS. És tòxica per al bestiar (528). Si les vaques en mengen, pixen sang (1339, 1340). VIA D'INTOXICACIÓ. Via interna (528). TOXICITAT EN ANIMALS. Sí (528).

\section{ALTRES OBSERVACIONS}

FONT 590. DESCRIPCIÓ FETA PER L'INFORMANT. Són males herbes de l'hort.

\section{Mespilus germanica L. (rosàcies)}

BCN 50768

\section{NOMS POPULARS}

Nespra (fruit) $(561,562,563)$

Nespró $(561,562,563)$

\section{USOS ALIMENTARIS}

Fruit

Ingestió de la part de la planta crua - Fresca (sense preparació)

FONTS 561, 562, 563. DESTINACIÓ. Alimentació humana.

\section{ALTRES OBSERVACIONS}

FONTS 561, 562, 563. DESCRIPCIÓ FETA PELS INFORMANTS. A casa en teníem i feien uns nespres ben macos i grossos.

\section{Meum athamanticum Jacq. subsp. athamanticum}

\section{(umbel·líferes)}

BCN 24933

\section{NOMS POPULARS}

Herba de meu (1319)

Herba del meu $(538,539,540,541,559,571,753,754,755,1296,1300,1310,1313,1314$ $1325,1326,1333,1334,1339,1340,1343,1344,1345,1346)$

Herba meu $(533,534,549,1332)$

Meu $(588,591,592,1317,1321,1322,1328,1329,1331,1337,1338,1341,1342,1347$ $1348,1349,1350,1351,1361,1362)$

\section{USOS MEDICINALS}

Arrel

Abortic

FONTS 533, 534, 538, 541, 559, 591, 592, 753, 754, 755, 1310, 1313, 1314, 1328, 1329 1361, 1362. DESCRIPCIÓ DE L'ÚS FETA PELS INFORMANTS. Per a quan s'esguerrava o avortava una vaca, se'ls feia aigua de meu $(533,534)$. És abortiva $(538,1310,1328,1329)$ Per a avortar. Es donava al bestiar (541). Tambe diuen que és abortiva i com que fa flaquejar molt les sangs et feia avortar (559). Per a fer avortar a les dones $(753,754,755)$. Per a avortar. Quan les dones quedaven embarassades i ja tenien massa fills es prenien aigua llavors ja tornava a venir la regla $(591,592)$. Les dones l'utilitzaven per a avortar, però no sap si a alguna li va funcionar $(1313)$. Per a avortar $(1361,1362)$. FORMA FARMACËUTICA US. Tisana (ús intern) $(533,534,541,591,592,753,754,755,1310,1313,1328,1329$, 1361, 1362). Vi medicinal (ús intern) $(538,559)$. Desconegut per l'informant (1314). PREPARACIO. Decocció $(533,534,541,591,592,753,754,755,1310,1328,1329,1361$, 1362). Herba barrejada amb vi (538). La feien bullir amb vi (559). DESTINACIO Medicina veterinària $(533,534,541,559,1314)$. Medicina humana $(538,591,592,753,754,755$, 
$1310,1313,1328,1329,1361,1362)$. OBSERVACIONS. També es deia que una dona de Queralbs en va prendre i es va morir (541). Abans deien "herba de meu per a fer xemenar les dones" (1313).

Anticatarral

FONTS 538, 1296, 1313, 1317, 1332, 1333, 1334, 1341, 1342, 1343, 1344, 1345, 1346, 1350, 1351. DESCRIPCIÓ DE L'ÚS FETA PELS INFORMANTS. Per als refredats (538, $1332,1333,1334,1341,1342,1344,1350,1351)$. Per als constipats $(1296,1317,1343$ 1345, 1346). Per al constipat (1313). FORMA FARMACĖUTICA I ÚS. Tisana (ús intern). PREPARACIÓ. Decocció $(538,1296,1317,1343,1344)$. La rel bullida en aigua (1332, 1333, $1334)$. En infusió de la rel $(1341,1342)$. Decocció. Aigua de la rel $(1345,1346)$. L'arrel bullida 1334). En infusió de la rel (1341, 1342). Decocció. Aigua de la rel (1345, 1346). L'arrel bullida
(1350, 1351). MODE D'UTILITZACIÓ/POSOLOGIA. Al vespre. Fer una novena (1332, 1333, (1350, 1351). MODE D'UTILITZACIÓ/POSOLOGIA. Al vespre. Fer una novena (1332, 1333,
1334). EFECTES SECUNDARIS. Sí. DESTINACIÓ. Medicina humana. OBSERVACIONS. Recorda que dos homes de Setcases se la prenien i van morir. Es diu que va ser per have abusat d'aquesta herba, és molt forta (1313). Se n'ha d'utilitzar molt poca, perquè rebaixa la sang. També diuen que és abortiva (1317). No es pot prendre més de nou dies, perquè és molt forta $(1332,1333,1334)$. S'ha de vigilar perquè rebaixa molt la sang i diuen que és abortiva $(1341,1342)$. S'ha de vigilar perquè rebaixa molt la sang $(1350,1351)$.

Antihipertensiu

FONTS 538, 559, 588, 753, 754, 755. DESCRIPCIÓ DE L'ÚS FETA PELS INFORMANTS Rebaixa molt la sang (538). Per a una persona forta de sang, la fa rebaixar (559). Per a rebaixar les sangs $(753,754,755)$. És per a rebaixar la sang i fer baixar la pressió (588). FORMA FARMACĖUTICA I ÚS. Tisana (ús intern). PREPARACIÓ. Decocció $(538,559,588$ $753,754,755)$. DESTINACIÓ. Medicina humana. OBSERVACIONS. És molt fort, s'ha de vigilar (588).

Antiinflamatori intestinal

FONT 1300. DESCRIPCIÓ DE L'ÚS FETA PER L'INFORMANT. Per al mal de ventre. FORMA FARMACĖUTICA I ÚS. Tisana (ús intern). PREPARACIÓ. Decocció. DESTINACIÓ. Medicina humana.

Coadjuvant del postpart

FONTS 538, 559, 571, 1310, 1313, 1317, 1319, 1322, 1325, 1326, 1328, 1329, 1339, 1340 $1341,1342,1347,1348,1349,1361,1362$. DESCRIPCIÓ DE L'ÚS FETA PELS INFORMANTS. També per a quan les vaques no podien fer les despulles, se'ls feia un parell
de galledes d'aigua de l'herba del meu (538). Per a ajudar a fer les despulles al bestiar (559, $1347,1348,1349)$. La rel és bona per a netejar les bèsties quan havien criat $(571)$. Per a fer les despulles a les vaques (1310). Per al bestiar, quan vedellaven i no quedaven nets, se'ls donava aigua de meu (1313). Per a ajudar a fer les despulles de les vaques quan han parit (1317). Per a fer les despulles del bestiar (1319). Per a ajudar a fer les despulles (1322). (1317). Per a fer les despulles del bestiar (1319). Per a ajudar a fer les despulles (1322).
Perquè el bestiar pogués fer els llits després de parir (1325, 1326). Per a ajudar a fer les despulles a les vaques $(1328,1329)$. Les comadrones també en duien per si les dones no acabaven de quedar netes $(1328,1329)$. Per a les vaques quan no havien fet les despulles $(1339,1340)$. Per a ajudar a fer els llits del bestiar $(1341,1342)$. Per a ajudar a fer les despulles del bestiar $(1361,1362)$. FORMA FARMACĖUTICA I ÚS. Tisana (ús intern) PREPARACIÓ. Decocció $(538,559,571,1310,1317,1319,1325,1326,1328,1329,1347$,
1348, 1349). Decocció. Aigua de la rel $(1322,1328,1329)$. Decocció. Aigua de l'arrel (1339, $1340)$. En infusió de la rel $(1341,1342)$. DESTINACIÓ. Medicina veterinària $(538,559,571$, 1310, 1313, 1319, 1322, 1325, 1326, 1328, 1329, 1339, 1340,1341, 1342, 1347, 1348, 1349) Medicina humana $(1317,1328,1329,1361,1362)$. OBSERVACIONS. És una herba molt forta (571).

Hematocatàrtic

FONTS 1332, 1333, 1334. DESCRIPCIÓ DE L'ÚS FETA PELS INFORMANTS. Neteja la sang. FORMA FARMACĖUTICA I ÚS. Tisana (ús intern). PREPARACIÓ. La rel bullida en sang. FORMA FARMALE MODE D'UTILITZACIÓ/POSOLOGIA. Al matí. Fer una novena. DESTINACIÓ. Medicina humana. OBSERVACIONS. No es pot prendre més de nou dies, perquè és molt forta.

Hipoglucemiant

FONTS 539, 540, 559. DESCRIPCIÓ DE L'ÚS FETA PELS INFORMANTS. Va bé per al que és diabètic $(539,540)$. Per a fer baixar el sucre (559). FORMA FARMACĖUTICA I ÚS. Tisana (ús intern). PREPARACIÓ. Decocció $(539,540,559)$. DESTINACIÓ. Medicina humana.

\section{No consta}

Abortiu

FONTS 1350, 1351. FORMA FARMACĖUTICA I ÚS. Desconegut per l'informant.

Desconegut per l'informant

FONT 549. FORMA FARMACĖUTICA I ÚS. Desconegut per l'informant. DESTINACIÓ Medicina veterinària. OBSERVACIONS. Per al bestiar, però no recordo quan els en donàvem.

\section{Planta sencera}

Abortiu

FONTS 1337, 1338. DESCRIPCIÓ DE L'ÚS FETA PELS INFORMANTS. És abortiu (1338). És abortiva (1337). FORMA FARMACĖUTICA I ÚS. Tisana (ús intern). PREPARACIÓ. Decocció. Aigua de tota la planta amb arrel $(1337,1338)$. DESTINACIÓ. Medicina humana. Coadjuvant del postpart

FONTS 1337, 1338. DESCRIPCIÓ DE L'ÚS FETA PELS INFORMANTS. S'usava per al bestiar per a ajudar-los a fer els llits. FORMA FARMACĖUTICA I ÚS. Tisana (ús intern). PREPARACIÓ. Decocció. DESTINACIÓ. Medicina veterinària.

\section{ACCIONS NOCIVES O TÒXIQUES}

Arre

FONT 1313. DESCRIPCIÓ DE L'ACCIÓ NOCIVA O TÒXICA FETA PER L'INFORMANT. Recorda que dos homes de Setcases se la prenien i van morir. Es diu que va ser per haver abusat d'aquesta herba, és molt forta. TOXICITAT LLIGADA A L'ÚS MEDICINAL. No. TOXICITAT EN ANIMALS. No.

\section{No consta}


FONTS 1314, 1332, 1333, 1334. DESCRIPCIÓ DE L'ACCIÓ NOCIVA O TÒXICA FETA PELS INFORMANTS. Només recorda que feia avortar les ovelles (1314). És abortiva (1332 $1333,1334)$.

\section{BARREGES AMB AQUEST TÀXON}

Arrel

FONT 1317. Entrevista 21, barreja I (vegeu catàleg de barreges)

FONT 1331. Entrevista 30, barreja IV (vegeu catàleg de barreges)

FONT 1321. Entrevista 37, barreja I (vegeu catàleg de barreges)

FONT 538. Entrevista 68, barreja II (vegeu catàleg de barreges)

\section{Mirabilis jalapa L. (nictaginàcies)}

BCN 64581

\section{NOMS POPULARS}

Damadenit $(520,521)$

\section{ALTRES USOS}

Planta viva ex situ

Ornamental: jardineria

FONTS 520, 521. DESCRIPCIÓ DE L'ÚS FETA PELS INFORMANTS. Per a fer bonic.

\section{Molopospermum peloponnesiacum (L.) W.D.J.Koch}

(umbel·líferes)

BCN 24934

\section{NOMS POPULARS}

Api bord (1321)

Àpit bord $(547,548)$

Coscoll $(515,516,532,533,534,538,539,540,541,546,559,569,570,571,586,587,588$, $589,591,592,747,753,754,755,1300,1310,1313,1314,1315,1316,1321,1337,1338$, $1341,1342,1347,1348,1349,1350,1351,1352)$

\section{USOS MEDICINALS}

\section{Lluc tendre}

Hipnòtic

FONTS 539, 540. DESCRIPCIÓ DE L'ÚS FETA PELS INFORMANTS. Fan venir son, és una mica adormidor. FORMA FARMACĖUTICA I ÚS. Sense forma farmacèutica (ús directe, ús intern). DESTINACIÓ. Medicina humana.

\section{USOS ALIMENTARIS}

Lluc tendre

Ingestió de la part de la planta crua - Fresca (sense preparació)

FONTS $515,516,532,533,534,538,539,540,541,546,547,548,559,570,571,586,587$ $588,589,591,592,747,753,754,755,1300,1310,1313,1314,1315,1316,1321,1337$ $1338,1341,1342,1347,1348,1349,1350,1351,1352$. DESCRIPCIÓ DE L'ÚS FETA PELS INFORMANTS. Per a amanir $(515,516,532,533,534,538,541,547,548,559,570,586$ $587,588,589,591,592,1321,1337,1338,1341,1342)$. Amanides, però a mi no m'agraden $587,588,589,591,592,1321,1337,1338,1341,1342)$. Amanides, però a mi no m'agraden
(747). Amanits $(539,540,546,753,754,755)$. Els agrada als isards $(539,540)$. Per a amanir, a les bèsties els agraden molt (571). Els he tastat però els trobo amargants i no en vaig buscar (1300). Es menja la planta amanida (1310). S'utilitza la part mascle de la plata, s'ha de pelar i per a amanir (1313). Se'ls mengen amanits (1314). Són bons amanits $(1315,1316)$ Per a amanir a la primavera $(1347,1348,1349)$. Per a menjar amanit $(1350,1351,1352)$. OBSERVACIONS. A nosaltres no ens agrada gens $(515,516)$. És al-lucinant $(539,540)$. DESTINACIÓ. Alimentació humana $(515,516,532,533,534,538,539,540,541,546,547$, $548,559,570,571,586,587,588,589,591,592,747,753,754,755,1300,1310,1313$, $1314,1315,1316,1321,1337,1338,1341,1342,1347,1348,1349,1350,1351,1352)$ Alimentació animal $(539,540)$.

\section{ALTRES OBSERVACIONS}

FONTS 570, 586, 587. DESCRIPCIÓ FETA PELS INFORMANTS. Més cap a Queralbs (570) Aquí no n'hi ha, cap a Tregurà si que se'n fan $(586,587)$.

\section{Monotropa hypopitys L. (pirolàcies)}

BCN 50020

\section{NOMS POPULARS}

Espàrrec bord (541)

Morus nigra L. (moràcies)

BCN 31289 


\section{NOMS POPULARS}

Móra (fruit) $(572,573)$

Morera $(572,573)$

\section{USOS ALIMENTARIS}

Fruit

Ingestió de la part de la planta crua - Fresca (sense preparació)

FONTS 572, 573. DESCRIPCIÓ DE L'ÚS FETA PELS INFORMANTS. Les móres d'arbre també són molt bones, a més alçada més bones són. DESTINACIÓ. Alimentació humana.

\section{Muscari comosum (L.) Mill. (liliàcies)}

BCN 27260

\section{NOMS POPULARS}

Calabruixes $(1353,1354)$

\section{ALTRES OBSERVACIONS}

FONTS 1353, 1354. DESCRIPCIÓ FETA PELS INFORMANTS. Són alls que surten al començament de la primavera.

\section{Myristica fragrans Houtt. (miristicàcies)}

BCN 50769

\section{NOMS POPULARS}

Nou moscada (llavor) $(524,553,588)$

\section{USOS ALIMENTARIS}

Llavor

Preparació de begudes - Beguda preparada amb aiguardent

FONTS 524, 553, 588. DESCRIPCIÓ DE L'ÚS FETA PELS INFORMANTS. Ratafia. Posa totes les herbes en aiguardent 21 dies a sol i serena. Es fa pels volts de Sant Joan. Sempre surt bona però no surt mai igual. Les herbes utilitzades son: nous verdes (Juglans regia), herba de Noè (Herniaria glabra), tarongina (Melissa officinalis), camamilla borda (Tanacetum parthenium), marialluïsa (Lippia triphylla), menta (Mentha spicata), salsufràgia (Peucedanum ostruthium), til.la (Tilia platyphyllos), nou moscada (Myristica fragrans) i clau (Syzygium aromaticum) (553). Ratafia. Abans si que n'havia fet, hi posava 14 o 15 herbes, no me'n recordo de totes. Nous verdes (Juglans regia), farigola (Thymus serpyllum), nou moscada (Myristica fragrans), marialluïsa (Lippia triphylla), menta (Mentha spicata), orenga (Origanum vulgare) i poniol (Satureja calamintha subsp. ascendens) (588). Amb les nous verdes, la mare feia alguna vegada ratafia. Recepta de ratafia: per un litre d'aiguardent hi posava tres nous (Juglans regia), una branca de canyella (Cinnamomum zeylanicum), una nou moscada (Myristica fragrans), tarongina (Melissa officinalis), algunes herbes més que no recordo, i tres cullerades de sucre. Deien que com més varietat d'herbes millor. Es posava amb una garrafa de vidre i es deixava a la finestra a sol i serena uns quants dies, no recordo quants. Es solia fer per Sant Pere (524). DESTINACIÓ. Alimentació humana $(524,553,588)$.

\section{Narcissus pseudonarcissus L. (amaril·lidàcies)}

\section{BCN 47849}

\section{NOMS POPULARS}

Puigestela $(520,521,569,570)$

\section{ALTRES USOS}

\section{Part aèria florida}

Ornamental: elaboració de rams

FONTS 569, 570. DESCRIPCIÓ DE L'ÚS FETA PELS INFORMANTS. La meva mare els deia aquest nom, ella era de Vallfogona. N'hi ha de grocs i de blancs i són bonics per a fer rams.

\section{ALTRES OBSERVACIONS}

FONTS 520, 521. DESCRIPCIÓ FETA PELS INFORMANTS. Són aquests narcisos de la muntanya.

\section{Nepeta cataria L. (labiades)}

BCN 24935

\section{NOMS POPULARS}

Herba gatera (1324)

Nepta $(504,505,506,529,530,531)$

\section{USOS MEDICINALS}

\section{Part aèria}

Antisèptic intern 
Apèndix 1. Catàleg de tàxons.

FONTS 529, 530, 531. DESCRIPCIÓ DE L'ÚS FETA PELS INFORMANTS. Per a infeccions de panxa. FORMA FARMACĖUTICA I ÚS. Tisana (ús intern). PREPARACIÓ. Decocció. DESTINACIÓ. Medicina humana.

Digestiu

FONT 504. DESCRIPCIÓ DE L'ÚS FETA PER L'INFORMANT. Com la marialluïsa, com a digestiva. FORMA FARMACĖUTICA I ÚS. Tisana (ús intern). PREPARACIÓ. Decocció. DESTINACIÓ. Medicina humana.

\section{USOS ALIMENTARIS}

\section{Part aèria}

Preparació de begudes - Beguda preparada amb licor

FONT 1324. DESCRIPCIÓ DE L'ÚS FETA PER L'INFORMANT. Per a fer ratafia. DESTINACIÓ Alimentació humana.

\section{ALTRES USOS}

\section{No consta}

Literatura oral popular: llegendes, gloses, contes, dites, refranys, poemes, cançons

FONTS 504, 505, 506. DESCRIPCIÓ DE L'ÚS FETA PELS INFORMANTS. La nepta tot el mal repta.

\section{Nicotiana tabacum L. (solanàcies)}

BCN 27239

\section{NOMS POPULARS}

Tabac (1210)

Tabaco (castellà) $(507,509,510,1325,1326)$

Tabaco (castellà) negre $(591,592)$

\section{USOS MEDICINALS}

\section{Fulla}

Antihelmíntic

FONTS 1325, 1326. DESCRIPCIÓ DE L'ÚS FETA PELS INFORMANTS. Matava els cucs. FORMA FARMACĖUTICA I ÚS. Cigarreta (ús intern). PREPARACIÓ. Les fulles, les feien assecar a l'ombra i després les trinxaven. El seu padrí feia servir el pelló de blat de moro tallat com si fos el paper de fumar i a dintre hi posava el "tabaco". DESTINACIO. Medicina humana.

Antipneumònic
FONT 1210. DESCRIPCIÓ DE L'ÚS FETA PER L'INFORMANT. Per a les pulmonies FORMA FARMACĖUTICA I ÚS. Emplastre (ús extern). PREPARACIÓ. Emplastres de les fulles de tabac bullides. DESTINACIÓ. Medicina humana.

Vulnerari

FONTS 507, 509, 510. DESCRIPCIÓ DE L'ÚS FETA PELS INFORMANTS. Per a les orelles dels conills que a vegades se'ls fan unes crostes. FORMA FARMACEUTICA I US. que se'ls unta. DESTINACIÓ. Medicina veterinària.

\section{ALTRES OBSERVACIONS}

FONTS 1325, 1326. DESCRIPCIÓ FETA PELS INFORMANTS. El "tabaco", el conreava a l'hort.

\section{BARREGES AMB AQUEST TÀXON}

Fulla

FONTS 591, 592. Entrevista 101 (vegeu catàleg de barreges)

\section{Ocimum basilicum L. (labiades)}

BCN 24936

\section{NOMS POPULARS}

Alfàbrega $(507,517,1293)$

Aufàbrega $(509,510,511,512,513,514,525,526,527,590)$

\section{USOS ALIMENTARIS}

Fulla

Condiment

FONT 1293. DESCRIPCIÓ DE L'ÚS FETA PER L'INFORMANT. Per a afegir als guisats. DESTINACIÓ. Alimentació humana.

\section{Part aèria}

Condiment

FONTS 507, 509, 510, 517, 525, 526, 527, 590. DESCRIPCIÓ DE L'ÚS FETA PELS INFORMANTS. Per a donar gust als cuinats $(507,509,510)$. Per a condimentar plats $(517)$. Per a cuinar $(525,526,527)$. Per a donar gust $(590)$. DESTINACIÓ. Alimentació humana $(507,509,510,517,525,526,527,590)$

\section{ALTRES USOS}




\section{Part aèria}

Lúdic: jocs i joguines

FONTS 507, 509, 510. DESCRIPCIÓ DE L'ÚS FETA PELS INFORMANTS. A les cases en plantaven en una galleda vella foradada i les noies en donaven un ramet als segadors per fer broma, significava que la noia es fixava en el noi que li donava.A les cases en plantaven en una galleda vella foradada i les noies en donaven un ramet als segadors per a fer broma, significava que la noia es fixava en el noi a qui li donava.

Repel·lents

FONTS 511, 512, 513, 514. DESCRIPCIÓ DE L'ÚS FETA PELS INFORMANTS. En poses un ram i espanta les mosques.

\section{ALTRES OBSERVACIONS}

FONT 590. DESCRIPCIÓ FETA PER L'INFORMANT. En tenim a l'hort, però se'ns mor a l'hivern.

\section{Olea europaea L. subsp. europaea (oleàcies)}

\section{BCN 24937}

\section{NOMS POPULARS}

Oli (producte elaborat) $(505,506,507,509,510,515,516,529,530,531,545,547,548,572$, $573,581,583,584,585,747,751,1361,1362)$

Oliva (fruit) $(525,526,527)$

Olivera $(507,509,510,518,519,520,521,528,529,530,531,536,537,564,569,570,574$, $575,576,577,590,746,1215,1298,1314,1315,1316,1325,1326,1330,1331,1336,1350$ $1351,1361,1362)$

\section{USOS MEDICINALS}

Fulla

Antihipertensiu

FONTS $507,509,510,518,519,520,521,528,529,530,531,536,537,569,570,574,575$ $576,577,590,746,1314,1315,1316,1330,1336,1350,1351,1361,1362$. DESCRIPCIO DE L'ÚS FETA PELS INFORMANTS. Per a fer baixar la pressió $(507,509,510,518,519$, $520,521,536,537,569,570,574,575,576,577,746,1314,1315,1316,1330,1336,1350$ $1351,1361,1362)$. Per a rebaixar la sang $(529,530,531,590)$. Fan baixar la pressió $(528)$ FORMA FARMACĖUTICA I ÚS. Tisana (ús intern). PREPARACIÓ. Decocció $(507,509,510$ $520,521,528,529,530,531,569,570,574,575,576,577,590,746,1314,1315,1316$ $1330,1350,1351,1361,1362)$. Decocció de les fullos $(518,519)$. Decocció. Aigua de
Antiprostatític

FONT 1298. DESCRIPCIÓ DE L'ÚS FETA PER L'INFORMANT. Va bé per a la pròstata FORMA FARMACĖUTICA I ÚS. Tisana (ús intern). PREPARACIÓ. Decocció. Aigua de les fulles. DESTINACIÓ. Medicina humana.

\section{Suc del fruit}

Analgèsic

FONT 747. DESCRIPCIÓ DE L'ÚS FETA PER L'INFORMANT. Per a treure el dolor de quan et fas un tall o una ferida. FORMA FARMACĖUTICA I ÚS. Essència (ús extern). PREPARACIÓ. Essència d'ús extern, se'n fan perfums d'oli i sucre DESTINACIÓ. Medicina humana.

Antifúngic

FONTS 507, 509, 510. DESCRIPCIÓ DE L'ÚS FETA PELS INFORMANTS. Per a curar els brians. FORMA FARMACĖUTICA I ÚS. Sense forma farmacèutica (ús directe, ús extern).

\section{Antihelmíntic}

FONTS 1361, 1362. DESCRIPCIÓ DE L'ÚS FETA PELS INFORMANTS. Per als cucs. FORMA FARMACĖUTICA I ÚS. Sense forma farmacèutica (ús directe, ús intern). MODE D'UTILITZACIO/POSOLOGIA. Una cullera d'oli en dejú. DESTINACIO. Medicina humana.

\section{Antiinflamatori intestina}

FONTS 515, 516. DESCRIPCIÓ DE L'ÚS FETA PELS INFORMANTS. Per al mal de ventre dels vedells. FORMA FARMACĖUTICA I ÚS. Suspensió (ús intern). PREPARACIÓ Oli amb anís. DESTINACIÓ. Medicina veterinària.

Antiotàlgic

FONTS 1361, 1362. DESCRIPCIÓ DE L'ÚS FETA PELS INFORMANTS. Oli calent, per al mal d'orelles. FORMA FARMACEUTICA I ÚS. Sense forma farmacèutica (ús directe, ús intern). DESTINACIÓ. Medicina humana.

Antipiròtic

FONT 747. DESCRIPCIÓ DE L'ÚS FETA PER L'INFORMANT. Va molt bé per a les cremades. FORMA FARMACĖUTICA I ÚS. Ungüent (ús extern). PREPARACIÓ. Oli ben barrejat en aigua fins que queda un ungüent. DESTINACIÓ. Medicina humana.

Antisèptic extern

FONTS 572, 573. DESCRIPCIÓ DE L'ÚS FETA PELS INFORMANTS. Per a ferides infectades FORMA FARMACEUUTICA I ÚS Embrocació (ús extern). PREPARACIÓ. Ol roent. DESTINACIO. Medicina humana.

Carminatiu

FONTS 547, 548. DESCRIPCIÓ DE L'ÚS FETA PELS INFORMANTS. Per a quan les vaques es botien. FORMA FARMACĖUTICA I ÚS. Tintura alcohòlica (ús intern). PREPARACIÓ. Es barrejava amb aiguardent. DESTINACIÓ. Medicina veterinària.

Laxant 
FONTS 505, 506. DESCRIPCIÓ DE L'ÚS FETA PELS INFORMANTS. Per als porcs quan estan malalts, els serveix de purga i els va molt bé. FORMA FARMACĖUTICA I ÚS. Solució col·loïdal (ús intern). PREPARACIÓ. Llet amb oli. DESTINACIÓ. Medicina veterinària.

Per a les punxades

FONT 751. DESCRIPCIÓ DE L'ÚS FETA PER L'INFORMANT. Per a calmar el mal de quan et punxes, per exemple amb un arç. FORMA FARMACĖUTICA I ÚS. Fumigació (ús extern). PREPARACIÓ. Agafes una brasa del foc, hi tires oli i et perfumes el mal amb el fum que fa. DESTINACIÓ. Medicina humana.

Per a trastorns de la pell o del teixit subcutan

FONTS 1350, 1351. DESCRIPCIÓ DE L'ÚS FETA PELS INFORMANTS. Per a les taques de la pell que surten quan et fas gran. FORMA FARMACĖUTICA I ÚS. Suspensió (ús extern). PREPARACIÓ. Es fa bullir neu primavera amb oli. DESTINACIÓ. Medicina humana.

Purgant

FONT 747. DESCRIPCIÓ DE L'ÚS FETA PER L'INFORMANT. Va bé per a purgar. FORMA FARMACĖUTICA I ÚS. Sense forma farmacèutica (ús directe, ús intern). MODE D'UTILITZACIÓ/POSOLOGIA. Una cullerada d'oli en dejú. DESTINACIÓ. Medicina humana. Vulnerari

FONTS 529, 530, 531. DESCRIPCIÓ DE L'ÚS FETA PELS INFORMANTS. Per a les ferides els talls. FORMA FARMACĖUTICA I ÚS. Fumigació (ús extern). PREPARACIÓ. Perfums d'oli al foc a terra. DESTINACIÓ Medicina humana.

\section{USOS ALIMENTARIS}

\section{Suc del fruit}

No consta el tipus d'ingesta - No consta el mode de preparació

FONTS 525, 526, 527. DESCRIPCIÓ DE L'ÚS FETA PELS INFORMANTS. L'oli d'oliva abans te'l feien estalviar molt i te'n posaven un rajolí [dit "rajoliu"] molt curt el temps de dir "tiro-liro" ja el tornaven a tenir endreçat a l'armari, ara quan amaneixo n'hi tiro un bon raig DESTINACIÓ. Alimentació humana.

\section{ALTRES USOS}

\section{Cendra}

Domèstic: ajudes a la llar

FONT 1215. DESCRIPCIÓ DE L'ÚS FETA PER L'INFORMANT. Per a fer lleixiu. Es feien bullir les cendres blanques d'alzina, arç blanc o fins i tot olivera i aquesta aigua es colava mantinguda calenta s'anava abocant en un cossi ple de roba que duia un forat el fons per on s'anava escolant l'aigua més freda del fons. Per a evitar impureses es posava un llençol de fil al damunt de la roba.

Suc del fruit

Cosmètic
FONTS 515, 516. DESCRIPCIÓ DE L'ÚS FETA PELS INFORMANTS. Oli ben deixatat amb aigua per a untar-te les mans i els llavis quan els tens tallats.

\section{ALTRES OBSERVACIONS}

FONTS 528, 564, 1298. DESCRIPCIÓ FETA PELS INFORMANTS. Aquí no n'hi ha, però la duiem de per avall (528). Abans n'hi havia algunes, el fred del 1956 les va matar (564). E seu pare les anava a buscar a Bianya (1298).

\section{BARREGES AMB AQUEST TÀXON}

Fulla

FONTS 1325, 1326. Entrevista 13, barreja II (vegeu catàleg de barreges)

FONT 1331. Entrevista 30, barreja III (vegeu catàleg de barreges)

FONTS 748, 749. Entrevista 49 (vegeu catàleg de barreges)

\section{Suc del fruit}

FONTS 1361, 1362. Entrevista 29, barreja II (vegeu catàleg de barreges)

FONTS 1361, 1362. Entrevista 29, barreja III (vegeu catàleg de barreges)

FONTS 505, 506. Entrevista 47, barreja I (vegeu catàleg de barreges)

FONT 545. Entrevista 72, barreja II (vegeu catàleg de barreges)

FONT 581. Entrevista 94, barreja II (vegeu catàleg de barreges)

FONTS 583, 584, 585. Entrevista 96, barreja III (vegeu catàleg de barreges)

\section{Onobrychis viciifolia Scop. (papilionàcies)}

\section{BCN 27245}

\section{NOMS POPULARS}

Trepadella $(560,561,562,563,571,582,583,584,585,586,587)$

Trepadella borda $(564,571)$

Veça $(565,566,567,569,570,572,573,580,583,584,585,1315,1316)$

\section{USOS ALIMENTARIS}

\section{Part aèria}

Ingestió de la part de la planta crua - Conservada dessecada a l'aire

FONTS 560, 561, 562, 563, 564, 565, 566, 567, 569, 570, 571, 580, 583, 584, 585, 1315 1316. DESCRIPCIÓ DE L'ÚS FETA PELS INFORMANTS. Per als conills i les ovelles (571).
Per als conills $(564,565,566,567)$. Es donava als conills $(561,562,563)$. Per a donar al bestiar (conills, vaques, cavalls) $(560)$. Es fa com a farratge $(569,570)$. Per al bestiar $(580$ 
$583,584,585)$. En donàvem al bestiar com a farratge $(1315,1316)$. DESTINACIÓ Alimentació animal $(560,561,562,563,564,565,566,567,569,570,571,580,583,584$ $585,1315,1316)$.

Ingestió de la part de la planta crua - Fresca (sense preparació)

FONTS 572, 573, 582, 586, 587. DESCRIPCIÓ DE L'ÚS FETA PELS INFORMANTS. S'ho menja el bestiar (582). Se la menja el bestiar $(572,573)$. La de mata petita, la pasturen les ovelles, si se'n fan un fart els fa mal $(586,587)$. DESTINACIÓ. Alimentació animal $(572,573$, $582,586,587)$.

\section{Ononis spinosa L. (papilionàcies)}

BCN 123786

\section{NOMS POPULARS}

Gaó $(541,553,569,570,583,584,585)$

\section{USOS MEDICINALS}

\section{Part aèria florida}

Antireumàtic

FONT 553. DESCRIPCIÓ DE L'ÚS FETA PER L'INFORMANT. Aigua per al reuma i el dolor. FORMA FARMACĖUTICA I ÚS. Tisana (ús intern). PREPARACIÓ. Decocció. MODE D'UTILITZACIÓ/POSOLOGIA. S'han de fer novenes. DESTINACIÓ. Medicina humana.

\section{ACCIONS NOCIVES O TÒXIQUES}

No consta

FONTS 569, 570. DESCRIPCIÓ DE L'ACCIÓ NOCIVA O TÒXICA FETA PELS INFORMANTS. Les punxades són molt dolentes.

\section{Opuntia maxima A.Berger (cactàcies)}

BCN 46078

\section{NOMS POPULARS}

Figa (fruit) (564)

Figuera de moro (564)

\section{USOS ALIMENTARIS}

Fruit
Ingestió de la part de la planta crua - Fresca (sense preparació)

FONT 564. DESCRIPCIÓ DE L'ÚS FETA PER L'INFORMANT. Les figues es mengen, però no en fan gaires. DESTINACIÓ. Alimentació humana.

\section{Origanum majorana L. (labiades)}

BCN 24938

\section{NOMS POPULARS}

Marduix $(505,506,517,522,523,529,530,531,746,1210,1215,1293,1301,1353,1354)$

\section{USOS MEDICINALS}

Fulla

Antibronquític

FONT 1210. DESCRIPCIÓ DE L'ÚS FETA PER L'INFORMANT. Aquest oli s'unta al pit i va be per a les bronquitis. FORMA FARMACEUTICA I US. Embrocació (ús extern). PREPARACIÓ. Les fulles seques s'estoven al vapor del bany maria i es bullen en oli i sagí. DESTINACIO. Medicina humana.

\section{Part aèria florida}

Antiotàlgic

FONTS $505,506,517,522,523,529,530,531,746,1293,1301,1353,1354$. DESCRIPCIÓ DE L'ÚS FETA PELS INFORMANTS. Per al mal d'orelles $(505,506,517,522,523,529,530$ $531,746,1293)$. Per al mal d'orelles (1301). La meva iaia en feia un oli per a les orelles
$(1353,1354)$. FORMA FARMACÉUTICA I ÚS. Embrocació (ús extern) $(505,506,517,522$, $523,746,1293,1301,1353,1354)$. Liniment (ús extern) $(529,530,531)$. PREPARACIÓ. Es $523,746,1293,1301,1353,1354)$. Liniment (ús extern) $(529,530,531)$. PREPARACIO. Es
posava en oli $(517,746)$. Bullit en oli $(505,506,529,530,531,1293,1301)$. En oli $(522,523)$. posava en oli $(517,746)$. Bullit en
DESTINACIÓ. Medicina humana.

\section{ALTRES USOS}

\section{Planta sencera}

Literatura oral popular: llegendes, gloses, contes, dites, refranys, poemes, cançons FONT 1215. DESCRIPCIÓ DE L'ÚS FETA PER L'INFORMANT. Al marduix l'amor li fuig

Origanum vulgare L. (labiades)

BCN 24939

NOMS POPULARS 
Orenga $(507,509,510,511,512,513,514,515,516,520,521,522,523,525,526,527,529$, $530,531,538,541,546,553,556,557,561,562,563,568,569,570,574,575,576,577$, $580,583,584,585,586,587,588,590,591,592,746,1294,1299,1313,1314,1317,1319$ $1321,1327,1331,1335,1337,1338,1339,1340,1341,1342,1343,1344,1350,1351,1352$ $1361,1362)$

\section{USOS MEDICINALS}

\section{No consta}

Desconegut per l'informant

FONTS 556, 557. DESCRIPCIÓ DE L'ÚS FETA PELS INFORMANTS. És medicinal. FORMA FARMACĖUTICA I ÚS. Desconegut per l'informant. DESTINACIÓ. Medicina humana.

\section{Part aèria florida}

Anticatarral

FONTS 529, 530, 531, 1299. DESCRIPCIÓ DE L'ÚS FETA PELS INFORMANTS. L'aigua és bona per als constipats $(529,530,531)$. Va bé per als constipats (1299). FORMA FARMACĖUTICA I ÚS. Tisana (ús intern). PREPARACIÓ. Decocció $(529,530,531)$. DESTINACIÓ. Medicina humana.

Antiinflamatori faringi

FONT 1327. DESCRIPCIÓ DE L'ÚS FETA PER L'INFORMANT. Per al mal de coll. FORMA FARMACĖUTICA I ÚS. Tisana (ús intern). PREPARACIÓ. En infusió. DESTINACIÓ. Medicina humana.

Antipneumònic

FONTS 1339, 1340. DESCRIPCIÓ DE L'ÚS FETA PELS INFORMANTS. Va bé per als pulmons. FORMA FARMACĖUTICA I ÚS. Tisana (ús intern). PREPARACIÓ. Decocció. DESTINACIO. Medicina humana.

Digestiu

FONTS 746, 1361, 1362. DESCRIPCIÓ DE L'ÚS FETA PELS INFORMANTS. És digestiva $(746,1361,1362)$. FORMA FARMACĖUTICA I ÚS. Tisana (ús intern). PREPARACIÓ. Decocció $(746)$. En infusió $(1361,1362)$. DESTINACIÓ. Medicina humana.

Vulnerari

FONTS 1341, 1342. DESCRIPCIÓ DE L'ÚS FETA PELS INFORMANTS. Per a ferides i talls. FORMA FARMACĖUTICA I ÚS. Embrocació (ús extern). PREPARACIÓ. Confitat en oli. DESTINACIÓ. Medicina humana.

\section{USOS ALIMENTARIS}

\section{Part aèria florida}

Condiment

FONTS $507,509,510,511,512,513,514,515,516,522,523,525,526,527,529,530,531$ $538,541,546,553,556,557,561,562,563,568,569,570,574,575,576,577,580,583$
$584,585,586,587,588,590,591,592,746,1294,1299,1313,1314,1317,1319,1321$, $1327,1331,1335,1337,1338,1350,1351,1352$. DESCRIPCIÓ DE L'ÚS FETA PELS INFORMANTS. Per a posar als cuinats. Nosaltres fem molta caça i sempre n'hi posem (591, 592). Per a guisar $(522,523,746)$. Per a donar gust als cuinats $(507,509,510,515,516$, $1294,1299,1337,1338)$. Per a cuinar $(511,512,513,514,561,562,563,586,587,1350$, $1294,1299,1337,1338)$. Per a cuinar $(511,512,513,514,561,562,563,586,587,1350$,
$1351)$. Per a guisar, per a fer el conill $(529,530,531)$. Per als guisats $(538,568)$. Per a posar $1351)$. Per a guisar, per a fer el conill $(529,530,531)$. Per als guisats $(538,568)$. Per a posar
als estofats $(546,574,575,576,577)$. A casa n'hi havia sempre, per a cuinar $(541)$. Per a posar als cuinats. Macerar vuit o deu dies orenga amb alls i oli, és boníssim per a amanir el pa $(553)$. Per a fer estofats $(556,557)$. És la reina per a cuinar $(569,570)$. Per a posar als guisats (580). Per a posar als cuinats (588). Romaní (Rosmarinus officinalis), llorer (Laurus nobilis), farigola (Thymus vulgaris) i orenga (Origanum vulgare). Piquem les herbes juntes i ho fem servir per a fer guisats (590). Per a donar gust al menjar $(583,584,585)$. Per a condimentar plats (1313). Per a donar gust $(1314,1317,1321,1331)$. Per a donar gust als guisats (1319). Per a donar gust als rostits (1327). Per a guisar caragols (1335). La meva padrina l'usava per a cuinar (1352). OBSERVACIONS. Els seus menjars eren molt especiats i molt bons (1352). DESTINACIÓ. Alimentació humana $(507,509,510,511,512,513,514$ i molt bons (1352). DESTNACI. Almentacio humana $(507,509,510,511,512,513,514$ $515,516,522,523,525,526,527,529,530,531,538,541,546,553,556,557,561,562$, $563,568,569,570,574,575,576,577,580,583,584,585,586,587,588,590,591,592$ $746,1294,1299,1313,1314,1317,1319,1321,1327,1331,1335,1337,1338,1350,1351$ 1352).

Preparació de begudes - Beguda preparada amb aiguardent

FONT 588. DESCRIPCIÓ DE L'ÚS FETA PER L'INFORMANT. Ratafia. Abans sí que n'havia fet, hi posava 14 o 15 herbes, no me'n recordo de totes. Nous verdes (Juglans regia), farigola (Thymus serpyllum), nou muscada (Myristica fragrans), marialluïsa (Lippia triphylla), menta (Mentha spicata), orenga (Origanum vulgare) i poniol (Satureja calamintha subsp. ascendens). DESTINACIÓ. Alimentació humana.

\section{ALTRES USOS}

\section{Part aèria}

Maneig agrosilvopastoral: obtenció de mel

FONTS 1343, 1344. DESCRIPCIÓ DE L'ÚS FETA PELS INFORMANTS. S'usava per a fer entrar les abelles als eixams.

\section{Part aèria florida}

Altres informacions

FONTS 525, 526, 527, 591, 592. DESCRIPCIÓ DE L'ÚS FETA PELS INFORMANTS. Abans la veníem, deu ser bona per medicina $(591,592)$. La compraven els herbolaris $(525,526$, 527).

Repel·lents

FONTS 520, 521. DESCRIPCIÓ DE L'ÚS FETA PELS INFORMANTS. Si poses rams d'orenga al rebost, no es posen les arnes als embotits.

\section{Planta sencera}


Apèndix 1. Catàleg de tàxons.

Literatura oral popular: llegendes, gloses, contes, dites, refranys, poemes, cançons

FONTS 1361, 1362. DESCRIPCIÓ DE L'ÚS FETA PELS INFORMANTS. Abans deien "I'orenga que tot el mal trenca".

\section{Ornithogalum umbellatum L. (liliàcies)}

BCN 27252

\section{NOMS POPULARS}

All bord $(1353,1354)$

All de bruixa $(547,548)$

\section{ALTRES OBSERVACIONS}

FONTS $547,548,1353,1354$. DESCRIPCIÓ FETA PELS INFORMANTS. Fan pudor (547, $548)$. Floreixen al maig i surten a l'hort, fa un all $(1353,1354)$.

\section{Oryza sativa L. (gramínies)}

BCN-Etno 16

\section{NOMS POPULARS}

Arròs $(505,506,1324,1330,1353,1354,1352)$

\section{USOS MEDICINALS}

Llavor

Antidiarreic

FONTS 505, 506, 1353, 1354. DESCRIPCIÓ DE L'ÚS FETA PELS INFORMANTS. Per a la diarrea dels vedells $(505,506)$. És antidiarreic $(1353,1354)$. FORMA FARMACĖUTICA I ÚS Suspensió (ús intern) $(505,506)$. Decocció (ús intern) $(1353,1354)$. PREPARACIÓ. Arròs bullit amb pa $(505,506)$. DESTINACIÓ. Medicina veterinària $(505,506)$. Medicina humana $(1353,1354)$

\section{BARREGES AMB AQUEST TÀXON}

Llavor

FONT 1330. Entrevista 32, barreja I (vegeu catàleg de barreges)

FONT 1352. Entrevista 41 (vegeu catàleg de barreges)

FONT 1324. Entrevista 5, barreja I (vegeu catàleg de barreges)

\section{Oxalis acetosella L. (oxalidàcies)}

BCN 28498

\section{NOMS POPULARS}

Cacauets $(586,587)$

\section{ALTRES OBSERVACIONS}

FONTS 586, 587. DESCRIPCIÓ FETA PELS INFORMANTS. És una plaga dels horts, es va escampant.

\section{Papaver rhoeas L. (papaveràcies)}

BCN 24940

\section{NOMS POPULARS}

Cascall (1335)

Gall (564)

Gallaret $(529,530,531,560,561,562,563,564,569,570,574,575,576,577,1297,1352)$ Rosella $(503,507,509,510,539,540,547,548,553,565,566,567,590,591,592,1215$ $1313,1347,1348,1349)$

Rosella de camp $(518,519,1337,1338)$

\section{USOS MEDICINALS}

\section{Flor}

Antiartrític

FONTS 1347, 1348, 1349. DESCRIPCIÓ DE L'ÚS FETA PELS INFORMANTS. Per a l'artrosi (1348). Per a l'artritis $(1347,1349)$. FORMA FARMACEUTICA I US, Liniment (ús extern). PREPARACIÓ. Posar en oli les roselles $(1347,1348,1349)$. DESTINACIÓ. Medicina humana.

Antiinflamatori faringi

FONTS 529, 530, 531, 1297, 1347, 1348, 1349. DESCRIPCIÓ DE L'ÚS FETA PELS INFORMANTS. Per al mal de coll $(529,530,531,1347,1349)$. Es feia servir per al mal de coll. S'untava un drap i es posava al coll (1297). Va bé per al mal de coll (1348). FORMA FARMACEUUTICA I ÚS. Tisana (ús intern) $(529,530,531)$. Embrocació (ús extern) (1297, $1347,1348,1349)$. PREPARACIÓ. Decocció en aigua $(529,530,531)$. La flor posada en oli (1297). Posar en oli les roselles. Es posa l'oli a sobre un drap i s'aplica directament al coll, 
llavors es tapa amb una bufanda ben calenta $(1347,1348,1349)$. DESTINACIÓ. Medicina humana.

Antiotàlgic

FONT 1215. DESCRIPCIÓ DE L'ÚS FETA PER L'INFORMANT. Per a quan tenien mal d'orella se'ls en tirava una gota. FORMA FARMACĖUTICA I ÚS. Gotes (ús intern). PREPARACIÓ. Rosella en oli. DESTINACIÓ. Medicina humana.

Vulnerari

FONTS 591, 592. DESCRIPCIÓ DE L'ÚS FETA PELS INFORMANTS. Va bé per als talls. FORMA FARMACĖUTICA I ÚS. Embrocació (ús extern). PREPARACIÓ. La flor es posa en oli. DESTINACIÓ. Medicina humana. OBSERVACIONS. La fèiem servir molt per als segadors a l'estiu que a vegades es tallaven.

Fruit

Sedant

FONT 1335. DESCRIPCIÓ DE L'ÚS FETA PER L'INFORMANT. Una seva tia en va fer aigua per a una criatura i llavors no la podien despertar. FORMA FARMACĖUTICA I ÚS. Tisana (ús intern). PREPARACIÓ. Es fa una infusió de la pellofa de la càpsula. DESTINACIÓ. Medicina humana. OBSERVACIONS. Recorda que una vegada unes oques es van atipar de cascalls van quedar ben adormides.

\section{No consta}

Antipirètic

FONT 553. DESCRIPCIÓ DE L'ÚS FETA PER L'INFORMANT. Per a fer suar. FORMA FARMACĖUTICA I ÚS. Tisana (ús intern). PREPARACIÓ. Decocció. DESTINACIÓ. Medicina humana.

Desconegut per l'informant

FONTS 574, 575, 576, 577. FORMA FARMACĖUTICA I ÚS. Desconegut per l'informant. DESTINACIÓ. Medicina humana. OBSERVACIONS. Per medicina, no recordo l'ús.

\section{USOS ALIMENTARIS}

Fulla

Ingestió de la part de la planta crua - Fresca (sense preparació)

FONTS 503, 507, 509, 510, 518, 519, 528, 539, 540, 547, 548, 565, 566, 567, 590, 1313 $1337,1338,1347,1348,1349$. DESCRIPCIÓ DE L'ÚS FETA PELS INFORMANTS. Quan són tendres són molt bones amanides $(503,528,539,540,547,548,567,590,1313)$. Abans s'amania $(507,509,510)$. Per a menjar amanides $(518,519)$. Quan és tendra, es donava als conills (528). Per als conills $(565,566)$. Quan són tendres es menjaven amanides (1337, 1338). Quan son tendres, s'amaneixen (1347, 1348, 1349). DESTINACIO. Alimentació humana $(503,507,509,510,518,519,528,539,540,547,548,567,590,1313,1337,1338$ $1347,1348,1349)$. Alimentació animal $(528,565,566)$

\section{ALTRES USOS}

\section{Flor}

Creences i pràctiques magicoreligioses

FONTS 564, 1352. DESCRIPCIÓ DE L'ÚS FETA PELS INFORMANTS. Per a fer les catifes [dit "alfombres"] de Corpus (564). Per a les catifes de Corpus (1352).

Lúdic: jocs i joguines

FONT 1352. DESCRIPCIÓ DE L'ÚS FETA PER L'INFORMANT. Per a jugar a gall, gallina o polla. Quan la flor és tancada primer és blanca (polla), després és rosa (gallina) i després és vermella (gall).

Ornamental: elaboració de rams

FONTS 569, 570.

\section{ACCIONS NOCIVES O TÒXIQUES}

Fruit

FONT 528. DESCRIPCIÓ DE L'ACCIÓ NOCIVA O TÒXICA FETA PER L'INFORMANT. EI rovell, de quan és seca, et fa mal de cap. Si el toques amb les mans, et queden grogues. VIA D'INTOXICACIÓ. Via externa.

\section{No consta}

FONTS 528, 561, 562, 563. DESCRIPCIÓ DE L'ACCIÓ NOCIVA O TÒXICA FETA PELS INFORMANTS. Quan han florit, aquella pols que fan és tòxica. Quan anàvem a segar ens feien molta caparra (528). Són tòxics. Aquella capsa que fan és tòxica $(561,562,563)$.

\section{ALTRES OBSERVACIONS}

FONT 560. DESCRIPCIÓ FETA PER L'INFORMANT. Es feien al mig del blat.

\section{BARREGES AMB AQUEST TÀXON}

\section{No consta}

FONTS 529, 530, 531. Entrevista 53, barreja IV (vegeu catàleg de barreges)

\section{Papaver somniferum L. (papaveràcies)}

BCN 24941

\section{NOMS POPULARS}

Adormidera (560)

Cascall $(503,520,521,561,562,563,581,588,748,749,1298,1339,1340)$ 
Fruit

Antiodontàlgic

FONT 581. DESCRIPCIÓ DE L'ÚS FETA PER L'INFORMANT. Per al mal de queixals. FORMA FARMACĖUTICA I ÚS. Sense forma farmacèutica (ús directe, ús extern). PREPARACIÓ. Es posava una capsa de cascall sota el coixí. DESTINACIÓ. Medicina

humana.

Hipnòtic

FONTS 503, 1339, 1340. DESCRIPCIÓ DE L'ÚS FETA PELS INFORMANTS. Una vegada la meva germana i jo ens vam quedar encarregades de vigilar el germà petit, en Pere i com que plorava molt li vam fer aigua de la càpsula de cascalls i quan va arribar la mare dormia com un parrac $(503)$. Va bé per a dormir $(1339,1340)$. FORMA FARMACĖUTICA I ÚS. Tisana (ús intern). PREPARACIÓ. Decocció $(503,1339,1340)$. MODE D'UTILITZACIÓ/POSOLOGIA. Una tassa d'aigua (503). DESTINACIÓ. Medicina humana.

Llavor

Antiodontàlgic

FONTS 520, 521, 581, 588, 748, 749. DESCRIPCIÓ DE L'ÚS FETA PELS INFORMANTS Te la poses al queixal $(748,749)$. Per al mal de queixals, és una droga $i$ els queixals s'adormen $(520,521)$. Per al mal de queixals $(581,588)$. FORMA FARMACEUTICA I ÚS Sense forma farmacèutica (ús directe, ús extern) $(748,749)$. Col-lutori (ús extern) $(520,521$ 581). Tisana (ús intern) (588). PREPARACIÓ. La grana picada amb un morter queda com una pasta $(748,749)$. Decocció. S'ha de glopejar $(520,521)$. Decocció i glopejar l'aigua (581). Infusió (588). DESTINACIO. Medicina humana.

Coadjuvant del part

FONT 560. DESCRIPCIÓ DE L'ÚS FETA PER L'INFORMANT. Es feia servir quan a una bèstia li costava tenir la cria; li donaven aigua d'adormidera perquè no patís tant. FORMA FARMACĖUTICA I ÚS. Tisana (ús intern). PREPARACIÓ. Decocció. DESTINACIÓ. Medicina humana.

\section{No consta}

Desconegut per l'informant

FONT 1298. FORMA FARMACĖUTICA I ÚS. Desconegut per l'informant. OBSERVACIONS. Diu que és droga i no l'usa per a res.

\section{ALTRES USOS}

\section{Planta viva ex situ}

Ornamental: jardineria

FONT 1298. DESCRIPCIÓ DE L'ÚS FETA PER L'INFORMANT. En té de plantats al jardí per a fer bonic.

\section{ALTRES OBSERVACIONS}

FONT 560. DESCRIPCIÓ FETA PER L'INFORMANT. N'hi havia a totes les cases de pagès.

\section{Paradisea Iiliastrum (L.) Bertol. (liliàcies)}

BCN 27270

\section{NOMS POPULARS}

Lliri blanc $(559,1321)$

\section{USOS MEDICINALS}

No consta

Desconegut per l'informant

FONT 1321. FORMA FARMACĖUTICA I ÚS. Macerat en oli (ús extern). PREPARACIÓ. Es posava en oli. DESTINACIÓ. Medicina humana. OBSERVACIONS. No recorda per què s'utilitzava.

\section{ALTRES USOS}

\section{Part aèria florida}

Ornamental: elaboració de rams

FONT 559. DESCRIPCIÓ DE L'ÚS FETA PER L'INFORMANT. Per a fer rams.

\section{Parietaria officinalis L. subsp. judaica (L.) Béguinot} (urticàcies)

BCN 24942

\section{NOMS POPULARS}

Blet $(507,509,510,520,521,525,526,527,547,548,560,564,582,590,746,1293,1296$ $1297,1300,1301,1310,1313,1314,1317,1318,1319,1325,1326,1327,1330,1336,1347$ $1348,1349,1350,1351,1353,1354,1361,1362)$

Blet de paret $(528,553,569,570,580,591,592,1324)$

Morella $(511,512,513,514,522,523,529,530,531,546,547,548,554,555,556,557,558$, $572,573,583,584,585,748,749,1213,1214)$

Morella roquera $(556,557)$

Morera roquera $(746)$

Parietària $(539,540)$ 


\section{USOS MEDICINALS}

\section{Part aèria}

Antihemorroïdal

FONTS $547,548,1353,1354$. DESCRIPCIÓ DE L'ÚS FETA PELS INFORMANTS. Per a les morenes $(547,548,1353,1354)$. FORMA FARMACĖUTICA I ÚS. Bany (ús extern). PREPARACIÓ. Decocció. Es feien banys de seient [dit "asiento"] $(547,548)$. Es feien banys de seient [dit "asiento"] $(1353,1354)$. DESTINACIÓ. Medicina humana.

Antiinflamatori

FONTS 554, 555, 556, 557. DESCRIPCIÓ DE L'ÚS FETA PELS INFORMANTS. Per a les inflamacions $(556,557)$. El meu home es va empassar una espina i se li va inflar el coll (554 555). FORMA FARMACĖUTICA I ÚS. Tisana (ús intern) (556, 557). Emplastre (ús extern) $(554,555)$. PREPARACIÓ. Decocció $(556,557)$. Per a fer emplastres. Vam anar a buscar la Roseta, que era una medecinera, primer li va senyar i li va dir una oració, va agafar greix i oll i el va fondre a la pala del foc a terra fins que va quedar ben roent, llavors hi va tirar les morelles que amb l'escalfor ja van quedar cuites i va fer l'emplastre, de seguida va reposa $(554,555)$. MODE D'UTILITZACIÓ/POSOLOGIA. Repetir el ritual vàries vegades, cada tres hores $(554,555)$. DESTINACIO. Medicina humana.

Antiinflamatori intestinal

FONTS 580, 1313. DESCRIPCIÓ DE L'ÚS FETA PELS INFORMANTS. Es donava per al ma de ventre de les truges $\mathrm{i}$ dels porcs (580). Per al mal de ventre (1313). FORMA FARMACĖUTICA I ÚS. Tisana (ús intern) (580). Emplastre (ús extern) (1313) PREPARACIÓ. Decocció (580). En emplastre. Es pica la planta i es posa en dobles de draps (1313). DESTINACIÓ. Medicina veterinària (580). Medicina humana (1313).

Antisèptic intern

FONTS 520, 521. DESCRIPCIÓ DE L'ÚS FETA PELS INFORMANTS. Aigües per a desinfectar i també per a donar lavatives a les truges i a les vaques que han parit $(520,521)$ És desinfectant i neteja $(520,521)$. FORMA FARMACĖUTICA I ÚS. Tisana (ús intern) (520 (520,521). Decocció Aigua per beure $(520)$. Es donava en lavatives $(520,521)$. DESTINACIO. Medicina veterinària $(520$ 521). Medicina humana $(520,521)$

Coadjuvant del part

FONT 558. DESCRIPCIÓ DE L'ÚS FETA PER L'INFORMANT. Aigua de morelles quan les vaques no podien vedellar. FORMA FARMACĖUTICA I ÚS. Tisana (ús intern). PREPARACIÓ. Decocció. Feia una aigua molt fina. DESTINACIÓ. Medicina veterinària.

Coadjuvant del postpart

FONTS $507,509,510,511,512,513,514,520,521,522,523,528,529,530,531,572,573$ $590,591,592,748,749,1296,1301,1310,1324,1325,1326,1336$. DESCRIPCIÓ DE L'ÚS FETA PELS INFORMANTS. Per a refrescar quan les truges havien godallat $(507,509,510)$ Per a quan les truges han parit, per a netejar-les $(511,512,513,514)$. Per a les truges quan havien godallat, serveix per a desinfectar $(748,749)$. Per a donar lavatives a les truges quan havien godallat, serveix per a desinfectar $(748,749)$. Per a donar lavatives a les truges quan
godallaven (es fan a les parets i s'enganxa) $(529,530,531)$. Per a les truges quan havien godallat $(522,523)$. Aigües per a desinfectar i també per a donar lavatives a les truges i a les vaques que han parit $(520,521)$. A les truges quan godallaven se'ls donava aigua de blets (528). Es posava par (520, 521 ). A les truges quar (528). Es posava en el abeurall de les truges quan havien godallat (590). Per a les truges quan havien parit, se'ls afegla al abeurall $(572,573)$. Se'ls donava a les truges quan havien parit $(591,592)$. Es donava al bestiar sobretot quan havia parit per a ajudar a netejar (1296) Per a les truges quan godallaven (1301). Se'n donava a les truges quan havien godallat (1310). Quan les truges godallaven, se'ls feia aigua de blets per a refrescar-les i netejar-les (1324). Quan godallaven les truges, per així refrescar-les i netejar-les $(1325,1326)$. Se'ls feia aigua al bestiar quan havien parit (1336). FORMA FARMACĖUTICA I ÚS. Bany (ús extern) $(507,509,510,590)$. Tisana (ús intern) $(511,512,513,514,520,521,522,523,528,572$ $573,591,592,748,749,1296,1301,1310,1324,1336)$. Ėnema (ús intern) $(529,530,531)$ Suspensió (ús intern) $(1325,1326)$. PREPARACIÓ. Decocció $(507,509,510,520,521,522$, $523,528,529,530,531,572,573,590,748,749,1301,1310,1324,1336)$. Aigua $(511,512$ $513,514)$. Decocció. Se'ls feia com una sopa de pa i se'ls barrejava un grapat de blets ( 591 592). Decocció. Es feia bullir l'aigua amb els blets (1296). Se'ls feia una sopa amb pa, blets un raig d'oli $(1325,1326)$. MODE D'UTILITZACIÓ/POSOLOGIA Un parell de dies (1325, un ra). DESTINACIÓ. Medina veteriaria (507,509,510,511, 512,513,514,520, 521,528, 1326). DESTINACIO. , 1336). Medicina humana $(522,523,590,591,592)$.

Desconegut per l'informant

FONTS 525, 526, 527. DESCRIPCIÓ DE L'ÚS FETA PELS INFORMANTS. Aigua per al bestiar. FORMA FARMACĖUTICA I ÚS. Tisana (ús intern). DESTINACIÓ. Medicina veterinària.

Digestiu

FONTS 1213,1214 . DESCRIPCIÓ DE L'ÚS FETA PELS INFORMANTS. Es donava quan els conills estaven empatxats. FORMA FARMACĖUTICA I ÚS. Tisana (ús intern). PREPARACIÓ. Decocció. DESTINACIÓ. Medicina veterinària.

Diürètic

FONTS 539, 540,1361, 1362. DESCRIPCIÓ DE L'ÚS FETA PELS INFORMANTS. Per a fer orinar $(539,540)$. Per a orinar $(1361,1362)$. FORMA FARMACĖUTICA I ÚS. Tisana (ús intern). PREPARACIÓ. Decocció $(539,540)$. En infusió $(1361,1362)$. DESTINACIÓ. Medicina humana. OBSERVACIONS. Me la va ensenyar un marista quan jo era jove (539, 540)

Laxant

FONT 553. DESCRIPCIÓ DE L'ÚS FETA PER L'INFORMANT. És laxant. FORMA FARMACĖUTICA I ÚS. Tisana (ús intern). PREPARACIÓ. Decocció. DESTINACIÓ. Medicina humana.

Litotríptic renal

FONTS 554, 555, 1330. DESCRIPCIÓ DE L'ÚS FETA PELS INFORMANTS. Fan fondre les pedres dels ronyons $(554,555)$. Per a trencar les pedres del ronyó (1330). FORMA FARMACĖUTICA I ÚS. Tisana (ús intern). PREPARACIÓ. Decocció $(554,555,1330)$. DESTINACIÓ. Medicina humana. 


\section{Purgant}

FONT 1319. DESCRIPCIÓ DE L'ÚS FETA PER L'INFORMANT. Per a purgar. FORMA FARMACĖUTICA I ÚS. Tisana (ús intern). Ėnema (ús intern). PREPARACIÓ. Decocció.Ferne lavatives. DESTINACIÓ. Medicina humana. Medicina veterinària.

Restauratiu

FONT 1336. DESCRIPCIÓ DE L'ÚS FETA PER L'INFORMANT. Se'ls feia aigua al bestiar, quan estava malalt. FORMA FARMACEUUTICA I ÚS. Tisana (ús intern). PREPARACIÓ Decocció. DESTINACIÓ. Medicina veterinària.

Salutifer

FONTS 546, 583, 584, 585, 746. DESCRIPCIÓ DE L'ÚS FETA PELS INFORMANTS. És molt refrescant (746). A les vaques els donàvem aigua de morelles per a refrescar els budells (546). És refrescant per al bestiar $(583,584,585)$. FORMA FARMACĖUTICA I ÚS. Tisana (ús intern). PREPARACIÓ. Decocció. Per a fer aigua (746). Decocció $(546,583,584,585)$. DESTINACIÓ. Medicina humana (746). Medicina veterinària $(546,583,584,585)$

\section{USOS ALIMENTARIS}

\section{Part aèria}

Ingestió de la part de la planta crua - Fresca (sense preparació)

FONT 564. DESCRIPCIÓ DE L'ÚS FETA PER L'INFORMANT. Per a les gallines. DESTINACIÓ. Alimentació animal.

\section{ALTRES OBSERVACIONS}

FONTS 522, 523, 546, 547, 548, 556, 557, 560, 748, 749. DESCRIPCIÓ FETA PELS INFORMANTS. És una planta que s'arrapa a la paret (s'assembla a l'herbasana i a la menta) $(748,749)$. Fa una fulla ampla i un espigó $(522,523)$. Les fulles de les morelles són greixoses $(748,749)$. Fa una fulla ampla i un espigó $(522,523)$. Les fulles de les morelles són greixoses
$(546)$. S'han de treure dels camps perquè ho invadeixen tot $(547,548)$. N'hi havia a les cases plantades a les vores de les parets $(547,548)$. Es fa als marges de les pedres $(556,557)$. No
plation plantades a les vores de les parets
es poden treure de les parets (560).

\section{BARREGES AMB AQUEST TÀXON}

\section{Part aèria}

FONT 1297. Entrevista 10 (vegeu catàleg de barreges)

FONT 1327. Entrevista 14, barreja I (vegeu catàleg de barreges)

FONT 1314. Entrevista 17, barreja III (vegeu catàleg de barreges)

FONT 1293. Entrevista 2, barreja II (vegeu catàleg de barreges)

FONT 1317. Entrevista 21, barreja II (vegeu catàleg de barreges)

FONTS 1347, 1348, 1349. Entrevista 27 (vegeu catàleg de barreges)

FONTS 1361, 1362. Entrevista 29, barreja III (vegeu catàleg de barreges)
FONT 1318. Entrevista 31, barreja I (vegeu catàleg de barreges)

FONT 1330. Entrevista 32, barreja II (vegeu catàleg de barreges)

FONTS 1350, 1351. Entrevista 39, barreja I (vegeu catàleg de barreges)

FONTS 529, 530, 531. Entrevista 53, barreja VIII (vegeu catàleg de barreges)

FONTS 520, 521. Entrevista 56, barreja IV (vegeu catàleg de barreges)

FONT 1300. Entrevista 8, barreja I (vegeu catàleg de barreges)

FONTS 572, 573. Entrevista 90, barreja I (vegeu catàleg de barreges)

FONT 582. Entrevista 95 (vegeu catàleg de barreges)

FONTS 583, 584, 585. Entrevista 96, barreja IV (vegeu catàleg de barreges)

\section{Paronychia argentea Lam. (cariofil·làcies)}

BCN 123793

\section{NOMS POPULARS}

Herba sanguinària $(522,523)$

Sanguinària $(538,1321)$

\section{USOS MEDICINALS}

\section{Part aèria}

Antihipertensiu

FONTS 522, 523, 538, 1321. DESCRIPCIÓ DE L'ÚS FETA PELS INFORMANTS. Per a fer baixar la pressió $(522,523)$. Va bé per a les sangs (538). Per a la pressió (1321). FORMA FARMACĖUTICA I ÚS. Tisana (ús intern). PREPARACIÓ. Decocció $(522,523,538,1321$ ). DESTINACIÓ. Medicina humana. OBSERVACIONS. Aquí no s'utilitza gaire, m'ho va dir un pastor que anava cap allà la Tallada (538).

\section{ALTRES OBSERVACIONS}

FONTS 522, 523. DESCRIPCIÓ FETA PELS INFORMANTS. Creix arrapada a terra a les roques i fa una flor blanca (522). Creix arrapada a terra a les roques (523).

\section{Paronychia kapela (Hacq.) Kerner (cariofil·làcies)}

BCN 412

\section{NOMS POPULARS}

Herba sanguinària $(1213,1214)$ 


\section{BARREGES AMB AQUEST TÀXON}

Part aèria florida

FONTS 1213, 1214. Entrevista 102, barreja V (vegeu catàleg de barreges)

\section{Petroselinum crispum (Mill.) Hill (umbel-líferes)}

BCN 24943

\section{NOMS POPULARS}

Julivert $(503,507,509,510,511,512,513,514,520,521,528,529,530,531,538,545,546$ $547,548,549,553,554,555,559,561,562,563,567,568,571,572,573,574,575,576$ $577,580,591,592,753,754,755,1213,1214,1215,1299,1300,1314,1318,1319,1323$ $1324,1327,1343,1344,1347,1348,1349,1350,1351,1361,1362)$

\section{USOS MEDICINALS}

Arrel

Abortiu

FONTS 1319, 1350, 1351. DESCRIPCIÓ DE L'ÚS FETA PELS INFORMANTS. Si les dones se'n posaven a baix podien avortar (1319). És abortiva, es posa l'arrel directament per baix (1350, 1351). FORMA FARMACĖUTICA I ÚS. Sense forma farmacèutica (ús directe, ús extern). DESTINACIO. Medicina humana.

Antiequimòtic

FONTS 591, 592. DESCRIPCIÓ DE L'ÚS FETA PELS INFORMANTS. Servia per a untar mals i per als trucs. FORMA FARMACEUUTICA I ÚS. Liniment (ús extern). PREPARACIÓ. Se'n feia un oli, fent bullir la rel en oli. DESTINACIO. Medicina humana.

Antieritematós

FONTS $753,754,755$. DESCRIPCIÓ DE L'ÚS FETA PELS INFORMANTS. Per a quan t'esvorres. FORMA FARMACEUTICA I US. Liniment (ús extern). PREPARACIO. Bullir arrels de julivert en oli. DESTINACIO. Medicina humana.

Antihipertensiu

FONTS 580, 591, 592. DESCRIPCIÓ DE L'ÚS FETA PELS INFORMANTS. Per a rebaixar la sang (580). Rebaixa la sang $(591,592)$. FORMA FARMACĖUTICA I ÚS. Tisana (ús intern). PREPARACIO. Decocció. Aigua de la rel $(580)$. Decocció $(591,592)$. DESTINACIO. Medicina humana.

Diürètic

FONTS 520, 521, 529, 530, 531. DESCRIPCIÓ DE L'ÚS FETA PELS INFORMANTS. Per a fer orinar. FORMA FARMACĖUTICA I ÚS. Tisana (ús intern). PREPARACIÓ. Decocció. DESTINACIO. Medicina humana.
Hematocatàrtic

FONT 1299. DESCRIPCIÓ DE L'ÚS FETA PER L'INFORMANT. És un purificant de la sang. FORMA FARMACĖUTICA I ÚS. Sense forma farmacèutica (ús directe, ús intern) PREPARACIÓ. Menjat amb arrel, cru. DESTINACIÓ. Medicina humana.

Per a trastorns del sistema musculoesquelètic

FONTS 554, 555. DESCRIPCIÓ DE L'ÚS FETA PELS INFORMANTS. Per a desengarrotar els nervis i per a posar els ossos més forts. FORMA FARMACĖUTICA I ÚS. Ungüent (ús extern). PREPARACIÓ. Arrel i greix de gallina, es barreja oli, greix i el julivert es fa coure. DESTINACIÓ. Medicina humana. OBSERVACIONS. En vaig tenir sort per al meu fill gran perquè caminés, quan tenia cinc anys encara no caminava.

Reforçant ossi

FONTS 554, 555. DESCRIPCIÓ DE L'ÚS FETA PELS INFORMANTS. Per a desengarrotar els nervis i per a posar els ossos més forts. FORMA FARMACĖUTICA I ÚS. Ungüent (ús extern). PREPARACIÓ. Arrel i greix de gallina, es barreja oli, greix i el julivert es fa coure. DESTINACIO. Medicina humana. OBSERVACIONS. En vaig tenir sort per al meu fill gran perquè caminés, quan tenia cinc anys encara no caminava.

\section{Part aèria}

Afrodisíac

FONTS 1361, 1362 DESCRIPCIÓ DE L'ÚS FETA PELS INFORMANTS. Per a què els conills vagin de conilla, cal fer-los menjar julivert. FORMA FARMACĖUTICA I ÚS. Sense forma farmacèutica (ús directe, ús extern). DESTINACIÓ. Medicina veterinària.

Antiequimòtic

FONTS $503,511,512,513,514,529,530,531,561,562,563,1347,1348,1349$ DESCRIPCIÓ DE L'ÚS FETA PELS INFORMANTS. Picat amb cansalada per a quan t'has fet DESCRIPCIO DE un truc $i$. surt el blau (503). Per als trucs (511, 512, 513, 514). Per a les patacades (529, $530,531)$. Et fa sortir el truc $(561,562,563)$. Per a fer sortir els morats $(1347,1348,1349)$. FORMA FARMACEUTICA I U. Ungüent (ús extern) (503, 511, 512, 513, 514, 529, 530 531). Emplastre (ús extern) $(561,562,563,1347,1348,1349)$. PREPARACIÓ. Picat amb cansalada $(511,512,513,514,529,531)$. Picat amb cansaldada (530). Barrejat amb greix per a fer emplastres. Es fa servir tota la planta $(561,562,563)$. Emplastres de julivert amb sagí $(1348,1349)$. Emplastre de julivert amb sagí (1347). EFECTES SECUNDARIS. No. DESTINACIÓ. Medicina humana.

Planta sencera

Vasotònic

FONTS 1343, 1344. DESCRIPCIÓ DE L'ÚS FETA PELS INFORMANTS. Per a la circulació FORMA FARMACĖUTICA I ÚS. Tisana (ús intern). PREPARACIÓ. Decocció. DESTINACIÓ. Medicina humana.

\section{USOS ALIMENTARIS}

\section{Part aèria}


Condiment

FONTS 507, 509, 510, 511, 512, 513, 514, 567, 568, 571, 572, 573, 574, 575, 576, 577, 580 1314,1327 . DESCRIPCIÓ DE L'ÚS FETA PELS INFORMANTS. Per a cuinar (507, 509, 510 $567,568,571,572,573,580,1327)$. Per a fer les picades $(511,512,513,514)$. Per a guisa $(574,575,576,577)$. Per a fer picades (1314). OBSERVACIONS. Gaire és abortiu (1327) DESTINACIÓ. Alimentació humana $(507,509,510,511,512,513,514,567,568,571,572$, $573,574,575,576,577,580,1314,1327)$

\section{ALTRES USOS}

\section{Part aèria}

Cosmètic

FONTS 572, 573. DESCRIPCIÓ DE L'ÚS FETA PELS INFORMANTS. Diu que va bé per a mantenir el cabell fi. Rentar-te'l amb aigua de julivert.

\section{Planta sencera}

Creences i pràctiques magicoreligioses

FONT 1215. DESCRIPCIÓ DE L'ÚS FETA PER L'INFORMANT. Tenir julivert al balcó o a casa porta mala sort. S'ha de tenir a l'hort.

\section{ACCIONS NOCIVES O TÒXIQUES}

\section{No consta}

FONT 559. DESCRIPCIÓ DE L'ACCIÓ NOCIVA O TÒXICA FETA PER L'INFORMANT.

Abortiva.

\section{Part aèria}

FONT 1327. DESCRIPCIÓ DE L'ACCIÓ NOCIVA O TÒXICA FETA PER L'INFORMANT. És abortiu. GRAU DE TOXICITAT. Baix. VIA D'INTOXICACIÓ. Via interna.

\section{ALTRES OBSERVACIONS}

FONT 568. DESCRIPCIÓ FETA PER L'INFORMANT. Sempre l'he vingut a buscar en aquesta paret.

\section{BARREGES AMB AQUEST TÀXON}

\section{Arrel}

FONTS 1213, 1214. Entrevista 102, barreja VI (vegeu catàleg de barreges)

FONT 1323. Entrevista 24 (vegeu catàleg de barreges)

FONT 1318. Entrevista 31, barreja IV (vegeu catàleg de barreges)

FONT 503. Entrevista 43 (vegeu catàleg de barreges)

FONT 528. Entrevista 61, barreja II (vegeu catàleg de barreges)
FONT 538. Entrevista 68, barreja I (vegeu catàleg de barreges) FONT 545. Entrevista 72, barreja I (vegeu catàleg de barreges) FONT 546. Entrevista 74, barreja I (vegeu catàleg de barreges) FONT 549. Entrevista 75, barreja I (vegeu catàleg de barreges) FONT 553. Entrevista 77, barreja I (vegeu catàleg de barreges) FONT 1300. Entrevista 8, barreja II (vegeu catàleg de barreges) FONTS 572, 573. Entrevista 90, barreja II (vegeu catàleg de barreges) No consta

FONTS 547, 548. Entrevista 73, barreja II (vegeu catàleg de barreges)

\section{Part aèria}

FONT 1314. Entrevista 17, barreja I (vegeu catàleg de barreges)

FONT 1324. Entrevista 5, barreja II (vegeu catàleg de barreges)

FONTS 574, 575, 576, 577. Entrevista 91, barreja II (vegeu catàleg de barreges)

\section{Planta sencera}

FONTS 520, 521. Entrevista 56, barreja II (vegeu catàleg de barreges)

\section{Peucedanum cervaria (L.) Lap. (umbel-líferes)}

BCN 24944

\section{NOMS POPULARS}

Julivertassa (1336)

\section{ACCIONS NOCIVES O TÒXIQUES}

Part aèria

FONT 1336. DESCRIPCIO DE L'ACCIO NOCIVA O TOXICA FETA PER L'INFORMANT. S les ovelles en mengen i estan prenys, les fa avortar.

\section{Peucedanum ostruthium (L.) Koch (umbel·líferes)} BCN 24945

\section{NOMS POPULARS}

Salsufragi $(538,541,553,554,555,556,557,558,559,572,573,580,1213,1214,1317$ $1321,1332,1333,1334)$ 


\section{USOS MEDICINALS}

\section{Arrel}

Digestiu

FONTS 1213, 1214. DESCRIPCIÓ DE L'ÚS FETA PELS INFORMANTS. Ajuda a pair. FORMA FARMACĖUTICA I ÚS. Tisana (ús intern). PREPARACIÓ. Decocció. DESTINACIÓ. Medicina humana.

Diürètic

FONTS 1213, 1214. DESCRIPCIÓ DE L'ÚS FETA PELS INFORMANTS. Depurativa de ronyó. FORMA FARMACĖUTICA I ÚS. Tisana (ús intern). PREPARACIÓ. Decocció. DESTINACIÓ. Medicina humana.

Fulla

Antiinflamatori intestina

FONT 553. DESCRIPCIÓ DE L'ÚS FETA PER L'INFORMANT. Per a la panxa. FORMA FARMACĖUTICA I ÚS. Tisana (ús intern). PREPARACIÓ. Decocció. DESTINACIÓ. Medicina humana.

Digestiu

FONTS 572, 573. DESCRIPCIÓ DE L'ÚS FETA PELS INFORMANTS. Per a pair. FORMA FARMACĖUTICA I ÚS. Tisana (ús intern). PREPARACIÓ. Decocció. DESTINACIÓ. Medicina humana.

Estomacal

FONTS 538, 541, 559. DESCRIPCIÓ DE L'ÚS FETA PELS INFORMANTS. Per al mal d'estómac (541). Van bé per al mal d'estómac (538). Per a l'estómac (559). FORMA FARMACEUTICA I ÚS. Tisana (ús intern). PREPARACIO. Decocció $(541,559)$. Decocció Les fulles amb infusió (538). DESTINACIO. Medicina humana. OBSERVACIONS. A casa sempre n'hi havia (541). Es molt amarganta (538).

Laxant

FONT 580. DESCRIPCIÓ DE L'ÚS FETA PER L'INFORMANT. És bona l'aigua per a ajudar a anar de ventre. FORMA FARMACEUTICA I US. Tisana (ús intern). PREPARACIO. Decocció. DESTINACIO. Medicina humana.

Tranquil-litzant

FONTS 554, 555. DESCRIPCIÓ DE L'ÚS FETA PELS INFORMANTS. En aigua per als nervis. FORMA FARMACEUTICA I ÚS. Tisana (ús intern). PREPARACIO. Decocció. DESTINACIÓ. Medicina humana.

\section{No consta}

Antiapendicític

FONTS 1332, 1333, 1334. DESCRIPCIÓ DE L'ÚS FETA PELS INFORMANTS. En Bonada hi curava la gent de l'apèndix. FORMA FARMACĖUTICA I ÚS. Desconegut per l'informant. DESTINACIÓ. Medicina humana.

Desconegut per l'informant
FONTS 556, 557, 1317. FORMA FARMACĖUTICA I ÚS. Desconegut per l'informant DESTINACIÓ. Medicina humana OBSERVACIONS. Era medicinal La padrina en feia manats. El salsufragi es menja tota l'herba bona dels voltants $(556,557)$.

\section{USOS ALIMENTARIS}

Fulla

Preparació de begudes - Beguda preparada amb aiguardent

FONT 553. DESCRIPCIÓ DE L'ÚS FETA PER L'INFORMANT. Ratafia. Posar totes les herbes en aiguardent 21 dies a sol i serena. Es fa pels volts de Sant Joan. Sempre surt bona però no surt mai igual. Les herbes utilitzades són: nous verdes (Juglans regia), herba de Noè (Herniaria glabra), tarongina (Melissa officinalis), camamilla borda (Tanacetum parthenium) marialluïsa (Lippia triphylla), menta (Mentha spicata), salsufràgia (Peucedanum ostruthium) til-la (Tilia platyphyllos), nou moscada (Myristica fragrans) i clau (Syzygium aromaticum) DESTINACIÓ. Alimentació humana.

\section{ALTRES USOS}

\section{No consta}

Altres informacions

FONT 1317. DESCRIPCIÓ DE L'ÚS FETA PER L'INFORMANT. Abans la compraven molt.

\section{ALTRES OBSERVACIONS}

FONT 538. DESCRIPCIÓ FETA PER L'INFORMANT. Cap a Núria i a Coma de Vaca n'hi ha.

\section{Peumus boldus Molina (monimiàcies)}

BC 606589

\section{NOMS POPULARS}

Boldo $(1353,1354)$

\section{USOS MEDICINALS}

Fulla

Hepatoprotector

FONTS 1353, 1354. DESCRIPCIÓ DE L'ÚS FETA PELS INFORMANTS. Va bé per al fetge. FORMA FARMACĖUTICA I ÚS. Tisana (ús intern). DESTINACIÓ. Medicina humana.

Phaseolus vulgaris L. (papilionàcies) 
BCN 27255

\section{NOMS POPULARS}

Fesol (fruit/llavor) (589)

Mongeta (fruit/llavor) $(503,515,516,517,590,753,754,755,1353,1354)$

Mongeta blanca (llavor) $(1213,1214)$

Mongetera $(507,509,510,525,526,527)$

\section{USOS MEDICINALS}

Fruit

Antiberrugós

FONT 590. DESCRIPCIÓ DE L'ÚS FETA PER L'INFORMANT. El suc de les mongetes per a les berruges. FORMA FARMACEUTICA I ÚS. Desconegut per l'informant. DESTINACIO. Medicina humana.

Fulla

Antiberrugós

FONTS 507, 509, 510, 525, 526, 527. DESCRIPCIÓ DE L'ÚS FETA PELS INFORMANTS Per a les berrugues $(507,509,510)$. Va bé per a curar berrugues, jo n'era ple i me les vaig curar així $(525,526,527)$. FORMA FARMACĖUTICA I ÚS. Sense forma farmacèutica (ús directe, ús extern) $(507,509,510)$. Bany (ús extern) $(525,526,527)$. PREPARACIÓ. Les fulles es fan servir quan són molles al matí $(507,509,510)$. Decocció. El suc de les fulles de la mongetera $(525,526,527)$. DESTINACIÓ. Medicina humana.

Llavor

Antifúngic

FONTS 753, 754, 755. DESCRIPCIÓ DE L'ÚS FETA PELS INFORMANTS. Per a curar els brians tant de persones com d'animals. FORMA FARMACEUTICA I US. Desconegut per l'informant. PREPARACIO. S'agafen set o nou mongetes seques (sempre senars) es torren en una paella [dit "padella"], s'aixafen i se'n fa farina. Llavors es barreja amb flor de sofre i oli. Amb aquesta barreja es frega el brià. DESTINACIÓ. Medicina humana i veterinària.

\section{USOS ALIMENTARIS}

Fruit

Ingestió de la part de la planta cuita - Cuita en aigua

FONTS 503, 515, 516, 589. DESCRIPCIÓ DE L'ÚS FETA PELS INFORMANTS. A I'hort sempre teniem mongetes que les fèiem al mig del blat de moro, així s'aprofitava més la terra (503). Per a menjar $(515,516)$. A l'hort en fem tant de baixos com d'aspra (589). DESTINACIÓ. Alimentació humana $(503,515,516,589)$.

No consta el tipus d'ingesta - No consta el mode de preparació
FONT 517.

Llavor

Ingestió de la part de la planta cuita - Cuita en aigua

FONTS 1353,1354 . DESCRIPCIÓ DE L'ÚS FETA PELS INFORMANTS. En fem sempre a l'hort i en mengem tot l'estiu. DESTINACIÓ. Alimentació humana.

\section{ALTRES OBSERVACIONS}

FONT 517. DESCRIPCIÓ FETA PER L'INFORMANT. A I'hort.

\section{BARREGES AMB AQUEST TÀXON}

Llavor

FONTS 1213, 1214. Entrevista 102, barreja VI (vegeu catàleg de barreges)

\section{Philadelphus coronarius L. (hidrangeàcies)}

BCN 27261

\section{NOMS POPULARS}

Xeringuilla $(524,541,560,564,1352)$

\section{ALTRES USOS}

\section{Part aèria florida}

Creences i pràctiques magicoreligioses

FONT 1352. DESCRIPCIÓ DE L'ÚS FETA PER L'INFORMANT. Se'n feien rams que es posaven a l'església per al mes de Maria.

Fuster: obtenció de materials per a la construcció

FONT 564. DESCRIPCIÓ DE L'ÚS FETA PER L'INFORMANT. Per a fer rams.

Ornamental: elaboració de rams

FONTS 524, 541, 560. DESCRIPCIÓ DE L'ÚS FETA PELS INFORMANTS. Fa bonic i quan floreix fa molta olor (524). Per a fer rams (541). Per a fer bonic (560).

\section{Phyllitis scolopendrium (L.) Newm. (polipodiàcies)}

BCN 24946

\section{NOMS POPULARS}

Herba melsera (1324) 


\section{USOS MEDICINALS}

\section{No consta}

Desconegut per l'informant

FONT 1324. FORMA FARMACĖUTICA I ÚS. Desconegut per l'informant. OBSERVACIONS. No en recorda l'ús.

\section{Physalis alkekengi L. (solanàcies)}

BCN 31293

\section{NOMS POPULARS}

Fanalet $(569,570)$

\section{ALTRES USOS}

\section{Planta viva ex situ}

Ornamental: jardineria

FONTS 569, 570. DESCRIPCIÓ DE L'ÚS FETA PELS INFORMANTS. Per a fer bonic.

\section{Pinus mugo Turra subsp. uncinata (Ramond ex DC. in Lam.} et DC.) Domin (pinàcies)

BCN 24947

\section{NOMS POPULARS}

$\mathrm{Pi}(532,533,534,549,556,557,1317,1321,1324,1327,1330,1332,1333,1334,1341$ $1342,1342,1347,1348,1349,1350,1351)$

Pi negre $(511,512,513,514,538,539,540,554,555,559,574,575,576,577,748,749$, $1313,1323)$

\section{USOS MEDICINALS}

\section{Fructificació}

Antiasmàtic

FONTS 574, 575, 576, 577, 748, 749. DESCRIPCIÓ DE L'ÚS FETA PELS INFORMANTS Per a l'asma $(748,749)$. Per a l'asma i per als refredats $(574,575,576,577)$. FORMA FARMACĖUTICA I ÚS. Xarop (ús intern). PREPARACIÓ. Pinyes verdes tallades a rodanxes i posades amb capes de sucre i nou dies a sol i serena $(748,749)$. Xarop amb sucre $(574$, 575, 576, 577). DESTINACIÓ. Medicina humana.

\section{Anticatarral}

FONTS 554, 555, 559, 574, 575, 576, 577, 1347, 1348, 1349. DESCRIPCIÓ DE L'ÚS FETA PELS INFORMANTS. Per als constipats $(559)$. Per a la tos i els refredats $(554,555)$. Per l'asma i per als refredats $(574,575,576,577)$. Per als refredats $(1347,1348,1349)$. FORMA FARMACĖUTICA I ÚS Xarop (ús intern) $(554,555,559,574,575,576,577)$. Tisana (ús intern) $(1347,1348,1349)$. PREPARACIO. Amb pinyes tendres i sucre es fa un xarop (559). Xarop de les pinyes tendres. Partir les pinyes en quatre trossos, una capa de pinyes i una de sucre i fins que la cassola de terra és plena, llavors nou dies a sol i serena, fa el suc i el coles amb un drap i es posa dins de pots. Si el fas amb pinyes de pi negre queda més fosc (554 $555)$. Xarop amb sucre $(574,575,576,577)$. Decocció de les pinyes verdes $(1347,1348$, 1349). DESTINACIÓ. Medicina humana.

Antiinflamatori faringi

FONTS 748, 749. DESCRIPCIÓ DE L'ÚS FETA PELS INFORMANTS. Per al mal de coll. FORMA FARMACĖUTICA I ÚS. Xarop (ús intern). PREPARACIÓ. Les pinyes verdes aixafades i macerades amb sucre candi. DESTINACIÓ. Medicina humana.

Antitussigen

FONTS 549, 554, 555, 1323. DESCRIPCIÓ DE L'ÚS FETA PELS INFORMANTS. Per a la tos (549). Per a la tos i els refredats $(554,555)$. Va molt bé per als constipats, sobretot quan tens tos (1323). FORMA FARMACĖUTICA I ÚS. Xarop (ús intern). PREPARACIÓ. Les pinyes petites del pi amb sucre per a fer xarops (549). Xarop de les pinyes tendres. Partir les pinyes en quatre trossos, una capa de pinyes i una de sucre i fins que la cassola de terra és plena, llavors nou dies a sol i serena, fa el suc i el coles amb un drap i es posa dins de pots. $\mathrm{Si}$ el fas amb pinyes de pi negre queda més fosc $(554,555)$. Xarop de les pinyes. S'agafen les pinyes verdes i s'aixafen una mica amb un martell, llavors es posen en un sac de fil, fent una capa de pinyes i una capa de sucre es penja el sac i es recull el suc que va fent amb un una capa ('ha d'esperar que no gotegi) i després es posa en ampolles (1323). DESTINACIÓ. Medicina humana. OBSERVACIONS. També es pot donar a la canalla (1323).

Expectorant

FONT 532. DESCRIPCIÓ DE L'ÚS FETA PER L'INFORMANT. Va bé per a destapar quan pinyes se'n fa un xarop. DESTINACIO. Medicina humana.

\section{Gemmes de les fulles}

Antiasmàtic

FONTS 539, 540. DESCRIPCIÓ DE L'ÚS FETA PELS INFORMANTS. Van bé per a l'asma. FORMA FARMACĖUTICA I ÚS. Tisana (ús intern). PREPARACIÓ. Els brots tendres bullits amb infusió. DESTINACIÓ. Medicina humana.

Antibronquític 
FONTS 533, 534. DESCRIPCIÓ DE L'ÚS FETA PELS INFORMANTS. Van bé per a les bronquitis. FORMA FARMACĖUTICA I ÚS. Tisana (ús intern). PREPARACIÓ. Decocció dels caps de pi quan són tendres. DESTINACIÓ. Medicina humana.

Anticatarral

FONTS 511, 512, 513, 514, 538, 556, 557, 1317. DESCRIPCIÓ DE L'ÚS FETA PELS INFORMANTS. Per als refredats $(511,512,513,514)$. Els brots tendres van bé per als refredats (538). Per a refredats de pit $(556,557)$. Per als constipats $(1317)$. FORMA FARMACÉUTICA I ÚS. Tisana (ús intern). PREPARACIÓ. Decocció $(511,512,513,514$ $538,556,557,1317)$. DESTINACIÓ. Medicina humana.

Desconegut per l'informant

FONT 1313. FORMA FARMACĖUTICA I ÚS. Desconegut per l'informant. DESTINACIÓ. Medicina humana. OBSERVACIONS. Diu que és molt medicinal, però que ells no l'utilizaven. Per al borm

FONT 538. DESCRIPCIÓ DE L'ÚS FETA PER L'INFORMANT. Per a les eugues, quan agafaven el borm [dit "born"] (constipat de cap). FORMA FARMACĖUTICA I ÚS. Tisana (ús intern). PREPARACIÓ. Decocció. Es bullien els brots tendres i se'Is posava amb un morralet, intern). PREPARACIO. Decocció. Es bullien els brots tendres i se'Is posava

\section{Inflorescència}

Antiasmàtic

FONT 1321. DESCRIPCIÓ DE L'ÚS FETA PER L'INFORMANT. Els caps de pi per a l'asma l'ofegament. FORMA FARMACĖUTICA I ÚS. Tisana (ús intern). DESTINACIÓ. Medicina humana.

Antibronquític

FONT 1327. DESCRIPCIÓ DE L'ÚS FETA PER L'INFORMANT. Va bé per a la bronquitis FORMA FARMACĖUTICA I ÚS. Tisana (ús intern). PREPARACIÓ. Decocció. Aigua dels caps de pi. DESTINACIÓ. Medicina humana.

Anticatarral

FONTS $1323,1324,1330,1332,1333,1334,1341,1342,1350,1351$. DESCRIPCIÓ DE L'ÚS FETA PELS INFORMANTS. Va bé per als refredats (1323). Per als constipats (1324 $1341,1342)$. Per als constipats, per a descongestionar (1330). Per als refredats $(1332,1333$ 1334). Els caps de pi per a destapar quan estàs refredat $(1350,1351)$. FORMA FARMACĖUTICA I ÚS. Tisana (ús intern) $(1323,1324,1330,1332,1333,1334,1341,1342$ $1350,1351)$. Aerosol (ús intern) (1324). PREPARACIO. En infusió, per a cada tassa tres flors (1323). S'ha de bullir tres minuts (1324). Per a fer bafs (1324). Decocció. Aigua dels caps de pi $(1330,1341,1342)$. Decocció Aigua de caps de pi $(1332,1333,1334)$. MODE D'UTILITZACIÓ/POSOLOGIA. Te'n prens tres o quatre cops al dia (1324). DESTINACIÓ. Medicina humana.

Antipirètic

FONT 1323. DESCRIPCIÓ DE L'ÚS FETA PER L'INFORMANT. Va bé per a la febre (fa baixar la febre bastant ràpidament). FORMA FARMACĖUTICA I ÚS. Tisana (ús intern). PREPARACIÓ. En infusió, per a cada tres flors. DESTINACIÓ. Medicina humana.

\section{Planta sencera}

Antitussigen

FONT 1323. DESCRIPCIÓ DE L'ÚS FETA PER L'INFORMANT. Recorda que abans, la gent que tenia tuberculosi, els feien passejar per les pinedes. FORMA FARMACĖUTICA I ÚS. Sense forma farmacèutica (ús directe, ús extern). DESTINACIÓ. Medicina humana.

\section{Resina}

Antiinflamatori faring

FONTS 748, 749. DESCRIPCIÓ DE L'ÚS FETA PELS INFORMANTS. Per a amorosir el coll i la boca. FORMA FARMACĖUTICA I ÚS. Sense forma farmacèutica (ús directe, ús intern). PREPARACIÓ. Reïna del pi beguda directament quan és ben líquida. DESTINACIÓ. Medicina humana.

\section{ALTRES USOS}

\section{Gemmes de les fulles}

Altres informacions

FONT 1313. DESCRIPCIÓ DE L'ÚS FETA PER L'INFORMANT. Els caps (cimals) dels pins els hi compraven, els hi pagaven a 10 rals.

\section{BARREGES AMB AQUEST TÀXON}

\section{Part aèria jove}

FONTS 539, 540. Entrevista 69 (vegeu catàleg de barreges)

Pinus sp. (pinàcies)

\section{NOMS POPULARS}

$\mathrm{Pi}(1352,1361,1362)$

\section{USOS MEDICINALS}

Resina

Analgèsic

FONT 1361. DESCRIPCIÓ DE L'ÚS FETA PER L'INFORMANT Per al dolor. FORMA FARMACĖUTICA I ÚS. Emplastre (ús extern). DESTINACIÓ. Medicina humana.

\section{ALTRES USOS}

\section{Fructificació}

Obtenció de combustible: llenya 
FONT 1352. DESCRIPCIÓ DE L'ÚS FETA PER L'INFORMANT. Les pinyes també per a cremar, però sobretot a estufes.

\section{Tija}

Maneig agrosilvopastoral: ús hortícola/agrícola

FONT 1352. DESCRIPCIÓ DE L'ÚS FETA PER L'INFORMANT. Se'n feia els esclopets que protegien els dits dels segadors.

Obtenció de combustible: llenya

FONT 1352. DESCRIPCIÓ DE L'ÚS FETA PER L'INFORMANT. Per a fer foc, espetega molt per la resina.

\section{BARREGES AMB AQUEST TÀXON}

\section{Resina}

FONTS 1361, 1362. Entrevista 29, barreja II (vegeu catàleg de barreges)

\section{Pinus sylvestris L. (pinàcies)}

BCN 27259

\section{NOMS POPULARS}

Esperit de trementina (producte elaborat) (588)

Pega (producte elaborat) $(561,562,563,588)$

Pega negra (producte elaborat) $(528,571,578,579,581)$

$\mathrm{Pi}(507,509,510,515,516,517,522,523,529,530,531,561,562,563,565,566,578,579$, $583,584,585)$

Pi blanc $(554,555)$

Pi rajolet $(520,521)$

Pi roig $(503,569,570,574,575,576,577,583,584,585,1295,1323)$

\section{USOS MEDICINALS}

\section{Fructificació}

Antiasmàtic

FONTS 515, 516, 574, 575, 576, 577. DESCRIPCIÓ DE L'ÚS FETA PELS INFORMANTS Per a la tos, els refredats i l'asma $(515,516)$. Per a l'asma i per als refredats $(574,575,576$, 577). FORMA FARMACĖUTICA I ÚS. Xarop (ús intern). PREPARACIÓ. Pinyes verdes macerades amb sucre. Les talles a làmines $i$ fas una capa de sucre $i$ una de pinyes, ho deixes que es vagi escorreguent i et prens aquell xarop que fa $(515,516)$. Xarop amb sucre
$(574,575,576,577)$. DESTINACIÓ. Medicina humana.

\section{Antibronquític}

FONTS 520, 521. DESCRIPCIÓ DE L'ÚS FETA PELS INFORMANTS. Per a les bronquitis FORMA FARMACĖUTICA I ÚS. Xarop (ús intern). PREPARACIÓ. Les pinyes verdes tallades pel mig i amb sucre. DESTINACIÓ. Medicina humana.

Anticatarral

FONTS 515, 516, 554, 555, 561, 562, 563, 565, 566, 569, 570, 574, 575, 576, 577 DESCRIPCIÓ DE L'ÚS FETA PELS INFORMANTS. Per a la tos, els refredats i l'asma (515, $516)$. Per a quan estàs refredat $(561,562,563)$. Va bé per als constipats i la tos $(565,566)$ Per als refredats $(569,570)$. Per a la tos i els refredats $(554,555)$. Per a l'asma i per als refredats $(574,575,576,577)$. FORMA FARMACĖUTICA I ÚS. Xarop (ús intern) PREPARACIÓ. Les talles a làmines i fas una capa de sucre i una de pinyes, ho deixes que es vagi escorrent $i$ et prens aquell xarop que fa (516). Pinyes verdes macerades amb sucre. Les talles a làmines i fas una capa de sucre i una de pinyes, ho deixes que es vagi escorreguent $i$ et prens aquell xarop que fa (515). Les pinyes ben tendres i esberlades posen amb sucre i la pinya deixa anar l'essència de pi i queda un xarop $(561,562,563)$. fo xarop amb pinyes tendres i sucre $(565,566)$. Les piny petites i map $(561,562,563)$. Es fa xarop amb pinyes tep $(560,570)$. Xaro, quedava com un xarop $(569,570)$. Xarop de les pinyes tendres. Partir les pinyes en quatre trossos, una capa de pinyes i una de sucre ins que la cassola de terra és plena, llavors nou dies a sol i serena, fa el suc i el coles amb un drap i es posa dins de pots. Si el fas amb pinyes de pi negre queda més fosc $(554,555)$. Xarop amb sucre $(574,575,576,577)$ DESTINACIÓ. Medicina humana.

Antitussigen

FONTS $515,516,554,555,561,562,563,565,566,1323$. DESCRIPCIÓ DE L'ÚS FETA PELS INFORMANTS. Per a la tos, els refredats i l'asma $(515,516)$. Per a la tos $(561,562$ $563)$. Va bé per als. Pentipats i la tos $(565,566)$ Per a la tos i els refredats $(554,555)$. Va molt bé per als constipats, sobretot quan tens tos (1323). FORMA FARMACĖUTICA I ÚS Xarop (ús intern). PREPARACIÓ. Les talles a làmines $i$ fas una capa de sucre $i$ una de pinyes, ho deixes que es vagi escorrent i et prens aquell xarop que fa (516). Pinyes verdes macerades amb sucre. Les talles a làmines i fas una capa de sucre i una de pinyes, ho deixes que es vagi escorreguent $i$ et prens aquell xarop que fa (515). Les pinyes ben tendres i esberlades es posen amb sucre i la pinya deixa anar l'essència de pi i queda un xarop (561, $562,563)$. Es fa xarop amb pinyes tendres i sucre $(565,566)$. Xarop de les pinyes tendres. Partir les pinyes en quatre trossos, una capa Partir les pinyes en quassola de terra es posa dins de pots. Si el fas amb pinyes de pi negre queda més fosc $(554,555)$. Xarop de les pinyes. Sagafen les pinyes verdes i s'aixafen una mica amb un mant, llavors es posen en un sac de fil, fent una capa de pinyes i una capa de sucre, es penja el sac i es recull el suc que va fent amb un recipient (s'ha d'esperar que no gotegi) i despres es posa en ampolles (1323). DESTINACIÓ. Medicina humana. OBSERVACIONS. També és pot donar a la canalla (1323).

Antiasmàtic 
FONTS 583, 584, 585. DESCRIPCIÓ DE L'ÚS FETA PELS INFORMANTS. Els brots de p van bé per a l'asma i per als refredats de pit. FORMA FARMACĖUTICA I ÚS. Tisana (ús intern). PREPARACIÓ. Decocció. DESTINACIÓ. Medicina humana.

Antibronquític

FONTS 507, 509, 510. DESCRIPCIÓ DE L'ÚS FETA PELS INFORMANTS. Va bé per als refredats i per a les bronquitis. FORMA FARMACĖUTICA I ÚS. Xarop (ús intern). PREPARACIÓ. Brots de pi amb sucre cremat $\mathrm{i}$ llet. Es feia cremar sucre amb quatre o cinc brots de pi i llavors s'hi afegia la llet. DESTINACIÓ. Medicina humana.

Anticatarral

FONTS $507,509,510,517,522,523,529,530,531,578,579,583,584,585$. DESCRIPCIÓ DE L'ÚS FETA PELS INFORMANTS. Els brots de pi van bé per a l'asma i per als refredats de pit $(583,584,585)$. Va bé per als refredats i per a les bronquitis $(507,509,510)$. Per als refredats $(517,522,523)$. Per als constipats $(529,530,531)$. Van bé per als constipats $(578$ 579). FORMA FARMACE்UTICA I ÚS. Tisana (ús intern) $(517,522,523,529,530,531,578$ $579,583,584,585)$. Xarop (ús intern) $(507,509,510)$. PREPARACIÓ Decocció $(522,523$ $529,530,531,583,584,585)$. Brots de pi amb sucre cremat i llet. Es feia cremar sucre amb quatre o cinc brots de pi i llavors s'hi afegia la llet $(507,509,510)$. Decocció. Fas aigua dels brots de pi i llavors cremes una mica de sucre amb una brasa del foc i ho barreges amb l'aigua (517). Decocció dels botons del pi quan surten a la primavera $(578,579)$. DESTINACIO. Medicina humana.

\section{Inflorescència}

Anticatarral

FONT 1323. DESCRIPCIÓ DE L'ÚS FETA PER L'INFORMANT. Va bé per als refredats. FORMA FARMACĖUTICA I ÚS. Tisana (ús intern). PREPARACIÓ. En infusió, per a cada tassa tres flors. DESTINACIÓ. Medicina humana.

Antipirètic

FONT 1323. DESCRIPCIÓ DE L'ÚS FETA PER L'INFORMANT. Per a la febre (fa baixar la febre bastant ràpidament). FORMA FARMACĖUTICA I ÚS. Tisana (ús intern) PREPARACIÓ. En infusió, per a cada tassa tres flors. DESTINACIÓ. Medicina humana.

\section{No consta}

Antiequimòtic

FONT 588. DESCRIPCIÓ DE L'ÚS FETA PER L'INFORMANT. Per a quan et feies un truc FORMA FARMACĖUTICA I ÚS. Loció (ús extern). DESTINACIÓ. Medicina humana OBSERVACIONS. Ho compràvem a les trementinaires.

Per a les punxades

FONT 581. DESCRIPCIÓ DE L'ÚS FETA PER L'INFORMANT. Per a punxades d'arç, estira i fa sortir la punxa. FORMA FARMACĖUTICA I ÚS. Desconegut per l'informant. DESTINACIÓ. Medicina humana.

Regenerador ossi

FONT 588. DESCRIPCIÓ DE L'ÚS FETA PER L'INFORMANT. Per ossos trencats de les bèsties. Es posava bé l'ós, s'immobilitzava, i llavors s'escalfava pega i s'hi posava. FORMA
FARMACĖUTICA I ÚS. Desconegut per l'informant. PREPARACIÓ. Escalfar la pega DESTINACIÓ. Medicina veterinària. OBSERVACIONS. Ho compràvem a les trementinaires.

Resolutiu

FONTS 578, 579. DESCRIPCIÓ DE L'ÚS FETA PELS INFORMANTS. Es feia servir per a estirar els mals del bestiar cap enfora. FORMA FARMACĖUTICA I ÚS. Desconegut per una paella vella que només la fèiem servir per a escalfar la pega.

\section{Planta sencera}

\section{Antituberculós}

FONT 1323. DESCRIPCIÓ DE L'ÚS FETA PER L'INFORMANT. Abans la gent que tenia tuberculosi els feien passejar per les pinedes. FORMA FARMACE்UTICA I ÚS. Sense forma farmacèutica (ús directe, ús extern). DESTINACIÓ. Medicina humana.

\section{USOS ALIMENTARIS}

\section{Part aèria jove}

Ingestió de la part de la planta crua - Fresca (sense preparació)

FONTS 565, 566. DESCRIPCIÓ DE L'ÚS FETA PELS INFORMANTS. Rama de pi verda se'Is hi donava als conills. DESTINACIÓ. Alimentació animal.

\section{Tija}

Ingestió de la part de la planta crua - Fresca (sense preparació)

FONTS 578, 579. DESCRIPCIÓ DE L'ÚS FETA PELS INFORMANTS. Es donaven les branques pelades de pi als conills i les anaven rosegant. DESTINACIÓ. Alimentació animal.

\section{ALTRES USOS}

Tija

Altres informacions

FONTS 583, 584, 585. DESCRIPCIÓ DE L'ÚS FETA PELS INFORMANTS. Per a fer els collars dels gossos.

Artesanal: elaboració de calçat

FONT 1295. DESCRIPCIÓ DE L'ÚS FETA PER L'INFORMANT. A casa fa 200 anys que fem esclops. Compràvem els pins al Masot, els tallàvem a la mida de $40 \mathrm{~cm}$ i en feien els esclops amb la fusta ben verda, quan estaven secs es pulien i s'hi posava la ganxola que era de cuiro de xai o de cabra i és el que protegeix el peu perquè no t'enceti. Hi havia diverses formes d'esclops: forma de gra d'all, forma de nas. OBSERVACIONS. Els números que es venien més era per a homes el 27 i per a dones el 25 . Solien durar un any, i llavors els havies de canviar. Per a fer sis parells d'esclops es tardava 14 hores. Valien sis o set pessetes i després de la guerra cap al final, 18 pessetes.

\section{BARREGES AMB AQUEST TÀXON}




\section{No consta}

FONTS 561, 562, 563. Entrevista 83 (vegeu catàleg de barreges)

FONT 571. Entrevista 89, barreja II (vegeu catàleg de barreges)

Part aèria jove

FONT 503. Entrevista 43 (vegeu catàleg de barreges)

FONT 528. Entrevista 61, barreja I (vegeu catàleg de barreges)

\section{Piper nigrum L. (piperàcies)}

BCN 38292

\section{NOMS POPULARS}

Pebre (fruit) $(507,509,510,528,571,574,575,576,577)$

Pebre negre (fruit) (1327)

\section{USOS MEDICINALS}

Fruit

Salutifer

FONTS 507, 509, 510. DESCRIPCIÓ DE L'ÚS FETA PELS INFORMANTS. Quan neixen els polls se'ls posava un gra de pebre a la boca perquè deien que es feien més valents. FORMA FARMACEUTICA I US. Sense forma farmacèutica (ús directe, ús intern). DESTINACIO Medicina veterinària.

\section{BARREGES AMB AQUEST TÀXON}

Fruit

FONT 1327. Entrevista 14, barreja IV (vegeu catàleg de barreges)

FONT 528. Entrevista 61, barreja II (vegeu catàleg de barreges)

FONT 571. Entrevista 89, barreja II (vegeu catàleg de barreges)

FONTS 574, 575, 576, 577. Entrevista 91, barreja II (vegeu catàleg de barreges)

\section{Pistacia lentiscus L. (anacardiàcies)}

BCN 24948

\section{NOMS POPULARS}

Llentiscle $(547,548,753,754,755,1321,1336)$

\section{USOS MEDICINALS}

Fruit

Hipoglucemiant

FONTS 753, 754, 755. DESCRIPCIÓ DE L'ÚS FETA PELS INFORMANTS. Per a fer baixar el sucre. FORMA FARMACĖUTICA I ÚS. Tisana (ús intern). PREPARACIÓ. Decocció. Aigua de les fulles i de les granes quan són ben negres. DESTINACIÓ. Medicina humana.

Fulla

Hipoglucemiant

FONTS 753, 754, 755. DESCRIPCIÓ DE L'ÚS FETA PELS INFORMANTS. Per a fer baixar el sucre. FORMA FARMACĖUTICA I ÚS. Tisana (ús intern). PREPARACIÓ. Decocció. Aigua de les fulles i de les granes quan són ben negres. DESTINACIO. Medicina humana.

Part aèria

Hipoglucemiant

FONT 1336. DESCRIPCIÓ DE L'ÚS FETA PER L'INFORMANT. Per a fer baixar el sucre. FORMA FARMACÈUTICA I ÚS. Tisana (ús intern). PREPARACIÓ. Decocció. DESTINACIÓ. Medicina humana.

\section{BARREGES AMB AQUEST TÀXON}

Fulla

FONTS 547, 548. Entrevista 73, barreja I (vegeu catàleg de barreges)

Pisum sativum L. (papilionàcies)

BCN 32140

\section{NOMS POPULARS}

Pèsol bord (564)

\section{USOS ALIMENTARIS}

No consta

No consta el tipus d'ingesta - No consta el mode de preparació

FONT 564. DESCRIPCIÓ DE L'ÚS FETA PER L'INFORMANT. Per als conills. DESTINACIÓ Alimentació animal.

\section{Plantago lanceolata L. (plantaginàcies)}

BCN 24949 


\section{NOMS POPULARS}

Plantatge $(520,521,547,564,565,566,572,573,590)$

Plantatge estret $(505,506,542,543,544,553,583,584,585,1299,1314,1330,1361,1362)$

Plantatge llarg $(548,556,557,1332,1333,1334,1335,1336)$

\section{USOS MEDICINALS}

\section{Fulla}

Antiberrugós

FONT 564. DESCRIPCIÓ DE L'ÚS FETA PER L'INFORMANT. Posada sobre la berruga amb un esparadrap a sobre. FORMA FARMACĖUTICA I ÚS. Sense forma farmacèutica (ús directe, ús extern). PREPARACIÓ. La fulla picada. DESTINACIÓ. Medicina humana.

Antibronquític

FONT 1299. DESCRIPCIÓ DE L'ÚS FETA PER L'INFORMANT. Va bé per als pulmons i per als bronquis. FORMA FARMACĖUTICA I ÚS. Tisana (ús intern). PREPARACIÓ. Decocció. DESTINACIÓ. Medicina humana.

Antiinflamatori faringi

FONTS 505, 506, 583, 584, 585. DESCRIPCIÓ DE L'ÚS FETA PELS INFORMANTS. Per al mal de coll. FORMA FARMACĖUTICA I ÚS. Tisana (ús intern). PREPARACIÓ. Decocció DESTINACIÓ. Medicina humana.

Antipneumònic

FONT 1299. DESCRIPCIÓ DE L'ÚS FETA PER L'INFORMANT. Va bé per als pulmons i per als bronquis. FORMA FARMACĖUTICA I ÚS. Tisana (ús intern). PREPARACIÓ. Decocció. DESTINACIÓ. Medicina humana.

Antisèptic bucal

FONTS 553, 556, 557, 583, 584, 585. DESCRIPCIÓ DE L'ÚS FETA PELS INFORMANTS. Per a glopejar per al mal de boca, per a tatxes (553). Per a les tatxes a la boca $(556,557$, 583, 584, 585). FORMA FARMACĖUTICA I ÚS. Col-lutori (ús extern). PREPARACIÓ Decocció $(553,556,557,583,584,585)$. DESTINACIÓ. Medicina humana.

Diürètic

FONTS 542, 543, 544. DESCRIPCIÓ DE L'ÚS FETA PELS INFORMANTS. Per a fer aigua, per a netejar [dit "llempiar"]. FORMA FARMACĖUTICA I ÚS. Tisana (ús intern) PREPARACIÓ. Decocció. DESTINACIÓ. Medicina humana.

\section{Part aèria}

Anticatarral

FONT 1335. DESCRIPCIÓ DE L'ÚS FETA PER L'INFORMANT. Per als constipats. FORMA FARMACĖUTICA I ÚS. Tisana (ús intern). PREPARACIÓ. Decocció. DESTINACIÓ. Medicina humana.

Antiinflamatori intestinal
FONT 1335. DESCRIPCIO DE L'ÚS FETA PER L'INFORMANT. Per a la panxa. FORMA FARMACĖUTICA I ÚS. Tisana (ús intern). PREPARACIÓ. Decocció. DESTINACIÓ. Medicina humana. OBSERVACIONS. No l'usen gaire.

Hematocatàrtic

FONTS 1332, 1333, 1334. DESCRIPCIÓ DE L'ÚS FETA PELS INFORMANTS. Per a netejar la sang. FORMA FARMACĖUTICA I ÚS. Tisana (ús intern). PREPARACIÓ. Decocció. DESTINACIÓ. Medicina humana.

\section{USOS ALIMENTARIS}

\section{Part aèria}

Ingestió de la part de la planta crua - Fresca (sense preparació)

FONTS 565, 566, 572, 573, 590. DESCRIPCIÓ DE L'ÚS FETA PELS INFORMANTS. Per als conills $(565,566)$. Es donava als conills $(572,573)$. Es donaven als conills (590). DESTINACIÓ. Alimentació animal $(565,566,572,573,590)$

\section{BARREGES AMB AQUEST TÀXON}

\section{Fulla}

FONT 1314. Entrevista 17, barreja II (vegeu catàleg de barreges)

FONTS 505, 506. Entrevista 47, barreja II (vegeu catàleg de barreges)

FONTS 520, 521. Entrevista 56, barreja II (vegeu catàleg de barreges)

FONTS 547, 548. Entrevista 73, barreja I (vegeu catàleg de barreges)

FONT 553. Entrevista 77, barreja III (vegeu catàleg de barreges)

\section{Part aèria}

FONT 1336. Entrevista 16, barreja III (vegeu catàleg de barreges)

FONTS 1361, 1362. Entrevista 29, barreja III (vegeu catàleg de barreges)

FONT 1330. Entrevista 32, barreja IV (vegeu catàleg de barreges)

\section{Plantago major L. (plantaginàcies)}

BCN 24950

\section{NOMS POPULARS}

Plantatge $(520,521,539,540,564)$

Plantatge ample $(518,519,542,543,544,553,556,557,578,579,583,584,585,1299$, $1343,1344,1361,1362)$

Plantatge rodó $(1327,1332,1333,1334)$ 


\section{USOS MEDICINALS}

Fulla

Antiberrugós

FONT 564. DESCRIPCIÓ DE L'ÚS FETA PER L'INFORMANT. Posada sobre la berruga amb un esparadrap a sobre. FORMA FARMACĖUTICA I ÚS. Sense forma farmacèutica (ús directe, ús extern). PREPARACIÓ. La fulla picada. DESTINACIÓ. Medicina humana.

Antibronquític

FONT 1299. DESCRIPCIÓ DE L'ÚS FETA PER L'INFORMANT. Va bé per als pulmons i per als bronquis. FORMA FARMACĖUTICA I ÚS. Tisana (ús intern). PREPARACIÓ. Decocció. DESTINACIÓ. Medicina humana.

Antiinflamatori faring

FONTS 518, 519, 583, 584, 585. DESCRIPCIÓ DE L'ÚS FETA PELS INFORMANTS. Per a fer gàrgares per al mal de coll $(518,519)$. Per al mal de coll $(583,584,585)$. FORMA FARMACĖUTICA I ÚS. Gargarisme (ús extern) $(518,519)$. Tisana (ús intern) $(583,584,585)$. PREPARACIÓ. Decocció $(518,519,583,584,585)$. DESTINACIÓ. Medicina humana.

Antipneumònic

FONT 1299. DESCRIPCIÓ DE L'ÚS FETA PER L'INFORMANT. Va bé per als pulmons i per als bronquis. FORMA FARMACĖUTICA I ÚS. Tisana (ús intern). PREPARACIÓ. Decocció. DESTINACIÓ. Medicina humana.

Antisèptic bucal

FONTS 553, 556, 557, 578, 579, 583, 584, 585. DESCRIPCIÓ DE L'ÚS FETA PELS INFORMANTS. Per a glopejar per al mal de boca, per a tatxes (553). Per a les tatxes a la boca $(556,557,583,584,585)$. Per a les llagues $(578,579)$. FORMA FARMACĖUTICA I ÚS. Collutori (ús extern) $(553,556,557,583,584,585)$. Sense forma farmacèutica (ús directe ús intern) $(578,579)$. PREPARACIÓ. Decocció $(553,556,557,583,584,585)$. Es posava la fulla directa $(578,579)$. DESTINACIÓ. Medicina humana.

Diürètic

FONTS 542, 543, 544. DESCRIPCIÓ DE L'ÚS FETA PELS INFORMANTS. Per a fer aigua per a netejar [dit "llempiar"]. FORMA FARMACĖUTICA I ÚS. Tisana (ús intern). PREPARACIÓ. Decocció. DESTINACIÓ. Medicina humana.

Per a les picades

FONTS 539, 540. DESCRIPCIÓ DE L'ÚS FETA PELS INFORMANTS. Per a les picades. FORMA FARMACĖUTICA I ÚS. Sense forma farmacèutica (ús directe, ús extern). PREPARACIÓ. T'has de fregar amb les fulles. DESTINACIÓ. Medicina humana.

\section{Part aèria}

Anticatarral

FONTS 1343, 1344. DESCRIPCIÓ DE L'ÚS FETA PELS INFORMANTS. Per als refredats. FORMA FARMACĖUTICA I ÚS. Tisana (ús intern). PREPARACIÓ. Decocció. DESTINACIÓ.

Medicina humana.

Hematocatàrtic
FONTS 1332, 1333, 1334. DESCRIPCIÓ DE L'ÚS FETA PELS INFORMANTS. Per a purificar la sang. FORMA FARMACĖUTICA I ÚS. Tisana (ús intern). PREPARACIÓ. Decocció. DESTINACIÓ. Medicina humana. OBSERVACIONS. És més medicinal que el plantatge llarg (Plantago lanceolata).

\section{BARREGES AMB AQUEST TÀXON}

Fulla

FONT 1327. Entrevista 14, barreja II (vegeu catàleg de barreges)

Part aèria

FONTS 1361, 1362. Entrevista 29, barreja III (vegeu catàleg de barreges)

Plantago ovata Forsk. (plantaginàcies)

BCN 20354

\section{NOMS POPULARS}

Plantatge $(1213,1214)$

\section{USOS MEDICINALS}

\section{Fulla}

Antiinflamatori faringi

FONTS 1213, 1214. DESCRIPCIÓ DE L'ÚS FETA PELS INFORMANTS. Per al coll. FORMA FARMACEUUTICA I ÚS. Tisana (ús intern). DESTINACIÓ. Medicina humana.

\section{Plantago sp. (plantaginàcies)}

\section{NOMS POPULARS}

Plantatge $(583,584,585,1350,1351,1352)$

\section{ALTRES USOS}

\section{Fulla}

Lúdic: jocs i joguines

FONT 1352. DESCRIPCIÓ DE L'ÚS FETA PER L'INFORMANT. Per a jugar a cuinetes, els eiem servir de bistecs.

\section{Part aèria}

Lúdic: jocs i joguines 
FONT 1352. DESCRIPCIÓ DE L'ÚS FETA PER L'INFORMANT. Per a jugar, es doblava i es disparava la flor com un tiragomes.

\section{BARREGES AMB AQUEST TÀXON}

Part aèria

FONTS 1350, 1351. Entrevista 39, barreja II (vegeu catàleg de barreges)

FONTS 583, 584, 585. Entrevista 96, barreja IV (vegeu catàleg de barreges)

\section{Platanus orientalis L. var. acerifolia Aiton (platanàcies)}

BCN 31294

\section{NOMS POPULARS}

Platana $(515,516)$

Plataner $(586,587)$

\section{USOS MEDICINALS}

\section{Parènquima cortica}

Antiodontàlgic

FONTS 515, 516, 586, 587. DESCRIPCIÓ DE L'ÚS FETA PELS INFORMANTS. Glopejar per al mal de queixals $(515,516)$. Per als queixals $(586,587)$. FORMA FARMACĖUTICA I US. Col·lutori (ús extern) $(515,516)$. Tisana (ús intern) $(586,587)$. PREPARACIÓ. Decocció. Fer aigua de la segona pela de les platanes $(515,516)$. Decocció. Aigua de la pela de plataner $(586,587)$. DESTINACIÓ. Medicina humana.

\section{Polygala calcarea F.W.Schultz (poligalàcies)}

BCN 24951

\section{NOMS POPULARS}

Angelets $(518,519,1293,1331,1335,1336)$

Flor blava $(746,747)$

Flor de maig (1293)

Herba blava $(504,505,506,507,509,510,511,512,513,514,517,520,521,524,529,530$, $531,546,547,548,552,554,555,556,557,558,561,562,563,565,566,567,569,570$ $571,572,573,578,579,580,590,748,749,750,751,752,753,754,755,1213,1214,1293$ $1294,1296,1299,1307,1308,1309,1310,1311,1312,1325,1326,1327,1335,1336,1339$ $1340,1341,1342,1361,1362$
Herba de bac (1294)

Herba de l'enflema $(529,530,531)$

Herba de la inflamació $(542,543,544,1293)$

\section{USOS MEDICINALS}

Part aèria florida

Anticatarral

FONTS 561, 562, 563. DESCRIPCIÓ DE L'ÚS FETA PELS INFORMANTS. Per als refredats. FORMA FARMACĖUTICA I ÚS. Tisana (ús intern). PREPARACIÓ. Decocció. DESTINACIÓ. Medicina humana.

Antidismenorreic

FONTS 554, 555. DESCRIPCIÓ DE L'ÚS FETA PELS INFORMANTS. Per a la regla de les dones. FORMA FARMACĖUTICA I ÚS. Tisana (ús intern). PREPARACIÓ. Decocció DESTINACIÓ. Medicina humana.

Antiinflamatori

FONTS 517, 524, 529, 530, 531, 542, 543, 544, 561, 562, 563, 751. DESCRIPCIÓ DE L'ÚS FETA PELS INFORMANTS. Per a les inflamacions $(517,561,562,563)$. Per a les inflamacions. Desinflama els nervis $(529,530,531)$ Va bé per a la inflamació $(524)$. Per a la inflamaciós. D51). Va bé per a lo $(529,530,531)$. Va be per a la Intació (524). Per a la ús. Tisana (ús intern). PREPARACIÓ. Decocció $(517,524,529,530,531,542,543,544$ US. Tisana (ús intern). PREPARACIO. Decocció (517,
$561,562,563,751)$. DESTINACIÓ. Medicina humana.

Antiinflamatori hepàtic

FONTS 1213, 1214. DESCRIPCIÓ DE L'ÚS FETA PELS INFORMANTS. Per a la fel inflamada. FORMA FARMACĖUTICA I ÚS. Tisana (ús intern). PREPARACIÓ. Infusió inflamada. FORMA FARMACÉĆ. MODE D'UTILITZACIÓ/POSOLOGIA. Un cop al dia, en novenes. DESTINACIÓ. Medicina humana.

Antiinflamatori intestinal

FONTS $504,518,519,520,521,546,554,555,558,565,566,567,571,580,748,749,750$ $752,753,754,755,1293,1294,1299,1307,1308,1309,1311,1312,1335$. DESCRIPCIÓ DE L'ÚS FETA PELS INFORMANTS. Per a les inflamacions (504). Per a la panxa $(518,519$ $567,748,749,750)$. Per als mals de panxa (752). Per a la canalla quan tenen gasos, per al ventre, per a pair (546). Mal de ventre de la canalla i per a les inflamacions $(520,521)$. Va bé per a la panxa, sobretot per als nens (558). Per a netejar [dit "llempiar"] el cos i la panxa (571). Va bé per a la panxa $(565,566,1311,1312)$. Per al ventre $(554,555)$. Per a les inflamacions de la panxa $(753,754,755)$. L'aigua és bona per al ventre $(580)$. Per al mal de panxa de la canalla (1293). Va molt bé per als budells. Se'n dóna a les criatures perquè no et farà mai mal (1294). Per als nens quan tenen mal de ventre (1299). La utilitzaven quan els nens eren petits i tenien mal de ventre $(1307,1308,1309)$. Per a la mainada quan tenia mal de ventre (1335). FORMA FARMACEUTICA I ÚS. Tisana (ús intern). PREPARACIÓ Decocció $(504,518,519,520,521,546,554,555,558,565,566,567,571,580,748,749$ 
Medicina humana. OBSERVACIONS. Fa una aigua tova i amorosa (1294). En tenen d'assecada $(1307,1308,1309)$. No pot fer cap mal, no "desasipa" (1335).

Antiinflamatori renal

FONTS 572, 573, 746. DESCRIPCIÓ DE L'ÚS FETA PELS INFORMANTS. Per a la inflamació i per a fer orinar (746). Per a l'enflema de ronyons $(572,573)$. FORMA FARMACĖUTICA I ÚS. Tisana (ús intern). PREPARACIÓ. Decocció (572, 573, 746). DESTINACIÓ. Medicina humana.

Antipelohèmic

FONTS 1325, 1326. DESCRIPCIÓ DE L'ÚS FETA PELS INFORMANTS. Aclareix la sang FORMA FARMACĖUTICA I ÚS. Tisana (ús intern). PREPARACIÓ. Decocció. DESTINACIÓ. Medicina humana.

Antiprostatític

FONTS 578, 579. DESCRIPCIÓ DE L'ÚS FETA PELS INFORMANTS. Per a la pròstata. FORMA FARMACĖUTICA I ÚS. Tisana (ús intern). PREPARACIÓ. Decocció. DESTINACIÓ. Medicina humana.

Antisèptic extern

FONTS 1213, 1214, 1325, 1326, 1339, 1340. DESCRIPCIÓ DE L'ÚS FETA PELS INFORMANTS. Les ferides es netegen amb una gasa de roba de fil $(1213,1214)$. Desinfecta ferides $(1325,1326)$. És molt desinfectant $(1339,1340)$. FORMA FARMACĖUTICA I ÚS. Bany (ús extern). PREPARACIÓ. Decocció $(1213,1214,1325,1326,1339,1340)$. DESTINACIÓ. Medicina humana.

Antisèptic intern

FONTS 552, 569, 570, 747, 1339, 1340. DESCRIPCIÓ DE L'ÚS FETA PELS INFORMANTS Per a les infeccions $(552,569,570,747)$. És molt desinfectant $(1339,1340)$. FORMA FARMACĖUTICA I ÚS. Tisana (ús intern). PREPARACIÓ. Decocció (552, 569, 570, 747, $1339,1340)$. DESTINACIÓ. Medicina humana $(569,570,747,1339,1340)$. Medicina humana 1339, 1340). DESTINACIO. Medicina humana $(569,570,747,1339,1340)$. Medicina humana
i veterinària (552). OBSERVACIONS. La meva [dit "meu"] mare també la feia servir per al bestiar (552).

Antisèptic urinari

FONTS 511, 512, 513, 514, 1299. DESCRIPCIÓ DE L'ÚS FETA PELS INFORMANTS. Per a les infeccions d'orina $(511,512,513,514,1299)$. FORMA FARMACĖUTICA I ÚS. Tisana (ús intern). PREPARACIÓ. Decocció $(511,512,513,514)$. DESTINACIÓ. Medicina humana. Carminatiu

FONTS 546, 1336. DESCRIPCIÓ DE L'ÚS FETA PELS INFORMANTS. Per a la canalla quan tenen gasos, per al ventre, per a pair (546). Per a la mainada quan tenien malestar (1336). FORMA FARMACĖUTICA I ÚS. Tisana (ús intern). PREPARACIÓ. Decocció $(546,1336)$ DESTINACIÓ. Medicina humana.

Desconegut per l'informant

FONT 1310. FORMA FARMACĖUTICA I ÚS. Desconegut per l'informant. OBSERVACIONS. N'havia collit, però no en recorda l'ús.
Digestiu

FONTS 546, $547,548,1307,1308,1309,1361,1362$ DESCRIPCIÓ DE L'ÚS FETA PELS INFORMANTS. Per a la canalla quan tenen gasos, per al ventre, per a pair (546). És digestiva $(547,548)$. Quan estàs rebotit $(1307,1308,1309)$. És digestiva, en donaven a la canalla $(1361,1362)$. FORMA FARMACĖUTICA I ÚS. Tisana (ús intern). PREPARACIÓ. Decocció $(546,547,548,1307,1308,1309)$. En infusió $(1361,1362)$. DESTINACIÓ Medicina humana. OBSERVACIONS. En tenen d'assecada $(1307,1308,1309)$.

Diürètic

FONTS 517, 556, 557, 571, 590, 746. DESCRIPCIÓ DE L'ÚS FETA PELS INFORMANTS Per a la inflamació i per a fer orinar $(746)$. Per a l'orina $(517,556,557)$. Per a fer orinar (571) Per a infeccions d'orina $(590)$. FORMA FARMACEUTICA I ÚS. Tisana (ús intern). PREPARACIÓ. Decocció $(517,556,557,571,590,746)$. DESTINACIO. Medicina humana.

Estomacal

FONTS 556, 557, 1327. DESCRIPCIÓ DE L'ÚS FETA PELS INFORMANTS. Per a l'estómac $(556,557)$. L'usa per a l'estómac (1327). FORMA FARMACĖUTICA I ÚS. Tisana (ús intern) PREPARACIO. Decocció $(556,557)$. En infusió (1327). MODE D'UTILITZACIO/POSOLOGIA. Es pren amb novenes (1327). DESTINACIO. Medicina humana.

Hematocatàrtic

FONTS 507, 509, 510. DESCRIPCIÓ DE L'ÚS FETA PELS INFORMANTS. Per a purificar les sangs. FORMA FARMACEUTICA I ÚS. Tisana (ús intern). PREPARACIÓ. Decocció. DESTINACIO. Medicina humana.

Hepatoprotector

FONTS 1296, 1327. DESCRIPCIÓ DE L'ÚS FETA PELS INFORMANTS. Diu que va bé per al fetge (1296). L'usa per al fetge (1327). FORMA FARMACEUTICA IUS. Tisana (ús intern). PREPARACIÓ. Decocció (1296). En infusió (1327). MODE D'UTILITZACIO/POSOLOGIA. Es pren en novenes (1327). DESTINACIO. Medicina humana. OBSERVACIONS. No la fa servir (1296)

Protector renal

FONTS 1341, 1342. DESCRIPCIÓ DE L'ÚS FETA PELS INFORMANTS. Va bé per als ronyons. FORMA FARMACĖUTICA I ÚS. Tisana (ús intern). PREPARACIÓ. En infusió. DESTINACIO Medicina humana.

Salutífer

FONTS 505, 506. DESCRIPCIÓ DE L'ÚS FETA PELS INFORMANTS. Per a refrescar els nadons. FORMA FARMACEUTICA I ÚS. Bany (ús extern). PREPARACIÓ. Decocció. DESTINACIO. Medicina humana.

\section{ALTRES USOS}

Planta sencera

Literatura oral popular: llegendes, gloses, contes, dites, refranys, poemes, cançons 
FONT 1213, 1214. DESCRIPCIÓ DE L'ÚS FETA PER L'INFORMANT. L'herba blava és l'herba de la inflamació, ho cura tot, fins i tot el ronyó.

\section{ALTRES OBSERVACIONS}

FONTS 520, 521, 753,754, 755. DESCRIPCIÓ FETA PELS INFORMANTS. N'hi ha de blanca, rosa i blava $(520,521)$. S'ha de collir el mes de maig $(753,754,755)$.

\section{BARREGES AMB AQUEST TÀXON}

\section{Part aèria florida}

FONT 1331. Entrevista 30, barreja II (vegeu catàleg de barreges)

FONT 746. Entrevista 45, barreja I (vegeu catàleg de barreges)

FONTS 529, 530, 531. Entrevista 53, barreja V (vegeu catàleg de barreges)

FONTS $753,754,755$. Entrevista 67 , barreja II (vegeu catàleg de barreges)

FONTS 554, 555. Entrevista 78, barreja V (vegeu catàleg de barreges)

\section{Polygala vayredae Costa (poligalàcies)}

BCN 16328

\section{ALTRES OBSERVACIONS}

FONTS 518, 519. DESCRIPCIÓ FETA PELS INFORMANTS. Quan érem petits i anàvem a estudi, n'hi havia allà a la vora del camí, ens hi fixàvem perquè fa una flor molt maca; en vàrem agafar i la vàrem provar de plantar, però no ens va viure. Més tard una senyora que va fer un llibre de la Vall del Bac ens va dir que no n'hi havia en tot Espanya.

\section{Polygonum aviculare L. (poligonàcies)}

BCN 24952

\section{NOMS POPULARS}

Estaca-rossins $(583,584,585)$

Passacamins $(528,553,564,569,570,588)$

Tiravaques (1324)

\section{USOS ALIMENTARIS}

Part aèria

Ingestió de la part de la planta crua - Fresca (sense preparació)
FONTS 528, 564, 569, 570, 583, 584, 585, 588, 1324. DESCRIPCIÓ DE L'ÚS FETA PELS INFORMANTS. Es donava per a menjar als conills $(528)$. Per als conills $(564,569,570,588)$ Ho piquen los. Elling i els conills també s'ho mengen $(583,584,585)$. Si en dónes als conills Ho piquen les gall (1324). DESTINACIÓ. Alim mones als conills $585,588)$. Alimentació humana $(1324)$.

\section{ALTRES OBSERVACIONS}

FONT 528. DESCRIPCIÓ FETA PER L'INFORMANT. Es fan als rostolls.

\section{Polygonum persicaria L. (poligonàcies)}

BCN 47685

\section{NOMS POPULARS}

Mala herba $(529,530,531)$

\section{USOS MEDICINALS}

\section{No consta}

Desconegut per l'informant

FONTS 529, 530, 531. FORMA FARMACĖUTICA I ÚS. Desconegut per l'informant. OBSERVACIONS. Segurament serveixen per a medicina.

\section{ALTRES OBSERVACIONS}

FONTS 529, 530, 531. DESCRIPCIÓ FETA PELS INFORMANTS. Són herbes que surten per aquí.

\section{Polypodium vulgare L. (polipodiàcies)}

BCN 123787

\section{NOMS POPULARS}

Falzia $(505,506)$

\section{ALTRES USOS}

\section{Fronda}

Literatura oral popular: llegendes, gloses, contes, dites, refranys, poemes, cançons 
Apèndix 1. Catàleg de tàxons.

FONTS 505, 506. DESCRIPCIÓ DE L'ÚS FETA PELS INFORMANTS. Si busqueu falzia tot l'any en trobareu, aneu al cor dels homes i sempre en cercareu (505). Si busqueu falzia tot l'any la trobareu, aneu al cor dels homes i sempre en cercareu (506).

\section{Populus nigra L. (salicàcies)}

BCN 113746

\section{NOMS POPULARS}

Pollancre $(568,1215)$

\section{ALTRES USOS}

Tija

Altres informacions

FONT 1215. DESCRIPCIÓ DE L'ÚS FETA PER L'INFORMANT. No és bo per a cremar.

Artesanal: elaboració de calçat

FONT 568. DESCRIPCIÓ DE L'ÚS FETA PER L'INFORMANT. Per a fer esclops.

\section{Populus sp. (salicàcies)}

\section{NOMS POPULARS}

Pollancre $(539,540)$

\section{ALTRES USOS}

Tija

Altres informacions

FONTS 539, 540. DESCRIPCIÓ DE L'ÚS FETA PELS INFORMANTS. Com es feia abans per serrar amb una ninyola.

\section{Portulaca oleracea L. (portulacàcies)}

BCN 24953

\section{NOMS POPULARS}

Verdolaga $(518,519,565,566,583,584,585,1213,1214,1324)$

\section{USOS ALIMENTARIS}

Fulla

Ingestió de la part de la planta crua - Fresca (sense preparació)

FONTS $518,519,565,566,1213,1214,1324$. DESCRIPCIÓ DE L'ÚS FETA PELS INFORMANTS. Per a amanir $(518,519)$. Es menjaven amanides $(565,566)$. Es menjava amanida quan era tendra (1324). CONSUMICIÓ. Entrant - Amanida (1213). DESTINACIÓ Alimentació humana $(518,519,565,566,1213,1214,1324)$.

ALTRES OBSERVACIONS

FONTS 583, 584, 585. DESCRIPCIÓ FETA PELS INFORMANTS. Surten a l'hort.

Potentilla erecta (L.) Räuschel (rosàcies)

BCN 24954

\section{NOMS POPULARS}

Tormentil·la (1324)

\section{USOS MEDICINALS}

Arrel

Antidiarreic

FONT 1324. DESCRIPCIÓ DE L'ÚS FETA PER L'INFORMANT. Va bé per a les diarrees. FORMA FARMACĖUTICA I ÚS. Tisana (ús intern). PREPARACIÓ. Decocció. DESTINACIÓ. Medicina humana.

Digestiu

FONT 1324. DESCRIPCIÓ DE L'ÚS FETA PER L'INFORMANT. Per a pair. FORMA FARMACĖUTICA I ÚS. Tisana (ús intern). PREPARACIÓ. Decocció. DESTINACIÓ. Medicina humana.

Potentilla neumanniana Reichenb. (rosàcies) BCN 24955

\section{NOMS POPULARS}

Gram negre (1324)

\section{USOS MEDICINALS}

No consta 
Desconegut per l'informant

FONT 1324. FORMA FARMACĖUTICA I ÚS. Desconegut per l'informant. OBSERVACIONS. No en recorda l'ús.

\section{Potentilla reptans L. (rosàcies)}

BCN 47660

\section{NOMS POPULARS \\ Gramònica (746)}

\section{USOS MEDICINALS}

Part aèria florida

Antisèptic bucal

FONT 746. DESCRIPCIÓ DE L'ÚS FETA PER L'INFORMANT. Per a fer aigua per a les tatxes de la boca. FORMA FARMACÉUTICA I ÚS. Col-lutori (ús extern). PREPARACIÓ. Decocció. DESTINACIO. Medicina humana.

\section{Primula veris L. (primulàcies)}

BCN 27280

\section{NOMS POPULARS}

Cucut $(525,526,527,547,548,581,590,1353,1354,1352)$

Flor de cucut (553)

\section{USOS MEDICINALS}

Flor

Anticatarral

FONT 553. DESCRIPCIÓ DE L'ÚS FETA PER L'INFORMANT. Es feia servir per als refredats. FORMA FARMACĖUTICA I ÚS. Tisana (ús intern). PREPARACIÓ. Decocció. DESTINACIÓ. Medicina humana.

\section{ALTRES USOS}

Part aèria florida

Ornamental: elaboració de rams
FONTS 525, 526, 527, 547, 548, 590, 1352, 1353, 1354. DESCRIPCIÓ DE L'ÚS FETA PELS INFORMANTS. Per a fer bonic $(525,526,527)$. Per a fer rams $(548)$. Es duien a l'església per a fer bonic (500). Per a fer (525, 526.527). Per a fer (547). Per a fer rams a primavera (1352). Per a fer per a fer bonic (590). Per a fer ramets (547). Per a fer rams a la primavera (1352). Per a fer ramets a la primavera, quan els veus fan molt

\section{ALTRES OBSERVACIONS}

FONT 1354. DESCRIPCIÓ FETA PER L'INFORMANT. Quan els veus fan molta il/lusió perquè vol dir que el fred se'n va.

\section{Prunella grandiflora (L.) Scholler (labiades)}

\section{BCN 24956}

\section{NOMS POPULARS}

Herba de la gangrena (517)

Herba del traïdor $(525,526,527,588,591,592,1294,1296,1298,1300,1313,1324,1330$ $1335,1339,1340,1343,1344,1345,1346,1350,1351,1352$

Xuclaabelles $(525,526,527)$

\section{USOS MEDICINALS}

Flor

Analgèsic

FONT 1335. DESCRIPCIÓ DE L'ÚS FETA PER L'INFORMANT. L'ha fet servir per a una mossegada de gos, li va treure el dolor. FORMA FARMACEUTICA I ÚS. Bany (ús extern). PREPARACIO. Decocció. La flor bullida i després fer-ne un bany. DESTINACIO. Medicina humana.

Antihemorroïdal

FONT 1335. DESCRIPCIÓ DE L'ÚS FETA PER L'INFORMANT. Va molt bé per a les morenes, és molt desinfectant i calma el dolor. FORMA FARMACEUTICA I US. Bany (ús extern). PREPARACIO. Decocció. La flor bullida i després fer-ne un bany. DESTINACIÓ. Medicina humana.

\section{No consta}

Per a trastorns del sistema sanguini

FONT 1215. DESCRIPCIÓ DE L'ÚS FETA PER L'INFORMANT. Una amiga meva la feia servir per a evitar que les ferides sagnessin. FORMA FARMACĖUTICA I ÚS. Desconegut per l'informant. DESTINACIÓ. Medicina humana.

Part aèria florida

Antigangrenós 
FONT 1294. DESCRIPCIÓ DE L'ÚS FETA PER L'INFORMANT. És antigangrena. FORMA FARMACĖUTICA I ÚS. Tisana (ús intern). PREPARACIÓ. Decocció. DESTINACIÓ. Medicina humana.

Antisèptic bucal

FONT 1324. DESCRIPCIÓ DE L'ÚS FETA PER L'INFORMANT. El seu pare tenia mal de morros i s'ho prenia. FORMA FARMACĖUTICA I ÚS. Tisana (ús intern). PREPARACIÓ. En infusió. DESTINACIÓ. Medicina humana.

Antisèptic extern

FONTS 517, 591, 592, 1296, 1298, 1300, 1313, 1324, 1330, 1339, 1340, 1343, 1344, 1345 1346, 1350, 1351, 1352. DESCRIPCIÓ DE L'ÚS FETA PELS INFORMANTS. Per a les ferides, és molt desinfectant $(517,1298,1330,1339,1340)$. Per a rentar mals $(591,592)$. Per a les infeccions, és molt desinfectant (1296). Per a desinfectar $(1300,1313,1343,1344)$. Per a netejar ferides (1324). Per a desinfectar ferides i punxades $(1345,1346)$. Per a banyar ferides infectades, com de forquetes $(1350,1351)$. Per a desinfectar mals externs (1352). FORMA FARMACËUTICA I ÚS. Bany (ús extern). PREPARACIÓ. Decocció. T'has de banyar FORMA FARMACEUTICA I US. Bany (ús extern). PREPARACIO. Decocció. T'has de banyar el mal amb aigua tan calenta com puguis (517). Decocció (591, 592, 1296, 1298, 1300, 1313

Antisèptic intern

FONTS 1330, 1343, 1344. DESCRIPCIÓ DE L'ÚS FETA PELS INFORMANTS. És desinfectant (1330). Per a desinfectar $(1343,1344)$. FORMA FARMACÉUTICA I ÚS. Tisana (ús intern). PREPARACIÓ. Decocció (1330, 1343, 1344). DESTINACIÓ. Medicina humana.

Per al panadís

FONTS 1350, 1351. DESCRIPCIÓ DE L'ÚS FETA PELS INFORMANTS. Per a espitlles, escaldar el dit amb l'aigua bullent. FORMA FARMACÉUTICA I ÚS. Bany (ús extern). DESTINACIÓ. Medicina humana.

Vulnerari

FONT 1313. DESCRIPCIÓ DE L'ÚS FETA PER L'INFORMANT. Per a banyar mals i ferides. FORMA FARMACĖUTICA I ÚS. Bany (ús extern). PREPARACIÓ. Decocció. DESTINACIÓ. Medicina humana.

\section{USOS ALIMENTARIS}

Flor

Ingestió de la part de la planta crua - Fresca (sense preparació)

FONT 1335. DESCRIPCIÓ DE L'ÚS FETA PER L'INFORMANT. La flor és dolça i quan eren petites se la menjaven. DESTINACIÓ. Alimentació humana.

\section{ALTRES USOS}

\section{Part aèria florida}

Maneig agrosilvopastoral: obtenció de mel
FONTS 525, 526, 527. DESCRIPCIO DE L'ÚS FETA PELS INFORMANTS. La flor és dolça i les abelles hi són sempre.

\section{ALTRES OBSERVACIONS}

FONT 517. DESCRIPCIÓ FETA PER L'INFORMANT. Planta petitat arrapada a terra que fa un brot i té la flor morada, surt a pertot arreu.

\section{Prunella vulgaris L. (labiades)}

BCN 29759

\section{NOMS POPULARS}

Herba de la gangrena $(522,523,529,530,531,581)$

Herba de la inflamació (568)

\section{USOS MEDICINALS}

\section{Part aèria florida}

Antihemorroïdal

FONTS 529, 530, 531. DESCRIPCIÓ DE L'ÚS FETA PELS INFORMANTS. Per a les morenes i per a desinfectar. FORMA FARMACĖUTICA I ÚS. Desconegut per l'informant. DESTINACIÓ. Medicina humana.

Antiinflamatori

FONT 568. DESCRIPCIÓ DE L'ÚS FETA PER L'INFORMANT. Per a la inflamació. FORMA FARMACĖUTICA I ÚS. Tisana (ús intern). PREPARACIÓ. Es prenia en infusió. DESTINACIÓ. Medicina humana.

Antisèptic extern

FONTS 522, 523, 529, 530, 531. DESCRIPCIÓ DE L'ÚS FETA PELS INFORMANTS. Per a desinfectar, també per a les morenes $(529,530,531)$. Per a desinfectar coses que es gangrenessin $(522,523)$. FORMA FARMACÈUTICA I ÚS. Desconegut per l'informant $(529$, $530,531)$. Bany (ús extern) $(522,523)$. PREPARACIÓ. Decocció $(522,523)$. DESTINACIÓ. Medicina humana.

Antiulcerós (per a úlceres gàstriques)

FONT 581. DESCRIPCIÓ DE L'ÚS FETA PER L'INFORMANT. També per a les llagues d'estómac, un que l'havien operat de llaga se li va curar bevent aigua d'aquesta. FORMA FARMACÉUTICA I ÚS. Tisana (ús intern). PREPARACIÓ. Decocció. DESTINACIÓ. Medicina humana.

Coadjuvant del postpart 
Apèndix 1. Catàleg de tàxons.

FONTS 522, 523. DESCRIPCIÓ DE L'ÚS FETA PELS INFORMANTS. Aigua per a les truges quan havien godallat. FORMA FARMACĖUTICA I ÚS. Tisana (ús intern). PREPARACIÓ. Decocció. DESTINACIÓ. Medicina veterinària.

Resolutiu

FONT 581. DESCRIPCIÓ DE L'ÚS FETA PER L'INFORMANT. Per a banyar ferides i també llagues que se'ls fan a la gent que està enllitada. FORMA FARMACĖUTICA I ÚS. Bany (ús extern). PREPARACIÓ. Decocció. DESTINACIÓ. Medicina humana.

Vulnerari

FONT 581. DESCRIPCIÓ DE L'ÚS FETA PER L'INFORMANT. Per a banyar ferides i també llagues que se'ls fan a la gent que està enllitada. FORMA FARMACĖUTICA I ÚS. Bany (ús extern). PREPARACIÓ. Decocció. DESTINACIÓ. Medicina humana.

\section{ALTRES USOS}

\section{Planta sencera}

Altres informacions

FONT 581. DESCRIPCIÓ DE L'ÚS FETA PER L'INFORMANT. És una planta que sempre hi van les abelles.

\section{ALTRES OBSERVACIONS}

FONTS 522, 523, 529, 530, 531, 568. DESCRIPCIÓ FETA PELS INFORMANTS. Cama curta i una floreta lila $(529,530,531)$. Fa un gosset blau i la flor és dolça $(522,523)$. Es fa a 1500 $\mathrm{m}$ i fa una flor lila. La baixaven de la muntanya (568).

\section{BARREGES AMB AQUEST TÀXON}

\section{Part aèria florida}

FONTS 529, 530, 531. Entrevista 53, barreja I (vegeu catàleg de barreges)

\section{Prunus avium (L.) L. (rosàcies)}

BCN 24957

\section{NOMS POPULARS}

Cirer $(524,541,572,573,589)$

Cirera (fruit) $(503,507,509,510,525,526,527,556,557,565,566,583,584,585,1327$ $1330,1347,1348,1349,1350,1351)$

Cirerer $(553,580,590)$

\section{USOS MEDICINALS}

\section{Fruit}

Antiinflamatori intestinal

FONTS 507, 509, 510, 565, 566. DESCRIPCIÓ DE L'ÚS FETA PELS INFORMANTS. Per a quan tens mal de ventre $(507,509,510)$. Te'n donaven quan tenies mal de ventre $(565,566)$. FORMA FARMACEUUTICA I ÚS. Tintura alcohòlica (ús intern). PREPARACIÓ. Confitades en aiguardent $(507,509,510)$. Posades en aiguardent $(565,566)$. DESTINACIO. Medicina

Antinauseabund

FONT 1327. DESCRIPCIÓ DE L'ÚS FETA PER L'INFORMANT. Per al mareig. FORMA FARMACEUTICA I US, Tintura alcohòlica (ús intern). PREPARACIO. Confitat en aiguardent. DESTINACIÓ. Medicina humana.

\section{Llavor}

Antidiarreic

FONTS 525, 526, 527. DESCRIPCIÓ DE L'ÚS FETA PELS INFORMANTS. Els pinyols de cirera no es paeixen i diuen que restrenyen. FORMA FARMACĖUTICA I ÚS. Sense forma farmacèutica (ús directe, ús intern). DESTINACIÓ. Medicina humana.

\section{Peduncle}

Antisèptic urinari

FONTS 556, 557, 1330. DESCRIPCIÓ DE L'ÚS FETA PELS INFORMANTS. Per a infeccions d'orina $(556,557,1330)$. FORMA FARMACĖUTICA I ÚS. Tisana (ús intern). PREPARACIO Decocció $(556,557)$. Decocció. Aigua de cues de cirera (1330). DESTINACIÓ. Medicina humana.

Diürètic

FONTS 1347, 1348, 1349, 1350, 1351. DESCRIPCIÓ DE L'ÚS FETA PELS INFORMANTS. Per a fer orinar $(1347,1348,1349,1350,1351)$. FORMA FARMACEUTICA I US. Tisana (ús intern). PREPARACIÓ. Infusió de les cues de cirera $(1347,1348,1349)$. DESTINACIÓ. Medicina humana.

\section{USOS ALIMENTARIS}

Fruit

Ingestió de la part de la planta crua - Fresca (sense preparació)

FONTS 524, 572, 573, 580, 589. DESCRIPCIÓ DE L'ÚS FETA PELS INFORMANTS. Aquestes cireres són molt bones (524). Ens mengem les cireres (580). Les cireres són bones (589). DESTINACIÓ. Alimentació humana (524, 572, 573, 580, 589).

Ingestió de la part de la planta cuita - Cuita en sucre

FONT 585. DESCRIPCIÓ DE L'ÚS FETA PER L'INFORMANT. Es posen en aiguardent i queda un licor molt bo. DESTINACIÓ. Alimentació humana.

Preparació de begudes - Beguda preparada amb aiguardent 
FONTS 541, 583, 584, 590. DESCRIPCIÓ DE L'ÚS FETA PELS INFORMANTS. Se'n feia licors (541). Es feia licor posant les cireres en aiguardent (590). Es posen en aiguardent queda un licor molt bo $(583,584)$. DESTINACIÓ. Alimentació humana $(541,583,584,590)$.

\section{ALTRES OBSERVACIONS}

FONTS 572, 573. DESCRIPCIÓ FETA PELS INFORMANTS. N'hi havia de llei i de bords.

\section{BARREGES AMB AQUEST TÀXON}

Parènquima cortical

FONT 553. Entrevista 77, barreja III (vegeu catàleg de barreges)

\section{Peduncle}

FONT 503. Entrevista 43 (vegeu catàleg de barreges)

\section{Prunus cerasifera Ehrh. (rosàcies)}

BCN 14365

\section{NOMS POPULARS}

Mirabolà (541)

\section{Prunus domestica L. subsp. domestica (rosàcies)}

BCN 46834

\section{NOMS POPULARS}

Pruna (fruit) $(572,573,590)$

Pruna d'escaldar (fruit) (503)

Pruna de coure (fruit) (747)

Pruner $(561,562,563,564)$

Prunera $(524,560,567,580)$

\section{USOS MEDICINALS}

\section{Fruit}

Antiinflamatori intestinal

FONT 503. DESCRIPCIÓ DE L'ÚS FETA PER L'INFORMANT. Per al mal de ventre: "A vegades deiem que teníem mal de ventre perquè ens en donessin". FORMA
FARMACĖUTICA I ÚS. Sense forma farmacèutica (ús directe, ús intern). PREPARACIÓ. Es posaven escampades en el forn de pa i es feien coure. DESTINACIÓ. Medicina humana.

\section{USOS ALIMENTARIS}

Fruit

Ingestió de la part de la planta crua - Fresca (sense preparació)

FONTS 524, 561, 562, 563, 564, 567, 580, 747. DESCRIPCIÓ DE L'ÚS FETA PELS INFORMANTS. Per a menjar i també per a confitura (747). N'hi havia de moltes varietats: clàudies, de frare, godes, cascavellic ["cascaballito] ros, Sant Jaume, Sant Miquel (524). Per a menjar les prunes (580). OBSERVACIONS. Hi teníem unes prunes clàudies molt bones (567). N'hi havia de diverses classes, prunes de coure $(561,562,563)$. Prunes de coure, la clàudia, la pruna negra (564). DESTINACIÓ. Alimentació humana $(524,561,562,563,564$, $567,580,747)$.

Ingestió de la part de la planta cuita - Cuita sense vehicle

FONTS 503, 560. DESCRIPCIÓ DE L'ÚS FETA PELS INFORMANTS. Es posaven escampades en el forn de pa i es feien coure (503). Són prunes molt sucoses i les coiem al forn, treien tot el suc que l'arpofitàvem per a fer confitura i les prunes quedaven seques com aquelles que venen i ens les menjàvem durant l'hivern, es conservaven molt bé (560). OBSERVACIONS. Eren boníssimes, a vegades dèiem que teníem mal de ventre perquè ens en donessin (503). DESTINACIÓ. Alimentació humana $(503,560)$.

Ingestió de la part de la planta cuita - Cuita en aigua

FONTS 572, 573. DESCRIPCIÓ DE L'ÚS FETA PELS INFORMANTS. N'hi havia de prunes d'escaldar, que es feien bullir i es pelaven. Després quan es pastava el pa, es feia una coca s'hi posaven les prunes. DESTINACIÓ. Alimentació humana.

Ingestió de la part de la planta cuita - Cuita en sucre

FONTS 560, 590, 747. DESCRIPCIÓ DE L'ÚS FETA PELS INFORMANTS. Per a fer confitura i també per a menjar (747). Es feia prunat (prunes i figues) es covia amb sucre llavors es colava, quedava com una confitura (560). Per a fer melmelades hi posem una mica de llimona perque no sigui tant dolça (590). DESTINACIO. Alimentació humana $(560,590$, 747)

\section{ALTRES OBSERVACIONS}

FONTS 560, 747. DESCRIPCIÓ FETA PELS INFORMANTS. A aquells marges del Bes era ple d'aquestes prunes, són com prunes bordes (747). Sortien soles a les vores de les feixes. Feien aquelles prunes que en dèiem prunes de coure (560).

Prunus domestica L. subsp. insititia (L.) Bonnier et Layens (rosàcies)

BCN 36689 


\section{NOMS POPULARS}

Prunyoner (541)

\section{USOS ALIMENTARIS}

Fruit

Ingestió de la part de la planta crua - Fresca (sense preparació)

FONT 541. DESCRIPCIÓ DE L'ÚS FETA PER L'INFORMANT. Es pot menjar i potser en feien melmelades. DESTINACIÓ. Alimentació humana.

Ingestió de la part de la planta cuita - Cuita en sucre

FONT 541. DESCRIPCIÓ DE L'ÚS FETA PER L'INFORMANT. Es pot menjar i potser en feien melmelades. DESTINACIO. Alimentació humana.

\section{ALTRES OBSERVACIONS}

FONT 541. DESCRIPCIÓ FETA PER L'INFORMANT. Arbre petit que fa uns fruits com un aranyó (Prunus spinosa) gros i també els ha de tocar el fred perquè siguin bons.

\section{Prunus dulcis (Mill.) Weeb. (rosàcies)}

BCN 46833

\section{NOMS POPULARS}

Oli d'ametlla dolça (producte elaborat) (590)

\section{BARREGES AMB AQUEST TÀXON}

\section{Oli de la llavor}

Entrevista 100 (vegeu catàleg de barreges)

\section{Prunus persica (L.) Batsch (rosàcies)}

BCN 46832

\section{NOMS POPULARS}

Presseguer $(524,564,580)$

\section{USOS ALIMENTARIS}

Fruit
Ingestió de la part de la planta crua - Fresca (sense preparació)

FONTS 524, 564, 580. DESCRIPCIÓ DE L'ÚS FETA PELS INFORMANTS. Eren molt petits però molt bons (524). OBSERVACIONS. Si el cuides hi ha anys que fa préssecs bons (580) DESTINACIÓ. Alimentació humana $(524,564,580)$.

\section{Prunus spinosa L. (rosàcies)}

BCN 24958

\section{NOMS POPULARS}

Aranyó (fruit) $(507,509,510,538,549,554,555,564,572,573,583,584,585,588,590$ $591,592,1215,1313,1321,1327,1337,1338,1341,1342)$

Aranyoner (541)

Arç $(574,575,576,577)$

Arç negre $(541,1325,1326,1335)$

\section{USOS MEDICINALS}

Flor

Diürètic

FONT 1335. DESCRIPCIÓ DE L'ÚS FETA PER L'INFORMANT És diürètica. FORMA FARMACĖUTICA I ÚS. Tisana (ús intern). PREPARACIÓ. Decocció. DESTINACIÓ. Medicina humana. OBSERVACIONS. No l'usa.

Fruit

Antidiarreic

FONTS 507, 509, 510. DESCRIPCIÓ DE L'ÚS FETA PELS INFORMANTS. Per a la diarrea FORMA FARMACĖUTICA I ÚS. Sense forma farmacèutica (ús directe, ús intern). Tisana (ús intern). PREPARACIÓ. Decocció. DESTINACIÓ. Medicina humana.

Salutífer

FONT 564. DESCRIPCIÓ DE L'ÚS FETA PER L'INFORMANT. Quan en menjo em trobo bé. Encara que siguin secs en menjo quan em trobo malament. Són com un antibiòtic. FORMA FARMACĖUTICA I ÚS. Sense forma farmacèutica (ús directe, ús intern). DESTINACIÓ. Medicina humana. OBSERVACIONS. Els aranyons al principi amosen molt, quan ja els hi ha tocat alguna glaçada són més bons.

Tranquil-litzant

FONT 1327. DESCRIPCIÓ DE L'ÚS FETA PER L'INFORMANT. Se'I prenen havent dinat perquè diu que els relaxa. FORMA FARMACEUTICA I ÚS. Tintura alcohòlica (ús intern). PREPARACIO. Confitat en aiguardent. DESTINACIO. Medicina humana. 


\section{USOS ALIMENTARIS}

Fruit

Ingestió de la part de la planta crua - Fresca (sense preparació)

FONTS 549, 564, 1215, 1321, 1341, 1342. DESCRIPCIÓ DE L'ÚS FETA PELS INFORMANTS. Es mengen, però no ens agradaven (549). Els porcs se'ls menjaven (564) En menjàvem quan anàvem a buscar aglans, per a treure la set (1215). Per a menjar (1341, 1342). Per a menjar cru (1321). OBSERVACIONS. Són més bons tocats per a la gelada $(1341,1342)$. DESTINACIÓ. Alimentació humana $(549,1215,1321,1341,1342)$. Alimentació animal (564).

Ingestió de la part de la planta cuita - Cuita en sucre

FONTS 1335, 1337, 1338. DESCRIPCIÓ DE L'ÚS FETA PELS INFORMANTS. Fa servir els aranyons per a fer melmelada (1335). N'ha fet melmelada $(1337,1338)$. OBSERVACIONS. S els aranyons són tocats per la gelada no són tan àcids (1335). DESTINACIÓ. Alimentació humana $(1335,1337,1338)$

Preparació de begudes - Beguda preparada amb licor

FONTS 1313, 1325, 1326, 1335. DESCRIPCIÓ DE L'ÚS FETA PELS INFORMANTS. Per a fer patxaran li ha donat la recepta una senyora de Navarra (1313). Amb els aranyons, en fan patxaran $(1325,1326)$. Fa servir els aranyons per a fer patxaran (1335). OBSERVACIONS $\mathrm{Si}$ els aranyons són tocats per la gelada no són tan àcids (1335). DESTINACIÓ. Alimentació humana $(1313,1325,1326,1335)$.

Preparació de begudes - Beguda preparada amb aiguardent

FONTS 538, 554, 555, 572, 573, 574, 575, 576, 577, 583, 584, 585, 588, 590, 591, 592 DESCRIPCIÓ DE L'ÚS FETA PELS INFORMANTS. Es posen en aiguardent i es fa un licor ho fan més els estiuejants que la gent d'aquí (538). Per a fer patxaran. Anís dolç i sec aranyons ben madurs quan ja els hi ha tocat les primeres glaçades. Una mà d'aranyons per un litre d'anís, uns quants grans de cafè i una mica de canyella $(554,555)$. Es posen amb anís i es fa un licor (588). Una vegada en vam fer licor (590). Per a fer patxaran $(572,573$, $591,592)$. En fem patxaran $(583,584,585)$. Per a fer patxaran amb els aranyons $(574,575$, $57,577)$. DESTINACIÓ. Alimentó humana $(538,554,555,572,573,574,575,576,577$, 583, 584, 585, 588, 590, 591, 592). Part aèria fructificada

Ingestió de la part de la planta cuita - Cuita sense vehicle

FONT 541. DESCRIPCIÓ DE L'ÚS FETA PER L'INFORMANT. Branca al forn, esclaten llavors te'ls menges. DESTINACIÓ. Alimentació humana.

\section{Psoralea bituminosa L. (papilionàcies)}

BCN 29761

NOMS POPULARS
Cabrulla $(520,521,564)$

\section{USOS ALIMENTARIS}

Part aèria

Ingestió de la part de la planta crua - Conservada dessecada a l'aire

FONTS 520, 521, 564. DESCRIPCIÓ DE L'ÚS FETA PELS INFORMANTS. Es collia per a donar a les cabres $(520,521)$. Se'ls hi donava cap a la tardor als conills. Planta alta i s'ha de donar quan és feta (564). DESTINACIÓ. Alimentació animal $(520,521,564)$.

\section{Pteridium aquilinum (L.) Kuhn (polipodiàcies)}

BCN 113735

\section{NOMS POPULARS}

Falguera $(520,521,553,559,560)$

\section{USOS MEDICINALS}

\section{Fronda}

Antihipertensiu

FONT 553. DESCRIPCIÓ DE L'ÚS FETA PER L'INFORMANT. Per a rebaixar la sang. FORMA FARMACĖUTICA I ÚS. Tisana (ús intern). PREPARACIÓ. Decocció. DESTINACIÓ. Medicina humana.

\section{USOS ALIMENTARIS}

\section{Fronda}

Ingestió de la part de la planta crua - Fresca (sense preparació)

FONT 559. DESCRIPCIÓ DE L'ÚS FETA PER L'INFORMANT. Les falgueres grosses quan són tendres són bones per a amanir. DESTINACIÓ. Alimentació humana.

\section{ALTRES USOS}

\section{Fronda}

Creences i pràctiques magicoreligioses

FONT 560. DESCRIPCIÓ DE L'ÚS FETA PER L'INFORMANT. Per a les catifes [dit "alfombres"] de Corpus.

Domèstic: ajudes a la llar

FONTS 520, 521. DESCRIPCIÓ DE L'ÚS FETA PELS INFORMANTS. Les posaves al cul de a panera quan anaves a collir maduixes. 


\section{Pulmonaria longifolia (Bast.) Boreau (boraginàcies)}

BCN 24959

\section{NOMS POPULARS}

Fulles de la Mare de Déu $(518,519,1299,1336)$

Pulmonària $(504,1299)$

\section{USOS MEDICINALS}

Fulla

Antibronquític

FONT 1299. DESCRIPCIÓ DE L'ÚS FETA PER L'INFORMANT. Per a les bronquitis. FORMA FARMACĖUTICA I ÚS. Tisana (ús intern). PREPARACIÓ. Les fulles en infusió. DESTINACIÓ. Medicina humana.

Antipneumònic

FONT 1336. DESCRIPCIÓ DE L'ÚS FETA PER L'INFORMANT. Per als pulmons. FORMA FARMACĖUTICA I ÚS. Tisana (ús intern). PREPARACIÓ. Decocció. DESTINACIÓ. Medicina humana.

No consta

FONT 504. DESCRIPCIÓ DE L'ÚS FETA PER L'INFORMANT. Per a les taques als pulmons. FORMA FARMACĖUTICA I ÚS. Tisana (ús intern). PREPARACIÓ. Decocció. DESTINACIÓ. Medicina humana.

No consta

Desconegut per l'informant

FONTS 518, 519. FORMA FARMACĖUTICA I ÚS. Desconegut per l'informant. OBSERVACIONS. No sé per a què serveix.

\section{ALTRES OBSERVACIONS}

FONTS 518, 519. DESCRIPCIÓ FETA PELS INFORMANTS. Té la fulla verda i grossa i fa unes taques.

\section{Punica granatum L. (litràcies)}

BCN 24960

\section{NOMS POPULARS}

Magrana (fruit) (752)
Magraner (564)

Malgrana (fruit) $(520,521,746,1347,1348,1349)$

\section{USOS MEDICINALS}

\section{Epicarpi}

Antiinflamatori faringi

FONTS 520, 521, 1347, 1348, 1349. DESCRIPCIÓ DE L'ÚS FETA PELS INFORMANTS. Per al mal de coll $(520,521,1347,1348,1349)$. FORMA FARMACĖUTICA I Ús. Tisana (ús intern). PREPARACIO. Decocció $(520,521)$. Decocció de la pell seca de malgrana (1347, 1348, 1349). DESTINACIÓ. Medicina humana.

\section{USOS ALIMENTARIS}

\section{Infructescència}

Ingestió de la part de la planta crua - Fresca (sense preparació)

FONT 564. OBSERVACIONS. És bord, les magranes no es poden menjar d'amargants

DESTINACIÓ. Alimentació humana.

\section{BARREGES AMB AQUEST TÀXON}

Epicarpi

FONT 746. Entrevista 45, barreja II (vegeu catàleg de barreges)

FONT 752. Entrevista 62, barreja II (vegeu catàleg de barreges)

\section{Pyrus communis L. subsp. communis (rosàcies)}

BCN 46831

\section{NOMS POPULARS}

Pera (fruit) $(590,746)$

Perer $(524,561,562,563,564,567,572,573,575,576,577,580,582,589)$

Perer de Puigcerdà (541)

Perera $(560,574)$

\section{USOS ALIMENTARIS}

Fruit

Ingestió de la part de la planta crua - Fresca (sense preparació) 
Apèndix 1. Catàleg de tàxons.

FONTS 524, 541, 560, 561, 562, 563, 564, 567, 572, 573, 574, 575, 576, 577, 580, 582, 589 DESCRIPCIÓ DE L'ÚS FETA PELS INFORMANTS. Són les mateixes que les de Bruguera (541). Les peres eren molt bones $(561,562,563)$. Fa unes peres molt guapes $(589)$. Hi havia peres de coure i peres de Puigcerdà. També teníem les peres del frare. Les peres les guardàvem colgades del gra de blat $(572,573)$. Fa peres bones $(580)$. Hi ha aquelles peres guardàvem colgades del gra de blat $(572,573)$. Fa peres bones $(580)$. Hi ha aquelles peres El meu avi era molt afeccionat a empeltar i els perers tenien el nom del lloc on havien anat a buscar l'empelt, el perer de Sant Boi, el perer d'en Roure. Aquest avi anava a la plaça vendre les peres i deia "compreu peres de can Bona Pera" i sembla que així va quedar e nom de can Ramon de la Pera, a les escritures posa can Ramon de la Torre (524). En vam plantar de cuixa de dona, però aquí no hi viuen bé (567). N'hi havia de més d'una classe (564). DESTINACIÓ. Alimentació humana (524, 541, 560, 561, 562, 563, 564, 567, 572, 573, $574,575,576,577,580,582,589$ )

Ingestió de la part de la planta cuita - Cuita en sucre

FONTS 590, 746. DESCRIPCIÓ DE L'ÚS FETA PELS INFORMANTS. En faig confitures (746). En fem melmelades, hi posem una mica de taronja (590). DESTINACIÓ. Alimentació humana $(590,746)$.

\section{ALTRES OBSERVACIONS}

FONTS 560, 564, 582. DESCRIPCIÓ FETA PELS INFORMANTS. N'hi havia als horts (560) En tinc a l'hort (582). Aquí a Beget no és país de peres, n'hi ha més a Rocabruna perquè busquen frescor (564).

\section{Pyrus malus L. subsp. malus (rosàcies)}

BCN 24961

\section{NOMS POPULARS}

Poma borda (fruit) $(554,555,1294)$

Pomera borda (541)

\section{USOS ALIMENTARIS}

Fruit

Preparació de begudes - Beguda preparada amb licor

FONTS 554, 555. DESCRIPCIÓ DE L'ÚS FETA PELS INFORMANTS. Amb anís se'n fa un licor que és boníssim, es pren com a digestiu. DESTINACIO. Alimentació humana.

\section{ALTRES USOS}

Part aèria
Maneig agrosilvopastoral: ús hortícola/agrícola

FONT 541. DESCRIPCIÓ DE L'ÚS FETA PER L'INFORMANT. S'agafen per a empeltar si fan unes bones pomes.

\section{BARREGES AMB AQUEST TÀXON}

Fruit

FONT 1294. Entrevista 6, barreja I (vegeu catàleg de barreges)

\section{Pyrus malus L. subsp. mitis (Wallr.) O.Bolòs et J.Vigo} (rosàcies)

BCN 24962

\section{NOMS POPULARS}

Poma (fruit) $(520,521,524,565,566,590,746,1314,1318,1353,1354)$

Pomer $(524,561,562,563,567,572,573,574,575,576,577,578,579,582,1297,1327)$

Pomera $(560,564,580,589)$

\section{USOS MEDICINALS}

Epicarpi

Hipolipemiant

FONTS 520, 521. DESCRIPCIÓ DE L'ÚS FETA PELS INFORMANTS. La pela bullida, aquesta aigua va bé per al colesterol. FORMA FARMACĖUTICA I ÚS. Tisana (ús intern). PREPARACIÓ. Decocció. DESTINACIÓ. Medicina humana.

Fruit

Anticatarral

FONT 1327. DESCRIPCIÓ DE L'ÚS FETA PER L'INFORMANT. Van bé quan estàs constipat. FORMA FARMACĖUTICA I ÚS. Tisana (ús intern). PREPARACIÓ. Pomes cuites DESTINACIO. Medicina humana.

\section{USOS ALIMENTARIS}

Fruit

Ingestió de la part de la planta crua - Conservada dessecada a l'aire

FONTS 560, 572, 573. DESCRIPCIO DE L'ÚS FETA PELS INFORMANTS. Les pomes es guardaven tot l'any, es posaven al mig de la palla $(572,573)$. OBSERVACIONS. Es guardaven a la pallissa i en tenies tot l'hivern. Hi havia pomes reinetes molt bones, pomes de 
Sant Jaume que eren les que venien més aviat, eren molt vermelles i molt grosses (560). DESTINACIÓ. Alimentació humana $(560,572,573)$.

Ingestió de la part de la planta crua - Fresca (sense preparació)

FONTS 524, 561, 562, 563, 564, 565, 566, 567, 574, 575, 576, 577, 578, 579, 580, 582, 589 DESCRIPCIÓ DE L'ÚS FETA PELS INFORMANTS. També en teníem molts de pomers (524). Els animals que engreixàvem que havien menjat cols (Brassica oleracea), pomes, blat de moro (Zea mays)... eren molt més bons que els que ara venen, la carn tenia un altre gust. I són més bones les femelles que no hagin parit (la polla, la truja...), que els mascles (565,

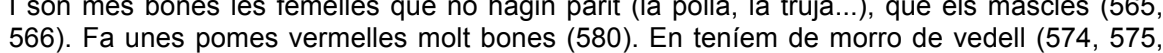
$576,577)$. OBSERVACIONS. Si que hi anaven bé, feien pomes bones (567). Ens duraven tot $576,577)$. OBSERVACIONS. Si que hi anaven bé, feien pomes bones (567). Ens duraven tot
l'hivern $(561,562,563)$. No se'n cullen gaires (582). Al Colomer teníem pomes de cor de bou l'hivern $(561,562,563)$. No se'n cullen gaires (582). Al Colomer teníem pomes de cor de bou i pomes vermelles $(578,579)$. La reineta era la més bona; la poma de can Planes era grossa i quan era covada era boníssima, semblava farina; la poma del ciri era llargaruda; i la poma $564,567,574,575,576,577,578,579,580,582,589)$. Alimentació animal $(565,566)$.

Ingestió de la part de la planta cuita - Cuita en sucre

FONTS 561, 562, 563, 590, 746, 1297, 1314, 1353, 1354. DESCRIPCIÓ DE L'ÚS FETA PELS INFORMANTS. En faig confitures (746). En fèiem confitura $(561,562,563)$. En fem melmelades, hi posem una mica de taronja (590). En fan melmelades (1297). Per a fer melmelades $(1314)$. Per a compotes i melmelada $(1353,1354)$. DESTINACIÓ. Alimentació humana $(561,562,563,590,746,1297,1314,1353,1354)$.

\section{ALTRES OBSERVACIONS}

FONT 589. DESCRIPCIÓ FETA PER L'INFORMANT. AI Grau n'hi havia moltes.

\section{BARREGES AMB AQUEST TÀXON}

Fruit

FONT 1327. Entrevista 14, barreja $\vee$ (vegeu catàleg de barreges)

FONT 1318. Entrevista 31, barreja II (vegeu catàleg de barreges)

FONT 746. Entrevista 45, barreja III (vegeu catàleg de barreges)

FONT 524. Entrevista 58 (vegeu catàleg de barreges)

FONTS 565, 566. Entrevista 85 (vegeu catàleg de barreges)

\section{Quercus ilex L. (fagàcies)}

BCN 24963

\section{NOMS POPULARS}

Alzina $(560,581,586,587,1215,1352)$
Aulina $(505,506,518,519,560,564,590,1339,1340,1345,1346,1361,1362)$

\section{USOS MEDICINALS}

Escorça

Antiherpètic

FONT 564. DESCRIPCIÓ DE L'ÚS FETA PER L'INFORMANT. Per a les panses i els herpes. La meva [dit "meu"] mare s'hi va curar un herpes de l'anus, s'hi posava un drap moll. FORMA FARMACÉUTICA I Ús. Bany (ús extern). Loció (ús extern). PREPARACIÓ. Decocció.En faig esperit. DESTINACIÓ. Medicina humana.

Antiodontàlgic

FONTS 586, 587. DESCRIPCIÓ DE L'ÚS FETA PELS INFORMANTS. Per a treure el mal de queixals. FORMA FARMACĖUTICA I ÚS. Tisana (ús intern). PREPARACIÓ. Decocció. Aigua de pela d'alzina. DESTINACIÓ. Medicina humana.

\section{Escorça}

Antisèptic extern

FONTS 1339, 1340, 1345, 1346, 1361, 1362. DESCRIPCIÓ DE L'ÚS FETA PELS INFORMANTS. Per a netejar les ferides 0 els punts d'una vaca quan se li ha fet cesària $(1339,1340)$. Per a banyar els punts de les vaques que se'ls ha fet la cesària $(1345,1346)$. Per a desinfectar ferides $(1361,1362)$. FORMA FARMACEUUTICA I ÚS. Bany (ús extern) PREPARACIÓ. Aigua bullida de l'escorça $(1339,1340)$. Decocció. Aigua de l'escorça (1345, 1346). Decocció $(1361,1362)$. DESTINACIÓ. Medicina veterinària $(1339,1340,1345,1346)$. Medicina humana $(1361,1362)$

\section{Escorça}

\section{Cicatritzant}

FONTS 586, 587. DESCRIPCIÓ DE L'ÚS FETA PELS INFORMANTS. La pela d'alzina també ajuda a fer pellar. FORMA FARMACĖUTICA I ÚS. Bany (ús extern). PREPARACIÓ. Decocció. DESTINACIÓ. Medicina humana.

Hematocatàrtic

FONTS 505, 506. DESCRIPCIÓ DE L'ÚS FETA PELS INFORMANTS. Per a les sangs. FORMA FARMACĖUTICA I ÚS. Tisana (ús intern). PREPARACIÓ. Decocció. Aigua de l'escorça. DESTINACIÓ. Medicina humana.

Per a la sarna

FONT 564. DESCRIPCIÓ DE L'ÚS FETA PER L'INFORMANT. Per a la sarna dels gossos quan els cau el pèl. FORMA FARMACĖUTICA I ÚS. Bany (ús extern). PREPARACIÓ. Decocció. Aigua d'escorça d'aulina. DESTINACIÓ. Medicina veterinària.

Resolutiu

FONT 590. DESCRIPCIÓ DE L'ÚS FETA PER L'INFORMANT. La pela és bona per a banyar els furóncols. FORMA FARMACĖUTICA I ÚS. Bany (ús extern). DESTINACIÓ. Medicina humana. 
Apèndix 1. Catàleg de tàxons.

Vulnerari

FONTS 518, 519. DESCRIPCIÓ DE L'ÚS FETA PELS INFORMANTS. L'escorça va bé per a fer pellar. FORMA FARMACĖUTICA I ÚS. Bany (ús extern). PREPARACIÓ. Decocció. S'ha de rentar les ferides amb aquesta aigua. DESTINACIÓ. Medicina humana.

Fulla

Antihipertensiu

FONTS 1345, 1346. DESCRIPCIÓ DE L'ÚS FETA PELS INFORMANTS. Per a fer baixar la pressió. FORMA FARMACÉUTICA I ÚS. Tisana (ús intern). PREPARACIÓ. Decocció. Aigua de les fulles. DESTINACIÓ. Medicina humana.

\section{Part aèria}

Vulnerari

FONT 581. DESCRIPCIÓ DE L'ÚS FETA PER L'INFORMANT. Per a banyar les ferides. FORMA FARMACĖUTICA I ÚS. Bany (ús extern). PREPARACIÓ. Decocció de les branques. DESTINACIÓ. Medicina humana i veterinària. OBSERVACIONS. La ferida queda negra però desinfecta molt.

\section{USOS ALIMENTARIS}

Fruit

Ingestió de la part de la planta crua - Fresca (sense preparació)

FONTS 560, 1215. DESCRIPCIÓ DE L'ÚS FETA PELS INFORMANTS. Les aglans són molt dolces i se'n donava als conills (560). N'anàvem a buscar per a engreixar els porcs (1215) DESTINACIÓ. Alimentació animal $(560,1215)$.

\section{Part aèria}

Ingestió de la part de la planta crua - Fresca (sense preparació)

FONT 564. DESCRIPCIÓ DE L'ÚS FETA PER L'INFORMANT. A I'hivern se'ls donava rama d'aulina, als conills. DESTINACIO. Alimentació animal.

\section{ALTRES USOS}

Cendra

Domèstic: ajudes a la llar

FONT 1215. DESCRIPCIÓ DE L'ÚS FETA PER L'INFORMANT. Per a fer lleixiu. Es feia bullir les cendres blanques d'alzina, arç blanc o fins $i$ tot olivera $i$ aquesta aigua es colava mantinguda calenta s'anava abocant en un cossi ple de roba que duia un forat el fons per on s'anava escolant l'aigua més freda del fons. Per a evitar impureses es posava un llençol de fil al damunt de la roba.

Folíol

Creences i pràctiques magicoreligioses
FONT 560. DESCRIPCIÓ DE L'ÚS FETA PER L'INFORMANT. Es posaven les fulles a les catifes [dit "alfombres"] de Corpus.

\section{Planta sencera}

Obtenció de combustible: llenya

FONT 560. DESCRIPCIÓ DE L'ÚS FETA PER L'INFORMANT. A I'hivern la gent anava a fer carbó. Es plantaven alzines i cada 4 o 5 anys es tallaven per a fer carbó que llavors el venien a les cases per encendre. Els carboners n'havien de saber molt, perquè sinó se'ls cremava tot, amb el fum ja es veia si es cremava bé. Per a fer carbó, les aulines han de ser joves, si són d'aquelles tan grosses no va bé. La gent les tallava i només en guardaven dues o tres de grosses aprop de la casa per a protegir del vent.

Tija

Fuster: construcció de vehicles amb rodes

FONT 1215. DESCRIPCIÓ DE L'ÚS FETA PER L'INFORMANT. Per a fer rodes.Per a les rodes de carro. Els cèrcols i els radis es feien d'alzina i el botó de freixe.

Maneig agrosilvopastoral: ús hortícola/agrícola

FONT 1352. DESCRIPCIÓ DE L'ÚS FETA PER L'INFORMANT. Per a fer els mànecs dels pics.

Obtenció de combustible: llenya

FONT 1352. DESCRIPCIÓ DE L'ÚS FETA PER L'INFORMANT. La duien de fora per a fer foc, ja que és una fusta que escalfa molt.

\section{ALTRES OBSERVACIONS}

FONT 590. DESCRIPCIÓ FETA PER L'INFORMANT. Aquí n'hi ha una.

\section{Quercus petraea (Matt.) Liebl. (fagàcies)}

BCN 24964

\section{NOMS POPULARS}

Aglà (fruit) (504)

Roure $(505,506,507,509,510,522,523,539,540,560,564,565,566,583,584,585,586$ $587,1317,1339,1340,1341,1342,1347,1348,1349,1352)$

\section{USOS MEDICINALS}

\section{Escorça}

Antisèptic extern 
Apèndix 1. Catàleg de tàxons.

FONTS 1339, 1340. DESCRIPCIÓ DE L'ÚS FETA PELS INFORMANTS. Per a netejar les ferides o els punts d'una vaca quan se li ha fet cesària. FORMA FARMACĖUTICA I ÚS. Bany (ús extern). PREPARACIÓ. Aigua bullida de l'escorça. DESTINACIÓ. Medicina veterinària.

\section{Escorça}

Cicatritzant

FONTS 586, 587. DESCRIPCIÓ DE L'ÚS FETA PELS INFORMANTS. Per a fer pellar (586, 587). FORMA FARMACĖUTICA I ÚS. Bany (ús extern). PREPARACIÓ. Decocció. Aigua de pela (587). Decocció. Aigua de la pela (586). DESTINACIÓ. Medicina humana.

Cicatritzant

FONTS 1347, 1348, 1349. DESCRIPCIÓ DE L'ÚS FETA PELS INFORMANTS. Ajuda a pellar. FORMA FARMACEUTICA I ÚS. Bany (ús extern). PREPARACIO. Decocció. DESTINACIÓ. Medicina humana.

\section{Escorça}

Hematocatàrtic

FONTS 505, 506. DESCRIPCIÓ DE L'ÚS FETA PELS INFORMANTS. Per a les sangs. FORMA FARMACĖUTICA I ÚS. Tisana (ús intern). PREPARACIÓ. Decocció. Aigua de l'escorça. DESTINACIÓ. Medicina humana.

Escorça

Vulnerari

FONTS 1347, 1348, 1349. DESCRIPCIÓ DE L'ÚS FETA PELS INFORMANTS. Per a banyar ferides. FORMA FARMACĖUTICA I ÚS. Bany (ús extern). PREPARACIÓ. Decocció DESTINACIO. Medicina humana.

Parènquima cortical

Antisèptic extern

FONTS 1341, 1342. DESCRIPCIÓ DE L'ÚS FETA PELS INFORMANTS. Es feia servir per a les vaques per a netejar els punts quan se'ls havia fet la cesària. FORMA FARMACĖUTICA ÚS. Bany (ús extern). PREPARACIÓ. Decocció. DESTINACIÓ. Medicina veterinària.

\section{USOS ALIMENTARIS}

\section{Fruit}

Ingestió de la part de la planta crua - Fresca (sense preparació)

FONTS 583, 584, 585. DESCRIPCIÓ DE L'ÚS FETA PELS INFORMANTS. Els aglans es donaven als porcs. DESTINACIÓ. Alimentació animal.

Ingestió de la part de la planta crua - Macerada en aigua

FONTS 560, 565, 566. DESCRIPCIÓ DE L'ÚS FETA PELS INFORMANTS. Les aglans de roure es donaven als porcs. Es feia una bassa amb les aglans i s'emplenava d'aigua i es deixaven confitar tot un any $i$ es donaven als porcs, la carn del porc que havia menjat aquests aglans era molt més bona (560). Les glans les posàvem en un dipòsit d'aigua que quedessin estovades i les donàvem als porcs. Eren millor així que seques perquè les paeixen millor $(565,566)$. DESTINACIÓ. Alimentació animal $(560,565,566)$

\section{ALTRES USOS}

Fruit

Artesanal: elaboració de bijuteria

FONT 504. DESCRIPCIÓ DE L'ÚS FETA PER L'INFORMANT. Les aglans les fa servir per a fer penjolls i clauers.

\section{Planta sencera}

Creences i pràctiques magicoreligioses

FONTS 507, 509, 510. DESCRIPCIÓ DE L'ÚS FETA PELS INFORMANTS. Per a curar els nens herniats. Un roure prim es tallava pel mig i s'hi posava una falca, s'hi feia passar el nen pel mig i s'hi deixava cada vegada una peça de roba. D'aquesta manera es curava l'hèrnia de la criatura.

Obtenció de combustible: carbó

FONT 560. DESCRIPCIÓ DE L'ÚS FETA PER L'INFORMANT. Es feia carbó, però no és tan bo com el d'aulina, es torna més aviat cendra.

Tija

Fuster: obtenció de materials per a la construcció

FONTS 539, 540. DESCRIPCIÓ DE L'ÚS FETA PELS INFORMANTS. Les llindes es fan de roure vell.

Obtenció de combustible: llenya

FONTS 522, 523, 1352. DESCRIPCIÓ DE L'ÚS FETA PELS INFORMANTS. Per a fer llenya $(522,523)$. Per a fer foc, fa un foc somort i escalfa molt (1352).

\section{BARREGES AMB AQUEST TÀXON}

Parènquima cortical

FONT 1317. Entrevista 21, barreja III (vegeu catàleg de barreges)

\section{Ramonda myconi (L.) Reichenb. (gesneriàcies)}

\section{BCN 24965}

\section{NOMS POPULARS}

Borraina de roca $(572,573)$

Orella d'ós $(504,505,506,511,512,513,514,515,516,518,519,520,521,525,526,527$ $536,537,542,543,544,554,555,559,560,569,570,571,578,579,583,584,585,586$ $587,591,592,746,747,748,749,750,753,754,755,1215,1293,1294,1296,1299,1301$, 
Apèndix 1. Catàleg de tàxons.

$1307,1308,1309,1310,1313,1314,1321,1322,1324,1325,1326,1327,1330,1335,1341$, $1342,1350,1351,1352,1361,1362)$

\section{USOS MEDICINALS}

Flor

Antihemorroïdal

FONT 1293. DESCRIPCIÓ DE L'ÚS FETA PER L'INFORMANT. Va bé per a les morenes. FORMA FARMACĖUTICA I ÚS. Embrocació (ús extern). PREPARACIÓ. La flor es fa bullir en oli. DESTINACIÓ. Medicina humana.

Antiinflamatori gàstric

FONT 1327. DESCRIPCIÓ DE L'ÚS FETA PER L'INFORMANT. Cura les infeccions de budells. FORMA FARMACÈUTICA I ÚS Tisana (ús intern). PREPARACIÓ. Decocció. DESTINACIÓ. Medicina humana.

Fulla

Anticatarral

FONT 1324. DESCRIPCIÓ DE L'ÚS FETA PER L'INFORMANT. Per als refredats i prevenció d'aquests. FORMA FARMACĖUTICA I ÚS. Tisana (ús intern). PREPARACIÓ. Si la planta és grossa només una fulla, si és petita tres fulles; cal bullir-les tres minuts. MODE D'UTILITZACIÓ/POSOLOGIA. Prendre'n durant 15 dies. DESTINACIÓ. Medicina humana. OBSERVACIONS. Li sembla que també neteja la sang, diu que et dóna molta escalfor als

Antitussigen

FONTS 505, 506. DESCRIPCIÓ DE L'ÚS FETA PELS INFORMANTS. Per a la tos. FORMA FARMACEUTICA I ÚS. Tisana (ús intern). PREPARACIÓ. Decocció. Aigua de les fulles. DESTINACIO. Medicina humana.

Hepatoprotector

FONT 1293. DESCRIPCIÓ DE L'ÚS FETA PER L'INFORMANT. Les fulles per al fetge FORMA FARMACĖUTICA I ÚS. Tisana (ús intern). PREPARACIÓ. Decocció. DESTINACIO. Medicina humana.

\section{No consta}

Desconegut per l'informant

FONTS 536, 537, 1307, 1308, 1309, 1341, 1342, 1352. FORMA FARMACĖUTICA I ÚS Desconegut per l'informant. DESTINACIÓ. Medicina humana. OBSERVACIONS. Se'n buscava molt però no recordem perquè servia $(536,537)$. Saben que és medicinal, però no recorden per a què va bé $(1307,1308,1309)$. No la fan servir, però els van dir que era medicinal $(1341,1342)$. No recordo per a què l'usaven (1352)

\section{Part aèria}

Anticatarral
FONTS 504, 511, 512, 513, 514, 515, 516, 518, 519, 520, 521, 525, 526, 527, 542, 543, 544 $554,555,586,587,591,502,746,748,749,750,1296,1321,1335,1350,1351$. 554, SPICIÓ DE L'ÚS FETA PELS INFORMANTS. Per als refreda $(504,511,512,513$, $514,518,510,525,526,527,542,543,544,501,592,746,748,749,750,1321)$. Per $514,518,519$ constipats i per a la tos $(515,516)$. Per als constipats $(520,521,554,555)$. Per als refredats la tos $(586,587)$. Per als constipats, destapa molt (1296). Per a constipats (1335). Per a destapar el pit quan estàs refredat $(1350,1351)$. FORMA FARMACĖUTICA I ÚS. Tisana (ús intern). PREPARACIÓ. Decocció $(504,511,512,513,514,515,516,518,519,520,521$, $525,526,527,542,543,544,554,555,586,587,591,592,746,748,749,750,1296,1321$, 1335). DESTINACIÓ. Medicina humana. OBSERVACIONS. Quan l'asseques queda molt petita i quan la poses en aigua torna a quedar grossa $(586,587)$.

Antidiarreic

FONTS 1314, 1335. DESCRIPCIÓ DE L'ÚS FETA PELS INFORMANTS. Per a la diarrea (1314). Per a diarrees (1335). FORMA FARMACĖUTICA I ÚS. Tisana (ús intern). PREPARACIÓ. Decocció $(1314,1335)$. DESTINACIÓ. Medicina humana.

Antihemorroïdal

FONTS 572, 573, 747, 753, 754, 755, 1299, 1313, 1330, 1361, 1362. DESCRIPCIÓ DE L'ÚS FETA PELS INFORMANTS. Banys del budell culà (747). Per a les morenes $(572,573,753$, $754,755,1299,1313,1330,1361,1362)$. FORMA FARMACĖUTICA I ÚS. Bany (ús extern) $(747,1313)$. Embrocació (ús extern) $(572,573,753,754,755,1299,1330,1361,1362)$. PREPARACIÓ. Fer bullir la planta en oli $(753,754,755)$. Bullida en oli amb un tupí de terra $(572,573)$. S'ha de fer bullir la planta en oli (1299). Decocció (1313). Confitada en oli (1330). La planta bullida en oli $(1361,1362)$. DESTINACIO. Medicina humana.

Antihipertensiu

FONTS 511, 512, 513, 514. DESCRIPCIÓ DE L'ÚS FETA PELS INFORMANTS. Per a fer baixar la pressió. FORMA FARMACEUUTICA I ÚS. Tisana (ús intern). PREPARACIO. Decocció. DESTINACIÓ. Medicina humana.

Antiinflamatori intestinal

FONTS 1294, 1310. DESCRIPCIÓ DE L'ÚS FETA PELS INFORMANTS. Per a les infeccions de la panxa (1294). Per al mal de ventre (1310). FORMA FARMACEUTICA I ÚS. Tisana (ús intern). PREPARACIÓ. Decocció. Fa servir tota la planta (1294). DESTINACIO Medicina humana. OBSERVACIONS. A casa seva solien donar herbes barrejades, però sempre en nombre senar (1310)

Antiotàlgic

FONT 1299. DESCRIPCIÓ DE L'ÚS FETA PER L'INFORMANT. Per al mal d'orelles. FORMA FARMACEUUTICA I ÚS. Embrocació (ús extern). PREPARACIÓ. S'ha de fer bullir la planta en oli. DESTINACIÓ. Medicina humana.

Antitussigen

FONTS 515, 516, 586, 587. DESCRIPCIÓ DE L'ÚS FETA PELS INFORMANTS. Per als constipats i per a la tos $(515,516)$. Per als refredats i la tos $(586,587)$. FORMA FARMACĖUTICA I ÚS. Tisana (ús intern). PREPARACIÓ. Decocció $(515,516,586,587)$. 
DESTINACIÓ. Medicina humana. OBSERVACIONS. Quan l'asseques queda molt petita i quan la poses en aigua torna a quedar grossa $(586,587)$

Expectorant

FONTS 1296, 1301. DESCRIPCIÓ DE L'ÚS FETA PELS INFORMANTS. Per als constipats, destapa molt (1296). Per al constipat, estova molt les reumes (1301). FORMA FARMACĖUTICA I ÚS. Tisana (ús intern). PREPARACIÓ. Decocció $(1296,1301)$. DESTINACIÓ. Medicina humana.

Hematocatàrtic

FONTS 1325, 1326. DESCRIPCIÓ DE L'ÚS FETA PELS INFORMANTS. Per a netejar la sang. FORMA FARMACĖUTICA I ÚS. Tisana (ús intern). PREPARACIÓ. Decocció de tota la planta. DESTINACIÓ. Medicina humana. OBSERVACIONS. La solen prendre barrejada amb altres herbes.

Tranquil·litzant

FONT 560. DESCRIPCIÓ DE L'ÚS FETA PER L'INFORMANT. Deien que era per a dormir, per a relaxar. FORMA FARMACEUUTICA I ÚS. Tisana (ús intern). PREPARACIÓ. Decocció DESTINACIÓ. Medicina humana. OBSERVACIONS. La gent n'anava a buscar i la venien a la farmàcia.

\section{Planta sencera}

Anticatarral

FONT 1322. DESCRIPCIÓ DE L'ÚS FETA PER L'INFORMANT. Quan estàs molt constipat t'ofegues. FORMA FARMACĖUTICA I ÚS. Tisana (ús intern). PREPARACIÓ. Decocció Aigua de tota la planta. DESTINACIÓ. Medicina humana.

\section{ALTRES OBSERVACIONS}

FONTS 518, 519, 542, 543, 544, 583, 584, 585, 1341, 1342. DESCRIPCIÓ FETA PELS INFORMANTS. A sota el Sitjar $(518,519)$. S'ha d'anar allà dalt a aquelles roques $(542,543$ $544)$. A Montgrony n'hi havia $(583,584,585)$. En tenen de plantada a l'hort $(1341,1342)$.

\section{BARREGES AMB AQUEST TÀXON}

Part aèria

FONT 1215. Entrevista 104, barreja I (vegeu catàleg de barreges)

FONT 1321. Entrevista 37, barreja II (vegeu catàleg de barreges)

FONT 750. Entrevista 50, barreja II (vegeu catàleg de barreges)

FONTS 753, 754, 755. Entrevista 67, barreja I (vegeu catàleg de barreges)

FONT 1296. Entrevista 7, barreja II (vegeu catàleg de barreges)

\section{Ranunculus acris L. (ranunculàcies)}

BCN 26664

\section{NOMS POPULARS}

Gata rabiosa $(541,574,575,576,577,586,587,588)$

\section{ACCIONS NOCIVES O TÒXIQUES}

\section{No consta}

FONTS 574, 575, 576, 577, 586, 587, 588. DESCRIPCIÓ DE L'ACCIÓ NOCIVA O TÒXICA FETA PELS INFORMANTS. És tòxica $(574,575,576,577)$. Mata els conills $(588)$. El bestiar se la menja abans de florir, quan té la flor no la toquen gaire, els hi fa mal, boteix $(586,587)$ TOXICITAT EN ANIMALS. Sí $(586,587,588)$.

\section{ALTRES OBSERVACIONS}

FONTS 586, 587. DESCRIPCIÓ FETA PELS INFORMANTS. A la Jonquerassa n'hi ha.

\section{Ranunculus bulbosus L. subsp. bulbosus (ranunculàcies)}

BCN 24966

\section{NOMS POPULARS}

Gata rabiosa $(515,516,524,529,530,531,545,546,564,569,570,571,578,579,581$ $582,1297,1298,1352)$

\section{ACCIONS NOCIVES O TOXIQUES}

No consta

FONTS 528, 564, 569, 570, 571, 578, 579, 581, 582, 1298. DESCRIPCIÓ DE L'ACCIÓ NOCIVA O TÒXICA FETA PELS INFORMANTS. És verinosa $(528,582)$. És tòxica $(569,570$ $571)$. Es vigilava de no collir-ne quan s'anava a buscar menjar per als conills $(578,579)$. No se's donava als conills (564). Les vaques no se la mengen (581). Sempre s'ha dit que és tòxica (1298). TOXICITAT EN ANIMALS. Sí $(564,578,579,581)$. OBSERVACIONS. No ho sé si és ben tòxica perquè una vegada en vaig donar a un conill $i$ en va menjar varies sé $\mathrm{si}$ es ben toxica perquè una
vegades i no es va morir (564).

\section{Part aèria}

FONTS 515, 516, 524, 529, 530, 531, 545, 546, 1297, 1352. DESCRIPCIÓ DE L'ACCIÓ NOCIVA O TÓXICA FETA PELS INFORMANTS. És verinosa, si en mengen els vedells petits es moren $(515,516)$. Les vaques no se les mengen $(529,530,531)$. Si en mengen les vaques queden botides (524). Planta tòxica (545). Tòxica (546). El bestiar la rebutja, encara que a vegades se la menja (1297). Si els conills en mengen els mata (1352). GRAU DE TOXICITAT. Letal $(515,516,1352)$. VIA D'INTOXICACIÓ. Via interna $(515,516,524)$ TOXICITAT EN ANIMALS. Sí $(515,516,524,529,530,531)$ 


\section{Ranunculus parnassifolius L. (ranunculàcies)}

BCN 24967

\section{NOMS POPULARS}

Herba de mal gra $(538,554,555,559,571)$

Herba del mal gra $(541,549,552,556,557,588,1315,1316,1317,1321,1322,1323,1330$ $1332,1333,1334,1337,1338,1341,1342,1350,1351,1353,1354)$

Herba mal gra $(533,534)$

\section{USOS MEDICINALS}

\section{No consta}

Antineoplàstic

FONTS 1315, 1316, 1341, 1342, 1353, 1354. DESCRIPCIÓ DE L'ÚS FETA PELS INFORMANTS. Va bé per als tumors $(1315,1316)$. Deien que estirava els quists (1341, 1342). Ha sentit a dir que cura el càncer $(1353,1354)$. FORMA FARMACEUTICA I ÚS Desconegut per l'informant. DESTINACIO. Medicina humana. OBSERVACIONS. No l'han fet servir mai $(1315,1316,1341,1342)$

Desconegut per l'informant

FONTS 559, 1323. FORMA FARMACĖUTICA I ÚS. Ungüent (ús extern) (559). Desconegut per l'informant (1323). PREPARACIO. Per a fer ungüents (559). DESTINACIO. Medicina humana. OBSERVACIONS. No en recorda l'ús (1323).

\section{Part aèria}

Antihemorroïdal

FONT 1330. DESCRIPCIÓ DE L'ÚS FETA PER L'INFORMANT. Per a les morenes. FORMA FARMACĖUTICA I ÚS. Embrocació (ús extern). PREPARACIÓ. Bullida en oli. DESTINACIÓ. Medicina humana.

Resolutiu

FONT 1330. DESCRIPCIÓ DE L'ÚS FETA PER L'INFORMANT. Per a les llagues i ferides infectades. FORMA FARMACĖUTICA I ÚS. Embrocació (ús extern). PREPARACIÓ. Bullida en oli. DESTINACIÓ. Medicina humana.

\section{Planta sencera}

Antigangrenós

FONTS 1332, 1333, 1334. DESCRIPCIÓ DE L'ÚS FETA PELS INFORMANTS. Va bé per a la gangrena. FORMA FARMACEUTICA I ÚS. Liniment (ús extern). PREPARACIÓ. Tota la planta amb arrel posada en oli. DESTINACIO. Medicina humana.

Antihemorroïdal
FONT 1322. DESCRIPCIÓ DE L'ÚS FETA PER L'INFORMANT. És molt bo per a les monta amb arMA bullir en Ol. DESTINACIÓ. Medicina humana. OBSERVACIONS. És una planta amb arrel a bullir en oli. DESTINACIO. Medicina humana. OBSERVACIONS. És una de les herbes més fortes que hi ha aquí dalt.

Antineoplàstic

FONTS 533, 534, 538, 541, 1317, 1321, 1322, 1337, 1338. DESCRIPCIÓ DE L'ÚS FETA PELS INFORMANTS. Per al fetge $(533,534)$. Aquí era per si et sortia un gra dolent $(533$, $534)$. Deien que si curava el càncer (538). Se n'untaven els grans, malures o càncers que en dien malgrans (541). Per als quists dolents (1317). Per a banyar grans dolents. Per a un gra a sota l'aixella se'l va banyar amb aigua d'aquesta herba i li va marxar (1321). Aquest oli a sota l'aixella se' va banyar amb aigua d'aquesta herba i li va marxar (1321). Aquest oll atura totes les infeccions, un seu conegut tenia càncer al llavi i durant dos anys el va anar aguantant amb aquest oli (1322). Deien que curava el càncer (1337, 1338). FORMA
FARMACEUUTICA I ÚS. Tisana (ús intern) $(533,534,538,1337,1338)$. Emplastre (ús extern) FARMACEUTICA I US. Tisana (ús intern) $(533,534,538,1337,1338)$. Emplastre (ús extern) (1322). PREPARACIÓ. Decocció $(533,534,1321,1337,1338)$. Fer-ne infusions (538). Es reparava amb greix de gallina o oli (541). Es fa coure la planta sencera amb arrel, amb oli i greix de gallina, queda com un ungüent que es posa directament sobre el mal i s'embolica amb un drap (1317). Posar tota la planta amb arrel a bullir en oli (1322). DESTINACIÓ. Medicina humana. OBSERVACIONS. Van venir dos xicots a buscar-ne pel seu pare que Antisèptic extern

FONT 1322. DESCRIPCIÓ DE L'ÚS FETA PER L'INFORMANT. Aquest oli cura ferides evita infeccions.Per a curar ferides infectades de les ovelles. FORMA FARMACĖUTICA I ÚS. Liniment (ús extern). PREPARACIÓ. Posar tota la planta amb arrel a bullir en oli.Oli d'herba de mal gra. DESTINACIÓ. Medicina humana. Medicina veterinària. OBSERVACIONS. És una de les herbes més fortes que hi ha aquí dalt.

No consta

FONT 549. DESCRIPCIÓ DE L'ÚS FETA PER L'INFORMANT Servia per a curar els bonys de les ovelles. FORMA FARMACĖUTICA I ÚS. Embrocació (ús extern). PREPARACIÓ. Se'n feia un oli. DESTINACIÓ. Medicina veterinària.

Resolutiu

FONTS 1317, 1350, 1351. DESCRIPCIÓ DE L'ÚS FETA PELS INFORMANTS. Cura furóncols (1317). Va bé per als furóncols i per a grans $(1350,1351)$. FORMA FARMACĖUTICA I ÚS. Emplastre (ús extern) (1317). Bany (ús extern) (1350, 1351). PREPARACIÓ. Es fa coure la planta sencera amb arrel, amb oli i greix de gallina, queda com un ungüent que es posa directament sobre el mal i s'embolica amb un drap (1317). Es fa un ungüent que es posa directament sobre el mal i s'embolica amb un drap (1317). Es fa bullir l'arrel en oli (en un tup

Vulnerari

FONTS 1322, 1332, 1333, 1334. DESCRIPCIÓ DE L'ÚS FETA PELS INFORMANTS. Aquest oli cura ferides i evita infeccions (1322). Per als talls i les ferides $(1332,1333,1334)$. FORMA FARMACĖUTICA I ÚS. Liniment (ús extern) (1322). Embrocació (ús extern) (1332, 1333 
Apèndix 1. Catàleg de tàxons.

1334). PREPARACIÓ. Posar tota la planta amb arrel a bullir en oli (1322). Tota la planta amb arrel posada en oli $(1332,1333,1334)$. DESTINACIÓ. Medicina humana. OBSERVACIONS. És una de les herbes més fortes que hi ha aquí dalt (1322).

\section{USOS ALIMENTARIS}

\section{Part à̀ria}

Ingestió de la part de la planta crua - Fresca (sense preparació)

FONTS 552, 571. DESCRIPCIÓ DE L'ÚS FETA PELS INFORMANTS. Les ovelles quan la veien se la menjaven (552). Les ovelles se la mengen, els agrada molt, però no en volen gaire. Quan l'han menjat queden molt tranquil-les com borratxes, els va molt bé, els queda la llana maca i molt groga (571). DESTINACIÓ. Alimentació animal $(552,571)$.

\section{ALTRES OBSERVACIONS}

FONTS $571,1315,1316$. DESCRIPCIÓ FETA PELS INFORMANTS. A la Serra d'Eina se'n fa (571). En tenen una plantada a l'hort $(1315,1316)$.

\section{BARREGES AMB AQUEST TÀXON}

Arrel

FONTS 554, 555. Entrevista 78, barreja I (vegeu catàleg de barreges)

Planta sencera

FONT 538. Entrevista 68, barreja II (vegeu catàleg de barreges)

\section{Raphanus raphanistrum $\mathrm{L}$. subsp. raphanistrum} (crucíferes)

BCN 30042

\section{NOMS POPULARS}

Ravenissa (529, 530, 531)

\section{USOS ALIMENTARIS}

\section{Part aèria}

Ingestió de la part de la planta crua - Fresca (sense preparació)

FONTS 529, 530, 531. DESCRIPCIÓ DE L'ÚS FETA PELS INFORMANTS. En surten moltes per aquí, abans les donàvem als conills. DESTINACIÓ. Alimentació animal.

\section{Raphanus raphanistrum $L$. subsp. sativus (L.) \\ Domin (crucíferes)}

BCN 27288

\section{NOMS POPULARS}

Rabequet $(574,575,576,577)$

\section{USOS ALIMENTARIS}

\section{Arrel}

Ingestió de la part de la planta crua - Fresca (sense preparació)

FONTS 574, 575, 576, 577. DESCRIPCIÓ DE L'ÚS FETA PELS INFORMANTS. En tenim a I'hort, per a amanir. DESTINACIÓ. Alimentació humana.

\section{Reichardia picroides (L.) Roth (compostes)}

BCN 113704

\section{NOMS POPULARS}

Cosconilla (564)

\section{USOS ALIMENTARIS}

Fulla

Ingestió de la part de la planta crua - Fresca (sense preparació)

FONT 564. DESCRIPCIÓ DE L'ÚS FETA PER L'INFORMANT. Per a amanir quan són tendres, a la primavera. DESTINACIÓ. Alimentació humana.

\section{ALTRES OBSERVACIONS}

FONT 564. DESCRIPCIÓ FETA PER L'INFORMANT. Fulles petites que fan com uns queixals.

Rhamnus alaternus L. (ramnàcies)

BCN 29769

NOMS POPULARS

Aladern (564) 


\section{USOS ALIMENTARIS}

\section{Part aèria}

Ingestió de la part de la planta crua - Fresca (sense preparació)

FONT 564. DESCRIPCIÓ DE L'ÚS FETA PER L'INFORMANT. Per als conills, a l'hivern se'ls donava la rama. DESTINACIÓ. Alimentació animal.

\section{Rhamnus frangula L. (ramnàcies)}

BCN 24968

\section{NOMS POPULARS}

Fràngula $(1324)$

\section{USOS MEDICINALS}

Escorça

Laxant

FONT 1324. DESCRIPCIÓ DE L'ÚS FETA PER L'INFORMANT. És laxant. FORMA FARMACĖUTICA I ÚS. Tisana (ús intern). PREPARACIÓ. L'escorça bullida. DESTINACIÓ.

Medicina humana.

\section{Rhinanthus mediterraneus (Sterneck) Senn.}

(escrofulariàcies)

BCN 27255

\section{NOMS POPULARS}

Esquellada $(524,586,587,1313,1352)$

Fusellada (541)

Herba esquellera $(520,521)$

Sorolla (541)

\section{USOS ALIMENTARIS}

\section{Part aèria}

Ingestió de la part de la planta crua - Fresca (sense preparació)
FONTS 586, 587. DESCRIPCIÓ DE L'ÚS FETA PELS INFORMANTS. Quan surt, les ovelles

\section{ACCIONS NOCIVES O TÒXIQUES}

No consta

FONTS 1313, 1352. DESCRIPCIÓ DE L'ACCIÓ NOCIVA O TÒXICA FETA PELS INFORMANTS. Allà on hi ha esquellada no hi creix res més (1313). Mata l'herba de les closes i el bestiar no se la menja (1352).

Part aèria

FONT 524. DESCRIPCIÓ DE L'ACCIÓ NOCIVA O TÒXICA FETA PER L'INFORMANT. Això és una pesta. El bestiar no se la menja. VIA D'INTOXICACIÓ. Via interna. TOXICITAT EN ANIMALS. Si.

\section{ALTRES OBSERVACIONS}

FONTS 520, 521. DESCRIPCIÓ FETA PELS INFORMANTS. És un paràsit dels prats.

\section{Rhododendron ferrugineum L. (ericàcies)}

BCN 24969

\section{NOMS POPULARS}

Gafet $(541,571)$

Neret $(511,512,513,514,541,559,1321)$

\section{ALTRES USOS}

\section{Part aèria florida}

Ornamental: elaboració de rams

FONTS 511, 512, 513, 514. DESCRIPCIÓ DE L'ÚS FETA PELS INFORMANTS. Per a fer rams.

\section{ACCIONS NOCIVES O TÒXIQUES}

\section{No consta}

FONT 559. DESCRIPCIÓ DE L'ACCIÓ NOCIVA O TÒXICA FETA PER L'INFORMANT. És una mica tòxic.

\section{ALTRES OBSERVACIONS}


Apèndix 1. Catàleg de tàxons.

FONTS 571, 1321. DESCRIPCIÓ FETA PELS INFORMANTS. Quan passes pel costat i està tan florit fa una nassada d'aquells flors que fan una olor tan bona (571). N'hi havia un a la segona marrada de la planca del xalet que floria blanc, és l'únic que s'ha vist d'aquest color a tota la zona (1321). OBSERVACIONS. L'havien retratat qui-sap-les vegades i sortia a les revistes, però al final de tant arrancar-li les flors el van matar (1321).

\section{Ribes petraeum Wulfen in Jacq. (saxifragàcies)}

BCN 24970

\section{NOMS POPULARS}

Brosella (fruit) $(525,526,527)$

Grosella (fruit) (1335)

Grosellera $(520,521)$

Ribes (541)

\section{USOS MEDICINALS}

Fruit

Antipiròtic

FONT 1335. DESCRIPCIÓ DE L'ÚS FETA PER L'INFORMANT. Per a les cremades. FORMA FARMACĖUTICA I ÚS. Emplastre (ús extern). PREPARACIÓ. Es fa un emplastre de les granes aixafades i posades directament sobre el mal. DESTINACIO. Medicina humana.

\section{USOS ALIMENTARIS}

Fruit

Ingestió de la part de la planta crua - Fresca (sense preparació)

FONTS 525, 526, 527, 541. DESCRIPCIÓ DE L'ÚS FETA PELS INFORMANTS. El fruit es menja. DESTINACIO. Alimentació humana.

Ingestió de la part de la planta cuita - Cuita en sucre

FONTS 520, 521. DESCRIPCIÓ DE L'ÚS FETA PELS INFORMANTS. En fem confitura DESTINACIO. Alimentació humana.

\section{ALTRES OBSERVACIONS}

FONT 541. DESCRIPCIÓ FETA PER L'INFORMANT. La padrina deien que n'agafaven allà al torrent anant cap a Serrat.

\section{Ricinus communis L. (euforbiàcies)}

BCN 46089

\section{NOMS POPULARS}

Oli de ricino (castellà) (producte elaborat) (590)

\section{BARREGES AMB AQUEST TÀXON}

\section{Oli de la llavor}

Entrevista 100 (vegeu catàleg de barreges)

Robinia pseudoacacia L. (papilionàcies)

BCN 31298

\section{NOMS POPULARS}

Escàcia $(515,516,572,573)$

\section{USOS MEDICINALS}

Parènquima cortical

Antitussigen

FONTS 572, 573. DESCRIPCIÓ DE L'ÚS FETA PELS INFORMANTS. Va bé per a la tos. FORMA FARMACĖUTICA I ÚS. Tisana (ús intern). PREPARACIÓ. Decocció. La segona pell de l'escàcia bullida. DESTINACIÓ. Medicina humana.

\section{ALTRES USOS}

\section{Planta viva in situ}

Creences i pràctiques magicoreligioses

FONTS 515, 516. DESCRIPCIÓ DE L'ÚS FETA PELS INFORMANTS. Diu que criden els llamps, per això no és bo tenir-ne prop de casa.

\section{Rorippa nasturtium-aquaticum (L.) Hayek (crucíferes)} BCN 24971

\section{NOMS POPULARS}

Api bord (1293)

Berro (castellà) $(564,1324)$

Creixen $(533,534,1293,1321)$ 
Greixen $(564,747)$

\section{USOS ALIMENTARIS}

Fulla

Ingestió de la part de la planta crua - Fresca (sense preparació)

FONTS 533, 534, 564, 747, 1293, 1321, 1324. DESCRIPCIÓ DE L'ÚS FETA PELS INFORMANTS. Per a amanir $(533,534,747,1321,1324)$. Es menjaven amanides (564). Per a menjar amanits (1293). DESTINACIÓ. Alimentació humana $(533,534,564,747,1293$, 1321, 1324).

\section{ALTRES OBSERVACIONS}

FONTS 564, 747. DESCRIPCIÓ FETA PELS INFORMANTS. Es fan a les fonts (747). Es fan per les fonts (564).

\section{Rosa canina L. (rosàcies)}

\section{BCN 29772}

\section{NOMS POPULARS}

Gavarrera (541)

Rosa de pastor $(543,544)$

Roser bord (582)

Roser de pastor (542)

\section{USOS MEDICINALS}

Flor

Antisèptic ocular

FONTS 542, 543, 544, 582. DESCRIPCIÓ DE L'ÚS FETA PELS INFORMANTS. Per als ulls (542, 543, 544, 582). FORMA FARMACĖUTICA I ÚS. Bany (ús extern). PREPARACIÓ. Decocció $(542,543,544)$. DESTINACIÓ. Medicina humana.

\section{Rosa gallica L. (rosàcies)}

BCN 24972

\section{NOMS POPULARS}

Rosa (1352)
Roser (1313)

Roser de jardí (1324)

\section{USOS MEDICINALS}

\section{Flor}

Antisèptic ocular

FONTS 1313, 1324, 1352. DESCRIPCIÓ DE L'ÚS FETA PELS INFORMANTS. Per a banyarse els ulls (1313). Amb els pètals et banyes els ulls quan els tens malalts (1324). Per a banyar els ulls malalts (1352). FORMA FARMACEUTICA I ÚS. Essència (ús extern) (1313). Bàlsam (ús extern) (1313). Bany (ús extern) (1324, 1352). PREPARACIO. Infusió de les flors (1313). Decocció (1324). Infusió dels pètals (1352). DESTINACIO. Medicina humana.

\section{ALTRES USOS}

\section{Flor}

Domèstic: ambientador

FONT 1313. DESCRIPCIÓ DE L'ÚS FETA PER L'INFORMANT. Per a fer olor.

\section{Rosa sp. (rosàcies)}

\section{NOMS POPULARS}

Escanyaguilles (507, 509, 510, 746)

Rosa $(529,530,531,539,540,553,554,555,560,583,584,585,746,1213,1214,1353$ 1354)

Rosa de bosc $(505,506)$

Roser $(520,521,528,561,562,563,564,569,570,590,1215,1339,1340)$

Roser bord (746)

Roser de bardissa (752)

Roser de pastor $(507,509,510)$

\section{USOS MEDICINALS}

Flor

Anticatarral

FONTS 1213, 1214. DESCRIPCIÓ DE L'ÚS FETA PELS INFORMANTS. Va bé per als constipats, porta molta vitamina C. FORMA FARMACĖUTICA I ÚS. Tisana (ús intern). PREPARACIÓ. Es pren en infusió. MODE D'UTILITZACIÓ/POSOLOGIA. Al matí i al vespre. DESTINACIÓ. Medicina humana. 
Apèndix 1. Catàleg de tàxons.

Antidiarreic

FONTS 1213, 1214. DESCRIPCIÓ DE L'ÚS FETA PELS INFORMANTS. Va bé per a la diarrea. FORMA FARMACĖUTICA I ÚS. Tisana (ús intern). PREPARACIÓ. Es pren en infusió. MODE D'UTILITZACIÓ/POSOLOGIA. Al matí i al vespre. DESTINACIÓ. Medicina humana.

Antipiròtic

FONTS 1213, 1214. DESCRIPCIÓ DE L'ÚS FETA PELS INFORMANTS. Alleuja les cremades del sol $(1213,1214)$. FORMA FARMACĖUTICA I ÚS. Bany (ús extern) PREPARACIÓ. L'aigua dels pètals (1214). Aigua dels pètals (1213). DESTINACIÓ. Medicina humana.

Antisèptic ocular

FONTS 505, 506, 520, 521, 528, 529, 530, 531, 539, 540, 553, 554, 555, 569, 570, 583, 584 $585,1213,1214,1339,1340,1353,1354$. DESCRIPCIÓ DE L'ÚS FETA PELS INFORMANTS. Per a banyar els ulls quan són malalts $(505,506)$. Per a banyar els ulls $(529$ $530,531,554,555)$. Les flors van bé per als ulls $(539,540)$. Són bones per als ulls $(520$ 521). Va bé per a banyar-se els ulls (528). Els pètals són molt bons per a banyar-te els ulls (553). Aigua per a la vista $(569,570)$. Les roses van bé per a banyar els ulls $(583,584,585)$ Per a rentar els ulls $(1213,1214)$. Per als ulls malalts $(1339,1340)$. Per a banyar els ulls malalts $(1353,1354)$ FORMA FARMACEUTICA I US. Bany (ús extern) $(505,506,520,521$ malalts (1353, 1354). Essència (ús in $1354)$. Essencia (ús int $531,539,540,553,569,570,583,584,585,1213,1214)$. Decocció. L'aigua de roses (528) Decocció. Aigua de les fors $(554,555)$. Essencia de pètals $(1353,1354)$. DESTINACIÓ. Medicina humana. OBSERVACIONS. D'un roser que sempre hem tingut aquí a casa que fa les roses una mica espellofides $(569,570)$

Fruit

Antiamigdalític

FONT 746. DESCRIPCIÓ DE L'ÚS FETA PER L'INFORMANT. Són les boles vermelles que fan els rosers bords $i$ se'n fa aigua per a les angines i per al mal de coll. FORMA FARMACEUTICA I ÚS. Tisana (ús intern). PREPARACIO. Decocció. DESTINACIO. Medicina humana.

Antiinflamatori faringi

FONTS 507, 509, 510, 746. DESCRIPCIÓ DE L'ÚS FETA PELS INFORMANTS. Són les boles vermelles que fan els rosers bords i se'n fa aigua per a les angines i per al mal de col (746). Per al mal de coll $(507,509,510)$. FORMA FARMACĖUTICA I ÚS. Tisana (ús intern) PREPARACIÓ. Decocció $(507,509,510,746)$. DESTINACIÓ. Medicina humana.

\section{Fulla}

Antisèptic ocular

FONT 746. DESCRIPCIÓ DE L'ÚS FETA PER L'INFORMANT. Per a banyar els ulls. FORMA FARMACĖUTICA I ÚS. Bany (ús extern). PREPARACIÓ. Decocció. Aigua de les fulles. DESTINACIÓ. Medicina humana.

\section{USOS ALIMENTARIS}

Flor

Ingestió de la part de la planta crua - Fresca (sense preparació)

FONTS 1213,1214 . DESCRIPCIÓ DE L'ÚS FETA PELS INFORMANTS. Els pètals es poden menjar en l'amanida. DESTINACIÓ. Alimentació humana.

\section{ALTRES USOS}

\section{Flor}

Cosmètic

FONTS 1213, 1214. DESCRIPCIÓ DE L'ÚS FETA PELS INFORMANTS. Es fan bullir les roses i es barreja mig litre d'aquesta aigua amb mig litre d'oli d'oliva i cera d'abelles. És un bon tònic.

Creences i pràctiques magicoreligioses

FONT 560. DESCRIPCIÓ DE L'ÚS FETA PER L'INFORMANT. Es posaven les fulles a les catifes [dit "alfombres"] de Corpus.

Domèstic: ambientador

FONTS 1213, 1214. DESCRIPCIÓ DE L'ÚS FETA PELS INFORMANTS. Essència de roses per a fer olor els armaris o per a posar al mocador.

\section{Part aèria florida}

Ornamental: elaboració de rams

FONTS 561, 562, 563, 564. DESCRIPCIÓ DE L'ÚS FETA PELS INFORMANTS. En teniem a casa per a fer bonic $(561,562,563)$. N'hi havia de moltes classes $(564)$.

\section{Planta viva ex situ}

Ornamental: jardineria

FONT 590. DESCRIPCIÓ DE L'ÚS FETA PER L'INFORMANT. Per a fer bonic.

\section{ALTRES OBSERVACIONS}

FONT 560. DESCRIPCIÓ FETA PER L'INFORMANT. N'hi havia aquí a Beget.

\section{BARREGES AMB AQUEST TÀXON}

\section{Flor}

FONTS 1213, 1214. Entrevista 102, barreja IV (vegeu catàleg de barreges)

FONTS 529, 530, 531. Entrevista 53, barreja VII (vegeu catàleg de barreges)

Fruit

FONT 746. Entrevista 45, barreja II (vegeu catàleg de barreges) 
Apèndix 1. Catàleg de tàxons.

FONT 752. Entrevista 62, barreja II (vegeu catàleg de barreges)

\section{Rosa tomentosa Sm. (rosàcies)}

BCN 24973

\section{NOMS POPULARS}

Cirera de pastor (fruit) $(561,562,563)$

Escanyaguilles (fruit) $(572,573,590)$

Grataculs (fruit) $(554,555,1313,1352)$

Rosa de bosc (1342)

Roser (524)

Roser bord $(528,538,553,572,573,1213,1214,1327,1347,1348,1349)$

Roser de bosc $(525,526,527,753,754,755,1324,1331,1341)$

Roser de guilla $(525,526,527)$

Roser de pastor $(520,521,524,569,570,590)$

\section{USOS MEDICINALS}

\section{Flor}

Antiinflamatori faring

FONT 590. DESCRIPCIÓ DE L'ÚS FETA PER L'INFORMANT. Per al mal de coll. FORMA FARMACĖUTICA I ÚS. Tisana (ús intern). PREPARACIÓ. Decocció. DESTINACIÓ. Medicina humana.

Antisèptic ocular

FONTS 1327, 1341, 1342, 1347, 1348, 1349. DESCRIPCIÓ DE L'ÚS FETA PELS INFORMANTS. Per a quan tens els ulls malalts $(1327)$. Per als ulls $(1341,1342)$. Per a banyar els ulls $(1347,1348,1349)$. FORMA FARMACEUTICA I US. Bany (ús extern) PREPARACIÓ. Decocció. Aigua de les roses $(1327,1347,1348,1349)$. Decocció. Aigua de les flors $(1341,1342)$. DESTINACIÓ. Medicina humana.

Fruit

Anticatarral

FONTS 520, 521, 561, 562, 563. DESCRIPCIÓ DE L'ÚS FETA PELS INFORMANTS. Va bé per als constipats $(520,521)$. En aigua per als constipats $(561,562,563)$. FORMA per als constipats (520, 521). En aigua per als constipats (561, 562, 563). FORMA
FARMACÉUTICA I US. Tisana (ús intern). PREPARACIÓ. Decocció $(520,521,561,562$, 563). DESTINACIÓ. Medicina humana. OBSERVACIONS. El fruit es diu escanyaguilles (520, 521).

Antidiarreic
FONTS 554, 555. DESCRIPCIO DE L'ÚS FETA PELS INFORMANTS. Per a fer tallar la diarrea (554). Per a tallar la diarrea (555). FORMA FARMACĖUTICA I ÚS. Tintura alcohòlica (ús intern). PREPARACIÓ. Amb anís $(554,555)$. DESTINACIÓ. Medicina humana.

Antigripal

FONT 1324. DESCRIPCIÓ DE L'ÚS FETA PER L'INFORMANT. Per a quan tens grip FORMA FARMACĖUTICA I ÚS. Tisana (ús intern). PREPARACIÓ. Decocció. DESTINACIÓ. Medicina humana.

Antiinflamatori faringi

FONTS 520, 521, 524, 525, 526, 527, 538, 554, 555, 590, 753, 754, 755, 1331 DESCRIPCIÓ DE L'ÚS FETA PELS INFORMANTS. Per al mal de coll $(520,521,524,525$, $526,527,538,554,555,590,1331)$. Les escanyaguilles del roser van bé per al rogall i el mal de coll $(753,754,755)$. Per al mal de coll, als nens els va molt bé (1331). FORMA FARMACEUTICA I ÚS. Tisana (ús intern) $(520,521,524,525,526,527,538,554,555,590$ $753,754,755,1331$ ). Xarop (ús intern) (1331). PREPARACIÓ. Decocció. El fruit, que és $753,754,755,1331)$. Xarop (ús intern) (1331). PREPARACIO. Decocció. El fruit, que és
l'escanyaguilles, en aigua (524). Decocció $(520,521,525,526,527,554,555,590,753,754$ l'escanyaguilles, en aigua (524). Decocció $(520,521,525,526,527,554,555,590,753,754$,
$755)$. Decocció. Aigua de les boles (538). Decocció. Les granes vermelles es passen pel passapuré i és bullen en aigua (1331). Xarop (1331). MODE D'UTILITZACIÓ/POSOLOGIA S'ha de prendre tres cops al dia (1331). DESTINACIÓ. Medicina humana. OBSERVACIONS. Quan el fruit cau (tapaculs) se'l mengen les guilles $(525,526,527)$. El fruit es diu escanyaguilles $(520,521)$

Hematocatàrtic

FONT 528. DESCRIPCIÓ DE L'ÚS FETA PER L'INFORMANT. Es feia servir per a netejar [dit "llempiar"] les sangs. FORMA FARMACĖUTICA I ÚS. Tisana (ús intern). PREPARACIÓ. Decocció. DESTINACIO. Medicina humana.

Per a l'afonia

FONTS 753, 754, 755. DESCRIPCIO DE L'ÚS FETA PELS INFORMANTS. Les escanyaguilles del roser van bé per al rogall i el mal de coll. FORMA FARMACEUTICA I ÚS. Tisana (ús intern). PREPARACIO. Decocció. DESTINACIÓ. Medicina humana.

Vitamínic

FONT 1324. DESCRIPCIÓ DE L'ÚS FETA PER L'INFORMANT. Té molta vitamina C FORMA FARMACĖUTICA I ÚS. Tisana (ús intern). PREPARACIÓ. Decocció. DESTINACIÓ. Medicina humana.

\section{No consta}

Antihemorroïdal

FONTS 753, 754, 755. DESCRIPCIÓ DE L'ÚS FETA PELS INFORMANTS. Va bé per a les morenes. FORMA FARMACĖUTICA I ÚS. Bany (ús extern). PREPARACIÓ. La bola que sembla un cotó que fa com un borró, se'n pot fer aigua. DESTINACIÓ. Medicina humana.

Antitussigen

FONTS 1213, 1214. DESCRIPCIÓ DE L'ÚS FETA PELS INFORMANTS. Per a la tos. FORMA FARMACĖUTICA I ÚS. Desconegut per l'informant. DESTINACIÓ. Medicina humana. 
Desconegut per l'informant

FONTS 569, 570. FORMA FARMACÈUTICA I ÚS. Desconegut per l'informant. DESTINACIÓ Medicina humana. OBSERVACIONS. Em sembla que se'n feia oli, però no recordo perquè servia.

\section{USOS ALIMENTARIS}

Fruit

Ingestió de la part de la planta crua - Fresca (sense preparació)

FONTS 572, 573. DESCRIPCIÓ DE L'ÚS FETA PELS INFORMANTS. Les rosegàvem quan eren madures i trèiem les granes. DESTINACIÓ. Alimentació humana.

Ingestió de la part de la planta cuita - Cuita en sucre

FONTS 1313, 1327. DESCRIPCIÓ DE L'ÚS FETA PELS INFORMANTS. En feien melmelades abans (1313). Del fruit (grataculs) en fa melmelades (1327). DESTINACIÓ. Alimentació humana $(1313,1327)$.

\section{No consta}

Preparació de begudes - Beguda preparada amb aiguardent

FONTS 1341, 1342. DESCRIPCIÓ DE L'ÚS FETA PELS INFORMANTS. Per a fer ratafia, es confita llor (Laurus nobilis), romaní (Rosmarinus officinalis), nous (Juglans regia), granes de ginebró (Juniperus communis), camamilla (Achillea ptarmica subsp. pyrenaica), ortigues (Urtica dioica), pela de taronja (Citrus sinensis), pela de llimona (Citrus limon), canyella (Cinnamomum zeylanicum), marialluïsa (Lippia triphylla), poniol (Satureja calamintha subsp. ascendens), rosa de bosc (Rosa tomentosa) i malva (Malva sylvestris) en aiguardent i es ascendens), rosa de bosc (Rosa tomentosa) i malva (Malva sylvestris) en aiguardent i es
deixa 40 dies a sol i a serena, llavors es cola i ja es pot beure. DESTINACIÓ. Alimentació humana.

\section{ALTRES USOS}

Fruit

Lúdic: jocs $\mathrm{i}$ joguines

FONT 1352. DESCRIPCIÓ DE L'ÚS FETA PER L'INFORMANT. Es partien i es tiraven a l'esquena dels nens, deixen anar els pels i fan molta picor.

\section{Planta viva ex situ}

Ornamental: jardineria

FONT 524. DESCRIPCIÓ DE L'ÚS FETA PER L'INFORMANT. N'hi ha per aquí fora, fan bonic i fan olor. OBSERVACIONS. Quan hi ha la primera rosa, corro tot el dia olorant-la.

\section{Rosmarinus officinalis L. (labiades)}

BCN 24974

\section{NOMS POPULARS}

Romaní $(503,505,506,507,509,510,515,516,518,519,520,521,522,523,529,530$ $531,532,533,534,536,537,539,540,546,547,548,549,553,554,555,558,560,561$ $562,563,565,566,569,570,571,572,573,578,579,580,581,590,747,750,752,753$, $754,755,1297,1301,1313,1321,1323,1325,1326,1327,1330,1331,1332,1333,1334$ $1335,1336,1341,1342,1343,1344,1350,1351,1353,1354,1361,1362)$

\section{USOS MEDICINALS}

\section{Part aèria florida}

Analgèsic

FONTS 546, 747. DESCRIPCIÓ DE L'ÚS FETA PELS INFORMANTS. Per al dolor (747). Per a desinfectar i treure el dolor quan et fas una ferida (546). FORMA FARMACEUTICA I US Sense forma farmacèutica (mescla medicamentosa) (ús extern) (747). Fumigació (ús extern) (546). PREPARACIÓ. Per un litre d'esperit de vi, dotze aspirines i dotze brots de romaní. T'has de fregar allà on tens el dolor (747). DESTINACIÓ. Medicina humana.

\section{Antiartrític}

FONT 532. DESCRIPCIÓ DE L'ÚS FETA PER L'INFORMANT. És bo per a l'artrosi. FORMA FARMACĖUTICA I ÚS. Tisana (ús intern). PREPARACIÓ. Decocció. DESTINACIÓ. Medicina humana.

Antibronquític

FONTS 507, 509, 510. DESCRIPCIÓ DE L'ÚS FETA PELS INFORMANTS. Per a la bronquitis. FORMA FARMACĖUTICA I ÚS. Tisana (ús intern). Aerosol (ús intern) PREPARACIÓ. Decocció.Per a fer bafs. DESTINACIÓ. Medicina humana.

Anticatarral

FONTS 515, 516, 520, 521, 522, 523, 561, 562, 563, 752, 1321, 1327. DESCRIPCIÓ DE L'ÚS FETA PELS INFORMANTS. Per als constipats $(515,516,520,521,522,523,561,562$, $563,1327)$. Per als refredats (752). Per a quan estàs constipat (1321). FORMA FARMACĖUTICA I ÚS. Tisana (ús intern) $(515,516,520,521,522,523,561,562,563,752$, $1321,1327)$. Aerosol (ús intern) $(561,562,563)$. PREPARACIÓ. Decocció $(515,516,520$ $521,522,523,561,562,563,752,1321)$. Bafs $(561,562,563)$. En infusió (1327). 521, 522, 523, 561, 562, 563,
DESTINACIÓ Medicina humana.

Antihipertensiu

FONTS 505, 506, 515, 516, 520, 521, 529, 530, 531, 533, 534, 549, 572, 573, 578, 579, 580, $750,1297,1301,1325,1326,1327,1350,1351,1361,1362$. DESCRIPCIÓ DE L'ÚS FETA PELS INFORMANTS. Per a rebaixar la sang $(505,506,520,521,529,530,531,549,580$ 1301). Per a fer baixar la pressió $(515,516,533,534,578,579,1327,1350,1351,1361$ $1362)$. Per a fer rebaixar la sang $(750)$. Per a fer baixar la tensió $(572,573)$. Per a compensar la pressió (1297). Per a regular la pressió $(1325,1326)$. FORMA FARMACĖUTICA I ÚS Tisana (ús intern). PREPARACIÓ. Decocció $(505,506,515,516,520,521,529,530,531$, $533,534,549,572,573,578,579,580,750,1297,1301,1325,1326,1350,1351,1361$, 1362). En infusio (1327). EFECTES SECUNDARIS. Si. DESTINACIO. Medicina humana. 
OBSERVACIONS. El meu pare sempre en prenia $(505,506)$. S'ha d'anar alerta perquè la rebaixa molt $(750)$.

Antiodontàlgic

FONT 558. DESCRIPCIÓ DE L'ÚS FETA PER L'INFORMANT. Per a glopejar quan tens mal de queixals. FORMA FARMACĖUTICA I ÚS. Colllutori (ús extern). PREPARACIÓ. Decocció. DESTINACIÓ. Medicina humana.

Coadjuvant del part

FONTS 507, 509, 510. DESCRIPCIÓ DE L'ÚS FETA PELS INFORMANTS. Per a quan no feien els llits. FORMA FARMACĖUTICA I ÚS. Sense forma farmacèutica (ús directe, ús intern). PREPARACIÓ. Es posaven dos brots de romaní en creu a l'esquena de les ovelles. DESTINACIÓ. Medicina veterinària.

Coadjuvant del postpart

FONTS 511, 512, 513, 514. DESCRIPCIÓ DE L'ÚS FETA PELS INFORMANTS. Es posaven dos brots de romaní en creu a l'esquena de les ovelles quan no feien els llits. FORMA FARMACĖUTICA I ÚS. Sense forma farmacèutica (ús directe, ús extern). DESTINACIÓ. Medicina veterinària.

Expectorant

FONTS 565, 566. DESCRIPCIÓ DE L'ÚS FETA PELS INFORMANTS. Va bé per a expectorar i per als pulmons $(565,566)$. FORMA FARMACĖUTICA I ÚS. Tintura alcohòlica (ús intern). PREPARACIÓ. Posar mig litre d'aiguardent, un quart de mel i romaní, deixar-ho nou dies a sol i serena (566). Posar mig litre d'aiguardent, un quart de mel i eucaliptus, nou dies a sol i serena (566). Posar mig litre d'aiguardent, un quart de mel i eucaliptus, prendre al matí $(565,566)$. DESTINACIÓ. Medicina humana.

Reforçant cerebral

FONT 1330. DESCRIPCIÓ DE L'ÚS FETA PER L'INFORMANT. Per a reforçar la memòria. FORMA FARMACĖUTICA I ÚS. Tisana (ús intern). PREPARACIÓ. Decocció. EFECTES SECUNDARIS. Sí. DESTINACIÓ. Medicina humana. OBSERVACIONS. Fa pujar la pressió. Salutifer

FONTS 539, 540. DESCRIPCIÓ DE L'ÚS FETA PELS INFORMANTS. Salutifer. FORMA FARMACĖUTICA I ÚS. Tisana (ús intern). PREPARACIÓ. Decocció. DESTINACIÓ. Medicina humana

Vasotònic

FONTS 1323, 1353, 1354. DESCRIPCIÓ DE L'ÚS FETA PELS INFORMANTS. Per a fer fregues quan tens mala circulació $(1323)$. Va bé per a la circulació $(1353,1354)$. FORMA FARMACĖUTICA I ÚS. Loció (ús extern). PREPARACIÓ. Confitat en alcohol de $70^{\circ}$ (1323) En esperit de vi $(1353,1354)$. DESTINACIÓ. Medicina humana.

Vulnerari

FONT 546. DESCRIPCIÓ DE L'ÚS FETA PER L'INFORMANT. Per a desinfectar i treure e dolor quan et fas una ferida. FORMA FARMACĖUTICA I ÚS. Fumigació (ús extern) PREPARACIÓ. Perfums. DESTINACIÓ. Medicina humana.

\section{Part aèria jove}

Analgèsic

FONTS 572, 573. DESCRIPCIÓ DE L'ÚS FETA PELS INFORMANTS. Va bé per al dolor, és un calmant. FORMA FARMACĖUTICA I ÚS. Loció (ús extern). PREPARACIÓ. Posat quan és verd amb esperit de vi. DESTINACIÓ. Medicina humana.

\section{USOS ALIMENTARIS}

\section{Part aèria}

Condiment

FONT 1313. DESCRIPCIÓ DE L'ÚS FETA PER L'INFORMANT. Per a donar gust als plats. DESTINACIÓ. Alimentació humana.

Preparació de begudes - Beguda preparada amb aiguardent

FONTS 1341, 1342. DESCRIPCIÓ DE L'ÚS FETA PELS INFORMANTS. Per a fer ratafia, es confita llor (Laurus nobilis), romaní (Rosmarinus officinalis), nous (Juglans regia), granes de , camamilla (Achillea ptarmica (Juglans regia), granes de ginebró (Juica), (Urtica dioica), pela de taronja (Citrus sinensis), pela de limona (Citrus limon), canyella (Cinnamomum zeylanicum), marialluîsa (Lippia triphylla), poniol (Satureja calamintha subsp. ascendens), rosa de bosc (Rosa tomentosa) i malva (Malva sylvestris) en aiguardent i es deixa 40 dies a sol i a serena, llavors es cola i ja es pot beure. DESTINACIÓ. Alimentació humana.

\section{Part aèria florida}

Condiment

FONTS 507, 509, 510, 520, 521, 569, 570, 571, 590. DESCRIPCIÓ DE L'ÚS FETA PELS INFORMANTS. Per a donar gust als cuinats $(507,509,510)$. Per a afegir als cuinats $(520$ 521). Per a cuinar $(569,570,571)$. Romaní (Rosmarinus officinalis), llorer (Laurus nobilis) farigola (Thymus vulgaris) i orenga (Origanum vulgare). Piquem les herbes juntes i ho fem servir per a fer guisats (590). DESTINACIO. Alimentació humana $(507,509,510,520,521$ 569, 570, 571, 590).

\section{ALTRES USOS}

\section{Part aèria}

Creences i pràctiques magicoreligioses

FONTS 560, 1325, 1326. DESCRIPCIÓ DE L'ÚS FETA PELS INFORMANTS. Per a beneir pel Ram (560). Quan feia mal temps i es veia a venir una pedregada es cremava una mica de romaní (560). A Beget i Rocabruna es beneïa un ram de llor (Laurus nobilis) i romani (Rosmarinus officinalis) guarnits amb galetes i rosaris de sucre el diumenge de rams (1325, 1326).

\section{Planta sencera}

Altres informacions 
FONT 1321. DESCRIPCIÓ DE L'ÚS FETA PER L'INFORMANT. Deu ser bo, perquè les abelles hi van molt.

\section{ALTRES OBSERVACIONS}

FONTS $539,540,549,558,1321,1325,1326$. DESCRIPCIÓ FETA PELS INFORMANTS. A l'hort $(539,540)$. En teníem plantat a l'hort (549). Per vall a tot arreu n'hi ha, allà dalt es mort (558). Floreix tot l'any a cada Mare de Déu (1321). En tenien a la Ginebrosa de Beget (1325 1326)

\section{BARREGES AMB AQUEST TÀXON}

\section{Part aèria florida}

FONTS 1325, 1326. Entrevista 13, barreja II (vegeu catàleg de barreges)

FONT 1335. Entrevista 15, barreja I (vegeu catàleg de barreges)

FONT 1336. Entrevista 16, barreja II (vegeu catàleg de barreges)

FONTS 1343, 1344. Entrevista 23, barreja I (vegeu catàleg de barreges)

FONT 1331. Entrevista 30, barreja I (vegeu catàleg de barreges)

FONT 503. Entrevista 43 (vegeu catàleg de barreges)

FONT 750. Entrevista 50, barreja III (vegeu catàleg de barreges)

FONTS 518, 519. Entrevista 54, barreja II (vegeu catàleg de barreges)

FONT 752. Entrevista 62, barreja I (vegeu catàleg de barreges)

FONTS 753, 754, 755. Entrevista 67, barreja IV (vegeu catàleg de barreges)

FONTS 539, 540. Entrevista 69 (vegeu catàleg de barreges)

FONTS 547, 548. Entrevista 73, barreja I (vegeu catàleg de barreges)

FONT 549. Entrevista 75, barreja III (vegeu catàleg de barreges)

FONT 553. Entrevista 77, barreja II (vegeu catàleg de barreges)

FONTS 554, 555. Entrevista 78, barreja II (vegeu catàleg de barreges)

FONT 571. Entrevista 89, barreja I (vegeu catàleg de barreges)

FONT 581. Entrevista 94, barreja I (vegeu catàleg de barreges)

\section{Part aèria jove}

FONTS 1332, 1333, 1334. Entrevista 11, barreja II (vegeu catàleg de barreges)

\section{Rubus caesius L. (rosàcies)}

BCN 24976

\section{NOMS POPULARS}

Esbarzer (541)

Romegró $(1332,1333,1334,1336)$

Romegueró $(518,519,520,521,528,553,583,584,585)$

\section{USOS MEDICINALS}

\section{Arre}

Hematocatàrtic

FONTS 520, 521, 1332, 1333, 1334. DESCRIPCIÓ DE L'ÚS FETA PELS INFORMANTS. És un purificant de la sang $(520,521)$. Per a netejar la sang $(1332,1333,1334)$. FORMA FARMACĖUTICA I ÚS. Tisana (ús intern). PREPARACIÓ. Decocció $(520,521)$. Fer bullir l'arrel $(1332,1333,1334)$. DESTINACIÓ. Medicina humana.

Resolutiu

FONT 528. DESCRIPCIÓ DE L'ÚS FETA PER L'INFORMANT. Són purificants de la sang. Jo en prenia una vegada que vaig tenir furóncols que deien que et sortien quan tenies les sangs
brutes. FORMA FARMACÉUTICA I ÚS. Tisana (ús intern). PREPARACIÓ. Decocció. DESTINACIÓ. Medicina humana.

Fulla

Antihipertensiu

FONTS 518, 519, 1336. DESCRIPCIÓ DE L'ÚS FETA PELS INFORMANTS. Per a fer baixar la pressió $(518,519)$. El seu avi se'n feia aigua per a fer baixar la pressió (1336). FORMA FARMACĖUTICA I ÚS. Tisana (ús intern). PREPARACIÓ. Decocció $(518,519,1336)$. DESTINACIÓ. Medicina humana.

\section{Turió}

Antisèptic bucal

FONT 553. DESCRIPCIÓ DE L'ÚS FETA PER L'INFORMANT. Brots tendres per a infeccions de boca i les genives. FORMA FARMACĖUTICA I ÚS. Col-lutori (ús extern). PREPARACIÓ. Decocció. DESTINACIÓ. Medicina humana.

\section{BARREGES AMB AQUEST TAXXN}

Arrel

FONT 528. Entrevista 61, barreja III (vegeu catàleg de barreges)

FONTS 583, 584, 585. Entrevista 96, barreja I (vegeu catàleg de barreges)

\section{Rubus idaeus L. (rosàcies)}

BCN 24977

\section{NOMS POPULARS}


Gerdó $(572,573)$

Jordó $(511,512,513,514,538,541,549,561,562,563,564,571,580,583,584,585,588$ $748,749,1313,1321,1337,1338,1353,1354)$

Jordonera (541)

\section{USOS ALIMENTARIS}

Fruit

Ingestió de la part de la planta crua - Fresca (sense preparació)

FONTS 511, 512, 513, 514, 549, 561, 562, 563, 564, 571, 572, 573, 580, 588, 748, 749 , 1321, 1337, 1338. DESCRIPCIÓ DE L'ÚS FETA PELS INFORMANTS. El fruit per a menjar $(511,512,513,514)$. Per a menjar $(572,573,580,588,748,749)$. Per a menjar quan són madurs (549). Per a menjar amb una mica de moscatell i sucre (571). Per a menjar amb madurs (549). Per a menjar amb una mica de moscatell i sucre (571). Per a menjar amb $562,563)$. DESTINACIÓ. Alimentació humana $(511,512,513,514,549,561,562,563,564$ $562,563)$. DESTINACIO. Alimentació humana $(511,512$,
$571,572,573,580,588,748,749,1321,1337,1338)$.

Ingestió de la part de la planta cuita - Cuita en sucre

FONTS 538, 572, 573, 1313, 1353, 1354. DESCRIPCIÓ DE L'ÚS FETA PELS INFORMANTS. Per a fer melmelades. Ho fan més els estiuejants que la gent del país (538). Ara se'n fan melmelades $(572,573)$. Per a fer melmelades $(1313,1353,1354)$. DESTINACIÓ Alimentació humana $(538,572,573,1313,1353,1354)$.

Preparació de begudes - Beguda preparada amb licor

FONTS 583, 584, 585. DESCRIPCIÓ DE L'ÚS FETA PELS INFORMANTS. Venien més tard que les maduixes, en fèiem licor, macerats amb anís. DESTINACIÓ. Alimentació humana.

\section{ALTRES USOS}

Fruit

Altres informacions

FONT 564. DESCRIPCIÓ DE L'ÚS FETA PER L'INFORMANT. S'anaven a buscar i es venien als senyors de Camprodon.

\section{Rubus ulmifolius Schott (rosàcies)}

BCN 24978

\section{NOMS POPULARS}

Móra (fruit) $(517,549,560,561,562,563,564,571,583,584,585,588,590,746,748,749$ $1215,1297,1313,1353,1354)$

Móra de romeguera (fruit) $(572,573)$
Romeguera $(505,506,518,519,520,521,528,529,530,531,564,580,747,1300,1314$, $1327,1330,1332,1333,1334,1336,1341,1342,1345,1346)$

\section{USOS MEDICINALS}

Fruit

Antihemorroïdal

FONT 517. DESCRIPCIÓ DE L'ÚS FETA PER L'INFORMANT. Per a les morenes. FORMA FARMACĖUTICA I ÚS. Supositori (ús intern). Sense forma farmacèutica (ús directe, ús intern). PREPARACIÓ. Es posa com a supositori i alhora en menges. DESTINACIÓ. Medicina humana.

Fulla

Antiherpètic

FONTS 1332, 1333, 1334. DESCRIPCIÓ DE L'ÚS FETA PELS INFORMANTS. Per a quan tens una pansa. FORMA FARMACEUTICA I US. Sense forma farmacèutica (ús directe, ús extern). PREPARACIO. Les fulles (de la part on no els ha tocat gaire el sol) es posen a sobre el llavi. DESTINACIO. Medicina humana.

Antipiròtic

FONT 747. DESCRIPCIÓ DE L'ÚS FETA PER L'INFORMANT. Per a les cremades. FORMA FARMACĖUTICA I ÚS. Sense forma farmacèutica (ús directe, ús intern). PREPARACIÓ. La part llisa fa supurar i la part rústica fa assecar. DESTINACIO. Medicina humana.

Resolutiu

FONTS 520, 521. DESCRIPCIÓ DE L'ÚS FETA PELS INFORMANTS. Les fulles van bé per a posar sobre les llagues. FORMA FARMACĖUTICA I ÚS. Sense forma farmacèutica (ús directe, ús extern). DESTINACIO. Medicina humana.

Vulnerari

FONTS 505, 506, 528, 529, 530, 531. DESCRIPCIÓ DE L'ÚS FETA PELS INFORMANTS Posades sobre els talls $(505,506)$. Les fulles van bé per a curar ferides (528). FORMA FARMACEUTICA I ÚS. Embrocació (ús extern) $(505,506)$. Sense forma farmacèutica (ús directe, ús extern) $(528,529,530,531)$. PREPARACIO. Fulles de romeguera untades en ol $(505,506)$ La part llisa fa supurar i la part rústica fa assecar $(529,530,531)$. El cantó llis de la fulla fa supurar la ferida i humana.

Turió

Antidiarreic

FONTS 1341, 1342. DESCRIPCIÓ DE L'ÚS FETA PELS INFORMANTS. Per a la diarrea FORMA FARMACĖUTICA I ÚS. Sense forma farmacèutica (ús directe, ús intern) PREPARACIO. Menjar els caps de romeguera. DESTINACIÓ. Medicina humana.

Antiinflamatori faringi

FONTS 564, 1300. DESCRIPCIÓ DE L'ÚS FETA PELS INFORMANTS. Per al mal de coll $(564,1300)$. FORMA FARMACĖUTICA I ÚS. Gargarisme (ús extern) (564). Tisana (ús intern) 
(1300). PREPARACIÓ. Decocció (564). Infusió de caps de romeguera tendra (1300). DESTINACIÓ. Medicina humana.

\section{USOS ALIMENTARIS}

Fruit

Ingestió de la part de la planta crua - Fresca (sense preparació)

FONTS $549,564,571,572,573,580,583,584,585,1215$. DESCRIPCIÓ DE L'ÚS FETA PELS INFORMANTS. Quan són madures són molt bones (549). Per a menjar $(571,572$ 573). Fan les móres i es mengen (580). En el temps de la gana els gossos també s'atipaven de móres $(564)$. Ens les menjàvem $(583,584,585)$. En menjàvem quan anàvem a busca aglans, per a treure la set (1215). DESTINACIÓ. Alimentació humana $(549,571,572,573$ $580,583,584,585,1215)$. Alimentació animal (564)

Ingestió de la part de la planta cuita - Cuita en sucre

FONTS 520, 521, 560, 561, 562, 563, 572, 573, 588, 590, 746, 748, 749, 1215, 1297, 1313 $1327,1353,1354$. DESCRIPCIÓ DE L'ÚS FETA PELS INFORMANTS. En faig confitures (746). Per a fer melmelades $(590,748,749,1313)$. Amb les móres en fem confitura (520 $521)$. Per a fer confitura $(560,561,562,563,588,1215)$. Ara es fan melmelades, abans no se'n feien $(572,573)$. Melmelada (1297). De les móres en fa melmelada (1327). En fem melmelada $(1353,1354)$. DESTINACIO. Alimentació humana $(520,521,560,561,562,563$, $572,573,588,590,746,748,749,1215,1297,1313,1327,1353,1354)$

Turió

Ingestió de la part de la planta crua - Fresca (sense preparació)

FONTS 1345, 1346. DESCRIPCIÓ DE L'ÚS FETA PELS INFORMANTS. Els caps de romeguera es donaven als procs. DESTINACIÓ. Alimentació animal.

\section{BARREGES AMB AQUEST TẢXON}

Fulla

FONT 1327. Entrevista 14, barreja II (vegeu catàleg de barreges)

No consta

FONT 1336. Entrevista 16, barreja III (vegeu catàleg de barreges)

Turió

FONT 1314. Entrevista 17, barreja II (vegeu catàleg de barreges)

FONT 1330. Entrevista 32, barreja IV (vegeu catàleg de barreges)

FONTS 518, 519. Entrevista 54, barreja III (vegeu catàleg de barreges)

\section{Rumex longifolius DC. in Lam. et DC. (poligonàcies)}

BCN 27298

\section{NOMS POPULARS}

Ribarbo (castellà) $(547,548)$

Ribardo (castellà) $(1311,1312,1339,1340,1345,1346)$

\section{USOS MEDICINALS}

\section{Arrel}

Protector renal

FONTS 547, 548. FORMA FARMACĖUTICA I ÚS. Desconegut per l'informant. DESTINACIÓ. Medicina humana. OBSERVACIONS. L'arrel recordo que deien que anava bé per a alguna cosa, sembla que era el ronyó

Purgant

FONTS 1311, 1312, 1339, 1340, 1345, 1346. DESCRIPCIÓ DE L'ÚS FETA PELS INFORMANTS. És purgant. FORMA FARMACĖUTICA I ÚS. Tisana (ús intern). PREPARACIÓ. Decocció. DESTINACIÓ. Medicina humana.

\section{Rumex scutatus L. (poligonàcies)}

BCN 24979

\section{NOMS POPULARS}

Badola $(528,541,553,574,575,576,577,580,591,592,1332,1333,1334)$

Madola $(748,749)$

Verola $(1353,1354)$

\section{USOS MEDICINALS}

Fulla

Antipruriginós

FONT 553. DESCRIPCIÓ DE L'ÚS FETA PER L'INFORMANT. Fregar quan t'ortigues, et fa sortir de seguida les butllofes i marxa el mal. FORMA FARMACĖUTICA I ÚS. Sense forma farmacèutica (ús directe, ús extern). DESTINACIÓ. Medicina humana.

\section{USOS ALIMENTARIS}

\section{Fulla}

Ingestió de la part de la planta crua - Fresca (sense preparació)

FONTS 528, 541, 574, 575, 576, 577, 580, 591, 592, 748, 749, 1332, 1333, 1334, 1353 1354. DESCRIPCIO DELUS FETA PELS INFORMANTS. Ens les menjavem aixi mateix, 
Apèndix 1. Catàleg de tàxons.

gust dolç $(748,749)$. Es donaven a les gallines (528). En menjàvem quan érem petits (528). Per a menjar $(541,580)$. Són bones, de petits ens en fèiem tips $(591,592)$. Quan passàvem per aquests camins en menjàvem $(574,575,576,577)$. Abans em menjava les fulles $(1332$ $1333,1334)$. De petits ens la menjàvem $(1353,1354)$. OBSERVACIONS. Són àcides (528, $541)$. DESTINACIÓ. Alimentació humana $(528,541,574,575,576,577,580,591,592,748$ $749,1332,1333,1334,1353,1354)$. Alimentació animal (528).

\section{Rumex sp. (poligonàcies)}

\section{NOMS POPULARS}

Llengua bovina $(520,521,539,540,547,548)$

Llengua de bou $(582,1352)$

\section{USOS MEDICINALS}

Fulla

Resolutiu

FONTS 539, 540. DESCRIPCIÓ DE L'ÚS FETA PELS INFORMANTS. Per a rebentar furóncols. FORMA FARMACĖUTICA I ÚS. Emplastre (ús extern). PREPARACIÓ. Es posava a sobre unes graelles [dit "grielles"] s'escalivava i ben calenta damunt del gra. DESTINACIÓ. Medicina humana.

\section{USOS ALIMENTARIS}

Fulla

Ingestió de la part de la planta crua - Fresca (sense preparació)

FONT 582. DESCRIPCIÓ DE L'ÚS FETA PER L'INFORMANT. Es donaven al bestiar. DESTINACIÓ Alimentació animal.

\section{ALTRES USOS}

Fulla

Lúdic: jocs i joguines

FONT 1352. DESCRIPCIÓ DE L'ÚS FETA PER L'INFORMANT. Quan jugàvem a cuinetes eren els bistecs.

\section{ALTRES OBSERVACIONS}

FONTS 547, 548. DESCRIPCIÓ FETA PELS INFORMANTS. A vegades s'escampen pels camps.
Ruscus aculeatus L. (liliàcies)

BCN 27273

\section{NOMS POPULARS}

Boix marí $(560,564,1352)$

\section{ALTRES USOS}

\section{Part aèria}

Ornamental: elaboració de rams

FONT 1352. DESCRIPCIÓ DE L'ÚS FETA PER L'INFORMANT. Per a fer rams per Nadal.

Part aèria fructificada

Ornamental: elaboració de rams

FONTS 560, 564. DESCRIPCIÓ DE L'ÚS FETA PELS INFORMANTS. Per a fer bonic per Nadal (560). Per a fer bonic (564)

\section{Ruta chalepensis L. (rutàcies)}

\section{BCN 24980}

\section{NOMS POPULARS}

Ruda $(503,505,506,507,509,510,511,512,513,514,517,520,521,525,526,527,528$ $529,530,531,536,537,541,542,543,544,545,547,548,549,553,554,555,556,557$ $558,560,561,562,563,564,565,566,567,568,571,572,573,574,575,576,577,578$ $579,580,581,583,584,585,588,590,591,592,748,749,753,754,755,1213,1214,1215$, $1293,1296,1300,1301,1311,1312,1313,1318,1320,1325,1326,1327,1328,1329,1332$ $1333,1334,1336,1339,1340,1341,1342,1343,1344,1345,1346,1347,1348,1349,1353$ $1354,1352,1361,1362)$

\section{USOS MEDICINALS}

\section{No consta}

Abortiu

FONT 1335. DESCRIPCIÓ DE L'ÚS FETA PER L'INFORMANT. Diuen que és abortiva FORMA FARMACĖUTICA I ÚS. Desconegut per l'informant. DESTINACIÓ. Medicina humana. OBSERVACIONS. No l'usen per a prendre.

\section{Part aèria}

Abortiu 
FONTS 553, 1213, 1214, 1215. DESCRIPCIÓ DE L'ÚS FETA PELS INFORMANTS. També diuen que és abortiva (553). La ruda va bé per a avortar (1215). Per als animals quan avortaven $(1213,1214)$. FORMA FARMACĖUTICA I ÚS. Desconegut per l'informant. DESTINACIÓ. Medicina veterinària.

Analgèsic

FONTS 572, 573, 1343, 1344. DESCRIPCIÓ DE L'ÚS FETA PELS INFORMANTS. Va bé per al dolor i per al reuma $(572,573)$. Per a fer fregues per al dolor $(1343,1344)$. FORMA FARMACĖUTICA I ÚS LOció (ús extern). PREPARACIÓ Posada en oli 40 dies a sol serena $(572,573)$. Confitada en esperit de vi $(1343,1344)$. DESTINACIÓ. Medicina humana. Anticefalàlgic

FONTS 517, 529,530,531. DESCRIPCIÓ DE L'ÚS FETA PELS INFORMANTS. Per al ma de cap $(517,529,530,531)$. FORMA FARMACĖUTICA I ÚS. Sense forma farmacèutica (ús directe, ús extern) (517). Fumigació (ús extern) $(529,530,531)$. PREPARACIÓ. Fregar-se amb un brot de ruda (517). Cremar ruda al foc $(529,530,531)$. DESTINACIÓ. Medicina

Antidepressiu

FONTS 565, 566. DESCRIPCIÓ DE L'ÚS FETA PELS INFORMANTS. Per a quan estàs deprimit. FORMA FARMACĖUTICA I ÚS. Decocció (ús intern). PREPARACIÓ. Un brot en xocolata desfeta. DESTINACIÓ. Medicina humana.

Antidiarreic

FONTS 1325, 1326. DESCRIPCIÓ DE L'ÚS FETA PELS INFORMANTS. Per a les diarrees. FORMA FARMACĖUTICA I ÚS. Decocció (ús intern). PREPARACIÓ. Es prenia en xocolata desfeta. DESTINACIÓ. Medicina humana.

Antidismenorreic

FONTS 1353, 1354. DESCRIPCIÓ DE L'ÚS FETA PELS INFORMANTS. Per al mal de ventre de la regla. FORMA FARMACĖUTICA I ÚS. Decocció (ús intern). PREPARACIÓ. Se'n feia aigua i ho barrejava amb xocolata. DESTINACIÓ. Medicina humana.

Antihelmíntic

FONTS 528, 571, 591, 592. DESCRIPCIÓ DE L'ÚS FETA PELS INFORMANTS. Deien que matava els cucs a la canalla (528). Se'n feia aigua per a matar els cucs (571). Es donava per als cucs $(591,592)$. FORMA FARMACĖUTICA I ÚS. Decocció (ús intern). PREPARACIÓ. Abans feien una tassa de xocolata amb un brotet de ruda (528). Decocció (571). Se'n feia aigua i ho barrejava amb xocolata, sola és de mal prendre $(591,592)$. DESTINACIÓ Medicina humana. OBSERVACIONS. És una aigua molt amargant, si no hi posaves sucre no te la podies beure (571).

Antiinflamatori intestinal

FONTS 505, 506, 525, 526, 527, 560, 561, 562, 563, 564, 567, 583, 584, 585, 748, 749 $1293,1320,1325,1326,1345,1346$. DESCRIPCIÓ DE L'ÚS FETA PELS INFORMANTS Per als mals de ventre $(505,506)$. Per al mal de panxa $(748,749)$. Deien que anava bé per al mal de ventre $(525,526,527)$. Per al mal de ventre $(564,567,1320,1325,1326)$. Per a la panxa $(561,562,563)$. Per a quan tens el ventre destorbat $(560)$. Era per a la panxa. Quan la mare estava fotuda sempre es feia xocolata i s'hi posava un brot de ruda $(583,584,585)$. (1293). Va bé i per al mal de ventre $(1345,1346)$. FORMA QARMACE STICA I ÚS. Decoció (ús int (n) $(505,506,525,526,527,560,567,584,585$ $1293,1325,1326,1345,1346$ ). Tis intés) (505, $(748,749,1320)$. Empla $567,584,585$ $1203,5325,1326,1345,1346$ ). Tús ina (ús inten) (748, 749,1320$)$. Emplastre (ús extern) $(561,562,563,564)$. Decocció (ús extern) (583). PREPARACIO. Es fa bullir en la xocolata $(505,506)$. Decoccio $(748,749)$. Es posava un brot a la xocolata $(525,526,527)$. Desfeta en xocolata (567). Trinxada petita i barrejada amb greix per a fer emplastres $(561,562,563)$. En xocolata (560). En feien emplastres (564). Es posava a la xocolata $(583,584,585,1345$, 1346). Xocolata desfeta amb ruda (1293). Es prenia en xocolata desfeta $(1325,1326)$. DESTINACIÓ. Medicina humana. OBSERVACIONS. Jo no ho he fet servir mai (567).

Antinauseabund

FONTS 1343, 1344. DESCRIPCIÓ DE L'ÚS FETA PELS INFORMANTS. Per al mareig FORMA FARMACĖUTICA I ÚS. Tisana (ús intern). PREPARACIÓ. Decocció. DESTINACIÓ. Medicina humana.

Antiodontàlgic

FONTS 1341, 1342. DESCRIPCIÓ DE L'ÚS FETA PELS INFORMANTS. Per al mal d'orelles FORMA FARMACĖUTICA I ÚS. Embrocació (ús extern). PREPARACIÓ. Es prepara en oli. DESTINACIÓ. Medicina humana.

Antiotàlgic

FONT 1352. DESCRIPCIÓ DE L'ÚS FETA PER L'INFORMANT. Aigua de ruda per al mal de les orelles. FORMA FARMACĖUTICA I ÚS. Gotes òtiques (ús extern). DESTINACIÓ. Medicina humana.

Antireumàtic

FONTS 572, 573. DESCRIPCIÓ DE L'ÚS FETA PELS INFORMANTS. Va bé per al dolor per al reuma. FORMA FARMACĖUTICA I ÚS. Loció (ús extern). PREPARACIÓ. Posada en oli 40 dies a sol i serena. DESTINACIÓ. Medicina humana.

Antisèptic extern

FONTS 1328, 1329. DESCRIPCIÓ DE L'ÚS FETA PELS INFORMANTS. Per a fregar els braguers de les vaques quan tenen un cop de sang $(1328,1329)$. FORMA FARMACĖUTICA I ÚS. Liniment (ús extern) (1328). Embrocació (ús extern) (1329). PREPARACIÓ. Confitada en oli $(1328,1329)$. DESTINACIÓ. Medicina veterinària.

Antisèptic ocular

FONTS 520, 521. DESCRIPCIÓ DE L'ÚS FETA PELS INFORMANTS. Per a rentar els ulls. FORMA FARMACĖUTICA I ÚS. Bany (ús extern). PREPARACIÓ. Decocció. DESTINACIÓ. Medicina humana.

\section{Cardiotònic}

FONTS 536, 537. DESCRIPCIÓ DE L'ÚS FETA PELS INFORMANTS. El padrí de la casa patia del cor i li feien aquest emplastre. FORMA FARMACĖUTICA I ÚS. Emplastre (ús extern). PREPARACIÓ. Per a fer emplastres es barrejava amb xocolata. DESTINACIÓ. Medicina humana.

Coadjuvant del part 
FONTS 511, 512, 513, 514, 558. DESCRIPCIÓ DE L'ÚS FETA PELS INFORMANTS. Se'n feia a les parteres per a avançar el part i per a començar a dilatar $(511,512,513,514)$. Per a les vaques que no podien vedellar (558). FORMA FARMACĖUTICA I ÚS. Tisana (ús intern) $(511,512,513,514)$. Sense forma farmacèutica (ús directe, ús extern) (558). PREPARACIÓ Se'ls posava un ramet de ruda a la cua (558). DESTINACIÓ. Medicina humana $(511,512$, Se's posava un ramet de ruda a la
$513,514)$. Medicina veterinària (558).

Coadjuvant del postpart

FONTS 528, 542, 543, 544, 581, 1339, 1340, 1343, 1344, 1345, 1346. DESCRIPCIÓ DE L'ÚS FETA PELS INFORMANTS. Per a ajudar a fer les despulles a les ovelles, sobretot quan feien un xai mort $(542,543,544)$. Les vaques quan no feien els llits se'ls penjava un brot de feien un xai mort $(542,543,544)$. Les vaques quan no feien els llits se'ls penjava un brot de
ruda a la cua $(528)$. Les vaques quan vedellen, a vegades, treuen les madregueres (la ruda a la cua (528). Les vaques quan vedellen, a vegades, treuen les madregueres (la
matriu) $\mathrm{i}$ ilavors com que són tan grosses no les pots tornar a posar. D'aquesta manera les fa contraure i llavors els les pots tornar a posar (581). Es lligava a la cua d'una vaca quan no havia acabat de fer les despulles. És desinfectant $(1339,1340)$. Es penjava un ram de ruda a les despulles de la vaca quan no acabaven de sortir $(1343,1344)$. Es posa un ram de ruda a la cua de la vaca per a ajudar-la que acabi de fer les despulles $(1345,1346)$. FORMA FARMACĖUTICA I ÚS. Tisana (ús intern) $(542,543,544)$. Sense forma farmacèutica (ús directe, ús extern) $(528,1339,1340,1343,1344,1345,1346)$. Liniment (ús extern) (581). PREPARACIÓ. Decocció $(543,544)$. Fas bullir ruda en oli i els les untes ben untades (581) DESTINACIÓ. Medicina veterinària.

Desconegut per l'informant

FONTS 556, 557, 578, 579, 588. FORMA FARMACĖUTICA I ÚS. Decocció (ús intern) (556, $557,588)$. Emplastre (ús extern) $(578,579)$. PREPARACIÓ. En xocolata $(556,557)$. Per a fer emplastres (578, 579). EFECTES SECUN OBSERVA Derva també servia molt. Em sembla que es posava a la xocolata (588).

Digestiu

FONTS 507, 509, 510, 1215, 1361, 1362. DESCRIPCIÓ DE L'ÚS FETA PELS INFORMANTS. Com a digestiva $(507,509,510)$. Per a fer pair (1215). És digestiva (1361, 1362). FORMA FARMACEUUTICA I ÚS. Decocció (ús intern) $(507,509,510,1215)$. Tisana (ús intern) $(1361,1362)$. PREPARACIÓ. Barrejada amb xocolata $(509,510)$. En xocolata (507). Es posava a la xocolata desfeta (1215). En infusió $(1361,1362)$. DESTINACIÓ. (507). Es posava

No consta

FONTS 581, 590, 1347, 1348, 1349. DESCRIPCIÓ DE L'ÚS FETA PELS INFORMANTS. Per a quan et mareges de cap (581). Anava molt bé per al mal dels llavis que els sortia als xais (590). Per als porcs quan tenien el tacó $(1347,1348,1349)$. FORMA FARMACĖUTICA I ÚS. Tisana (ús intern) (581). Embrocació (ús extern) (590). Emplastre (ús extern) (1347, 1348, 1349). PREPARACIÓ. Decocció (581). Es feia en oli, es sofregia i se'ls untava als morros als xais (590). Bullida en oli $i$ en emplastre $(1347,1348)$. Bullida en oli i en emplastres (1349) DESTINACIÓ. Medicina humana (581). Medicina veterinària $(590,1347,1348,1349)$ OBSERVACIONS. Això ho va dir un herbolari (581).

Per a trastorns del sistema sensorial
FONT 1327. DESCRIPCIÓ DE L'ÚS FETA PER L'INFORMANT. L'usa per al cap-rodo (vertigen). FORMA FARMACĖUTICA I ÚS. Tisana (ús intern). PREPARACIÓ. En infusió. DESTINACIÓ. Medicina humana.

Reforçant ossi

FONT 545. DESCRIPCIÓ DE L'ÚS FETA PER L'INFORMANT. Es fa servir per a reforçar ossos trencats, es posa directament a sobre el mal. FORMA FARMACĖUTICA I ÚS. Loció (ús extern). PREPARACIÓ. Es fa bullir la ruda en aiguardent i s'hi afegeix sabó natural. (ús extern). PREPARACIO. Es

Sedant

FONT 503. FORMA FARMACĖUTICA I ÚS. Decocció (ús intern). PREPARACIÓ. Es posava un brotet a la xocolata. DESTINACIÓ. Medicina humana.

Tranquil-litzant

FONTS 520, 521, 561, 562, 563, 572, 573, 580, 583, 584, 585, 1213, 1214, 1311, 1312, $1339,1340,1347,1348,1349$. DESCRIPCIÓ DE L'ÚS FETA PELS INFORMANTS. Per a relaxar $(520,521)$. Per als nervis $(561,562,563,572,573,1339,1340,1347,1348,1349)$. Va bé per als nervis $(580)$. Calma els nervis $(583,584,585)$. Per a calmar els nervis $(1213$, $1214)$. Diu que és bona per als nervis $(1311,1312)$. FORMA FARMACĖUTICA I ÚS. Decocció (ús intern) $(520,521,561,562,563,572,573,583,584,585,1213,1214,1311$. Decocció (ús intern) $(520,521,561,562,563,572,573,583,584,585,1213,1214,1311$,
$1312,1347,1348,1349)$. Tisana (ús intern) $(580,1339,1340)$. PREPARACIÓ. En xocolata $(520,521,561,562,563,572,573)$. Decocció $(580,1339,1340)$. Es posava a la xocolata $(583,584,585,1213,1214)$. Xocolata desfeta amb ruda $(1311,1312)$. Un brot de ruda bullida amb una presa de xocolata $(1347,1348,1349)$. MODE D'UTILITZACIÓ/POSOLOGIA. Se'n fa una novena $(1347,1348,1349)$. DESTINACIÓ. Medicina humana. OBSERVACIONS. És de mal prendre perquè és amargant (580).

Vulnerari

FONTS 505, 506, 1336. DESCRIPCIÓ DE L'ÚS FETA PELS INFORMANTS. Serveix per a untar mals $(505,506)$. Per a curar ferides del bestiar (1336). FORMA FARMACĖUTICA I ÚS. Liniment (ús extern) $(505,506)$. Embrocació (ús extern) (1336). PREPARACIÓ. Es fa bullir en oli $(505,506)$. Per a fer oli $(1336)$. DESTINACIO. Medicina humana $(505,506)$. Medicina veterinària (1336).

\section{USOS ALIMENTARIS}

\section{Part aèria}

Condiment

FONTS 511, 512, 513, 514, 520, 521, 529, 530, 531, 541, 553, 554, 555, 574, 575, 576, 577 . $1213,1214,1296,1301,1335$. DESCRIPCIÓ DE L'ÚS FETA PELS INFORMANTS. Barrejada amb xocolata de pedra $(554,555)$. Es posava a la xocolata $(511,512,513,514$,

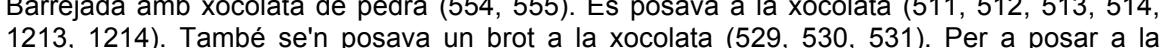
xocolata $(520,521,541,574,575,576,577)$. Es posava a la xocolata i deien que era més bona (553). Per a fer xocolata (1296). Per a donar gust a la xocolata (1301). Per a donar gust a l'estofat (1335). OBSERVACIONS. Igual que la menta (Mentha sp.) (554, 555). 
Apèndix 1. Catàleg de tàxons.

DESTINACIÓ. Alimentació humana (520, 521, 529, 530, 531, 541, 553, 554, 555, 574, 575 $576,577,1213,1214,1296,1301,1335)$.

\section{ALTRES USOS}

Planta sencera

Altres informacions

FONTS 1311, 1312. DESCRIPCIÓ DE L'ÚS FETA PELS INFORMANTS. En fan rams a la cuina per a sentir-ne l'olor.

Creences i pràctiques magicoreligioses

FONTS 554, 555. DESCRIPCIÓ DE L'ÚS FETA PELS INFORMANTS. Protegeix de les bruixes.

Literatura oral popular: llegendes, gloses, contes, dites, refranys, poemes, cançons

FONT 1215. DESCRIPCIÓ DE L'ÚS FETA PER L'INFORMANT. Qui té ruda a casa no es casa.

\section{Planta viva in situ}

Creences i pràctiques magicoreligioses

FONTS 1332, 1333, 1334. DESCRIPCIÓ DE L'ÚS FETA PELS INFORMANTS. Si tens una planta de ruda a casa espanta tots els mals.

\section{ACCIONS NOCIVES O TÒXIQUES}

\section{No consta}

FONTS 528, 572, 573. DESCRIPCIÓ DE L'ACCIÓ NOCIVA O TÒXICA FETA PELS INFORMANTS. És una mica tòxica, tot i que es pot prendre $(528)$. És abortiva $(572,573)$. TOXICITAT LLIGADA A L'ÚS MEDICINAL. Sí (528).

\section{ALTRES OBSERVACIONS}

FONTS 511, 512, 513, 514, 547, 548, 549, 553, 560, 564, 572, 573, 1311, 1312 DESCRIPCIÓ FETA PELS INFORMANTS. Totes les cases tenien una galleda vella amb una planta de ruda al costat de la casa $(511,512,513,514)$. N'hi havia a totes les cases $(547$ 548). A casa n'hi havia (549). A tots els horts n'hi havia, de ruda (553). Es tenia a l'hort (560). N'hi havia als horts $(564)$. N'hi havia a I'hort $(572,573)$. En tenen a l'hort $(1311,1312)$.

\section{BARREGES AMB AQUEST TÀXON}

\section{Part aèria}

FONTS 1213, 1214. Entrevista 102, barreja IV (vegeu catàleg de barreges) FONTS 1213, 1214. Entrevista 102, barreja VI (vegeu catàleg de barreges) FONT 1335. Entrevista 15, barreja III (vegeu catàleg de barreges)
FONT 1293. Entrevista 2, barreja I (vegeu catàleg de barreges) FONT 1318. Entrevista 31, barreja IV (vegeu catàleg de barreges) FONT 1313. Entrevista 4, barreja I (vegeu catàleg de barreges) FONT 528. Entrevista 61, barreja I (vegeu catàleg de barreges) FONTS 753, 754, 755. Entrevista 67, barreja I (vegeu catàleg de barreges) FONTS 547, 548. Entrevista 73, barreja I (vegeu catàleg de barreges) FONTS 547, 548. Entrevista 73, barreja II (vegeu catàleg de barreges) FONT 1300. Entrevista 8, barreja II (vegeu catàleg de barreges) FONTS 561, 562, 563. Entrevista 83 (vegeu catàleg de barreges) FONTS 572, 573. Entrevista 90, barreja II (vegeu catàleg de barreges)

\section{Salix alba L. subsp. alba (salicàcies)}

\section{BCN 27240}

\section{NOMS POPULARS}

Sàlic (568)

Saula $(591,592,1215,1295,1352)$

\section{USOS MEDICINALS}

\section{Fulla}

Antihipertensiu

FONTS 591, 592. DESCRIPCIÓ DE L'ÚS FETA PELS INFORMANTS. Per a fer baixar la pressió. FORMA FARMACĖUTICA I ÚS. Tisana (ús intern). PREPARACIÓ. Decocció de les fulles, quan acaben de sortir. DESTINACIÓ. Medicina humana.

\section{USOS ALIMENTARIS}

\section{Part aèria}

Ingestió de la part de la planta crua - Fresca (sense preparació)

FONT 1352. DESCRIPCIÓ DE L'ÚS FETA PER L'INFORMANT. Per a menjar els conills i les cabres. OBSERVACIONS. La gent deia que anaven a fer rama, podaven les branques de les saules i les donaven a les cabres i aquestes s'hi penjaven i anaven arrencant les fulles. DESTINACIO. Alimentació animal.

\section{ALTRES USOS}

Part aèria 
Apèndix 1. Catàleg de tàxons.

Artesanal: elaboració d'escombres

FONT 1215. DESCRIPCIÓ DE L'ÚS FETA PER L'INFORMANT. Les branques per a fer escombres.

Tija

Artesanal: elaboració de calçat

FONTS 568, 1215, 1295. DESCRIPCIÓ DE L'ÚS FETA PELS INFORMANTS. Per a fer esclops $(568,1215)$. També fèiem esclops de saula, anava molt bé per a treballar perquè és una fusta molt tova, però la gent de pagès solia voler els de pi perquè eren més forts duraven més (1295). OBSERVACIONS. És lleugera, el pi també es podia utilitzar, però pesa massa (1215)

\section{Salix caprea L. (salicàcies)}

BCN 27283

\section{NOMS POPULARS}

Gatell $(547,548)$

Gatsaule (1352)

\section{ALTRES USOS}

\section{Part aèria florida}

Ornamental: elaboració de rams

FONTS 547, 548, 1352. DESCRIPCIÓ DE L'ÚS FETA PELS INFORMANTS. És el prime que floreix, en fèiem rams $(547,548)$. Eren els primers rams que es podien fer a la primavera, és molt primerenc (1352).

\section{Salix purpurea L. (salicàcies)}

BCN 123788

\section{NOMS POPULARS}

Sàlic (541)

Salvia officinalis L. (labiades)

BCN 24981

\section{NOMS POPULARS}

Sàlvia $(504,507,509,510,520,521,522,523,524,532,539,540,561,562,563,568,569$, $570,1294,1311,1312,1335,1341,1342)$

\section{USOS MEDICINALS}

Llavor

Hipnòtic

FONT 1335. DESCRIPCIÓ DE L'ÚS FETA PER L'INFORMANT. Ajuda a dormir. FORMA FARMACĖUTICA I ÚS. Tisana (ús intern). PREPARACIÓ. Decocció. Aigua de les granes. DESTINACIÓ. Medicina humana.

\section{No consta}

Desconegut per l'informant

FONTS 507, 509, 510. FORMA FARMACĖUTICA I ÚS. Desconegut per l'informant. OBSERVACIONS. No en recordo l'ús.

\section{Part aèria}

Antidismenorreic

FONTS 520, 521. DESCRIPCIÓ DE L'ÚS FETA PELS INFORMANTS. Per a la menopausa i per als dolors de regla. FORMA FARMACĖUTICA I ÚS. Tisana (ús intern). PREPARACIÓ.

Decocció. DESTINACIÓ. Medicina humana.

Antihipertensiu

FONT 504. DESCRIPCIÓ DE L'ÚS FETA PER L'INFORMANT. Per a la gent que té la pressió alta. FORMA FARMACËUTICA I US. Tisana (ús intern). PREPARACIO Decocció. DESTINACIÓ. Medicina humana.

Antiinflamatori intestinal

FONTS 1311, 1312. DESCRIPCIÓ DE L'ÚS FETA PELS INFORMANTS. Per a quan té ma de ventre FORMA FARMACEUTICA I US. Tisana (ús intern). PREPARACIO. Decocció. Sant Joan de les Abadesses.

Antiodontàlgic

FONTS 522, 523. DESCRIPCIÓ DE L'ÚS FETA PELS INFORMANTS. Per al mal de queixals. FORMA FARMACĖUTICA I ÚS. Col-lutori (ús extern). PREPARACIÓ. Decocció, per a glopejar. DESTINACIÓ. Medicina humana.

\section{Digestiu}

FONTS 524, 539, 540, 1294. DESCRIPCIÓ DE L'ÚS FETA PELS INFORMANTS. Més aviat per a l'estómac (524). Va bé per a tot. Per a la circulació, digestiva, estomacal, diürètica (539, 540). És bona per a tot Quan tens l'estómac carregat (1294). FORMA FARMACÉUTICA Ús. Tisana (ús intern). PREPARACIÓ. Decocció $(524,539,540)$. DESTINACIÓ. Medici US. Tisana (ús intern). PREPARACIO. Decocció (524, 539, 540). DESTINACIO. Medicina
humana. Diürètic 
FONTS 539, 540. DESCRIPCIÓ DE L'ÚS FETA PELS INFORMANTS. Va bé per a tot. Per a la circulació, digestiva, estomacal, diürètica. FORMA FARMACĖUTICA I ÚS. Tisana (ús intern). PREPARACIÓ. Decocció. DESTINACIÓ. Medicina humana.

\section{Estomacal}

FONTS 539, 540. DESCRIPCIÓ DE L'ÚS FETA PELS INFORMANTS. Va bé per a tot. Per a la circulació, digestiva, estomacal, diürètica. FORMA FARMACĖUTICA I ÚS. Tisana (ús intern). PREPARACIÓ. Decocció. DESTINACIÓ. Medicina humana.

Galactòfug

FONTS 561, 562, 563. DESCRIPCIÓ DE L'ÚS FETA PELS INFORMANTS. Es passava a les gosses quan havien cadellat perquè els marxés la llet. FORMA FARMACĖUTICA I ÚS. Sense forma farmacèutica (ús directe, ús extern). DESTINACIÓ. Medicina veterinària.

Hematocatàrtic

FONT 532. DESCRIPCIÓ DE L'ÚS FETA PER L'INFORMANT. És depurativa. FORMA FARMACĖUTICA I ÚS. Tisana (ús intern). PREPARACIÓ. Decocció. DESTINACIÓ. Medicina humana.

Hipoglucemiant

FONTS 569, 570. DESCRIPCIÓ DE L'ÚS FETA PELS INFORMANTS. Per al sucre. FORMA FARMACĖUTICA I ÚS. Tisana (ús intern). PREPARACIÓ. Decocció. DESTINACIÓ. Medicina humana.

Per a trastorns associats a la menopausa

FONTS 520, 521. DESCRIPCIÓ DE L'ÚS FETA PELS INFORMANTS. Per a la menopausa per als dolors de regla. FORMA FARMACĖUTICA I ÚS. Tisana (ús intern). PREPARACIÓ. Decocció. DESTINACIÓ. Medicina humana.

Resolutiu

FONT 568. DESCRIPCIÓ DE L'ÚS FETA PER L'INFORMANT. Per als furóncols. FORMA FARMACĖUTICA I ÚS. Sense forma farmacèutica (ús directe, ús extern). PREPARACIÓ. Es posaven les fulles. DESTINACIÓ. Medicina humana.

Tranquil·litzant

FONT 1294. DESCRIPCIÓ DE L'ÚS FETA PER L'INFORMANT. És bona per a tot. És tranquil-litzant. FORMA FARMACĖUTICA I ÚS. Tisana (ús intern). DESTINACIÓ. Medicina humana.

Vasotònic

FONTS 539, 540, 1341, 1342. DESCRIPCIÓ DE L'ÚS FETA PELS INFORMANTS. Va bé per a tot. Per a la circulació, digestiva, estomacal, diürètica $(539,540)$. Per a la circulació $(1341$ 1342). FORMA FARMACĖUTICA I ÚS. Tisana (ús intern). PREPARACIÓ. Decocció (539, 540). En infusió $(1341,1342)$. DESTINACIÓ. Medicina humana.

\section{ALTRES OBSERVACIONS}

FONTS 507, 509, 510, 539, 540. DESCRIPCIÓ FETA PELS INFORMANTS. En tenim a l'hort $(507,509,510,539)$. En tinc plantada a l'hort (540).

\section{BARREGES AMB AQUEST TÀXON}

\section{Part aèria}

FONT 1294. Entrevista 6, barreja II (vegeu catàleg de barreges)

\section{Salvia pratensis L. (labiades)}

\author{
BCN 24982
}

\section{NOMS POPULARS}

Sàlvia $(1213,1214)$

Sàlvia silvestre (1324)

Tàrrec (524)

\section{USOS MEDICINALS}

Fulla

Antidismenorreic

FONTS 1213, 1214. DESCRIPCIÓ DE L'ÚS FETA PELS INFORMANTS. Per a evitar els dolors menstruals i els fogots durant la menopausa. FORMA FARMACĖUTICA I ÚS. Tisana (ús intern). DESTINACIÓ. Medicina humana.

Antisèptic bucal

FONTS 1213, 1214, 1324. DESCRIPCIÓ DE L'ÚS FETA PELS INFORMANTS. Per a netejar les dents, es freguen amb una fulla $(1213,1214)$. La fulla neteja les dents, és molt desinfectant (1324). FORMA FARMACĖUTICA I ÚS. Sense forma farmacèutica (ús directe, ús extern). DESTINACIÓ. Medicina humana.

Digestiu

FONTS 1213, 1214. DESCRIPCIÓ DE L'ÚS FETA PELS INFORMANTS. Com a digestiva, tonificant $i$ calmant. FORMA FARMACĖUTICA I ÚS. Tisana (ús intern). MODE D'UTILITZACIÓ/POSOLOGIA. Durant una novena, dos cops al dia. DESTINACIÓ. Medicina humana.

Per a trastorns associats a la menopausa

FONTS 1213, 1214. DESCRIPCIÓ DE L'ÚS FETA PELS INFORMANTS. Per a evitar els dolors menstruals i els fogots durant la menopausa. FORMA FARMACĖUTICA I ÚS. Tisana (ús intern). DESTINACIÓ. Medicina humana.

Tònic

FONTS 1213, 1214. DESCRIPCIÓ DE L'ÚS FETA PELS INFORMANTS. Com a digestiva tonificant $\mathrm{i}$ calmant. FORMA FARMACĖUTICA I ÚS. Tisana (ús intern). MODE 
D'UTILITZACIÓ/POSOLOGIA. Durant una novena, dos cops al dia. DESTINACIÓ. Medicina humana.

Tranquil·litzant

FONTS 1213, 1214. DESCRIPCIÓ DE L'ÚS FETA PELS INFORMANTS. Com a digestiva, tonificant i calmant. FORMA FARMACĖUTICA I ÚS. Tisana (ús intern). MODE D'UTILITZACIÓ/POSOLOGIA. Durant una novena, dos cops al dia. DESTINACIÓ. Medicina humana.

\section{Part aèria florida}

Per a trastorns associats a la menopausa

FONT 1324. DESCRIPCIÓ DE L'ÚS FETA PER L'INFORMANT. Per a la menopausa. FORMA FARMACĖUTICA I ÚS. Tisana (ús intern). PREPARACIÓ. Planta florida en infusió. DESTINACIÓ. Medicina humana.

Per a trastorns del sistema sensorial

FONT 1324. DESCRIPCIÓ DE L'ÚS FETA PER L'INFORMANT. Per al vertigen. FORMA FARMACĖUTICA I ÚS. Tisana (ús intern). PREPARACIÓ. En infusió. DESTINACIÓ. Medicina humana.

\section{ALTRES USOS}

Fulla

Planta fumable

FONT 524. DESCRIPCIÓ DE L'ÚS FETA PER L'INFORMANT. Abans les fulles s'assecaven i es fumaven.

\section{Planta sencera}

Literatura oral popular: llegendes, gloses, contes, dites, refranys, poemes, cançons

FONTS 1213, 1214. DESCRIPCIÓ DE L'ÚS FETA PELS INFORMANTS. Qui té sàlvia a l'hort, gran remei té a prop.

\section{BARREGES AMB AQUEST TÀXON}

Fulla

FONTS 1213, 1214. Entrevista 102, barreja V (vegeu catàleg de barreges)

\section{Salvia verbenaca L. (labiades)}

\section{BCN 113580}

\section{NOMS POPULARS}

Tàrrec $(520,521,554,555)$

\section{ALTRES USOS}

Fulla

Planta fumable

FONTS 520, 521. DESCRIPCIÓ DE L'ÚS FETA PELS INFORMANTS. Abans es fumaven.

\section{BARREGES AMB AQUEST TÀXON}

Fulla

FONTS 554, 555. Entrevista 78, barreja IV (vegeu catàleg de barreges)

\section{Sambucus ebulus L. (adoxàcies)}

BCN 24983

\section{NOMS POPULARS}

Èvol $(1324,1337,1338)$

\section{USOS MEDICINALS}

Part aèria

Antibrucel·lòtic

FONTS 1337, 1338. DESCRIPCIÓ DE L'ÚS FETA PELS INFORMANTS. El seu germà va tenir les febres de Malta i el van curar. Així li van trencar les febres $(1337,1338)$. FORMA FARMACĖUTICA I ÚS. Emplastre (ús extern). PREPARACIÓ. Posar un rovell d'ou al dit gros del peu i emplastres d'èvols a la planta dels peus (1338). Posar un rovell d'ou al dit gros del peu i emplastres d'evòls a la planta dels peus (1337). DESTINACIÓ. Medicina humana.

\section{ALTRES USOS}

\section{Planta sencera}

Creences i pràctiques magicoreligioses

FONT 1324. DESCRIPCIÓ DE L'ÚS FETA PER L'INFORMANT. Ėvol, per a la potestat que Déu m'ha donat, mata'm les febres aviat. Mentre es diu aquesta oració, s'ha de retorçar la planta. OBSERVACIONS. Recorda aquest ús d'abans, ella no n'ha fet servir mai.

\section{Sambucus nigra L. (adoxàcies)}

BCN 24984

NOMS POPULARS 
Bonarbre $(1213,1214)$

Sabuc $(503,505,506,507,509,510,511,512,513,514,515,516,524,525,526,527,528$ $529,530,531,532,533,534,536,537,538,541,542,543,544,545,546,547,548,549$ $553,554,555,556,557,558,559,560,561,562,563,564,565,566,567,569,570,571$ $572,573,574,575,576,577,580,581,583,584,585,588,589,590,591,592,746,747$ $748,749,750,753,754,755,1213,1214,1215,1293,1294,1296,1297,1299,1300,1301$, $1307,1308,1309,1310,1313,1314,1315,1316,1317,1318,1319,1320,1322,1323,1325$ $1326,1328,1329,1330,1331,1332,1333,1334,1337,1338,1339,1340,1341,1342,1343$ $1344,1345,1346,1347,1348,1349,1350,1351,1353,1354,1352,1361,1362)$

Sabuquer (517)

Saüc $(520,521,522,523,746,1210,1213,1214)$

Saüquer $(1213,1214)$

\section{USOS MEDICINALS}

\section{Escorça}

Desconegut per l'informant

FONTS 569, 570. FORMA FARMACĖUTICA I ÚS. Desconegut per l'informant. DESTINACIÓ Medicina humana. OBSERVACIONS. L'escorça també és bona per a medicina.

Hipouricemiant

FONT 1331. DESCRIPCIÓ DE L'ÚS FETA PER L'INFORMANT. Per a l'àcid úric. FORMA FARMACĖUTICA I ÚS. Tisana (ús intern). PREPARACIÓ. Decocció. DESTINACIÓ. Medicina humana.

Fruit

Antibronquític

FONT 1299. DESCRIPCIÓ DE L'ÚS FETA PER L'INFORMANT. Per a les bronquitis. FORMA FARMACĖUTICA I ÚS. Xarop (ús intern). MODE D'UTILITZACIÓ/POSOLOGIA. Has de fe uns quants dies una cullerada al mati una al vespre. DESTINACIO. Medicina humana.

Anticatarral

FONTS 515, 516, 528, 538, 546, 553, 571. DESCRIPCIÓ DE L'ÚS FETA PELS INFORMANTS. Va bé per als refredats $(515,516)$. Es prenia quan estaves refredat $(538)$. Es prenia per a refredats i grips (546). Per als refredats (528). Per als constipats (553). Per a la tos i refredats (571). FORMA FARMACEUTICA I US. Xarop (ús intern). PREPARACIO. De la grana se'n feia xarop (538). Amb les granes i sucre en fèiem xarop (546). Les granes amb sucre per a fer xarop (553). DESTINACIO. Medicina humana.

Antigripal

FONT 546. DESCRIPCIO DE L'ÚS FETA PER L'INFORMANT. Es prenia per a refredats grips. FORMA FARMACEUTICA I US. Xarop (ús intern). PREPARACIO. Amb les granes sucre en fèiem xarop. DESTINACIÓ. Medicina humana.

Antihipertensiu
FONTS 1332, 1333, 1334. DESCRIPCIÓ DE L'ÚS FETA PELS INFORMANTS. Per a regular la sang. FORMA FARMACĖUTICA I ÚS. Xarop (ús intern). PREPARACIÓ. Fer bullir les granes, afegir-hi sucre i colar-ho. DESTINACIÓ. Medicina humana.

Antiinflamatori

FONT 545. DESCRIPCIÓ DE L'ÚS FETA PER L'INFORMANT. Va bé per a les enflemes, infeccions... FORMA FARMACĖUTICA I ÚS. Xarop (ús intern). PREPARACIÓ. Dels fruits se'n fa xarop. DESTINACIÓ. Medicina humana.

Antiinflamatori faringi

FONT 1297. DESCRIPCIÓ DE L'ÚS FETA PER L'INFORMANT. Va bé quan tenen mal de coll. FORMA FARMACĖUTICA I ÚS. Tisana (ús intern). PREPARACIÓ. Amb la grana en fa melmelada. DESTINACIÓ. Medicina veterinària.

Antiinflamatori intestina

FONTS 522, 523, 547, 548, 562, 588, 590, 1314, 1319, 1322, 1328, 1329, 1330, 1332, 1333 $1334,1337,1338,1341,1342,1349$. DESCRIPCIÓ DE L'ÚS FETA PELS INFORMANTS. La grana també és bona per al mal de panxa $(522,523)$ Es prenia per a la panxa $(547,548$ gran 590). Per a panxa (562). Per al mal de ventre $(1314,1328,1329,1341,1342)$. Va per al mal de vente (1319). Per al mal de panxa $(1322,1332,1333,1334)$. Per als vedels per al mal de ventre (1319). Per al mal de panxa (1322, 1332, 1333, 1334). Per als vedells que tenen malament la panxa (1330). Va be per al mal de panxa (1330). S'usava per al ma de panxa (1337, 1338). Per a quan tens mal de ventre (1349). FORMA FARMACEUTICA ÚS. Tisana (ús intern) $(522,523)$. Xarop (ús intern) $(547,548,562,588,590,1314,1319$, 1322, 1328, 1329, 1330, 1332, 1333, 1334, 1337, 1338, 1341, 1342, 1349). PREPARACIÓ. Decocció $(522,523)$. Amb els fruits $i$ sucre se'n fa xarop $(547,548)$. Xarop dels raïms $(562)$. Dels raïms en feia un xarop (588). Del raïm del sabuc amb sucre en fèiem xarop (590). Amb les granes se'n feia un xarop (bullir les granes amb sucre i després colar-ho) (1314). Amb les granes abans se'n feia xarop (1319). Amb les granes se'n feia un xarop (1322). Es feia un xarop que es barrejava amb aigua $(1328,1329)$. De la grana se'n fa xarop $(1330,1341$, 1342). Fer bullir les granes, afegir-hi sucre i colar-ho $(1332,1333,1334)$. La grana de sabuc es bullia amb sucre i se'n feia xarop $(1337,1338)$. Amb les granes se'n fa xarop (1349). es bulla amb́ DESTINACIO. Medina humana $(522,523,547,548,562,588,590,1314,1319,1322$ (1328, 1329). Medicina veteinaia (1330). OBSERVACIONS. Tedicina humana i velerinària (1328, 1329). Medicina veterinària (1330). OBSERVACIONS. També en feien essència, però jo no n'he fet mai $(547,548)$. També per a beure quan tens set $(1319)$.

Antisèptic intern

FONTS 520, 521. DESCRIPCIÓ DE L'ÚS FETA PELS INFORMANTS. Van bé per a les infeccions de ventre i l'enflema. FORMA FARMACĖUTICA I ÚS. Xarop (ús intern). PREPARACIÓ. Les granes en xarop. DESTINACIÓ. Medicina humana.

Antitussigen

FONTS 532, 547, 548, 571. DESCRIPCIÓ DE L'ÚS FETA PELS INFORMANTS. S'utilitza com a reforçant i també per a la tos (532). Es prenia per a la tos (548). Per a la tos (547). Per a la tos i refredats (571). FORMA FARMACÈUTICA I ÚS. Xarop (ús intern). PREPARACIÓ També dels fruits se'n fa xarop (532). Amb els fruits i sucre se'n fa xarop $(547,548)$. També dels fruits se'n fa xarop (532). Amb els fruits i sucre se'n fa xarop $(547,548)$.
DESTINACIÓ. Medicina humana. OBSERVACIONS. El sabuc és molt medicinal, abans 
deien: "allà on hi viu un sabuc ja s'hi pot fer un poble" (532). També en feien essència, però jo no n'he fet mai $(547,548)$

Desconegut per l'informant

FONTS 533, 534, 1310. FORMA FARMACĖUTICA I ÚS. Xarop (ús intern). PREPARACIÓ. Amb les granes se'n feia xarop. Les granes es barrejaven amb sucre i es feia bullir (1310). DESTINACIÓ. Medicina humana.

Digestiu

FONT 1299. DESCRIPCIÓ DE L'ÚS FETA PER L'INFORMANT. Va bé per a les indigestions. FORMA FARMACĖUTICA I ÚS. Xarop (ús intern). MODE D'UTILITZACIÓ/POSOLOGIA. Has de fer uns quants dies una cullerada al matí una al vespre. DESTINACIÓ. Medicina humana.

\section{Expectorant}

FONT 1210. DESCRIPCIÓ DE L'ÚS FETA PER L'INFORMANT. Per a ajudar a expectorar. FORMA FARMACĖUTICA I ÚS. Fumigació (ús extern). PREPARACIÓ. Cremar les granes al foc (perfums). DESTINACIÓ. Medicina humana.

Hematocatàrtic

FONTS 574, 575, 576, 577. DESCRIPCIÓ DE L'ÚS FETA PELS INFORMANTS. Es pren com a purificant de la sang. FORMA FARMACĖUTICA I ÚS. Xarop (ús intern). PREPARACIÓ. Del raïm se'n pot fer xarop amb sucre. DESTINACIÓ. Medicina humana.

\section{Laxant}

FONT 1299. DESCRIPCIÓ DE L'ÚS FETA PER L'INFORMANT. Per al restrenyiment. FORMA FARMACĖUTICA I ÚS. Essència (ús intern). MODE D'UTILITZACIÓ/POSOLOGIA. Has de fer uns quants dies una cullerada al matí una al vespre. DESTINACIÓ. Medicina humana.

Restauratiu

FONTS 1337, 1338. DESCRIPCIÓ DE L'ÚS FETA PELS INFORMANTS. Per al bestiar quan estava malalt. FORMA FARMACĖUTICA I ÚS. Xarop (ús intern). PREPARACIÓ. La grana de sabuc es bullia amb sucre i se'n feia xarop. DESTINACIÓ. Medicina veterinària.

\section{Fulla}

\section{Galactòfug}

FONT 1213. DESCRIPCIÓ DE L'ÚS FETA PER L'INFORMANT. Per a retirar la llet de les mares una vegada acabat el període de l'alletament $i$ així evitar una mastitis. FORMA FARMACĖUTICA I ÚS. Sense forma farmacèutica (ús directe, ús extern). PREPARACIÓ. Es posen les fulles directament sobre els pits. MODE D'UTILITZACIÓ/POSOLOGIA. Canviar les fulles per unes de noves cada dia. DESTINACIÓ. Medicina humana.

\section{Inflorescència}

\section{Analgèsic}

FONTS 572, 573, 1318, 1353, 1354. DESCRIPCIÓ DE L'ÚS FETA PELS INFORMANTS. Anava bé per a quan et punxaves, és un desinfectant i calmava el dolor $(572,573)$. Per al dolor (1318). Quan et fas mal, et treu el dolor (1353). Per a quan et fas mal, et treu el dolor (1354). FORMA FARMACĖUTICA I ÚS. Fumigació (ús extern). PREPARACIÓ. Amb la flor en feien perfums amb el rescals del foc $(572,573)$. Perfums de la flor $(1318,1353,1354)$. DESTINACIÓ. Medicina humana.

Antiacneic

FONTS 1213, 1214. DESCRIPCIÓ DE L'ÚS FETA PELS INFORMANTS. Per a l'acne. FORMA FARMACĖUTICA I ÚS. Bany (ús extern). PREPARACIÓ. Decocció. Es fan banys amb l'aigua de les flors. DESTINACIÓ. Medicina humana.

Antibronquític

FONT 1331. DESCRIPCIÓ DE L'ÚS FETA PER L'INFORMANT. Per a les bronquitis. FORMA FARMACĖUTICA I ÚS. Tisana (ús intern). PREPARACIÓ. En infusió. DESTINACIÓ. Medicina humana.

Anticatarral

FONTS 507, 509, 510, 511, 512, 513, 514, 528, 529, 530, 531, 545, 546, 547, 548, 553, 556, $557,558,567,569,570,574,575,576,577,580,581,746,1213,1214,1215,1294,1299$, $1310,1313,1314,1315,1316,1322,1330,1331,1343,1344,1345,1346,1347,1348,1349$, 1350, 1351, 1361, 1362. DESCRIPCIÓ DE L'ÚS FETA PELS INFORMANTS. Per als refredats $(511,512,513,514,528,546,567,569,570,580,746,1215,1330,1347,1348$ $1349,1350,1351)$. La flor s'usava per als refredats $(507,509,510)$. Per als constipats ( 529 , $530,531,553,1213,1214,1294,1299,1313,1322,1331,1343,1344,1345,1346,1361$ 1362). Va bé per als constipats (545). Per a quan estaves constipat (546). Per als constipats, tos $(547,548)$. La flor és bona per als refredats, ben dolceta, estova molt $(556,557)$. Respirar aquell fum destapava molt quan estàs refredat $(556,557)$. La flor és molt bona per als constipats $i$ la tos (558). La flor va molt bé per als constipats (581). Quan estàs refredat (574, $575,576,577)$. Per als constipats barrejada amb altres herbes que no recorda (1310). Va bé per als refredats $(1314,1315,1316)$. FORMA FARMACĖUTICA I ÚS. Tisana (ús intern) (507, $509,510,528,529,530,531,545,546,547,548,553,556,557,558,580,581,746,1299$, 1310, 1313, 1314, 1315, 1316, 1322, 1330, 1331, 1343, 1344, 1345, 1346, 1347, 1348, 1349 $1350,1351,1361,1362)$. Essència (ús intern) $(511,512,513,514,528,546,553,569,570$ $1294,1310)$. Fumigació (ús extern) $(556,557,574,575,576,577,580,1213,1214,1215)$. Melit (ús intern) (567). Aerosol (ús intern) (1213,1214). PREPARACIÓ. 1213, 1214, 1215). Melit (ús intern) (567). Aerosol (ús intern) (1213, 1214). PREPARAClO. Decocció (507, 509, $510,528,529,530,531,556,557,558,580,581,746,1310,1315,1316,1322,1330,1343$, 1344, 1347, 1348, les flors (546). Un got d'aigua amb les gotes d'essència (546). Decocció. Aigua de la flor $(547,548)$. La flor en infusió $(553,1345,1346)$. Perfums (brases i flor) $(556,557)$. Decocció. Aigua de la flor amb mel (567). Es feien perfums (580). La flor per a fer perfums $(574,575$, $576,577)$. Posaven la flor al caliu i en feien perfums (1215). S'inhalen perfums de les flors o també se'n fan bafs $(1213,1214)$. La flor seca en infusió (1299). S'assecava la flor i es bevia en infusió (1313). En infusió $(1331,1361,1362)$. DESTINACIÓ. Medicina humana. OBSERVACIONS. També en feien essència, però jo no n'he fet mai $(547,548)$.

Anticefalàlgic

FONTS $536,537,747,1300,1301,1325,1326,1347,1348,1349$. DESCRIPCIÓ DE L'ÚS FETA PELS INFORMANTS. Per al mal de cap $(536,537,747,1300,1301,1347,1348$, 1349). Per al mal de cap amb un drap moll d'essència al front $(1325,1326)$. Per a quan tens mal de cap $(1347,1348,1349)$. FORMA FARMACĖUTICA I ÚS. Fumigació (ús extern) (747, 
$1300,1301,1347,1348,1349)$. Tisana (ús intern) $(536,537)$. Essència (ús extern) (1325, $1326,1347,1348,1349$ ). PREPARACIÓ. Drap perfumat amb flor de sabuc cremada al foc a terra $(747)$. Decocció $(536,537)$. La flor per a fer perfums (es posava oli en el rescals del foc $i$ a sobre la flor amb una mica de sucre) (1300). Perfums de la flor (1301). N'havien fet essència, i es feia quan la flor era ben molla, perquè així en sortia més $(1325,1326)$. En essència, i es feia quan la flor era ben molla, perquè així en sortia més $(1325,1326)$. En
essència, mulles un drap i te'l poses al front $(1347,1348,1349)$. La flor seca serveix per a fer essència, mulles un drap i te'l poses al front $(1347,1348,1349)$. La flor seca serveix per a fer
perfums. Perfumes un drap i te'l poses al front $(1347,1348,1349)$. DESTINACIÓ. Medicina humana.

Antidiarreic

FONTS 1347, 1348, 1349. DESCRIPCIÓ DE L'ÚS FETA PELS INFORMANTS. Per a la diarrea. FORMA FARMACĖUTICA I ÚS. Essència (ús intern). MODE D'UTILITZACIÓ/POSOLOGIA. Beure'n una cullerada. DESTINACIÓ. Medicina humana.

Antiequimòtic

FONTS 554, 555, 1300. DESCRIPCIÓ DE L'ÚS FETA PELS INFORMANTS. Per a quan t'has fet un cop o un morat (554). Per a fer banys quan t'has fet un cop o un morat (555). Anava bé quan et feies un truc (1300). FORMA FARMACĖUTICA I ÚS. Bany (ús extern) $(554,555)$. Fumigació (ús extern) (1300). PREPARACIÓ. Decocció $(554,555)$. La flor per a fer perfums (es posava oli en el rescals del foc i a sobre la flor amb una mica de sucre) (1300). DESTINACIÓ. Medicina humana.

Antigripal

FONT 1323. DESCRIPCIÓ DE L'ÚS FETA PER L'INFORMANT. Per a quan tenies grip FORMA FARMACĖUTICA I ÚS. Fumigació (ús extern). PREPARACIÓ. Perfums de la flor. DESTINACIÓ. Medicina humana.

Antihipertensiu

FONTS 1213, 1214. DESCRIPCIÓ DE L'ÚS FETA PELS INFORMANTS. Fa disminuir el sucre de la sang i també fa baixar la pressió arterial. FORMA FARMACĖUTICA I ÚS. Tisana (ús intern). PREPARACIÓ. Les flors es prenen en infusió. DESTINACIÓ. Medicina humana.

Antiinflamatori gàstric

FONT 1299. DESCRIPCIÓ DE L'ÚS FETA PER L'INFORMANT. Per a les infeccions de panxa i estómac. FORMA FARMACĖUTICA I ÚS. Essència (ús intern). MODE D'UTILITZACIÓ/POSOLOGIA. Només calen unes gotes. DESTINACIÓ. Medicina humana.

Antiinflamatori intestinal

FONTS 515, 516, 517, 520, 521, 522, 523, 525, 526, 527, 538, 549, 554, 555, 558, 559, 561 $562,563,565,566,572,573,588,590,591,592,753,754,755,1293,1310,1313,1317$ $1323,1325,1326,1330,1331,1332,1333,1334,1337,1338,1341,1342,1343,1344,1345$ $1346,1350,1351,1352$. DESCRIPCIÓ DE L'ÚS FETA PELS INFORMANTS. És molt bo per a la panxa i el mareig $(591,592)$. Per als mals de panxa $(515,516)$. Per al mal de ventre $(517,520,521,538,549,554,555,1310,1323,1331,1341,1342,1350,1351)$. De la flor en faig essència i va molt bé per al mal de panxa $(522,523)$. L'esperit va bé per al ventre $(525$, 526 527). Per a quan estàs marejat i tens mal de panxa (559). Quan tens mareig i mal de panxa (558). Per a la panxa prenia per al mal de ventre $(565,566)$. Per a mals de ventre $(753,754,755)$. L'essència és molt bona per a la panxa (588). Va bé per a la panxa i per al mareig (590). Era molt medicinal, per a la panxa (573). El seu pare hi tenia molta fe per als mals de ventre de l'estiu, que en deien una calor d'estiu (1293). Per a quan tenien mal de ventre (1313). Va bé per al mal de ventre (1317). Se la prenien per al mal de ventre $(1325,1326)$. Per als vedells que tenen malament la panxa (1330). Per al mal de panxa $(1330,1352)$. Per a totes les infeccions de la panxa $(1332,1333,1334)$. S'usava per al mal de ventre $(1337,1338)$. Per a quan el de la panxa $(1332,1333,1334)$. S'usava per al mal de ventre $(1337,1338)$. Per a quan el
bestiar tenia mal de ventre $(1341,1342)$. Per a quan tenies mal de ventre $(1343,1344)$. Per a bestiar tenia mal de ventre $(1341,1342)$. Per a quan tenies mal de ventre $(1343,1344)$. Per a quan tens mal de ventre $(1345,1346)$. FORMA FARMACEUTICA I US. Tintura alcohòlica (ús intern) $(591,592,1331,1337,1338,1350,1351)$. Essència (ús intern) $(515,516,517,520$,
$521,522,523,525,526,527,538,549,558,559,561,562,563,565,566,572,573,588$ $590,753,754,755,1293,1313,1317,1323,1325,1326,1330,1332,1333,1334,1341$, $1342,1343,1344,1345,1346,1352)$. Tisana (ús intern) $(517,554,555,1310,1323,1341$ 1342). Xarop (ús intern) $(561,563)$. Emplastre (ús extern) $(1341,1342)$. PREPARACIÓ Esperit $(591,592)$. Essència o també l'aigua de la flor (517). Decocció. Aigua de la flor (517). Xarop dels raïms $(561,563)$. Decocció $(554,555,1310)$. A sobre d'una olla que no sigui porosa poses un drap de fil i los flors. Tot plegat va a A sobre del caliu del foc a terra. porosa poses unt fressèncla va caient a dins de l'olla. Es necessitava molta flor. Després en un got d'aigua fresca s'hi posava una cullerada d'essencia (1293). Es bevia una mica d'aigua amb un rajol d'essència (1313). Infusió de la flor (1323). Nhavien fet essencia, i es feia quan la flor era ben molla, perquè així en sortia més $(1325,1326)$. Esperit de sabuc $(1331)$. Esperit de la flor (es tardava un mes a fer-lo) $(1337,1338)$. La flor en infusió $(1341,1342)$. Aplicar directament a sobre la panxa amb tovalloles molles de l'aigua de sabuc $(1341,1342)$. Essència de sabuc barrejada amb aigua $(1341,1342)$. L'essència, es posava amb un drap a sobre el ventre $(1345,1346)$. MODE D'UTILITZACIÓ/POSOLOGIA. Una cullerada $(1337,1338)$. DESTINACIÓ. Medicina humana $(515,516,517,520,521,522,523,525,526,527,538$, $549,554,555,558,559,561,562,563,565,566,572,573,588,590,591,592,753,754$, $755,1293,1310,1313,1317,1323,1325,1326,1330,1331,1332,1333,1334,1337,1338$ $1341,1342,1343,1344,1345,1346,1350,1351,1352)$. Medicina veterinària $(1330,1341$ 1342). OBSERVACIONS. Diu que aquesta essència és molt estimada, que molta gent n'hi ha demanat, fins i tot un metge. També de la grana se'n feia xarop (1293).

Antinauseabund

FONTS 558, 559, 560, 561, 562, 563, 590, 591, 592, 1313. DESCRIPCIÓ DE L'ÚS FETA PELS INFORMANTS. És molt bo per a la panxa i el mareig $(591,592)$. Per a quan estàs marejat $\mathrm{i}$ tens mal de panxa (559). Quan tens mareig i mal de panxa (558). Per a la panxa i el mareig $(561,562,563)$. Per a quan tenies mareig $(560)$. Va bé per a la panxa i per al mareig (590). Per a quan tenien mareig (1313). FORMA FARMACE்UTICA I ÚS. Tintura alcohòlica (ús intern) $(560,591,592)$. Essència (ús intern) $(558,559,561,562,563,590,1313)$. PREPARACIÓ. Esperit $(591,592)$. En feien esperit (560). Es bevia una mica d'aigua amb un PREPARACIO. Esperit $(591,592)$. En feien esperit (560).
rajolí d'essència (1313). DESTINACIÓ. Medicina humana.

Antiodontàlgic

FONTS 522, 523, 542, 543, 544. DESCRIPCIÓ DE L'ÚS FETA PELS INFORMANTS. Per a mals de queixals $(522,523)$. Mal de queixals $(542,543,544)$. FORMA FARMACĖUTICA I ÚS. Aerosol (ús intern) $(522,523)$. Fumigació (ús extern) $(542,543,544)$. PREPARACIÓ Se'n feien vapors de la flor (la mare feia bullir la flor dins d'una olla i entomava aquells 
vapors) $(522,523)$. Fer perfums al rescals del foc $(542,543,544)$. DESTINACIÓ. Medicina humana.

Antiofídic

FONT 564. DESCRIPCIÓ DE L'ÚS FETA PER L'INFORMANT. Per a les mossegades d'escurçó. FORMA FARMACĖUTICA I ÚS. Fumigació (ús extern). PREPARACIÓ. Perfums de flor de sabuc. DESTINACIÓ. Medicina veterinària. OBSERVACIONS. Mossegades d'escurçó: una vegada a la gossa la va mossegar un escurçó, el primer que vaig fer va ser punxar-li ben punxat amb espinacals (Eryngium campestre), després vaig fer un pipí en un punxar-li ben punxat amb espinacals (Eryngium campestre), despres vaig fer un pipi en un
mocador i l'hi vaig apretar una estona, quan vaig arribar a casa li vaig fer perfums de flor de mocador i 'hi vaig apretar una estona, quan vaig arribar a casa li vaig fer perfums de flor de
sabuc (Sambucus nigra) i els alternava amb perfums de farigola (Thymus vulgaris). Es va sabuc (Sambucus nigra) i els alternava
curar, al cap de 48 hores ja menjava.

Antiparotidític

FONTS 1213, 1214. DESCRIPCIÓ DE L'ÚS FETA PELS INFORMANTS. Per a les galteres. FORMA FARMACĖUTICA I ÚS. Fumigació (ús extern). PREPARACIÓ. Escalfaven draps de llana amb el fum de la flor de sabuc cremada al braser (perfum). DESTINACIÓ. Medicina humana.

Antipirètic

FONTS 554, 555. DESCRIPCIÓ DE L'ÚS FETA PELS INFORMANTS. Per a fer baixar la febre. FORMA FARMACÉUTICA I ÚS. Essència (ús intern). DESTINACIÓ. Medicina humana.

Antipleurític

FONTS 529, 530, 531. DESCRIPCIÓ DE L'ÚS FETA PELS INFORMANTS. Per a les pleures i pulmonies. FORMA FARMACĖUTICA I ÚS. Essència (ús intern). DESTINACIÓ. Medicina humana.

Antipneumònic

FONTS 529, 530, 531. DESCRIPCIÓ DE L'ÚS FETA PELS INFORMANTS. Per a les pleures i pulmonies. FORMA FARMACĖUTICA I ÚS. Essència (ús intern). DESTINACIÓ. Medicina humana.

Antisèptic extern

FONTS $511,512,513,514,515,516,520,521,524,528,529,530,531,536,537,542,543$ $544,549,560,748,749,1328,1329$. DESCRIPCIÓ DE L'ÚS FETA PELS INFORMANTS. Aquell fum és molt desinfectant $(511,512,513,514)$. Per a desinfectar ferides $(515,516$, $520,521,748,749,1328,1329)$. La flor per a rentar les ferides $(529,530,531)$. La flor es feia servir per a fer perfums (524). Per a desinfectar mals $(536,537)$. Per a infeccions $(542,543$ 544). Una vegada em vaig clavar una espina d'arç i no em treia el mal, em van fer perfums. Aquell fum et calma completament el dolor, és posar oli en un llum (528). S'utilitzaven per a desinfectar (549). Quan tenies ferides (560). FORMA FARMACĖUTICA I ÚS. Fumigació (ús extern) $(511,512,513,514,515,516,520,521,524,528,536,537,542,543,544,549,560$ $748,749)$. Bany (ús extern) $(529,530,531)$. Fum (ús extern) $(1328,1329)$. PREPARACIÓ. Es posava en un pot la flor de sabuc, una mica de sucre i una mica d'oli i llavors s'hi cremava roba de fil $(511,512,513,514)$. Perfums de la flor amb caliu del foc $(748,749)$. Perfums de flor $(515,516,520,521,536,537)$. Decocció $(529,530,531)$. Fer perfums al rescals del foc
$(542,543,544)$. Perfums amb caliu del foc, oli, sucre i flor de sabuc (528). Assecàvem les flors per a fer perfums (549). La flor seca per a fer perfums (560). Perfums de les flors al foc $(1328,1329)$. DESTINACIÓ. Medicina humana.

Antisèptic intern

FONTS 529, 530, 531, 1299. DESCRIPCIÓ DE L'ÚS FETA PELS INFORMANTS. Es feia servir per a les infeccions de ventre i per al tifus [dit "tífols"] $(529,530,531)$. Per a les infeccions de panxa i estómac (1299). FORMA FARMACĖUTICA I ÚS. Essència (ús intern). MODE D'UTILITZACIÓ/POSOLOGIA. Només calen unes gotes (1299). DESTINACIÓ. MODE D'UTILITZAC
Medicina humana.

Antisèptic ocular

FONTS 505, 506, 520, 521, 561, 562, 563, 572, 573, 581, 746, 750, 1215, 1293, 1320, 1322 1337, 1338. DESCRIPCIÓ DE L'ÚS FETA PELS INFORMANTS. Per a rentar els ulls (505, $506,746)$. Per als ulls $(750,1215)$. La flor és un desinfectant per als ulls $(520,521)$. Per a la $506,746)$. Per als ulls $(750,1215)$. La flor és un desinfectant per als ulls $(520,521)$. Per a la
vista $(520,521)$. Per al mal d'ulls $(561,562,563,1337,1338)$. L'essència va bé per a banyar vista $(520,521)$. Per al mal d'ulls $(561,562,563,1337,1338)$. L'essència va bé per a banyar
els ulls $(581)$. Era molt medicinal, va bé per a banyar els ulls $(572,573)$. Per a rentar-se els ulls, per a les infeccions dels ulls (1293). Per a rentar els ulls quan et fan picor (1320). Per a fregar els ulls si hi tens pols d'estar al camp treballant (1322). FORMA FARMACĖUTICA I ÚS. Bany (ús extern) $(520,521,746,1320,1337,1338)$. Essència (ús extern) $(505,506,572$, $573,581,750,1293)$. Essència (ús intern) $(520,521)$. Fumigació (ús extern) $(561,562,563$, 1215). Desconegut per l'informant (1322). PREPARACIÓ. Decocció (520, 521, 746, 1337, 1338). Per a fer perfums al foc $(561,562,563)$. Posaven la flor al caliu i en fèien perfums (1215). A sobre d'una olla que no sigui porosa poses un drap de fil i les flors. Tot plegat va a sobre del caliu del foc a terra. L'essència va caient a dins de l'olla. Es necessitava molta flor. Després en un got d'aigua fresca s'hi posava una cullerada d'essència (1293). La flor de got d'aigua fresca s'hi posava una cullerada d'essencia (1293). La flor de sabuc en infusió (1320). DESTINACIÓ. Medicina humana. OBSERVACIONS. Diu que aquesta essència és molt estimada, que molta gent n'hi ha demanat, fins i tot un metge. També de la grana se'n feia xarop (1293).

Antitific

FONTS 522, 523, 529, 530, 531. DESCRIPCIÓ DE L'ÚS FETA PELS INFORMANTS. Es feia servir per a les infeccions de ventre i per al tifus [dit "tifols"] $(529,530)$. Es feia servir per a les infeccions de ventre i per al tifus [dit "tífols"] (531). A un nen que tenia el tifus [dit "tifols"] li van curar només en essència (522). A un nen que tenia tifus [dit "tífols"] li van curar només van curar només en essència (522). A un nen que tenia tifus [dit "tífols"] li van curar només
en essència (523). FORMA FARMACĖUTICA I ÚS. Essència (ús intern). DESTINACIÓ. Medicina humana.

\section{Antitussigen}

FONTS 532, 547, 548, 558, 1332, 1333, 1334. DESCRIPCIÓ DE L'ÚS FETA PELS INFORMANTS. Va bé per a la tos i els pulmons (532). Per als constipats, tos $(547,548)$. La flor és molt bona per als constipats i la tos $(558)$. Per a quan tens tos $(1332,1333,1334)$. FORMA FARMACEUUTICA I ÚS. Tisana (ús intern). PREPARACIÓ. Decocció. Aigua de les flors $(532)$. Decocció $(548,558)$. Decocció. Aigua de la flor $(547)$. La flor en infusió (1332, 1333, 1334). DESTINACIÓ. Medicina humana. OBSERVACIONS. El sabuc és molt medicinal, abans deien allà on hi viu un sabuc ja s'hi pot fer un poble (532). També en feien essència, però jo no n'he fet mai $(547,548)$. 
Desconegut per l'informant

FONTS 554, 555, 569, 570, 583, 584, 585. FORMA FARMACĖUTICA I ÚS. Fumigació (ús extern) $(554,555,569,570,583,584,585)$. Essència (ús intern) $(583,584,585)$ PREPARACIÓ. Se'n feien perfums $(569,570)$. Per a fer perfums $(554,555)$. Se'n feien perfums al foc a terra $(583,584,585)$. DESTINACIÓ. Medicina humana.

Digestiu

FONTS 746, 1310. DESCRIPCIÓ DE L'ÚS FETA PELS INFORMANTS. En essència quan tens pesadesa d'estómac (746). Per a pair (1310). FORMA FARMACĖUTICA I ÚS. Essència (ús intern) (746). Tisana (ús intern) (1310). PREPARACIÓ. Decocció (1310). DESTINACIÓ. Medicina humana.

Estomacal

FONTS 541, 564. DESCRIPCIÓ DE L'ÚS FETA PELS INFORMANTS. Per al mal d'estómac (541). Per a l'estómac, era la medicina de la padrina (564). FORMA FARMACĖUTICA I ÚS. Essència (ús intern) (541). Tisana (ús intern) (564). PREPARACIÓ. Decocció. L'aigua de la flor (564). DESTINACIÓ. Medicina humana.

Expectorant

FONT 1210. DESCRIPCIÓ DE L'ÚS FETA PER L'INFORMANT. Per a ajudar a expectorar. FORMA FARMACĖUTICA I ÚS. Tisana (ús intern). PREPARACIÓ. Infusions de la flor DESTINACIÓ. Medicina humana.

Galactòfug

FONTS 583, 584, 585, 1214, 1337, 1338. DESCRIPCIÓ DE L'ÚS FETA PELS INFORMANTS. Per al bestiar que vols que perdin la llet $(583,584,585)$. Per a retirar la lle de les mares una vegada acabat el període de l'alletament i així evitar una mastitis (1214) Per a fer recular la llet de les dones $(1337,1338)$. FORMA FARMACEUTICA I ÚS. Fumigació (ús extern) $(583,584)$. Fum (ús extern) $(585,1337,1338)$. Sense forma farmacèutica (ús directe, ús extern) (1214). PREPARACIÓ. Perfums (583, 584, 585). Es posen les fulles directament sobre els pits (1214). Perfums de la flor $(1337,1338)$. MODE D'UTILITZACIÓ/POSOLOGIA Canviar les fulles per unes de noves DESTINACIÓ. Medicina veterinària $(583,584,585)$. Medicina humano $(1214,1337,1338)$. Hipoglucemiant

FONTS 1213, 1214. DESCRIPCIÓ DE L'ÚS FETA PELS INFORMANTS. Fa disminuir el sucre de la sang i també fa baixar la pressió arterial. FORMA FARMACĖUTICA I ÚS. Tisana (ús intern). PREPARACIÓ. Les flors es prenen en infusió. DESTINACIÓ. Medicina humana. Per a l'afonia

FONTS 1350, 1351. DESCRIPCIÓ DE L'ÚS FETA PELS INFORMANTS. Va bé per al rogall. FORMA FARMACĖUTICA I ÚS. Tisana (ús intern). PREPARACIÓ. Fas aigua de la flor de sabuc i afegeixes sucre cremat. DESTINACIÓ. Medicina humana.

Per a les punxades

FONTS 1213, 1214, 1296, 1297, 1319, 1323, 1330, 1331, 1343, 1344, 1361, 1362 DESCRIPCIÓ DE L'ÚS FETA PELS INFORMANTS. Per a les punxades $(1213,1214,1323)$. Quan et fas una punxada $(1296,1331)$. Per a quan et fas una punxada (1297). Per a punxades metzinoses (1319). Per a punxades infectades (1330). Per a punxades (1343 1344). Per a les punxades fondes $(1361,1362)$. FORMA FARMACĖUTICA I ÚS. Fumigació (ús extern) $(1213,1214,1323,1361,1362)$. Fum (ús extern) $(1296,1297,1319,1330,1331$ $1343,1344)$. Essència (ús intern) (1297). PREPARACIÓ. S'apliquen draps calents impregnats amb perfums de les flors $(1213,1214)$. La flor és bona per a fer perfums (1296). Amb la flor se'n fan perfums (1297). Perfums al foc amb oli i sucre (1319). Perfums de la flor Amb la flor se'n fan perfums (1297). Perfums al foc amb oli i sucre (1319). Perfums de la flor
(1323). Per a fer perfums (1330). Perfums de la flor amb un raig de lleixiu (1331). Se'n feien (1323). Per a fer perfums (1330). Perfums de la flor amb un raig de lleixiu (1331). Se'n feien
perfums $(1343,1344)$. Perfums de la flor amb oli i sucre $(1361,1362)$. DESTINACIÓ. perfums $(1343,1344$

Per a trastorns associats a la menopausa

FONTS 1213, 1214. DESCRIPCIÓ DE L'ÚS FETA PELS INFORMANTS. Per a les calors de la menopausa. FORMA FARMACĖUTICA I ÚS. Tisana (ús intern). PREPARACIÓ. Les flors es prenen en infusió. MODE D'UTILITZACIÓ/POSOLOGIA. Es beu l'aigua de les flors una vegada cada dos o tres dies. DESTINACIÓ. Medicina humana.

Per a trastorns de la pell o del teixit subcutani

FONT 1314. DESCRIPCIÓ DE L'ÚS FETA PER L'INFORMANT. Per a l'erisipela [dit "per a les desipeldes de la cara"] (mal que es posava entre la pell i l'ós principalment a sota el nas) FORMA FARMACĖUTICA I ÚS. Fum (ús extern). PREPARACIÓ. Perfums de flor de sabuc amb sucre i caliu. DESTINACIO. Medicina humana.

Salutífer

FONT 1330. FORMA FARMACÈUTICA I ÚS. Essència (ús intern). PREPARACIÓ. Per a esmorzar els donava una mica d'essència de sabuc amb un rovell d'ou i sucre. DESTINACIÓ Medicina humana.

Vulnerari

FONTS 522, 523, 556, 557, 571, 750, 1307, 1308, 1309, 1323. DESCRIPCIÓ DE L'ÚS FETA PELS INFORMANTS. Per a talls i ferides (750). Perfums al foc per a les ferides $(522,523)$. Per a ferides $(556,557)$. Per a les ferides, calmava (571). Quan t'has fet un tall $(1307,1308$, 1309). Per als talls (1323). FORMA FARMACĖUTICA I US. Fumigació (ús extern) (522, 523, 556, 557, 571, 750, 1323). Fum (ús extern) $(1307,1308,1309)$. PREPARACIÓ. Perfums (750). Perfums (brases i flor) $(556,557)$. Amb la flor es feien perfums (571). Perfums de flor de sabuc $(1307,1308,1309)$. Perfums de la flor (1323). DESTINACIÓ. Medicina humana.

\section{USOS ALIMENTARIS}

Fruit

Ingestió de la part de la planta cuita - Cuita en aigua

FONT 1215. DESCRIPCIÓ DE L'ÚS FETA PER L'INFORMANT. Del fruit del sabuc se'n feia un xarop. Bullit i colat, es donava per a beure als pagesos per a treure la set. DESTINACIÓ. Alimentació humana.

Ingestió de la part de la planta cuita - Cuita en sucre

FONTS 569, 570, 1297, 1317, 1345, 1346, 1347, 1348, 1349, 1353, 1354. DESCRIPCIÓ DE L'ÚS FETA PELS INFORMANTS. Se'n feien melmelades (569). Se'n feien melmelades (570). 
Amb la grana en fa melmelada $(1297,1317)$. La grana amb sucre per a fer melmelades $(1345,1346)$. Per a fer melmelades $(1347,1348,1349,1353,1354)$. OBSERVACIONS. Diu que va bé quan tenen mal de coll (1297). DESTINACIÓ. Alimentació humana $(569,570$ 1297, 1317, 1345, 1346, 1347, 1348, 1349, 1353, 1354).

Preparació de begudes - Beguda preparada amb aigua

FONTS 1313,1319, 1330,1337, 1338, 1343, 1344, 1345, 1346. DESCRIPCIÓ DE L'ÚS FETA PELS INFORMANTS. Amb el fruit se'n feia un xarop, es bullien els fruits amb sucre llavors s'utilitzava com a refresc barrejant-lo amb aigua fresca (1313). Per a beure quan tens set (1319). Per a beure'n a l'estiu quan fa calor (1330). El xarop de sabuc es barrejava amb aigua per a quan tenies set $(1337,1338)$. Amb les granes es feia xarop i es prenia barreja amb aigua quan tenies molta set $(1343,1344)$. Amb la grana és fa xarop i aquest el feien servir per a no beure aigua sola, treu molt la set $(1345,1346)$. DESTINACIÓ. Alimentació humana $(1313,1319,1330,1337,1338,1343,1344,1345,1346)$.

Preparació de begudes - Beguda preparada amb sucre sense fermentació

FONTS 505, 506, 507, 509, 510, 529, 530, 531, 559, 560, 572, 573, 580, 583, 584, 585, 746. DESCRIPCIÓ DE L'ÚS FETA PELS INFORMANTS. Es feia xarop per a beure a l'estiu. No s'utilitzava per a medicina, era una gormanderia. Es fa bullir el raïm del saüc fins que quedi líquid, es cola i s'hi afegeix sucre (746). El raïm s'usava per a fer-ne xarop i a l'estiu es bevia com a refrescant $(507,509,510)$. Del raïm se'n fa xarop per a beure com a refresc a l'estiu $(505,506)$. Amb el raïm se'n fa xarop que és molt refrescant $(529,530,531)$. Amb les granes se'n feia un xarop. Es feia servir per a beure quan tenies molta set (559). En feien xarop i es prenia com a refresc d'estiu (560). Del raïm se'n fa un xarop que barrejat amb aigua a l'estiu és molt refrescant (580). Xarop per a beure (572). Xarop de granes per a beure (573). Amb els raïmets en fèiem xarop i es bevia a l'estiu com a refrescant $(583,584,585)$. DESTINACIÓ. Alimentació humana $(505,506,507,509,510,529,530,531,550,560,572$. $573,580,583,584,585,746)$

\section{Inflorescència}

Ingestió de la part de la planta cuita - Cuita en oli

FONTS 554, 555, 565, 566, 569, 570, 581, 1213, 1214. DESCRIPCIÓ DE L'ÚS FETA PELS INFORMANTS. La flor arrebossada amb farina i ou $(565,566)$. Les flors arrebossades són molt bones $(569,570)$. La flor arrebossada amb llet, farina i ou és molt bona. Amb la farina l'ou faig com una crema clareta i la tiro per sobre $(554,555)$. La flor és molt bona arrebossada (581). Amb la flor se'n fan truites $(1213,1214)$. DESTINACIÓ. Alimentació humana $(554,555,565,566,569,570,581,1213,1214)$

Preparació de begudes - Beguda preparada amb aigua

FONT 581. DESCRIPCIÓ DE L'ÚS FETA PER L'INFORMANT. L'essència és molt bona barrejada amb aigua fresca a l'estiu per a refrescar. DESTINACIÓ. Alimentació humana.

\section{ALTRES USOS}

Altres informacions
FONTS 589, 591, 592. DESCRIPCIÓ DE L'ÚS FETA PELS INFORMANTS. La collíem i l'assecàvem a l'ombra i la veníem (589). La flor també la veníem $(591,592)$.

Creences i pràctiques magicoreligioses

FONT 503. DESCRIPCIÓ DE L'ÚS FETA PER L'INFORMANT. Quan hi havia tronades es cremava flor de sabuc, farigola o altres plantes que fessin olor i es deien oracions: "La mare de Déu passa per un camí al bon Jesús hi encontrà".

\section{Tija}

Artesanal: elaboració d'instruments musicals

FONT 1215. DESCRIPCIÓ DE L'ÚS FETA PER L'INFORMANT. De les branques en fèien pipes i flautes, treien l'esponja i la tapaven amb paper de fumar.

Artesanal: elaboració de pipes de fumar

FONT 1215. DESCRIPCIÓ DE L'ÚS FETA PER L'INFORMANT. De les branques en fèien pipes i flautes, treien l'esponja i la tapaven amb paper de fumar.

\section{ACCIONS NOCIVES O TÒXIQUES}

Fruit

FONT 524. DESCRIPCIÓ DE L'ACCIÓ NOCIVA O TÒXICA FETA PER L'INFORMANT. Si els tudons es mengen els raïms de sabuc queden borratxos. VIA D'INTOXICACIÓ. Via interna.

\section{ALTRES OBSERVACIONS}

FONTS 1213, 1214. DESCRIPCIÓ FETA PELS INFORMANTS. Antigament al costat de totes les cases de pagès hi havia un sabuc per les seves propietats medicinals.Per a les fulles i les flors es pot confondre amb l'èvol (Sambucus ebulus), molt tòxic, però aquest és molt més baix.

\section{BARREGES AMB AQUEST TÀXON}

\section{Inflorescència}

FONTS 1339, 1340. Entrevista 22, barreja II (vegeu catàleg de barreges)

FONT 1320. Entrevista 34, barreja II (vegeu catàleg de barreges)

FONTS 529, 530, 531. Entrevista 53, barreja II (vegeu catàleg de barreges)

FONT 747. Entrevista 55 (vegeu catàleg de barreges)

FONT 1294. Entrevista 6, barreja I (vegeu catàleg de barreges)

FONTS $753,754,755$. Entrevista 67 , barreja II (vegeu catàleg de barreges) FONT 549. Entrevista 75, barreja II (vegeu catàleg de barreges)

FONTS 554, 555. Entrevista 78, barreja V (vegeu catàleg de barreges)

FONT 1310. Entrevista 9 (vegeu catàleg de barreges) 
FONT 581. Entrevista 94, barreja $\mathrm{V}$ (vegeu catàleg de barreges)

FONTS 583, 584, 585. Entrevista 96, barreja II (vegeu catàleg de barreges)

Parènquima cortical

FONT 746. Entrevista 45, barreja IV (vegeu catàleg de barreges)

FONT 553. Entrevista 77, barreja III (vegeu catàleg de barreges)

\section{Sanguisorba minor Scop. (rosàcies)}

\section{BCN 24985}

\section{NOMS POPULARS}

Pimpinella $(1332,1333,1334)$

\section{USOS MEDICINALS}

Flor

Antisèptic ocular

FONTS 1332, 1333, 1334. DESCRIPCIÓ DE L'ÚS FETA PELS INFORMANTS. Per als ulls quan estan malalts. FORMA FARMACËUTICA I US. Bany (ús extern). PREPARACIO. Decocció. Aigua de la flor quan encara no ha explotat. DESTINACIÓ. Medicina humana.

\section{Santolina chamaecyparissus L. (compostes)}

BCN 24986

\section{NOMS POPULARS}

Botja $(583,584,585,591,592)$

Camamilla $(515,516,517,518,519,522,523,529,530,531,560,564,565,566,589,747$ $751,752,1215)$

Camamilla borda (581)

Camamilla de Bianya (524)

Camamilla de bosc $(505,506)$

Camamilla de botó $(586,587,753,754,755,1299,1300,1310,1314,1315,1316,1323$, $1325,1326,1327,1331,1335,1336,1339,1340,1345,1346,1347,1348,1349)$

Camamilla de botó groc $(1294,1296,1318,1361,1362)$

Camamilla de l'hort $(1339,1340)$

Camamilla de pastor $(586,587)$

Camamilla del botó $(515,516,536,537,746,750)$
Espernallat $(520,521,561,562,563)$

Espernatallat $(507,509,510)$

Herba de Sant Joan (1335)

Santolina $(1213,1214)$

\section{USOS MEDICINALS}

\section{Inflorescència}

Antidepressiu

FONT 1335. DESCRIPCIÓ DE L'ÚS FETA PER L'INFORMANT. Va bé per a les depressions FORMA FARMACĖUTICA I ÚS. Tisana (ús intern). PREPARACIÓ. Decocció. DESTINACIÓ. Medicina humana.

Antiinflamatori intestinal

FONTS $505,506,515,516,517,518,519,522,523,529,530,531,536,537,560,561,562$ $563,564,565,566,581,583,584,585,586,587,589,591,592,747,750,751,752,753$ $754,755,1294,1296,1299,1300,1310,1314,1315,1316,1318,1323,1325,1326,1331$ $1335,1336,1339,1340,1361,1362$. DESCRIPCIÓ DE L'ÚS FETA PELS INFORMANTS Per als mals de ventre. Aquesta no l'hem fet servir mai $(505,506)$. Per a mals de panxa $(515$ $516,536,537,752)$. Per al mal de ventre dels vedells $(515,516)$. Per a la panxa $(560,564$ $581,589,591,592,750,753,754,755,1339,1340)$. Per al mal de panxa $(517,522,523$ $1335,1336)$. Per al mal de ventre del bestiar (747). Per al mal de ventre $(518,519,529,530$ $531,565,566,747,1299,1310,1314,1323,1325,1326,1331,1361,1362)$. Per a mals de panxa, per a pair (751). També és com una camamilla, per a la panxa $(583,584,585)$ Va be pan a la panxa $(586,587)$. Va molt bé per a la panxa (1294). Quan tens ma de ventre (1315, per a la panxa (586, 587). Va molt be per a la panxa (1294). Quan tens mal de ventre (1315, PREPARACIÓ . Decóó $(505,506,515,516,517,518,519,522,523,529,530,531,536$

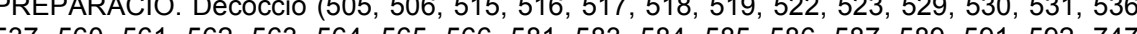
$537,560,561,562,563,564,565,566,581,583,584,585,586,587,589,591,592,747$ 750, 751,752, 753, 754, 755, 1294, 1296, $1290,1300,1315,1316,1318,1323,1325,1326$ $1331,1335,1336,1339,1340)$. Decocció. Aigua de camamilla amb polvos de bicarbona (747). En infusió $(1361,1362)$. DESTINACIÓ. Medicina humana $(505,506,515,516,517$ $518,519,522,523,529,530,531,536,537,560,561,562,563,564,565,566,581,583$ $584,585,586,587,589,591,592,747,750,751,752,753,754,755,1294,1296,1299$ $1300,1310,1314,1315,1316,1318,1323,1325,1326,1331,1335,1336,1339,1340,1361$ $1362)$. Medicina veterinària $(515,516,747)$. OBSERVACIONS. Allà a Beget la sabatera en venia (747). Aquesta fa olor $(522,523)$. Diuen que és més bona que la camamilla dolça, quan hi va haver el còlera deien que la gent que en va prendre es va salvar $(561,562,563)$. Hi ha llocs que és més dolca que en altres (581). Fa com un coixi (583). Li agrada més que la de muntanya, perquè és molt suau (1294). És la que hi ha aquí, és molt bona de gust (1206). muntanya, perqué és molt suau (1294). És la que hi ha aquí, és mós bona de gust (1296) Quan no en tenen de la dolça (Matricaria chamomilla) (1299). Es més dolça, li agrada més (1300). És la més bona de totes (1310). La fa senir molt poc, diu que és millor la de muntanya (Achillea ptarmica subsp. pyrenaica) (1323). Quan no n'hi ha de la de muntanya (Achillea ptarmica subsp. pyrenaica) $(1339,1340)$

Antinauseabund 
FONTS 1315, 1316, 1327, 1331, 1336. DESCRIPCIÓ DE L'ÚS FETA PELS INFORMANTS. Quan tens mareig o fàstic $(1315,1316)$. Per al mareig $(1327,1331,1336)$. FORMA FARMACĖUTICA I ÚS. Tisana (ús intern). PREPARACIÓ Decocció $(1315,1316,1327$, $1331,1336)$. DESTINACIÓ. Medicina humana. OBSERVACIONS. No li agrada gaire (1327). Antisèptic ocular

FONTS 1294, 1299, 1314, 1339, 1340, 1347, 1348, 1349. DESCRIPCIÓ DE L'ÚS FETA PELS INFORMANTS. Per a la conjuntivitis (1294). Per a rentar els ulls (1299). Per a banyar els ulls $(1314,1347,1348,1349)$. Per als ulls $(1339,1340)$. FORMA FARMACĖUTICA I ÚS. Bany (ús extern). PREPARACIÓ. Decocció $(1294,1299,1339,1340,1347,1348,1349$ ). DESTINACIÓ. Medicina humana. OBSERVACIONS. Li agrada més que la de muntanya, perquè és molt suau (1294). Quan no en tenen de la dolça (Matricaria chamomilla) (1299) Quan no n'hi ha de la de muntanya (Achillea ptarmica subsp. pyrenaica) $(1339,1340)$

Digestiu

FONTS $507,509,510,520,521,536,537,746,751,1347,1348,1349$. DESCRIPCIÓ DE L'ÚS FETA PELS INFORMANTS. Digestiva (746). És diürètica i digestiva. L'havíem donat a un marrà que no podia pixar $(507,509,510)$. Per als mals de panxa, per a pair $(751)$. Va be per a pair $(536,537)$. Per a ajudar a pair. Té les mateixes propietats que la dolça (Matricaria chamomilla) $(520,521)$. Per a pair $(1347,1348,1349)$. FORMA FARMACĖUTICA I ÚS Tisana (ús intern). PREPARACIÓ. Decocció $(507,509,510,520,521,536,537,746,751$ 1347, 1348, 1349). DESTINACIÓ. Medicina humana (520, 521, 536, 537, 746, 751, 1347 $1348,1349)$. Medicina humana i veterinària $(507,509,510)$. OBSERVACIONS. És camamilla, però molt amargant $(520,521)$

Diürètic

FONTS 507, 509, 510. DESCRIPCIÓ DE L'ÚS FETA PELS INFORMANTS. És diürètica digestiva. L'havíem donat a un marrà que no podia pixar. FORMA FARMACĖUTICA I ÚS. Tisana (ús intern). PREPARACIO. Decocció. DESTINACIO. Medicina humana i veterinària.

Estomacal

FONT 1335. DESCRIPCIÓ DE L'ÚS FETA PER L'INFORMANT. Per al mal d'estómac. FORMA FARMACĖUTICA I ÚS. Tisana (ús intern). PREPARACIÓ. Decocció. DESTINACIÓ. Medicina humana.

Tranquil·litzant

FONTS 536, 537, 1339, 1340. DESCRIPCIÓ DE L'ÚS FETA PELS INFORMANTS. Relaxa $(536,537)$. Per als nervis $(1339,1340)$. FORMA FARMACEUTICA I US. Tisana (ús intern). PREPARACIÓ. Decocció $(536,537,1339,1340)$. DESTINACIÓ. Medicina humana. OBSERVACIONS. Quan no n'hi ha de la de muntanya (Achillea ptarmica subsp. pyrenaica) $(1339,1340)$.

\section{USOS ALIMENTARIS}

Part aèria

Ingestió de la part de la planta crua - Fresca (sense preparació)
FONTS 583, 584, 585. DESCRIPCIÓ DE L'ÚS FETA PELS INFORMANTS. El bestiar se la menja molt $(583,584,585)$. OBSERVACIONS. Fa com un coixí (584). DESTINACIÓ. Alimentació animal $(583,584,585)$.

\section{ALTRES USOS}

\section{Inflorescència}

Cosmètic

FONT 1335. DESCRIPCIÓ DE L'ÚS FETA PER L'INFORMANT. Va bé per a rentar els cabells, però els aclareix de color.

Domèstic: ambientador

FONTS 1213, 1214. DESCRIPCIÓ DE L'ÚS FETA PELS INFORMANTS. Perfums per a la roba.

\section{ALTRES OBSERVACIONS}

FONTS 581, 583, 584, 585, 586, 587, 589, 1215, 1318, 1323, 1345, 1346. DESCRIPCIÓ FETA PELS INFORMANTS. Es fa en els solells i marges (581). L'anàvem a buscar a la Tusquera (589). Fa com un coixí $(583,584,585)$. Es fa pels marges $(586,587)$. Aquesta no és pas bona com l'altra camamilla (Matricaria chamomilla) (1215). En té una planta a l'hort (1318). En té una plantada a l'hort $(1323)$. En té plantada a l'hort $(1345,1346)$ OBSERVACIONS. No la utilitza gaire $(1345,1346)$

\section{BARREGES AMB AQUEST TÀXON}

\section{Inflorescència}

FONTS 1325, 1326. Entrevista 13, barreja I (vegeu catàleg de barreges)

FONT 1336. Entrevista 16, barreja I (vegeu catàleg de barreges)

FONT 1318. Entrevista 31, barreja III (vegeu catàleg de barreges)

FONTS 1315, 1316. Entrevista 38 (vegeu catàleg de barreges)

FONT 746. Entrevista 45, barreja III (vegeu catàleg de barreges)

FONT 747. Entrevista 55 (vegeu catàleg de barreges)

FONT 1294. Entrevista 6, barreja II (vegeu catàleg de barreges)

FONT 564. Entrevista 84, barreja I (vegeu catàleg de barreges)

\section{Saponaria ocymoides L. (cariofil·làcies)}

BCN 123789

NOMS POPULARS 
Herba sabonosa (503)

\section{USOS MEDICINALS}

\section{Part aèria}

Coadjuvant del postpart

FONT 503. DESCRIPCIÓ DE L'ÚS FETA PER L'INFORMANT. Quan les truges havien godallat $i$ agafaven febre se'ls posava aquest emplastre sobre la panxa. FORMA godallat i agafaven febre se's posava aquest emplastre sobre la panxa. FORMA
FARMACÉUTICA I ÚS. Emplastre (ús extern). PREPARACIÓ. La mare la treballava fins que li feia sortir I'escuma. MODE D'UTILITZACIÓ/POSOLOGIA. Uns quants dies després del li feia sortir l'escuma. MODE D'UTILITZAC
part. DESTINACIÓ. Medicina veterinària.

\section{Saponaria officinalis L. (cariofil·làcies)}

BCN 24987

\section{NOMS POPULARS}

Herba sabonera $(505,506,1324)$

Sabó de gitana (541)

\section{ALTRES USOS}

Part aèria florida

Cosmètic

FONTS 541, 1324. DESCRIPCIÓ DE L'ÚS FETA PELS INFORMANTS. Per a rentar-se les mans. La flor fa una escuma (541). Com a xampú del cabell (1324).

Domèstic: ajudes a la llar

FONTS 505, 506, 1324. DESCRIPCIÓ DE L'ÚS FETA PELS INFORMANTS. Per a rentar roba negra S'ha de bullir i colar llavors s'hi posa roba negra perquè s'estovi i llavors ben fregada $(505,506)$. Abans en feien sabó per a rentar la roba $(1324)$.

\section{Sarothamnus scoparius (L.) Wimm. ex Koch (papilionàcies)} BCN 24988

\section{NOMS POPULARS}

Ginesta $(538,539,540,541,547,548,553,560,561,562,563,564,571,586,587,588$ $589,591,592,1215,1300,1322,1332,1333,1334,1352)$

Ginestra $(569,570)$

Gòdua (564)

\section{USOS MEDICINALS}

Flor

Diaforètic

FONTS 539, 540. DESCRIPCIÓ DE L'ÚS FETA PELS INFORMANTS. Per a fer suar FORMA FARMACĖUTICA I ÚS. Tisana (ús intern). PREPARACIÓ. La flor assecada i en infusió. EFECTES SECUNDARIS. Sí. DESTINACIO. Medicina humana.

Litotríptic renal

FONTS 547, 548, 553, 561, 562, 563, 1322, 1332, 1333, 1334. DESCRIPCIÓ DE L'ÚS FETA PELS INFORMANTS. Per a les pedres de ronyó $(547,548)$. Servia per a desfer les pedres del ronyó $(553)$. Per a les pedres del ronyó $(561,562,563)$. Desfà les pedres de ronyó $(1322$ 1332, 1333, 1334). FORMA FARMACEUTICA I ÚS. Macerat en oli (ús intern). PREPARACIO. Se'n feia un oli. S'agafa l'oli i s'hi posa la ginesta, es deixa a sol i serena com a mínim vuit dies $(547,548)$. Es posava en oli (553). La flor en oli i després d'una novena a a minit vit do sol i ser D'UTILITZACIÓ/POSOLOGIA. S'ha de prendre una cullorada en dejú $(547,548)$. Una D'UTILITZACIOßPOSOLOGIA. Sha de prendre (1322). Una cullo en dejú (547, 548). Una cullerada en dejú fent una novena i descansant (1322). Una cullerada en dejú $(1332,1333$ 1334). DESTINACIÓ. Medicina humana.

\section{Llavor}

Diürètic

FONT 1300. DESCRIPCIÓ DE L'ÚS FETA PER L'INFORMANT. Va molt bé per a orinar FORMA FARMACĖUTICA I ÚS. Tisana (ús intern). PREPARACIÓ. Decocció. La grana es treu de les tavelles quan és seca i es fa aigua. DESTINACIO. Medicina humana.

\section{No consta}

Desconegut per l'informant

FONTS 591 592. FORMA FARMACĖUTICA I ÚS. Desconegut per l'informant. PREPARACIÓ. Se'n feia esperit. DESTINACIÓ. Medicina humana.

\section{ALTRES USOS}

\section{Part aèria}

Artesanal: elaboració d'escombres

FONTS 588, 589. DESCRIPCIÓ DE L'ÚS FETA PELS INFORMANTS. Per a fer escombres (588)

Domèstic: ajudes a la llar

FONTS 591, 592. DESCRIPCIÓ DE L'ÚS FETA PELS INFORMANTS. Agafàvem brimes de ginesta i a sobre hi posàvem les carlines (Carlina acanthifolia subsp. cynara) per a no punxar-nos.

Obtenció de combustible: llenya 
FONTS 1215, 1352. DESCRIPCIÓ DE L'ÚS FETA PELS INFORMANTS. Per a cremar (1215). Ginestes seques servien d'encenalls (1352).

\section{Part aèria florida}

Creences i pràctiques magicoreligioses

FONTS 560, 564, 586, 587, 1352. DESCRIPCIÓ DE L'ÚS FETA PELS INFORMANTS. S'anava a buscar cap a Rocabruna per a fer les catifes [dit "alfombres"] de Corpus (560). De vegades s'anava a buscar a Rocabruna perquè és diferent de la d'aquí, per a fer les catifes [dit "afombres"] de Corpus. La de Rocabruna en diuen gòdua, em sembla (564). Per a guarni les esglésies $(586,587)$. Per a les catifes de Corpus (1352). OBSERVACIONS. A Rocabruna no sé si en diuen gòdua. Una altra observació: per a fer catifes de Corpus s'usava només la flor però de vegades es posaven rams de ginesta florida en petits altars que posaven al carrer el dia de Corpus (564).

Ornamental: elaboració de rams

FONTS 538, 569, 571. DESCRIPCIÓ DE L'ÚS FETA PELS INFORMANTS. Per a fer rams (538).

Tija

Altres informacions

FONT 1215. DESCRIPCIÓ DE L'ÚS FETA PER L'INFORMANT. Per a pegar.

\section{ACCIONS NOCIVES O TÒXIQUES}

Flor

FONTS 539, 540. DESCRIPCIÓ DE L'ACCIÓ NOCIVA O TÒXICA FETA PELS INFORMANTS. És una mica tòxica. VIA D'INTOXICACIÓ. Via interna. TOXICITAT LLIGADA A L'ÚS MEDICINAL. Sí.

\section{ALTRES OBSERVACIONS}

FONTS 561, 562, 563. DESCRIPCIÓ FETA PELS INFORMANTS. Són bones les ginestes de la muntanya, les de cap a Ribes.

\section{Satureja calamintha (L.) Scheele subsp. ascendens (Jord.) Briq. (labiades)}

BCN 24989

\section{NOMS POPULARS}

Hisop (541)

Poliol $(518,519,529,530,531,1298,1313)$
Poniol (507, 509, 510, 511, 512, 513, 514, 515, 516, 539, 540, 553, 588, 746, 748, 749, 753 $754,755,1293,1294,1296,1301,1321,1323,1330,1331,1335,1341,1342,1343,1344$ $1347,1348,1349)$

\section{USOS MEDICINALS}

\section{Part aèria florida}

\section{Anticatarral}

FONTS 515, 516. DESCRIPCIÓ DE L'ÚS FETA PELS INFORMANTS. Per al constipat. FORMA FARMACĖUTICA I ÚS. Tisana (ús intern). PREPARACIÓ. Decocció. DESTINACIÓ. Medicina humana.

Antigripal

FONTS 518, 519. DESCRIPCIÓ DE L'ÚS FETA PELS INFORMANTS. Aigua per al grip. FORMA FARMACĖUTICA I ÚS. Tisana (ús intern). PREPARACIÓ. Decocció. DESTINACIÓ. Medicina humana.

Antiinflamatori intestina

FONTS 553, 1298. DESCRIPCIÓ DE L'ÚS FETA PELS INFORMANTS. Per al mal de ventre o per al mareig. T'ho fa sortir per alt o per baix, va molt bé (553). Per al mal de ventre (1298). FORMA FARMACĖUTICA I ÚS. Tisana (ús intern). PREPARACIÓ. Decocció $(553,1298)$. DESTINACIÓ. Medicina humana.

Antinauseabund

FONT 553. DESCRIPCIÓ DE L'ÚS FETA PER L'INFORMANT. Per al mal de ventre o per al mareig. T'ho fa sortir per alt o per baix, va molt bé. FORMA FARMACĖUTICA I ÚS. Tisana (ús intern). PREPARACIÓ. Decocció. DESTINACIÓ. Medicina humana.

Digestiu

FONTS 507, 509, 510, 511, 512, 513, 514, 529, 530, 531, 746, 748, 749, 1293, 1296, 1331 DESCRIPCIÓ DE L'ÚS FETA PELS INFORMANTS. Digestiva (746). Com a digestiva (507, $509,510)$. Digestiu $(511,512,513,514)$. Per a beure, va bé per a la panxa $(748,749)$. Per al mal d'estómac $(529,530,531)$. Quan et trobes carregat d'estómac (1293). Per a fer pair (1296). Per a pair (1331). FORMA FARMACĖUTICA I ÚS. Tisana (ús intern) $(507,509,510$ $529,530,531,746,748,749,1293,1296,1331)$. Tintura alcohòlica (ús intern) $(511,512$ $513,514)$. PREPARACIÓ. Decocció $(509,510,529,530,531,746,748,749,1293,1296)$. Decoccció (507). El poniol verd florit macerat en aiguardent dolç $(511,512,513,514)$. En infusió (1331). DESTINACIO. Medicina humana.

Diürètic

FONTS 1294, 1335. DESCRIPCIÓ DE L'ÚS FETA PELS INFORMANTS. Fa orinar (1294) Per a fer orinar (1335). FORMA FARMACEUUTICA I ÚS. Tisana (ús intern). PREPARACIO. Decocció (1294). En infusió (1335). DESTINACIO. Medicina humana.

Estomacal 
FONTS 539, 540. DESCRIPCIÓ DE L'ÚS FETA PELS INFORMANTS. Estomacal. FORMA FARMACĖUTICA I ÚS. Tisana (ús intern). PREPARACIÓ. Decocció. DESTINACIÓ. Medicina humana.

Salutifer

FONTS 748, 749, 1323. DESCRIPCIÓ DE L'ÚS FETA PELS INFORMANTS. És una aigua molt bona, me la bec encara que no tingui cap mal $(748,749)$. És molt bo $(1323)$. FORMA FARMACĖUTICA I ÚS. Tisana (ús intern). PREPARACIÓ Decocció $(748,749,1323$ ). MODE D'UTILITZACIÓ/POSOLOGIA. Als matins (1323). DESTINACIÓ. Medicina humana.

Tranquil-litzant

FONTS $588,746,1301,1313,1323,1330,1341,1342,1347,1348,1349$. DESCRIPCIÓ DE L'ÚS FETA PELS INFORMANTS. Per a relaxar quan estàs nerviós (746). És bo per als nervis (588). Per als nervis $(1301,1330,1341,1342,1347,1348,1349)$. Per a tranquil-litzar (1313). T'ajuda a descansar (1323). FORMA FARMACÉUTICA I ÚS. Tisana (ús intern). PREPARACIÓ. Decocció $(588,746,1301,1323,1330)$. En infusió $(1341,1342,1347,1348$ 1349). DESTINACIÓ. Medicina humana.

\section{USOS ALIMENTARIS}

\section{Part aèria florida}

Preparació de begudes - Beguda preparada amb aiguardent

FONTS 588, 1341, 1342. DESCRIPCIÓ DE L'ÚS FETA PELS INFORMANTS. Ratafia. Abans sí que n'havia fet, hi posava 14 o 15 herbes, no me'n recordo de totes. Nous verdes (Juglans regia), farigola (Thymus serpyllum), nou moscada (Myristica fragrans), marialluïsa (Lippia triphylla), menta (Mentha spicata), orenga (Origanum vulgare) i poniol (Satureja calamintha subsp. ascendens) (588). Per a fer ratafia, es confita llor (Laurus nobilis), roman (Rosmarinus officinalis), nous (Juglans regia), granes de ginebró (Juniperus communis), camamilla (Achillea ptarmica subsp. pyrenaica), ortigues (Urtica dioica), pela de taronja (Citrus sinensis), pela de llimona (Citrus limon), canyella (Cinnamomum zeylanicum), marialluisa (Lippia triphylla), poniol (Satureja calamintha subsp. ascendens), rosa de bosc (Rosa tome (Lsa) i malva (Mava sylvestris) en aiguardent i s deixa 40 dies a soli a sero (Rosa tomentosa) i malva (Malva sylve 1342). DESTINACIÓ. Alimentació humana $(588,1341$ 1342).

\section{ALTRES OBSERVACIONS}

FONTS 541, 1296. DESCRIPCIÓ FETA PELS INFORMANTS. Una dona de Sant Quirze, que vivia allà a Ribes, en deia hisop (541). En té plantat a l'hort (1296).

\section{BARREGES AMB AQUEST TÀXON}

\section{Part aèria florida}

FONTS 1343, 1344. Entrevista 23, barreja III (vegeu catàleg de barreges)

FONTS $753,754,755$. Entrevista 67, barreja VIII (vegeu catàleg de barreges)
Satureja fruticosa (L.) Briq. (labiades)

\section{BCN 123790}

\section{USOS MEDICINALS}

\section{Part aèria}

Per a l'afonia

FONT 1215. DESCRIPCIÓ DE L'ÚS FETA PER L'INFORMANT. Per al rogall. FORMA FARMACĖUTICA I ÚS. Tisana (ús intern). DESTINACIÓ. Medicina humana. OBSERVACIONS. Ho receptava la curandera.

\section{Satureja hortensis L. (labiades)}

\section{BCN 29945}

\section{NOMS POPULARS}

Sajolida $(504,507,509,510,511,512,513,514,522,523,524,746,1324,1336)$

\section{USOS ALIMENTARIS}

\section{Part aèria florida}

Condiment

FONTS 504, 507, 509, 510, 511, 512, 513, 514, 522, 523, 524, 746, 1324, 1336 DESCRIPCIO DE L'ÚS FETA PELS INFORMANTS. Per a cuinar (504). Per a donar gust als cuinats $(746)$. Per a fer l'escabetx de les sardines $(507,509,510)$. Per a posar als rostits $(511,512,513,514)$. Per a donar gust $(522,523)$. Els francesos en posen a les conserves d'olives, jo no l'he fet servir mai (524). Per a donar gust als caragols (1324). Per a cuinar caragols (1336). DESTINACIÓ. Alimentació humana $(504,507,509,510,511,512,513,514$ $522,523,524,746,1324,1336)$.

\section{ALTRES OBSERVACIONS}

FONT 1336. DESCRIPCIÓ FETA PER L'INFORMANT. En té plantada a l'hort.

\section{Satureja montana L. (labiades)}

BCN 113741

NOMS POPULARS 
Sajolida $(520,521,528,538,545,546,547,548,553,569,570,580,581,583,584,585)$

\section{USOS MEDICINALS}

\section{No consta}

Desconegut per l'informant

FONT 538. FORMA FARMACĖUTICA I ÚS. Desconegut per l'informant. OBSERVACIONS. Me n'han parlat, però no recordo per a què va bé.

\section{Part aèria florida}

Antiàlgic ciàtic

FONT 545. DESCRIPCIÓ DE L'ÚS FETA PER L'INFORMANT. És bona per a la ciàtica [dit "asiàtica"]. FORMA FARMACĖUTICA I ÚS. Liniment (ús extern). PREPARACIÓ. Fer-la bullir en oli. DESTINACIÓ. Medicina humana.

Digestiu

FONT 553. DESCRIPCIÓ DE L'ÚS FETA PER L'INFORMANT. Ajuda la digestió. FORMA FARMACĖUTICA I ÚS. Tisana (ús intern). PREPARACIÓ. Decocció. DESTINACIÓ. Medicina humana.

\section{USOS ALIMENTARIS}

\section{Part aèria florida}

Condiment

FONTS 520, 521, 528, 545, 546, 553, 569, 570, 580, 581, 583, 584, 585. DESCRIPCIÓ DE L'ÚS FETA PELS INFORMANTS. Per a posar als guisats (545). Per als estofats (546). Per a condiment $(520,521)$. Per a posar als cuinats (528). Per a confitar les olives (553). Per a confitar olives $(569,570)$. Es fa servir per a cuinar $(580)$. Es fa servir per a condimentar $(581)$. Es posava a la xocolata, és molt aromàtica $(583,584,585)$. OBSERVACIONS. A casa no la fem servir (581). DESTINACIÓ. Alimentació humana (520, 521, 528, 545, 546, 553, 569, 570, $580,581,583,584,585)$.

\section{BARREGES AMB AQUEST TÀXON}

Part aèria florida

FONTS 547, 548. Entrevista 73, barreja I (vegeu catàleg de barreges)

\section{Saxifraga geranioides L. (saxifragàcies)}

BCN 24991

\section{NOMS POPULARS}

Herba de les set sagnies (1300)

\section{USOS MEDICINALS}

\section{Part aèria}

Antihipertensiu

FONT 1300. DESCRIPCIÓ DE L'ÚS FETA PER L'INFORMANT. Li han dit que fa baixar molt la pressió. S'ha de tenir cura. FORMA FARMACĖUTICA I ÚS. Tisana (ús intern). PREPARACIÓ. Decocció. MODE D'UTILITZACIO/POSOLOGIA. Ell se'n prenia set dies un got al matí, sobretot a la primavera. DESTINACIÓ. Medicina humana. OBSERVACIONS. Aquesta planta, els la baixava el vaquer de Rojà

Hematocatàrtic

FONT 1300. DESCRIPCIÓ DE L'ÚS FETA PER L'INFORMANT. Purifica molt la sang. S'ha de tenir cura. FORMA FARMACEUUTICA I ÚS. Tisana (ús intern). PREPARACIÓ. Decocció. MODE D'UTILITZACIÓ/POSOLOGIA. Ell se'n prenia set dies un got al matí, sobretot a la primavera. DESTINACIÓ. Medicina humana. OBSERVACIONS. Aquesta planta, els la baixava el vaquer de Rojà.

\section{ALTRES OBSERVACIONS}

FONT 1300. DESCRIPCIÓ FETA PER L'INFORMANT. N'hi ha molt poca i poca gent la coneix, n'hi ha a les esquerdes de Rojà.

\section{Saxifraga longifolia Lap. subsp. longifolia (saxifragàcies)}

BCN 123791

\section{NOMS POPULARS}

Corona de rei $(511,512,513,514,520,521,522,523,539,540,547,548,559,560,564$ $569,570,571,572,573,583,584,585,590,591,592,748,749,750,1213,1214,1321)$

\section{USOS MEDICINALS}

Fulla

Coadjuvant del postpart

FONTS 1213, 1214. DESCRIPCIÓ DE L'ÚS FETA PELS INFORMANTS. Aquesta planta es feia servir per a fer expulsar la placenta de les bèsties que acabaven de parir. Generalment era utilitzada per a les vaques $(1213,1214)$. FORMA FARMACEUTICA I US. Tisana (ús intern). PREPARACIÓ. Decocció. En un perol es posava una mica de corona de rei, la part de les fulles, i segó. Es barrejava tot ben barrejat amb aigua i es donava a l'animal (1213, 1214). DESTINACIÓ. Medicina veterinària (1214). Medicina humana (1213).

\section{No consta}

Abortiu 
FONTS 511, 512, 513, 514. DESCRIPCIÓ DE L'ÚS FETA PELS INFORMANTS. És abortiva. FORMA FARMACĖUTICA I ÚS. Desconegut per l'informant. DESTINACIÓ. Medicina humana.

Desconegut per l'informant

FONTS 591, 592. FORMA FARMACĖUTICA I ÚS. Desconegut per l'informant. DESTINACIÓ. Medicina humana. OBSERVACIONS. No recordo per a què s'utilitzava, però sí que a casa n'hi havia.

\section{Part aèria}

Abortiu

FONTS 522, 523, 748, 749. DESCRIPCIÓ DE L'ÚS FETA PELS INFORMANTS. Quan les ovelles avortaven, les ajudava a acabar d'avortar $(748,749)$. Una noia en va prendre per a avortar i li va sortir bé, però no saps el que va patir $(522,523)$. FORMA FARMACĖUTICA ÚS. Tisana (ús intern) $(748,749)$. Desconegut per l'informant $(522,523)$. PREPARACIÓ Decocció $(748,749)$. DESTINACIÓ. Medicina veterinària $(748,749)$. Medicina humana $(522$, 523).

Coadjuvant del part

FONTS 522, 523. DESCRIPCIÓ DE L'ÚS FETA PELS INFORMANTS. Per al bestiar quan no podia parir o per a una vaca que no acabi de quedar neta. FORMA FARMACĖUTICA I ÚS. Desconegut per l'informant. DESTINACIO. Medicina veterinària.

Coadjuvant del postpart

FONTS 520, 521, 571, 572, 573, 583, 584, 585, 590. DESCRIPCIÓ DE L'ÚS FETA PELS INFORMANTS. Per a netejar el bestiar quan ha parit, I'última vegada que en van veure va ser al Pedraforca $(520,521)$. Es feia aigua de la planta per a netejar les bèsties quan havien parit (571). Se'Is donava a les vaques per a quan havien vedellat (590). Per a les vaques quan no feien els llits, se'ls donava aigua $(572,573)$. Per a les ovelles que no podien fer la placenta $(583,584,585)$. FORMA FARMACEUTICA I ÚS. Bany (ús extern) $(520,521)$. Tisana (ús intern) $(571,572,573,583,584,585,590)$. PREPARACIÓ Decocció $(520,521,571,572$ $573,583,584,585,590)$. DESTINACIÓ. Medicina veterinària.

\section{ALTRES USOS}

Planta viva ex situ

Ornamental: jardineria

FONT 564. DESCRIPCIÓ DE L'ÚS FETA PER L'INFORMANT. En tinc a l'hort per a fer bonic.

\section{ACCIONS NOCIVES O TÒXIQUES}

\section{No consta}

FONTS 520, 521, 539, 540, 547, 548, 559, 560, 572, 573. DESCRIPCIÓ DE L'ACCIO NOCIVA O TOXICA FETA PELS INFORMANTS. És abortiva $(520,521,539,540,572,573)$ És abortiva per al bestiar i les persones $(547,548)$. Abortiva $(559)$. Deien que feia avortar les dones (560). TOXICITAT EN ANIMALS. Sí $(547,548)$.

\section{BARREGES AMB AQUEST TÀXON}

Fulla

FONT 1321. Entrevista 37, barreja I (vegeu catàleg de barreges)

FONT 1321. Entrevista 37, barreja II (vegeu catàleg de barreges)

Part aèria

FONT 750. Entrevista 50, barreja II (vegeu catàleg de barreges)

Part aèria florida

FONTS 583, 584, 585. Entrevista 96, barreja III (vegeu catàleg de barreges)

\section{Saxifraga paniculata Mill. (saxifragàcies)}

BCN 24992

\section{NOMS POPULARS}

Corona de rei $(541,549,553,753,754,755,1310,1319,1327,1328,1329,1350,1351)$

\section{USOS MEDICINALS}

\section{No consta}

Desconegut per l'informant

FONT 549. FORMA FARMACĖUTICA I ÚS. Desconegut per l'informant. DESTINACIÓ. Medicina veterinària. OBSERVACIONS. Era per al bestiar, però no recordo per a què.

\section{Part aèria}

Abortiu

FONTS $541,753,754,755,1319,1327,1350,1351$. DESCRIPCIÓ DE L'ÚS FETA PELS INFORMANTS. Per a avortar $(541,1350,1351)$. És abortiva $(753,754,755,1327)$. Diu que les dones ho feien servir per a avortar (1319). FORMA FARMACĖUTICA I ÚS. Tisana (ús intern) $(541,753,754,755,1327,1350,1351)$. Desconegut per l'informant (1319). PREPARACIÓ Decocció $(541,753,754,755,1327,1350,1351)$. DESTINACIÓ. Medicina humana. OBSERVACIONS. No ho recordo gaire (1319).

Antiinflamatori intestinal

FONT 1310. DESCRIPCIÓ DE L'ÚS FETA PER L'INFORMANT. Per al mal de ventre. FORMA FARMACĖUTICA I ÚS. Tisana (ús intern). PREPARACIÓ. Decocció. DESTINACIÓ. Medicina humana.

Coadjuvant del postpart

FONTS 1310, 1328, 1329. DESCRIPCIÓ DE L'ÚS FETA PELS INFORMANTS. Per a ajudar el bestiar a fer les despulles. FORMA FARMACĖUTICA I ÚS. Tisana (ús intern). PREPARACIÓ. Decocció. DESTINACIÓ. Medicina veterinària. 


\section{ACCIONS NOCIVES O TÒXIQUES}

\section{No consta}

FONT 553. DESCRIPCIÓ DE L'ACCIÓ NOCIVA O TÒXICA FETA PER L'INFORMANT. És abortiva.

\section{ALTRES OBSERVACIONS}

FONT 549. DESCRIPCIÓ FETA PER L'INFORMANT. N'hi havia a Roc del Corb.

\section{Scabiosa columbaria L. (dipsacàcies)}

\section{BCN 24993}

\section{NOMS POPULARS}

Escabiosa $(505,506,520,521,524,525,526,527,529,530,531,539,540,541,549,553$ $572,573,583,584,585,588,590,591,592,1215,1293,1301,1313,1314,1318,1331$ $1339,1340,1343,1344,1345,1346,1347,1348,1349,1353,1354,1352)$

Herba d'escabiosa $(529,530,531,1300)$

\section{USOS MEDICINALS}

\section{Part aèria}

Per a trastorns del sistema immunitar

FONT 1215. DESCRIPCIÓ DE L'ÚS FETA PER L'INFORMANT. Per a la rubèola. FORMA FARMACĖUTICA I ÚS. Tisana (ús intern). PREPARACIÓ. Decocció. DESTINACIÓ. Medicina humana. OBSERVACIONS. S'utilitza la de la fulla dividida.

Per al xarampió

FONTS $1215,1293,1300,1301$. DESCRIPCIÓ DE L'ÚS FETA PELS INFORMANTS. Per al xarampió (1215). Per a fer sortir els grans de la rosa a la mainada $(1293,1300,1301)$. FORMA FARMACĖUTICA I ÚS. Tisana (ús intern). PREPARACIÓ. Decocció (1215, 1300 1301). Decocció. Aigua de tota la planta (1293). MODE D'UTILITZACIÓ/POSOLOGIA. Set o nou dies d'escapiosa. Sempre les herbes es prenen en cicles de dies senars (1300) DESTINACIÓ. Medicina humana. OBSERVACIONS. S'utilitza la de la fulla dividida (1215).

\section{Part aèria florida}

\section{Antidiftèric}

FONT 1314. DESCRIPCIÓ DE L'ÚS FETA PER L'INFORMANT. Per a curar la distenta. FORMA FARMACEUTICAIUUS. Tisana (ús intern). PREPARACIO. Decocció. DESTINACIO. Medicina humana.

Antipirètic
FONTS 539, 540. DESCRIPCIÓ DE L'ÚS FETA PELS INFORMANTS. Per a fer baixar la Tisana (ús intern). PREPARACIÓ. Decocció. DESTINACIÓ. Medicina humana.

Antisèptic ocular

FONTS 539, 540. DESCRIPCIÓ DE L'ÚS FETA PELS INFORMANTS. Per als ulls. FORMA FARMACĖUTICA I ÚS. Bany (ús extern). PREPARACIÓ. Decocció. DESTINACIÓ. Medicina humana.

\section{Hematocatàrtic}

FONTS 572, 573, 591, 592. DESCRIPCIÓ DE L'ÚS FETA PELS INFORMANTS. Per a netejar la sang. Vaig tenir una vegada un vesper, que em van dir que et surt perquè tens la sang bruta. Em va anar molt bé, tenia la sang ben negra i després de fer el remei, la sang es va tornar ben vermella $(572,573)$. És depurativa. Es donava a la canalla quan estaven tapats i els sortien grans a la cara i erupcions $(591,592)$. FORMA FARMACĖUTICA I ÚS. Tisana i els sortien grans a la cara i erupcions $(591,592)$. FORMA FARMACEUTICA US. Tisana
(ús intern). PREPARACIÓ. Decocció (572, 573, 591, 592). MODE D'UTILITZACIÓ/POSOLOGIA. Una tasseta al matí $\mathrm{i}$ una altra al vespre $(572,573)$. DESTINACIÓ. Medicina humana.

Per a la sarna

FONTS 525, 526, 527, 1343, 1344. DESCRIPCIÓ DE L'ÚS FETA PELS INFORMANTS. Per al socarró dels porcs (se'ls feien unes escates, és com una ronya) $(525,526,527)$. Per a rentar la ronya dels godalls $(1343,1344)$. FORMA FARMACĖUTICA I ÚS. Sense forma farmacèutica (ús directe, ús extern) $(525,526,527)$. Bany (ús extern) $(1343,1344)$. PREPARACIÓ. Se li frega la planta directament $(525,526,527)$. Decocció $(1343,1344)$. DESTINACIÓ. Medicina veterinària.

Per a la varicel.la

FONT 1331. DESCRIPCIÓ DE L'ÚS FETA PER L'INFORMANT. Per a fer sortir els grans de la varicel·la. FORMA FARMACĖUTICA I ÚS. Tisana (ús intern). PREPARACIÓ. Decocció. DESTINACIO. Medicina humana.

Per a trastorns del sistema immunitari

FONTS 505, 506, 549, 553, 588, 590. DESCRIPCIÓ DE L'ÚS FETA PELS INFORMANTS Rubèola. Per a la canalla quan tenen la rosa $(505,506)$. Rubèola. Per a la rosa i el xarampió (549). Rubèola. Te la donaven quan a la canalla els sortia la rosa (553). Rubèola. Quan tenies la rosa et banyaven les flors que et sortien amb aquesta aigua (588). Rubèola. Per a la mainada quan tenien la rosa (590). FORMA FARMACEUTICA I US. Tisana (ús intern) (505, $506,549,553,590)$. Bany (ús extern) (588). PREPARACIÓ. Decocció (505, 506, 549, 553 , $588,590)$. DESTINACIO. Medicina humana. OBSERVACIONS. La mare ens posava una peça vermella a l'habitació (549).

Per al xarampió

FONTS 520, 521, 524, 529, 530, 531, 541, 549, 572, 573, 583, 584, 585, 1313, 1318, 1339 , 1340, 1345, 1346, 1347, 1348, 1349, 1352, 1353, 1354. DESCRIPCIÓ DE L'ÚS FETA PELS INFORMANTS. Per al xarampió $(529,530,531,541,572,573,583,584,585,1352)$. Per a aquestes malalties dels grans de la canalla (524). Per a la mainada quan tenien el xarampió $(520,521)$. Per a la rosa i el xarampió $(549)$. Per a fer sortir els grans del xarampió (1313, 
1318). Per a fer sortir els grans de la rosa a la canalla $(1339,1340)$. Per a fer sortir els grans de la rosa $(1345,1346,1347,1348,1349,1353,1354)$. FORMA FARMACĖUTICA I ÚS Tisana (ús intern). PREPARACIÓ. Decocció $(520,521,524,529,530,531,541,549,572$, $573,583,584,585,1313,1318,1339,1340,1345,1346,1347,1348,1349)$. DESTINACIÓ. Medicina humana. OBSERVACIONS. La mare quan baixava a portar la llet hi havia dones Medicina humana. OBSERVACIONS. La mare quan baixava a portar la llet hi havia dones que li deien: "em portaries herba d'escabiosa?" (524). La mare ens posava una peça vermella $(1352)$

\section{BARREGES AMB AQUEST TÀXON}

Part aèria florida

FONTS 529, 530, 531. Entrevista 53, barreja X (vegeu catàleg de barreges)

\section{Scrophularia nodosa L. (escrofulariàcies)}

BCN 8020

\section{NOMS POPULARS}

Setge $(505,506)$

\section{USOS MEDICINALS}

\section{No consta}

Vulnerari

FONTS 505, 506. DESCRIPCIÓ DE L'ÚS FETA PELS INFORMANTS. Es posava a sobre les ferides. FORMA FARMACĖUTICA I ÚS. Sense forma farmacèutica (ús directe, ús extern). DESTINACIÓ. Medicina humana.

\section{ALTRES USOS}

\section{Planta sencera}

Literatura oral popular: llegendes, gloses, contes, dites, refranys, poemes, cançons FONTS 505, 506. DESCRIPCIÓ DE L'ÚS FETA PELS INFORMANTS. La setge no ha de menester el metge.

\section{ALTRES OBSERVACIONS}

FONTS 505, 506. DESCRIPCIÓ FETA PELS INFORMANTS. Planta que es fa a prop dels horts. Semblant a la pota de cavall, però és ben llisa. De color verd, fa un espigot a dalt, és força alta i fa mala olor.

\section{Secale cereale L. (gramínies)}

BCN 27243

\section{NOMS POPULARS}

Mestall (589)

Sègle $(541,569,570,589,1352)$

\section{USOS ALIMENTARIS}

\section{Llavor}

Ingestió de la part de la planta crua - Fresca (sense preparació)

FONT 589. DESCRIPCIÓ DE L'ÚS FETA PER L'INFORMANT. Es donava al bestiar. OBSERVACIONS. Es barrejaven granes de blat i sègle $\mathrm{i}$ el que sortia era mestall. DESTINACIÓ. Alimentació animal.

\section{Part aèria}

Ingestió de la part de la planta crua - Conservada dessecada a l'aire

FONTS 569, 570, 589. DESCRIPCIÓ DE L'ÚS FETA PELS INFORMANTS. Es fa com farratge $(569,570)$. Menjar per al bestiar (589). DESTINACIÓ. Alimentació animal $(569,570$, 589)

\section{ALTRES USOS}

\section{Llavor}

Maneig agrosilvopastoral: ús en la matança del porc, com a conservant

FONT 1352. DESCRIPCIÓ DE L'ÚS FETA PER L'INFORMANT. Per a conservar les llonganisses. S'emplenava un calaix d'aquells grossos de les cases amb gra de sègle i les llonganisses s'hi posaven per damunt.

Tija

Lúdic: jocs i joguines

FONT 1352. DESCRIPCIÓ DE L'ÚS FETA PER L'INFORMANT. Les tiges, les tallàvem i en èiem xiulanys.

\section{Sedum album L. (crassulàcies)}

BCN 47680

\section{NOMS POPULARS}

Arròs de paret $(541,553,578,579,1213,1214)$ 


\section{USOS MEDICINALS}

\section{Part aèria}

Antipiròtic

FONTS 578, 579, 1213, 1214. DESCRIPCIÓ DE L'ÚS FETA PELS INFORMANTS. Per a les cremades $(578,579)$. Per a les cremades, es frega la planta directament per sobre la pell i és refrescant $(1213,1214)$. FORMA FARMACĖUTICA I ÚS. Sense forma farmacèutica (ús directe, ús extern). PREPARACIÓ. S'aixafava la part aèria $i$ es posava on t'havies fet la cremada $(578,579)$. DESTINACIÓ. Medicina humana.

Antipruriginós

FONTS 1213, 1214. DESCRIPCIÓ DE L'ÚS FETA PELS INFORMANTS. Per a les ortigades. FORMA FARMACĖUTICA I ÚS. Sense forma farmacèutica (ús directe, ús extern) DESTINACIÓ. Medicina humana.

\section{ALTRES USOS}

\section{Part aèria}

Lúdic: jocs i joguines

FONTS 1213, 1214. DESCRIPCIÓ DE L'ÚS FETA PELS INFORMANTS. La canalla del poble, quan érem petits, utilitzàvem aquesta planta per a jugar a cuinetes.

\section{BARREGES AMB AQUEST TÀXON}

\section{Part aèria}

FONTS 1213, 1214. Entrevista 102, barreja I (vegeu catàleg de barreges)

FONT 553. Entrevista 77, barreja III (vegeu catàleg de barreges)

\section{Sedum dasyphyllum L. (crassulàcies)}

BCN 24994

\section{NOMS POPULARS}

Arròs de bruixes (1300)

Arròs de paret $(505,506,511,512,513,514,522,523,528,529,530,531,535,538,552$, $553,560,564,582,590)$

Herba d'arròs $(547,548)$

\section{USOS MEDICINALS}

\section{Part aèria}

Antiinflamatori intestinal
FONTS 522, 523. DESCRIPCIÓ DE L'ÚS FETA PELS INFORMANTS. Per als mals de ventre. FORMA FARMACĖUTICA I ÚS. Tisana (ús intern). PREPARACIÓ. Decocció. DESTINACIÓ. Medicina humana.

Antipruriginós

FONTS $511,512,513,514,529,530,531,548,552$. DESCRIPCIÓ DE L'ÚS FETA PELS INFORMANTS. Urticària: "Per a fregar-te quan t'ortigues, et treu aquella urticària" $(511,512$, $513,514)$. Per a les ortigades [dit "urtrigades"] $(529,530,531)$. Per a quan t'ortigues, fregart'ho amb l'arròs (552). Per a les ortigades (548). FORMA FARMACEUUTICA I ÚS. Sense forma farmacèutica (ús directe, ús extern). PREPARACIÓ. Fregar-se amb la planta (511, $512,513,514)$. T'has de fregar $(529,530,531)$. DESTINACIÓ. Medicina humana.

Antitífic

FONTS 505, 506. DESCRIPCIÓ DE L'ÚS FETA PELS INFORMANTS. La meva germana va tenir tifus [dit "els tífols"] i li feien emplastres d'aquesta planta. FORMA FARMACĖUTICA I ÚS. Emplastre (ús extern). PREPARACIÓ. S'aixafava aprofitant tot el suc i es posava en un drap a sobre la panxa. DESTINACIÓ. Medicina humana.

Per a la irritació

FONT 547. DESCRIPCIÓ DE L'ÚS FETA PER L'INFORMANT. Per a les ortigades. FORMA FARMACĖUTICA I ÚS. Sense forma farmacèutica (ús directe, ús extern). DESTINACIÓ. Medicina humana.

\section{Per a les picades}

FONTS 547, 548. DESCRIPCIÓ DE L'ÚS FETA PELS INFORMANTS. Per a les picades. FORMA FARMACĖUTICA I ÚS. Sense forma farmacèutica (ús directe, ús extern). DESTINACIÓ. Medicina humana.

\section{USOS ALIMENTARIS}

\section{Part aèria}

Ingestió de la part de la planta crua - Fresca (sense preparació)

FONTS 538, 560, 564. DESCRIPCIÓ DE L'ÚS FETA PELS INFORMANTS. Es donava als polls quan eren petits (538). Agradava molt a les gallines (560). Per a les gallines (564). DESTINACIÓ. Alimentació animal $(538,560,564)$

\section{ALTRES USOS}

\section{Part aèria}

Artesanal: elaboració de joguines

FONT 528. DESCRIPCIÓ DE L'ÚS FETA PER L'INFORMANT. Quan érem canalla hi jugàvem.

Lúdic: jocs i joguines

FONT 590. DESCRIPCIÓ DE L'ÚS FETA PER L'INFORMANT. Per a jugar a cuinetes quan érem nens. 


\section{Planta viva ex situ}

Ornamental: jardineria

FONT 535. DESCRIPCIÓ DE L'ÚS FETA PER L'INFORMANT. Fa bonic a la casa.

\section{BARREGES AMB AQUEST TÀXON}

\section{Part aèria}

FONT 1300. Entrevista 8, barreja II (vegeu catàleg de barreges)

FONT 582. Entrevista 95 (vegeu catàleg de barreges)

\section{Sedum sp. (crassulàcies)}

\section{NOMS POPULARS}

Arròs de paret $(580)$

Arròs de paret petit (564)

\section{Sedum telephium L. subsp. maximum (L.) Krock.} (crassulàcies)

BCN 24995

\section{NOMS POPULARS}

Arròs de paret $(1298,1328,1329)$

Bàlsam $(520,521,1299)$

Bàlsam de paret $(583,584,585)$

Fava grassa $(1213,1214)$

Herba grassa $(1332,1333,1334)$

Matafoc $(524,535,591,592,748,749,1293,1343,1344)$

\section{USOS MEDICINALS}

Fulla

Antifúngic

FONTS 591, 592, 1293, 1343, 1344. DESCRIPCIÓ DE L'ÚS FETA PELS INFORMANTS. Per a matar els brians. És molt efectiu $(591,592)$. Per a curar els brians, tant per al bestiar com per a les persones (1293). S'usa per a untar els brians tant a les persones com als animals $(1343,1344)$. FORMA FARMACĖUTICA I ÚS. Emplastre (ús extern) $(591,592)$. Embrocació (ús extern) (1293). Pomada (ús extern) $(1343,1344)$. PREPARACIÓ. S'ha de sofregir en oli i (591, 592). Es foia bulir (591, 592). Es fela bulir la planta en fins que quedi com una pomada $(1343,1344)$. DES Medicina humana i veterinària $(1293,1343,1344)$

Antiinflamatori

FONTS 1328, 1329. DESCRIPCIÓ DE L'ÚS FETA PELS INFORMANTS. Fa baixar molt la inflor quan t'has fet mal. FORMA FARMACĖUTICA I ÚS. Liniment (ús extern).

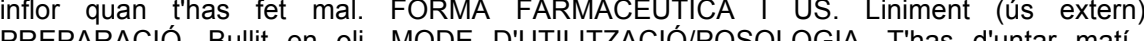
PREPARACIO. Bullí en oli. MODE DUUTILITZACIOPOSOLOGIA. Thas d'untar matí vespre. DESTINACIÓ. Medicina humana. OBSERVACIONS. Li va passar una roda sobre el peu i s'hi va fer aquesta cura.

Antipiròtic

FONTS 520, 521. DESCRIPCIÓ DE L'ÚS FETA PELS INFORMANTS. Per a les cremades. FORMA FARMACĖUTICA I ÚS. Desconegut per l'informant. DESTINACIÓ. Medicina FORMA
humana.

Vulnerari

FONTS 583, 584, 585, 1299. DESCRIPCIÓ DE L'ÚS FETA PELS INFORMANTS. La fulla és refrescant $(583,584,585)$. Per a les ferides (1299). FORMA FARMACE்UTICA I ÚS. Sense forma farmacèutica (ús directe, ús intern) $(583,584,585)$. Sense forma farmacèutica (ús directe, ús extern) (1299). PREPARACIÓ. La part carnosa de la fulla es posa directament (1299). DESTINACIÓ. Medicina humana.

\section{No consta}

Desconegut per l'informant

FONTS 748, 749, 1298. DESCRIPCIÓ DE L'ÚS FETA PELS INFORMANTS. No en conec I'ús $(748,749)$. FORMA FARMACĖUTICA I ÚS. Desconegut per l'informant. OBSERVACIONS. Recorda que hi havia un metge de Ripoll que comprava arròs de paret $\mathrm{i}$ en feia un oli que després venia com a medicinal etiquetat i que tenia molta fama (1298).

\section{Suc de la fulla}

Vulnerari

FONTS 1332, 1333, 1334. DESCRIPCIÓ DE L'ÚS FETA PELS INFORMANTS. Directament sobre la ferida. FORMA FARMACĖUTICA I ÚS. Sense forma farmacèutica (ús directe, ús extern). DESTINACIÓ. Medicina humana.

\section{ALTRES USOS}

\section{Planta viva ex situ}

Ornamental: jardineria

FONT 535. DESCRIPCIÓ DE L'ÚS FETA PER L'INFORMANT. Fan bonic.

\section{ALTRES OBSERVACIONS}


FONT 524. DESCRIPCIÓ FETA PER L'INFORMANT. Aquí fora n'hi ha molts.

\section{BARREGES AMB AQUEST TÀXON}

Part aèria

FONTS 1213, 1214. Entrevista 102, barreja VI (vegeu catàleg de barreges)

\section{Sempervivum arachnoideum L. (crassulàcies)}

\section{BCN 26422}

\section{NOMS POPULARS}

Vel de núvia (569)

\section{ALTRES USOS}

Planta viva ex situ

Ornamental: jardineria

FONTS 569, 570. DESCRIPCIÓ DE L'ÚS FETA PELS INFORMANTS. Plantada en un test.

\section{Sempervivum montanum L. (crassulàcies)}

BCN 24996

\section{NOMS POPULARS}

Matafoc (587)

\section{ALTRES OBSERVACIONS}

FONT 587. DESCRIPCIÓ FETA PER L'INFORMANT. Per aquí dalt n'hi ha.

\section{Sempervivum tectorum L. (crassulàcies)}

BCN 24997

\section{NOMS POPULARS}

Matafoc $(507,509,510,553,554,555,569,570,578,579,586)$

Matafoc de muntanya (1322)

Sempervívum (541)
Sempreviva (1324)

Te de roca (1321)

USOS MEDICINALS

Fulla

Antisèptic extern

FONT 1324. DESCRIPCIÓ DE L'ÚS FETA PER L'INFORMANT. Quan et fas un tall, te'l fregues amb una fulla d'aquesta planta fent sortir el suc; ho desinfecta molt. FORMA FARMACĖUTICA I ÚS. Sense forma farmacèutica (ús directe, ús extern). DESTINACIÓ. Medicina humana.

Part aèria

Antifúngic

FONT 1322. DESCRIPCIÓ DE L'ÚS FETA PER L'INFORMANT. Per a curar els brians del bestiar. FORMA FARMACĖUTICA I ÚS. Embrocació (ús extern). PREPARACIÓ. Bullit en oli. DESTINACIÓ. Medicina veterinària.

Antipiròtic

FONTS 507, 509, 510, 578, 579. DESCRIPCIÓ DE L'ÚS FETA PELS INFORMANTS. Per a les cremades $(507,509,510,578,579)$. FORMA FARMACĖUTICA I ÚS. Emplastre (ús PXEPARACIÓ. Preparar un emplastre aixafant i posant sobre un drap $(507,500,510)$. PREPTINACIÓ. Medicina humana.

\section{ALTRES USOS}

\section{Planta viva ex sit}

Ornamental: jardineria

FONTS 541, 569, 570. DESCRIPCIÓ DE L'ÚS FETA PELS INFORMANTS. Els cullen i els planten als testos (541). Plantada en un test $(569,570)$

ALTRES OBSERVACIONS

FONT 586. DESCRIPCIÓ FETA PER L'INFORMANT. Per aquí dalt n'hi ha.

\section{BARREGES AMB AQUEST TÀXON}

\section{Part aèria}

FONTS 554, 555. Entrevista 78, barreja IV (vegeu catàleg de barreges)

Senecio leucophyllus DC. (compostes)

BCN 24998 


\section{NOMS POPULARS}

Herba blanca $(511,512,513,514,529,530,531,533,534,538,539,540,541,552,554$ $555,556,557,559,571,591,592,753,754,755,1294,1296,1300,1310,1313,1314,1317$ $1321,1331,1341,1342,1343,1344,1347,1348,1349,1350,1351,1352,1361,1362)$

\section{USOS MEDICINALS}

\section{No consta}

Desconegut per l'informant

FONT 1300. FORMA FARMACĖUTICA I ÚS Desconegut per l'informant DESTINACIÓ. Medicina humana. OBSERVACIONS. És molt bona, però no recordo per a què anava bé

\section{Part aèria florida}

Anticatarral

FONTS $591,592,753,754,755,1296,1314,1321,1343,1344,1350,1351$. DESCRIPCIÓ DE L'ÚS FETA PELS INFORMANTS. Per als constipats $(753,754,755,1296,1343,1344)$ Per als refredats $(591,592,1350,1351)$. Per als refredats de sang (el de mal de coll, però que no estàs tapat de pit) (1314). Per a constipats, destapa molt (1321). FORMA FARMACĖUTICA I ÚS. Tisana (ús intern). PREPARACIÓ. Decocció (591, 592, 753, 754 $755,1296,1314,1321,1343,1344,1350,1351)$. DESTINACIÓ. Medicina humana. OBSERVACIONS. És millor que l'orella d'ós (Ramonda myconi) (1296).

Antihipertensiu

FONTS 511, 512, 513, 514, 533, 534, 552, 559, 1294, 1313, 1317, 1321, 1341, 1342, 1347 $1348,1349,1352,1361,1362$. DESCRIPCIO DE L'US FETA PELS INFORMANTS. Per a fer baixar la pressió $(511,512,513,514,533,534,1294,1313,1321,1347,1348,1349,1352$ $1361,1362)$. Rebaixa la pressió $(552)$. Per a rebaixar la sang $(559,1317,1341,1342)$. FORMA FARMACĖUTICA I ÚS. Tisana (ús intern). PREPARACIÓ. Decocció $(511,512,513$ $514,533,534,552,559,1294,1313,1321,1361,1362)$. En infusió $(1341,1342,1347,1348$ 1349). MODE D'UTILITZACIÓ/POSOLOGIA. Una novena (1313). DESTINACIÓ. Medicina humana.

Antiinflamatori intestinal

FONT 1310. DESCRIPCIÓ DE L'ÚS FETA PER L'INFORMANT. Per al mal de ventre. FORMA FARMACĖUTICA I ÚS. Tisana (ús intern). DESTINACIÓ. Medicina humana.

Antipelohèmic

FONTS 538, 571. DESCRIPCIÓ DE L'ÚS FETA PELS INFORMANTS. Per a aclarir la sang (538). Per a aclarir i purificar la sang (571). FORMA FARMACĖUTICA I Ús. Tisana (ús intern). PREPARACIÓ. Decocció $(538,571)$. DESTINACIÓ. Medicina humana.

Coadjuvant del postpart

FONTS 539, 540. DESCRIPCIÓ DE L'ÚS FETA PELS INFORMANTS. Per a ajudar a fer els llits a les vaques. FORMA FARMACĖUTICA I ÚS. Tisana (ús intern). PREPARACIÓ. Decocció. DESTINACIÓ. Medicina veterinària.
Hematocatàrtic

FONT 571. DESCRIPCIÓ DE L'ÚS FETA PER L'INFORMANT. Per a aclarir i purificar la sang. FORMA FARMACĖUTICA I ÚS. Tisana (ús intern). PREPARACIÓ. Decocció. DESTINACIÓ. Medicina humana.

Protector renal

FONT 1296. DESCRIPCIÓ DE L'ÚS FETA PER L'INFORMANT. Per a les infeccions dels ronyons. FORMA FARMACĖUTICA I ÚS. Tisana (ús intern). PREPARACIÓ. Decocció. DESTINACIÓ. Medicina humana.

Restauratiu

FONTS 529, 530, 531. DESCRIPCIÓ DE L'ÚS FETA PELS INFORMANTS. Quan et trobaves malament en prenies. FORMA FARMACĖUTICA I ÚS. Tisana (ús intern). PREPARACIÓ. Decocció. DESTINACIÓ. Medicina humana.

\section{ALTRES USOS}

\section{Planta sencera}

Altres informacions

FONTS 556, 557. DESCRIPCIÓ DE L'ÚS FETA PELS INFORMANTS. En recolliem.

\section{ALTRES OBSERVACIONS}

FONTS 511, 512, 513, 514, 552. DESCRIPCIÓ FETA PELS INFORMANTS. Surt agafada a les roques i fa una floreta petita blanca seca $(511,512,513,514)$. En vaig portar de la muntanya i la vaig plantar en un test, però no va viure (552).

\section{BARREGES AMB AQUEST TAXXN}

Part aèria florida

FONT 1331. Entrevista 30, barreja IV (vegeu catàleg de barreges)

FONT 1296. Entrevista 7, barreja I (vegeu catàleg de barreges)

FONT 1296. Entrevista 7, barreja II (vegeu catàleg de barreges)

FONTS 554, 555. Entrevista 78, barreja I (vegeu catàleg de barreges)

\section{Senecio vulgaris L. (compostes)}

BCN 24999

\section{NOMS POPULARS}

Escaldabecs (564)

Matafoc $(528,580)$ 
Xenixell $(1322,1350,1351)$

\section{USOS MEDICINALS}

Part aèria

Antisèptic extern

FONTS 1350, 1351. DESCRIPCIÓ DE L'ÚS FETA PELS INFORMANTS. Per a les infeccions. FORMA FARMACĖUTICA I ÚS. Embrocació (ús extern). PREPARACIÓ. Fer bullir en oli. DESTINACIÓ. Medicina humana.

Per al panadís

FONT 528. DESCRIPCIÓ DE L'ÚS FETA PER L'INFORMANT. Servien per a fer emplastres per a curar les espitlles. FORMA FARMACĖUTICA I ÚS. Emplastre (ús extern). DESTINACIÓ. Medicina humana.

\section{USOS ALIMENTARIS}

\section{Part aèria}

Ingestió de la part de la planta crua - Fresca (sense preparació)

FONT 580. DESCRIPCIÓ DE L'ÚS FETA PER L'INFORMANT. Es donaven als conills, però a vegades els feien mal. DESTINACIÓ. Alimentació animal.

\section{BARREGES AMB AQUEST TÀXON}

\section{Part aèria}

FONT 1322. Entrevista 28, barreja I (vegeu catàleg de barreges)

FONTS 1350, 1351. Entrevista 39, barreja II (vegeu catàleg de barreges)

FONT 528. Entrevista 61, barreja II (vegeu catàleg de barreges)

\section{Sequoiadendron giganteum (Lindl.) Buchholz}

(cupressàcies)

BCN 27276

\section{NOMS POPULARS}

Sequoia (1352)

\section{ALTRES USOS}

Escorça

Lúdic: jocs i joguines
FONT 1352. DESCRIPCIÓ DE L'ÚS FETA PER L'INFORMANT. Es feia servir l'escorça, que se separa molt bé de l'arbre, per a jugar a fer cases i pessebres.

\section{Silene ciliata Pourr. (cariofil·làcies)}

BCN 25000

\section{NOMS POPULARS}

Herba ronyonera $(1317,1345,1346)$

\section{USOS MEDICINALS}

\section{Part aèria}

Protector renal

FONTS 1317, 1345, 1346. DESCRIPCIÓ DE L'ÚS FETA PELS INFORMANTS. Per als ronyons (1317). Va bé per als ronyons $(1345,1346)$. FORMA FARMACĖUTICA I ÚS. Tisana (ús intern). PREPARACIÓ. Decocció $(1317,1345,1346)$. DESTINACIÓ. Medicina humana.

\section{Silene vulgaris (Moench) Garcke subsp. vulgaris}

(cariofil·làcies)

BCN 25001

\section{NOMS POPULARS}

Corretjola (1313)

Esclafidor $(528,532,541,547,548,572,573,590,1213,1214,1313,1324,1353,1354)$

Pet (1352)

\section{USOS ALIMENTARIS}

Fulla

Ingestió de la part de la planta crua - Fresca (sense preparació)

FONTS 532, 572, 573, 1213, 1214, 1313, 1324. DESCRIPCIÓ DE L'ÚS FETA PELS INFORMANTS. Quan són tendres per a menjar amanits (532). Quan són tendres s'amanien $(572,573)$. Per a amanir $(1213,1214)$. Les que es fan per al mig del blat i són ben tendres, per a amanir (1313). Es mengen amanits quan són tendres (1324). DESTINACIÓ Alimentació humana $(532,572,573,1213,1214,1313,1324)$.

Part aèria

Ingestió de la part de la planta crua - Fresca (sense preparació) 
FONTS 528, 590. DESCRIPCIÓ DE L'ÚS FETA PELS INFORMANTS. Es donaven als conills (528). Per a donar als conills (590). DESTINACIÓ. Alimentació animal $(528,590)$

\section{ALTRES USOS}

Flor

Lúdic: jocs i joguines

FONTS 1352, 1353, 1354. DESCRIPCIÓ DE L'ÚS FETA PELS INFORMANTS. Per a jugar a fer-los petar.

\section{Part aèria florida}

Artesanal: elaboració de joguines

FONTS 547, 548. DESCRIPCIÓ DE L'ÚS FETA PELS INFORMANTS. Quan érem petits els fèiem petar.

\section{Sisymbrium officinale (L.) Scop. (cruciferes)}

BCN 25002

\section{NOMS POPULARS}

Herba de les cantaires (555)

Herba del constipat $(529,530,531)$

Herba dels cantaires $(554,1324)$

\section{USOS MEDICINALS}

Part aèria florida

Anticatarral

FONTS 529, 530, 531, 554, 555. DESCRIPCIÓ DE L'ÚS FETA PELS INFORMANTS Infusions per a la tos i els refredats de coll $(554,555)$. FORMA FARMACĖUTICA I ÚS Tisana (ús intern). PREPARACIO. Decocció $(529,530,531)$. DESTINACIO. Medicina humana. OBSERVACIONS. La tenim seca $(529,530,531)$.

Antiinflamatori faringi

FONT 1324. DESCRIPCIÓ DE L'ÚS FETA PER L'INFORMANT. Desinflama el coll. FORMA FARMACĖUTICA I ÚS. Tisana (ús intern). PREPARACIÓ. En infusió. DESTINACIÓ Medicina humana.

Antitussigen

FONTS 554, 555. DESCRIPCIÓ DE L'ÚS FETA PELS INFORMANTS. Infusions per a la tos els refredats de coll. FORMA FARMACEUTICA I ÚS. Tisana (ús intern). DESTINACIO. Medicina humana.

\section{ALTRES OBSERVACIONS}

FONTS 529, 530, 531. DESCRIPCIÓ FETA PELS INFORMANTS. Fa la flor groga.

\section{BARREGES AMB AQUEST TÀXON}

\section{Part aèria florida}

FONTS 529, 530, 531. Entrevista 53, barreja VII (vegeu catàleg de barreges)

\section{Solanum dulcamara L. (solanàcies)}

BCN 25003

\section{NOMS POPULARS}

Dolçamara $(541,591,592,1324,1339,1340)$

Herba dolçamara $(529,530,531)$

\section{USOS MEDICINALS}

\section{Part aèria}

Analgèsic

FONTS 1339, 1340. DESCRIPCIÓ DE L'ÚS FETA PELS INFORMANTS. Per al dolor FORMA FARMACĖUTICA I ÚS. Tisana (ús intern). PREPARACIÓ. Decocció. DESTINACIÓ. Medicina humana.

Antipsoriàsic

FONT 1324. DESCRIPCIÓ DE L'ÚS FETA PER L'INFORMANT. Per a rentar-se en cas de psoriasi. FORMA FARMACĖUTICA I ÚS. Bany (ús extern). PREPARACIÓ. Decocció DESTINACIO. Medicina humana.

Hematocatàrtic

FONTS 529, 530, 531. DESCRIPCIÓ DE L'ÚS FETA PELS INFORMANTS. Per a purificar la sang. FORMA FARMACEUTICA I ÚS. Tisana (ús intern). PREPARACIÓ. Decocció DESTINACIO. Medicina humana.

Per al malestar / Fatiga

FONTS 591, 592. DESCRIPCIÓ DE L'ÚS FETA PELS INFORMANTS. Es feia aigua quan la mainada estaven empiocats. FORMA FARMACĖUTICA I ÚS. Tisana (ús intern). PREPARACIO. Decocció. DESTINACIO. Medicina humana.

\section{ALTRES OBSERVACIONS}

FONTS 529, 530, 531. DESCRIPCIÓ FETA PELS INFORMANTS. Mata grossa, fulla semblant a l'heura. 


\section{Solanum lycopersicum L. (solanàcies)}

BCN 27289

\section{NOMS POPULARS}

Tomàquet (fruit) $(504,1353,1354)$

Tomata (fruit) $(507,509,510)$

\section{USOS MEDICINALS}

Fruit

Per al panadís

FONTS 507, 509, 510. DESCRIPCIÓ DE L'ÚS FETA PELS INFORMANTS. Per als voltadits. FORMA FARMACĖUTICA I ÚS. Sense forma farmacèutica (ús directe, ús extern). PREPARACIÓ. Una tomata oberta i embolicar-hi el dit. DESTINACIÓ. Medicina humana.

\section{USOS ALIMENTARIS}

\section{Fruit}

Ingestió de la part de la planta crua - Conservada en oli

FONTS 504, 1353, 1354. DESCRIPCIÓ DE L'ÚS FETA PELS INFORMANTS. Per a fer conserves. DESTINACIÓ. Alimentació humana.

Ingestió de la part de la planta crua - Fresca (sense preparació)

FONT 504. DESCRIPCIÓ DE L'ÚS FETA PER L'INFORMANT. Per a amanir. DESTINACIÓ. Alimentació humana.

\section{Solanum melongena L. (solanàcies)}

BCN 25004

\section{NOMS POPULARS}

Albergínia (fruit) (1330)

\section{USOS MEDICINALS}

Fruit

Hipolipemiant

FONT 1330. DESCRIPCIÓ DE L'ÚS FETA PER L'INFORMANT. Fa baixar el colesterol. FORMA FARMACĖUTICA I ÚS. Tisana (ús intern). PREPARACIÓ. En un litre d'aigua, bullir una albergínia mitjana amb dues cullerades de mill dels ocells (Panicum miliaceum), durant 20 minuts. Deixar-ho reposar 20 minuts. MODE D'UTILITZACIÓ/POSOLOGIA. Prendre'n un got en dejú durant 30 dies i si cal allagar-ho a 90 dies. DESTINACIÓ. Medicina humana.

\section{Solanum nigrum L. (solanàcies)}

BCN 25005

\section{ACCIONS NOCIVES O TÒXIQUES}

No consta

FONT 1324. DESCRIPCIÓ DE L'ACCIÓ NOCIVA O TÒXICA FETA PER L'INFORMANT. Herba tòxica al mig de les patates.

\section{Solanum tuberosum L. (solanàcies)}

\section{BCN 25006}

\section{NOMS POPULARS}

Patata (tubrecle) $(505,506,507,509,510,517,571,572,573,746)$

Trumfa $(1361,1362)$

\section{USOS MEDICINALS}

\section{Tubercle}

Anticefalàlgic

FONTS 1361, 1362. DESCRIPCIÓ DE L'ÚS FETA PELS INFORMANTS. Quan tens mal de cap, cal posar mitja patata a cada pols. FORMA FARMACĖUTICA I ÚS. Sense forma farmacèutica (ús directe, ús extern). DESTINACIÓ. Medicina humana.

Antipiròtic

FONTS 507, 509, 510. DESCRIPCIÓ DE L'ÚS FETA PELS INFORMANTS. Per a les cremades del sol. FORMA FARMACĖUTICA I ÚS. Sense forma farmacèutica (ús directe, ús extern). PREPARACIÓ. Posar talls de patata a la cara. DESTINACIÓ. Medicina humana.

\section{USOS ALIMENTARIS}

\section{Tubercle}

Ingestió de la part de la planta crua - Fresca (sense preparació)

FONT 571. DESCRIPCIÓ DE L'ÚS FETA PER L'INFORMANT. Per a les gallines, els donàvem les patates petites. DESTINACIÓ. Alimentació animal.

Ingestió de la part de la planta cuita - Cuita en aigua 
Apèndix 1. Catàleg de tàxons.

FONTS 517, 572, 573, 746. DESCRIPCIÓ DE L'ÚS FETA PELS INFORMANTS. A casa meva en fèiem saions. Les cases de pagès et deixaven un tros de terra per a fer-hi els saions, te'l llauraven i t'hi posaven els fems i llavors tu t'espavilaves (746). Les patates d'aqui dalt són molt bones, a més alçada més bones són les patates $(572,573)$. DESTINACIÓ. Alimentació humana $(517,572,573,746)$.

\section{ALTRES OBSERVACIONS}

FONT 517. DESCRIPCIÓ FETA PER L'INFORMANT. A l'hort.

\section{BARREGES AMB AQUEST TÀXON}

Tubercle

FONTS 505, 506. Entrevista 47, barreja I (vegeu catàleg de barreges)

\section{Solidago virgaurea L. (compostes)}

BCN 25007

\section{NOMS POPULARS}

Vara d'or $(1293,1299,1324)$

\section{USOS MEDICINALS}

\section{Inflorescència}

Contraverí

FONT 1324. DESCRIPCIÓ DE L'ÚS FETA PER L'INFORMANT. La va utilitzar per a un gos que es va intoxicar. FORMA FARMACĖUTICA I ÚS. Tisana (ús intern). PREPARACIÓ. En infusió, la flor. DESTINACIÓ. Medicina veterinària.

Hematocatàrtic

FONT 1324. DESCRIPCIÓ DE L'ÚS FETA PER L'INFORMANT. Neteja la sang. FORMA FARMACĖUTICA I ÚS. Tisana (ús intern). PREPARACIÓ. En infusió, la flor. MODE D'UTILITZACIÓ/POSOLOGIA. Fent novenes. DESTINACIÓ. Medicina humana.

Hepatoprotector

FONT 1324. DESCRIPCIÓ DE L'ÚS FETA PER L'INFORMANT. Per al fetge. FORMA FARMACĖUTICA I ÚS. Tisana (ús intern). PREPARAĆÓ. En infusió, les flors. MODE D'UTILITZACIÓ/POSOLOGIA. Fent novenes. DESTINACIÓ. Medicina humana.

Protector renal

FONT 1324. DESCRIPCIÓ DE L'ÚS FETA PER L'INFORMANT. Per als ronyons. FORMA FARMACĖUTICA I ÚS. Tisana (ús intern). PREPARAClÓ. En infusió, les flors. MODE D'UTILITZACIÓ/POSOLOGIA. Fent novenes. DESTINACIÓ. Medicina humana.

\section{Part aèria florida}

Antisèptic urinari

FONT 1293. DESCRIPCIÓ DE L'ÚS FETA PER L'INFORMANT. Per a infeccions d'orina. FORMA FARMACÉUTICA I ÚS. Tisana (ús intern). PREPARACIÓ. Decocció. DESTINACIÓ. Medicina humana.

Diürètic

FONT 1299. DESCRIPCIÓ DE L'ÚS FETA PER L'INFORMANT. Per a evitar la retenció de líquids. FORMA FARMACĖUTICA I ÚS. Tisana (ús intern). PREPARACIÓ. Decocció. DESTINACIÓ. Medicina humana.

\section{Sonchus oleraceus L. (compostes)}

BCN 25008

\section{NOMS POPULARS}

Lletissó $(564,582,590,1215,1322,1332,1333,1334,1350,1351)$

Lletsó $(528,553,561,562,563,583,584,585,1213,1214)$

\section{USOS MEDICINALS}

\section{Part aèria}

Antisèptic extern

FONTS 1350, 1351. DESCRIPCIÓ DE L'ÚS FETA PELS INFORMANTS. Per a les infeccions. FORMA FARMACĖUTICA I ÚS. Embrocació (ús extern). PREPARACIÓ. Fer bullir en oli. DESTINACIO. Medicina humana.

Vulnerari

FONTS 1332, 1333, 1334. DESCRIPCIÓ DE L'ÚS FETA PELS INFORMANTS. Per a les ferides tant per a les persones com per al bestiar. FORMA FARMACĖUTICA I ÚS Embrocació (ús extern). PREPARACIÓ. Bullit en oli. DESTINACIÓ. Medicina humana veterinària.

\section{USOS ALIMENTARIS}

\section{Part aèria}

Ingestió de la part de la planta crua - Fresca (sense preparació)

FONTS 528, 561, 562, 563, 564, 583, 584, 585, 590, 1213, 1214, 1215. DESCRIPCIÓ DE L'ÚS FETA PELS INFORMANTS. Per a donar als conills $(528,583,584,585,590)$. Es donaven a les oques $\mathrm{i}$ als conills $(561,562,563)$. Per als conills $(564)$. Quan eren tendres es menjaven amanits en temps de guerra (1215). DESTINACIÓ. Alimentació animal $(528,561$, $562,563,564,583,584,585,590,1213,1214)$. Alimentació humana (1215). 


\section{ALTRES OBSERVACIONS}

FONT 582. DESCRIPCIÓ FETA PER L'INFORMANT. Es fan als horts.

\section{BARREGES AMB AQUEST TÀXON}

Part aèria

FONT 1322. Entrevista 28, barreja I (vegeu catàleg de barreges)

\section{Sorbus aria (L.) Crantz (rosàcies)}

BCN 123792

\section{NOMS POPULARS}

Moixera (541)

\section{Sorbus aucuparia L. (rosàcies)}

BCN 25009

\section{NOMS POPULARS}

Moixera $(541,559,580,1341,1342)$

\section{USOS MEDICINALS}

\section{Part aèria}

Per a trastorns del sistema immunitari

FONTS 1341, 1342. DESCRIPCIÓ DE L'ÚS FETA PELS INFORMANTS. Quan els porcs tenien el mal blau es posava moixera a dins la cort. FORMA FARMACĖUTICA I ÚS. Sense forma farmacèutica (ús directe, ús extern). DESTINACIÓ. Medicina veterinària.

\section{ALTRES USOS}

Planta viva ex situ

Ornamental: jardineria

FONT 580. DESCRIPCIÓ DE L'ÚS FETA PER L'INFORMANT. Fa bonic, està ben florida.

\section{Sorbus domestica L. (rosàcies)}

BCN 46827

\section{NOMS POPULARS}

Serva (fruit) (517)

Servera (517)

\section{USOS MEDICINALS}

Fruit

Antidiarreic

FONT 517. DESCRIPCIÓ DE L'ÚS FETA PER L'INFORMANT. Per a tallar la diarrea FORMA FARMACĖUTICA I ÚS. Sense forma farmacèutica (ús directe, ús intern). PREPARACIÓ. Menjar directament les serves. DESTINACIÓ. Medicina humana. OBSERVACIONS. És una prunera, però fa les prunes molt més petites i no tan bones. Allà a la Vilada n'hi havia, de serveres.

\section{Sorghum bicolor (L.) Moench (gramínies)}

\section{BCN 31310}

\section{NOMS POPULARS}

Melca (589)

\section{USOS ALIMENTARIS}

\section{No consta}

Ingestió de la part de la planta crua - Conservada dessecada a l'aire

FONT 589. DESCRIPCIÓ DE L'ÚS FETA PER L'INFORMANT. Es donava al bestiar. DESTINACIÓ. Alimentació animal.

\section{Spartium junceum L. (papilionàcies)}

BCN 29956

\section{NOMS POPULARS}

Ginesta $(564)$

\section{ALTRES USOS}

Part aèria florida

Creences i pràctiques magicoreligioses 
FONT 564. DESCRIPCIÓ DE L'ÚS FETA PER L'INFORMANT. La d'aquí és la típica per a les catifes [dit "alfombres"] de Corpus. Anàvem a buscar-la a la Ginebrosa o al Sunyer.

\section{Stachys byzantina C.Koch (labiades)}

BCN 25010

\section{NOMS POPULARS}

Argentina (1324)

Orella de xai $(535,1324)$

\section{USOS MEDICINALS}

Fulla

Antisèptic extern

FONT 1324. DESCRIPCIÓ DE L'ÚS FETA PER L'INFORMANT. Quan et fas un tall et poses una fulla primer pel cantó llis perquè surti la bruticia, i llavors pel cantó pelut per a desinfectar. FORMA FARMACĖUTICA I US. Sense forma farmacèutica (ús directe, ús extern). DESTINACIO. Medicina humana.

Hemostàtic extern

FONT 535. DESCRIPCIÓ DE L'ÚS FETA PER L'INFORMANT. Per a estroncar la sang quan et fas un tall. FORMA FARMACEUTICA I US. Sense forma farmacèutica (ús directe, ús extern). DESTINACIO. Medicina humana.

\section{Stachys officinalis (L.) Trevisan (labiades)}

BCN 25011

\section{NOMS POPULARS}

Betònica (1324)

\section{USOS MEDICINALS}

Part aèria

Vulnerari

FONT 1324. DESCRIPCIÓ DE L'ÚS FETA PER L'INFORMANT. Per a banyar les llagues. FORMA FARMACĖUTICA I ÚS. Bany (ús extern). PREPARACIÓ. Decocció. DESTINACIÓ.

Medicina humana.
Stellaria media (L.) Vill. (cariofil·làcies)

BCN 27251

\section{NOMS POPULARS}

Borrissol $(583,584,585)$

Morró $(528,553,569,570,571,572,573,574,575,576,577,1353,1354,1352)$

\section{USOS ALIMENTARIS}

\section{Part aèria}

Ingestió de la part de la planta crua - Fresca (sense preparació)

FONTS 528, 569, 570, 571, 572, 573, 574, 575, 576, 577, 583, 584, 585, 1352, 1353, 1354. DESCRIPCIO DE L'US FETA PELS INFORMANTS. Es donaven a les gallines, els va molt bé, les fa pondre molt (528). Per a les gallines $(571,574,575,576,577)$. Es donaven a les gallines $(569,570)$. En menjaven les gallines $(572,573)$. Les gallines ho piquen $(583,584$, 585). Per a menjar els conills (1352). Abans, quan teníem gallines, els donàvem grapats de morrons $(1353,1354)$. DESTINACIÓ. Alimentació animal $(528,569,570,571,572,573,574$, $575,576,577,583,584,585,1352,1353,1354)$.

\section{Stevia rebaudiana (Bertoni) Bertoni (compostes)}

BCN 30644

\section{NOMS POPULARS}

Estèvia $(1213,1214)$

\section{USOS MEDICINALS}

\section{Part aèria}

Hipoglucemiant

FONTS 1213, 1214. DESCRIPCIÓ DE L'ÚS FETA PELS INFORMANTS. Per a fer baixar el sucre. FORMA FARMACĖUTICA I ÚS. Tisana (ús intern). DESTINACIÓ. Medicina humana.

\section{Symphytum officinale L. (boraginàcies)}

BCN 25012

\section{NOMS POPULARS}

Consolda major (1324) 


\section{USOS MEDICINALS}

Arrel

Vulnerari

FONT 1324. DESCRIPCIÓ DE L'ÚS FETA PER L'INFORMANT. Va bé per a banyar les llagues. FORMA FARMACĖUTICA I ÚS. Bany (ús extern). PREPARACIÓ. Decocció. Aigua de les rels. DESTINACIO. Medicina humana.

\section{Syringa vulgaris L. (oleàcies)}

BCN 27250

\section{NOMS POPULARS}

Lilà $(524,541,549,560,561,562,563,564,571,580,1353,1354,1352)$

\section{ALTRES USOS}

Part aèria florida

Creences i pràctiques magicoreligioses

FONT 1352. DESCRIPCIÓ DE L'ÚS FETA PER L'INFORMANT. Se'n feien rams que es posaven a l'església per al mes de Maria.

Ornamental: elaboració de rams

FONTS 524, 541, 549, 560, 561, 562, 563, 564, 571, 580. DESCRIPCIÓ DE L'ÚS FETA PELS INFORMANTS. Per a fer rams $(541,549,560,564)$. Per a flors $(561,562,563)$. Per a fer bonic (580).

\section{Planta viva in situ}

Ornamental: jardineria

FONTS 1353, 1354. DESCRIPCIÓ DE L'ÚS FETA PELS INFORMANTS. A casa sempre n'hem tingut. Al mes de maig, quan floreix, és molt bonic i fa molta olor.

\section{Syzygium aromaticum (L.) Merr. et Perry (mirtàcies)}

BCN 47279

\section{NOMS POPULARS}

Clau (553)

USOS ALIMENTARIS

\section{Poncella}

Preparació de begudes - Beguda preparada amb aiguardent

FONT 553. DESCRIPCIÓ DE L'ÚS FETA PER L'INFORMANT. Ratafia. Posar totes les herbes en aiguardent 21 dies a sol i serena. Es fa pels volts de Sant Joan. Sempre surt bona però no surt mai igual. Les herbes utilitzades són: nous verdes (Juglans regia), herba de Noè (Herniaria glabra), tarongina (Melissa officinalis), camamilla borda (Tanacetum parthenium), (Herniaria glabra), tarongina (Melissa officinalis), camamilla borda (Tanacetum parthenium), marialluïsa (Lippia triphylla), menta (Mentha spicata), salsufràgia (Peucedanum ostruthium) tilla (Tilia platyphyllos), nou moscada (Myristica fragrans) i clau (Syzygium aromaticum)

Tagetes patula L. (compostes)

BCN 30022

\section{NOMS POPULARS}

Clavell de moro (528)

\section{ALTRES USOS}

Planta viva ex situ

Ornamental: jardineria

FONT 528. DESCRIPCIÓ DE L'ÚS FETA PER L'INFORMANT. En tinc per a fer bonic.

\section{Tamus communis L. (dioscoreàcies)}

BCN 25013

\section{USOS MEDICINALS}

Fruit

Antivaricós

FONT 1324. DESCRIPCIÓ DE L'ÚS FETA PER L'INFORMANT. Per a treure les venetes vermelles que surten quan et fas gran. FORMA FARMACĖUTICA I ÚS. Pomada (ús extern). PREPARACIÓ. Amb les boles en fa una pomada. DESTINACIÓ. Medicina humana.

\section{Tanacetum parthenium (L.) Schultz Bip. (compostes)} BCN 25014

\section{NOMS POPULARS}

Camamilla $(525,526,527,541,1215,1300)$ 
Apèndix 1. Catàleg de tàxons.

Camamilla amarga (1301)

Camamilla amarganta $(507,509,510)$

Camamilla borda $(505,506,511,512,513,514,515,516,547,548,552,553,556,557,569$ $570,572,573,574,575,576,577,578,579,580,583,584,585,746,748,749,1293,1314$ 1336)

Camamilla de parets $(1310,1328,1329)$

Herba tanarida $(1332,1333,1334)$

Tanarida $(1300,1318)$

\section{USOS MEDICINALS}

\section{Fulla}

Digestiu

FONT 1310. DESCRIPCIÓ DE L'ÚS FETA PER L'INFORMANT. És digestiva. FORMA FARMACEUTICA I ÚS. Tisana (ús intern). DESTINACIÓ. Medicina humana OBSERVACIONS. La que fa una margarida petita. A l'estiu es feia servir la flor, a l'hivern les fulles i tenia el mateix efecte i gust.

\section{Inflorescència}

\section{Antidiarreic}

FONTS 525, 526, 527, 1328, 1329. DESCRIPCIÓ DE L'ÚS FETA PELS INFORMANTS. Es feia servir com a camamilla. Quan els vedells tenien diarrea o quedaven enfitats se'ls feia aigua d'aquesta herba $(525,526,527)$. Per a donar-los al bestiar quan tenien la foira (1328, 1329) FORMA FARMACĖUTICA I ÚS. Tisana (ús intern). PREPARACIÓ Decocció (525, $526,527,1328,1329)$ DESTINACIÓ. Medicina veterinària. OBSERVACIONS. També la gent $526,527,1328,1329)$. DESTINACIO. Medicina veterinària. OBSERVACIONS. També la gent en prenia $(525,526,527)$

Antiinflamatori intestinal

FONTS $505,506,507,509,510,515,516,547,548,556,557,574,575,576,577,578,579$ $580,583,584,585,746,1301,1314$. DESCRIPCIÓ DE L'ÚS FETA PELS INFORMANTS. Per als mals de ventre. El meu pare no en volia cap altra $(505,506)$. Per al mal de ventre $(507,509,510,746,1301,1314)$. Per a mals de panxa $(515,516)$. Per a la panxa, però no va tan bé $(556,557)$. Per a la panxa $(574,575,576,577,578,579,583,584,585)$. És bona per tan be $(556,557)$. Per a la panxa $(574,575,576,577,578,579,583,584,585)$. Es bona per a la panxa (580). FORMA FARMACEUTICA I US. Tisana (ús intern) $(505,506,507,509$,

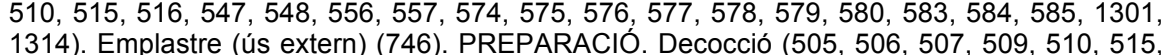
1314). Emplastre (ús extern) (746). PREPARACIO. Decocció (505, 506, 507, 509, 510, 515 feia aigua d'aquesta camamilla, es mullaven draps i es posaven a sobre la panxa (746). Decocció (557). DESTINACIÓ. Medicina humana. OBSERVACIONS. És molt amarganta. L'avi d'aquí a casa deia que era millor que la de muntanya $(547,548)$. Es molt amargant $(580,1301)$.

Antinauseabund
FONT 1301. DESCRIPCIÓ DE L'ÚS FETA PER L'INFORMANT. Per al mareig. FORMA humana. OBSERVACIONS. És molt amargant.

Antisèptic ocular

FONTS 507, 509, 510, 746, 1314. DESCRIPCIÓ DE L'ÚS FETA PELS INFORMANTS. Per a banyar els ulls $(746,1314)$. Per als ulls $(507,509,510)$. FORMA FARMACĖUTICA I ÚS. Bany (ús extern). PREPARACIÓ. Decocció $(507,509,510,746)$. DESTINACIÓ. Medicina Bany (ús
humana.

Desconegut per l'informant

FONTS 748, 749, 1318, 1336. DESCRIPCIÓ DE L'ÚS FETA PELS INFORMANTS. Se'n fa aigua però nosaltres no n'hem pres mai $(748,749)$. Diuen que la tandarida treu el bou de mort a vida (1318). Se'n feia aigua per al bestiar (1336). FORMA FARMACËUTICA I ÚS. mort a vida (1318). Se'n feia aigua per al bestiar (1336). FORMA FARMACÉS humana $(748,749)$. Medicina veterinària $(1318,1336)$.

Digestiu

FONTS 541, 553, 1301, 1310, 1328, 1329. DESCRIPCIÓ DE L'ÚS FETA PELS INFORMANTS. Es feia servir com la camamilla. Digestiu (541). Digestiva (553). Per a pair INFORMANTS. Es feia servir com la camamilla. Digestiu (541). Digestiva (553). Per a pair (1301, 1328, 1329). Es digestiva (1310). FORMA FARMACEUTICA IUS. Tisana (ús intern). PREPARACIO. Decocció $(541,553,1301,1328,1329)$. DESTINACIO. Medicina humana. OBSERVACIONS. És molt amargant (1301). La que fa una margarida petita. A l'estiu es feia servir la flor, a l'hivern les fulles i tenia el mateix efecte i gust (1310).

\section{No consta}

Desconegut per l'informant

FONTS 552, 569, 570, 572, 573. FORMA FARMACÈUTICA I ÚS. Desconegut per l'informant. DESTINACIO. Medicina humana. OBSERVACIONS. Potser que sigui bona però no la fem servir $(552)$. Nosaltres no la fèiem servir $(569,570)$. A vegades també se'n prenia $(572,573)$.

\section{Part aèria}

\section{Antidiarreic}

FONT 1300. DESCRIPCIÓ DE L'ÚS FETA PER L'INFORMANT. Als vedells, quan tenien diarrea. FORMA FARMACĖUTICA I ÚS. Tisana (ús intern). PREPARACIÓ. Se'Is donava camamilla amb carbonat barrejat amb oli, però sense bullir. DESTINACIÓ. Medicina veterinària. OBSERVACIONS. Nosaltres sempre n'hem dit camamilla, però va passar un home i va dir que es deia tanarida.

Digestiu

FONT 1293. FORMA FARMACĖUTICA I ÚS. Tisana (ús intern). PREPARACIÓ. Decocció DESTINACIÓ. Medicina humana. OBSERVACIONS. És amargant. A la seva sogra li agradava molt.

Salutífer

FONT 1300. FORMA FARMACĖUTICA I ÚS. Tisana (ús intern). PREPARACIÓ. Decocció. MODE D'UTILITZACIÓ/POSOLOGIA. El seu germà cada dia se'n fa una tassa. DESTINACIÓ. Medicina humana. 


\section{USOS ALIMENTARIS}

\section{Inflorescència}

Preparació de begudes - Beguda preparada amb aiguardent

FONT 553. DESCRIPCIÓ DE L'ÚS FETA PER L'INFORMANT. Ratafia. Posar totes les herbes en aiguardent 21 dies a sol i serena. Es fa pels volts de Sant Joan. Sempre surt bona però no surt mai igual. Les herbes utilitzades són: nous verdes (Juglans regia), herba de Noè (Herniaria glabra), tarongina (Melissa officinalis), camamilla borda (Tanacetum parthenium) marialluïsa (Lippia triphylla), menta (Mentha spicata), salsufràgia (Peucedanum ostruthium) DESTINACIÓ. Alimentació humana.

\section{ALTRES USOS}

\section{Part aèria florida}

Ornamental: elaboració de rams

FONTS 511, 512, 513, 514. DESCRIPCIÓ DE L'ÚS FETA PELS INFORMANTS. Si de cas per a fer un ram (511). Si de cas per a fer un ram $(512,513,514)$.

Planta sencera

Literatura oral popular: llegendes, gloses, contes, dites, refranys, poemes, cançons

FONTS 1318, 1332, 1333, 1334. DESCRIPCIÓ DE L'ÚS FETA PELS INFORMANTS. La tandarida treu el bou de mort a vida (1318). L'herba danarida torna el bou mort a vida (1332 $1333,1334)$.

\section{ALTRES OBSERVACIONS}

FONTS 1215, 1293, 1300, 1310. DESCRIPCIÓ FETA PELS INFORMANTS. D'aquesta n'hi ha a Camprodon, a la muralla (1215). Se'n fa pertot arreu (1293). N'hi ha molta allà fora a casa seva (1300). N'hi havia a totes les cases de pagès, sortia a les parets (1310).

\section{Tanacetum vulgare L. (compostes)}

BCN 29803

\section{NOMS POPULARS}

Herba cuquera $(554,555,583,584,585)$

Tanarida $(511,512,513,514,518,519,525,526,527,529,530,531,541,553,554,555$ $556,557,558,569,570,580,586,587,590,748,749)$

\section{USOS MEDICINALS}

\section{Inflorescència}

Abortiu

FONT 580. DESCRIPCIÓ DE L'ÚS FETA PER L'INFORMANT. Es feia servir per a ajudar les vaques a avortar, quan no podien criar el vedell. FORMA FARMACĖUTICA I ÚS. Tisana (ús intern). PREPARACIÓ. Decocció. DESTINACIÓ. Medicina veterinària. OBSERVACIONS. És amargant com el fel.

Antihelmíntic

FONTS 554, 555, 583, 584, 585. DESCRIPCIÓ DE L'ÚS FETA PELS INFORMANTS. Per als cucs. FORMA FARMACĖUTICA I ÚS. Tisana (ús intern). PREPARACIÓ. Decocció. DESTINACIÓ. Medicina humana.

Antihipertensiu

FONTS 518, 519. DESCRIPCIÓ DE L'ÚS FETA PELS INFORMANTS. Per a fer baixar la pressió. FORMA FARMACĖUTICA I ÚS. Tisana (ús intern). PREPARACIÓ. Decocció de dos botons. DESTINACIÓ. Medicina humana.

Coadjuvant del postpart

FONTS 529, 530, 531. DESCRIPCIÓ DE L'ÚS FETA PELS INFORMANTS. Per a les vaques quan vedellaven; els treu la inflamació i les fa orinar. FORMA FARMACEUTICA I ÚS. Tisana (ús intern). PREPARACIÓ. Decocció. DESTINACIÓ. Medicina veterinària.

Desconegut per l'informant

FONTS 511, 518, 519. DESCRIPCIÓ DE L'ÚS FETA PELS INFORMANTS. Se'n donava a les vaques quan estaven malaltes (511). Aigua per al bestiar $(518,519)$. FORMA FARMACĖUTICA I ÚS. Tisana (ús intern). PREPARACIÓ. Decocció $(511,518,519)$. DESTINACIÓ. Medicina veterinària.

Hematocatàrtic

FONTS 583, 584, 585. DESCRIPCIÓ DE L'ÚS FETA PELS INFORMANTS. Per a purificar la sang. FORMA FARMACĖUTICA I ÚS. Tisana (ús intern). PREPARACIÓ. Decocció. DESTINACIÓ. Medicina humana.

No consta

FONTS 512, 513, 514, 586, 587, 590. DESCRIPCIÓ DE L'ÚS FETA PELS INFORMANTS. Se' $n$ donava a les vaques quan estaven malaltes $(512,513,514)$. Es donava al bestiar quan estaven malalts (590). Se'n donava als vedells quan estaven malalts $(586,587)$.FORMA M $587,590)$. DESTINACIÓ. Medicina veterinària.

\section{ALTRES USOS}

\section{No consta}

Literatura oral popular: llegendes, gloses, contes, dites, refranys, poemes, cançons

FONTS 511, 512, 513, 514, 518, 519, 748, 749. DESCRIPCIÓ DE L'ÚS FETA PELS INFORMANTS. La tanarida torna el bou de mort a vida $(511,512,513,514)$. La tanarida treu el bou de mort a vida $(748,749)$. Herba tanarida treu el bou de mort a vida $(518,519)$. 


\section{Part aèria florida}

Maneig agrosilvopastoral: ús hortícola/agrícola

FONT 558. DESCRIPCIÓ DE L'ÚS FETA PER L'INFORMANT. En fèiem feixets i ens les compraven.

Ornamental: elaboració de rams

FONTS 569, 570.

Planta sencera

Literatura oral popular: llegendes, gloses, contes, dites, refranys, poemes, cançons

FONTS 525, 526, 527, 590. DESCRIPCIÓ DE L'ÚS FETA PELS INFORMANTS. Treu el bou de mort a vida.

\section{ACCIONS NOCIVES O TÒXIQUES}

No consta

FONT 553. DESCRIPCIÓ DE L'ACCIÓ NOCIVA O TÒXICA FETA PER L'INFORMANT. No la tocava la gent.

\section{ALTRES OBSERVACIONS}

FONTS 525, 526, 527, 590. DESCRIPCIÓ FETA PELS INFORMANTS. Abans si que n'h havia, ara no n'hi ha enlloc $(525,526,527)$. Es fa a les parets velles i la fulla és com la camamilla (Matricaria chamomilla), però la flor és groga (590).

\section{Taraxacum dissectum (Ledeb.) Ledeb. (compostes)}

BCN 25016

\section{NOMS POPULARS}

Xicoia $(520,521,528,529,530,531,532,538,539,540,541,546,547,548,549,552,554$, $555,556,557,558,559,567,568,569,570,571,572,573,574,575,576,577,581,583$ $584,585,748,749,750,1297)$

Xicoina $(505,506,511,512,513,514,515,516,518,519,529,530,531,553,564,578,579$, $586,587,588,590,591,592,747,753,754,755,1215,1298,1300,1313,1314,1315,1316$, $1321,1330,1337,1338,1341,1342,1347,1348,1349,1350,1351,1353,1354,1352)$

Xicoina de muntanya $(565,566,589)$

\section{USOS MEDICINALS}

Fulla

Diürètic
FONT 1314. DESCRIPCIÓ DE L'ÚS FETA PER L'INFORMANT. Fan orinar. FORMA FARMACĖUTICA I ÚS. Sense forma farmacèutica (ús directe, ús intern). PREPARACIÓ. Se les mengen amanides. DESTINACIÓ. Medicina humana.

Hematocatàrtic

FONTS 554, 555, 1215, 1341, 1342, 1352. DESCRIPCIÓ DE L'ÚS FETA PELS INFORMANTS. És un purificant de la sang $(554,555)$. És bona per a la sang, la purifica (1215). Netegen molt la sang $(1341,1342)$. Per a netejar la sang (1352). FORMA FARMACĖUTICA I ÚS Sense forma farmacèutica (ús directe, ús intern). PREPARACIÓ Fulles per a amanir $(554,555)$. Menjades amanides $(1341,1342)$. Menjades en amanida (1352). DESTINACIÓ. Medicina humana.

\section{USOS ALIMENTARIS}

Fulla

Ingestió de la part de la planta crua - Fresca (sense preparació)

FONTS 505, 506, 511, 512, 513, 514, 515, 516, 518, 519, 520, 521, 528, 529, 530, 531, 532 $538,539,540,541,546,547,548,549,552,553,554,555,556,557,558,559,564,565$, $566,567,569,570,571,572,573,574,575,576,577,578,579,581,583,584,585,586$, $587,588,589,590,591,592,747,748,749,750,753,754,755,1297,1298,1300,1313$, $1314,1315,1316,1321,1330,1337,1338,1341,1342,1347,1348,1349,1350,1351,1352$, 1353. DESCRIPCIÓ DE L'ÚS FETA PELS INFORMANTS. Les de muntanya són molt bones $(505,506)$. Es mengen amanides a la primavera $(511,512,513,514)$. Per a amanir $(515$, $516,518,519,520,521,528,529,530,531,532,538,541,552,553,556,557,558,559$ $565,566,569,570,571,572,573,574,575,576,577,578,579,583,584,585,586,587$ $588,589,590,591,592,748,749,750,1321,1352)$. Les de muntanya són bones amanides (747). Es $(547,548)$. Les menjavem amanides $(549)$. Per a amanir. Aquil a casa en mengem moltes, dematí, migdia i vespre. Es un purificant de la sang (554, 555). Per a menjar amanides (581, $753,754,755,1315,1316)$. Quan són tendres, amanides (564). Les fulles amanides a la primavera (1297). En van a buscar i en mengen amanides (1300). Les fulles abans que floreixi, quan són ben tendres per a amanir (1313). Se les mengen amanides (1314). Es menja amanida (1330). Menjades amanides $(1341,1342)$. Per a amanir, a la primavera $(1347,1348,1349)$. Per a menjar amanit $(1350,1351)$. Per a amanir a la primavera (1353) DESTINACIÓ. Alimentació humana $(505,506,511,512,513,514,515,516,518,519,520$, $521,528,529,530,531,532,538,539,540,541,546,547,548,549,552,553,554,555$, $556,557,558,559,564,565,566,567,569,570,571,572,573,574,575,576,577,578$ $579,581,583,584,585,586,587,588,589,590,591,592,747,748,749,750,753,754$ $755,1297,1298,1300,1313,1314,1315,1316,1321,1330,1337,1338,1341,1342,1347$. 1348, 1349, 1350, 1351, 1352, 1353).

Ingestió de la part de la planta cuita - Cuita sense vehicle

FONT 1354. DESCRIPCIÓ DE L'ÚS FETA PER L'INFORMANT. Per a amanir a la primavera. DESTINACIÓ. Alimentació humana.

\section{Part aèria}


Apèndix 1. Catàleg de tàxons.

Ingestió de la part de la planta crua - Fresca (sense preparació)

FONTS 568, 590. DESCRIPCIÓ DE L'ÚS FETA PELS INFORMANTS. Es donaven als conills (568). Per a donar als conills (590). DESTINACIÓ. Alimentació animal $(568,590)$.

\section{ALTRES USOS}

Flor

Altres informacions

FONT 1215. DESCRIPCIÓ DE L'ÚS FETA PER L'INFORMANT. Amb les flors en fan coses.

Fulla

Altres informacions

FONT 1298. DESCRIPCIÓ DE L'ÚS FETA PER L'INFORMANT. Recorda que abans al temps de la misèria passaven dones que n'havien anat a collir a la muntanya i les venien, un plat valia 10 cèntims.

\section{ALTRES OBSERVACIONS}

FONTS 520, 521, 529, 530, 531, 549, 571, 578, 579, 1215. DESCRIPCIÓ FETA PELS INFORMANTS. S'anaven a buscar al Pla d'Anyella $(529,530,531)$. Es fa a dalt la muntanya $(520,521)$. A la Cubil n'anàvem a buscar $(549)$. N'hi ha moltes al Pla d'Anyella (571). Aquí no n'hi ha, s'ha d'anar més cap a la muntanya $(578,579)$. Les tendres es fan en les talperes [dit "tupiners"] (1215).

\section{BARREGES AMB AQUEST TÀXON}

Arrel

FONTS 529, 530, 531. Entrevista 53, barreja IX (vegeu catàleg de barreges)

\section{Taraxacum officinale Weber in Wiggers (compostes)}

BCN 25015

\section{NOMS POPULARS}

Pixacans $(528,532,533,534,539,540,547,548,549,553,567,569,570,571,572,573$ $574,575,576,577,580,748,749,1213,1214)$

Pixallits $(507,509,510,524,536,537,541,549,1213,1214,1352,1361,1362)$

Xicoia d'horta $(583,584,585)$

Xicoina $(505,506,564,565,566,589,1307,1308,1309,1327,1335)$

Xicoina de prat $(1330)$

\section{USOS MEDICINALS}

Fulla

Diürètic

FONTS 507, 509, 510. DESCRIPCIÓ DE L'ÚS FETA PELS INFORMANTS. És diürètica. FORMA FARMACĖUTICA I ÚS. Tisana (ús intern). PREPARACIÓ. Decocció. Aigua de les fulles. DESTINACIÓ. Medicina humana.

\section{Inflorescència}

Antihipertensiu

FONTS 536, 537. DESCRIPCIÓ DE L'ÚS FETA PELS INFORMANTS. Per a fer baixar la pressió. FORMA FARMACEUTICA I ÚS. Tisana (ús intern). PREPARACIO. Decocció. Aigua de les flors. DESTINACIO. Medicina humana.

Hipoglucemiant

FONTS 1307, 1308, 1309, 1327, 1335. DESCRIPCIÓ DE L'ÚS FETA PELS INFORMANTS Va bé per al sucre $(1307,1308,1309)$. Per a fer baixar el sucre $(1327,1335)$. FORMA FARMACEUTICA I ÚS. Tisana (ús intern). PREPARACIO. N'agafa cinc o sis flors i en fa una infusió $(1307,1308,1309)$. Infusió de les flors (1327). Decocció. Aigua de la flor (1335). MODE D'UTILITZACIÓ/POSOLOGIA. Es pren durant nou dies (novena) $(1307,1308,1309$ ). DESTINACIÓ. Medicina humana. OBSERVACIONS, Diuen que els sembla que això de $\operatorname{dir}(1307,1308,1309)$.

Làtex

Antiberrugós

FONTS 1361, 1362. DESCRIPCIÓ DE L'ÚS FETA PELS INFORMANTS. Per a les berrugues. FORMA FARMACĖUTICA I ÚS. Sense forma farmacèutica (ús directe, ús extern). DESTINACIÓ. Medicina humana.

\section{No consta}

Hematocatàrtic

FONTS 574, 575, 576, 577. DESCRIPCIÓ DE L'ÚS FETA PELS INFORMANTS. Per a purificar la sang. FORMA FARMACĖUTICA I ÚS. Desconegut per l'informant. DESTINACIÓ. Medicina humana.

\section{Planta sencera}

Hematocatàrtic

FONT 1330. DESCRIPCIÓ DE L'ÚS FETA PER L'INFORMANT. Per a depurar la sang FORMA FARMACĖUTICA I ÚS. Tisana (ús intern). PREPARACIÓ. Decocció. Aigua de tota la planta amb arrel. MODE D'UTILITZACIÓ/POSOLOGIA. Fent novenes. DESTINACIÓ. Medicina humana.

Hipoglucemiant

FONT 1330. DESCRIPCIÓ DE L'ÚS FETA PER L'INFORMANT. Per a fer baixar el sucre. FORMA FARMACĖUTICA I ÚS. Tisana (ús intern). PREPARACIÓ. Decocció. Aigua de tota 
la planta amb arrel. MODE D'UTILITZACIÓ/POSOLOGIA. Fent novenes. DESTINACIÓ. Medicina humana.

\section{USOS ALIMENTARIS}

Arrel

Condiment

FONT 580. DESCRIPCIÓ DE L'ÚS FETA PER L'INFORMANT. La rel, la meva consogra la posa als guisats diu que refresca. DESTINACIÓ. Alimentació humana.

\section{Fulla}

Ingestió de la part de la planta crua - Fresca (sense preparació)

FONTS 505, 506, 524, 528, 532, 533, 534, 539, 540, 547, 548, 553, 565, 566, 574, 575, 576 $577,583,584,585,589,748,749,1213,1214$. DESCRIPCIÓ DE L'ÚS FETA PELS INFORMANTS. Per a menjar amanit, és amargant (528). Les d'aquí baix han de ser molt tendres, si no amarguen molt $(505,506)$. Si són ben tendres també són bones amanides $(748,749)$. Quan són tendres es mengen amanits (524). Per a amanir (532, 533, 534, 553, $589)$. Es mengen amanits $(539,540)$. També es poden amanir si són ben tendres $(547,548)$ Quan són ben tendres són bones amanides $(565,566)$. Per a amanir. També són bones, però és més fina la de muntanya $(583,584,585)$. Per a amanir quan són tendres $(574,575$ $576,577)$. DESTINACIÓ Alimentació humana $(505,506,524,528,532,533,534,530,540$, $547,548,553,565,566,574,575,576,577,583,584,585,589,748,749,1213,1214)$. Alimentació animal $(1213,1214)$.

Ingestió de la part de la planta cuita - Cuita en aigua

FONT 528. DESCRIPCIÓ DE L'ÚS FETA PER L'INFORMANT. Hi ha gent que se la menja com a verdura. DESTINACIÓ. Alimentació humana.

\section{Part aèria}

Ingestió de la part de la planta crua - Fresca (sense preparació)

FONTS 541, 564, 567, 569, 570, 572, 573. DESCRIPCIÓ DE L'ÚS FETA PELS INFORMANTS. Per als conills. DESTINACIÓ. Alimentació animal.

\section{ALTRES USOS}

Inflorescència

Cosmètic

FONT 549. DESCRIPCIÓ DE L'ÚS FETA PER L'INFORMANT. La flor passada pel túrmix barrejada amb llard és una crema per a la cara.

Planta viva in situ

Creences i pràctiques magicoreligioses

FONTS 528, 1352. DESCRIPCIÓ DE L'ÚS FETA PELS INFORMANTS. Diuen que si la mainada hi juguen, es pixen al llit (528). Deien que si tocaves els pixallits et pixaves al llit (1352).

\section{Taxus baccata L. (taxàcies)}

\section{BCN 25017}

\section{NOMS POPULARS}

Arbre quiner $(554,555)$

Quina $(591,592)$

Quiner $(511,512,513,514,1322)$

Teix $(511,512,513,514,520,521,541,561,562,563,1352)$

\section{USOS MEDICINALS}

Parènquima cortical

\section{Anticatarral}

FONTS 541, 561, 562, 563. DESCRIPCIÓ DE L'ÚS FETA PELS INFORMANTS. Per a fer bafs quan estàs constipat (541). Per als refredats $(561,562,563)$. FORMA FARMACĖUTICA I ÚS. Aerosol (ús intern) (541). Tisana (ús intern) $(561,562,563)$. PREPARACIÓ. Decocció (541, 561,562 563). EFECTES SECUNDARIS Sí. DESTINACIÓ Medicina humana. OBSERVACIONS. Però deien que no es fes gaire perquè és una mica tòxic (541).

Antisèptic extern

FONTS 511, 512, 513, 514, 520, 521, 591, 592. DESCRIPCIÓ DE L'ÚS FETA PELS INFORMANTS. Per a desinfectar $(520,521)$. Per a desinfectar ferides $(511,512,513,514)$. Per a netejar mals $(591,592)$. FORMA FARMACĖUTICA I ÚS. Bany (ús extern). PREPARACIÓ. Decocció. La pela (quina) bullida, fa l'aigua ben vermella, segurament per això se'n diu quina $(520,521)$. Decocció. S'utilitza la segona escorça i s'aplica tan calenta això se'n diu quina $(520,521)$. Decocció. S'utilitza la segona escorça i s'aplica tan calenta
com puguis $(511,512,513,514)$. Decocció $(591,592)$. DESTINACIÓ. Medicina humana. Com puguis $(511,512,513,514)$. Decocció $(591,592)$. D
OBSERVACIONS. Sempre teniem brocs de quina $(591,592)$

Desconegut per l'informant

FONT 1322. FORMA FARMACĖUTICA I ÚS. Desconegut per l'informant. DESTINACIÓ. Medicina humana. OBSERVACIONS. La segona pela del quiner, recorda que la receptava un curandero de Cavallera, però no recorda per a què.

\section{ALTRES USOS}

Fruit

Lúdic: jocs i joguines

FONT 1352. DESCRIPCIÓ DE L'ÚS FETA PER L'INFORMANT. Els arils dels teixos eren el dinar de les nines.

Parènquima cortical 


\section{Cosmètic}

FONTS 520, 521. DESCRIPCIÓ DE L'ÚS FETA PELS INFORMANTS. Una parenta nostra per a fer créixer el cabell feia bullir aigua de pela de teix i llavors hi barrejava una o dues pastilles de sublimat (farmàcia) i s'hi rentava cada dia el cap.

\section{ACCIONS NOCIVES O TÒXIQUES}

\section{No consta}

FONT 541. DESCRIPCIÓ DE L'ACCIÓ NOCIVA O TÒXICA FETA PER L'INFORMANT. Però deien que és una mica tòxic. VIA D'INTOXICACIÓ. Via interna. TOXICITAT LLIGADA A L'ÚS MEDICINAL. Sí.

\section{BARREGES AMB AQUEST TÀXON}

Parènquima cortical

FONTS 554, 555. Entrevista 78, barreja IV (vegeu catàleg de barreges)

\section{Teucrium chamaedrys L. (labiades)}

BCN 2131

\section{NOMS POPULARS}

Timó (750)

\section{USOS MEDICINALS}

\section{Part aèria}

Anticatarral

FONT 750. DESCRIPCIÓ DE L'ÚS FETA PER L'INFORMANT. Per a quan estàs constipat. FORMA FARMACĖUTICA I ÚS. Aerosol (ús intern). PREPARACIÓ. Bafs. DESTINACIÓ. Medicina humana.

\section{ALTRES OBSERVACIONS}

FONT 750. DESCRIPCIÓ FETA PER L'INFORMANT. Semblant a la farigola (Thymus vulgaris), però més grossa, i no fa tanta olor.

\section{Teucrium polium L. (labiades)}

BCN 25018

\section{NOMS POPULARS}

Herba felera $(518,519,753,754,755,1299,1324)$

\section{USOS MEDICINALS}

Part aèria

Antiictèric

FONTS $518,519,753,754,755$. DESCRIPCIÓ DE L'ÚS FETA PELS INFORMANTS. Per al fel. FORMA FARMACĖUTICA I ÚS. Tisana (ús intern). PREPARACIÓ. Decocció. DESTINACIÓ. Medicina humana.

Antinauseabund

FONT 1299. DESCRIPCIÓ DE L'ÚS FETA PER L'INFORMANT. Quan estàs marejat t'ho fa tirar amunt o avall. FORMA FARMACĖUTICA I ÚS. Tisana (ús intern). DESTINACIÓ. Medicina humana.

Hepatoprotector

FONT 1324. DESCRIPCIÓ DE L'ÚS FETA PER L'INFORMANT. Per al fetge. FORMA FARMACĖUTICA I ÚS. Tisana (ús intern). PREPARACIÓ. Decocció. DESTINACIÓ. Medicina humana.

\section{ALTRES OBSERVACIONS}

FONTS 518, 519, 753, 754, 755. DESCRIPCIÓ FETA PELS INFORMANTS. A Bianya n'hi ha $(518,519)$. És blanquinosa i fa fortor de fel, allò tant amargant $(518,519)$. N'hi ha cap a Sant Salvador de Bianya $(753,754,755)$.

\section{Thymus serpyllum L. (labiades)}

\section{BCN 25019}

\section{NOMS POPULARS}

Farigola (588)

Farigola borda (588)

Farigola de muntanya (1317)

Farigolet $(1332,1333,1334)$

Farigoleta $(504,535,559,574,575,576,577,1293,1294,1300,1319,1322,1328,1329$, $1335,1339,1340,1347,1348,1349,1361,1362)$

Farigoleta de pastor $(753,754,755,1350,1351)$

Salseta de pastor $(1213,1214)$

Serpol $(569,570)$

Serpoll $(1213,1214,1321,1324)$ 
Apèndix 1. Catàleg de tàxons.

Timó $(518,519)$

\section{USOS MEDICINALS}

Part aèria florida

Antiasmàtic

FONT 1321. DESCRIPCIÓ DE L'ÚS FETA PER L'INFORMANT. Per a l'asma. FORMA FARMACĖUTICA I ÚS. Tisana (ús intern). PREPARACIÓ. Decocció. DESTINACIÓ. Medicina humana.

Anticatarral

FONTS 504, 1300, 1317. DESCRIPCIÓ DE L'ÚS FETA PELS INFORMANTS. Per als refredats $(504,1317)$. Per a constipats $(1300)$. FORMA FARMACĖUTICA I ÚS. Tisana (ús intern). PREPARACIÓ. Decocció $(504,1300)$. Aigua de farigola amb mel i llimona (1317) intern). PREPARACIO. Decocció
DESTINACIÓ. Medicina humana.

Antidiarreic

FONTS $518,519,1293,1335,1339,1340,1350,1351$. DESCRIPCIÓ DE L'ÚS FETA PELS INFORMANTS. Per a la diarrea $(518,519)$. Per a les diarrees $(1293,1335,1350,1351)$. Per a la diarrea del bestiar $(1339,1340)$. FORMA FARMACĖUTICA I ÚS. Tisana (ús intern). PREPARACIÓ. Decocció $(518,519,1293,1335)$. En infusió $(1339,1340)$. DESTINACIÓ. Medicina humana $(518,519,1293,1350,1351)$. Medicina humana i veterinària (1335). Medicina humana $(518,519,1293,1350,1351)$. Medicina humana i veterinària (1335),
Medicina veterinària $(1339,1340)$. OBSERVACIONS. Als vedells els ho dóna amb biberó (1335).

Antiinflamatori intestinal

FONTS 535, 1293, 1294, 1328, 1329. DESCRIPCIÓ DE L'ÚS FETA PELS INFORMANTS. Quan les bèsties estan malament de la panxa (535). Va bé per a la panxa (535). Per al ventre (1293). Per a mals de ventre (1294). Per al mal de ventre $(1328,1329)$. FORMA FARMACĖUTICA I ÚS. Tisana (ús intern). PREPARACIÓ. Decocció $(535,1293,1294,1328$ 1329). DESTINACIÓ. Medicina veterinària (535). Medicina humana $(535,1293,1294,1328$ 1329).

Antisèptic extern

FONTS 559, 574, 575, 576, 577, 1213, 1214, 1317, 1319, 1322, 1347, 1348, 1349 DESCRIPCIÓ DE L'ÚS FETA PELS INFORMANTS. Serveix com la farigola (Thymus vulgaris), com a desinfectant (559). Per a desinfectar (574, 575, 576, 577, 1213, 1214, 1319, $1347,1348,1349)$. Per a desinfectar ferides $(1317,1322)$. FORMA FARMACĖUTICA I ÚS Bany (ús extern). PREPARACIO. Decocció $(559,574,575,576,577,1213,1214,1317$ $1319,1322,1347,1348,1349)$ DESTINACIÓ Medicina humana OBSERVACIONS. És una planta parenta de la farigola (Thymus vulgaris) i en té les mateixes propietats $(1213,1214)$. ymus vulgaris) la fa servir $(1347,1348,1349)$

Antisèptic intern

FONTS 559, $574,575,576,577,588,1319,1322,1347,1348,1349$. DESCRIPCIÓ DE L'ÚS FETA PELS INFORMANTS. Serveix com la farigola (Thymus vulgaris), com a desinfectant
(559). Per a desinfectar $(574,575,576,577,588,1319,1322,1347,1348,1349)$. FORMA FARMACĖUTICA I ÚS. Tisana (ús intern). PREPARACIÓ. Decocció (559, 574, 575, 576 $577, \quad 588,1319,1322,1347,1348,1349)$. DESTINACIÓ. Medicina humana OBSERVACIONS. És millor que la farigola (Thymus vulgaris) (1322). Si no té farigola OBSERVACIONS. Es millor que la farigola (Thy
(Thymus vulgaris) la fa servir $(1347,1348,1349)$.

Antitussigen

FONTS 569, 570, 1324. DESCRIPCIÓ DE L'ÚS FETA PELS INFORMANTS. Per a la tos $(569,570)$. Per a quan tens mal al pit, és calmant de la tos i expectorant (1324). FORMA FARMACEUTICA I ÚS. Tisana (ús intern) $(569,570)$. Essència (ús intern) (1324). PREPARACIÓ. Decocció $(569,570)$. MODE D'UTILITZACIÓ/POSOLOGIA. Se'n prenen tres PREPARACIO. Decocció $(569,570)$. MODE D
gotes (1324). DESTINACIÓ. Medicina humana.

gotes (132 FONTS 1324, 1361, 1362. DESCRIPCIÓ DE L'ÚS FETA PELS INFORMANTS. És digestiva
$(1324,1361,1362)$. FORMA FARMACĖUTICA I ÚS. Tisana (ús intern). PREPARACIÓ. (1324, 1361, 1362). FORMA FARMACEUTICA I US. Tisana (ús intern).
Decocció (1324). En infusió $(1361,1362)$. DESTINACIÓ. Medicina humana.

Estomacal

FONTS 588, 1332, 1333, 1334. DESCRIPCIÓ DE L'ÚS FETA PELS INFORMANTS. Per a l'estómac (588). Per al mal d'estómac (1332, 1333, 1334). FORMA FARMACĖUTICA I ÚS.
Tisana (ús intern). PREPARACIÓ. Decocció (588, 1332, 1333, 1334). DESTINACIÓ. Tisana (ús intern)

Expectorant

FONT 1324. DESCRIPCIÓ DE L'ÚS FETA PER L'INFORMANT. Per a quan tens mal al pit, és calmant de la tos i expectorant. FORMA FARMACĖUTICA I ÚS. Essència (ús intern). MODE D'UTILITZACIÓ/POSOLOGIA. Se'n prenen tres gotes. DESTINACIÓ. Medicina humana.

\section{USOS ALIMENTARIS}

\section{Part aèria}

Condiment

FONTS 1347, 1348, 1349. DESCRIPCIÓ DE L'ÚS FETA PELS INFORMANTS. Per a posar als cuinats. DESTINACIÓ. Alimentació humana.

\section{Part aèria florida}

Condiment

FONT 588. DESCRIPCIÓ DE L'ÚS FETA PER L'INFORMANT. Per a posar a la vedella. DESTINACIÓ. Alimentació humana.

Preparació de begudes - Beguda preparada amb aiguardent

FONT 588. DESCRIPCIÓ DE L'ÚS FETA PER L'INFORMANT. Ratafia. Abans sí que n'havia fet hi posava 14015 herbes, no me'n recordo de totes. Nous verdes (Juglans regia), farigola (Thymus serpyllum), nou moscada (Myristica fragrans), marialluïsa (Lippia triphylla), menta 
(Mentha spicata), orenga (Origanum vulgare) i poniol (Satureja calamintha subsp. ascendens). DESTINACIÓ. Alimentació humana.

\section{ALTRES OBSERVACIONS}

FONTS 518, 519, 1319. DESCRIPCIÓ FETA PELS INFORMANTS. Creix arrapada al terra, és peluda i vermellosa. Se'n fa als solells de la Vall del Bac $(518,519)$. La que tenim aquí dalt (1319)

\section{BARREGES AMB AQUEST TÀXON}

\section{Part aèria florida}

FONTS 753, 754, 755. Entrevista 67, barreja III (vegeu catàleg de barreges)

\section{Thymus vulgaris L. (labiades)}

BCN 25023

\section{NOMS POPULARS}

Farigola $(503,504,505,506,507,509,510,511,512,513,514,517,520,521,524,528$, $529,530,531,532,536,537,538,539,540,541,542,543,544,545,546,547,548,549$ $552,553,554,555,556,557,558,559,560,561,562,563,564,565,566,567,568,569$, $570,571,572,573,574,575,576,577,578,579,580,581,582,583,584,585,586,587$ $589,590,591,592,746,747,750,751,752,753,754,755,1210,1213,1214,1293,1294$ $1296,1298,1299,1300,1301,1307,1308,1309,1310,1311,1312,1313,1314,1315,1316$ $1317,1318,1319,1320,1321,1323,1324,1325,1326,1327,1328,1329,1330,1331,1332$ $1333,1333,1334,1335,1336,1337,1338,1339,1340,1341,1342,1343,1344,1345,1346$ $1347,1348,1349,1350,1351,1353,1354,1352,1361,1362)$

Farigola de muntanya (588)

Timó $(517,518,519,522,523,529,530,531,583,584,585)$

\section{USOS MEDICINALS}

\section{Part aèria florida}

Anticatarral

FONTS 549, 552, 561, 562, 563. DESCRIPCIÓ DE L'ÚS FETA PELS INFORMANTS. Per a quan estàs constipat (552). Per als refredats (549). Per als constipats $(561,562,563)$ FORMA FARMACEUTICA I ÚS. Tisana (ús intern) $(549,552)$. Melit (ús intern) $(561,562$ 563). PREPARACIÓ. Decocció $(549,552)$. Decocció. Amb mel $(561,562,563)$ DESTINACIÓ. Medicina humana. OBSERVACIONS. És molt bona, diuen que ho cura tot (549).

Antidiarreic
FONTS 591, 592, 1213, 1214, 1331, 1335. DESCRIPCIÓ DE L'ÚS FETA PELS INFORMANTS. Per a la diarrea dels vedells $(501,502)$. Per a la diarrea $(1213,1214,1331$ 1335). FORMA FARMACEUTICA I ÚS. Tisana (ús in Pr). PREPARACIÓ. Decoció (591, 1335). FORMA FARMACEUTICA I US. Tisana (ús inte $)$. PREPARACIO. Decocció (591, $1214,1331,1335)$

Antiestàtic ruminal

FONT 581. DESCRIPCIÓ DE L'ÚS FETA PER L'INFORMANT. Quan les vaques perden la capacitat del remuc, que normalment és perquè han pres massa productes químics. FORMA FARMACĖUTICA I ÚS. Tisana (ús intern). PREPARACIÓ. Decocció. Vuit litres d'aigua de farigola. DESTINACIÓ. Medicina veterinària. OBSERVACIONS. També els donava uns sobres del veterinari.

Antihemorroïdal

FONTS 518, 519. DESCRIPCIÓ DE L'ÚS FETA PELS INFORMANTS. Per a banyar les morenes. FORMA FARMACĖUTICA I ÚS. Bany (ús extern). DESTINACIÓ. Medicina humana.

Antihipertensiu

FONTS 529, 530, 531, 1328, 1329, 1361, 1362. DESCRIPCIÓ DE L'ÚS FETA PELS INFORMANTS. Per a fer baixar la pressió $(529,530,531,1361,1362)$. Per a baixar la pressió $(1328,1329)$. FORMA FARMACĖUTICA I ÚS. Tisana (ús intern). PREPARACIÓ. Decocció $(529,530,531,1328,1329,1361,1362)$. DESTINACIÓ. Medicina humana. OBSERVACIONS. A ella no li va bé $(1328,1329)$.

Antiinflamatori

FONTS 507, 509, 510, 580. DESCRIPCIÓ DE L'ÚS FETA PELS INFORMANTS. Quan neixen els vedells, de vegades se'ls inflama el llombrígol i els el rentàvem amb aigua de farigola $(507,509,510)$. Per a rentar ferides, desinfecta i desinflama (580). FORMA FARMACĖUTICA I ÚS. Bany (ús extern). PREPARACIÓ. Decocció $(507,509,510,580)$ DESTINACIÓ. Medicina veterinària $(507,509,510)$. Medicina humana $(580)$.

Antiinflamatori bucal

FONT 1214. DESCRIPCIÓ DE L'ÚS FETA PER L'INFORMANT. Com a desinfectant bucal, glopejar aigua de farigola. FORMA FARMACĖUTICA I Ús. Colllutori (ús extern). PREPARACIÓ. Decocció. DESTINACIÓ. Medicina humana.

Antiinflamatori faringi

FONTS 567, 1213, 1214, 1313. DESCRIPCIÓ DE L'ÚS FETA PELS INFORMANTS. Per a infeccions de coll (567). Per al mal de coll, es fan gàrgares d'aigua de farigola amb suc de llimona i sucre $(1213,1214)$. Va bé per a tot. És un desinfectant (1313). FORMA FARMACĖUTICA I ÚS. Suspensió (ús intern) (567). Gargarisme (ús extern) (1213, 1214 1313). PREPARACIÓ. Sopes de farigola (567). Decocció $(1213,1214)$. DESTINACIÓ. Medicina humana.

Antiinflamatori intestinal

FONTS 547, 548, 572, 573, 752. DESCRIPCIÓ DE L'ÚS FETA PELS INFORMANTS. Per als mals de panxa i per a desinfectar $(752)$. Quan tens la panxa malament $(547,548)$. Per a la 
panxa (572, 573). FORMA FARMACĖUTICA I ÚS. Tisana (ús intern) $(572,573,752)$. Suspensió (ús intern) $(547,548)$. PREPARACIÓ. Decocció $(572,573,752)$. Prendre amb sopa de pa $(547,548)$. DESTINACIÓ Medicina humana i veterinària $(752)$. Medicina humana $(547,548,572,573)$. OBSERVACIONS. També es feia servir molt per al bestiar (752).

Antiodontàlgic

FONTS 549, 558, 1213, 1214. DESCRIPCIÓ DE L'ÚS FETA PELS INFORMANTS. Per al mal de queixals (549). També va bé per a glopejar quan et fan mal els queixals (558). Per al mal de queixal, glopejar aigua de farigola $(1213,1214)$. FORMA FARMACĖUTICA I ÚS. Tisana (ús intern) (549). Col-lutori (ús extern) $(558,1213,1214)$. PREPARACIÓ. Decocció $(549,558,1213,1214)$. DESTINACIÓ. Medicina humana. OBSERVACIONS. És molt bona, $(549,558,1213,1214)$. DEST
diuen que ho cura tot (549).

Antiofídic

FONT 564. DESCRIPCIÓ DE L'ÚS FETA PER L'INFORMANT. Per a mossegades d'escurçó. FORMA FARMACĖUTICA I ÚS. Fumigació (ús extern). PREPARACIÓ. Perfums de farigola. DESTINACIÓ. Medicina veterinària. OBSERVACIONS. Mossegades d'escurçó: una vegada la gossa la va mossegar un escurçó, el primer que vaig fer va ser punxar-li ben punxat amb espinacals (Eryngium campestre), després vaig fer un pipí en un mocador i li vaig apretar una estona, quan vaig arribar a casa li vaig fer perfums de flor de sabuc (Sambucus nigra) i els alternava amb perfums de farigola (Thymus vulgaris). Es va curar, al cap de 48 hores ja menjava.

Antipneumònic

FONT 1319. DESCRIPCIÓ DE L'ÚS FETA PER L'INFORMANT. Per a un vedell que tenia pulmonia. FORMA FARMACEUTICA I ÚS. Aerosol (ús intern). PREPARACIÓ. Bafs. DESTINACIÓ. Medicina veterinària.

Antisèptic bucal

FONTS 547, 548, 1213, 1337, 1338. DESCRIPCIÓ DE L'ÚS FETA PELS INFORMANTS. Va be per a les llagues a la boca (548). Va be per a les llagues de la boca (547). Com a desinfectant bucal, glopejar aigua de farigola (1213). Quan et fa mal la boca, per a desinfectar (1337, 1338). FORMA FARMACEUTICA I ÚS. Col-lutori (ús extern). PREPARACIÓ. Decocció. Millor glopejar amb una punteta de sal $(547,548)$. Decocció (1213). Per a glopejar $(1337,1338)$. DESTINACIÓ. Medicina humana.

Antisèptic extern

FONTS 504, 505, 506, 507, 509, 510, 511, 512, 513, 514, 517, 518, 519, 520, 521, 522, 523 $524,528,529,530,531,532,536,537,542,543,544,546,547,548,549,553,554,555$ $556,557,559,560,561,562,563,564,567,568,569,570,571,572,573,574,575,576$ $577,578,579,580,582,583,584,585,586,587,588,589,590,591,592,747,750,751$ $752,1213,1214,1293,1296,1297,1298,1209,1300,1301,1307,1308,1309,1311,1312$ $1314,1315,1316,1318,1310,1320,1321,1323,1324,1325,1326,1327,1330,1336,1339$ $1340,1311,1342,1343,1344,1345,1346,1347,1348,1349,1350,1351,1352,1353,1354$ DESCRIPCIÓ DE L'ÚS DESCRIPCIO DE LU $563,567,568,569,570,571,574,575,576,577,582,583,584,585,586,587,588,589$
$590,591,592,747,750,1293,1296,1298,1300,1311,1312,1319,1321,1323,1324,1339$, $1340,1341,1342,1345,1346,1347,1348,1349,1350,1351,1352)$. Per a desinfectar, per a rentar ferides $(507,509,510)$. Per a desinfectar ferides $(505,506,524,578,579,1301,1318$ $1320,1327,1343,1344)$. Per a rentar mals $(517)$. Per a rentar ferides $(560,751)$. Decocció. Per als mals de panxa i per a desinfectar (752). És desinfectant, porta antibiòtic (532). Per a netejar [dit "llempiar"], et treu les infeccions $(542,543,544)$. Per a desinfectar mals i també netejar [dit "llempiar"], et treu les infeccions $(542,543,544)$. Per a desinfectar mals i tambe
per a prendre (546). Per a rentar. És molt desinfectant (528). És molt desinfectant, per a per a prendre (546). Per a rentar. Es molt desinfectant (528). Es molt desinfectant, per a desinfectar i per a tot (559). Per a rentar ferides, desinfe (564). Per a desinfectar. És un antibiòtic molt fluix $(572,573)$. Per a desinfectar ferides i infeccions de la pell $(1213,1214)$. És molt bon desinfectant (1297). És la planta més desinfectant que hi ha $(1307,1308,1309)$. Com a desinfectant (1314). Per a desinfectar tant persones com animals $(1315,1316)$. Per a desinfectar ferides del bestiar (1319). Per a aplicar directament a ferides, és molt desinfectant $(1325,1326)$. Per a rentar ferides, és molt desinfectant (1330). És molt desinfectant (1336). Per a rentar mals, desinfecta molt (1353, 1354). FORMA FARMACÈUTICA I ÚS. Bany (ús extern). PREPARACIÓ. Decocció (504 $505,506,507,509,510,511,512,513,514,517,518,519,520,521,522,523,524$ (504 $505,530,531,532,536,537,542,543,514,517,518,519,520,521,522,523,524,528$ $529,530,531,532,536,537,542,543,544,546,547,548,549,553,554,555,556,557$, $579,560,561,562,563,564,567,568,569,570,571,572,573,574,575,576,577,578$ $579,580,582,583,584,585,586,587,588,589,590,591,592,747,750,751,1213,1214$, $1293,1296,1297,1301,1307,1308,1309,1311,1312,1314,1315,1316,1318,1319,1320$, $1321,1323,1324,1325,1326,1327,1330,1336,1339,1340,1341,1342,1343,1344,1345$, 1346, 1347, 1348, 1349, 1350, 1351). Decocció. Aigua de la flor (1298). DESTINACIÓ. Medicina humana $(504,505,506,507,509,510,511,512,513,514,517,518,519,520$, $521,522,523,524,528,529,530,531,532,536,537,542,543,544,546,547,548,549$, $553,554,555,556,557,559,560,561,562,563,564,567,568,569,570,571,572,573$ $574,575,576,577,578,579,580,582,583,584,585,586,587,588,589,590,591,592$, $747,750,751,1213,1214,1293,1296,1297,1298,1299,1300,1301,1307,1308,1309$, $1311,1312,1314,1318,1319,1320,1321,1323,1324,1325,1326,1327,1330,1336,1339$ $13401341,1342,1343,1344,1345,1346,1347,1348,1349,1350,1351,1352,1353$ 1354). Medina 1354). Medicina huma OBSERVACIONS. A mi m'agrada més la de la gangrena (Prunella grandiflora) (517). També es fela servir molt Aer al bestlar (752). És molt bona, diuen que ho cura tot(549). Per a beure és molt forta $(583,584,585)$. Feu servir roba de fil $(1213,1214)$. En tenen sempre $(1307$, 1308, 1309)

Antisèptic gingival

FONTS 1213, 1214. DESCRIPCIÓ DE L'ÚS FETA PELS INFORMANTS. Per a les genives inflamades, glopejar aigua de farigola. FORMA FARMACĖUTICA I ÚS. Col·lutori (ús extern) PREPARACIÓ. Decocció. DESTINACIÓ. Medicina humana.

Antisèptic intern

FONTS 504, 511, 512, 513, 514, 520, 521, 522, 523, 528, 529, 530, 531, 532, 536, 537, 542 , $543,544,546,549,553,554,555,558,559,561,562,563,567,568,569,570,571,572$ $573,574,575,576,577,578,579,580,582,586,588,589,590,591,592,747,750,752$ 1293, 1296, 1297, 1298, 1299, 1300, 1301, 1307, 1308, 1309, 1310, 1311, 1312, 1313, 1314, 
1315, 1316, 1318, 1319, 1320, 1321, 1323, 1324, 1325, 1326, 1327, 1336, 1339, 1340, 1341, $1342,1343,1344,1345,1346,1347,1348,1349,1350,1351,1352$. DESCRIPCIÓ DE L'ÚS FETA PELS INFORMANTS. Per a desinfectar $(504,511,512,513,514,521,522,523,529$, $530,531,536,537,549,553,554,555,561,562,563,567,568,569,570,571,574,575$ $576,577,578,579,580,582,586,588,589,590,591,592,747,750,1293,1296,1298$, $1300,1310,1311,1312,1318,1319,1320,1321,1323,1324,1327,1339,1340,1341,1342$ $1343,1344,1345,1346,1347,1348,1349,1350,1351,1352)$. Per als mals de panxa i per a desinfectar (752). És desinfectant, porta antibiòtic (532). Per a netejar [dit "llempiar"], et treu les infeccions $(542,543,544)$. Per a desinfectar mals i també per a prendre $(546)$. Per a desinfectar (520). Per a beure. És molt desinfectant (528). És molt bona per a desinfectar per a tot (559). Aigua per a netejar i depurar (558). Per a desinfectar a les bèsties quan havien parit (571). Per a desinfectar. És un antibiòtic molt fluix $(572,573)$. És molt bon desinfectant (1297). Per a netejar el cos (1299). Per a prendre (1301). És la planta més desinfectant que hi ha $(1307,1308,1309)$. Va bé per a tot. És un desinfectant $(1313)$. Com desinfectant (1314). Per a desinfectar tant persones com animals $(1315,1316)$. És molt desinfectant $(1325,1326,1336)$. FORMA FARMACEUTICA I US. Tisana (ús intern) (504, ( $511,512,513,514,520,521,522,523,528,529,530,531,532,536,537,542,543,544$ $546,549,553,554,555,558,559,561,562,563,567,568,569,570,571,572,573,574$ $1297,1298,1299,1301,1307,1308,1309,1310,1311,1312,1313,1314,1315,1316,1318$ $1297,1298,1299,1301,1307,1308,1309,1310,1311,1312,1313,1314,1315,1316,1318$ $1319,1320,1321,1323,1324,1325,1326,1327,1336,1339,1340,1341,1342,1343,1344$ $1345,1346,1347,1348,1349,1350,1351,1352)$. Gargarisme (ús extern) (1300). Ėnema (ús intern) $(1350,1351)$. PREPARACIÓ. Decocció $(504,511,512,513,514,520,521,522,523$ $528,529,530,531,532,536,537,542,543,544,546,549,553,554,555,558,559,561$ $562,563,567,568,569,570,571,572,573,574,575,576,577,578,579,580,582,586$ $588,589,591,592,747,750,752,1293,1296,1297,1301,1307,1308,1309,1311,1312$ $1314,1315,1316,1318,1319,1320,1321,1323,1324,1325,1326,1327,1336,1339,1340$ $1341,1342,1343,1344,1345,1346,1347,1348,1349,1350,1351)$. Ús intern (590). Decocció. Aigua de la flor (1298). En lavativa (1350, 1351). MODE D'UTILITZACIO/POSOLOGIA. Durant 9 dies (1299). DESTINACIO. Medicina humana (504 $511,512,513,514,520,521,522,523,528,529,530,531,532,536,537,542,543,544$ $546,549,553,554,555,558,559,561,562,563,567,568,569,570,571,572,573,574$ $575,576,577,578,579,580,582,586,588,589,590,591,592,747,750,1293,1296,1297$ $1298,1299,1300,1301,1307,1308,1309,1310,1311,1312,1314,1318,1319,1320,1321$ $1323,1324,1325,1326,1327,1336,1339,1340,1341,1342,1343,1344,1345,1346,1347$ $1348,1349,1350,1351,1352)$. Medicina humana i veterinària $(752,1313,1315,1316)$ Medicina veterinària (571). OBSERVACIONS. També es feia servir molt per al bestiar (752) És molt bona, diuen que ho cura tot (549). En Mariano va tenir càncer de coll, i diu que va tenir sort d'aquesta planta, va fer gàrgares tres setmanes tres cops al dia fins que li va dona de baixa i només li van fer tractament però no el van haver d'operar. Aquesta cura, la hi va dir el metge (1300). En tenen sempre $(1307,1308,1309)$.

Antisèptic ocular

FONTS 511, 512, 513, 514, 1213, 1214, 1315, 1316, 1337, 1338, 1350, 1351. DESCRIPCIO DE L'US FETA PELS INFORMANTS. Per a banyar els ulls, diuen que porta antibiòtic (511, $512,513,514)$. Per a netejar els ulls, es fan banys $(1213,1214)$. Per a ulls malalts (1315
1316). Per als ulls, per a desinfectar $(1337,1338)$. Per als ulls malalts $(1350,1351)$. FORMA FARMACĖUTICA I ÚS. Bany (ús extern). PREPARACIÓ. Decocció $(511,512,513,514$, $1315,1316,1337,1338,1350,1351)$. Decocció. Aigua ben bullida amb un polsim de sal $(1213,1214)$. DESTINACIÓ. Medicina humana $(511,512,513,514,1213,1214,1315,1316$ 1337, 1338, 1350). Medicina humana i veterinària (1351). OBSERVACIONS. No n'abuseu, perquè pot fer pujar la pressió ocular $(1213,1214)$

perquè pot fer pujar la p
Coadjuvant del part

FONT 564. DESCRIPCIÓ DE L'ÚS FETA PER L'INFORMANT. A can França la feien servir per ajudar a parir una bèstia, les rentaven amb farigola. També els en feien lavatives. Medicina veterinària.

Digestiu

FONT 581. DESCRIPCIÓ DE L'ÚS FETA PER L'INFORMANT. Quan tens l'estómac inflamat perquè has anat a un convit i has menjat massa. $\mathrm{Si}$ et prens l'aigua de farigola no fa el mateix, fa molt més efecte les sopes de pa, actua com a esponja i et va posant l'estómac a to de mica en mica. FORMA FARMACĖUTICA I ÚS. Suspensió (ús intern). PREPARACIÓ. Sopa escaldada amb aigua de farigola. DESTINACIÓ. Medicina humana.

\section{Estomacal}

FONTS 1213, 1214. DESCRIPCIÓ DE L'ÚS FETA PELS INFORMANTS. Per al mal d'estómac. FORMA FARMACĖUTICA I ÚS. Tisana (ús intern). DESTINACIÓ. Medicina humana.

Hipolipemiant

FONT 549. DESCRIPCIÓ DE L'ÚS FETA PER L'INFORMANT. Baixa el colesterol. FORMA FARMACĖUTICA I ÚS. Tisana (ús intern). PREPARACIÓ. Decocció. DESTINACIÓ. Medicina humana. OBSERVACIONS. És molt bona, diuen que ho cura tot.

Per a l'afonia

FONTS 1213, 1214. DESCRIPCIÓ DE L'ÚS FETA PELS INFORMANTS. Per a l'afonia, es fan gàrgares d'aigua de farigola amb suc de llimona i sucre. FORMA FARMACĖUTICA I ÚS. Gargarisme (ús extern). PREPARACIÓ. Decocció. DESTINACIÓ. Medicina humana.

Per al panadís

FONTS 1213, 1214. DESCRIPCIÓ DE L'ÚS FETA PELS INFORMANTS. Per als voltadits. FORMA FARMACĖUTICA I ÚS. Bany (ús extern). PREPARACIÓ. Decocció. DESTINACIÓ. Medicina humana. OBSERVACIONS. Feu servir roba de fil.

Resolutiu

FONT 1319. DESCRIPCIÓ DE L'ÚS FETA PER L'INFORMANT. Un dels meus germans petits, va tenir un vesper (bony ple de pus) al coll i l'hi van curar només banyant-l'hi amb aigua de farigola. FORMA FARMACÉUTICA I ÚS. Bany (ús extern). PREPARACIÓ. Decocció. DESTINACIÓ. Medicina humana.

Salutífer

FONTS 1213, 1214. DESCRIPCIÓ DE L'ÚS FETA PELS INFORMANTS. Si voleu prevenir els constipats d'hivern. FORMA FARMACĖUTICA I ÚS. Tisana (ús intern). MODE 
Apèndix 1. Catàleg de tàxons.

D'UTILITZACIÓ/POSOLOGIA. Nou dies seguits, abans d'anar a dormir al mes d'octubre. S us en voleu assegurar, podeu fer una altra novena després d'haver descansat uns nou dies. DESTINACIÓ. Medicina humana.

Tònic

FONT 538. DESCRIPCIÓ DE L'ÚS FETA PER L'INFORMANT. Me'n prenc quan estic cansat, et fa passar la set, et neteja la panxa i sembla que et refà. FORMA FARMACĖUTICA I ÚS Suspensió (ús intern). PREPARACIÓ. Sopes de pa ben clares amb un brot de farigola. A vegades m'hi poso un parell de rostes de cansalada. DESTINACIÓ. Medicina humana.

Vulnerari

FONTS 1294, 1297. DESCRIPCIÓ DE L'ÚS FETA PELS INFORMANTS. Per a les llagues, quan a una persona no li va bé res de la farmàcia, la farigola fa miracles (1294). Per a desinfectar les ferides del bestiar (1297). FORMA FARMACĖUTICA I ÚS. Bany (ús extern). PREPARACIÓ. Se'n feia aigua (1297). DESTINACIÓ. Medicina humana (1294). Medicina veterinària (1297). OBSERVACIONS. Ella només cull les puntes florides (1294).

\section{USOS ALIMENTARIS}

\section{Flor}

Ingestió de la part de la planta cuita - Cuita en aigua

FONT 581. DESCRIPCIÓ DE L'ÚS FETA PER L'INFORMANT. Per a fer una sopa per caprici, la fas just amb les flors que cauen quan asseques la planta i és molt més suau i molt bona. DESTINACIÓ. Alimentació humana.

\section{Condiment}

FONTS 1213, 1214, 1317, 1319, 1325, 1326, 1327, 1336, 1337, 1338, 1341, 1342, 1352 DESCRIPCIO DE L'ÚS FETA PELS INFORMANTS. És un bon condiment per a la carn $(1213,1214)$. Per a donar gust (1317). Sopa de pa amb farigola (1319). Per a donar gust als rostits $(1325,1326)$. Per a afegir els rostits $(1327)$. Per a als rostits $(1336)$. Per als cuinats $(1337,1338)$. Per a donar gust als cuinats $(1341,1342)$. La meva padrina l'usava per a cuinar (1352). OBSERVACIONS. És molt bona (1319). Els seus menjars eren molt especiats i molt bons (1352). DESTINACIÓ. Alimentació humana $(1213,1214,1317,1319,1325,1326,1327$. 1336, 1337, 1338, 1341, 1342, 1352)

Ingestió de la part de la planta cuita - Cuita en aigua

FONTS 1213, 1214. DESCRIPCIÓ DE L'ÚS FETA PELS INFORMANTS. Sopa de pa amb aigua de farigola. DESTINACIÓ. Alimentació humana.

\section{Part aèria florida}

Condiment

FONTS 511, 512, 513, 514, 528, 545, 560, 569, 570, 571, 590, 591, 592, 746. DESCRIPCIÓ DE L'ÚS FETA PELS INFORMANTS. Per a guisar (746). Per a donar gust als cuinats (511, $512,513,514)$. Per posar als guisats $(545)$. La sopa de pa s'hi posa un brotet de farigola (528). Per a cuinar $(569,570,571)$. Per a fer sopa de pa i un brot de farigola (560). Roman
(Rosmarinus officinalis), llorer (Laurus nobilis), farigola (Thymus vulgaris) i orenga (Origanum vulgare). Piquem les herbes juntes $\mathrm{i}$ ho fem servir per a fer guisats $(590)$. Per als cuinats $(591,592)$. DESTINACIÓ. Alimentació humana $(511,512,513,514,528,545,560,569,570$, 571, 590, 591, 592, 746).

Ingestió de la part de la planta cuita - Cuita en aigua

FONTS 520,521, 565, 566, 571, 747. DESCRIPCIÓ DE L'ÚS FETA PELS INFORMANTS. Cal fer bullir aigua amb farigola i llavors escaldar-t'hi la sopa (747). Per a fer sopes $(520,521$ $565,566,571)$. DESTINACIÓ. Alimentació humana $(520,521,565,566,571,747)$.

\section{ALTRES USOS}

\section{Part aèria}

Creences i pràctiques magicoreligioses

FONT 1210. DESCRIPCIÓ DE L'ÚS FETA PER L'INFORMANT. La seva mare i la seva tia provenien de can Camades de la Roca, era un lloc que hi havia molt ambient de bruixes i la seva tia la Maria Sagué sempre tenia un ramet de farigola penjat a la porta per a protegir la casa, que no hi entressin les bruixes.

\section{Part aèria florida}

Creences i pràctiques magicoreligioses

FONT 503. DESCRIPCIÓ DE L'ÚS FETA PER L'INFORMANT. Quan hi havia tronades es cremava flor de sabuc (Sambucus nigra), farigola (Thymus vulgaris) o altres plantes que encontrà".

\section{Planta sencera}

Literatura oral popular: llegendes, gloses, contes, dites, refranys, poemes, cançons

FONTS 1213, 1214. DESCRIPCIÓ DE L'ÚS FETA PELS INFORMANTS. L'aigua de farigola tot ho consola.

\section{ALTRES OBSERVACIONS}

FONTS 541, 1294, 1319, 1337, 1338. DESCRIPCIÓ FETA PELS INFORMANTS. La padrina me'n feia anar a buscar, perquè allà no n'hi ha gaire (541). Diu que a la Creueta ha anat desapareixent perquè la gent l'arrenca (1294). Diu que per avall la cullen el divendres sant (1319). La portaven de l'Alt Empordà, ells feien la transhumància i passaven I'hivern a Vilajuïga $(1337,1338)$.

\section{BARREGES AMB AQUEST TÀXON}

\section{Part aèria florida}

FONTS 1213, 1214. Entrevista 102, barreja III (vegeu catàleg de barreges)

FONTS 1213, 1214. Entrevista 102, barreja V (vegeu catàleg de barreges)

FONTS 1332, 1333, 1334. Entrevista 11, barreja I (vegeu catàleg de barreges) 
FONTS 1325, 1326. Entrevista 13, barreja I (vegeu catàleg de barreges) FONT 1336. Entrevista 16, barreja IV (vegeu catàleg de barreges) FONT 1317. Entrevista 21, barreja I (vegeu catàleg de barreges) FONTS 1343, 1344. Entrevista 23, barreja III (vegeu catàleg de barreges) FONT 1330. Entrevista 32, barreja VI (vegeu catàleg de barreges) FONT 1330. Entrevista 32, barreja VII (vegeu catàleg de barreges) FONTS 1315, 1316. Entrevista 38 (vegeu catàleg de barreges) FONT 503. Entrevista 43 (vegeu catàleg de barreges)

FONT 750. Entrevista 50, barreja III (vegeu catàleg de barreges) FONTS 529, 530, 531. Entrevista 53, barreja I (vegeu catàleg de barreges) FONTS 520, 521. Entrevista 56, barreja IV (vegeu catàleg de barreges) FONTS $753,754,755$. Entrevista 67 , barreja II (vegeu catàleg de barreges) FONTS 539, 540. Entrevista 69 (vegeu catàleg de barreges)

FONT 1296. Entrevista 7, barreja II (vegeu catàleg de barreges) FONT 546. Entrevista 74, barreja II (vegeu catàleg de barreges) FONT 546. Entrevista 74, barreja III (vegeu catàleg de barreges) FONT 564. Entrevista 84, barreja I (vegeu catàleg de barreges) FONT 571. Entrevista 89, barreja I (vegeu catàleg de barreges) FONT 1310. Entrevista 9 (vegeu catàleg de barreges)

FONT 581. Entrevista 94, barreja III (vegeu catàleg de barreges)

FONT 581. Entrevista 94, barreja V (vegeu catàleg de barreges)

\section{Tilia platyphyllos Scop. (tiliàcies)}

BCN 25024

\section{NOMS POPULARS}

Flor de tell (bràctea i inflorescència) $(505,506,507,509,510,515,516,517,518,519,520$ $521,528,538,541,546,547,548,549,553,554,555,556,557,558,560,561,562,563$ $564,565,566,569,570,571,572,573,574,575,576,577,578,579,590,591,592,746$ $747,748,749,750,751,753,754,755,1294,1298,1299)$

Tell $(511,512,513,514,525,526,527,529,530,531,533,534,549,580,580,586,587$ $588,589,746,752,753,754,755,1215,1293,1296,1297,1310,1311,1312,1313,1314$ $1315,1316,1317,1318,1319,1323,1325,1326,1328,1329,1330,1331,1332,1333,1334$, $1336,1337,1338,1339,1340,1341,1342,1343,1344,1345,1346,1347,1348,1349,1353$ $1354,1352,1361,1362)$

Til·la (bràctea i inflorescència) $(529,530,531,553,1320,1324,1327,1335)$
Til·er $(580)$

\section{USOS MEDICINALS}

Bràctea i inflorescència

Anticatarral

FONTS $505,506,507,509,510,511,512,513,514,515,516,517,518,519,520,521,528$ $529,530,531,533,534,538,546,547,548,549,553,554,555,556,557,558,561,562$ $563,572,573,574,575,576,577,578,579,588,589,590,591,592,746,748,749,751$ $752,753,754,755,1215,1311,1312,1317,1325,1326,1328,1329,1332,1333,1334$ 1335, 1336, 1337, 1338, 1343, 1344,1345,1346, 1353, 1354. DESCRIPCIÓ DE L'ÚS FETA PELS INFORMANTS. Per als refredats $(505,506,507,509,510,511,512,513,514,517$, PELS INFORMANTS. Per als refredats (505, 506, 507, 509, 510, 511, 512, 513, 514, 517 $563,572,573,578,579,589,591,592,746,1215,1311,1312,1325,1326,1343,1344)$. Per als refredats, et calma el constipat i t'ajuda a dormir $(748,749)$. Per als constipats $(515,516$ $533,534,574,575,576,577,751,1317,1328,1329,1336,1345,1346,1353,1354)$. La flor és bona per als refredats $(588,752)$. Per als constipats, mal de coll $(547,548)$. Per a constipats $(549,1332,1333,1334)$. La flor va bé per als refredats $(753,754,755)$. Es prenia per als refredats de sang (590). Va bé per als constipats (1335). Per als refredats de sang (1337, 1338). FORMA FARMACÉUTICA I ÚS. Tisana (ús intern) $(505,506,507,509,510$ $511,512,513,514,515,516,517,518,519,520,521,528,529,530,531,533,534,538$ $511,512,51,514,515,516,517,518,519,520,521,528,529,530,531,533,534,538$ $546,547,548,553,554,555,558,561,562,563,572,573,574,575,576,577,578,579$ $588,589,590,591,592,746,748,749,751,752,753,754,755,1215,1311,1312,1317$, $1353,1326,1328,1329,1332,1333,1334,1335,1336,1337,1338,1343,1344,1345,1346$, 1353, 1354). Melt (ús inten) (549, 556, 557). PREPARACIO. Decocció (505, 506, 507, 509 $510,511,512,513,514,515,516,517,518,519,520,521,528,529,530,531,538,547$, $548,553,554,555,558,561,562,563,572,573,574,575,576,577,578,579,588,589$, $590,591,592,746,748,749,751,752,754,755,1215,1325,1326,1343,1344,1345$, $1346)$. Decocció. Aigua de la flor de tell $(533,534,1336,1337,1338)$. Decocció. Per a quan estàs refredat la flor bullida (546). Amb mel i sucre $(549)$. Amb mel $(556,557)$. Decoció $(753)$. Decocció, mel i un raig de llimona $(1328,1329)$. Decocció. Quasi sempre barrejada amb altres herbes $(1332,1333,1334)$. Decocció. Aigua de la flor (1335). MODE D'UTILITZACIÓ/POSOLOGIA. Fer novenes (1215). EFECTES SECUNDARIS. Sí. DESTINACIÓ. Medicina humana OBSERVACIONS, "És l'herba que aquí a casa hi tenim més fe" $(511,512,513,514)$. A mi no em va bé perquè em rebaixa molt la sang (517). Aban més en veniem i ens vam comprar un joc de cafè $(518,519)$. Sha de vigilar, perque baixa molt la pressió (547, 548). S'ha de vigilar, perque rebaixa molt la sang (588). Es l'aigua que m'agrada menys, el gust que té no és bo $(572,573)$. Rebaixa molt la sang $(1215)$.

Antigripal

FONTS 574, 575, 576, 577. DESCRIPCIÓ DE L'ÚS FETA PELS INFORMANTS. Per a les grips. FORMA FARMACĖUTICA I ÚS. Tisana (ús intern). PREPARACIÓ. Decocció. grips. FORMA FARMACEUTICA

Antihipertensiu 
FONTS 515, 516, 520, 521, 556, 557, 560, 564, 580, 590, 591, 592, 1314, 1318, 1319, 1330 , 1339, 1340. DESCRIPCIÓ DE L'ÚS FETA PELS INFORMANTS. Per a fer baixar la pressió $(564,591,592,1330)$. Per a rebaixar la sang $(515,516,556,557,560,590,1318)$. Per a rebaixar la sang. S'ha de vigilar, perquè rebaixa molt $(520,521)$. L'aigua és bona per a rebaixar la pressió $(580)$. Rebaixa la sang $(1314,1339,1340)$. Rebaixa molt la sang $(1319)$ rebaixar la pressió (580). Rebaixa la sang (1314, 1339, 1340). Rebaixa molt la sang (1319). $521,556,557,560,564,580,590,591,592,1314,1318,1319,1330,1339,1340$ ). DESTINACIÓ. Medicina humana.

Antiinflamatori faringi

FONTS 547, 548. DESCRIPCIÓ DE L'ÚS FETA PELS INFORMANTS. Per als constipats, mal de coll. FORMA FARMACĖUTICA I ÚS. Tisana (ús intern). PREPARACIÓ. Decocció EFECTES SECUNDARIS. Sí. DESTINACIÓ. Medicina humana. OBSERVACIONS. S'ha de vigilar, perquè baixa molt la pressió

Antipelohèmic

FONT 571. DESCRIPCIÓ DE L'ÚS FETA PER L'INFORMANT. Per a aclarir la sang. FORMA FARMACĖUTICA I ÚS. Tisana (ús intern). PREPARACIÓ. Decocció. DESTINACIÓ. Medicina humana.

Antipirètic

FONT 1330. DESCRIPCIÓ DE L'ÚS FETA PER L'INFORMANT. Per a la febre. FORMA FARMACĖUTICA I ÚS. Tisana (ús intern). PREPARACIÓ. Decocció. DESTINACIÓ. Medicina humana.

Antisèptic extern

FONTS 591, 592, 1298. DESCRIPCIÓ DE L'ÚS FETA PELS INFORMANTS. Per a rentar mals $(591,592)$. Com a desinfectant $(1298)$. FORMA FARMACĖUTICA I ÚS. Bany (ús extern). PREPARACIÓ. Decocció $(591,592)$. Decocció. Aigua de la flor (1298) DESTINACIÓ. Medicina humana.

Antitussigen

FONT 1330. DESCRIPCIÓ DE L'ÚS FETA PER L'INFORMANT. Per a la tos. FORMA FARMACĖUTICA I ÚS. Tisana (ús intern). PREPARACIÓ. Decocció. DESTINACIÓ. Medicina humana.

Desconegut per l'informant

FONTS 541, 569, 570. FORMA FARMACĖUTICA I ÚS. Tisana (ús intern). PREPARACIÓ. Decocció. Un tupí d'aigua de flor de tell amb una aspirina a darrera $(569,570)$. DESTINACIÓ Medicina humana. OBSERVACIONS. Per a fer infusions (541)

Hematocatàrtic

FONT 1296. DESCRIPCIÓ DE L'ÚS FETA PER L'INFORMANT. La flor, per a netejar les sangs. FORMA FARMACĖUTICA I ÚS. Tisana (ús intern). PREPARACIÓ. Decocció. DESTINACIÓ. Medicina humana.

Litotríptic renal
FONT 1313. DESCRIPCIO DE L'US FETA PER L'INFORMANT. Va bé per a les pedres dels ronyons. FORMA FARMACĖUTICA I ÚS. Tisana (ús intern). DESTINACIÓ. Medicina humana.

Salutífer

FONT 549. DESCRIPCIÓ DE L'ÚS FETA PER L'INFORMANT. Per quan fa molt fred a I'hivern. FORMA FARMACĖUTICA I ÚS. Sense forma farmacèutica (mescla medicamentosa) (ús intern). PREPARACIÓ. Flor de tell amb sucre i un rovell d'ou, tot ben calent. MODE D'UTILITZACIÓ/POSOLOGIA. Abans d'anar a dormir. DESTINACIÓ. Medicina humana.

Sedant

FONTS 1315, 1316. DESCRIPCIÓ DE L'ÚS FETA PELS INFORMANTS. És sedant. FORMA FARMACĖUTICA I ÚS. Tisana (ús intern). PREPARACIÓ. Decocció. DESTINACIÓ. Medicina humana.

Tranquil-litzant

FONTS 529, 530, 531, 533, 534, 546, 564, 565, 566, 572, 573, 574, 575, 576, 577, 586, 587 $747,1215,1294,1296,1297,1299,1310,1313,1318,1327,1330,1335,1341,1342,1347$. $1348,1349,1352,1361,1362$. DESCRIPCIÓ DE L'ÚS FETA PELS INFORMANTS. Per a relaxar (747). Per als nervis $(529,530,531,533,534,574,575,576,577,586,587,1215$, $1327,1330,1341,1342,1347,1348,1349,1352,1361,1362)$. Va bé per als nervis (546). Per a quan no pots dormir, és relaxant $(565,566)$. Per a calmar els nervis $(564,572,573)$. És Per a quan no pots dormir, és relaxant $(565,566)$. Per a calmar els nervis $(564,572,573)$. Es
molt tranquil-litzant (1294). La flor, per a calmar (1296). Va molt bé per als nervis (1297). Relaxant (1299). És tranquil-litzant (1310). Per a tranquil-litzar $(1313,1335)$. La flor va bé per als nervis (1318). FORMA FARMACĖUTICA I ÚS. Tisana (ús intern) $(529,530,531,533$, $534,546,564,565,566,572,573,574,575,576,577,586,587,747,1215,1294,1296$, $1297,1310,1313,1318,1327,1330,1335,1341,1342,1347,1348,1349,1352,1361$, 1362). Bany (ús extern) (1299). PREPARACIÓ. Decocció (529, 530, 531, 564, 565, 566, 572 , $573,574,575,576,577,586,587,747,1215,1296,1310,1318,1330,1361,1362)$. Decocció. Aigua de la flor de tell $(533,534)$. Només la flor escaldada. Poses la flor en un colador i hi tires aigua per sobre (546). La infusió de la flor (1294). Decocció L'aigua de la flor (1297) Per a fer banys, fas aigua la meitat flor i le mitat full i la poses a la banyera (1299) En infusió $(1327,1347,1348,1349)$. Decció. Aigua fulla la poses a la banyera (1299). En infusió (1327, 1347, 1348, 1349). Decocció. Aigua de la for (1335). La llor en infusió (1215). EFECTES SECUNDARIS SI. DESTINACIÓ (1215). EFECTES SECUNDARIS. SI. DESTINACIO. Medicina humana. OBSERVACIONS És l'aigua que m'agrada menys, el gust que té no és bo $(572,573)$. Rebaixa molt la sang (1215). En té, però no la fa servir (1299). A casa la barrejaven amb altres herbes (1310).

Vulnerari

FONTS 1337, 1338, 1339, 1340. DESCRIPCIÓ DE L'ÚS FETA PELS INFORMANTS. Per a curar ferides $(1337,1338)$. Per a les llagues del bestiar $(1339,1340)$. FORMA FARMACĖUTICA I ÚS. Bany (ús extern). PREPARACIÓ. Decocció. Aigua de la flor de tell $(1337,1338)$. Decocció. Aigua de la flor $(1339,1340)$. DESTINACIÓ. Medicina humana $(1337,1338)$. Medicina veterinària $(1339,1340)$.

\section{Parènquima cortical}

Antiàlgic ciàtic 
FONT 1331. DESCRIPCIÓ DE L'ÚS FETA PER L'INFORMANT. En emplastres per al dolor ciàtic. FORMA FARMACĖUTICA I ÚS. Emplastre (ús extern). PREPARACIÓ. La segona pela del tell estovada amb llet tota la nit, fa com una gelatina. DESTINACIÓ. Medicina humana.

Antidiarreic

FONTS 1339, 1340. DESCRIPCIÓ DE L'ÚS FETA PELS INFORMANTS. Per a la diarrea dels vedells. FORMA FARMACĖUTICA I ÚS. Tisana (ús intern). PREPARACIÓ. Decocció. Aigua de la segona pela del tell. DESTINACIÓ. Medicina veterinària.

Antiequimòtic

FONT 588. DESCRIPCIÓ DE L'ÚS FETA PER L'INFORMANT. Per als trucs. FORMA FARMACĖUTICA I ÚS. Emplastre (ús extern). PREPARACIÓ. Segona pela de tell, es feia emplastres. La pela crua amb una mica d'aigua o llet per amorosir-la una mica. DESTINACIÓ. Medicina humana.

Antiinflamatori

FONT 1319. DESCRIPCIÓ DE L'ÚS FETA PER L'INFORMANT. En llocs inflamats O infectats. FORMA FARMACĖUTICA I ÚS. Bany (ús extern). PREPARACIÓ. Aigua de la segona pela de tell, amb draps. DESTINACIÓ. Medicina humana. OBSERVACIONS. Aquest remei l'hi van fer quan se li va acumular la llet als pits després de parir.

Antipiròtic

FONT 1323. DESCRIPCIÓ DE L'ÚS FETA PER L'INFORMANT. Per a cremades i

ALTRES USOS que no recorda. FORMA FARMACĖUTICA I ÚS. Emplastre (ús extern) PREPARACIÓ. Emplastres de la segona pela de tell. DESTINACIÓ. Medicina humana.

Antisèptic extern

FONTS 580, 591, 592, 1319, 1345, 1346. DESCRIPCIÓ DE L'ÚS FETA PELS INFORMANTS. La segona pela del tell és molt desinfectant per a rentar ferides $(591,592)$ És bona per a rentar ferides (580). En llocs inflamats o infectats (1319). Per a desinfectar ferides per al bestiar $(1345,1346)$. FORMA FARMACĖUTICA I ÚS. Bany (ús extern). PREPARACIÓ. Decocció $(591,592)$. Decocció de la segona pela (580). Aigua de la segona pela de tell, amb draps (1319). Decocció. Aigua de la segona pela de tell $(1345,1346)$. DESTINACIÓ. Medicina humana $(580,591,592,1319)$. Medicina veterinària $(1345,1346)$ OBSERVACIONS. Fa una aigua molt llefiscosa (580). Aquest remei l'hi van fer quan se li va acumular la llet als pits després de parir (1319)

Antiulcerós (per a úlceres gàstriques)

FONT 1293. DESCRIPCIÓ DE L'ÚS FETA PER L'INFORMANT. Va bé per a la gent que té llaga d'estómac. FORMA FARMACEUUTICA I ÚS. Macerat en aigua (ús intern). PREPARACIÓ. La segona pela del tell, posada a estovar, fa una aigua molt amorosa. DESTINACIÓ. Medicina humana.

Hipouricemiant

FONTS 511, 512, 513, 514. DESCRIPCIÓ DE L'ÚS FETA PELS INFORMANTS. Per al mal de gota. FORMA FARMACĖUTICA I ÚS. Tisana (ús intern). PREPARACIÓ. Decocció S'utilitza la segona escorça. DESTINACIÓ. Medicina humana. OBSERVACIONS. "És I'herba que aquí a casa hi tenim més fe".
Litotríptic renal

FONT 1352. DESCRIPCIÓ DE L'ÚS FETA PER L'INFORMANT. Per a les pedres dels ronyons. FORMA FARMACĖUTICA I ÚS. Tisana (ús intern). PREPARACIÓ. Aigua de la segona pela. DESTINACIÓ. Medicina humana.

Per a les punxades

FONT 1330. DESCRIPCIÓ DE L'ÚS FETA PER L'INFORMANT. Per a les punxades infectades. FORMA FARMACĖUTICA I ÚS. Bany (ús extern). PREPARACIÓ. La segona pela de tell bullida en aigua, amb una perola rentada amb sorra, fa com una clara d'ou (aigua llefiscosa). DESTINACIÓ. Medicina humana. OBSERVACIONS. EI seu pare es va punxa amb unes forquetes i es revolcava del mal, una veïna gran li va preparar tovalloles calentes molles d'aquesta aigua i al cap d'una hora era curat.

Vulnerari

FONTS 517, 525, 526, 527, 1313, 1314. DESCRIPCIÓ DE L'ÚS FETA PELS INFORMANTS És molt bona per a banyar talls i ferides $(517)$. La segona peloia per als talls $(525,526,527)$ Per a les ferides (1313). Es posava directament sobre del mal (1314). FORMA FARMACĖUTICA I ÚS. Bany (ús extern) $(517,525,526,527,1313)$. Emplastre (ús extern) (1314). PREPARACIÓ. Decocció. S'utilitza la segona escorça (517). Decocció $(525,526$, 527). Aigua de la segona pela de tell (1313). De la segona pela de tell bullida es feia un emplastre (1314). DESTINACIÓ. Medicina humana.

\section{USOS ALIMENTARIS}

\section{Bràctea i inflorescència}

Preparació de begudes - Beguda preparada amb aiguardent

FONT 553. DESCRIPCIÓ DE L'ÚS FETA PER L'INFORMANT. Ratafia. Posar totes les herbes en aiguardent 21 dies a sol i serena. Es fa per als volts de Sant Joan. Sempre surt bona però no surt mai igual. Les herbes utilitzades són: nous verdes (Juglans regia), herba de Noè (Herniaria glabra), tarongina (Melissa officinalis), camamilla borda (Tanacetum parthenium), marialluïsa (Lippia triphylla), menta (Mentha spicata), salsufràgia (Peucedanum ostruthium), til-la (Tilia platyphyllos), nou moscada (Myristica fragrans) i clau (Syzygium aromaticum). DESTINACIÓ. Alimentació humana.

\section{ALTRES USOS}

\section{Bràctea i inflorescència}

Altres informacions

FONTS 560, 591, 592, 1310, 1332, 1333, 1334. DESCRIPCIÓ DE L'ÚS FETA PELS INFORMANTS. Es venia molt abans $(591,592)$. La gent la venia a la farmàcia $(560)$. De flor, se'n collia molta per a vendre (1310). Abans collien la flor de tell per a vendre $(1332,1333$ 1334).

\section{Planta viva in situ}

Creences i pràctiques magicoreligioses 
FONT 1352. DESCRIPCIÓ DE L'ÚS FETA PER L'INFORMANT. Dormir la migdiada a l'ombra d'un tell és sa i fa reposar molt.

\section{BARREGES AMB AQUEST TÀXON}

Bràctea i inflorescència

FONTS 1332, 1333, 1334. Entrevista 11, barreja I (vegeu catàleg de barreges)

FONTS 1332, 1333, 1334. Entrevista 11, barreja III (vegeu catàleg de barreges)

FONTS 1325, 1326. Entrevista 13, barreja I (vegeu catàleg de barreges)

FONT 1330. Entrevista 32, barreja $V$ (vegeu catàleg de barreges)

FONT 1320. Entrevista 34, barreja II (vegeu catàleg de barreges)

FONT 1324. Entrevista 5, barreja IV (vegeu catàleg de barreges)

FONT 750. Entrevista 50, barreja I (vegeu catàleg de barreges)

FONTS 529, 530, 531. Entrevista 53, barreja VII (vegeu catàleg de barreges)

FONT 752. Entrevista 62, barreja I (vegeu catàleg de barreges)

FONTS 753, 754, 755. Entrevista 67, barreja VI (vegeu catàleg de barreges)

FONT 549. Entrevista 75, barreja III (vegeu catàleg de barreges)

FONT 564. Entrevista 84, barreja II (vegeu catàleg de barreges)

Parènquima cortical

FONT 746. Entrevista 45, barreja IV (vegeu catàleg de barreges)

\section{Trifolium alpinum L. (papilionàcies)}

BCN 25025

\section{NOMS POPULARS}

Regalèssia $(554,555,1361,1362)$

Regalíssia $(528,533,534,541,549,554,555,559,571,586,587,1296,1300,1313,1317$ $1321,1332,1333,1334,1347,1348,1349,1350,1351)$

\section{USOS MEDICINALS}

\section{Arrel}

Anticatarral

FONTS 554, 555, 559, 1350, 1351, 1361, 1362. DESCRIPCIÓ DE L'ÚS FETA PELS INFORMANTS. Per als constipats $(554,555,559,1361,1362)$. Per als refredats (1350, 1351). FORMA FARMACĖUTICA I ÚS. Tisana (ús intern). PREPARACIÓ. Decocció (559, $1350,1351,1361,1362)$. Decocció. Aigua de la rel $(554,555)$. DESTINACIÓ. Medicina humana. OBSERVACIONS. Es fa servir la rel i costa, perquè en aquest país no es fa gaire grossa (559).

Antiinflamatori intestinal

FONT 1300. DESCRIPCIÓ DE L'ÚS FETA PER L'INFORMANT. És bona per al mal de ventre. FORMA FARMACĖUTICA I ÚS. Tisana (ús intern). PREPARACIÓ. Decocció de la rel. DESTINACIÓ. Medicina humana.

Deshabituant del tabac

FONTS 533, 534. DESCRIPCIÓ DE L'ÚS FETA PELS INFORMANTS. L'arrel és bona per a mastegar. Va bé per als que deixen de fumar. FORMA FARMACĖUTICA I ÚS. Sense forma farmacèutica (ús directe, ús intern). DESTINACIÓ. Medicina humana.

Salutifer

FONT 528. DESCRIPCIÓ DE L'ÚS FETA PER L'INFORMANT. Te'n poses un tronquet a la boca i va bé aquella dolcor. FORMA FARMACĖUTICA I ÚS. Sense forma farmacèutica (ús directe, ús intern). DESTINACIÓ. Medicina humana.

Flor

Anticatarral

FONTS 1332, 1333, 1334. DESCRIPCIÓ DE L'ÚS FETA PELS INFORMANTS. Va molt bé per als refredats. FORMA FARMACĖUTICA I ÚS. Tisana (ús intern). PREPARACIÓ. Decocció. DESTINACIÓ. Medicina humana.

\section{Planta sencera}

Anticatarral

FONT 1296. DESCRIPCIÓ DE L'ÚS FETA PER L'INFORMANT. Va molt bé per als constipats de sang (els que et raja el nas, tens mal de cap, mal al cos). FORMA FARMACĖUTICA I ÚS. Tisana (ús intern). PREPARACIÓ. Decocció. S'utilitza l'arrel i el brot. DESTINACIÓ. Medicina humana.

\section{USOS ALIMENTARIS}

Arrel

Ingestió de la part de la planta crua - Fresca (sense preparació)

FONTS $571,1313,1317,1321,1347,1348,1349$. DESCRIPCIÓ DE L'ÚS FETA PELS INFORMANTS. La rel rosegada et fa passar la set (571). S'arrenca la rel i es xucla, té molt bon gust i amoroseix el coll (1313). Quan vaig cap aquí dalt me'n poso una rel a la boca bon gust i amoroseix el coll (1313). Quan vaig cap aqui dalt me'n poso una rel a la boca
(1317). L'arrel per a llepar $(1347,1348,1349)$. Per a menjar cru (1321). DESTINACIÓ. Alimentació humana $(571,1313,1317,1321,1347,1348,1349)$

\section{Part aèria}

Ingestió de la part de la planta crua - Fresca (sense preparació)

FONTS 528, 533, 534, 549, 571, 586, 587. DESCRIPCIÓ DE L'ÚS FETA PELS INFORMANTS. Al bestiar li agrada molt $(533,534)$. És el menjar més bó que hi ha per a bestiar (528). Se'l menja el bestiar (549). A les ovelles els agrada molt i els va molt bé, els $h$ 
fa la llana groga i maca, els dóna molta fortalesa (571). És bon menjar $(586,587)$. OBSERVACIONS. A la primavera encara no comença a sortir ja se la mengen fins que la planta és seca cap allà mig setembre, després ja no la volen, la planta es mor i deu canviar el gust (571). L'Albert de Queralbs em va dir que amb dos grapats de regalíssia i un rajolí d'aigua, una vaca ja viu tot l'estiu, una mica exagerat! $(586,587)$. DESTINACIÓ. Alimentació animal $(528,533,534,549,571,586,587)$.

\section{ALTRES OBSERVACIONS}

FONTS 586, 587. DESCRIPCIÓ FETA PELS INFORMANTS. Aquí n'hi ha poca, una mica a Coll del Pal.

\section{Trifolium incarnatum L. (papilionàcies)}

BCN 25026

\section{NOMS POPULARS}

Fenc $(507,509,510,554,555,580,1345,1346,1352)$

\section{USOS MEDICINALS}

Flor

Diürètic

FONTS 1345, 1346. DESCRIPCIÓ DE L'ÚS FETA PELS INFORMANTS. Per a fer orinar. FORMA FARMACĖUTICA I ÚS. Tisana (ús intern). PREPARACIÓ. En infusió. DESTINACIÓ. Medicina humana.

\section{USOS ALIMENTARIS}

Part aèria

Ingestió de la part de la planta crua - Conservada dessecada a l'aire

FONT 580. DESCRIPCIÓ DE L'ÚS FETA PER L'INFORMANT. El donem al bestiar. DESTINACIÓ. Alimentació animal.

\section{ACCIONS NOCIVES O TÒXIQUES}

\section{Part aèria}

FONTS 507, 509, 510, 1345, 1346, 1352. DESCRIPCIÓ DE L'ACCIÓ NOCIVA O TÒXICA FETA PELS INFORMANTS. Quan es troba barrejat el fenc (Trifolium incarnatum) i l'alfals (Medicago sativa), fa un vapor perquè fermenta i no t'hi pots posar a sobre, és perillós, perquè et faria mal, et tapa $i$ et fa estossegar $(507,509,510)$. Diuen que no es pot dormir sobre el fenc, que et pots morir $(1345,1346)$. Dormir a sobre del fenc és molt dolent (1352). GRAU DE TOXICITAT. Letal $(1345,1346)$. VIA D'INTOXICACIÓ. Via interna $(507,509,510)$.

\section{Trifolium pratense L. (papilionàcies)}

BCN 25027

\section{NOMS POPULARS}

Trèfola $(564,565,566,578,579,580,583,584,585,586,587,589,746,1215,1310)$

Trèfola borda $(572,573)$

Trefolet $(556,557,582)$

Trèvol (568)

Trevolet (571)

\section{USOS MEDICINALS}

\section{No consta}

\section{Resolutiu}

FONT 582. DESCRIPCIÓ DE L'ÚS FETA PER L'INFORMANT. T'ho posaven sobre les llagues. FORMA FARMACĖUTICA I ÚS. Embrocació (ús extern). PREPARACIÓ. Es posava en oli. DESTINACIÓ. Medicina humana.

\section{USOS ALIMENTARIS}

\section{Part aèria}

Ingestió de la part de la planta crua - Conservada dessecada a l'aire

FONTS 564, 572, 573, 578, 579, 580, 583, 584, 585, 589, 746, 1310. DESCRIPCIÓ DE L'ÚS FETA PELS INFORMANTS. En planten i l'usen per a alimentar al bestiar (746). Per als conills $(578,579)$. Per al bestiar $(572,573,580,589)$. Per als conills i per als porcs $(564)$. És bo per al bestiar, però si en menja gaire queda inflat $(583,584,585)$. Se'n donava als porcs, quan no hi havia gaire menjar (1310). DESTINACIÓ. Alimentació animal (564, 572, 573, 578, $579,580,583,584,585,589,746,1310)$

Ingestió de la part de la planta crua - Fresca (sense preparació)

FONTS 565, 566, 571, 586, 587. DESCRIPCIÓ DE L'ÚS FETA PELS INFORMANTS. En mengen les ovelles (571). Engegàvem els porcs a la userda. També en donàvem als conills $(565,566)$. Per a pa $571,586,587)$. Per pasturar et bestiar $(586,0$

\section{ACCIONS NOCIVES O TÒXIQUES}

Part aèria jove

FONTS 556, 557. DESCRIPCIÓ DE L'ACCIÓ NOCIVA O TÒXICA FETA PELS INFORMANTS. Boteix les vaques i les ovelles. En aquells dies tan covats d'estiu, si es 
mengen el trefolet tendre els fa mal, si ja ha florit no passa res. VIA D'INTOXICACIÓ. Via interna. TOXICITAT EN ANIMALS. Sí.

\section{BARREGES AMB AQUEST TÀXON}

Flor

FONT 1215. Entrevista 104, barreja II (vegeu catàleg de barreges)

\section{Trifolium repens $\mathrm{L}$. (papilionàcies)}

\section{BCN 31313}

\section{NOMS POPULARS}

Trefoló $(583,584,585)$

\section{USOS ALIMENTARIS}

Part aèria

Ingestió de la part de la planta crua - Fresca (sense preparació)

FONTS 583, 584, 585. DESCRIPCIÓ DE L'ÚS FETA PELS INFORMANTS. El bestiar se la menja. OBSERVACIONS. És més petita que la trèfola. DESTINACIÓ. Alimentació animal.

\section{Triticum aestivum L. (gramínies)}

BCN 27284

\section{NOMS POPULARS}

Blat $(503,507,509,510,560,561,562,563,565,566,571,1353,1354,1352)$

Mestall (589)

Segon (producte elaborat) $(520,521,750)$

\section{USOS MEDICINALS}

Llavor

Antiequimòtic

FONTS 561, 562, 563. DESCRIPCIÓ DE L'ÚS FETA PELS INFORMANTS. Per a treure els trucs i et treu el mal. FORMA FARMACĖUTICA I ÚS. Emplastre (ús extern). PREPARACIÓ. Farina de blat amb aiguardent sec. DESTINACIÓ. Medicina humana.

Segó

Per als penellons
FONTS 507, 509, 510. DESCRIPCIÓ DE L'ÚS FETA PELS INFORMANTS. Per als penellons. FORMA FARMACĖUTICA | ÚS. Desconegut per l'informant. PREPARACIÓ. Segon de blat torrat i posat a dins d'un mitjó per anar a dormir. DESTINACIÓ. Medicina humana.

\section{USOS ALIMENTARIS}

\section{Llavor}

Ingestió de la part de la planta crua - Fresca (sense preparació)

FONTS 571, 589. DESCRIPCIÓ DE L'ÚS FETA PELS INFORMANTS. Per a les gallines els barrejàvem una mica de farina i als conills els donàvem gra (571). Es donava al bestiar (589). OBSERVACIONS. Es barrejaven granes de blat i sègol i el que sortia era mestall (589). DESTINACIÓ. Alimentació animal $(571,589)$

Ingestió de la part de la planta cuita - Cuita sense vehicle

FONTS 503, 565, 566, 589, 1353, 1354. DESCRIPCIÓ DE L'ÚS FETA PELS INFORMANTS Per a fer pa (503). La mare pastava la farina i feia un pa de $4 \mathrm{~kg}$ que es guardava molt. $\mathrm{Si}$ tenia un xic de sucre i una mica d'oli feia una coca i era boníssima $(565,566)$. Abans a les cases ens fèiem sempre pa $(589)$. La farina de blat per a fer pa $(1353,1354)$ OBSERVACIONS. El blat no se li ha de fer res, només a l'hora de segar-lo. Nosaltres portàvem el nostre blat a la farinera que era a ca la Irene. També el podies portar al Molí petit i al Molí gran que era a ca l'Espona (503). Nosaltres al Grau cada 15 dies fèiem una pastarada (589). Abans a les cases se'l feien $(1353,1354)$. DESTINACIÓ. Alimentació humana $(503,565,566,589,1353,1354)$.

\section{ALTRES USOS}

Llavor

Maneig agrosilvopastoral: ús en la matança del porc

FONT 1352. DESCRIPCIÓ DE L'ÚS FETA PER L'INFORMANT. Per a conservar les llonganisses, s'emplenava un calaix d'aquells grossos de les cases amb gra de blat i les llonganisses s'hi posaven per damunt.

\section{ALTRES OBSERVACIONS}

FONT 560. DESCRIPCIÓ FETA PER L'INFORMANT. Es plantava a Beget.

\section{BARREGES AMB AQUEST TÀXON}

Llavor

FONTS 505, 506. Entrevista 47, barreja I (vegeu catàleg de barreges)

FONTS 520, 521. Entrevista 56, barreja I (vegeu catàleg de barreges)

Segó

FONT 750. Entrevista 50, barreja IV (vegeu catàleg de barreges) 


\section{Trollius europaeus L. (ranunculàcies)}

\section{BCN 27267}

\section{NOMS POPULARS}

Absolva (528)

Cloclou (1321)

Flor de Sant Pere (1313)

Gata rabiosa $(553,554,555)$

Gata rabiosa de la muntanya (581)

Rovell d'ou (541)

\section{USOS MEDICINALS}

\section{Part aèria}

Antisèptic intern

FONT 528. DESCRIPCIÓ DE L'ÚS FETA PER L'INFORMANT. Es feia servir per a les infeccions del bestiar. FORMA FARMACĖUTICA I ÚS. Tisana (ús intern). PREPARACIÓ. Decocció. Em sembla que es feien aigua de tota la planta. DESTINACIÓ. Medicina veterinària.

\section{ALTRES USOS}

Flor

Ornamental: elaboració de rams

FONT 1313. DESCRIPCIÓ DE L'ÚS FETA PER L'INFORMANT. Per a fer rams.

\section{Part aèria florida}

Ornamental: elaboració de rams

FONTS 546, 1321. DESCRIPCIÓ DE L'ÚS FETA PELS INFORMANTS. Per a fer rams, es fa a les molleres (546). Per a fer rams (1321).

\section{ACCIONS NOCIVES O TÒXIQUES}

\section{No consta}

FONT 553. DESCRIPCIÓ DE L'ACCIÓ NOCIVA O TÒXICA FETA PER L'INFORMANT. ÉS tòxica. Havíem de vigilar que no n'hi hagués en el menjar dels conills. VIA D'INTOXICACIÓ. Via interna. TOXICITAT EN ANIMALS. Sí.

\section{ALTRES OBSERVACIONS}

FONTS 528, 581, 586, 587, 1321. DESCRIPCIÓ FETA PELS INFORMANTS. Es fan als mollerius (528). És un símil a la gata rabiosa (Ranunculus bulbosus subsp. bulbosus), però més grossa (528). Es troba barrejada amb l'àrnica (Arnica montana subsp. montana) i és molt maca (581). La gent n'agafa pensant que agafa àrnica (Arnica montana subsp. montana) $(586,587)$. Es fan a la vora de l'aigua $(1321)$

\section{Tropaeolum majus L. (tropeolàcies)}

BCN 47647

\section{NOMS POPULARS}

Caputxina $(1213,1214)$

\section{BARREGES AMB AQUEST TÀXON}

\section{No consta}

FONTS 1213, 1214. Entrevista 102, barreja II (vegeu catàleg de barreges)

\section{Tussilago farfara L. (compostes)}

BCN 25028

\section{NOMS POPULARS}

Pota de cavall $(505,506,511,512,513,514,517,518,519,524,529,530,531,541,553$ $556,557,568,578,579,583,584,585,586,587,590,591,592,748,749,1298,1299,1310$ $1313,1317,1318,1319,1321,1322,1327,1328,1329,1332,1333,1334,1337,1338,1345$, $1346,1347,1348,1349,1352,1361,1362$

\section{USOS MEDICINALS}

Flor

Antitussigen

FONT 1299. DESCRIPCIÓ DE L'ÚS FETA PER L'INFORMANT. Va bé per a la tos. FORMA FARMACĖUTICA I ÚS. Tisana (ús intern). PREPARACIÓ. La flor en infusió. DESTINACIÓ. Medicina humana.

\section{Fulla}

Antiequimòtic

FONTS 1332, 1333, 1334. DESCRIPCIÓ DE L'ÚS FETA PELS INFORMANTS. Per als trucs FORMA FARMACĖUTICA I ÚS. Sense forma farmacèutica (ús directe, ús extern). DESTINACIÓ. Medicina humana.

Antihemorroïdal 
FONT 1317. DESCRIPCIÓ DE L'ÚS FETA PER L'INFORMANT. Per a les morenes. FORMA FARMACĖUTICA I ÚS. Sense forma farmacèutica (ús directe, ús extern). PREPARACIÓ. Posada directament pel cantó llis. DESTINACIÓ. Medicina humana.

Antisèptic extern

FONTS 1313, 1328, 1329, 1332, 1333, 1334, 1347, 1348, 1349. DESCRIPCIÓ DE L'ÚS FETA PELS INFORMANTS. Quan tens una ferida (1313). Per a posar a les ferides. Per un cantó estira i per l'altre pella $(1328,1329)$. S'aplica directament sobre la ferida primer la fulla de sota i quan es veu el mal net, es gira la fulla perquè fa pellar $(1332,1333,1334)$. Per a posar a les ferides. Pel cantó llis, estira i pel cantó pelut, fa pellar $(1347,1348,1349)$. FORMA FARMACE்UTICA I ÚS. Sense forma farmacèutica (ús directe, ús extern). PREPARACIÓ. T'hi poses una fulla, primer pel cantó llis perquè la ferida quedi net ai després pel cantó pelut perquè cicatritzi (1313). DESTINACIÓ. Medicina humana.

Cicatritzant

FONTS $1313,1328,1329,1332,1333,1334,1347,1348,1349$. DESCRIPCIÓ DE L'ÚS FETA PELS INFORMANTS. Quan tens una ferida (1313). Per a posar a les ferides. Per un cantó estira i per l'altre pella $(1328,1329)$. S'aplica directament sobre la ferida primer la fulla de sota i quan es veu el mal net, es gira la fulla perquè fa pellar $(1332,1333,1334)$. Per a posar a les ferides. Pel cantó llis, estira i pel cantó pelut, fa pellar $(1347,1348,1349)$ FORMA FARMACĖUTICA I ÚS. Sense forma farmacèutica (ús directe, ús extern) (1313, $1328,1329,1332,1333,1334,1347,1348,1349)$. PREPARACIO. T'hi poses una fulla primer pel cantó llis perquè la ferida quedi net ai després pel cantó pelut perquè cicatritz (1313). DESTINACIÓ. Medicina humana.

Expectorant

FONT 1299. DESCRIPCIÓ DE L'ÚS FETA PER L'INFORMANT. Són expectorants. FORMA FARMACEUUTICA I ÚS. Tisana (ús intern). PREPARACIÓ. Les fulles en infusió DESTINACIÓ. Medicina humana.

Resolutiu

FONTS 1327, 1337, 1338. DESCRIPCIÓ DE L'ÚS FETA PELS INFORMANTS. Quan tens un gra que no rebenta (1327). Per a les llagues $(1337,1338)$. FORMA FARMACEUTICA I ÚS. Sense forma farmacèutica (ús directe, ús extern). PREPARACIÓ. Es posa la pota de caval pel cantó fi i ajuda sortir la porqueria (1327). Es posava directament la fulla per la banda peluda sobre la ferida $(1337,1338)$. DESTINACIÓ. Medicina humana.

Vulnerari

FONTS $505,506,511,512,513,514,517,518,519,524,529,530,531,553,556,557,578$ $579,583,584,585,586,587,590,591,592,748,749,1298,1310,1318,1319,1321,1322$ 1332, 1333, 1334, 1345, 1346, 1352, 1361, 1362. DESCRIPCIÓ DE L'ÚS FETA PELS INFORMANTS. Per a posar a les ferides $(505,506,748,749,1322)$. Per a les ferides, per un cań́ na i Per l'altre fa pellar $(511,512,513,514)$. Per a les ferides $(517,518,519,529$, $530,531,553,578,579,590,1319,1352)$. Per a posar a $530,531,553,578,579,590,1319,1352)$. Per a posar a sobre les ferides (524, 1361, 1362). Es posa primer la cara neta perque no sinfecti i quan la ferida es veu maca es posa la cara peluda, que es la que ajuda a pellar $(556,557)$. Per a posar directament sobre les llagues (592). Per a posar directament a sobre les llagues (591). Per a les ferides, per una cara fa supurar i per l'altra fa pellar $(583,584,585)$. Per a curar els talls $(586,587)$. Recorda que les supurar i per latra fapellar (583, 584,585$)$. Per a curar els tall ( 586,587 ). Recorda (1298). Per a les fides ma curadiraven (1298). Per a les feides mal quan la ferida les ferides (1318). Per als mals (1321). Per a lagues i ferides $(1332,1333,1334)$. Per a cura ferides (1345, 1346). FORMA FARMACEUTICA I US. Sense forma farmaceutica (ús directe, ús extern). PREPARACIO. S'aplica directament sobre la ferida (1346). S'aplica directament a sobre la ferida (1345). MODE D'UTILITZACIÓ/POSOLOGIA. Es posa la fulla primer pel cantó pelut i llavors pel llis $(505,506)$. Primer el cantó llis i després pel pelut $(524)$. DESTINACIÓ Medicina humana. OBSERVACIONS. Però no va gaire bé perquè el mal sempre et queda moll (1321).

No consta

Desconegut per l'informant

FONT 568. FORMA FARMACĖUTICA I ÚS. Emplastre (ús extern). PREPARACIÓ. Per a fer emplastres. DESTINACIÓ. Medicina humana.

Typha latifolia L. (tifàcies)

BCN 31314

\section{NOMS POPULARS}

Boga (750)

\section{BARREGES AMB AQUEST TÀXON}

\section{Part aèria}

FONT 750. Entrevista 50, barreja IV (vegeu catàleg de barreges)

\section{Ulmus minor Mill. (ulmàcies)}

\section{BCN 27244}

\section{NOMS POPULARS}

Om $(528,541,565,566,568,572,573,583,584,585,589,1353,1354)$

\section{USOS ALIMENTARIS}

Fulla

Ingestió de la part de la planta crua - Fresca (sense preparació)

FONTS 568, 572, 573, 583, 584, 585. DESCRIPCIÓ DE L'ÚS FETA PELS INFORMANTS. Les fulles es donaven als porcs (568). Quan havia passat Sant Joan, s'eixonaven les fulles 
Apèndix 1. Catàleg de tàxons.

d'om i es donaven als porcs $(572,573)$. S'eixonaven les fulles d'om per a donar als porcs $(583,584,585)$. OBSERVACIONS. Les omes fan la fulla més ampla i anaven més bé per a eixonar. Van agafar la malura i es van anar morint tots $(583,584,585)$. DESTINACIÓ. Alimentació animal $(568,572,573,583,584,585)$

\section{Part aèria}

Ingestió de la part de la planta crua - Fresca (sense preparació)

FONTS 541, 565, 566, 589. DESCRIPCIÓ DE L'ÚS FETA PELS INFORMANTS. Per als conills $(541)$. La rama d'om es donava per a engreixar els porcs $(565,566)$. Per al bestia rama d'om (589). DESTINACIÓ. Alimentació animal $(541,565,566,589)$.

\section{ALTRES USOS}

Tija

Maneig agrosilvopastoral: ús hortícola/agrícola

FONT 528. DESCRIPCIÓ DE L'ÚS FETA PER L'INFORMANT. Per a fer les creuetes per a agafar ocells.

\section{ALTRES OBSERVACIONS}

FONTS 1353, 1354. DESCRIPCIÓ FETA PELS INFORMANTS. Tenen una malaltia que els mata, quasi no n'hi ha.

\section{Umbilicus rupestris (Salisb.) Dandy (crassulàcies)}

BCN 25029

\section{NOMS POPULARS}

Barretets (553)

Barretets de paret $(569,570,582)$

Barrets de paret $(1296,1300,1332,1333,1334,1335,1339,1340)$

\section{USOS MEDICINALS}

Part aèria

Analgèsic

FONT 1335. DESCRIPCIÓ DE L'ÚS FETA PER L'INFORMANT. Per al dolor. FORMA FARMACĖUTICA I ÚS. Pomada (ús extern). PREPARACIÓ. Per a fer pomada. Es fan bullir els barrets en oli i s'hi posa cera. DESTINACIÓ. Medicina humana.

Antieritematós

FONT 1296. DESCRIPCIÓ DE L'ÚS FETA PER L'INFORMANT. Per a les escaldades. FORMA FARMACĖUTICA I ÚS. Embrocació (ús extern). PREPARACIÓ. Es posava en oli tota la planta, no recorda si amb alguna altra, i s'untava la ferida amb aquest oli. DESTINACIÓ. Medicina humana.

Antipiròtic

FONTS 569, 570, 1335. DESCRIPCIÓ DE L'ÚS FETA PELS INFORMANTS. Per a les cremades $(569,570)$. Va bé per a les cremades (1335). FORMA FARMACĖUTICA I ÚS. Sense forma farmacèutica (ús directe, ús extern) $(569,570)$. Pomada (ús extern) (1335). PREPARACIÓ. Es treu la pela i es posa directament sobre la pell $(569,570)$. Per a fer pomada. Es fan bullir els barrets en oli i s'hi posa cera (1335). DESTINACIÓ. Medicina humana.

Diürètic

FONT 553. DESCRIPCIÓ DE L'ÚS FETA PER L'INFORMANT. Per a fer orinar. FORMA FARMACĖUTICA I ÚS. Tisana (ús intern). PREPARACIÓ. Decocció. DESTINACIÓ. Medicina humana.

Vulnerari

FONTS 1332, 1333, 1334. DESCRIPCIÓ DE L'ÚS FETA PELS INFORMANTS. Quan et fas mal $(1332,1333,1334)$. FORMA FARMACE்UTICA I ÚS. Sense forma farmacèutica (ús directe, ús intern) (1332). Sense forma farmacèutica (ús directe, ús extern) $(1333,1334$ ). directe, ús inIó La fulla aplicada directament $(1332,1333,1334)$. DESTINACIÓ. Medicina humana.

\section{BARREGES AMB AQUEST TÀXON}

\section{Part aèria}

FONTS 1339, 1340. Entrevista 22, barreja I (vegeu catàleg de barreges)

FONT 1300. Entrevista 8, barreja II (vegeu catàleg de barreges)

FONT 582. Entrevista 95 (vegeu catàleg de barreges)

\section{Urocystis occulta (Wallroth) Fuckel (urocistidàcies)}

BCN MR-001

\section{NOMS POPULARS}

Carbó (1310)

\section{USOS MEDICINALS}

Micel.li

Abortiu

FONT 1310. DESCRIPCIÓ DE L'ÚS FETA PER L'INFORMANT. Era abortiu. FORMA FARMACĖUTICA I ÚS. Tisana (ús intern). PREPARACIÓ. Decocció dels grans de segle que es carbonaven (es tornaven negres). DESTINACIÓ. Medicina veterinària. 


\section{Urtica dioica L. (urticàcies)}

BCN 25030

\section{NOMS POPULARS}

Ortiga $(505,506,507,509,510,522,523,532,538,541,547,548,553,556,557,560,565$ $566,567,571,572,573,578,579,582,583,584,585,586,587,588,589,747,748,749$ $750,753,754,755,1213,1214,1296,1297,1298,1300,1301,1310,1313,1318,1320$ $1323,1324,1325,1326,1327,1328,1329,1330,1332,1333,1334,1341,1342,1343,1344$ $1345,1346,1352,1361,1362$

Ortiga major $(1213,1214)$

Ortigó $(1331,1337)$

\section{USOS MEDICINALS}

\section{Arrel}

Antigripal

FONT 1323. DESCRIPCIÓ DE L'ÚS FETA PER L'INFORMANT. Per a no agafar el grip. FORMA FARMACEUUTICA I ÚS. Tisana (ús intern). PREPARACIO. Decocció. Aigua d'arre d'ortiga. DESTINACIÓ. Medicina humana.

Antihipertensiu

FONTS 583, 584, 585, 1297, 1345, 1346. DESCRIPCIÓ DE L'ÚS FETA PELS INFORMANTS. Per a rebaixar la sang $(583,584,585)$. Va bé per a la pressió (1297). Per fer baixar la pressió $(1345,1346)$. FORMA FARMACEUTICA I ÚS. Tisana (ús intern). PREPARACIÓ Decocció Aigua de les arrels $(583,584,585)$. Decocció. Aigua de l'arrel (1297, 1345, 1346). DESTINACIÓ. Medicina humana.

Antitussigen

FONTS 588, 1318. DESCRIPCIÓ DE L'ÚS FETA PELS INFORMANTS. Per a la tos de les criatures (588). Per a la tos de la canalla (1318). FORMA FARMACĖUTICA I ÚS. Tisana (ús intern). PREPARACIÓ. Decocció. Cal bullir la rel (588). Decocció. Aigua de la rel (1318). DESTINACIÓ Medicina humana. OBSERVACIONS. No se'Is en podia donar gaire perquè és molt forta (588).

Hematocatàrtic

FONTS 556, 557, 1300, 1323, 1332, 1333, 1334. DESCRIPCIÓ DE L'ÚS FETA PELS INFORMANTS. L'arrel és bona per a netejar la sang $(556,557)$. Deien que anava bé per a netejar la sang (1300). Per a netejar les sangs (1323). Per a netejar la sang (1332, 1333, 1334). FORMA FARMACĖUTICA I ÚS. Tisana (ús intern). PREPARACIÓ. Decocció (556 $557,1300,1332,1333,1334)$. Decocció. Aigua d'arrel d'ortiga (1323). DESTINACIÓ Medicina humana.

No consta
Desconegut per l'informant

FONT 1310. FORMA FARMACĖUTICA I ÚS. Tisana (ús intern). DESTINACIÓ. Medicina humana. OBSERVACIONS. Saben d'algú que se'n pren, però ells no ho han provat mai.

\section{Part aèria}

Analgèsic

FONTS 1343, 1344. DESCRIPCIÓ DE L'ÚS FETA PELS INFORMANTS. Per al dolor FORMA FARMACEUUTICA I ÚS. Sense forma farmacèutica (ús directe, ús extern). PREPARACIO. Fregues d'ortigues, queda tot abutllofat, però al cap de poc et marxa el dolor. DESTINACIO. Medicina humana.

Antialopècic

FONTS 1213, 1214. DESCRIPCIÓ DE L'ÚS FETA PELS INFORMANTS. Per a la caiguda dels cabells. FORMA FARMACĖUTICA I ÚS. Bany (ús extern). PREPARACIÓ. Es posen unes quantes fulles en aigua tebia ies deixen reposal humana.

Antiartrític

FONTS 1361, 1362. DESCRIPCIÓ DE L'ÚS FETA PELS INFORMANTS. Per a fer baixar la pressió, per a la circulació i per a l'artritis. FORMA FARMACĖUTICA I ÚS. Tisana (ús intern). PREPARACIÓ. Decocció. DESTINACIÓ. Medicina humana.

\section{Antiequimòtic}

FONT 1337. DESCRIPCIÓ DE L'ÚS FETA PER L'INFORMANT. Per als trucs. FORMA FARMACĖUTICA I ÚS. Emplastre (ús extern). PREPARACIÓ. Picada amb cansalada es feien emplastres. DESTINACIÓ. Medicina humana.

Antigripal

FONT 1330. DESCRIPCIÓ DE L'ÚS FETA PER L'INFORMANT. Per a depurar la sang, prevé d'agafar grip. FORMA FARMACĖUTICA I ÚS. Tisana (ús intern). PREPARACIÓ. Decocció MODE D'UTILITZACIÓ/POSOLOGIA. S'ha de fer a la primavera i a la tardor. DESTINACIÓ. Medicina humana.

\section{Antihipertensiu}

FONTS 522, 523, 567, 578, 579, 582, 747, 750, 1298, 1328, 1329, 1341, 1342, 1361, 1362 DESCRIPCIÓ DE L'ÚS FETA PELS INFORMANTS. Per a fer rebaixar la sang (750). Per fer baixar la pressió $(522,523,567,578,579,582,747,1328,1329)$. Per a rebaixar la sa (1298, 1341,1342). Per a for bix

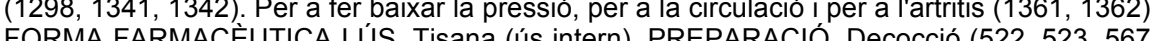
$578,579,582,747,750,1298,1328,1329,1341,1342,1361,1362)$. DESTINACIÓ. 578, 579, 582, 747, 750, 1298, 1328, $1329,1341,1342,1361,1362)$. DESTINAClÓ. Medicina humana. OBSERVACIONS. El meu home n'havia pres molta i li baixava una mica (747).

Antiinflamatori pancreàtic

FONT 1324. DESCRIPCIÓ DE L'ÚS FETA PER L'INFORMANT. Per al pàncrees. FORMA FARMACĖUTICA I ÚS. Tisana (ús intern). PREPARACIÓ. Caldo d'ortigues amb porro (Allium porrum), api (Apium graveolens) i pastanaga (Daucus carota subsp. sativus). DESTINACIÓ. 
Medicina humana. OBSERVACIONS. Quan arrenquen el bull ja no pessiguen i quan han granat ja no es poden fer servir.

Antireumàtic

FONT 1324. DESCRIPCIÓ DE L'ÚS FETA PER L'INFORMANT. Per al reumatisme. FORMA FARMACĖUTICA I ÚS. Tisana (ús intern). PREPARACIÓ. Caldo d'ortigues amb porro (Allium porrum), api (Apium graveolens) i pastanaga (Daucus carota subsp. sativus). DESTINACIÓ. Medicina humana. OBSERVACIONS. Quan arrenquen el bull ja no pessiguen i quan han granat ja no es poden fer servir.

Coadjuvant en el tractament antiobesitat

FONT 1300. DESCRIPCIÓ DE L'ÚS FETA PER L'INFORMANT. Li sembla que les feien servir per a aprimar. FORMA FARMACĖUTICA I ÚS. Tisana (ús intern). PREPARACIÓ. Decocció. DESTINACIÓ. Medicina humana.

Desconegut per l'informant

FONT 1296. FORMA FARMACĖUTICA I ÚS. Tisana (ús intern). DESTINACIÓ. Medicina humana. OBSERVACIONS. Ha sentit a dir que va bé. Va provar de beure'n en infusió però no li va agradar el gust.

Diürètic

FONT 1301. DESCRIPCIÓ DE L'ÚS FETA PER L'INFORMANT. Per a fer orinar. FORMA FARMACĖUTICA I ÚS. Tisana (ús intern). PREPARACIÓ. Decocció. DESTINACIÓ. Medicina humana.

Hematocatàrtic

FONTS $753,754,755,1320,1324,1330$. DESCRIPCIÓ DE L'ÚS FETA PELS INFORMANTS. Per a netejar les sangs $(753,754,755)$. Per a depurar la sang $(1320)$. Va bé perquè depura la sang (1324). Per a depurar la sang, prevé d'agafar grip (1330). FORMA FARMACĖUTICA I ÚS. Tisana (ús intern). PREPARACIÓ. Decocció $(753,754,755,1330)$ Escaldada (1320). Caldo d'ortigues amb porro (Allium porrum), api (Apium graveolens) Escaldada (1320). Caldo d'ortigues amb porro (Allium porrum), api (Apium graveolens)
pastanaga (Daucus carota subsp. sativus) (1324). MODE D'UTILITZACIÓ/POSOLOGIA. S'ha pastanaga (Daucus carota subsp. sativus) (1324). MODE D'UTILITZACCO/POSOLOGIA. S'ha
de fer a la primavera i a la tardor (1330). DESTINACIÓ. Medicina humana. OBSERVACIONS. Quan arrenquen el bull ja no pessiguen i quan han granat ja no es poden fer servir (1324).

Hemostàtic extern

FONTS 505, 506. DESCRIPCIÓ DE L'ÚS FETA PELS INFORMANTS. En emplastre per a parar les hemorràgies. Per a la canalla quan li surt sang del nas. FORMA FARMACĖUTICA I ÚS. Emplastre (ús extern). PREPARACIÓ. S'aixafa ben aixafada i es posa en el lloc on surt la sang. DESTINACIÓ. Medicina humana.

No consta

FONTS 1328, 1329. DESCRIPCIÓ DE L'ÚS FETA PELS INFORMANTS. Abans deien que a un home que agafava mal de dones se li donés aigua d'ortigues. FORMA FARMACĖUTICA ÚS. Tisana (ús intern). PREPARACIÓ. Decocció. DESTINACIÓ. Medicina humana.

Per a augmentar la fertilitat
FONTS 507, 509, 510. DESCRIPCIÓ DE L'ÚS FETA PELS INFORMANTS. En Gratunya, a les vaques que no quedaven prenyades, quan el toro les havia acabat de muntar els fregava la vulva amb un grapat d'ortigues, llavors la vaca s'estirava i guardava més el semen. FORMA FARMACEUTICA I ÚS. Sense forma farmacèutica (ús directe, ús extern). FORMA FARMACEUTICA I US.

Protector renal

FONT 538. DESCRIPCIÓ DE L'ÚS FETA PER L'INFORMANT. Va bé per als ronyons. FORMA FARMACĖUTICA I ÚS. Tisana (ús intern). PREPARACIÓ. Decocció. DESTINACIÓ. Medicina humana.

Tranquil·litzant

FONT 1331. DESCRIPCIÓ DE L'ÚS FETA PER L'INFORMANT. Per als nervis. FORMA FARMACĖUTICA I ÚS. Tisana (ús intern). PREPARACIÓ. Decocció. DESTINACIÓ. Medicina humana.

Vasotònic

FONTS $1327,1343,1344,1361,1362$. DESCRIPCIÓ DE L'ÚS FETA PELS INFORMANTS. Per a la mala circulació (1327). Per a la circulació $(1343,1344)$. Per a fer baixar la pressió, per a la circulació i per a l'artritis $(1361,1362)$. FORMA FARMACĖUTICA I ÚS. Tisana (ús per a la circulació i per a l'artritis $(1361,1362)$. FORMA FARMACEUTICA I US. Tisana (ús
intern). PREPARACIÓ. Decocció (1327, 1343, 1344, 1361, 1362). MODE intern). PREPARACIO. Decocció (1327, 1343, 1344, 1361, 1362). MODE D'UTILITZACIO/POSOLOGIA. S'han de fer novenes (1327). EFECTES SECUNDARIS. Sí. baixar la pressió (1327).

\section{Part aèria jove}

Hipoglucemiant

FONTS 1325, 1326. DESCRIPCIÓ DE L'ÚS FETA PELS INFORMANTS. Per a fer baixar el sucre. FORMA FARMACĖUTICA I ÚS. Tisana (ús intern). PREPARACIÓ. Decocció de les fulles tendres assecades a l'ombra. DESTINACIÓ. Medicina humana.

\section{USOS ALIMENTARIS}

Fulla

Condiment

FONTS 565, 566, 584. DESCRIPCIÓ DE L'ÚS FETA PELS INFORMANTS. Amb sopa de pa les ortigues han de ser tendres $(565,566)$. La Conxita pertany a un grup que es diuen ortigaires i cuinen de tot posant-l'hi ortigues, han fet carquinyolis, coques, gaspatxo... La

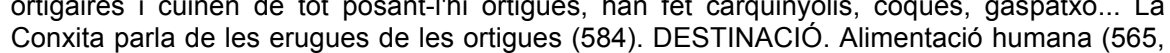
566, 584)

Ingestió de la part de la planta cuita - Cuita en aigua

FONTS 532, 1213, 1214. DESCRIPCIÓ DE L'ÚS FETA PELS INFORMANTS. Per a posar al caldo de verdures. Les faig bullir una estona i després les trec (532). Bullida com a verdura $(1213,1214)$. DESTINACIO. Alimentació humana $(532,1213,1214)$.

Ingestió de la part de la planta cuita - Cuita en oli 
Apèndix 1. Catàleg de tàxons.

FONTS 560, 565, 566, 748, 749, 1213, 1214, 1300. DESCRIPCIÓ DE L'ÚS FETA PELS INFORMANTS. Hi ha gent que en fa truita $(565,566,748,749)$. Quan van venir els hippies en feien truites (560). En truita $(1213,1214)$. Hi ha gent que les amania (1300). DESTINACIÓ. Alimentació humana $(560,565,566,748,749,1213,1214,1300)$.

\section{Part aèria}

Ingestió de la part de la planta cuita - Cuita en aigua

FONTS $560,571,572,573,582,589,1310,1313,1320,1325,1326,1352$. DESCRIPCIÓ DE L'ÚS FETA PELS INFORMANTS. Enferinades i bullides es donaven als porcs en temps de misèria (571). Per el perolat dels porcs se n'hi posaven, junt amb les cols (Brassica oleracea) i les patates (Solanum tuberosum) (560). Se'ls hi donava bullides als porcs, quan no hi havia gaire res (582). Es posaven en el perolat dels porcs (589). Es donava a les gallines aixafades amb una mica de patata (Solanum tuberosum) i pols de segon (Triticum aestivum) $(572,573)$. Ortigues ben tendres, escaldades en aigua bullent i una mica enfarinades, es donaven als porcs quan no hi havia res més per a menjar (1310). Anàvem buscar saques d'ortigues per a donar els porcs (1313). Al caldo sempre n'hi poso, juntament amb altres verdures (1320). amb altres ver $(1325,1326$ ) Se'n donaven de bullides per a menjar als porcs, barrejades amb $(560,571,572,573,582,589,1310,1313,1325,1326,1352)$. Alimentació humana (1320). Ingestió de la part de la planta cuita - Cuita en oli

FONT 1331. DESCRIPCIÓ DE L'ÚS FETA PER L'INFORMANT. Per a fer truita. OBSERVACIONS. És molt bona. DESTINACIÓ. Alimentació humana.

Preparació de begudes - Beguda preparada amb aiguardent

FONTS 1341, 1342. DESCRIPCIÓ DE L'ÚS FETA PELS INFORMANTS. Per a fer ratafia, es confita llor (Laurus nobilis), romaní (Rosmarinus officinalis), nous (Juglans regia), granes de ginebró (Juniperus communis), camamilla (Achillea ptarmica subsp. pyrenaica), ortigues (Urtica dioica), pela de taronja (Citrus sinensis), pela de llimona (Citrus limon), canyella (Cinnamomum zeylanicum), marialluïsa (Lippia triphylla), poniol (Satureja calamintha subsp. ascendens), rosa de bosc (Rosa tomentosa) i malva (Malva sylvestris) en aiguardent i es deixa 40 dies a sol i a serena, llavors es cola i ja es pot beure. DESTINACIÓ. Alimentació humana.

\section{ALTRES USOS}

Part aèria

Creences i pràctiques magicoreligioses

FONT 541. DESCRIPCIÓ DE L'ÚS FETA PER L'INFORMANT. Despullar-se i revolcar-se damunt de les ortigues va bé per al reuma.

\section{ACCIONS NOCIVES O TÒXIQUES}

\section{No consta}

FONTS 547, 548. DESCRIPCIÓ DE L'ACCIÓ NOCIVA O TÒXICA FETA PELS INFORMANTS. El bestiar no se la menja. TOXICITAT EN ANIMALS. Sí.

\section{ALTRES OBSERVACIONS}

FONTS 586, 587. DESCRIPCIÓ FETA PELS INFORMANTS. Surten pertot arreu.

\section{BARREGES AMB AQUEST TÀXON}

Arre

FONTS 572, 573. Entrevista 90, barreja III (vegeu catàleg de barreges)

FONTS 583, 584, 585. Entrevista 96, barreja I (vegeu catàleg de barreges)

\section{Part aèria}

FONTS 1213, 1214. Entrevista 102, barreja II (vegeu catàleg de barreges)

FONT 1324. Entrevista 5, barreja III (vegeu catàleg de barreges)

FONT 532. Entrevista 63, barreja II (vegeu catàleg de barreges)

\section{Urtica sp. (urticàcies)}

\section{NOMS POPULARS}

Ortiga $(580,590,591,592,1215)$

\section{USOS MEDICINALS}

\section{Part aèria}

Hematocatàrtic

FONTS 591, 592, 1215. DESCRIPCIÓ DE L'ÚS FETA PELS INFORMANTS. També es pot prendre per a netejar la sang $(591,592)$. Per a depurar la sang (1215). FORMA FARMACĖUTICA I ÚS. Tisana (ús intern). PREPARACIÓ. Decocció $(591,592,1215)$ DESTINACIÓ. Medicina humana.

Hemostàtic extern

FONTS 591, 592. DESCRIPCIÓ DE L'ÚS FETA PELS INFORMANTS. Quan et rajava sang del nas. FORMA FARMACĖUTICA I ÚS. Emplastre (ús extern). PREPARACIÓ. Es picaven es posava un emplastre als peus. DESTINACIÓ. Medicina humana.

Reforçant ossi

FONT 580. DESCRIPCIÓ DE L'ÚS FETA PER L'INFORMANT. Per a quan et falta calç, diu que en porten molta. FORMA FARMACĖUTICA I ÚS. Tisana (ús intern). PREPARACIÓ Decocció. DESTINACIÓ. Medicina humana.

\section{USOS ALIMENTARIS}

\section{Part aèria}


Apèndix 1. Catàleg de tàxons.

Ingestió de la part de la planta cuita - Cuita en aigua

FONT 590. DESCRIPCIÓ DE L'ÚS FETA PER L'INFORMANT. Es donaven als porcs, s'escaldaven i es barrejaven amb una mica de segó. DESTINACIÓ. Alimentació animal.

\section{Urtica urens L. (urticàcies)}

BCN 25031

\section{NOMS POPULARS}

Ortiga barragana $(1301,1324)$

Ortiga rènega $(532,538,553,574,575,576,577)$

Ortiga rònega $(1213,1214)$

Ortigall (560)

Ortigó $(583,584,585,586,587,748,749,1324,1338)$

\section{USOS MEDICINALS}

\section{No consta}

Desconegut per l'informant

FONTS 583, 584, 585. FORMA FARMACĖUTICA I ÚS. Desconegut per l'informant. OBSERVACIONS. Són bons per a medicina.

Part aèria

Analgèsic

FONT 553. DESCRIPCIÓ DE L'ÚS FETA PER L'INFORMANT. Et fregues allà on et fa dolor, queda embutllofat $i$ et treu l'àcid que tens a dins. FORMA FARMACĖUTICA I ÚS. Sense forma farmacèutica (ús directe, ús extern). DESTINACIÓ. Medicina humana.

Antiequimòtic

FONT 1338. DESCRIPCIÓ DE L'ÚS FETA PER L'INFORMANT. Per als trucs. FORMA FARMACEUUTICA I ÚS. Emplastre (ús extern). PREPARACIÓ. Picada amb cansalada es feien emplastres. DESTINACIÓ. Medicina humana.

Antihipertensiu

FONTS 532, 574, 575, 576, 577, 1213, 1214. DESCRIPCIÓ DE L'ÚS FETA PELS INFORMANTS. Per a fer baixar la pressió $(532,574,575,576,577)$. Fa baixar la pressió $(1213,1214)$. FORMA FARMACEUTICA I US. Tisana (ús intern). PREPARACIO. Decocció. Tant es pot fer servir verda com seca (532). Decocció $(574,575,576,577)$. DESTINACIÓ. Medicina humana.

Antiinflamatori faringi
FONTS 748, 749. DESCRIPCIÓ DE L'ÚS FETA PELS INFORMANTS. Per al mal de coll. FORMA FARMACĖUTICA I ÚS. Tisana (ús intern). PREPARACIÓ. Decocció. DESTINACIÓ. Medicina humana.

Antiinflamatori/Antiàlgic muscular

FONTS 748, 749. DESCRIPCIÓ DE L'ÚS FETA PELS INFORMANTS. Hi curàvem les vaques quan anaven coixes, els feia baixar la inflamació. FORMA FARMACĖUTICA I ÚS. Desconegut per l'informant. DESTINACIÓ. Medicina veterinària.

Diürètic

FONT 1301. DESCRIPCIÓ DE L'ÚS FETA PER L'INFORMANT. Fa orinar molt. FORMA FARMACĖUTICA I ÚS. Tisana (ús intern). PREPARACIÓ. Decocció. DESTINACIÓ. Medicina humana.

Protector renal

FONT 538. DESCRIPCIÓ DE L'ÚS FETA PER L'INFORMANT. Per als ronyons. FORMA FARMACEUUTICA I ÚS. Tisana (ús intern). PREPARACIÓ. Decocció. DESTINACIÓ. Medicina humana. OBSERVACIONS. Si et pessiguen, el mal no dura tant com amb les altres.

\section{USOS ALIMENTARIS}

Fulla

Ingestió de la part de la planta cuita - Cuita en ol

FONT 532. DESCRIPCIÓ DE L'ÚS FETA PER L'INFORMANT. Es fan truites. DESTINACIÓ. Alimentació humana.

\section{ALTRES OBSERVACIONS}

FONTS 560, 583, 584, 585, 586, 587. DESCRIPCIÓ FETA PELS INFORMANTS. Aquells que surten als horts més petites (560). Surten per aquí a l'hort $(583,584,585)$. Es fan als horts, cap a la tardor quan deixes un tros que ja no hi ha res, en surten molts $(586,587)$.

\section{Vaccinium myrtillus L. (ericàcies)}

\section{BCN 25032}

\section{NOMS POPULARS}

Gerdó $(1341,1342)$

Nabiu $(511,512,513,514,538,572,573,583,584,585,1313,1321,1337,1338)$

\section{USOS ALIMENTARIS}

Fruit

Ingestió de la part de la planta crua - Fresca (sense preparació) 
FONTS $511,512,513,514,572,573,1321,1337,1338$. DESCRIPCIÓ DE L'ÚS FETA PELS INFORMANTS. El fruit per a menjar $(511,512,513,514)$. Es menja; des de petit que en menjo, aquí dalt n'hi ha molt. Quan anàvem amb el ramat i passàvem en algun lloc que n'hi havia en menjàvem $(572,573)$. Per a menjar $(1337,1338)$. Per a menjar cru (1321). DESTINACIÓ. Alimentació humana $(511,512,513,514,572,573,1321,1337,1338)$.

Ingestió de la part de la planta cuita - Cuita en sucre

FONTS 538, 583, 584, 585, 1313, 1341, 1342. DESCRIPCIÓ DE L'ÚS FETA PELS INFORMANTS. Per a fer melmelades. Ho fan més els estiuejants que la gent del país (538). Se'n pot fer melmelada, però abans no en feien servir $(583,584,585)$. En fa melmelades (1313). Per a melmelades $(1341,1342)$. DESTINACIÓ. Alimentació humana $(538,583,584$ $585,1313,1341,1342$ )

\section{Valeriana officinalis L. (caprifoliàcies)}

BCN 25033

\section{NOMS POPULARS}

Valeriana $(504,505,506,507,509,510,520,521,525,526,527,529,530,531,539,540$ $553,554,555,556,557,558,564,571,590,591,592,746,1215,1293,1311,1312,1313$ $1317,1318,1323,1324,1330,1337,1338,1347,1348,1349,1352,1361,1362)$

\section{USOS MEDICINALS}

\section{Arrel}

Anticatarral

FONT 558. DESCRIPCIÓ DE L'ÚS FETA PER L'INFORMANT. L'arrel és bona per als refredats. FORMA FARMACĖUTICA I ÚS. Tisana (ús intern). PREPARACIÓ. Decocció Quan tens l'aigua feta hi tires una raget de llet. DESTINACIÓ. Medicina humana. OBSERVACIONS. Era la medicina de la meva iaia.

Antidepressiu

FONT 509. DESCRIPCIÓ DE L'ÚS FETA PER L'INFORMANT. Serveix per a les depressions i per als nervis. FORMA FARMACEUTICA I US. Tisana (ús intern). PREPARACIO. Decocció. DESTINACIO. Medicina humana.

Antiinflamatori intestinal

FONTS 1337, 1338. DESCRIPCIÓ DE L'ÚS FETA PELS INFORMANTS. Per a quan tens I'histeri revoltat (mal de panxa). FORMA FARMACĖUTICA I ÚS. Tisana (ús intern) PREPARACIÓ. Decocció. Aigua de l'arrel. DESTINACIÓ. Medicina humana.

Hematocatàrtic

FONTS 525, 526, 527. DESCRIPCIÓ DE L'ÚS FETA PELS INFORMANTS. L'arrel fa molta bravada i és un purificant de la sang. FORMA FARMACEUUTICA I US. Tisana (ús intern). PREPARACIO. Decocció. DESTINACIO. Medicina humana.
Hipnòtic

FONTS 1293, 1311, 1312. DESCRIPCIÓ DE L'ÚS FETA PELS INFORMANTS. Per a dormi (1293). Fa dormir $(1311,1312)$. FORMA FARMACĖUTICA I ÚS. Tisana (ús intern) PREPARACIÓ. Decocció. Aigua de la planta (1293). Decocció. S'ha de bullir l'aigua amb les arrels cinc minuts $(1311,1312)$. DESTINACIÓ. Medicina humana

Orexigen

FONTS 556, 557. DESCRIPCIÓ DE L'ÚS FETA PELS INFORMANTS. Per a persones que perdien la gana. FORMA FARMACĖUTICA I ÚS. Tisana (ús intern). PREPARACIÓ. Decocció. DESTINACIÓ. Medicina humana. OBSERVACIONS. La padrina li va fer prendre amb una partera que no tenia gana i estava molt decaiguda i li va anar bé $\mathrm{i}$ es va anar curant. Per a trastorns del sistema musculoesquelètic

FONTS 554, 555. DESCRIPCIÓ DE L'ÚS FETA PELS INFORMANTS. Va bé per als nervis quan els tens adolorits. FORMA FARMACĖUTICA I ÚS. Liniment (ús extern). PREPARACIÓ. Amb l'arrel es fa un oli. Es cou la rel en oli bo en una cassola de terra. DESTINACIÓ. Medicina humana.

Sedant

FONTS 529, 530, 531. DESCRIPCIÓ DE L'ÚS FETA PELS INFORMANTS. La rel va bé per als nervis, ajuda a dormir. FORMA FARMACĖUTICA I ÚS. Tisana (ús intern). PREPARACIÓ. Decocció. DESTINACIÓ. Medicina humana.

Tranquil·litzant

FONTS 504, 505, 506, 507, 509, 510, 520, 521, 529, 530, 531, 539, 540, 553, 556, 557, 590 $591,592,746,1311,1312,1313,1317,1318,1323,1330,1347,1348,1349,1352,1361$ 1362. DESCRIPCIÓ DE L'ÚS FETA PELS INFORMANTS. Quan estaves nerviós $(556,557)$ Per a relaxar (504). Aigua de l'arrel per als nervis (746). Serveix per a les depressions i per als nervis $(507,509,510)$. Per als nervis $(505,506,1311,1312,1317,1318,1323,1330$, $1347,1348,1349,1352,1361,1362)$. La rel va bé per als nervis, ajuda a dormir $(529,530$ 531) Va bé per a dormir $(539,540)$. Va bé per als nervis $(520,521,1313)$. Calma els nervis (553). És bona per a (553). Es intern) (556, 557). Tisana (ús intern) (504, 505, 506, 507,509, 510, 520, 521, 529, 530, 531 $1349,1352,1361,1362)$. PREPARACIÓ. Bar 1349, 1352, 1361, 1362). PREPARACIO. Barrejada amb xocolata desfeta $(556,557)$. Decoccio $(504,507,509,510,520,521,529,530,531,539,540,553,590,746,1330,1347$, $1348,1352,1361,1362)$. Decocció. Aigua de l'arrel $(505,506,1349)$. Decocció. Es fa aigua de la rel $(591,592)$. Decocció. S'ha de bullir l'aigua amb les arrels cinc minuts $(1311,1312)$. Infusió de l'arrel (1313). Decocció. Aigua de la rel (1318). Decocció. Aigua de rel (1323). EFECTES SECUNDARIS. Sí. DESTINACIÓ. Medicina humana. OBSERVACIONS. Si agafes una rel has de vigilar que els gats no te la trobin, perquè se la mengen, en són bojos (505, 506). No se'n pot abusar, perquè aflaqueix la vista (1313).

\section{ALTRES USOS}

No consta 
Apèndix 1. Catàleg de tàxons.

Literatura oral popular: llegendes, gloses, contes, dites, refranys, poemes, cançons

FONTS 509, 553, 556, 557, 1215. DESCRIPCIÓ DE L'ÚS FETA PELS INFORMANTS. Si vols la dona sana dóna-li aigua de valedriana $(509,556,557)$. Si vols tenir la dona sana I dónes un got de valeriana (553). "Valedriana la mujer sana." (1215).

\section{BARREGES AMB AQUEST TÀXON}

Arrel

FONT 1324. Entrevista 5, barreja IV (vegeu catàleg de barreges)

FONT 564. Entrevista 84, barreja II (vegeu catàleg de barreges)

FONT 571. Entrevista 89, barreja III (vegeu catàleg de barreges)

\section{Valerianella locusta (L.) Laterrade (caprifoliàcies)}

BCN 49861

\section{NOMS POPULARS}

Canonge (504)

Margarita $(590)$

Marieta $(503,505,506,507,509,510)$

\section{USOS ALIMENTARIS}

Fulla

Ingestió de la part de la planta crua - Fresca (sense preparació)

FONTS 503, 504, 505, 506, 507, 509, 510, 590. DESCRIPCIÓ DE L'ÚS FETA PELS INFORMANTS. Es mengen amanits (504). Quan són tendres es mengen amanides i són més bones que les roselles (503). Creixen als camps que s'havien tret els naps, molt aviat a la primavera. Abans s'amania $(507,509,510)$. Amanides a la primavera $(505,506)$. Fan una es menjaven amanides (590). OBSERVACIONS Són les marietes de la iaia Maria (504). DESTINACIÓ. Alimentació humana (503, 504, 505, 506, 507 $509,510,590)$.

\section{ALTRES OBSERVACIONS}

FONT 503. DESCRIPCIÓ FETA PER L'INFORMANT. Es fan al mateix lloc i al mateix temps que les roselles (Papaver rhoeas)

\section{Veratrum album L. (liliàcies)}

BCN 25034

\section{NOMS POPULARS}

Baladre $(528,542,543,544,547,548,553,559,568,574,575,577,588,1310,1317,1328$ $1329,1332,1333,1334,1337,1338,1341,1342,1343,1344)$

\section{USOS MEDICINALS}

Arre

Pediculicida

FONT 588. DESCRIPCIÓ DE L'ÚS FETA PER L'INFORMANT. Per a treure els polls, a les vaques també els ho fèiem. FORMA FARMACĖUTICA I ÚS. Bany (ús extern) PREPARACIÓ. Decocció. L'arrel ben neta i bullida i després et banyaven el cap amb aquella aigua. DESTINACIÓ. Medicina humana i veterinària.

\section{No consta}

Pediculicida

FONTS 1332, 1333, 1334. DESCRIPCIÓ DE L'ÚS FETA PELS INFORMANTS. Cal rentars'hi el cap, per a matar els polls. FORMA FARMACĖUTICA I ÚS. Bany (ús extern) DESTINACIÓ. Medicina humana.

\section{Part aèria}

Per a la sarna

FONTS 1343, 1344. DESCRIPCIÓ DE L'ÚS FETA PELS INFORMANTS. Per a rentar la ronya de les ovelles. FORMA FARMACĖUTICA I ÚS. Bany (ús extern). PREPARACIÓ. Decocció. DESTINACIÓ. Medicina veterinària.

\section{ALTRES USOS}

Arrel

Altres informacions

FONTS 1337, 1338, 1341, 1342. DESCRIPCIÓ DE L'ÚS FETA PELS INFORMANTS. L'arrel, la compraven els herbolaris $(1337,1338)$. Els herbolaris abans en compraven la rel $(1341$, 1342).

\section{Suc de la fulla}

Ús halièutic

FONT 1310. DESCRIPCIÓ DE L'ÚS FETA PER L'INFORMANT. Si el xafaves amb un bastó llavors aquell suc el tiraves al riu podies pescar molt, perquè les truites quedaven com mortes; de tota manera les truites que no agafaves es recuperaven.

\section{ACCIONS NOCIVES O TÒXIQUES}

No consta 
Apèndix 1. Catàleg de tàxons.

FONTS 528, 547, 548, 553, 559, 568, 574, 575, 576, 577, 1317, 1328, 1329, 1332, 1333 , $1334,1337,1338,1341,1342$. DESCRIPCIÓ DE L'ACCIÓ NOCIVA O TÒXICA FETA PELS INFORMANTS. És verinós $(528)$. El bestiar no se la menja $(547,548)$. És verinós. L'arrel és com una ceba (553). Tòxic (559). És tòxica. Les bèsties no se la mengen pas (568). És tòxica $(574,575,576,577,1341,1342)$. L'arrel es venia $(1317)$. És tòxic, el bestiar no se'l menja $(1328,1329)$. És tòxic $(1332,1333,1334)$. Ells recorden que si les cabres en menjaven vomitaven $(1337,1338)$. TOXICITAT EN ANIMALS. Sí $(547,548,568)$.

\section{ALTRES OBSERVACIONS}

FONTS 542, 543, 544. DESCRIPCIÓ FETA PELS INFORMANTS. S'assembla molt a la genciana (Gentiana lutea).

\section{Verbascum pulverulentum Vill. (escrofulariàcies)}

BCN 25035

\section{NOMS POPULARS}

Blenera (564)

Borrassa (571)

Croca $(583,584,585)$

Cua de guilla $(583,584,585,589,1293,1300,1313,1317,1327,1331,1332,1333,1333$, $1334,1343,1344,1347,1348,1349)$

Flor de torpa $(554,555,1293)$

Herba ploranera (541)

Santjoans $(586,587)$

Torpa $(528,541,553,572,573,580)$

\section{USOS MEDICINALS}

\section{Arrel}

Per als penellons

FONTS 1347, 1348, 1349. DESCRIPCIÓ DE L'ÚS FETA PELS INFORMANTS. Per a banyar els penellons $(1347,1348)$. Per als penellons (1349). FORMA FARMACĖUTICA I ÚS. Bany (ús extern). PREPARACIÓ. Decocció. Aigua de la rel $(1347,1348,1349)$. DESTINACIÓ. Medicina humana.

\section{Flor}

Antiasmàtic

FONTS 572, 573, 1327. DESCRIPCIÓ DE L'ÚS FETA PELS INFORMANTS. Va bé per a l'asma $(572,573)$. Va bé per a la gent que s'ofega (1327). FORMA FARMACĖUTICA I ÚS
Tisana (ús intern). PREPARACIÓ. Decocció (572, 573). Decocció. Aigua de la flor (1327). DESTINACIO Medicina humana.

\section{Anticatarral}

FONTS 553, 1313. DESCRIPCIÓ DE L'ÚS FETA PELS INFORMANTS. Per a estovar els refredats de pit (553). Per als refredats (1313). FORMA FARMACEUTICA I ÚS. Cataplasma ben calenta (553). Decocció (1313). DESTINACIÓ. Medicina humana.

Digestiu

FONT 1331. DESCRIPCIÓ DE L'ÚS FETA PER L'INFORMANT. Per a pair. FORMA FARMACĖUTICA I ÚS. Tisana (ús intern). PREPARACIÓ. Infusió de la flor. DESTINACIÓ. Medicina humana.

Hepatoprotector

FONT 1300. DESCRIPCIÓ DE L'ÚS FETA PER L'INFORMANT. Va bé per a les infeccions del fetge. FORMA FARMACEUTICA I US. TISana (Us intern). PREPARACIO. InfuSio de del

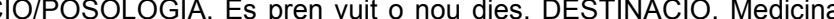
humana.

Fulla

Antieczematós

FONTS 1343, 1344. DESCRIPCIÓ DE L'ÚS FETA PELS INFORMANTS. Per a èczemes o mals externs, per a fer-ne fregues. FORMA FARMACĖUTICA I ÚS. Decocció (ús extern) PREPARACIÓ. Les fulles bullides amb llet de cabra. DESTINACIÓ. Medicina humana.

Vulnerari

FONTS 572, 573. DESCRIPCIÓ DE L'ÚS FETA PELS INFORMANTS. Les fulles diuen que van bé per a les fístules. FORMA FARMACĖUTICA I ÚS. Desconegut per l'informant. DESTINACIÓ. Medicina humana.

\section{No consta}

Desconegut per l'informant

FONT 1293. FORMA FARMACĖUTICA I ÚS. Desconegut per l'informant. DESTINACIÓ. Medicina humana. OBSERVACIONS. Recorda que la seva mare la usava, la que només fa una espiga, però no sap per a què.

\section{ALTRES USOS}

Flor

Ús halièutic

FONTS $541,1317,1332,1333,1334$. DESCRIPCIÓ DE L'ÚS FETA PELS INFORMANTS S'utilitzava per a emmetzinar les truites (541). Si l'aixafes i la tires a una basa del riu, les truites queden atordides i les pots pescar (1317). Per a emborratxar truites quan vols pescar truites queden atordid

Part aèria 
Apèndix 1. Catàleg de tàxons.

Artesanal: elaboració d'escombres

FONTS 583, 584, 585. DESCRIPCIÓ DE L'ÚS FETA PELS INFORMANTS. Per a fer escombres.

Maneig agrosilvopastoral: ús hortícola/agrícola

FONTS 586, 587. DESCRIPCIÓ DE L'ÚS FETA PELS INFORMANTS. Quan fas les bales de palla trenquen el plàstic, perquè fan una tronca molt gruixuda.

Part aèria florida

Creences i pràctiques magicoreligioses

FONT 541. DESCRIPCIÓ DE L'ÚS FETA PER L'INFORMANT. Es donava un cop a la soca de la planta fent que es remogués i deia als nens: si reses un parenostre davant de l'herba ploranera veuràs com cauen les flors.

\section{ACCIONS NOCIVES O TÒXIQUES}

\section{Flor}

FONT 528. DESCRIPCIÓ DE L'ACCIÓ NOCIVA O TÒXICA FETA PER L'INFORMANT. Quan la flor és seca, la pols t'ofega. VIA D'INTOXICACIÓ. Via interna.

\section{No consta}

FONTS 572, 573, 1332, 1333, 1334. DESCRIPCIÓ DE L'ACCIÓ NOCIVA O TÒXICA FETA PELS INFORMANTS. Si els animals en mengen, els ve tos $(572,573)$. És verinosa $(1332$ 1333, 1334). TOXICITAT EN ANIMALS. Sí $(572,573)$.

\section{ALTRES OBSERVACIONS}

FONTS 583, 584, 585. DESCRIPCIÓ FETA PELS INFORMANTS. Aquesta planta tapa les canonades de l'aigua.

\section{Verbascum thapsus L. (escrofulariàcies)}

BCN 29817

\section{NOMS POPULARS}

Tabaco (castellà) $(1213,1214)$

\section{USOS MEDICINALS}

Flor

Antitussigen

FONTS 1213,1214 . DESCRIPCIÓ DE L'ÚS FETA PELS INFORMANTS. És bona per a la tos. FORMA FARMACĖUTICA I ÚS. Desconegut per l'informant. DESTINACIÓ. Medicina humana.

\section{ALTRES USOS}

Fulla

Planta fumable

FONTS 1213, 1214. DESCRIPCIÓ DE L'ÚS FETA PELS INFORMANTS. Les fulles es fumaven.

\section{Verbena officinalis L. (verbenàcies)}

\section{BCN 25036}

\section{NOMS POPULARS}

Berbena $(504,511,512,513,514,518,519,520,521,525,526,527,553,565,566,569$ $570,572,573,578,579,581,591,592,753,754,755,1299,1311,1312,1314,1322,1323$ $1325,1326,1327,1330,1332,1333,1334,1335,1336,1339,1340,1341,1342,1343,1344$ 1350,1351

\section{USOS MEDICINALS}

Fulla

Antiequimòtic

FONT 1335. DESCRIPCIÓ DE L'ÚS FETA PER L'INFORMANT. Per a fer sortir els trucs. Fa desaparèixer l'hematoma. FORMA FARMACĖUTICA I ÚS. Emplastre (ús extern). PREPARACIÓ. S'han de picar les fulles de les berbenes i fregir-les amb una mica de greix de porc, només que quedin toves, i posar-les al mig de dos draps en contacte amb el mal. DESTINACIÓ. Medicina humana.

\section{No consta}

Desconegut per l'informant

FONT 553. FORMA FARMACĖUTICA I ÚS. Desconegut per l'informant. PREPARACIÓ. Emplastres i també per a beure. DESTINACIO. Medicina humana.

\section{Part aèria florida}

Analgèsic

FONTS 511, 512, 513, 514 DESCRIPCIÓ DE L'ÚS FETA PELS INFORMANTS. Per a fer emplastres per a un maluc [dit "una cadera"] que li feia molt mal (513). Per a fer emplastres per a un maluc [dit "una cadera"] que li feia molt mal $(511,512,514)$. FORMA per a un maluc [dit "una cadera"] que li feia molt mal (511, 512, 5

Anticefalàlgic

FONTS 1341, 1342. DESCRIPCIÓ DE L'ÚS FETA PELS INFORMANTS. Per al mal de cap. FORMA FARMACĖUTICA I ÚS. Emplastre (ús extern). PREPARACIÓ. Cal fer una truita de berbenes i posar-la directament al cap. DESTINACIÓ. Medicina humana. 
Antiequimòtic

FONTS 518, 519, 520, 521, 525, 526, 527, 565, 566, 569, 570, 1311, 1312, 1322, 1323 $1327,1330,1332,1333,1334,1336,1341,1342,1343,1344,1350,1351$. DESCRIPCIÓ DE L'ÚS FETA PELS INFORMANTS. Per a trucs quan et queda un sangtraït $(518,519)$. Per a fer emplastres, estira molt, fa sortir la sang dolenta a fora $(525,526,527)$. Per a treure els cops $(520,521)$. Per a fer sortir els trucs a fora $(565,566)$. Feien sortir la inflamació $(569,570)$. Per als trucs, els fa sortir cap enfora $(1311,1312)$. Per a fer sortir els hematomes (1322). Per a fer sortir la sang dolenta (1323). Per als trucs, te'l fa sortir a fora (1327). Per a fer sortir la sang fora dels hematomes $(1330)$. Per a treure els hematomes $(1332,1333,1334)$. Fa sortir els hematomes $(1341,1342,1343,1344)$. Per a fer sortir els trucs $(1350,1351)$. FORMA FARMACÈUTICA I ÚS. Emplate (ús extern) $(518,519,520,521,525,526,527,569,570$ 1311 1312, 1322, 1323, 1327, 1330,1332,1333,1334, 1336, 1341, 1342, 1343, 1344, 1350 1351). Ungü (ús ex, 1351). Ungüent (ús extern) $(565,566)$. PREPARACIO. Berbenes rescaldades amb greix ferne un emplastre amb un drap doblat amb números senars [dit "senassos"] $(518,519)$. Es fa fondre greix de porc i quan és ben calent s'hi escalden les berbenes. Es posen a sobre vuit nou plecs de draps perquè sinó és massa forta $(565,566)$. Per a fer emplastres. Es posava la planta picada amb cansalada o greix de porc i clara d'ou deixatada a sobre 9 dobles de drap $(569,570)$. Agafes la planta i la trinxes petita i la poses dins d'una plata de terra amb una mica de greix de porc, la fas fregir fins que sigui roent, però que no quedi seca, llavors la poses dins d'un drap doblegat nou vegades i deixates una clara d'ou. Poses aquesta barreja sobre el lloc on et fa mal $(1311,1312)$. En emplastres (1322). En emplastres. Es piquen i s posa una mica de greix de porc, s'escalfa al foc i llavors es barregen amb una clara d'ou (és refrescant), es posa directament a sobre la pell amb set dobles de drap, es van canviant a mesura que els dobles del drap van quedant bruts de sang (1323). Fregides amb oli i es fa un emplastre (1327). Picada amb sagi al morter, rescalfada a la paella i barrejada amb una clar a punt (1327). Picado anb clar a punt de neu es posava a sobre els mals, amb nou dobles de drap (1330). Per a fer emplastres. Picada amb sagi de porc. Es i llavor es col-loca sobre la part a tractar (1332, 1333, 1334). Tallada ben petita i rossejada al foc posada entre nou plecs d'un drap de fil (que la berbena quedi en el segon plec), i aplicada directament on tens el mal $(1341,1342)$. Picades amb una mica de greix per a fe emplastres, sempre amb un drap de fil doblat nou vegades $(1343,1344)$. En emplastre amb greix i una mica de vinagre. Cal picar la planta amb cansalada $(1350,1351)$. MODE D'UTILITZACIÓ/POSOLOGIA. S'ha de fer tres dies una, tres o cinc vegades (sempre senars) $(1311,1312)$. Fer novenes $(1341,1342)$. DESTINACIÓ. Medicina humana OBSERVACIONS. El drap queda vermell de sang $(1311,1312)$. També la preparen fregida amb oli, enlloc de sagí, depenent de les característiques del mal $(1332,1333,1334)$.

Antiinflamatori/Antiàlgic muscular

FONT 504. DESCRIPCIÓ DE L'ÚS FETA PER L'INFORMANT. Per a treure l'aigua del genoll. FORMA FARMACÉUTICA I ÚS. Emplastre (ús extern). DESTINACIÓ. Medicina humana.

Antineoplàstic

FONT 1332. DESCRIPCIÓ DE L'ÚS FETA PER L'INFORMANT. Per al càncer. FORMA FARMACEUTICA I US. Emplastre (ús extern). PREPARACIO. Per a fer emplastres. Picada amb sagi de porc. Es posa a sobre de nou dobles d'un drap de fil i llavors es col'loca sobre la part a tractar. DESTINACIÓ. Medicina humana. OBSERVACIONS. Una seva coneguda tenia càncer en un ull i se'l va curar fent aquests emplastres de berbena.

Antipleurític

FONTS 572, 573. DESCRIPCIÓ DE L'ÚS FETA PELS INFORMANTS. Deien que et trencava les pleures. FORMA FARMACĖUTICA I ÚS. Emplastre (ús extern). PREPARACIÓ. Picades i aixafades te la posaven al costat. DESTINACIÓ. Medicina humana.

Antipneumònic

FONTS 581, 1341, 1342. DESCRIPCIÓ DE L'ÚS FETA PELS INFORMANTS. Per als pulmons $(581)$. Per a trencar les pulmonies $(1341,1342)$. FORMA FARMACĖUTICA I ÚS. Emplastre (ús extern). PREPARACIÓ. S'aga la berbena fresca i es pica amb un martell ben aixafa, llavors es pOsa en una paella amb greix de porc i es fregeix un mica i amb draps es posa al pulmó i diu que l'endemà el drap és brut de sang (581). Tallada ben petita rossejada al foc, posada entre nou plecs d'un drap de fil (que la berbena quedi en el segon plec), i aplicada directament on tens el mal (1341, 1342). MODE
D'UTILITZACIÓ/POSOLOGIA. Fer novenes $(1341,1342)$. DESTINACIÓ. Medicina humana. Antisèptic bucal

FONT 504. DESCRIPCIÓ DE L'ÚS FETA PER L'INFORMANT. Per a glopejar quan tens tatxes a la boca. FORMA FARMACĖUTICA I ÚS. Collutori (ús extern). PREPARACIÓ. Decocció. DESTINACIÓ. Medicina humana.

Cardiotònic

FONTS $753,754,755$. DESCRIPCIÓ DE L'ÚS FETA PELS INFORMANTS. L'aigua va bé per al cor. FORMA FARMACĖUTICA I ÚS. Tisana (ús intern). PREPARACIÓ. Decocció. DESTINACIÓ. Medicina humana.

Digestiu

FONTS 578, 579. DESCRIPCIÓ DE L'ÚS FETA PELS INFORMANTS. Per a ajudar a pair. FORMA FARMACĖUTICA I ÚS. Tisana (ús intern). PREPARACIÓ. Decocció. DESTINACIÓ. Medicina humana.

Hipouricemiant

FONTS 504, 753, 754, 755. DESCRIPCIÓ DE L'ÚS FETA PELS INFORMANTS. Per al mal de gota (504). Per al dolor de gota $(753,754,755)$. FORMA FARMACĖUTICA I ÚS. Emplastre (ús extern) (504). Desconegut per l'informant $(753,754,755)$. DESTINACIÓ. Medicina humana

\section{Per a la melsa}

FONTS 1339, 1340. DESCRIPCIÓ DE L'ÚS FETA PELS INFORMANTS. Posada al cantó per al mal de la melsa. FORMA FARMACĖUTICA I ÚS. Emplastre (ús extern). PREPARACIÓ Berbenes fregides i en emplastre. DESTINACIÓ. Medicina humana.

Per al lipoma

FONTS 1325, 1326. DESCRIPCIÓ DE L'ÚS FETA PELS INFORMANTS. Li va curar una llúpia de greix que tenia al cap. FORMA FARMACĖUTICA I ÚS. Emplastre (ús extern). PREPARACIÓ. En emplastres, la planta picada amb clara d'ou i entremig dels draps. DESTINACIÓ. Medicina humana. 
Resolutiu

FONTS 591, 592. DESCRIPCIÓ DE L'ÚS FETA PELS INFORMANTS. Per a estirar mals. FORMA FARMACĖUTICA I ÚS. Emplastre (ús extern). PREPARACIÓ. Ben picades i bullides amb oli i se'n feien emplastres. DESTINACIÓ. Medicina humana.

Antiequimòtic

FONT 1299. DESCRIPCIÓ DE L'ÚS FETA PER L'INFORMANT. Quan tens un mal que no es cura, fa sortir el mal cap enfora. FORMA FARMACEUUTICA I ÚS. Emplastre (ús extern). PREPARACIÓ. Picada quan és tendra i posada a sobre una fulla de col (Brassica oleracea). DESTINACIÓ. Medicina humana.

\section{BARREGES AMB AQUEST TÀXON}

Part aèria florida

FONTS 591, 592. Entrevista 101 (vegeu catàleg de barreges)

FONT 1314. Entrevista 17, barreja I (vegeu catàleg de barreges)

FONT 1322. Entrevista 28, barreja II (vegeu catàleg de barreges)

FONT 1330. Entrevista 32, barreja $V$ (vegeu catàleg de barreges)

FONTS 520, 521. Entrevista 56, barreja I (vegeu catàleg de barreges)

FONTS 753, 754, 755. Entrevista 67, barreja $\vee$ (vegeu catàleg de barreges)

\section{Veronica officinalis L. (plantaginàcies)}

BCN 25037

\section{NOMS POPULARS}

Herba de Santa Caterina (1324)

\section{USOS MEDICINALS}

Part aèria florida

Expectorant

FONT 1324. DESCRIPCIÓ DE L'ÚS FETA PER L'INFORMANT. És expectorant. FORMA FARMACĖUTICA I ÚS. Tisana (ús intern). PREPARACIÓ. Decocció. DESTINACIÓ. Medicina humana.

Laxant

FONT 1324. DESCRIPCIÓ DE L'ÚS FETA PER L'INFORMANT. És laxant. FORMA FARMACĖUTICA I ÚS. Tisana (ús intern). PREPARACIÓ. Decocció. DESTINACIÓ. Medicina humana.
Tònic

FONT 1324. DESCRIPCIÓ DE L'ÚS FETA PER L'INFORMANT. A la primavera quan et trobes dèbil. FORMA FARMACĖUTICA I ÚS. Tisana (ús intern). PREPARACIÓ. Decocció. DESTINACIÓ. Medicina humana.

\section{Veronica persica Poiret in Lam. (plantaginàcies)}

BCN 25038

\section{NOMS POPULARS}

Blauet $(1332,1333,1334)$

\section{USOS MEDICINALS}

\section{Part aèria}

Per a trastorns del sistema immunitari

FONTS 1332, 1333, 1334. DESCRIPCIÓ DE L'ÚS FETA PELS INFORMANTS. Per als porcs, quan agafaven el mal blau. FORMA FARMACEUTICA I ÚS. Tisana (ús intern). PREPARACIO. Decocció. DESTINACIO. Medicina veterinària.

\section{Veronica serpyllifolia L. (plantaginàcies)}

BCN 27295

\section{NOMS POPULARS}

Herba de l'ull $(1350,1351)$

Herba del mal d'ull (1321)

\section{USOS MEDICINALS}

\section{No consta}

Antisèptic ocular

FONT 1321. DESCRIPCIÓ DE L'ÚS FETA PER L'INFORMANT. Per a banyar els ulls FORMA FARMACĖUTICA I ÚS. Bany (ús extern). PREPARACIÓ. Decocció. DESTINACIÓ. Medicina humana.

Desconegut per l'informant

FONTS 1350, 1351. FORMA FARMACĖUTICA I ÚS. Desconegut per l'informant. DESTINACIÓ. Medicina humana. 


\section{Viburnum lantana L. (adoxàcies)}

BCN 27281

\section{NOMS POPULARS}

Cartellatge $(524,564,1215,1352)$

Tortellatge (541)

\section{ALTRES USOS}

Tija

Altres informacions

FONT 1352. DESCRIPCIÓ DE L'ÚS FETA PER L'INFORMANT. Per a buscar aigua. S'agafava una branca que fes forcat i quan es trobava aigua la branca s'aixecava.

Artesanal: elaboració de bastons

FONTS 524, 541, 564, 1215. DESCRIPCIÓ DE L'ÚS FETA PELS INFORMANTS. Per a fer bastons $(564,1215)$

\section{ALTRES OBSERVACIONS}

FONT 564. DESCRIPCIÓ FETA PER L'INFORMANT. Si culls un ram de boles vermelles al cap de molt poca estona venen negres.

\section{Viburnum opulus L. (adoxàcies)}

BCN 27254

\section{NOMS POPULARS}

Mató (1352)

Pompa (564)

\section{ALTRES USOS}

Part aèria florida

Creences i pràctiques magicoreligioses

FONT 1352. DESCRIPCIÓ DE L'ÚS FETA PER L'INFORMANT. A l'església en duien rams a mes de maig.

Ornamental: elaboració de rams

FONT 564. DESCRIPCIÓ DE L'ÚS FETA PER L'INFORMANT. En fèiem rams i els portàvem al cementiri.
Viburnum tinus L. (adoxàcies)

BCN 30012

NOMS POPULARS

Marfull (553)

Vicia faba L. (papilionàcies)

BCN 49339

\section{NOMS POPULARS}

Fava (llavor) $(565,1322)$

\section{USOS ALIMENTARIS}

Llavor

Ingestió de la part de la planta crua - Macerada en aigua

FONTS 565, 566. DESCRIPCIÓ DE L'ÚS FETA PELS INFORMANTS. Estovades per a les vaques. DESTINACIO. Alimentació animal.

\section{ALTRES USOS}

No consta

Literatura oral popular: llegendes, gloses, contes, dites, refranys, poemes, cançons

FONTS 520, 521. DESCRIPCIÓ DE L'ÚS FETA PELS INFORMANTS. Els tudons canten

"dolcíssims llegums tants que se'n sembren i tan pocs que se'n cull".

\section{BARREGES AMB AQUEST TÀXON}

Llavor

FONT 1322. Entrevista 28, barreja II (vegeu catàleg de barreges)

Vicia sativa L. (papilionàcies)

BCN 47746

NOMS POPULARS

Veça $(586,587)$ 


\section{USOS ALIMENTARIS}

\section{Part aèria}

Ingestió de la part de la planta crua - Fresca (sense preparació)

FONTS 586, 587. DESCRIPCIÓ DE L'ÚS FETA PELS INFORMANTS. Per a pasturar les ovelles. Abans partien les muntanyes a trossos, perquè la deixaven granar i així s'anava escampant. DESTINACIÓ. Alimentació animal.

\section{Vinca difformis Pourr. (apocinàcies)}

BCN 52597

\section{NOMS POPULARS}

Vincapervinca (528)

\section{ALTRES USOS}

Part aèria florida

Ornamental: elaboració de rams

FONT 528. DESCRIPCIÓ DE L'ÚS FETA PER L'INFORMANT. Per a fer bonic.

\section{Vinca major L. (apocinàcies)}

BCN 25039

\section{NOMS POPULARS}

Flor de Pasqua $(572,573)$

Herba de vincapervinca $(574,575,576,577)$

Vinca $(1339,1340)$

Vincapervinca $(524,569,570,748,749,1352)$

\section{USOS MEDICINALS}

\section{No consta}

Desconegut per l'informant

FONTS 748, 749, 1352. FORMA FARMACĖUTICA I ÚS. Desconegut per l'informant. DESTINACIÓ. Medicina humana. OBSERVACIONS. És medicinal però no sabem per a què la fèiem servir $(748,749)$. No recordo per a què, pero sé que la feien servir (1352).

Part aèria

\section{Anticatarral}

FONT 524. DESCRIPCIÓ DE L'ÚS FETA PER L'INFORMANT. Per al mal de coll. FORMA FARMACĖUTICA I ÚS. Tisana (ús intern). PREPARACIÓ. Decocció. DESTINACIÓ. Medicina humana.

Antihipertensiu

FONTS 1339, 1340. DESCRIPCIÓ DE L'ÚS FETA PELS INFORMANTS. Per a fer baixar la pressió. FORMA FARMACĖUTICA I ÚS. Tisana (ús intern). PREPARACIÓ. En infusió DESTINACIÓ. Medicina humana.

Antisèptic ocular

FONTS 574, 575, 576, 577. DESCRIPCIÓ DE L'ÚS FETA PELS INFORMANTS. Anava bé per a fregar els ulls. FORMA FARMACĖUTICA I ÚS. Bany (ús extern). PREPARACIÓ Decocció. DESTINACIÓ. Medicina humana.

\section{ALTRES USOS}

\section{Planta viva ex situ}

Ornamental: jardineria

FONTS 569, 570, 572, 573. DESCRIPCIÓ DE L'ÚS FETA PELS INFORMANTS. Per a fer bonic.

Vincetoxicum hirundinaria Medic. (asclepiadàcies)

\section{BCN 25040}

\section{NOMS POPULARS}

Pebrotera borda (1324)

\section{USOS MEDICINALS}

\section{Part aèria}

Antisèptic extern

FONT 1324. DESCRIPCIÓ DE L'ÚS FETA PER L'INFORMANT. Per a desinfectar. FORMA FARMACĖUTICA I ÚS. Fumigació (ús extern). PREPARACIÓ. Per a fer perfums al foc. DESTINACIÓ. Medicina humana i veterinària.

Viola alba Besser (violàcies)

BCN 27286

NOMS POPULARS 
Viola $(505,506,1353,1354)$

Violeta $(547,548)$

\section{USOS MEDICINALS}

\section{Part aèria florida}

Antiinflamatori faring

FONTS 505, 506. DESCRIPCIÓ DE L'ÚS FETA PELS INFORMANTS. Per al mal de coll. FORMA FARMACĖUTICA I ÚS. Tisana (ús intern). PREPARACIÓ. Decocció. DESTINACIÓ. Medicina humana.

\section{ALTRES USOS}

\section{Part aèria florida}

Ornamental: elaboració de rams

FONTS 547, 548. DESCRIPCIÓ DE L'ÚS FETA PELS INFORMANTS. En fem ramets i fan molta olor.

\section{ALTRES OBSERVACIONS}

FONTS 1353, 1354. DESCRIPCIÓ FETA PELS INFORMANTS. A la primavera sempre en surt una matarrada aquí a l'entrada de l'hort.

\section{BARREGES AMB AQUEST TÀXON}

\section{Part aèria florida}

FONTS 505, 506. Entrevista 47, barreja II (vegeu catàleg de barreges)

\section{Viola tricolor L. (violàcies)}

BCN 25041

\section{NOMS POPULARS}

Pensament silvestre (1324)

\section{USOS MEDICINALS}

Planta sencera

Antiherpètic

FONT 1324. DESCRIPCIÓ DE L'ÚS FETA PER L'INFORMANT. Per als herpes. FORMA FARMACĖUTICA I ÚS. Tisana (ús intern). PREPARACIÓ. La planta seca en infusió. DESTINACIÓ. Medicina humana.
Hematocatàrtic

FONT 1324. DESCRIPCIÓ DE L'ÚS FETA PER L'INFORMANT. És depurativa. FORMA FARMACĖUTICA I ÚS. Tisana (ús intern). PREPARACIÓ. La planta seca en infusió DESTINACIÓ. Medicina humana.

\section{Viscum album L. (santalàcies)}

BCN 25042

\section{NOMS POPULARS}

Vesquercí $(511,512,513,514,515,516,518,519,535,564,747,748,749,753,754,755$ 1335)

\section{USOS MEDICINALS}

Fulla

Anticatarral

FONT 564. DESCRIPCIÓ DE L'ÚS FETA PER L'INFORMANT. Per als refredats. FORMA FARMACĖUTICA I ÚS. Tisana (ús intern). PREPARACIÓ. Decocció. DESTINACIÓ. Medicina humana.

\section{Part aèria}

\section{Anticatarra}

FONTS 515, 516, 747. DESCRIPCIÓ DE L'ÚS FETA PELS INFORMANTS. Per als refredats. FORMA FARMACĖUTICA I ÚS. Tisana (ús intern). PREPARACIÓ. Decocció. DESTINACIÓ. Medicina humana.

Antihipertensiu

FONTS 748, 749. DESCRIPCIÓ DE L'ÚS FETA PELS INFORMANTS. Per a fer baixar la pressió. La meva mare hi tenia molta fe. FORMA FARMACĖUTICA I ÚS. Tisana (ús intern). PREPARACIÓ. Decocció. DESTINACIÓ. Medicina humana.

Protector renal

FONT 535. DESCRIPCIÓ DE L'ÚS FETA PER L'INFORMANT. Va bé per als ronyons i per a depurar, l'escarcit d'arç és el més medicinal. FORMA FARMACĖUTICA I ÚS. Tisana (ús intern). PREPARACIÓ. Decocció. DESTINACIÓ. Medicina veterinària.

\section{Part aèria jove}

Anticatarral

FONTS 518, 519. DESCRIPCIÓ DE L'ÚS FETA PELS INFORMANTS. Per als refredats. FORMA FARMACĖUTICA I ÚS. Tisana (ús intern). PREPARACIÓ. Decocció. Aigua dels brots. DESTINACIO. Medicina humana.

Planta sencera 
Apèndix 1. Catàleg de tàxons.

\section{Anticatarra}

FONT 1335. DESCRIPCIÓ DE L'ÚS FETA PER L'INFORMANT. Va bé per als constipats. FORMA FARMACĖUTICA I ÚS. Tisana (ús intern). PREPARACIÓ. Decocció. DESTINACIÓ Medicina humana. OBSERVACIONS. En té un pot, però no li agrada perquè li han dit que s'ha de mesurar molt bé, perquè pot ser verinós, i no el fa servir.

\section{ALTRES USOS}

\section{Planta sencera}

Creences i pràctiques magicoreligioses

FONTS 511, 512, 513, 514. DESCRIPCIÓ DE L'ÚS FETA PELS INFORMANTS. Poder arreplegar vesquerci deien que no agafaries cap mal.

\section{ACCIONS NOCIVES O TÒXIQUES}

\section{Planta sencera}

FONT 1335. DESCRIPCIÓ DE L'ACCIÓ NOCIVA O TÒXICA FETA PER L'INFORMANT. Pot ser verinós. TOXICITAT LLIGADA A L'ÚS MEDICINAL. Sí.

\section{ALTRES OBSERVACIONS}

FONTS 518, 519, 748, 749. DESCRIPCIÓ FETA PELS INFORMANTS. Es fa a sobre d'un altre arbre (moixera, arç) $(748,749)$. A Resclusanys i a sota les Planelles $(518,519)$.

\section{Vitis vinifera L. (vitàcies)}

BCN 25043

\section{NOMS POPULARS}

Parra $(564,567,590)$

Raïm (fruit) $(547,548,560)$

Raïmera (1327)

Vi (producte elaborat) $(507,509,510,536,537,547,548,553,1210,1352)$

Vinagre (producte elaborat) $(505,506,515,516,518,519,525,526,527,528,532,546,553$ $565,566,567,568,571,572,573,574,575,576,577,583,584,585,747,748,749,750$ $751,1345,1346,1353,1354,1361,1362)$

\section{USOS MEDICINALS}

Suc del fruit

Analgèsic
FONTS 1353, 1354. DESCRIPCIO DE L'ÚS FETA PELS INFORMANTS. Per a fer fregues quan has fet un mal gest. FORMA FARMACĖUTICA I ÚS. Sense forma farmacèutica (ús directe, ús extern). DESTINACIÓ. Medicina humana.

Antibacterià

FONT 1352. DESCRIPCIÓ DE L'ÚS FETA PER L'INFORMANT. Per als mussols. FORMA FARMACEUTICA I ÚS Sense forma farmacèutica (ús directe ús extern) PREPARACIÓ. Mullar un dre OBSERVACIONS. Si el mussol no et marxava anaves a casa OBSERVACIONS. Si corrent.

Anticatarral

FONT 1352. DESCRIPCIÓ DE L'ÚS FETA PER L'INFORMANT. Per als refredats. FORMA FARMACĖUTICA I ÚS. Sense forma farmacèutica (ús directe, ús intern). PREPARACIÓ. Vi calent. DESTINACIÓ. Medicina humana.

Anticefalàlgic

FONT 546. DESCRIPCIÓ DE L'ÚS FETA PER L'INFORMANT. Per al mal de cap. FORMA FARMACĖUTICA I ÚS. Emplastre (ús extern). PREPARACIÓ. Et posaven una mitja plena de cendra i vinagre. DESTINACIÓ. Medicina humana. OBSERVACIONS. No sé si és gaire bo perquè diuen que el vinagre treu la memòria.

Antiequimòtic

FONTS 525, 526, 527, 571, 574, 575, 576, 577. DESCRIPCIÓ DE L'ÚS FETA PELS INFORMANTS. Va bé per a fer sortir els hematomes $(525,526,527)$. Per a les patacades (571). Per a les trompades del bestiar, ben fregat amb vinagre $(574,575,576,577)$. FORMA FARMACĖUTICA I ÚS. Emplastre (ús extern) $(525,526,527,571)$. Sense forma farmacèutica (ús directe, ús extern) $(574,575,576,577)$. PREPARACIÓ. Barrejat amb sal que quedi com una pastilla $(525,526,527)$. Terra argila i vinagre (571). DESTINACIÓ. Medicina humana $(525,526,527,571)$. Medicina veterinària $(574,575,576,577)$.

Antieritematós

FONTS 572, 573, 583, 584, 585. DESCRIPCIÓ DE L'ÚS FETA PELS INFORMANTS. Per a esborradures a la regatera: passava a la gent que anava molt a cavall. Fa molt mal, però et treu el foc de dins i fa que et surti la abans la crosta $(572,573)$. Per a les ortigades $(583,584$ $585)$. FORMA FARMACĖUTICA I ÚS. Bany (ús extern). PREPARACIÓ. Posar sal i vinagre $(572,573)$. DESTINACIÓ. Medicina humana. OBSERVACIONS. Va bé per a tot, és una medicina molt bona $(583,584,585)$

Antiherpètic

FONTS 583, 584, 585. DESCRIPCIÓ DE L'ÚS FETA PELS INFORMANTS. Per als herpes FORMA FARMACĖUTICA I ÚS. Desconegut per l'informant. PREPARACIÓ. Vinagre amb cendra. DESTINACIO. Medicina humana.

Antihipertensiu

FONT 532. DESCRIPCIÓ DE L'ÚS FETA PER L'INFORMANT. Per a les eugues si tenen un cop de sang. FORMA FARMACEUTICA I US. Emplastre (ús extern). PREPARACIO. Terragila amb vinagre. DESTINACIO. Medicina veterinària. 
Antiinflamatori

FONTS 583, 584, 585. DESCRIPCIÓ DE L'ÚS FETA PELS INFORMANTS. Per a treure la inflamació.Per als vedells quan s'inflamen. FORMA FARMACĖUTICA I ÚS. Desconegut per l'informant. PREPARACIÓ. Vinagre amb cendra. DESTINACIÓ. Medicina humana. Medicina veterinària. OBSERVACIONS. Va bé per a tot, és una medicina molt bona.

Antiinflamatori faringi

FONTS 567, 1361, 1362. DESCRIPCIÓ DE L'ÚS FETA PELS INFORMANTS. Per al mal de coll $(567,1361,1362)$. FORMA FARMACĖUTICA I ÚS. Emplastre (ús extern) PREPARACIÓ. Ens feien una manxiula que era rescals (cendra calenta) i vinagre. Ho posàvem enmig de dos draps, ben calent al coll (567). Emplastre de cendra amb vinagre ben calent $(1361,1362)$. DESTINACIÓ. Medicina humana.

Antipirètic

FONTS 505, 506, 515, 516, 546, 553, 565, 566, 568, 583, 584, 585, 747, 748, 749, 1361 1362. DESCRIPCIO DE L'ÚS FETA PELS INFORMANTS. Per a fer baixar la febre als porcs $(505,506)$. Per a fer baixar la febre $(515,516,546,565,566,568,583,584,585,747,748$, 749). Per a la febre (553). Torrades amb vinagre als peus per a fer baixar la febre (1361, 1362). FORMA FARMACEUTICA I ÚS. Emplastre (ús extern) (505, 506, 515, 516, 546, 553 $565,566,568,747,748,749)$. Desconegut per l'informant $(583,584,585)$. Vinagre medicina (ús extern) $(1361,1362)$. PREPARACIO. Emplastres de terragila i vinagre $(505,506)$. (Uarrejat a bo sali a dins d'un drap, Barrejat amb (Medicago satio de pa xopada amb vinagre, es posa a les plantes dels peus (747). Et posaven la cendra i e vinagre a les plantes dels peus (546). Torrades als peus amb vinagre (748, 749). Torrades amb vinagre als peus (553). Torrades amb vinagre al front $\mathrm{i}$ als peus (568). Torrades de pa amb vinagre i posades a la planta del peu $(565,566)$. DESTINACIÓ. Medicina veterinària $(505,506)$. Medicina humana $(515,516,546,553,565,566,568,583,584,585,747,748$ $749,1361,1362)$. OBSERVACIONS. Va bé per a tot, és una medicina molt bona $(583,584$ $585)$.

Coadjuvant del postpart

FONTS 536, 537. DESCRIPCIÓ DE L'ÚS FETA PELS INFORMANTS. Per a fer fer la placenta a les bèsties. FORMA FARMACĖUTICA I ÚS. Vi medicinal (ús intern) DESTINACIÓ. Medicina veterinària.

Desconegut per l'informant

FONT 751. FORMA FARMACĖUTICA I ÚS. Emplastre (ús extern). PREPARACIÓ. El vinagre calent es posa amb un drap al cap. DESTINACIÓ. Medicina humana.

No consta

FONTS 547, 548. DESCRIPCIÓ DE L'ÚS FETA PELS INFORMANTS. Per a quan les vaques s'espantaven. FORMA FARMACÉUTICA I ÚS. Vi medicinal (ús intern). PREPARACIÓ. Se'Is donava vi barrejat amb sucre. DESTINACIÓ. Medicina veterinària.

Orexigen
FONT 1210. DESCRIPCIÓ DE L'ÚS FETA PER L'INFORMANT. Prendre un got de vi per a

Pediculicida

FONTS 1353, 1354. DESCRIPCIÓ DE L'ÚS FETA PELS INFORMANTS. Per a matar els polls de la canalla. FORMA FARMACĖUTICA I ÚS. Sense forma farmacèutica (ús directe, ús extern). DESTINACIÓ. Medicina humana.

Per a les picades

FONTS 547, 548. DESCRIPCIÓ DE L'ÚS FETA PELS INFORMANTS. El suc del raïm va bé per a les picades de les abelles. FORMA FARMACĖUTICA I ÚS. Sense forma farmacèutica (ús directe, ús extern). DESTINACIÓ. Medicina humana.

Salutífer

FONTS 507, 509, 510. DESCRIPCIÓ DE L'ÚS FETA PELS INFORMANTS. Quan neixien els polls se'ls donava vi perquè es fessin més valents. FORMA FARMACĖUTICA I ÚS. V medicinal (ús intern). DESTINACIÓ. Medicina veterinària.

\section{USOS ALIMENTARIS}

Fruit

Ingestió de la part de la planta crua - Fresca (sense preparació)

FONTS 567, 590. DESCRIPCIÓ DE L'ÚS FETA PELS INFORMANTS. Fa un raïm negre molt bo (567). Tenim una parra, fa el raïm petit i força aspre (590). DESTINACIÓ. Alimentació

Preparació de begudes - Beguda preparada per fermentació

FONT 1327. DESCRIPCIÓ DE L'ÚS FETA PER L'INFORMANT. Un any en va fer vi i li va quedar molt suau, però bo. OBSERVACIONS. La té per a fer bonic. DESTINACIÓ. Alimentació humana.

\section{Suc del fruit}

Preparació de begudes - Beguda preparada amb vi

FONTS 560, 564. DESCRIPCIÓ DE L'ÚS FETA PELS INFORMANTS. Es feia vi. Primer es feia la mostera que era molt dolç però llavors es tornava vi verd que era molt aspre (560). En feien la mostera, el vi prensat després de la primera ebullició i la gent se'l prenia (564). OBSERVACIONS. Hi havia unes quantes cases que tenien vinya, a can Nicot en feien llavors hi podies anar a prendre un got de vi verd. Encara a can Pardal queda alguna parra abandonada (560). DESTINACIÓ. Alimentació humana $(560,564)$.

\section{BARREGES AMB AQUEST TÀXON}

Suc del fruit

FONTS 1345, 1346. Entrevista 25 (vegeu catàleg de barreges)

FONT 750. Entrevista 50, barreja IV (vegeu catàleg de barreges) 
FONTS 518, 519. Entrevista 54, barreja IV (vegeu catàleg de barreges)

FONT 528. Entrevista 61, barreja II (vegeu catàleg de barreges)

FONT 546. Entrevista 74, barreja III (vegeu catàleg de barreges)

FONT 553. Entrevista 77, barreja III (vegeu catàleg de barreges)

\section{Xanthium spinosum L. (compostes)}

BCN 25044

\section{NOMS POPULARS}

Herba catxurrera (1324)

Herba espitllera $(529,530,531)$

\section{USOS MEDICINALS}

Fruit

Hepatoprotector

FONTS 529, 530, 531, 1324. DESCRIPCIÓ DE L'ÚS FETA PELS INFORMANTS. La que fa gats és bona per al fetge $(529,530,531)$. Per a l'hepatitis i el mal de fetge (1324). FORMA FARMACĖUTICA I ÚS. Tisana (ús intern). PREPARACIÓ. Decocció $(529,530,531)$. Decoció. Aigua dels fruits (1324). DESTINACIO. Medicin Paquita en va prendre durant molt de temps, ara el seu cos ja no li accepta aquesta aigua diu que és perquè té el fetge curat (1324).

\section{Zea mays L. (gramínies)}

BCN 25045

\section{NOMS POPULARS}

Blat de moro $(503,505,506,517,525,526,527,541,554,555,560,565,566,571,589$ $747,750,752,1311,1312,1314,1323,1330,1331,1336,1343,1344,1345,1346,1347$ $1348,1349,1350,1351,1352)$

Blat de moro vermell $(528,572,573)$

Cabellera de blat de moro $(507,509,510,515,516,518,519,520,521,529,530,531,532$, $556,557,588,1293,1361,1362)$

Cabells de blat de moro $(522,523,565,566,751)$

Pèl de panotxa $(583,584,585)$

\section{USOS MEDICINALS}

\section{Estils i estigmes}

Antihipertensiu

FONTS 528, 1314. DESCRIPCIÓ DE L'ÚS FETA PELS INFORMANTS. Per a fer baixar la pressió $(528,1314)$. FORMA FARMACĖUTICA I ÚS. Tisana (ús intern). PREPARACIÓ Decocció (528). Decocció. Aigua de la cabellera (1314). DESTINACIO. Medicina humana.

Diürètic

FONTS 507, 509, 510, 517, 518, 519, 520, 521, 522, 523, 525, 526, 527, 529, 530, 531, 554 $555,556,557,565,566,572,573,583,584,585,588,751,752,1293,1323,1330,1336$ $1343,1344,1345,1346,1347,1348,1349,1350,1351,1352,1361,1362$. DESCRIPCIÓ DE L'ÚS FETA PELS INFORMANTS. Diürètica $(507,509,510)$. Per a fer orinar $(517,518,519$, $520,521,525,526,527,529,530,531,554,555,588,751,1293,1323,1330,1336,1343$ $1344,1345,1346,1347,1348,1349,1352)$. Per a l'751, $1293,1323,1330,1336,1343$ $1344,1345,1346,1347,1348,1349,1352)$. Per a l'orina $(522,523,556,557)$. Es diürètic (752). Per a ajudar a orinar $(565,566)$. Per a Orinar $(572,573,1361,1362)$. Per a fer pixa (583, 584, 585). Per a pixar (1350, 1351). FORMA FARMACEUTICA IÚS. Tisana (ús intern). PREPARACIO. Do $530,531,554,555,556,557,565,566,572,573,583,584,585,588,751,752,1350,1351)$. Decocció. Aigua de la cabellera $(517,1293,1330,1336,1343,1344,1345,1346,1347$, $1348,1349)$. Infusió de cabellera de blat de moro (1323). Aigua de la cabellera (1352). En infusió $(1361,1362)$. DESTINACIÓ. Medicina humana. OBSERVACIONS. El fuet, no recordo perquè es feia servir (517).

Protector renal

FONTS 515, 516, 532, 1311, 1312. DESCRIPCIÓ DE L'ÚS FETA PELS INFORMANTS. Per als ronyons $(515,516,532,1311,1312)$. FORMA FARMACEUTICA I US. Tisana (ús intern) PREPARACIO. Decocció $(515,516,532)$. Decocció. Aigua de la cabellera $(1311,1312)$. DESTINACIO. Medicina humana $(515,516,1311,1312)$. Medicina veterinaria $(532)$.

\section{USOS ALIMENTARIS}

\section{Llavor}

Ingestió de la part de la planta crua - Fresca (sense preparació)

FONTS 503, 505, 506, 565, 566, 571, 589, 747. DESCRIPCIÓ DE L'ÚS FETA PELS INFORMANTS. Quan és tendra es dóna al bestiar (503). La grana es donava a les gellines (503). Per a donar les gallines, als porcs, als conills $(505,506)$. A can Batlle fèiem molt blat (503). Per a dit de mor Els animals que engreixavem que havien menjat cols (Brassica oleracea), pomes (Pyrus malus subsp. mitis), blat de moro... eren molt més bons que els que ara venen, la carn tenia un altre gust. I son més bones les femelles que no hagin parit (la polla, la truja...), que els mascles $(565,566)$. En fèiem per als porcs $(589)$. DESTINACIÓ. Alimentació animal (503, $565,566,571,589,747)$.

Ingestió de la part de la planta crua - Macerada en aigua

FONT 503. DESCRIPCIÓ DE L'ÚS FETA PER L'INFORMANT. S'estovava en aigua calenta i sal $\mathrm{i}$ a les vaques els agradava molt. DESTINACIÓ. Alimentació animal. 
Apèndix 1. Catàleg de tàxons.

Ingestió de la part de la planta cuita - Cuita sense vehicle

FONTS 541, 565, 566. DESCRIPCIÓ DE L'ÚS FETA PELS INFORMANTS. Es feien crispetes a la cendra del foc a terra (541). La mare feia pa de farina de blat de moro i és molt bo $(565,566)$. DESTINACIÓ. Alimentació humana $(541,565,566)$.

Ingestió de la part de la planta cuita - Cuita en aigua

FONTS 505, 506, 589. DESCRIPCIÓ DE L'ÚS FETA PELS INFORMANTS. Se'n feien farinetes $(505,506)$. Se'n feia farro, per la guerra se'n menjava molt. També es feia farratjó, es sembra sis o set grans de blat de moro i no es deixa granar, es talla tendre (589). DESTINACIÓ. Alimentació humana (589).

\section{ALTRES USOS}

\section{Arrel}

Maneig agrosilvopastoral: ús hortícola/agrícola

FONT 503. DESCRIPCIÓ DE L'ÚS FETA PER L'INFORMANT. La rel s'utilitzava com a abonament de la terra.

\section{No consta}

Maneig agrosilvopastoral: ús hortícola/agrícola

FONT 503. DESCRIPCIÓ DE L'ÚS FETA PER L'INFORMANT. Els espigots van bé per a fer foc.

Tèxtil: elaboració de fibres

FONT 1352. DESCRIPCIÓ DE L'ÚS FETA PER L'INFORMANT. De les pellofes se'n feien les màrfegues.

Tèxtil: elaboració de matalassos

FONT 503. DESCRIPCIÓ DE L'ÚS FETA PER L'INFORMANT. Amb els pellons es feien màrfegues.

\section{ALTRES OBSERVACIONS}

FONTS 560, 747. DESCRIPCIÓ FETA PELS INFORMANTS. Beget era el país del blat de moro i Rocabruna el país de les patates (Solanum tuberosum) (747). Es plantava a Beget (560).

\section{BARREGES AMB AQUEST TÀXON}

\section{Estils i estigmes}

FONTS 1343, 1344. Entrevista 23, barreja II (vegeu catàleg de barreges)

FONT 1331. Entrevista 30, barreja II (vegeu catàleg de barreges)

FONT 503. Entrevista 43 (vegeu catàleg de barreges)

FONT 750. Entrevista 50, barreja I (vegeu catàleg de barreges)
FONTS 572, 573. Entrevista 90, barreja I (vegeu catàleg de barreges)

\section{No consta}

FONT 528. Entrevista 61, barreja I (vegeu catàleg de barreges) 
Apèndix 2. Catàleg de barreges.

\section{Abortiu}

\section{Entrevista 50, barreja II}

FONT 477. Ripoll (el Ripollès)

INGREDIENTS:

Ramonda myconi (L.) Reichenb. (gesneriàcies) - Part aèria

Saxifraga longifolia Lap. subsp. longifolia (saxifragàcies) - Part aèria

FORMA FARMACĖUTICA I ÚS. Tisana (ús intern)

EFECTES SECUNDARIS. No consta

DESTINACIÓ. Medicina humana

DESCRIPCIÓ DE L'ÚS FETA PER L'INFORMANT. Per a l'embaràs de les dones quan volien avortar.

PREPARACIÓ. Decocció.

\section{Analgèsic}

Entrevista 11, barreja II

FONT 879. Vilallonga de Ter (el Ripollès)

INGREDIENTS:

Arnica montana L. subsp. montana (compostes) - Inflorescència

Hypericum perforatum $\mathrm{L}$. (gutíferes) - Part aèria florida

Lavandula angustifolia Mill. (labiades) - Summitat florífera

Rosmarinus officinalis L. (labiades) - Part aèria jove

FORMA FARMACĖUTICA I ÚS. Loció (ús extern)

EFECTES SECUNDARIS. No consta

DESTINACIO. Medicina humana

DESCRIPCIÓ DE L'ÚS FETA PER L'INFORMANT. Per al dolor.

PREPARACIÓ. Prepara una ampolla amb aquestes herbes i esperit de vi.

\section{Entrevista 15, barreja III}

FONT 880. Camprodon (el Ripollès)

INGREDIENTS:

Laurus nobilis $\mathrm{L}$. (lauràcies) - Fulla

Lavandula angustifolia Mill. (labiades) - Summitat florifera

Ruta chalepensis $L$. (rutàcies) - Part aèria

FORMA FARMACĖUTICA I ÚS. Loció (ús extern)

EFECTES SECUNDARIS. No consta

DESTINACIO. Medicina humana

DESCRIPCIÓ DE L'ÚS FETA PER L'INFORMANT. Per a fer fregues a llocs adolorits.

PREPARACIO. Confitades en esperit de vi.

\section{Entrevista 17, barreja I}

FONT 863. Molló (el Ripollès)

INGREDIENTS:

Althaea officinalis L. (malvàcies) - Arrel

Allium sativum $L$. (amaril-lidàcies) - Bulb
Petroselinum crispum (Mill.) Hill (umbel-líferes) - Part aèria

Verbena officinalis L. (verbenàcies) - Part aèria florida

FORMA FARMACĖUTICA I ÚS. Liniment (ús extern)

EFECTES SECUNDARIS. No consta

DESTINACIÓ. Medicina humana

DESCRIPCIÓ DE L'ÚS FETA PER L'INFORMANT. Anava bé per als ossos adolorits o esquerdats.

PREPARACIÓ. Es bullia en ol

\section{Entrevista 23, barreja I}

FONT 885. Vilallonga de Ter (el Ripollès)

INGREDIENTS:

Artemisia absinthium L. (compostes) - Part aèria

Rosmarinus officinalis $L$. (labiades) - Part aèria florida

FORMA FARMACËUTICA I ÚS. Liniment (ús extern)

EFECTES SECUNDARIS. No consta

DESTINACIÓ. Medicina humana

DESCRIPCIÓ DE L'ÚS FETA PER L'INFORMANT. Per al dolor.

PREPARACIÓ. Confitat en oli.

Entrevista 23, barreja I

FONT 885. Vilallonga de Ter (el Ripollès)

INGREDIENTS:

Artemisia absinthium L. (compostes) - Part aèria

Rosmarinus officinalis L. (labiades) - Part aèria florida

FORMA FARMACEUTICA I US. Loció (ús extern)

EFECTES SECUNDARIS. No consta

DESTINACIO. Medicina humana

DESCRIPCIÓ DE L'ÚS FETA PER L'INFORMANT. Per al dolor.

PREPARACIÓ. Confitat en esperit de vi.

\section{Entrevista 24}

FONT 872. Vilallonga de Ter (el Ripollès)

NGREDIENTS:

Bryonia cretica L. subsp. dioica (Jacq.) Tutin (cucurbitàcies) - Arrel

Eryngium campestre L. (umbel-liferes) - Arrel

Petroselinum crispum (Mill.) Hill (umbel-liferes) - Arre

FORMA FARMACËUTICA I ÚS. Pomada (ús extern)

EFECTES SECUNDARIS. No consta

DESTINACIÓ. Medicina humana

DESCRIPCIÓ DE L'ÚS FETA PER L'INFORMANT. Va bé per al dolor.

PREPARACIÓ. S'ha de bullir totes les plantes en oli i llavors afegir-hi la cera i queda com una pomada.

\section{Entrevista 29, barreja II}

FONT 897. Llanars (el Ripollès) 
Apèndix 2. Catàleg de barreges.

INGREDIENTS:

Olea europaea L. subsp. europaea (oleàcies) - Suc del fruit

Pinus sp. (pinàcies) - Resina (Exsudat)

FORMA FARMACĖUTICA I ÚS. Emplastre (ús extern)

EFECTES SECUNDARIS. No consta

DESTINACIO. Medicina humana

LINFORMANT. Per al dolor

PREPARACIÓ. Pegat d'oli amb resina de pi.

OBSERVACIONS. Abans ho compràvem a les trementinaires.

Entrevista 30, barreja

FONT 878. Camprodon (el Ripollès)

INGREDIENTS:

Lavandula angustifolia Mill. (labiades) - Summitat florifera

Rosmarinus officinalis $L$. (labiades) - Part aèria florida

FORMA FARMACĖUTICA I ÚS. Loció (ús extern)

EFECTES SECUNDARIS. No consta

DESTINACIÓ. Medín

R L'INFORMANT. Per a fer fregues per al dolor.

PREPARACIÓ. Tot confitat en esperit de vi.

\section{Entrevista 53, barreja II}

FONT 276. Les Llosses (el Ripollès)

INGREDIENTS:

Lavandula angustifolia Mill. (labiades) - Summitat florifera

Sambucus nigra $L$. (adoxàcies) - Inflorescència

FORMA FARMACĖUTICA I ÚS. Fumigació (ús extern)

EFECTES SECUNDARIS. No consta

DESTINACIÓ. Medicina humana

DESCRIPCIÓ DE L'ÚS FETA PER L'INFORMANT. Per al dolor.

PREPARACIÓ. Perfumats al foc.

Entrevista 63, barreja

FONT 277. Queralbs (el Ripollès)

INGREDIENTS:

Allium sativum L. (amaril-lidàcies) - Bulb

Geranium robertianum L. (geraniàcies) - Part aèria

FORMA FARMACEUTICA IUS. Emplastre (ús extern)

EFECTES SECUNDARIS. No consta

DESTINACIO. Medicina humana

DESCRIPCIÓ DE L'ÚS FETA PER L'INFORMANT. Per al dolor.

PREPARACIO. Aixafar les plantes en oli i fer-ne emplastres.

\section{Entrevista 67, barreja IV}

FONT 480. Sant Joan de les Abadesses (el Ripollès)

INGREDIENTS:
Arnica montana L. subsp. montana (compostes) - Inflorescència

Cannabis sativa L. (cannabàcies) - No consta

Hypericum perforatum L. (gutíferes) - Part aèria florida

Juniperus communis L. (cupressàcies) - Fructificació

Lavandula angustifolia Mill. (labiades) - Summitat florifera

Rosmarinus officinalis $\mathrm{L}$. (labiades) - Part aèria florida

FORMA FARMACĖUTICA I ÚS. Loció (ús extern)

EFECTES SECUNDARIS. No consta

DESTINACIÓ. Medicina humana

DESCRIPCIÓ DE L'ÚS FETA PER L'INFORMANT. Per al dolor.

PREPARACIÓ. Posar totes les herbes en esperit de vi i fer-ne fregues.

OBSERVACIONS. Les granes ben madures que ja siguin negres.

\section{Entrevista 72, barreja}

FONT 285. Planoles (el Ripollès)

INGREDIENTS:

Calendula officinalis $L$. (compostes) - Inflorescència

Hypericum perforatum $L$. (gutiferes) - Part aèria florida

Petroselinum crispum (Mill.) Hill (umbel-líferes) - Arre

FORMA FARMACEUTICA I ÚS. Liniment (ús extern)

EFECTES SECUNDARIS. No consta

DESTINACIÓ Medicina humana

DESCRIPCIÓ DE L'ÚS FETA PER L'INFORMANT. És molt bo com a reforçant d'ossos, per als trencats, per a l'artrosi, per a les picors, per al dolor en general sempre que no hi hag ferida. L'oncle m'ho va ensenyar a fer, deia que te n'has de posar fins que arriba un moment que el mal l'escup, vol dir que ja estàs curat.

PREPARACIÓ. En una cassola de terra s'hi posa un litre d'oli i s'hi afegeix un grapat d'herba de Sant Joan, un tros de greix de gallina, un tros de cera de mel, tres o quatre arrels de julivert i dos o tres bojacs. Amb el foc molt baix s'espera que bulli i llavors es deixa mtija hora més. Quan es tebi és cola.

\section{Entrevista 77, barreja II}

FONT 290. Pardines (el Ripollès)

C:

Eucalyptus globulus Labill. (mirtàcies) - Fruit

Lavandula angustifolia Mill. (labiades) - Summitat florifera

Rosmarinus officinalis L. (labiades) - Part aèria florida

FORMA FARMACEUTICA I ÚS. Loció (ús extern)

EFECTES SECUNDARIS. No consta

DESTINACIO. Medicina humana

DESCRIPCIO DE L'US FETA PER L'INFORMANT. Va bé per al dolor, per a les articulacions, per a quan estàs estellat.

PREPARACIÓ. Es posen les herbes amb esperit de vi (dos litres) i es deixa 21 dies a sol i serena i es cola amb un drap de fil. De romaní i espígol, una embostada, i d'eucaliptus, set grans. 
Apèndix 2. Catàleg de barreges.

\section{Entrevista 83}

FONT 296. Ripoll (el Ripollès)

INGREDIENTS:

Allium sativum L (amaril-lidàcies) - Bulb

Hypericum perforatum $L$. (gutíferes) - Part aèria florida

Pinus sylvestris $L$. (pinàcies) - No consta

FORMA FARMACĖUTICA I ÚS. Ungüent (ús extern)

EFECTES SECUNDARIS. No consta

DESTINACIÓ. Medicina veterinària

DESCRIPCIO DE L'ÚS FETA PER L'INFORMANT. Per a les metes de les vaques quan els $h$ feien mal de munyir-les.

PREPARACIÓ. Amb un tupí de terra que sigui nou, greix rentat tres vegades, una mica d'oli, una mica de pega, tres grans d'all o cinc (sempre senars, depenent de la mida del tupí), un brot de ruda i un brot d'herba de cop. Es deixa bullir i, quan està fet l'ungüent, ell sol ja para de bullir. No cal colar-lo, només cal que treguis els brots de les plantes.

OBSERVACIONS. Això ho va dir un curandero, en Solses de Ripoll. Fa molts anys que és mort.

\section{Entrevista 90, barreja II}

FONT 303. Ribes de Freser (el Ripollès)

\section{INGREDIENTS:}

Geranium robertianum L. (geraniàcies) - Part aèria

Petroselinum crispum (Mill.) Hill (umbel-líferes) - Arre

Ruta chalepensis L. (rutàcies) - Part aèria

FORMA FARMACEUTICA I USS. Ungüent (ús extern)

EFECTES SECUNDARIS. No consta

DESTINACIO. Medicina humana

DESCRIPCIO DE L'ÚS FETA PER L'INFORMANT. Va bé untar-se quan tens dolor i artrosi.

PREPARACIÓ. Es fa bullir en oli i greix de gallina.

Entrevista 102, barreja IV

FONT 788. Queralbs (el Ripollès)

REDIENTS:

(asparagàcies) - Suc de la fulla

Althaea officinalis L. (malvàcies) - Arrel

Rosa sp. (rosàcies) - Flor

Ruta chalepensis $L$. (rutàcies) - Part aèria

FORMA FARMACEUTICA IUS. Tisana (ús intern)

EFECTES SECUNDARIS. No consta

DESTINACIO. Medicina humana

DESCRIPCIO DE L'US FETA PER L'INFORMANT. Va bé per al dolor i el reuma dels genolls. PREPARACIÓ. Es fa bullir tot.

\section{Antialopècic}

\section{Entrevista 102, barreja II}

FONT 788, Queralbs (el Ripollès)

INGREDIENTS:

Tropaeolum majus L. (tropeolàcies) - No consta

Urtica dioica $L$. (urticàcies) - Part aèria

FORMA FARMACĖUTICA I ÚS. Desconegut per l'informant

EFECTES SECUNDARIS. No consta

DESTINACIÓ. Medicina humana

DESCRIPCIO DE L'US FETA PER L'INFORMANT. Anava bé per als cabells

PREPARACIÓ. Es posava a sol i serena.

\section{Antiamigdalític}

\section{Entrevista 45, barreja II}

FONT 473. Ogassa (el Ripollès)

INGREDIENTS:

Althaea officinalis L. (malvàcies) - Arrel

Punica granatum L. (litràcies) - Epicarpi

Rosa sp. (rosàcies) - Fruit

FORMA FARMACEUTICA I ÚS. Tisana (ús intern)

EFECTES SECUNDARIS. No consta

DESTINACIO. Medicina humana

DESCRIPCIO DE L'ÚS FETA PER L'INFORMANT. Per a les angines i el mal de coll.

PREPARACIÓ. Decocció.

\section{Antiartrític}

\section{Entrevista 23, barreja I}

FONT 885. Vilallonga de Ter (el Ripollès)

INGREDIENTS:

Artemisia absinthium L. (compostes) - Part aèria

Rosmarinus officinalis $L$. (labiades) - Part aèria florida

FORMA FARMACĖUTICA I ÚS. Liniment (ús extern)

EFECTES SECUNDARIS. No consta

DESTINACIO. Medicina humana

DESCRIPCIO DE L'US FETA PER L'INFORMANT. Per a l'artrosi.

PREPARACIÓ. Confitat en oli.

\section{Entrevista 23, barreja}

FONT 885. Vilallonga de Ter (el Ripollès)

INGREDIENTS:

Artemisia absinthium L. (compostes) - Part aèria

Rosmarinus officinalis $L$. (labiades) - Part aèria florida

FORMA FARMACĖUTICA I ÚS. Loció (ús extern)

EFECTES SECUNDARIS. No consta

DESTINACIÓ. Medicina humana 
Apèndix 2. Catàleg de barreges.

DESCRIPCIÓ DE L'ÚS FETA PER L'INFORMANT. Per a l'artrosi.

PREPARACIÓ. Confitat en esperit de vi.

Entrevista 72, barreja I

FONT 285. Planoles (el Ripollès)

alendula officinalis $\mathrm{L}$. (compostes) - Inflorescència

Hypericum perforatum $\mathrm{L}$. (gutiferes) - Part aèria florida

Petroselinum crispum (Mill.) Hill (umbel-líferes) - Arre

FORMA FARMACEUTICA I ÚS. Liniment (ús extern)

EFECTES SECUNDARIS. No consta

DESTINACIO. Medicina humana

DESCRIPCIÓ DE L'ÚS FETA PER L'INFORMANT. És molt bo com a reforçant d'ossos, pe als trencats, per a l'artrosi, per a les picors, per al dolor en general sempre que no hi hagi ferida. L'oncle m'ho va ensenyar a fer, deia que te n'has de posar fins que arriba un moment que el mal l'escup, vol dir que ja estàs curat.

PREPARACIÓ. En una cassola de terra s'hi posa un litre d'oli i s'hi afegeix un grapat d'herba de Sant Joan, un tros de greix de gallina, un tros de cera de mel, tres o quatre arrels de julivert $i$ dos o tres bojacs. Amb el foc molt baix s'espera que bulli $i$ llavors es deixa mtija hora més. Quan es tebi és cola.

\section{Entrevista 90, barreja II}

FONT 303. Ribes de Freser (el Ripollès)

INGREDIENTS:

Geranium robertianum L. (geraniàcies) - Part aèria

Petroselinum crispum (Mill.) Hill (umbel-líferes) - Arre

Ruta chalepensis $L$. (rutàcies) - Part aèria

FORMA FARMACEUUTICA I ÚS. Ungüent (ús extern)

EFECTES SECUNDARIS. No consta

DESTINACIÓ Medicina humana

DESCRIPCIÓ DE L'ÚS FETA PER L'INFORMANT. Va bé untar-se quan tens dolor i artrosi.

PREPARACIÓ. Es fa bullir en oli i greix de gallina.

\section{Antiberrugós}

\section{Entrevista 29, barreja}

FONT 897. Llanars (el Ripollès)

INGREDIENTS:

Citrus limon (L.) Burm. (rutàcies) - Suc del fruit

Citrus sinensis (L.) Osbeck (rutàcies) - Suc del fruit

FORMA FARMACEUTICA I ÚS. Sense forma farmacèutica (mescla medicamentos, ús extern)

EFECTES SECUNDARIS. No consta

DESTINACIÓ. Medicina humana

DESCRIPCIÓ DE L'ÚS FETA PER L'INFORMANT. Es posa el suc a sobre de les berrugues.
Entrevista 78, barreja III

FONT 291. Planoles (el Ripollès)

INGREDIENTS:

Buxus sempervirens $L$. (buxàcies) - Fulla

Chelidonium majus $L$. (papaveràcies) - Part aèria

FORMA FARMACĖUTICA I ÚS. Loció (ús extern)

EFECTES SECUNDARIS. No consta

DESTINACIO. Medicina humana

DESCRIPCIO DE L'US FETA PER LINFORMANT. Per a curar les berrugues.

PREPARACIÓ. Macerat els celidonis i les fulles de boix en esperit de vi.

Anticatarral

\section{Entrevista 6, barreja I}

FONT 847. Camprodon (el Ripollès)

INGREDIENTS:

Althaea officinalis L. (malvàcies) - Arrel

Ficus carica L. (moràcies) - Fruit

Hyssopus officinalis $\mathrm{L}$. (labiades) - Part aèria florida

Pyrus malus L. subsp. malus (rosàcies) - Fruit

Sambucus nigra $L$. (adoxàcies) - Inflorescència

FORMA FARMACĖUTICA I ÚS. Xarop (ús intern)

EFECTES SECUNDARIS. No consta

DESTINACIÓ. Medicina humana

DESCRIPCIÓ DE L'ÚS FETA PER L'INFORMANT. Per als constipats.

PREPARACIO. En fa un xarop. Es posen totes aquestes herbes a bullir uns 15 minuts.

\section{Entrevista 11, barreja II}

FONT 879. Vilallonga de Ter (el Ripollès)

INGREDIENTS:

Arnica montana L. subsp. montana (compostes) - Inflorescència

Hypericum perforatum $\mathrm{L}$. (gutíferes) - Part aèria florida

Lavandula angustifolia Mill. (labiades) - Summitat florífera

Rosmarinus officinalis $L$. (labiades) - Part aèria jove

FORMA FARMACĖUTICA I ÚS. Loció (ús extern)

EFECTES SECUNDARIS. No consta

DESTINACIÓ. Medicina humana

DESCRIPCIO DE L'US FETA PER L'INFORMANT. L'usa per a untar-se quan està constipat.

PREPARACIO. Prepara una ampolla amb aquestes herbes i esperit de vi.

Entrevista 14, barreja IV

FONT 875. Sant Pau de Segúries (el Ripollès)

INGREDIENTS:

Lavandula angustifolia Mill. (labiades) - Summitat florifera

Piper nigrum L. (piperàcies) - Fruit

FORMA FARMACĖUTICA I ÚS. Emplastre (ús extern) 
Apèndix 2. Catàleg de barreges.

EFECTES SECUNDARIS. No consta

DESTINACIO Medicina hUMARA

DESCRIPCIÓ DE L'ÚS FETA PER L'INFORMANT. Per a quan estàs molt constipat i t'ofegues.

PREPARACIÓ. Picar espígol amb pebre negre i fer un emplastre per a posar a l'esquena o al pit.

\section{Entrevista 15, barreja I}

FONT 880. Camprodon (el Ripollès)

INGREDIENTS:

Lavandula angustifolia Mill. (labiades) - Summitat florifera

Rosmarinus officinalis $L$. (labiades) - Part aèria florida

FORMA FARMACEUTICA I ÚS. Loció (ús extern)

EFECTES SECUNDARIS. No consta

DESTINACIÓ. Medicina humana

DESCRIPCIO DE L'US FETA PER L'INFORMANT. Per a quan estàs constipat.

PREPARACIÓ. En esperit de vi per a fer fregues.

Entrevista 15, barreja II

FONT 880. Camprodon (el Ripollès)

Althaea officinalis L. (malvàcies) - Arre

Citrus limon (L.) Burm. (rutàcies) - Epicarpi

Citrus sinensis (L.) Osbeck (rutacies) - Epicarpi

FORMA FARMACËUTICA I US. Xarop (ús intern)

EFECTES SECUNDARIS. No consta

DESTINACIO. Medicina humana

DESCRIPCIÓ DE L'US FETA PER L'INFORMANT. Per als constipats.

PREPARACIÓ. Es fa sucre cremat i s'hi afegeix aigua amb l'arrel de malví, una pela de llimona, una pela de taronja, es fa bullir i queda un xarop.

Entrevista 16, barreja II

FONT 881. Sant Pau de Segúries (el Ripollès)

ENTS:

Lavandula angustifolia Mill. (labiades) - Summitat florifera

Rosmarinus officinalis L. (labiades) - Part aèria florida

FORMA FARMACĖUTICA I ÚS. Loció (ús extern)

EFECTES SECUNDARIS. No consta

DESTINACIO. Medicina humana

DESCRIPCIO DE L'ÚS FETA PER L'INFORMANT. Quan estàs constipat.

PREPARACIÓ. Confitat en esperit de vi, per a fer-te fregues al pit o l'esquena.

\section{Entrevista 16, barreja IV}

FONT 881. Sant Pau de Segúries (el Ripollès)

INGREDIENTS:

Citrus limon (L.) Burm. (rutàcies) - Suc del fruit
Thymus vulgaris $L$. (labiades) - Part aèria florida

FORMA FARMACÈUTICA I ÚS. Tisana (ús intern)

EFECTES SECUNDARIS. No consta

DESTINACIÓ. Medicina humana

DESCRIPCIÓ DE L'ÚS FETA PER L'INFORMANT. Va molt bé per als constipats.

PREPARACIÓ. Decocció. Aigua de farigola amb un raig de llimona i una cullerada de mel.

\section{Entrevista 21, barreja}

FONT 865. Setcases (el Ripollès)

INGREDIENTS:

Meum athamanticum Jacq. subsp. athamanticum (umbel-liferes) - Arrel

Thymus vulgaris $L$. (labiades) - Part aèria florida

FORMA FARMACEUUTICA I ÚS. Tisana (ús intern)

EFECTES SECUNDARIS. No consta

DESTINACIÓ. Medicina humana

DESCRIPCIÓ DE L'ÚS FETA PER L'INFORMANT. Per a quan estàs constipat.

PREPARACIÓ. Decocció.

\section{Entrevista 34, barreja}

FONT 869. Camprodon (el Ripollès)

Citrus limon (L.) Burm. (rutàcies) - Suc del fruit

Citrus sinensis (L.) Osbeck (rutàcies) - Suc del fruit

FORMA FARMACEUTICA I ÚS. Sense forma farmacèutica (mescla medicamentosa, ús

intern)

EFECTES SECUNDARIS. No consta

DESTINACIO. Medicina humana

DESCRIPCIÓ DE L'ÚS FETA PER L'INFORMANT. Per a no constipar-se. És antioxidant.

PREPARACIÓ. Suc de taronja amb un raig de llimona.

MODE D'UTILITZACIÓ/POSOLOGIA. Cada matí en dejú.

\section{Entrevista 34, barreja}

FONT 869. Camprodon (el Ripollès)

NGREDIENTS:

Achillea ptarmica L. subsp. pyrenaica (Sibth. ex Godr. in Gren. et Godr.) Rouy

(compostes) - Inflorescència

Citrus limon (L.) Burm. (rutàcies) - Suc del fruit

Sambucus nigra L. (adoxàcies) - Inflorescència

Tilia platyphyllos Scop. (tiliàcies) - Bràctea i inflorescència

FORMA FARMACEUTICA I ÚS. Tisana (ús intern)

EFECTES SECUNDARIS. No consta

DESTINACIO. Medicina humana

DESCRIPCIÓ DE L'US FETA PER L'INFORMANT. Per als constipats.

PREPARACIÓ. Infusió amb una cullerada de mel. 
Apèndix 2. Catàleg de barreges.

FONT 263. Sant Joan de les Abadesses (el Ripollès)

INGREDIENTS:

Lavandula angustifolia Mill. (labiades) - Summitat florifera

Pinus sylvestris $L$. (pinàcies) - Part aèria jove

Rosmarinus officinalis $L$. (labiades) - Part aèria florid

Thymus vulgaris $L$. (labiades) - Part aèria florida

FORMA FARMACĖUTICA I ÚS. Sense forma farmacèutica (mescla medicamentosa, ús

extern)

EFECTES SECUNDARIS. No consta

DESTINACIÓ. Medicina humana

DESCRIPCIÓ DE L'ÚS FETA PER L'INFORMANT. Quan estàs refredat et fregues el pit l'esquena amb aquesta barreja fins que et queda la mà seca.

PREPARACIO. Es posen totes les plantes en mig litre d'esperit de vi, un quart de litre d'aiguarràs i una pastilla de càmfora.

\section{Entrevista 50, barreja I}

FONT 477. Ripoll (el Ripollès)

INGREDIENTS:

Asperula cynanchica L. (rubiàcies) - Part aèria florida

Tilia platyphyllos Scop. (tiliàcies) - Bràctea i inflorescència

Zea mays L. (gramínies) - Estils i estigmes

FORMA FARMACEUTICA I ÚS. Tisana (ús intern)

EFECTES SECUNDARIS. No consta

DESTINACIÓ. Medicina humana

DESCRIPCIO DE L'US FETA PER L'INFORMANT. Per als refredats.

PREPARACIÓ. Decocció. Aigua amb una cullerada de mel.

\section{Entrevista 50, barreja III}

FONT 477. Ripoll (el Ripollès)

INGREDIENTS:

Rosmarinus officinalis $\mathrm{L}$. (labiades) - Part aèria florida

Thymus vulgaris $\mathrm{L}$. (labiades) - Part aèria florida

FORMA FARMACĖUTICA I ÚS. Aerosol (ús intern)

EFECTES SECUNDARIS. No consta

DESTINACIO. Medicina humana

DESCRIPCIO DE L'US FETA PER L'INFORMANT. Per als refredats.

PREPARACIÓ. Per a fer bafs [dit "bafos"].

\section{Entrevista 53, barreja VI}

FONT 276. Les Llosses (el Ripollès)

INGREDIENTS:

Anthemis arvensis L. (compostes) - Inflorescència

Lavandula angustifolia Mill. (labiades) - Summitat florifera

FORMA FARMACEUTICA I ÚS. LOció (ús extern)

EFECTES SECUNDARIS. No consta

DESTINACIÓ. Medicina humana
DESCRIPCIÓ DE L'ÚS FETA PER L'INFORMANT. Per a fer fregues per als refredats. PREPARACIÓ. En esperit de vi.

Entrevista 53, barreja VII

FONT 276. Les Llosses (el Ripollès)

Rosa sp. (rosàcies) - Flor

Sisymbrium officinale (L.) Scop. (cruciferes) - Part aèria florida

Tilia platyphyllos Scop. (tiliàcies) - Bràctea i inflorescència

FORMA FARMACĖUTICA I ÚS. Tisana (ús intern)

EFECTES SECUNDARIS. No consta

DESTINACIO. Medicina humana

DESCRIPCIO DE L'ÚS FETA PER L'INFORMANT. Per als constipats.

PREPARACIO. Decocció.

OBSERVACIONS. També porta l'herba del constipat, la de la flor groga.

\section{Entrevista 54, barreja}

FONT 270. Sant Joan de les Abadesses (el Ripollès)

NGREDIENTS:

Arnica montana L. subsp. montana (compostes) - Inflorescència

Lavandula angustifolia Mill. (labiades) - Summitat florifera

Rosmarinus officinalis $L$. (labiades) - Part aèria florida

FORMA FARMACĖUTICA I ÚS. Loció (ús extern)

EFECTES SECUNDARIS. No consta

DESTINACIO. Medicina humana

DESCRIPCIO DE L'US FETA PER L'INFORMANT. Per als refredats.

PREPARACIÓ. En esperit de vi. T'has de fer fregues a l'esquena i al pit.

\section{Entrevista 58}

FONT 273. Sant Joan de les Abadesses (el Ripollès)

INGREDIENTS:

Althaea officinalis L. (malvàcies) - Arrel

Pyrus malus L. subsp. mitis (Wallr.) O.Bolòs et J.Vigo (rosàcies) - Fruit

FORMA FARMACĖUTICA I ÚS. Decocció (ús intern)

EFECTES SECUNDARIS. No consta

DESTINACIO. No consta

DESCRIPCIÓ DE L'ÚS FETA PER L'INFORMANT. Va bé per als constipats.

PREPARACIÓ. Es fa bullir, juntament amb sucre roig. Fa una aigua molt llefiscosa.

Entrevista 62, barreja

FONT 479. Campdevànol (el Ripollès)

INGREDIENTS:

Rosmarinus officinalis L. (labiades) - Part aèria florida

Tilia platyphyllos Scop. (tiliàcies) - Bràctea i inflorescència

FORMA FARMACĖUTICA I ÚS. Tisana (ús intern)

EFECTES SECUNDARIS. No consta 
Apèndix 2. Catàleg de barreges.

DESTINACIÓ. Medicina humana

DESCRIPCIÓ DE L'ÚS FETA PER L'INFORMANT. Per als constipats [dit "enconstipats"]

PREPARACIÓ. Decocció. Aigua de romaní i flor de tell.

Entrevista 67, barreja VI

FONT 480. Sant Joan de les Abadesses (el Ripollès)

INGREDIENTS:

Tilia platyphyllos Scop. (tiliàcies) - Bràctea i inflorescència

Viscum album L. subsp. album (santalàcies) - Part aèria

FORMA FARMACĖUTICA I ÚS. Tisana (ús intern)

EFECTES SECUNDARIS. Si

DESTINACIÓ. Medicina humana

DESCRIPCIÓ DE L'ÚS FETA PER L'INFORMANT. Per als refredats.

PREPARACIÓ. Decocció.

OBSERVACIONS. L'escarcí s'ha de vigilar perquè accelera el cor.

\section{Entrevista 67, barreja VIII}

FONT 480. Sant Joan de les Abadesses (el Ripollès)

GREDIENTS:

Antennaria dioica (L.) Gaertn. (compostes) - No consta

Satureja calamintha (L.) Scheele subsp. ascendens (Jord.) Briq. (labiades) - Part aèria

florida

FORMA FARMACĖUTICA I ÚS. Tisana (ús intern)

EFECTES SECUNDARIS. No consta

DESTINACIO. Medicina humana

DESCRIPCIO DE L'US FETA PER L'INFORMANT. Per als refredats.

PREPARACIO. Decocció.

\section{Entrevista 68, barreja II}

FONT 281. Queralbs (el Ripollès)

INGREDIENTS:

Achillea ptarmica L. subsp. pyrenaica (Sibth. ex Godr. in Gren. et Godr.) Rouy

(compostes) - Inflorescència

Meum athamanticum Jacq. subsp. athamanticum (umbel-liferes) - Arrel

Ranunculus parnassifolius $L$. (ranunculàcies) - Planta sencera

FORMA FARMACĖUTICA I ÚS. Tisana (ús intern)

EFECTES SECUNDARIS. No consta

DESTINACIÓ. Medicina humana

DESCRIPCIO DE L'US FETA PER L'INFORMANT. Per als refredats.

PREPARACIO. DecOcció.

MODE D'UTILITZACIÓ/POSOLOGIA. Una tasseta al matí en dejú.

\section{Entrevista 69}

FONT 282. Queralbs (el Ripollès)

INGREDIENTS:

Citrus limon (L.) Burm. (rutàcies) - Fruit
Lavandula angustifolia Mill. (labiades) - Summitat florífera

Pinus mugo Turra subsp. uncinata (Ramond ex DC. in Lam et DC.) Domin (pinàcies) - Part aèria jove

Rosmarinus officinalis $L$. (labiades) - Part aèria florida

Thymus vulgaris $L$. (labiades) - Part aèria florida

FORMA FARMACE்UTICA I ÚS. Xarop (ús intern)

EFECTES SECUNDARIS. No consta

DESTINACIÓ. Medicina veterinària

DESCRIPCIÓ DE L'ÚS FETA PER L'INFORMANT. L'utilitzo per als refredats de pit, destapa molt.

PREPARACIÓ. Torrem en una cassola de terra dues cullerades de sucre i hi afegim un litre d'aigua, set o vuit brots de pi tendres, farigola, una mica d'espígol, una mica de romaní, una llimona i mitja, quan s'ha reduït dos dits l'aigua hi afegim dues cullerades de mel. Es treu del foc i s'hi afegeix el suc d'una llimona i mitja i es tapa.

\section{Entrevista 75, barreja II}

FONT 288. Ribes de Freser (el Ripollès)

INGREDIENTS:

Glycyrrhiza glabra L. (papilionàcies) - Arrel

Sambucus nigra L. (adoxàcies) - Inflorescència

FORMA FARMACĖUTICA I ÚS. Desconegut per l'informant

EFECTES SECUNDARIS. No consta

DESTINACIÓ. Medicina humana

DESCRIPCIO DE L'US FETA PER L'INFORMANT. Per als refredats.

PREPARACIÓ. Flor de sabuc i pega dolça.

\section{Entrevista 78, barreja II}

FONT 291. Planoles (el Ripollès)

INGREDIENTS:

Lavandula angustifolia Mill. (labiades) - Summitat florífera

Mentha pulegium L. (labiades) - Part aèria florida

Rosmarinus officinalis $L$. (labiades) - Part aèria florida

FORMA FARMACĖUTICA I ÚS. Tintura alcohòlica (ús extern)

EFECTES SECUNDARIS. No consta

DESTINACIO. Medicina humana

DESCRIPCIÓ DE L'ÚS FETA PER L'INFORMANT. Va bé per a la tos i els refredats. Destapa molt.

PREPARACIÓ. Posar les herbes en esperit de vi camforat.

\section{Entrevista 85}

FONT 298. Sant Joan de les Abadesses (el Ripollès)

INGREDIENTS:

Althaea officinalis L. (malvàcies) - Arre

Eucalyptus globulus Labill. (mirtàcies) - Fulla

Pyrus malus L. subsp. mitis (Wallr.) O.Bolòs et J.Vigo (rosàcies) - Fruit

FORMA FARMACËUTICA I ÚS. Xarop (ús intern) 
Apèndix 2. Catàleg de barreges.

EFECTES SECUNDARIS. No consta

DESTINACIÓ. Medicina humana

PREPARACIÓ. Es fa bullir la rel de malví, la poma i les dues fulles d'eucaliptus i s'hi posa una mica de sucre cremat.

Entrevista 90, barreja III

FONT 303. Ribes de Freser (el Ripollès)

INGREDIENTS:

Althaea officinalis L. (malvàcies) - Arre

Urtica dioica L. (urticàcies) - Arrel

FORMA FARMACEUTICA I US. Tisana (ús intern)

EFECTES SECUNDARIS. No consta

DESTINACIO. Medicina humana

DESCRIPCIÓ DE L'ÚS FETA PER L'INFORMANT. Te la donaven per a la distenta.

PREPARACIÓ. Decocció. Arrel d'ortiga i arrel de malví es bullia i s'hi afegia sucre candi.

\section{Entrevista 94, barreja V}

FONT 307. Campdevànol (el Ripollès)

DIENTS:

Sambucus nigra L. (adoxàcies) - Inflorescència

Thymus vulgaris $L$. (labiades) - Part aèria florida

FORMA FARMACĖUTICA I ÚS. Tisana (ús intern)

EFECTES SECUNDARIS. No consta

DESTINACIO. Medicina humana

DESCRIPCIO DE L'US FETA PER L'INFORMANT. Per als refredats.

PREPARACIO. Decoccio.

\section{Entrevista 97}

FONT 310. Ogassa (el Ripollès)

INGREDIENTS:

Arnica montana L. subsp. montana (compostes) - Inflorescència

Artemisia absinthium L. (compostes) - Part aèria

FORMA FARMACĖUTICA I ÚS. Loció (ús extern)

EFECTES SECUNDARIS. No consta

DESTINACIO. Medicina humana

DESCRIPCIO DE L'US FETA PER L'INFORMANT. Et fas fregues quan estàs tapat.

PREPARACIÓ. Es posa en esperit de vi.

\section{Anticefalàlgic}

\section{Entrevista 25}

FONT 886. Llanars (el Ripollès)

INGREDIENTS:

Brassica oleracea L. (cruciferes) - Llavor

Vitis vinifera $L$. (vitàcies) - Suc del fruit

FORMA FARMACE்UTICA I ÚS. Emplastre (ús extern)
EFECTES SECUNDARIS. No consta

DESTINACIÓ Medicina humana

DESCRIPCIÓ DE L'ÚS FETA PER L'INFORMANT. Treia el mal de cap. Estira la sang avall.

PREPARACIÓ. La grana de col picada amb vinagre i posada als peus.

Entrevista 72, barreja II

FONT 285. Planoles (el Ripollès)

INGREDIENTS:

Brassica oleracea L. (cruciferes) - Fulla

Olea europaea $L$. subsp. europaea (oleàcies) - Suc del fruit

FORMA FARMACEUTICA I US. Emplastre (ús extern)

EFECTES SECUNDARIS. No consta

DESTINACIÓ. Medicina humana

DESCRIPCIÓ DE L'ÚS FETA PER L'INFORMANT. Per a la pròstata, per al mal de cap o per al mal de panxa, te l'has de posar on et fa mal.

PREPARACIÓ. Col calenta al rescals del foc i untada d'oli.

\section{Antidiarreic}

Entrevista 22, barreja II

FONT 883. Llanars (el Ripollès)

INGREDIENTS:

Achillea ptarmica L. subsp. pyrenaica (Sibth. ex Godr. in Gren. et Godr.)

Rouy (compostes) - Inflorescència

Sambucus nigra $L$. (adoxàcies) - Inflorescència

FORMA FARMACĖUTICA I ÚS. Tisana (ús intern)

EFECTES SECUNDARIS. No consta

DESTINACIO. Medicina humana

DESCRIPCIÓ DE L'ÚS FETA PER L'INFORMANT. Per a la diarrea del bestiar.

PREPARACIÓ Decocció.

Entrevista 32, barreja

FONT 877. Vilallonga de Ter (el Ripollès)

NGREIENTS:

Citrus limon (L.) Burm. (rutàcies) - Epicarp

Oryza sativa L. (gramínies) - Llavor

FORMA FARMACEUTICA I US. Decocció (ús intern)

EFECTES SECUNDARIS. No consta

DESTINACIÓ. Medicina veterinària

DESCRIPCIO DE L'US FETA PER L'INFORMANT. Per als vedells quan tenen diarrea.

PREPARACIO. Arròs bullit amb pela de llimona.

\section{Entrevista 32, barreja VII}

FONT 877. Vilallonga de Ter (el Ripollès)

INGREDIENTS:

Allium sativum L. (amaril·lidàcies) - Bulb 
Apèndix 2. Catàleg de barreges.

Thymus vulgaris $\mathrm{L}$. (labiades) - Part aèria florida

FORMA FARMACÈUTICA I ÚS. Suspensió (ús intern)

EFECTES SECUNDARIS. No consta

DESTINACIÓ. Medicina humana

DESCRIPCIÓ DE L'ÚS FETA PER L'INFORMANT. Per a quan tens diarrea.

PREPARACIÓ. Fer una sopa amb pa torrat, un gra d'all, un raig d'oli i farigola ben bullit. OBSERVACIONS. Si no se't posa bé aquesta sopa a la panxa no se't posa bé res.

\section{Entrevista 41}

FONT 890. Sant Joan de les Abadesses (el Ripollès)

INGREDIENTS:

Daucus carota L. subsp. sativus (Hoffm.) Arcang. (umbel-liferes) - Arrel

Oryza sativa L. (gramínies) - Llavor

FORMA FARMACĖUTICA I ÚS. Decocció (ús intern)

EFECTES SECUNDARIS. No consta

DESTINACIÓ

DESCRIPCIÓ DE L'ÚS FETA PER L'INFORMANT. Per a les diarrees.

PREPARACIÓ. Aigua d'arròs i pastanaga, tot ben bullit.

\section{Entrevista 67, barreja III}

FONT 480. Sant Joan de les Abadesses (el Ripollès)

INGREDIENTS:

Achillea millefolium L. (compostes) - Inflorescència

Thymus serpyllum L. (labiades) - Part aèria florida

FORMA FARMACËUTICA I ÚS. Tisana (ús intern)

EFECTES SECUNDARIS. No consta

DESTINACIO. Medicina humana

DESCRIPCIO DE L'US FETA PER L'INFORMANT. Per a la diarrea.

PREPARACIÓ. Decocció.

\section{Antiequimòtic}

Entrevista 4, barreja I

FONT 862. Llanars (el Ripollès)

INGREDIENTS:

Medicago sativa L. subsp. sativa (papilionàcies) - Part aèria

Ruta chalepensis L. (rutàcies) - Part aèria

FORMA FARMACEUTICA I US. Emplastre (ús extern)

EFECTES SECUNDARIS. No consta

DESTINACIO. Medicina humana

DESCRIPCIO DE L'ÚS FETA PER L'INFORMANT. Per als trucs.

PREPARACIÓ. Tot ben picat amb cansalada i entremig de dos draps.

\section{Entrevista 5, barreja II}

FONT 873. Camprodon (el Ripollès)

INGREDIENTS:
Geranium robertianum $\mathrm{L}$. (geraniàcies) - Part aèria

Petroselinum crispum (Mill.) Hill (umbel-líferes) - Part aèria

FORMA FARMACEUUTICA I ÚS. Emplastre (ús extern)

EFECTES SECUNDARIS. No consta

DESTINACIÓ. Medicina humana

'INFORMANT. Va bé per als cops.

PREPARACIÓ. Es talla tot petit i es barreja amb greix.

Entrevista 11, barreja

FONT 879. Vilallonga de Ter (el Ripollès)

INGREDIENTS:

Arnica montana L. subsp. montana (compostes) - Inflorescència

Hypericum perforatum $L$. (gutíferes) - Part aèria florida

Lavandula angustifolia Mill. (labiades) - Summitat florifera

Rosmarinus officinalis L. (labiades) - Part aèria jove

FORMA FARMACĖUTICA I ÚS. Loció (ús extern)

EFECTES SECUNDARIS. No consta

DESTINACIÓ. Medicina humana

DESCRIPCIÓ DE L'ÚS FETA PER L'INFORMANT. Per als trucs.

PREPARACIÓ. Prepara una ampolla amb aquestes herbes i esperit de vi.

\section{Entrevista 53, barreja IV}

FONT 276. Les Llosses (el Ripollès)

INGREDIENTS:

Hypericum perforatum $\mathrm{L}$. (gutíferes) - Part aèria florida

Papaver rhoeas L. (papaveràcies) - No consta

FORMA FARMACĖUTICA I ÚS. Liniment (ús extern)

EFECTES SECUNDARIS. No consta

DESTINACIO Medicina humana

DESCRIPCIÓ DE L'ÚS FETA PER L'INFORMANT. Per a les patacades.

PREPARACIÓ. En oli.

Entrevista 56, barreja

FONT 271. Vallfogona de Ripollès (el Ripollès)

INGREDIENTS:

Hypericum perforatum L. (gutíferes) - Part aèria florida

Verbena officinalis $L$. (verbenàcies) - Part aèria florida

FORMA FARMACEUTICA I ÚS. Ungüent (ús extern)

EFECTES SECUNDARIS. No consta

DESTINACIÓ. Medicina humana

DESCRIPCIÓ DE L'ÚS FETA PER L'INFORMANT. Anava bé per a treure els trucs cap enfora.

PREPARACIÓ. S'aixafaven les berbenes amb cansalada i s'hi afegia oli de cop.

Entrevista 67, barreja V

FONT 480. Sant Joan de les Abadesses (el Ripollès) 
Apèndix 2. Catàleg de barreges.

\section{INGREDIENTS:}

Medicago sativa L. subsp. sativa (papilionàcies) - Part aèria

Verbena officinalis L. (verbenàcies) - Part aèria florida

FORMA FARMACĖUTICA I ÚS. Emplastre (ús extern)

EFECTES SECUNDARIS. No consta

DESTINACIO. Medicina human

DESCRIPCIO DE LUS FETA PER L'INFORMANT. Per a fer sortir els cops.

PREPARACIÓ. Es fan emplastres, juntament amb cansalada blanca (que no hagi esta salada).

Entrevista 68, barreja

FONT 281. Queralbs (el Ripollès)

INGREDIENTS:

Medicago sativa L. subsp. sativa (papilionàcies) - Part aèria

Petroselinum crispum (Mill.) Hill (umbel-líferes) - Arre

FORMA FARMACEUTICA I ÚS. Ungüent (ús extern)

EFECTES SECUNDARIS. No consta

DESTINACIÓ Medicina humana

DESCRIPCIÓ DE L'ÚS FETA PER L'INFORMANT. Per a fer sortir els morats quan et feies un truc.

PREPARACIÓ. Picades amb greix de gallina.

\section{Entrevista 91, barreja}

FONT 304. Pardines (el Ripollès)

INGREDIENTS:

Arnica montana L. subsp. montana (compostes) - Inflorescència

Lilium candidum L. (liliàcies) - Flor

FORMA FARMACĖUTICA I UUS. Loció (ús extern)

EFECTES SECUNDARIS. No consta

DESTINACIÓ. Medicina humana

DESCRIPCIÓ DE L'ÚS FETA PER L'INFORMANT. Per als cops.

PREPARACIÓ. En esperit de vi.

\section{Entrevista 94, barreja I}

FONT 307. Campdevànol (el Ripollès)

INGREDIENTS:

Arnica montana L. subsp. montana (compostes) - Inflorescència

Hypericum perforatum $L$. (gutíferes) - Part aèria florida

Lavandula angustifolia Mill. (labiades) - Summitat florifera

Rosmarinus officinalis $\mathrm{L}$. (labiades) - Part aèria florida

FORMA FARMACĖUTICA I ÚS. Loció (ús extern)

EFECTES SECUNDARIS. No consta

DESTINACIO Medicina humana

PREPARACIÓ. Poso les herbes en esperit de vi i les deixo set o vuit dies a sol i serena.

Llavors ho poso dins d'una ampolla hermètica.
Entrevista 94, barreja I

FONT 307 . Campdevànol (el Ripollès)

INGREDIENTS:

Arnica montana L. subsp. montana (compostes) - Inflorescència

Hypericum perforatum L. (gutíferes) - Part aèria florida

Lavandula angustifolia Mill. (labiades) - Summitat florífera

Rosmarinus officinalis $L$. (labiades) - Part aèria florid

FORMA FARMACĖUTICA I ÚS. Liniment (ús extern)

EFECTES SECUNDARIS. No consta

DESTINACIÓ. Medicina humana

PREPARACIO. Poso les herbes en oli i les deixo set o vuit dies a sol i serena. Llavors ho poso dins d'una ampolla hermètica.

\section{Entrevista 102, barreja VI}

FONT 788. Queralbs (el Ripollès)

INGREDIENTS:

Achillea ptarmica L. subsp. pyrenaica (Sibth. ex Godr. in Gren. et Godr.)

Rouy (compostes) - Inflorescència

Eryngium bourgatii Gouan (umbel-líferes) - Arrel

Hypericum perforatum $L$. (gutíferes) - Part aèria florida

Petroselinum crispum (Mill.) Hill (umbel-líferes) - Arrel

Phaseolus vulgaris L. (papilionàcies) - Llavor

Ruta chalepensis $L$. (rutàcies) - Part aèria

Sedum telephium L. subsp. maximum (L.) Krock. (crassulàcies) - Part aèria

FORMA FARMACĖUTICA I ÚS. Liniment (ús extern)

EFECTES SECUNDARIS. No consta

DESTINACIÓ. Medicina humana

DESCRIPCIÓ DE L'ÚS FETA PER L'INFORMANT. Va bé per a fer fregues a les masegades i els trucs.

PREPARACIÓ. Posar tots els ingredients en una cassola amb oli a punt de bullir i una cullerada sopera de greix de gallina, després deixar-ho reposar durant tres dies a sol i serena. Colar-ho i guardar-ho en un pot de vidre. També es pot posar tot en un pot amb oli fred i deixar-ho durant nou dies a sol i serena.

OBSERVACIONS. Aquest oli no es pot aplicar directament a sobre d'una ferida.

\section{Antifúngic}

Entrevista 77, barreja III

FONT 290. Pardines (el Ripollès)

INGREDIENTS:

Plantago lanceolata L. (plantaginàcies) - Fulla

Prunus avium (L.) L. (rosàcies) - Parènquima cortical

Sambucus nigra L. (adoxàcies) - Parènquima cortical

Sedum album L. (crassulàcies) - Part aèria

Vitis vinifera $L$. (vitàcies) - Suc del fruit

FORMA FARMACĖUTICA I ÚS. Embrocació (ús extern) 
Apèndix 2. Catàleg de barreges.

EFECTES SECUNDARIS. No consta

DESTINACIO Medicina hUMana

DESCRIPCIÓ DE L'ÚS FETA PER L'INFORMANT. Per a la circulació de la sang, la gangrena [dit "cangrena"] i els fongs dels peus.

PREPARACIÓ. Es bullen totes les herbes en dos gots d'oli, en una cassola de terra fins que es redueix a la meitat, es cola i ja ho tens a punt.

\section{Antigangrenós}

\section{Entrevista 77, barreja III}

FONT 290. Pardines (el Ripollès)

INGREDIENTS:

Plantago lanceolata L. (plantaginàcies) - Fulla

Prunus avium (L.) L. (rosàcies) - Parènquima cortical

Sambucus nigra L. (adoxàcies) - Parènquima cortical

Sedum album L. (crassulàcies) - Part aèria

Vitis vinifera L. (vitàcies) - Suc del fruit

FORMA FARMACĖUTICA I ÚS. Embrocació (ús extern)

EFECTES SECUNDARIS. No consta

DESTINACIÓ. Medicina humana

DESCRIPCIÓ DE L'ÚS FETA PER L'INFORMANT. Per a la circulació de la sang, la gangrena [dit "cangrena"] i els fongs dels peus.

PREPARACIÓ. Es bullen totes les herbes en dos gots d'oli, en una cassola de terra fins que es redueix a la meitat, es cola $\mathrm{i}$ ja ho tens a punt.

\section{Entrevista 83}

FONT 296. Ripoll (el Ripollès)

INGREDIENTS:

Allium sativum $L$, (amaril-lidàcies) - Bulb

Hypericum perforatum $L$. (gutíferes) - Part aèria florida

Pinus sylvestris L. (pinàcies) - No consta

Ruta chalepensis L. (rutàcies) - Part aèria

FORMA FARMACĖUTICA I ÚS. Ungüent (ús extern)

EFECTES SECUNDARIS. No consta

DESTINACIÓ Medicina humana

PREPARACIÓ. Amb un tupí de terra que sigui nou, greix rentat tres vegades, una mica d'oli, una mica de pega, tres grans d'all o cinc (sempre senars, depenent de la mida del tupi), un brot de ruda i un brot d'herba de cop. Es deixa bullir i, quan està fet l'ungüent, ell sol ja para de bullir. No cal colar-lo, només cal que treguis els brots de les plantes.

PREPARACIO. Es comprava a la farmàcia oli d'ametlles dolces, oli de ricí i xarop de xicoina, allà mateix a la farmàcia t'ho barrejaven.

MODE D'UTILITZACIÓ/POSOLOGIA. Es prenia a cullerades.

OBSERVACIONS. Pel que fa al xarop de xicoina, no s'ha pogut determinat l'espècie.

\section{Antihelmíntic}

\section{Entrevista 14, barreja III}

FONT 875. Sant Pau de Segúries (el Ripollès)

INGREDIENTS:

Allium cepa L. (amaril·lidàcies) - Bulb

Artemisia absinthium L. (compostes) - Llavor

FORMA FARMACĖUTICA I ÚS. Xarop (ús intern)

EFECTES SECUNDARIS. No consta

DESTINACIÓ. Medicina humana

DESCRIPCIÓ DE L'ÚS FETA PER L'INFORMANT. Per a quan la mainada tenien cucs se'Is feia aquest remei.

PREPARACIÓ. S'aixafa el donzell amb la ceba, s'hi afegeix vi, es cola tot plegat i es pren com un xarop a culleradetes.

\section{Entrevista 73, barreja}

FONT 287. Campelles (el Ripollès)

INGREDIENTS:

Petroselinum crispum (Mill.) Hill (umbel-liferes) - No consta

Ruta chalepensis $L$. (rutàcies) - Part aèria

FORMA FARMACĖUTICA I ÚS. Emplastre (ús extern)

EFECTES SECUNDARIS. No consta

DESTINACIÓ. Medicina humana

DESCRIPCIO DE L'US FETA PER L'INFORMANT. Es posava un emplastre sobre el lombrígol i deien que feia sortir els cucs. No recordo si hi posaven altres plantes.

PREPARACIO. Barrejat amb fel de porc ben picat en un morter.

\section{Entrevista 100}

FONT 313. Llanars (el Ripollès)

INGREDIENTS:

Prunus dulcis (Mill) Weeb. (rosàcies) - Oli de la llavor

Ricinus communis L (euforbì̀cies) - Oli de la llavor

FORMA FARMACĖUTICA I ÚS. Sense forma farmacèutica (mescla medicamentosa, ús intern)

EFECTES SECUNDARIS. No cons

DESCRIPCIÓ DE L'ÚS FETA PER L'INFORMANT. Per als cucs de la canalla.

\section{Antihemorroïdal}

\section{Entrevista 2, barreja I}

FONT 846. Camprodon (el Ripollès)

INGREDIENTS:

Cucurbita pepo L. var. pepo (cucurbitàcies) - Flor

Ruta chalepensis $L$. (rutàcies) - Part aèria

FORMA FARMACĖUTICA I ÚS. Pomada (ús extern)

EFECTES SECUNDARIS. No consta

DESTINACIÓ. Medicina humana 
Apèndix 2. Catàleg de barreges.

DESCRIPCIÓ DE L'ÚS FETA PER L'INFORMANT. La fa servir per a ferides, morenes, i diu que va bé per a moltes coses.

PREPARACIÓ. Es fa una pomada amb la flor de carabassa i la ruda picades i fregides amb greix de porc i llavors es cola.

\section{Entrevista 21, barreja II}

FONT 865. Setcases (el Ripollès)

INGREDIENTS:

Malva sylvestris L. (malvàcies) - Part aèria florida

Parietaria officinalis L. subsp. judaica (L.) Béguinot (urticàcies) - Part aèria

FORMA FARMACEUTICA I US. Bany (ús extern)

EFECTES SECUNDARIS. No consta

DESTINACIO. Medicina humana

DESCRIPCIO DE L'US FETA PER L'INFORMANT. Per a les morenes.

PREPARACIO. Decocció.

\section{Entrevista 56, barreja IV}

FONT 271. Vallfogona de Ripollès (el Ripollès)

REDIENTS:

Parietaria officinalis L. subsp. judaica (L.) Béguinot (urticàcies) - Part aèria

Thymus vulgaris $L$. (labiades) - Part aèria florida

FORMA FARMACE்UTICA I ÚS. Bany (ús extern)

EFECTES SECUNDARIS. No consta

DESTINACIO. Medicina humana

DESCRIPCIÓ DE L'ÚS FETA PER L'INFORMANT. Per a fer banys de seient [dit "asiento"]

PREPARACIO. Decocció.

\section{Entrevista 104, barreja I}

FONT 789. Manresa (El Bages)

INGREDIENTS:

Hypericum perforatum L. (gutiferes) - Part aèria florida

Malva sylvestris $\mathrm{L}$. (malvàcies) - Flor

Ramonda myconi (L.) Reichenb. (gesneriàcies) - Part aèria

FORMA FARMACĖUTICA I ÚS. Embrocació (ús extern)

EFECTES SECUNDARIS. No consta

DESTINACIÓ. Medicina humana

DESCRIPCIÓ DE L'ÚS FETA PER L'INFORMANT. Per a les morenes.

PREPARACIO. Macerava en oli l'orella d'ós amb flor de malva i d'hipèric, vint-i-un dies a sol serena.

\section{Antiherpètic}

\section{Entrevista 50, barreja IV}

FONT 477. Ripoll (el Ripollès)

INGREDIENTS:

Lactuca sativa L. (compostes) - Fulla
Triticum aestivum L. (gramínies) - Sego

Typha latifolia L. (tifàcies) - Part aèria

Vitis vinifera $L$. (vitàcies) - Suc del fruit

FORMA FARMACĖUTICA I ÚS. Ungüent (ús extern)

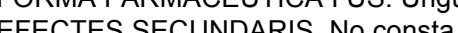

DESTINACIÓ Medicina humana

DESTINACIÓ. Medicina humana

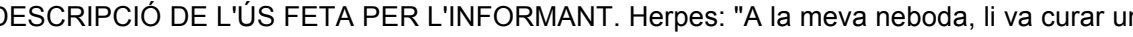
herpes amb aquest ungüent una noia de Sant Joan, també li deia una oració".

PREPARACIÓ. Emplastre sobre d'un drap de fil.

\section{Antihipertensiu}

\section{Entrevista 13, barreja II}

FONT 874. Camprodon (el Ripollès)

INGREDIENTS:

Olea europaea L. subsp. europaea (oleàcies) - Fulla

Rosmarinus officinalis $\mathrm{L}$. (labiades) - Part aèria florida

FORMA FARMACĖUTICA I ÚS. Tisana (ús intern)

EFECTES SECUNDARIS. No consta

(Úl humana

DESCRIPCIO DE LUSS FETA PER L'INFORMANT. Per a regular la pressió. PREPARACIÓ. Decocció

\section{Entrevista 32, barreja V}

FONT 877. Vilallonga de Ter (el Ripollès)

INGREDIENTS:

Lippia triphylla (L'Hér.) O.Kuntze (labiades) - Part aèria

Thymus vulgaris $L$. (labiades) - Part aèria florida

FORMA FARMACEUTICA IUS. Tisana (ús

EFECTES SECUNDARIS. No consta

DESTINACIÓ. Medicina humana

DESCRIPCIÓ DE L'ÚS FETA PER L'INFORMANT. Per a la pressió alta.

MODE D'UTILITZACIÓ/POSOLOGIA. En novenes.

\section{Entrevista 49}

FONT 476. Ribes de Freser (el Ripollès)

INGREDIENTS:

Hedera helix L. (araliàcies) - No consta

Juglans regia L. (juglandàcies) - Fulla

Olea europaea L. subsp. europaea (oleàcies) - Fulla

FORMA FARMACĖUTICA I ÚS. Tisana (ús intern)

EFECTES SECUNDARIS. No consta

DESTINACIÓ. Medicina humana

DESCRIPCIÓ DE L'ÚS FETA PER L'INFORMANT. Per a fer baixar la pressió.

PREPARACIÓ. Decocció. 
Apèndix 2. Catàleg de barreges.

\section{Entrevista 75, barreja III \\ FONT 288. Ribes de Freser (el Ripollès)}

INGREDIENTS:

Rosmarinus officinalis L. (labiades) - Part aèria florida

Tila platyphyllos Scop. (tiliàcies) - Bràctea i inflorescència

FORMA FARMACEUTICA I ÚS. Tisana (ús intern)

EFECTES SECUNDARIS. No consta

DESTINACIÓ. Medicina humana

DESCRIPCIÓ DE L'ÚS FETA PER L'INFORMANT. Per a rebaixar la sang. A la gent grassa o amb la cara molt vermella se'Is donava aquesta aigua perquè rebaixa.

PREPARACIÓ. Decocció.

\section{Entrevista 96, barreja \\ FONT 309. Pardines (el Ripollès)}

INGREDIENTS:

Rubus caesius L. (rosàcies) - Arrel

Urtica dioica L. (urticàcies) - Arrel

FORMA FARMACĖUTICA I ÚS. Tisana (ús intern)

EFECTES SECUNDARIS. No consta

DESTINACIÓ. Medicina humana

PER L'INFORMANT. Per a rebaixar la sang.

PREPARACIÓ. Decocció.

\section{Antiinflamatori}

\section{Entrevista 24}

FONT 872. Vilallonga de Ter (el Ripollès)

INGREDIENTS:

Bryonia cretica L. subsp. dioica (Jacq.) Tutin (cucurbitàcies) - Arrel

Eryngium campestre L. (umbel-líferes) - Arrel

Petroselinum crispum (Mill.) Hill (umbel-liferes) - Arre

FORMA FARMACËUTICA I ÚS. Pomada (ús extern)

EFECTES SECUNDARIS. No consta

DESTINACIO. Medicina humana

DESCRIPCIO DE L'US FETA PER L'INFORMANT. Va bé per a les inflamacions.

PREPARACIÓ. S'ha de bullir totes les plantes en oli i llavors afegir-hi la cera i queda com una pomada.

Entrevista 56, barreja II

FONT 271. Vallfogona de Ripollès (el Ripollès)

INGREDIENTS:

Medicago sativa L. subsp. sativa (papilionàcies) - Part aèria

Petroselinum crispum (Mill.) Hill (umbel-líferes) - Planta sencera

FORMA FARMACEUTICA I UUS. Ungüent (ús extern)

EFECTES SECUNDARIS. No consta
DESTINACIÓ. Medicina humana

DESCRIPCIÓ DE L'ÚS FETA PER L'INFORMANT. Per a treure la inflamació quan et fas un truc.

PREPARACIÓ. Picat amb cansalada.

Entrevista 74, barreja I

FONT 286. Ribes de Freser (el Ripollès)

INGREDIENTS:

Arnica montana L. subsp. montana (compostes) - Inflorescència

Hypericum perforatum $\mathrm{L}$. (gutíferes) - Part aèria florida

Petroselinum crispum (Mill.) Hill (umbel·líferes) - Arre

FORMA FARMACEUTICA I US. Ungüent (ús extern)

EFECTES SECUNDARIS. No consta

DESTINACIÓ. Medicina humana

DESCRIPCIÓ DE L'ÚS FETA PER L'INFORMANT. Va molt bé per a quan estàs espunyit i per a tendons inflamats. T'untes allà on et fa mal i t'ho tapes amb una llana que quedi ben calent.

PREPARACIÓ. Faig un ungüent fent bullir les herbes en oli i greix de gallina, es cola i s'hi afegeix cera nova.

\section{Antiinflamatori faringi}

\section{Entrevista 4, barreja I}

FONT 862. Llanars (el Ripollès)

INGREDIENTS:

Medicago sativa L. subsp. sativa (papilionàcies) - Part aèria

Ruta chalepensis $L$. (rutàcies) - Part aèria

FORMA FARMACĖUTICA I ÚS. Emplastre (ús extern)

EFECTES SECUNDARIS. No consta

DESTINACIÓ. Medicina humana

DESCRIPCIÓ DE L'ÚS FETA PER L'INFORMANT. Per al mal de coll.

PREPARACIÓ. Tot ben picat amb cansalada i entremig de dos draps.

\section{Entrevista 14, barreja II}

FONT 875. Sant Pau de Segúries (el Ripollès)

INGREDIENTS:

Plantago major L. (plantaginàcies) - Fulla

Rubus ulmifolius Schott (rosàcies) - Fulla

FORMA FARMACEUTICA I US. Tisana (ús intern)

EFECTES SECUNDARIS. No consta

DESTINACIO. Medicina humana

DESCRIPCIO DE L'ÚS FETA PER L'INFORMANT. Per al mal de coll.

PREPARACIÓ. Decocció.

Entrevista 17, barreja II

FONT 863. Molló (el Ripollès) 
Apèndix 2. Catàleg de barreges.

INGREDIENTS:

Crataegus monogyna Jacq. subsp. monogyna (rosàcies) - Flor

Plantago lanceolata L. (plantaginàcies) - Fulla

Rubus ulmifolius Schott (rosàcies) - Turió

FORMA FARMACĖUTICA I ÚS. Gargarisme (ús extern)

EFECTES SECUNDARIS. No consta

DESTINACIO. Medicina humana

.

PREPARACIÓ. Es bullia i s'hi afegia mel.

\section{Entrevista 32, barreja IV}

FONT 877. Vilallonga de Ter (el Ripollès)

INGREDIENTS:

Malva sylvestris L. (malvàcies) - Flor

Plantago lanceolata L. (plantaginàcies) - Part aèria

Rubus ulmifolius Schott (rosàcies) - Turió

FORMA FARMACEUUTICA I ÚS. Gargarisme (ús extern)

FORA

EFECTES SECUNDARIS. No consta

DESCRIPCIÓ DE L'ÚS FETA PER L'INFORMANT. Per al mal de coll.

PREPARACIÓ. Per a fer gàrgares.

\section{Entrevista 45, barreja II}

FONT 473. Ogassa (el Ripollès)

INGREDIENTS:

Althaea officinalis L. (malvàcies) - Arre

Punica granatum L. (litràcies) - Epicarpi

Rosa sp. (rosàcies) - Fruit

FORMA FARMACĖUTICA I ÚS. Tisana (ús intern)

EFECTES SECUNDARIS. No consta

DESTINACIÓ. Med

DESTINACIO. MEIIC'

PER L'INFORMANT. Per a les angines i el mal de coll.

PREPARACIÓ Decocció.

\section{Entrevista 47, barreja II}

FONT 265. Sant Joan de les Abadesses (el Ripollès)

INGREDIENTS:

Althaea officinalis L. (malvàcies) - Arre

Plantago lanceolata $\mathrm{L}$. (plantaginàcies) - Fulla

Viola alba Besser (violàcies) - Part aèria florida

FORMA FARMACEUTICA I ÚS. Tisana (ús intern)

EFECTES SECUNDARIS. No consta

DESTINACIO. Medicina humana

DESCRIPCIÓ DE L'US FETA PER L'INFORMANT. Per al mal de coll.

PREPARACIÓ. Decocció.
Entrevista 62, barreja II

FONT 479. Campdevànol (el Ripollès)

INGREDIENTS:

Punica granatum L. (litràcies) - Epicarpi

Rosa sp. (rosàcies) - Fruit

FORMA FARMACEUTICA I ÚS. Tisana (ús intern)

EFECTES SECUNDARIS. No consta

DESTINACIÓ. Medicina humana

DESCRIPCIÓ DE L'ÚS FETA PER L'INFORMANT. Ens la feien prendre quan teniem mal de

coll.

PREPARACIÓ. Decocció. L'aigua de les cireretes de pastor barrejades amb peles de magrana.

\section{Entrevista 84, barreja}

FONT 297. Camprodon (el Ripollès)

INGREDIENTS:

Santolina chamaecyparissus L. (compostes) - Inflorescència

Thymus vulgaris $L$. (labiades) - Part aèria florida

FORMA FARMACĖUTICA I ÚS. Aerosol (ús intern)

EFECTES SECUNDARIS. No consta

DESTINACIÓ. Medicina humana

DESCRIPCIO DE L'US FETA PER L'INFORMANT. Per a fer bafs [dit "bafos"] per al mal de coll durant set o vuit minuts.

PREPARACIO. Decocció.

\section{Antiinflamatori gàstric}

\section{Entrevista 45, barreja III}

FONT 473. Ogassa (el Ripollès)

INGREDIENTS:

Allium cepa L. (amaril·lidàcies) - Bulb

Bryonia cretica L. subsp. dioica (Jacq.) Tutin (cucurbitàcies) - Arrel

Cucumis sativus $L$. (cucurbitàcies) - Fruit

Cucurbita pepo L. var. oblonga Link (cucurbitàcies) - Fruit

Lippia triphylla (L'Hér.) O.Kuntze (labiades) - Part aèria

Melissa officinalis $L$. (labiades) - Part aèria

Pyrus malus L. subsp. mitis (Wallr.) O.Bolòs et J.Vigo (rosàcies) - Fruit

Santolina chamaecyparissus $L$. (compostes) - Inflorescència

FORMA FARMACĖUTICA I ÚS. Ungüent (ús extern)

EFECTES SECUNDARIS. No consta

DESTINACIO. Medicina humana

DESCRIPCIÓ DE L'ÚS FETA PER L'INFORMANT. Va bé per a la gàstrica [dit "gàstiga"] tifulosa o sigui per a les infeccions del ventre, et fa baixar la infecció, desinflama i et fa orinar. PREPARACIÓ. Es fa coure tot tallat petit amb greix de porc es cola amb un drap de fil i queda un ungüent. Se n'unta el ventre i s'hi posa un drap a sobre. 
Apèndix 2. Catàleg de barreges.

\section{Antiinflamatori intestinal}

\section{Entrevista 28, barreja II}

FONT 871. Camprodon (el Ripollès)

INGREDIENTS:

Verbena officinalis $L$. (verbenàcies) - Part aèria florida

Vicia faba L. (papilionàcies) - Llavor

FORMA FARMACĖUTICA I ÚS. Emplastre (ús extern)

EFECTES SECUNDARIS. No consta

DESTINACIÓ. Medicina humana

DESCRIPCIÓ DE L'ÚS FETA PER L'INFORMANT. Per a quan tens un mal de ventre molt fort.

PREPARACIÓ. Berbena picada amb faves seques mòltes i en emplastre.

OBSERVACIONS. No recorda si hi havia alguna altra planta.

\section{Entrevista 31, barreja III}

FONT 866. Vilallonga de Ter (el Ripollès)

INGREDIENTS:

Lippia triphylla (L'Hér.) O.Kuntze (labiades) - Part aèria

Santolina chamaecyparissus L. (compostes) - Inflorescència

FORMA FARMACĖUTICA I ÚS. Tisana (ús intern)

EFECTES SECUNDARIS. No consta

DESTINACIÓ. Medicina humana

DESCRIPCIO DE L'ÚS FETA PER L'INFORMANT. Va bé per a la panxa.

PREPARACIÓ. En infusió.

MODE D'UTILITZACIÓ/POSOLOGIA. En pren cada dia una tassa.

\section{Entrevista 32, barreja}

FONT 877. Vilallonga de Ter (el Ripollès)

INGREDIENTS:

Citrus limon (L.) Burm. (rutàcies) - Epicarpi

Oryza sativa L. (gramínies) - Llavor

FORMA FARMACĖUTICA I ÚS. Decocció (ús intern)

EFECTES SECUNDARIS. No consta

DESTINACIÓ. Medicina humana

DESCRIPCIO DE L'ÚS FETA PER L'INFORMANT. Per als vedells quan tenen mal de ventre. PREPARACIÓ. Arròs bullit amb pela de llimona.

\section{Entrevista 38}

FONT 864. Camprodon (el Ripollès)

INGREDIENTS:

Santolina chamaecyparissus L. (compostes) - Inflorescència

Thymus vulgaris $L$. (labiades) - Part aèria florida

FORMA FARMACĖUTICA I ÚS. Tisana (ús intern)

EFECTES SECUNDARIS. No consta

DESTINACIÓ. Medicina humana
DESCRIPCIÓ DE L'ÚS FETA PER L'INFORMANT. Quan tens mal de ventre.

PREPARACIÓ. Decocció.

Entrevista 56, barreja I

FONT 271. Vallfogona de Ripollès (el Ripollès)

INGREDIENTS:

Allium cepa L. (amaril·lidàcies) - Bulb

Triticum aestivum L. (gramínies) - Llavor

FORMA FARMACËUTICA I ÚS. Emplastre (ús extern)

EFECTES SECUNDARIS. No consta

DESTINACIO. Medicina humana

DESCRIPCIO DE L'US FETA PER L'INFORMANT. Per al mal de panxa.

PREPARACIÓ. La ceba picada amb cansalda i barrejada amb segó [dit "segon"] per a fer emplastres.

\section{Entrevista 67, barreja II}

FONT 480. Sant Joan de les Abadesses (el Ripollès)

INGREDIENTS:

Polygala calcarea F.W.Schultz (poligalàcies) - Part aèria florida

Sambucus nigra L. (adoxàcies) - Inflorescència

Thymus vulgaris $L$. (labiades) - Part aèria florida

FORMA FARMACĖUTICA I ÚS. Tisana (ús intern)

EFECTES SECUNDARIS. No consta

DESTINACIO. Medicina humana

DESCRIPCIO DE L'US FETA PER L'INFORMANT. Per a inflamacions de panxa.

PREPARACIO. Decoccio.

\section{Entrevista 72, barreja II}

FONT 285. Planoles (el Ripollès)

INGREDIENTS:

Brassica oleracea L. (cruciferes) - Fulla

Olea europaea L. subsp. europaea (oleàcies) - Suc del fruit

FORMA FARMACĖUTICA I ÚS. Emplastre (ús extern)

EFECTES SECUNDARIS. No consta

DESTINACIO. Medicina humana

DESCRIPCIO DE L'US FETA PER L'INFORMANT. Per a la pròstata, per al mal de cap o per al mal de panxa, te l'has de posar on et fa mal.

PREPARACIO. Col calenta al rescals del foc i untada d'oli.

\section{Entrevista 80}

FONT 293. Campdevànol (el Ripollès)

INGREDIENTS:

Matricaria chamomilla L. (compostes) - Inflorescència

Mentha spicata L. (labiades) - Part aèria

FORMA FARMACĖUTICA I ÚS. Tisana (ús intern)

EFECTES SECUNDARIS. No consta 
Apèndix 2. Catàleg de barreges.

DESTINACIÓ. Medicina humana

DESCRIPCIÓ DE L'ÚS FETA PER L'INFORMANT. Per a quan tens mal de panxa, per a ajudar a pair.

PREPARACIÓ Decocció.

\section{Antiinflamatori renal}

\section{Entrevista 45, barreja I}

FONT 473. Ogassa (el Ripollès)

INGREDIENTS:

Lippia triphylla (L'Hér.) O.Kuntze (labiades) - Part aèria

Polygala calcarea F.W.Schultz (poligalàcies) - Part aèria florida

FORMA FARMACËUTICA I ÚS. Tisana (ús intern)

EFECTES SECUNDARIS. No consta

DESTINACIÓ. Medicina humana

DESCRIPCIÓ DE L'ÚS FETA PER L'INFORMANT. Per a la inflamació.

PREPARACIÓ. Decocció.

\section{Antinauseabund}

\section{Entrevista 38}

FONT 864. Camprodon (el Ripollès)

INGREDIENTS:

Santolina chamaecyparissus L. (compostes) - Inflorescència

Thymus vulgaris $L$. (labiades) - Part aèria florida

FORMA FARMACĖUTICA I ÚS. Tisana (ús intern)

EFECTES SECUNDARIS. No consta

DESTINACIO. Medicina humana

DESCRIPCIO DE L'US FETA PER L'INFORMANT. Per al mareig.

PREPARACIÓ. Decocció.

Entrevista 94, barreja III

FONT 307. Campdevànol (el Ripollès)

Achillea millefolium L. (compostes) - Inflorescència

Thymus vulgaris $L$. (labiades) - Part aèria florida

FORMA FARMACÈUTICA I ÚS. Tisana (ús intern)

EFECTES SECUNDARIS. No consta

DESTINACIO. Medicina humana

DESCRIPCIÓ DE L'US FETA PER L'INFORMANT. Per al mareig.

PREPARACIO. Decocció.

\section{Antineoplàstic}

Entrevista 78, barreja I

FONT 291. Planoles (el Ripollès)
INGREDIENTS:

Ranunculus parnassifolius L. (ranunculàcies) - Arrel

Senecio leucophyllus DC. (compostes) - Part aèria florida

FORMA FARMACĖUTICA I ÚS. Cataplasma (ús extern)

EFECTES SECUNDARIS. No consta

DESTINACIÓ. Medicina humana

DESCRIPCIO DE L'US FETA PER L'INFORMANT. Per als càncers.

PREPARACIÓ. Picades amb greix per a fer cataplasmes.

OBSERVACIONS. A una dona de Nevà que tenia el seu germà amb càncer, li feien aquests cataplasmes.

Antiodontàlgic

\section{Entrevista 53, barreja IX}

FONT 276. Les Llosses (el Ripollès)

INGREDIENTS:

Eryngium campestre L. (umbel-líferes) - Arrel

Taraxacum dissectum (Ledeb.) Ledeb. (compostes) - Arrel

FORMA FARMACĖUTICA I ÚS. Tisana (ús intern)

EFECTES SECUNDARIS. No const

DESTINACIO. Medicina humana

DESCRIPCIO DE L'US FETA PER L'INFORMANT. Per als nens quan els sortien les dents.

PREPARACIÓ. Decocció.

OBSERVACIONS. També hi posava arrel de jonc, però no s'ha pogut determinar la planta.

Entrevista 73, barreja I

FONT 287. Campelles (el Ripollès)

INGREDIENTS:

Pistacia lentiscus L. (anacardiàcies) - Fulla

Planta lentiscus L. (anacardicies) -Fulla

Rosmarinus officinalis $L$. (labiades) - Part aèria florida

Ruta chalepensis $L$. (rutàcies) - Part aèria

Sutareja montana L. (labiades) - Part aèria florida

FORMA FARMACĖUTICA I ÚS. Col-lutori (ús extern)

EFECTES SECUNDARIS. No consta

DESTINACIÓ. Medicina humana

DESCRIPCIÓ DE L'ÚS FETA PER L'INFORMANT. Es glopejava per al mal de queixals, quan tenies càries.

PREPARACIO. Es bullia amb vi.

\section{Antiofídic}

Entrevista 94, barreja II

FONT 307. Campdevànol (el Ripollès)

INGREDIENTS:

Allium sativum L. (amaril·lidàcies) - Bulb 
Apèndix 2. Catàleg de barreges.

Olea europaea L. subsp. europaea (oleàcies) - Suc del fruit

FORMA FARMACĖUTICA I ÚS. Liniment (ús extern)

EFECTES SECUNDARIS. No consta

DESTINACIÓ. Medicina veterinària

DESCRIPCIÓ DE L'ÚS FETA PER L'INFORMANT. Quan les vaques els pessiga un escurçó, que normalment és al costat del braguer on tenen la pell més prima. Quan havíem munyit els fèiem un bon massatge amb aquest allioli, i ja l'endemà quan tornaven a munyir els començava a sortir tota la porqueria.

PREPARACIÓ. Fer un allioli negat amb cabeça d'alls i anar-hi afegint oli.

Entrevista 96, barreja II

FONT 309. Pardines (el Ripollès)

INGREDIENTS:

Allium sativum L. (amaril·lidàcies) - Bulb

Sambucus nigra L. (adoxàcies) - Inflorescència

FORMA FARMACĖUTICA I ÚS. Desconegut per l'informant

EFECTES SECUNDARIS. No consta

DESTINACIÓ. Medicina humana

DESCRIPCIÓ DE L'ÚS FETA PER L'INFORMANT. Per a pessigades d'escurçó.

PREPARACIÓ. Perfums de sabuc i tres grans d'all.

\section{Entrevista 96, barreja III}

FONT 309. Pardines (el Ripollès)

INGREDIENTS:

Allium sativum L. (amaril·lidàcies) - Bulb

Olea europaea $L$. subsp. europaea (oleàcies) - Suc del fruit

FORMA FARMACEUTICA I US. Sense forma farmacèutica (mescla medicamentosa, ús extern)

EFECTES SECUNDARIS No consta

DESTINACIÓ Medicina humana

DESCRIPCIÓ DE L'ÚS FETA PER L'INFORMANT Fregar-te amb allioli per a les mossegades d'escurḉ i embolicar-ho amb un parrac.

PREPARACIÓ Allioli.

\section{Antipirètic}

\section{Entrevista 54, barreja IV}

FONT 270. Sant Joan de les Abadesses (el Ripollès)

INGREDIENTS:

Brassica nigra (L.) Koch in Roehl (cruciferes) - Llavor

Brassica oleracea L. (crucíferes) - Llavor

Vitis vinifera $L$. (vitàcies) - Suc del fruit

FORMA FARMACĖUTICA I ÚS. Desconegut per l'informant

EFECTES SECUNDARIS. No consta

DESTINACIÓ. Medicina humana

DESCRIPCIÓ DE L'ÚS FETA PER L'INFORMANT. Per a fer baixar la febre.
PREPARACIÓ. S'utilitzen torrades amb vinagre, juntament amb la grana de col i la mostassa.

\section{Entrevista 91, barreja II}

FONT 304. Pardines (el Ripollès)

NGREDIENTS:

Allium sativum L. (amaril-lidàcies) - Bulb

Linum usitatissimum L. subsp. usitatissimum (linàcies) - Llavor

Petroselinum crispum (Mill.) Hill (umbel-líferes) - Part aèria

Piper nigrum $\mathrm{L}$. (piperàcies) - Fruit

FORMA FARMACĖUTICA I ÚS. Emplastre (ús extern)

EFECTES SECUNDARIS. No consta

DESTINACIO. Medicina humana

DESCRIPCIÓ DE L'ÚS FETA PER L'INFORMANT. Per a fer baixar la febre.

PREPARACIÓ. Dues llesques de pa torrat i al mig s'hi posava julivert, all, pebre i grana de lli. Es posava a les plantes dels peus.

OBSERVACIONS. D'aquest remei en dèiem mostasses.

\section{Antipiròtic}

Entrevista 45, barreja IV

FONT 473. Ogassa (el Ripollès)

INGREDIENTS:

Jasonia tuberosa (L.) DC. (compostes) - Part aèria florida

Sambucus nigra L. (adoxàcies) - Parènquima cortical

Tilia platyphyllos Scop. (tiliàcies) - Parènquima cortical

FORMA FARMACEUTICA I US. Ungüent (ús extern)

EFECTES SECUNDARIS. No consta

DESTINACIO. Medicina humana

DESCRIPCIÓ DE L'ÚS FETA PER L'INFORMANT Va bé per a les cremades.

PREPARACIÓ. Es fa un ungüent amb cera nova d'abella.

\section{Entrevista 53, barreja III}

FONT 276. Les Llosses (el Ripollès)

INGREDIENTS:

Arnica montana L. subsp. montana (compostes) - Inflorescència

Hypericum perforatum L. (gutíferes) - Part aèria florida

FORMA FARMACĖUTICA I US. Embrocació (ús extern)

EFECTES SECUNDARIS. No consta

DESTINACIO. Medicina humana

DESCRIPCIO DE L'US FETA PER L'INFORMANT. Per a les cremades.

PREPARACIO. Posada en oli i tapada es deixa dos mesos com a mínim, llavors ja es pot fer

servir.

Entrevista 78, barreja IV

FONT 291. Planoles (el Ripollès)

INGREDIENTS: 
Apèndix 2. Catàleg de barreges.

Alkanna tinctoria Tausch (boraginàcies) - Arrel

Salvia verbenaca L. (labiades) - Fulla

Sempervivum tectorum $\mathrm{L}$. (crassulàcies) - Part aèria

Taxus baccata L. (taxàcies) - Parènquima cortical

FORMA FARMACĖUTICA I ÚS. Ungüent (ús extern)

EFECTES SECUNDARIS. No consta

DESTINACIO. Medicina humana

列 PREPARACIO. Es posen les plantes amb meitat greix i meitat cansalada i es fa coure to plegat. Queda una pomada de color rosa.

\section{Entrevista 95}

FONT 308. Molló (el Ripollès)

INGREDIENTS:

Bellis perennis L. (compostes) - Inflorescència

Parietaria officinalis L. subsp. judaica (L.) Béguinot (urticàcies) - Part aèria

Sedum dasyphyllum $L$. (crassulàcies) - Part aèria

Umbilicus rupestris (Salisb.) Dandy (crassulàcies) - Part aèria

FORMA FARMACĖUTICA I ÚS. Embrocació (ús extern)

EFECTES SECUNDARIS. No consta

DESTINACIO. Medicina humana

DESCRIPCIO DE L'ÚS FETA PER L'INFORMANT. Servia per a les cremadures.

PREPARACIÓ. Es feia un oli. S'havien de coure les plantes en oli.

OBSERVACIONS. La Justina de can França es va cremar i la meva [dit "meu"] mare la va curar. Em sembla que hi posava set plantes, pero no me'n recordo.

\section{Antipneumònic}

\section{Entrevista 103}

FONT 786. Camprodon (el Ripollès)

INGREDIENTS:

Juniperus communis L. (cupressàcies) - Tija

Linum usitatissimum $L$ subsp usitatissimum (linàcies) - Llavor

FORMA FARMACĖUTICA I ÚS. Sense forma farmacèutica (mescla medicamentosa, ús extern)

EFECTES SECUNDARIS. No consta

DESTINACIÓ. Medicina humana

DESCRIPCIO DE L'ÚS FETA PER L'INFORMANT. Es posava entre dos draps al pit per a tractar les pulmonies.

PREPARACIO. Merda blanca de gos, grana de lli i oli de ginebre, tot remenat.

\section{Antiprostatític}

Entrevista 13, barreja I

FONT 874. Camprodon (el Ripollès)

INGREDIENTS:
Santolina chamaecyparissus L. (compostes) - Inflorescència

Thymus vulgaris $\mathrm{L}$. (labiades) - Part aèria florida

Tilia platyphyllos Scop. (tiliàcies) - Bràctea i inflorescència

FORMA FARMACĖUTICA I ÚS. Tisana (ús intern)

EFECTES SECUNDARIS. No consta

DESCRIPCIO DE L'US FETA PER L'INFORMANT. Li han dit que ha de beure molta aigua per a la pròstata, per a no beure tanta aigua clara beu això.

PREPARA

MODE D'UTILITZACIÓ/POSOLOGIA. Cada matí una tassa.

\section{Entrevista 72, barreja II}

FONT 285. Planoles (el Ripollès)

INGREDIENTS:

Brassica oleracea L. (cruciferes) - Fulla

Olea europaea L. subsp. europaea (oleàcies) - Suc del fruit

FORMA FARMACĖUTICA I ÚS. Emplastre (ús extern)

EFECTES SECUNDARIS. No consta

DESTINACIÓ. Medicina humana

列 al mal de panxa, te l'has de posar on et fa mal.

PREPARACIÓ. Col calenta al rescals del foc $\mathrm{i}$ untada d'oli.

\section{Antipruriginós}

Entrevista 96, barreja IV

FONT 309. Pardines (el Ripollès)

INGREDIENTS:

Malva sylvestris L. (malvàcies) - Part aèria florida

Parietaria officinalis L. subsp. judaica (L.) Béguinot (urticàcies) - Part aèria

Plantago sp. (plantaginàcies) - Part aèria

FORMA FARMACĖUTICA I ÚS. Sense forma farmacèutica (mescla medicamentosa, ús extern)

EFECTES SECUNDARIS. No consta

DESTINACIÓ. Medicina humana

DESCRIPCIO DE L'ÚS FETA PER L'INFORMANT. Fregar-te amb les tres herbes quan et fas una ortigada.

\section{Antireumàtic}

\section{Entrevista 63, barreja I}

FONT 277. Queralbs (el Ripollès)

INGREDIENTS:

Allium sativum L. (amaril·lidàcies) - Bulb

Geranium robertianum $L$. (geraniàcies) - Part aèria

FORMA FARMACĖUTICA I ÚS. Emplastre (ús extern) 
Apèndix 2. Catàleg de barreges.

EFECTES SECUNDARIS. No consta

DESTINACIO Medicina hUMana

DESCRIPCIÓ DE L'ÚS FETA PER L'INFORMANT. Per al reuma.

PREPARACIÓ. Aixafar les plantes en oli i fer-ne emplastres.

\section{Entrevista 102, barreja IV}

FONT 788. Queralbs (el Ripollès)

INGREDIENTS:

Agave americana $L$. (asparagàcies) - Suc de la fulla

Althaea officinalis L. (malvàcies) - Arrel

Rosa sp. (rosàcies) - Flor

Ruta chalepensis $L$. (rutàcies) - Part aèria

FORMA FARMACĖUTICA I ÚS. Tisana (ús intern)

EFECTES SECUNDARIS. No consta

DESTINACIÓ Medicina humana

DESCRIPCIÓ DE L'ÚS FETA PER L'INFORMANT. Va bé per al dolor i el reuma dels genolls.

PREPARACIÓ. Es fa bullir tot.

\section{Antisèptic bucal}

\section{Entrevista 9}

FONT 860. Camprodon (el Ripollès)

INGREDIENTS:

Achillea ptarmica L. subsp. pyrenaica (Sibth. ex Godr. in Gren. et Godr.) Rouy (compostes) - Inflorescència

Sambucus nigra L. (adoxàcies) - Inflorescència

Thymus vulgaris $L$. (labiades) - Part aèria florida

FORMA FARMACĖUTICA I ÚS. Col·lutori (ús extern)

EFECTES SECUNDARIS. No consta

DESTINACIÓ Medicina humana

DESCRIPCIÓ DE L'ÚS FETA PER L'INFORMANT. S'usava molt per a infeccions bucals.

PREPARACIÓ. Infusió.

\section{Entrevista 16, barreja III}

FONT 881. Sant Pau de Segúries (el Ripollès)

INGREDIENTS:

Jasonia tuberosa (L.) DC. (compostes) - Part aèria florida

Plantago lanceolata L. (plantaginàcies) - Part aèria

Rubus ulmifolius Schott (rosàcies) - No consta

FORMA FARMACEUTICA I US. Col-lutori (ús extern)

EFECTES SECUNDARIS. No consta

DESTINACIÓ. Medicina humana

DESCRIPCIO DE L'US FETA PER L'INFORMANT. Quan tens tatxes a la boca.

PREPARACIÓ. Decocció.

Entrevista 54, barreja III
FONT 270. Sant Joan de les Abadesses (el Ripollès)

INGREDIENTS:

Hieracium pilosella L. (compostes) - Fulla
Rubus ulmifolius Schott (rosàcies) - Turió

FORMA FARMACĖUTICA I ÚS. Col-lutori (ús extern)

EFECTES SECUNDARIS. No consta

DESTINACIÓ. Medicina humana

DESCRIPCIO DE L'ÚS FETA PER L'INFORMANT. Per a les tatxes de mal de la boca de la

PREPARACIÓ. Decocció.

\section{Entrevista 56, barreja}

FONT 271. Vallfogona de Ripollès (el Ripollès)

INGREDIENTS:

Hieracium pilosella L. (compostes) - Fulla

Plantago lanceolata L. (plantaginàcies) - Fulla

FORMA FARMACĖUTICA I ÚS. Col-lutori (ús extern)

EFECTES SECUNDARIS. No consta

DESTINACIÓ. Medicina humana

DESCRIPCIÓ DE L'ÚS FETA PER L'INFORMANT. Per a les tatxes de la boca de la canalla. PREPARACIÓ. Decocció.

\section{Antisèptic extern}

Entrevista 8, barreja II

FONT 853. Camprodon (el Ripollès)

INGREDIENTS:

Althaea officinalis L. (malvàcies) - Arrel

Allium sativum $L$ (amaril-lidàcies) - Bulb

Bryonia cretica L. subsp. dioica (Jacq.) Tutin (cucurbitàcies) - Arrel

Bryonia cretica L. subsp. dioica (Jacq.) Tutn

Petroselinum crispum (Mill.) Hill (umbel-líferes) - Arrel

Ruta chalepensis L. (rutàcies) - Part aèria

Sedum dasyphyllum $L$. (crassulàcies) - Part aèria

Umbilicus rupestris (Salisb.) Dandy (crassulàcies) - Part aèria

FORMA FARMACĖUTICA I US. Embrocació (ús extern)

EFECTES SECUNDARIS. No consta

DESTINACIO. Medicina humana

DESCRIPCIO DE L'ÚS FETA PER L'INFORMANT. S'utilitzava per a ferides, infeccions grans.

PREPARACIÓ. Es posaven totes aquestes plantes en un tupí de terra a bullir en oli bo d'amanir, llavors es colava.

\section{Entrevista 31, barreja IV}

FONT 866. Vilallonga de Ter (el Ripollès)

INGREDIENTS: 
Apèndix 2. Catàleg de barreges.

Allium sativum L. (amaril·lidàcies) - Bulb

Bryonia cretica L. subsp. dioica (Jacq.) Tutin (cucurbitàcies) - Arrel

Fraxinus excelsior $\mathrm{L}$. (oleàcies) - Parènquima cortical

Petroselinum crispum (Mill.) Hill (umbel-liferes) - Arrel

Ruta chalepensis L. (rutàcies) - Part aèria

作

EFECTES SECUNDARIS. No consta

DESTINACIÓ. Medicina humana

DESCRIPCIÓ DE L'ÚS FETA PER L'INFORMANT. S'utilitzava per a ferides, infeccions i per a curar mals externs.

PREPARACIÓ. En un tupí de terra es fan bullir aquestes herbes en oli.

\section{Entrevista 39, barreja}

FONT 888. Setcases (el Ripollès)

INGREDIENTS:

Malva sylvestris L. (malvàcies) - Part aèria

Parietaria officinalis L. subsp. judaica (L.) Béguinot (urticàcies) - Part aèria

FORMA FARMACĖUTICA I ÚS. Bany (ús extern)

EFECTES SECUNDARIS. No consta

DESTINACIO. Medicina humana

DESCRIPCIO DE L'ÚS FETA PER L'INFORMANT. Per a infeccions.

PREPARACIÓ. Decocció.

\section{Entrevista 39, barreja II}

FONT 888. Setcases (el Ripollès)

INGREDIENTS:

Allium sativum L. (amaril-lidàcies) - Bulb

Plantago sp. (plantaginàcies) - Part aèria

Senecio vulgaris $\mathrm{L}$. (compostes) - Part aèria

FORMA FARMACĖUTICA I ÚS. Embrocació (ús extern)

EFECTES SECUNDARIS. No consta

DESTINACIÓ. Medicina humana

DESCRIPCIÓ DE L'ÚS FETA PER L'INFORMANT. Per a les infeccions.

PREPARACIÓ. Es fa bullir en oli.

\section{Entrevista 53, barreja}

FONT 276. Les Llosses (el Ripollès)

INGREDIENTS:

Fraxinus excelsior L. (oleàcies) - Fulla

Prunella vulgaris $L$. (labiades) - Part aèria florida

Thymus vulgaris $L$. (labiades) - Part aèria florida

FORMA FARMACĖUTICA I ÚS. Bany (ús extern)

EFECTES SECUNDARIS. No consta

DESTINACIÓ. Medicina humana

DESCRIPCIÓ DE L'ÚS FETA PER L'INFORMANT. Per a desinfectar ferides.

PREPARACIÓ. Decocció.

\section{Entrevista 89, barreja}

FONT 302. Toses (el Ripollès)

INGREDIENTS:

Rosmarinus officinalis $\mathrm{L}$. (labiades) - Part aèria florida

Thymus vulgaris $L$. (labiades) - Part aèria florida

FORMA FARMACĖUTICA I ÚS. Bany (ús extern)

EFECTES SECUNDARIS. No consta

DESTINACIÓ. Medicina humana

DESCRIPCIÓ DE L'ÚS FETA PER L'INFORMANT. Per a rentar mals i ferides de les persones

PREPARACIÓ. Decocció.

OBSERVACIONS. També forma part de la barreja la "sivina", aquesta planta no està identificada tot i que creiem que es tracta d'una espècie de Juniperus.

\section{Entrevista 96, barreja III}

FONT 309. Pardines (el Ripollès)

INGREDIENTS:

Allium cepa L. (amaril-lidàcies) - Bulb

Centaurea calcitrapa L. (compostes) - Inflorescència

Malva sylvestris L. (malvàcies) - Part aèria florida

Saxifraga longifolia Lap. subsp. longifolia (saxifragàcies) - Part aèria florida

FORMA FARMACĖUTICA I ÚS. Bany (ús extern)

EFECTES SECUNDARIS. No consta

DESTINACIÓ. Medicina veterinària

DESCRIPCIÓ DE L'ÚS FETA PER L'INFORMANT. Per a netejar les truges quan havien godallat.

PREPARACIÓ. Decocció.

\section{Antisèptic intern}

Entrevista 8, barreja I

FONT 853. Camprodon (el Ripollès)

INGREDIENTS:

Malva sylvestris $L$. (malvàcies) - Part aèria florida

Parietaria officinalis L. subsp. judaica (L.) Béguinot (urticàcies) - Part aèria

FORMA FARMACĖUTICA I ÚS. Tisana (ús intern)

EFECTES SECUNDARIS. No consta

DESTINACIÓ. Medicina humana

DESCRIPCIO DE L'US FETA PER L'INFORMANT. Per a les infeccions de budells.

PREPARACIO. Infusió.

\section{Antisèptic ocular}

Entrevista 72, barreja III

FONT 285. Planoles (el Ripollès) 
Apèndix 2. Catàleg de barreges.

INGREDIENTS:

Allium cepa L. (amaril-lidàcies) - Bulb

Citrus limon (L.) Burm. (rutàcies) - Suc del fruit

FORMA FARMACĖUTICA I ÚS. Bany (ús extern)

EFECTES SECUNDARIS. No consta

DESCRIPCIÓ DE L'ÚS FETA PER L'INFORMANT. El suc que fa és bo per a la vista, quan tens cataractes.

PREPARACIÓ. Ratlles una ceba tendra, coles el suc amb un drap de cotó i t'hi neteges els ulls.

\section{Antitussigen}

\section{Entrevista 14, barreja V}

FONT 875. Sant Pau de Segúries (el Ripollès)

INGREDIENTS:

Althaea officinalis L. (malvàcies) - Arrel

Althaea officinalis $L$. (malvàcies) - Arrel
Pyrus malus L. subsp. mitis (Wallr.) O.Bolòs et J.Vigo (rosàcies) - Fruit

Pyrus malus L. subsp. mitis (Wallr.) O.Bolòs et J.

EFECTES SECUNDARIS. No consta

EFECTES SECUNDARIS. No cons

DESTINACIO. Medicina humana

DESCRIPCIO DE L'US FETA PER L'INFORMANT. S'usa per a la tos.

PREPARACIÓ. Decocció d'ambdues i queda com un xarop.

\section{Entrevista 46}

FONT 266. Sant Joan de les Abadesses (el Ripollès)

INGREDIENTS:

Althaea officinalis L. (malvàcies) - Arre

Citrus limon (L.) Burm (rutàcies) - Fruit

FORMA FARMACĖUTICA I ÚS. Xarop (ús intern)

EFECTES SECU

DESTINACIÓ. Medicina humana

DESCRIPCIÓ DE L'ÚS FETA PER L'INFORMANT. Per a la tos.

PREPARACIÓ. Es fa cremar sucre amb la rel, s'hi talla una llimona i s'hi afegeix aigua i es deixa bullir que redueixi per meitat.

\section{Entrevista 78, barreja II}

FONT 291. Planoles (el Ripollès)

INGREDIENTS:

Lavandula angustifolia Mill. (labiades) - Summitat florífera

Mentha pulegium L. (labiades) - Part aèria florida

Rosmarinus officinalis L. (labiades) - Part aèria florida

FORMA FARMACĖUTICA I ÚS. Tintura alcohòlica (ús extern)

EFECTES SECUNDARIS. No consta

DESTINACIÓ. Medicina humana
DESCRIPCIÓ DE L'ÚS FETA PER L'INFORMANT. Va bé per a la tos i els refredats. Destapa molt.

PREPARACIÓ. Posar les herbes amb esperit de vi camforat.

\section{Coadjuvant del postpart}

\section{Entrevista 8, barreja I}

FONT 853. Camprodon (el Ripollès)

INGREDIENTS:

Malva sylvestris L. (malvàcies) - Part aèria florida

Parietaria officinalis L. subsp. judaica (L.) Béguinot (urticàcies) - Part aèria

FORMA FARMACEUTICA I US. Tisana (ús intern)

EFECTES SECUNDARIS. No consta

DESTINACIÓ. Medicina veterinària

DESCRIPCIÓ DE L'ÚS FETA PER L'INFORMANT. Per a les vaques quan no havien fet les despulles.

PREPARACIÓ. Infusió.

\section{Entrevista 10}

FONT 850. Camprodon (el Ripollès)

INGREDIENTS:

Malva sylvestris $L$. (malvàcies) - Part aèria florida

Parietaria officinalis L. subsp. judaica (L.) Béguinot (urticàcies) - Part aèria

FORMA FARMACĖUTICA I UUS. Tisana (ús intern)

EFECTES SECUNDARIS. No consta

DESTINACIÓ. Medicina humana

DESCRIPCIÓ DE L'ÚS FETA PER L'INFORMANT. Se'n donava a les truges quan havien parit per a desinfectar-les.

PREPARACIÓ. Decocció.

\section{Entrevista 14, barreja I}

FONT 875. Sant Pau de Segúries (el Ripollès)

INGREDIENTS:

Malva sylvestris L. (malvàcies) - Part aèria florida

Parietaria officinalis L. subsp. judaica (L.) Béguinot (urticàcies) - Part aèria

FORMA FARMACĖUTICA I ÚS. Tisana (ús intern)

EFECTES SECUNDARIS. No consta

DESTINACIÓ. Medicina humana

DESCRIPCIO DE L'ÚS FETA PER L'INFORMANT. Abans es donava a les parteres tres o quatre dies després de tenir la criatura, per a netejar.

PREPARACIO. Decocció.

\section{Entrevista 27}

FONT 887. Molló (el Ripollès)

INGREDIENTS:

Beta vulgaris $L$. subsp. vulgaris var. vulgaris (quenopodiàcies) - Fulla 
Apèndix 2. Catàleg de barreges.

Parietaria officinalis L. subsp. judaica (L.) Béguinot (urticàcies) - Part aèria

FORMA FARMACĖUTICA I ÚS. Suspensió (ús intern)

EFECTES SECUNDARIS. No consta

DESTINACIÓ Medicina veterinària

DESCRIPCIÓ DE L'ÚS FETA PER L'INFORMANT. Es donava a les truges quan havien

CIÓ. Es feia aigua i s'hi barrejava pa sec

\section{Entrevista 29, barreja III}

FONT 897. Llanars (el Ripollès)

INGREDIENTS:

Malva sylvestris $L$. (malvàcies) - Part aèria

Olea europaea $L$. subsp. europaea (oleàcies) - Suc del fruit

Parietaria officinalis L. subsp. judaica (L.) Béguinot (urticàcies) - Part aèria

Plantago lanceolata L. (plantaginàcies) - Part aèria

Plantago major $\mathrm{L}$. (plantaginàcies) - Part aèria

FORMA FARMACĖUTICA I ÚS. Tisana (ús intern)

EFECTES SECUNDARIS. No consta

EFECTES SECUNDARIS. No consta
DESTINACIÓ. Medicina veterinària

DESCRIPCIÓ DE L'ÚS FETA PER L'INFORMANT. Per a les truges quan han godellat i no poden orinar.

PREPARACIO.

\section{Entrevista 30, barreja IV}

FONT 878. Camprodon (el Ripollès)

INGREDIENTS:

Meum athamanticum Jacq. subsp. athamanticum (umbel-liferes) - Arrel

Senecio leucophyllus DC. (compostes) - Part aèria florida

FORMA FARMACĖUTICA I ÚS. Tisana (ús intern)

EFECTES SECUNDARIS. No consta

DESTINACIÓ. Medicina veterinària

DESCRIPCIÓ DE L'ÚS FETA PER L'INFORMANT. Per a ajudar a fer les despulles del bestiar.

PREPARACIÓ. Decocció.

\section{Entrevista 31, barreja}

FONT 866. Vilallonga de Ter (el Ripollès)

INGREDIENTS:

Beta vulgaris $L$. subsp. vulgaris var. vulgaris (quenopodiàcies) - Fulla

Parietaria officinalis L. subsp. judaica (L.) Béguinot (urticàcies) - Part aèria

FORMA FARMACËUTICA I ÚS. Suspensió (ús intern)

EFECTES SECUNDARIS. No consta

DESTINACIO Medicina veterinària

DESCRIPCIÓ DE L'ÚS FETA PER L'INFORMANT. Per a netejar les trugues quan havien godallat.

PREPARACIÓ. Brou amb blets, bledes, pa i aigua.

\section{Entrevista 32, barreja II}

FONT 877. Vilallonga de Ter (el Ripollès)

INGREDIENTS:

Beta vulgaris $L$. subsp. vulgaris var. vulgaris (quenopodiàcies) - Fulla

Parietaria officinalis L. subsp. judaica (L.) Béguinot (urticàcies) - Part aèria

FORMA FARMACĖUTICA I ÚS. Suspensió (ús intern)

EFECTES SECUNDARIS. No consta

DESTINACIÓ. Medicina humana

DESCRIPCIÓ DE L'ÚS FETA PER L'INFORMANT. Quan les truges havien godallat, els anava bé per a netejar la panxa.

PREPARACIO. Brou de pa bullit amb bledes i blets.

\section{Entrevista 37, barreja I}

FONT 870 . Setcases (el Ripollès)

INGREDIENTS:

Meum athamanticum Jacq. subsp. athamanticum (umbel-liferes) - Arrel

Saxifraga longifolia Lap. subsp. Iongifolia (saxifragàcies) - Fulla

FORMA FARMACĖUTICA I ÚS. Tisana (ús intern)

EFECTES SECUNDARIS. No consta

DESTINACIO. Medicina humana

DESCRIPCIÓ DE L'ÚS FETA PER L'INFORMANT. Per a ajudar a fer les despulles de les vaques.

PREPARACIÓ. Decocció.

Entrevista 37, barreja II

FONT 870. Setcases (el Ripollès)

INGREDIENTS:

Ramonda myconi (L.) Reichenb. (gesneriàcies) - Part aèria

Saxifraga longifolia Lap. subsp. longifolia (saxifragàcies) - Fulla

FORMA FARMACĖUTICA I ÚS. Tisana (ús intern)

EFECTES SECUNDARIS. No consta

DESCRIPCIÓ DE L'ÚS FETA PER L'INFORMANT. Per a netejar les vaques quan havien vedellat o havien tingut un avortament.

PREPARACIÓ. Decocció

\section{Entrevista 53, barreja VII}

FONT 276. Les Llosses (el Ripollès)

INGREDIENTS:

Allium cepa L. (amaril·lidàcies) - Bulb

Malva sylvestris $\mathrm{L}$. (malvàcies) - No consta

Parietaria officinalis L. subsp. judaica (L.) Béguinot (urticàcies) - Part aèria

FORMA FARMACĖUTICA I ÚS. Tisana (ús intern)

EFECTES SECUNDARIS. No consta

DESTINACIÓ. Medicina veterinària 
Apèndix 2. Catàleg de barreges.

DESCRIPCIÓ DE L'ÚS FETA PER L'INFORMANT. Per a les truges quan godallaven, per a fer baixar la inflamació.

PREPARACIÓ Decocció.

\section{Entrevista 54, barreja I}

FONT 270. Sant Joan de les Abadesses (el Ripollès)

INGREDIENTS:

Arundo donax L. (gramínies) - Fulla

Ceterach officinarum DC. in Lam. et DC. (polipodiàcies) - Fronda

FORMA FARMACĖUTICA I ÚS. Tisana (ús intern)

EFECTES SECUNDARIS. No consta

DESTINACIO. Medicina veterinària

DESCRIPCIÓ DE L'ÚS FETA PER L'INFORMANT. Per a ajudar una vaca a fer les despulles.

PREPARACIÓ. Decocció.

\section{Entrevista 89, barreja I}

FONT 302. Toses (el Ripollès)

INGREDIENTS:

Rosmarinus officinalis L. (labiades) - Part aèria florida

Thymus vulgaris $L$. (labiades) - Part aèria florida

FORMA FARMACĖUTICA I ÚS. Tisana (ús intern)

EFECTES SECUNDARIS. No consta

DESTINACIÓ. Medicina veterinària

DESCRIPCIO DE L'ÚS FETA PER L'INFORMANT. Per a netejar i purgar les ovelles quan havien xaiat.

PREPARACIO. Decocció.

OBSERVACIONS. També forma part de la barreja la "sivina", aquesta planta no està identificada tot i que creiem que es tracta d'una espècie de Juniperus.

\section{Entrevista 90, barreja I}

FONT 303. Ribes de Freser (el Ripollès)

INGREDIENTS:

Parietaria officinalis L. subsp. judaica (L.) Béguinot (urticàcies) - Part aèria

Zea mays L. (gramínies) - Estils i estigme

FORMA FARMACĖUTICA I ÚS. Tisana (ús intern)

EFECTES SECUNDARIS. No consta

DESTINACIÓ. Medicina veterinària

DESCRIPCIÓ DE L'ÚS FETA PER L'INFORMANT. Per a quan les truges havien parit, se'Is afegia a l'abeurall.

PREPARACIÓ. Decocció. Aigua de les morelles i una espiga de blat de moro vermell.

\section{Desconegut per l'informant}

Entrevista 74, barreja III

FONT 286. Ribes de Freser (el Ripollès)

INGREDIENTS:
Medicago sativa L. subsp. sativa (papilionàcies) - Part aèria

Thymus vulgaris $L$. (labiades) - Part aèria florida

Thymus vulgaris $L$. (labiades) - Part aè vinifera $L$. (vitàcies) - Suc del fruit
Vitis

FORMA FARMACĖUTICA I ÚS. Emplastre (ús extern)

EFECTES SECUNDARIS. No consta

DESTINACIÓ Medicina humana

DESCRIPCIÓ DE L'ÚS FETA PER L'INFORMANT. Les plantes tendres ben picades ruixades amb vinagre. Se'n feia un emplastre amb una mitja gruixuda $i$ tot ben calent a sobre la panxa.

\section{Entrevista 102, barreja V}

FONT 788. Queralbs (el Ripollès)

INGREDIENTS:

Achillea ptarmica L. subsp. pyrenaica (Sibth. ex Godr. in Gren. et Godr.)

Althaea officinalis L. (malvàcies) - Arrel

Fraxinus excelsior L (oleàcies) - Fulla

Paronychia kapela (Hacq.) Kerner (cariofil·làcies) - Part aèria florida

Salvia pratensis $L$. (labiades) - Fulla

Thymus vulgaris $L$. (labiades) - Part aèria florida

FORMA FARMACE்UTICA I ÚS. Tisana (ús intern)

EFECTES SECUNDARIS. No consta

DESTINACIÓ. Medicina humana

PREPARACIÓ. Es feia aigua de totes les plantes i s'hi ratllava una mica de serp blanca.

\section{Entrevista 104, barreja II}

FONT 789. Manresa (el Bages)

INGREDIENTS:

Medicago sativa L. subsp. sativa (papilionàcies) - Part aèria

Trifolium pratense $\mathrm{L}$. (papilionàcies) - Flor

per l'informant

EFECTES SECUNDARIS. No consta

DESTINACIÓ. No consta

OBSERVACIONS. No en recorda l'ús.

\section{Digestiu}

Entrevista 2, barreja II

FONT 846. Camprodon (el Ripollès)

INGREDIENTS:

Carum carvi L. (umbel-líferes) - Llavor

Parietaria officinalis L. subsp. judaica (L.) Béguinot (urticàcies) - Part aèria

FORMA FARMACĖUTICA I ÚS. Tisana (ús intern)

EFECTES SECUNDARIS. No consta

DESTINACIÓ. Medicina humana 
Apèndix 2. Catàleg de barreges.

DESCRIPCIÓ DE L'ÚS FETA PER L'INFORMANT. Per a la canalla quan estaven empatxats. Per a refrescar-los.

PREPARACIÓ. Decocció.

\section{Entrevista 16, barreja I}

FONT 881. Sant Pau de Segúries (el Ripollès)

\section{INGREDIENTS:}

Lippia triphylla (L'Hér.) O.Kuntze (labiades) - Part aèria

Santolina chamaecyparissus L. (compostes) - Inflorescència

FORMA FARMACĖUTICA I ÚS. Tisana (ús intern)

EFECTES SECUNDARIS. No consta

DESTINACIO. Medicina humana

DESCRIPCIO DE L'ÚS FETA PER L'INFORMANT. Quan no saps què tens perquè has pait malament.

PREPARACIÓ. En infusió.

\section{Entrevista 53, barreja V}

FONT 276. Les Llosses (el Ripollès)

Herniaria glabra L. (cariofil·làcies) - Part aèria

Mentha sp. (labiades) - Part aèria

Polygala calcarea F.W.Schultz (poligalàcies) - Part aèria florida

FORMA FARMACĖUTICA I ÚS. Tisana (ús intern)

EFECTES SECUNDARIS. No consta

DESTINACIO. Medicina humana

DESCRIPCIO DE L'ÚS FETA PER L'INFORMANT. Per a ajudar a pair.

PREPARACIÓ. Decocció.

FONTrevista $\mathbf{5 5}$ V75. Vallfogona de Ripollès (el Ripollès)

INGREDIENTS:

Sambucus nigra L. (adoxàcies) - Inflorescència

Santolina chamaecyparissus L. (compostes) - Inflorescència

FORMA FARMACĖUTICA I ÚS. Tisana (ús intern)

EFECTES SECUNDARIS. No consta

DESTINACIÓ. Medicina humana

DESCRIPCIÓ DE L'ÚS FETA PER L'INFORMANT. Va bé per a l'estómac.

PREPARACIO. Decocció.

\section{Entrevista 74, barreja II}

FONT 286. Ribes de Freser (el Ripollès)

INGREDIENTS:

Herniaria glabra L. (cariofil·àcies) - Part aèria

Matricaria chamomilla L. (compostes) - Inflorescència

Thymus vulgaris (labiades) - Part aèria florida

FORMA FARMACĖUTICA I ÚS. Tisana (ús intern)
EFECTES SECUNDARIS. No consta

DESTINACIÓ. Medicina humana

DESCRIPCIÓ DE L'ÚS FETA PER L'INFORMANT. Per a fer pair.

PREPARACIÓ. Decocció.

OBSERVACIONS. La camamilla la sembro.

\section{Entrevista 80}

FONT 293. Campdevànol (el Ripollès)

NGREDIENTS:

Matricaria chamomilla L. (compostes) - Inflorescència

Mentha spicata $L$. (labiades) - Part aèria

FORMA FARMACËUTICA I ÚS. Tisana (ús intern)

EFECTES SECUNDARIS. No consta

DESTINACIÓ. Medicina humana

DESCRIPCIÓ DE L'ÚS FETA PER L'INFORMANT. Per a quan tens mal de panxa, per a ajudar a pair.

PREPARACIÓ. Decocció.

Entrevista 94, barreja IV

FONT 307. Campdevànol (el Ripollès)

INGREDIENTS:

Matricaria chamomilla L. (compostes) - Inflorescència

Mentha spicata L. (labiades) - Part aèria

FORMA FARMACĖUTICA I ÚS. Tisana (ús intern)

EFECTES SECUNDARIS. No consta

DESTINACIÓ. Medicina humana

DESCRIPCIÓ DE L'ÚS FETA PER L'INFORMANT. Digestiu.

PREPARACIÓ. En infusió.

\section{Entrevista 102, barreja I}

FONT 788. Queralbs (el Ripollès)

INGREDIENTS:

Achillea ptarmica L. subsp. pyrenaica (Sibth. ex Godr. in Gren. et Godr.)

Rouy (compostes) - Inflorescència

Sedum album L. (crassulàcies) - Part aèria

FORMA FARMACĖUTICA I ÚS. Tisana (ús intern)

EFECTES SECUNDARIS. No consta

DESTINACIO. Medicina humana

DESCRIPCIÓ DE L'ÚS FETA PER L'INFORMANT. És un digestiu que va bé per a l'estómac.

PREPARACIO. Es pren en infusió.

Diürètic

Entrevista 23, barreja II

FONT 885. Vilallonga de Ter (el Ripollès)

INGREDIENTS: 
Apèndix 2. Catàleg de barreges.

Asperula cynanchica L. (rubiàcies) - Part aèria florida

Equisetum arvense L. (equisetàcies) - Part aèria estèril

Zea mays L. (gramínies) - Estils i estigmes

FORMA FARMACĖUTICA I ÚS. Tisana (ús intern)

EFECTES SECUNDARIS. No consta

L'INFORMANT. Per a fer orinar. PREPARACIÓ. Decocció.

\section{Entrevista 30, barreja II}

FONT 878. Camprodon (el Ripollès)

INGREDIENTS:

Polygala calcarea F.W.Schultz (poligalàcies) - Part aèria florida

Zea mays L. (gramínies) - Estils i estigmes

FORMA FARMACĖUTICA I ÚS. Tisana (ús intern)

EFECTES SECUNDARIS. No consta

DESTINACIÓ MEdî

DESCRIPCIÓ DE L'US

LETA PER L'INFORMANT. Per a fer orinar.

PREPARACIÓ. Decocció.

\section{Entrevista 36}

FONT 854. Sant Pau de Segúries (el Ripollès)

INGREDIENTS:

Asperula cynanchica L. (rubiàcies) - Part aèria florida

Equisetum arvense L. (equisetàcies) - Part aèria estèril

Lithospermum officinale L. (boraginàcies) - Part aèria fructificada

FORMA FARMACËUTICA I ÚS. Tisana (ús intern)

EFECTES SECUNDARIS. No consta

DESTINACIO. Medicina humana

DESCRIPCIÓ DE L'ÚS FETA PER L'INFORMANT. Per a fer orinar.

PREPARACIÓ. Decocció.

\section{Entrevista 43}

FONT 263. Sant Joan de les Abadesses (el Ripollès)

INGREDIENTS:

Arundo donax L. (gramínies) - Arrel

Petroselinum crispum (Mill.) Hill (umbel-líferes) - Arre

Prunus avium (L.) L. (rosàcies) - Peduncle

Zea mays L. (graminies) - Estils i estigmes

FORMA FARMACEUTICA I US. Tisana (ús intern)

EFECTES SECUNDARIS. No consta

DESTINACIO. Medicina humana

DESCRIPCIÓ DE L'ÚS FETA PER L'INFORMANT. T'ajuda a orinar.

Entrevista 45, barreja

FONT 473. Ogassa (el Ripollès)
INGREDIENTS:

Lippia triphylla (L'Hér.) O.Kuntze (labiades) - Part aèria

Polygala calcarea F.W. Schultz (poligalàcies) - Part aèria florida

FORMA FARMACĖUTICA I ÚS. Tisana (ús intern)

EFECTES SECUNDARIS. No consta

ina humana

PREPARACIÓ. Decocció.

Entrevista 45, barreja III

FONT 473. Ogassa (el Ripollès)

INGREDIENTS:

Allium cepa L. (amaril-lidàcies) - Bulb

Bryonia cretica L. subsp. dioica (Jacq.) Tutin (cucurbitàcies) - Arrel

Cucumis sativus L (cucurbitàcies) - Fruit

Cucurbita pepo L. var. oblonga Link (cucurbitàcies) - Fruit

Cucurbita pepo L. Var. Oblonga Link (cucurbitàcies) - Frut

Lippia triphylla (L'Hér.) O.Kuntze (labiades) - Part aèria

Pyrus malus L. subsp. mitis (Wallr.) O.Bolòs et J.Vigo (rosàcies) - Fruit

Santolina chamaecyparissus L. (compostes) - Inflorescència

FORMA FARMACĖUTICA I ÚS. Ungüent (ús extern)

EFECTES SECUNDARIS. No consta

DESTINACIÓ. Medicina humana

DESCRIPCIÓ DE L'ÚS FETA PER L'INFORMANT. Va bé per a la gàstrica [dit "gàstiga"] tifulosa o sigui per a les infeccions del ventre, et fa baixar la infecció, desinflama i et fa orinar. PREPARACIO. Es fa coure tot tallat petit amb greix de porc, es cola amb un drap de fil queda un ungüent. Se n'unta el ventre i s'hi posa un drap a sobre.

\section{Estomacal}

Entrevista 5, barreja I

FONT 873. Camprodon (el Ripollès)

INGREDIENTS:

Citrus limon (L.) Burm. (rutàcies) - Suc del fruit

Oryza sativa L. (gramínies) - Llavo

FORMA FARMACĖUTICA I ÚS. Sense forma farmacèutica (mescla medicamentosa, ús intern)

EFECTES SECUNDARIS. No consta

DESTINACIO. Medicina humana

DESCRIPCIO DE L'US FETA PER L'INFORMANT. Per a netejar l'estómac i els budells, fa baixar la panxa.

PREPARACIÓ. Es fa un suc de llimona amb aigua tèbia i mel i es comença posant-hi un gra d'arròs i es va pujant d'un en un cada dia fins arribar a trenta i llavors es baixa de la mateixa manera.

Expectorant 
Apèndix 2. Catàleg de barreges.

\section{Entrevista 97}

FONT 310. Ogassa (el Ripollès)

INGREDIENTS:

Arnica montana L. subsp. montana (compostes) - Inflorescència

Artemisia absinthium L. (compostes) - Part aèri

FORMA FARMACĖUTICA I ÚS. Loció (ús extern)

EFECTES SECUNDARIS. No consta

DESTINACIÓ. Medicina humana

DESCRIPCIÓ DE L'ÚS FETA PER L'INFORMANT. Et fas fregues quan estàs tapat.

PREPARACIÓ. Es posava en esperit de vi.

\section{Hematocatàrtic}

\section{Entrevista 11, barreja III}

FONT 879. Vilallonga de Ter (el Ripollès)

INGREDIENTS:

Eryngium bourgatii Gouan (umbel-líferes) - Arrel

Tilia platyphyllos Scop. (tiliàcies) - Bràctea i inflorescència

FORMA FARMACĖUTICA I ÚS. Tisana (ús intern)

EFECTES SECUNDARIS. No consta

DESTINACIÓ. Medicina humana

DESCRIPCIÓ DE L'ÚS FETA PER L'INFORMANT. Per a netejar la sang.

PREPARACIÓ. Decocció.

\section{Entrevista 32, barreja III}

FONT 877. Vilallonga de Ter (el Ripollès)

INGREDIENTS:

Allium cepa L. (amaril-lidàcies) - Bulb

Allium sativum $\mathrm{L}$. (amaril-lidàcies) - Bulb

Apium graveolens $L$. (umbel-líferes) - Part aèria

Apium graveolens $\mathrm{L}$. (umbel-líferes) - Part
Carum carvi L. (umbel-líferes) - Llavor

Citrus limon (L.) Burm. (rutàcies) - Fruit

Foeniculum vulgare Mill. (umbel-liferes) - Part aèria

Mentha spicata L. (labiades) - Part aèria

FORMA FARMACĖUTICA I ÚS. Macerat en aigua (ús intern)

EFECTES SECUNDARIS. No consta

DESTINACIÓ. Medicina humana

DESCRIPCIÓ DE L'ÚS FETA PER L'INFORMANT. Per a netejar la sang.

PREPARACIO. Es posen totes les plantes a mullega en aigua la nit abans i l'endemà es beu l'aigua.

OBSERVACIONS. És un remei de la seva mare.

\section{Entrevista 68, barreja II}

FONT 281. Queralbs (el Ripollès)

INGREDIENTS:

\begin{abstract}
Achillea ptarmica L. subsp. pyrenaica (Sibth.
ex

Godr.

Gren.

et Godr.)

Rouy (compostes) - Inflorescència

Meum athamanticum Jacq. subsp. athamanticum (umbel-liferes) - Arrel

Ranunculus parnassifolius $L$. (ranunculàcies) - Planta sencera

FORMA FARMACĖUTICA I ÚS. Tisana (ús intern)

EFECTES SECUNDARIS. No const

DESTINACIÓ. Medicina humana

DESCRIPCIÓ DE L'ÚS FETA PER L'INFORMANT. EI meu pare deia que era una purga per a les sangs.

PREPARACIÓ. Decocció. Posava les herbes en un tupí de terra al foc a terra.

MODE D'UTILITZACIÓ/POSOLOGIA. Es prenia aquesta barreja a la primavera i a la tardor.

S'havia d'esperar una hora abans de menjar.
\end{abstract}

\section{Hemostàtic extern}

\section{Entrevista 56, barreja III}

FONT 271. Vallfogona de Ripollès (el Ripollès)

INGREDIENTS:

Achillea millefolium L. (compostes) - Inflorescència

Agrimonia eupatoria L. (rosàcies) - Part aèria

FORMA FARMACĖUTICA I ÚS. Tisana (ús intern)

EFECTES SECUNDARIS. No consta

DESTINACIÓ. Medicina humana

DESCRIPCIÓ DE L'ÚS FETA PER L'INFORMANT. Per a estroncar les sangs quan tens hemorràgia, per exemple sang al nas, en infusió.

PREPARACIO. Infusió.

\section{Hepatoprotector}

\section{Entrevista 7, barreja I}

FONT 849. Camprodon (el Ripollès)

INGREDIENTS:

Carum carvi L. (umbel líferes) - Llavor

Senecio leucophyllus DC. (compostes) - Part aèria florida

FORMA FARMACĖUTICA I ÚS. Tisana (ús intern)

EFECTES SECUNDARIS. No consta

DESTINACIÓ. Medicina humana

DESCRIPCIÓ DE L'ÚS FETA PER L'INFORMANT. Per a les infeccions de ronyons.

PREPARACIÓ. Decocció.

\section{Hipolipemiant}

\section{Entrevista 34, barreja}

FONT 869. Camprodon (el Ripollès)

INGREDIENTS:

Citrus limon (L.) Burm. (rutàcies) - Suc del fruit 
Apèndix 2. Catàleg de barreges.

Citrus sinensis (L.) Osbeck (rutàcies) - Suc del fruit

FORMA FARMACĖUTICA I ÚS. Sense forma farmacèutica (mescla medicamentosa, ús

intern)

EFECTES SECUNDARIS. No consta

DESTINACIÓ Medicina humana

DESCRIPCIÓ DE L'ÚS FETA PER L'INFORMANT. Evita que tinguis colesterol.

PREPARACIÓ. Suc de taronja amb un raig de llimona.

MODE D'UTILITZACIÓ/POSOLOGIA. Cada matí en dejú.

\section{Hipouricemiant}

Entrevista 28, barreja

FONT 871. Camprodon (el Ripollès)

INGREDIENTS:

Allium sativum L. (amaril·lidàcies) - Bulb

Senecio vulgaris $L$. (compostes) - Part aèria

Sonchus oleraceus $L$. (compostes) - Part aèria

FORMA FARMACĖUTICA I ÚS. Liniment (ús extern)

EFECTES SECUNDARIS. No consta

DESTINACIÓ. No consta

DESCRIPCIÓ DE L'ÚS FETA PER L'INFORMANT. Per al mal de gota.

PREPARACIÓ. Bullir els lletissons en oli amb uns quants xerixells i uns grans d'all.

\section{Laxant}

Entrevista 17, barreja III

FONT 863. Molló (el Ripollès)

INGREDIENTS:

Malva sylvestris L. (malvàcies) - Part aèria florida

Parietaria officinalis L. subsp. judaica (L.) Béguinot (urticàcies) - Part aèria

FORMA FARMACĖUTICA I UUS. Ėnema (ús intern)

EFECTES SECUNDARIS. No consta

DESTINACIÓ. Medicina humana

R L'INFORMANT. Per al bestiar, quan tenia restrenyiment. PREPARACIÓ. Se'n feia aigua per a fer lavatives.

\section{Entrevista 31, barreja II}

FONT 866. Vilallonga de Ter (el Ripollès)

INGREDIENTS:

Centaurium erythraea Rafn subsp. majus (Hoffms. et Link) Laínz (gencianàcies) - Part aèria florida

Pyrus malus L. subsp. mitis (Wallr.) O.Bolòs et J.Vigo (rosàcies) - Fruit

FORMA FARMACĖUTICA I ÚS. Tisana (ús intern)

EFECTES SECUNDARIS. No consta

DESTINACIÓ. Medicina humana

DESCRIPCIÓ DE L'ÚS FETA PER L'INFORMANT. Per a anar de ventre.
PREPARACIÓ. Es fa bullir amb un litre d'aigua, un brot de Santa Margarida amb tres o quatre talls de poma i es deixa nou dies a sol i serena.

MODE D'UTILITZACIÓ/POSOLOGIA. Una tassa en dejú.

OBSERVACIONS. Aquest remei l'hi va dir el seu germà una vegada que tenia molt dolor a la panxa i no podia anar de ventre.

\section{Litotríptic rena}

\section{Entrevista 4, barreja II}

FONT 862. Llanars (el Ripollès)

INGREDIENTS:

Equisetum arvense L. (equisetàcies) - Part aèria estèril

Herniaria glabra L. (cariofil·làcies) - Part aèria

FORMA FARMACĖUTICA I ÚS. Tisana (ús intern)

EFECTES SECUNDARIS. No consta

DESTINACIO. Medicina humana

DESCRIPCIÓ DE L'ÚS FETA PER L'INFORMANT. Per a les pedres.

PREPARACIÓ. Decocció.

\section{Per a l'ictus apoplèctic/cerebra}

\section{Entrevista 30, barreja III}

FONT 878. Camprodon (el Ripollès)

INGREDIENTS:

Lippia triphylla (L'Hér.) O.Kuntze (labiades) - Part aèria

Olea europaea L. subsp. europaea (oleàcies) - Fulla

FORMA FARMACĖUTICA I ÚS. Tisana (ús intern)

EFECTES SECUNDARIS. No consta

DESTINACIO Medicina humana

DESCRIPCIÓ DE L'ÚS FETA PER L'INFORMANT. Per a prevenir les feridures.

PREPARACIÓ. Decocció.

Entrevista 91, barreja

FONT 304. Pardines (el Ripollès)

NGREDIENTS:

Allium sativum $\mathrm{L}$. (amaril·lidàcies) - Bulb

Linum usitatissimum L. subsp. usitatissimum (linàcies) - Llavor

Petroselinum crispum (Mill.) Hill (umbel-líferes) - Part aèria

Piper nigrum L. (piperàcies) - Fruit

FORMA FARMACEUTICA I ÚS. Emplastre (ús extern)

EFECTES SECUNDARIS. No consta

DESTINACIO Medicina humana

DESCRIPCIÓ DE L'ÚS FETA PER L'INFORMANT. Quan tenies un cop de sang.

PREPARACIÓ. Dues llesques de pa torrat i al mig s'hi posava julivert, all, pebre i grana de lli. Es posava a les plantes dels peus.

OBSERVACIONS. D'aquest remei en dèiem mostasses. 
Apèndix 2. Catàleg de barreges.

\section{Per a la irritació}

Entrevista 72, barreja

FONT 285. Planoles (el Ripollès)

Calendula officinalis L. (compostes) - Inflorescència

Hypericum perforatum $\mathrm{L}$. (gutíferes) - Part aèria florida

Petroselinum crispum (Mill.) Hill (umbel-líferes) - Arre

FORMA FARMACEUTICA I ÚS. Liniment (ús extern)

EFECTES SECUNDARIS. No consta

DESTINACIÓ. Medicina humana

DESCRIPCIÓ DE L'ÚS FETA PER L'INFORMANT. És molt bo com a reforçant d'ossos, pe als trencats, per a l'artrosi, per a les picors, per al dolor en general sempre que no hi hagi ferida. L'oncle m'ho va ensenyar a fer, deia que te n'has de posar fins que arriba un moment que el mal l'escup, vol dir que ja estàs curat.

PREPARACIÓ. En una cassola de terra s'hi posa un litre d'oli i s'hi afegeix un grapat d'herba de Sant Joan, un tros de greix de gallina, un tros de cera de mel, tres o quatre arrels de julivert i dos o tres bojacs. Amb el foc molt baix s'espera que bulli i llavors es deixa mtija hora més. Quan es tebi és cola.

\section{Per a la varicel-la}

\section{Entrevista 53, barreja $X$}

FONT 276. Les Llosses (el Ripollès)

INGREDIENTS:

Hieracium pilosella L. (compostes) - No consta

Scabiosa columbaria L. (dipsacàcies) - Part aèria florida

FORMA FARMACĖUTICA I ÚS. Tisana (ús intern)

EFECTES SECUNDARIS. No consta

DESTINACIÓ Medicina humana

DESCRIPCIÓ DE L'ÚS FETA PER L'INFORMANT. Juntament amb carn de serp, se'n feia aigua per a quan tenies la verola borda (varicel·la) o xarampió. PREPARACIÓ. Decocció.

\section{Per a les picades}

\section{Entrevista 28, barreja I}

FONT 871. Camprodon (el Ripollès)

INGREDIENTS:

Allium sativum L. (amaril·lidàcies) - Bulb

Senecio vulgaris $L$. (compostes) - Part aèria

Sonchus oleraceus $L$. (compostes) - Part aèria

FORMA FARMACĖUTICA I ÚS. Liniment (ús extern)

EFECTES SECUNDARIS. No consta

DESTINACIÓ. Medicina humana
DESCRIPCIÓ DE L'ÚS FETA PER L'INFORMANT. Per a picades verinoses, et desapareix la inflor.

PREPARACIÓ. Bullir els lletissons en oli amb uns quants xerixells i uns grans d'all.

\section{Entrevista 53, barreja III}

FONT 276. Les Llosses (el Ripollès)

INGREDIENTS:

Arnica montana L. subsp. montana (compostes) - Inflorescència

Hypericum perforatum L. (gutíferes) - Part aèria florida

FORMA FARMACĖUTICA I ÚS. Embrocació (ús extern)

EFECTES SECUNDARIS. No consta

DESTINACIÓ. Medicina humana

DESCRIPCIO DE L'US FETA PER L'INFORMANT. Per a les picades d'abella.

PREPARACIÓ. Posada en oli i tapada es deixa dos mesos com a mínim, llavors ja es pot fer servir.

\section{Entrevista 63, barreja II}

FONT 277. Queralbs (el Ripollès)

NGREDIENTS:

Medicago sativa L. subsp. sativa (papilionàcies) - Part aèria

Urtica dioica L. (urticàcies) - Part aèria

FORMA FARMACĖUTICA I ÚS. Emplastre (ús extern)

EFECTES SECUNDARIS. No consta

DESTINACIÓ. Medicina humana

DESCRIPCIÓ DE L'ÚS FETA PER L'INFORMANT. Per a desinfectar quan tenies una picada.

PREPARACIO. Trinxades amb cansalada per a fer emplastres.

\section{Entrevista 67, barreja}

FONT 480. Sant Joan de les Abadesses (el Ripollès)

INGREDIENTS:

Alkanna tinctoria Tausch (boraginàcies) - Arrel

Ramonda myconi (L.) Reichenb. (gesneriàcies) - Part aèria

Ruta chalepensis L. (rutàcies) - Part aèria

FORMA FARMACEUTICA I ÚS. Embrocació (ús extern)

EFECTES SECUNDARIS. No consta

DESTINACIO. Medicina humana

DESCRIPCIÓ DE L'ÚS FETA PER L'INFORMANT. Va bé per a les picades.

PREPARACIÓ. S'ha de bullir les plantes en oli.

\section{Per a trastorns de la pell o del teixit subcutani}

Entrevista 77, barreja

FONT 290. Pardines (el Ripollès)

INGREDIENTS:

Allium cepa L. (amaril-lidàcies) - Bulb

Petroselinum crispum (Mill.) Hill (umbel-liferes) - Arre 
Apèndix 2. Catàleg de barreges.

FORMA FARMACĖUTICA I ÚS. Embrocació (ús extern)

EFECTES SECUNDARIS. No consta

DESTINACIO Medicina humana

DESCRIPCIÓ DE L'ÚS FETA PER L'INFORMANT. Va bé per a mals de la pell, nafres que et surten quan et fas gran

En una cassola de terra s'hi posen els alls (tres, cinc o set) i les rels de julivert (tres arrels) i es deixen bullir en oli, quan són rossos ho treus del foc i hi afegeixes cera verge de buc.

\section{Per a trastorns del sistema musculoesquelètic}

Entrevista 61, barreja I

FONT 275. Pardines (el Ripollès)

INGREDIENTS:
Achillea ptarmica L. subsp. pyrenaica (Sibth.
escència

Allium sativum $\mathrm{L}$. (amaril-lidàcies) - Bulb

Geranium robertianum $L$. (geraniàcies) - Part aèria jove

Pinus sylvestris $L$. (pinàcies) - Part aèria jove

Ruta chalepensis $L$. (rutàcies) - Part aè

Zea mays L. (gramínies) - No consta

FORMA FARMACĖUTICA I ÚS. Ungüent (ús extern)

EFECTES SECUNDARIS. No consta

DESTINACIÓ. Medicina humana

DESCRIPCIÓ DE L'ÚS FETA PER L'INFORMANT. Per a curar un esperó de la sola del peu.

PREPARACIÓ. Es fa un ungüent. Es posa en una cassola de terra mig litre d'oli i sagí ranci fins que es fongui, llavors s'hi afegeixen totes les herbes i s'hi fan bullir. Després es cola i es pot posar en un pot de vidre. S'utilitzen tres grans d'all.

\section{Per al lipoma}

Entrevista 75, barreja I

FONT 288. Ribes de Freser (el Ripollès)

INGREDIENTS:

Geranium robertianum $\mathrm{L}$. (geraniàcies) - Part aèria

Petroselinum crispum (Mill.) Hill (umbel-liferes) - Arre

FORMA FARMACEUUTICA I ÚS. Ungüent (ús extern)

EFECTES SECUNDARIS. No consta

DESTINACIO. Medicina humana

DESCRIPCIÓ DE L'ÚS FETA PER L'INFORMANT. A la Mercè la seva mare li va curar un quist [dit "quiste"] que tenia a la mà.

PREPARACIÓ. Bullir les herbes en greix de gallina i oli d'oliva.

Per al malestar / Per a la fatiga

Entrevista 11, barreja I
FONT 879. Vilallonga de Ter (el Ripollès)

INGREDIENTS:

Arnica montana L. subsp. montana (compostes) - Inflorescència

Thymus vulgaris $\mathrm{L}$. (labiades) - Part aèria florida

Tilia platyphyllos Scop. (tiliàcies) - Bràctea i inflorescència

FORMA FARMACEUTICA IUS. Tisana (ús intern)

EFECTES SECUNDARIS. No consta

DESTINACIO. Medicina humana

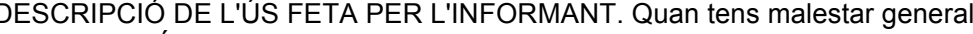

PREPARACIÓ. Fer bullir les tres herbes.

Per al panadís

\section{Entrevista 61, barreja II}

FONT 275. Pardines (el Ripollès)

INGREDIENTS:

Allium sativum $\mathrm{L}$. (amaril-lidàcies) - Bulb

Petroselinum crispum (Mill.) Hill (umbel-líferes) - Arrel

Piper nigrum L. (piperàcies) - Fruit

Senecio vulgaris $L$. (compostes) - Part aèria

Vitis vinifera $L$. (vitàcies) - Suc del fruit

FORMA FARMACĖUTICA I ÚS. Emplastre (ús extern)

EFECTES SECUNDARIS. No consta

DESTINACIÓ. Medicina humana

DESCRIPCIÓ DE L'ÚS FETA PER L'INFORMANT. Per a curar les espitlles.

REPARACIO. Es piquen les plantes barrejades, es torra ben torrat al foc $\mathrm{i}$ es fa un pegat,

ha de ser una manxiula molt forta.

\section{Entrevista 89, barreja II}

FONT 302. Toses (el Ripollès)

INGREDIENTS:

Allium sativum L. (amaril-lidàcies) - Bulb

Pinus sylvestris $L$. (pinàcies) - No consta

Piper nigrum L. (piperàcies) - Fruit

FORMA FARMACEUTICA I ÚS. Embrocació (ús extern)

EFECTES SECUNDARIS. No consta

DESTINACIÓ. Medicina veterinària

DESCRIPCIÓ DE L'ÚS FETA PER L'INFORMANT. Es feia servir per a les espitlles de les ovelles, les feia rebentar i feia sortir el pus de dintre.

PREPARACIO. Es bullia amb una mica d'oli.

\section{Per al xarampió}

\section{Entrevista 53, barreja $X$}

FONT 276. Les Llosses (el Ripollès)

INGREDIENTS: 
Apèndix 2. Catàleg de barreges.

Hieracium pilosella L. (compostes) - No consta

Scabiosa columbaria L. (dipsacàcies) - Part aèria florida

FORMA FARMACĖUTICA I ÚS. Tisana (ús intern)

EFECTES SECUNDARIS. No consta

DESTINACIÓ. Med

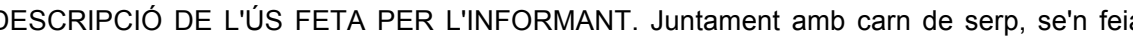
aigua per a quan tenies la verola borda (varicel·la) o xarampió.

PREPARACIÓ. Decocció.

\section{Per als esquinços}

\section{Entrevista 72, barreja I}

FONT 285. Planoles (el Ripollès)

INGREDIENTS:

Calendula officinalis L. (compostes) - Inflorescència

Hypericum perforatum $L$. (gutíferes) - Part aèria florida

Petroselinum crispum (Mill.) Hill (umbel-líferes) - Arrel

PORMA FARMACEUTICA I ÚS. Liniment (ús extern)

EFECTES SECUNDARIS. No consta

DESTINACIÓ. Medicina humana

DESCRIPCIÓ DE L'ÚS FETA PER L'INFORMANT. És molt bo com a reforçant d'ossos, pe als trencats, per a l'artrosi, per a les picors, per al dolor en general sempre que no hi hag ferida. L'oncle m'ho va ensenyar a fer, deia que te n'has de posar fins que arriba un moment que el mal l'escup, vol dir que ja estàs curat.

PREPARACIÓ. En una cassola de terra s'hi posa un litre d'oli i s'hi afegeix un grapat d'herba de Sant Joan, un tros de greix de gallina, un tros de cera de mel, tres o quatre arrels de julivert i dos o tres bojacs. Amb el foc molt baix s'espera que bulli i llavors es deixa mtija hora més. Quan es tebi és cola.

\section{Protector renal}

Entrevista 4, barreja II

FONT 862. Llanars (el Ripollès)

Equisetum arvense L. (equisetàcies) - Part aèria estèril

Herniaria glabra L. (cariofil·àcies) - Part aèria

FORMA FARMACĖUTICA I ÚS. Tisana (ús intern)

EFECTES SECUNDARIS. No consta

DESTINACIO. Medicina humana

DESCRIPCIO DE L'US FETA PER L'INFORMANT. Per als ronyons.

PREPARACIO. Decocció.

\section{Purgant}

Entrevista 22, barreja I

FONT 883. Llanars (el Ripollès)

\section{INGREDIENTS:}

Malva sylvestris L. (malvàcies) - Part aèria

Umbilicus rupestris (Salisb.) Dandy (crassulàcies) - Part aèria

FORMA FARMACĖUTICA I ÚS. Tisana (ús intern)

EFECTES SECUNDARIS. No consta

DESTINACIÓ Medicina veterinària

DESCRIPCIÓ DE L'ÚS FETA PER L'INFORMANT. Se'ls feia prendre als pollins quan necessitaven una purga.

PREPARACIÓ. Decocció

\section{Reforçant ossi}

\section{Entrevista 72, barreja}

FONT 285. Planoles (el Ripollès)

INGREDIENTS:

Calendula officinalis $\mathrm{L}$. (compostes) - Inflorescència

Hypericum perforatum $\mathrm{L}$. (gutíferes) - Part aèria florida

Petroselinum crispum (Mill.) Hill (umbel-líferes) - Arrel

FORMA FARMACEUTICA I ÚS. Liniment (ús extern)

EFECTES SECUNDARIS. No consta

DESTINACIO. Medicina humana

DESCRIPCIÓ DE L'ÚS FETA PER L'INFORMANT. És molt bo com a reforçant d'ossos, per als trencats, per a l'artrosi, per a les picors, per al dolor en general sempre que no hi hag ferida. L'oncle m'ho va ensenyar a fer, deia que te n'has de posar fins que arriba un moment que el mal l'escup, vol dir que ja estàs curat.

PREPARACIO. En una cassola de terra s'hi posa un litre d'oli i s'hi afegeix un grapat d'herba de Sant Joan, un tros de greix de gallina, un tros de cera de mel, tres o quatre arrels de julivert i dos o tres bojacs. Amb el foc molt baix s'espera que bulli i llavors es deixa mtija hora més. Quan es tebi és cola.

\section{Entrevista 102, barreja III}

FONT 788. Queralbs (el Ripollès)

NGREDIENTS:

Citrus limon (L.) Burm. (rutàcies) - Suc del fruit

Thymus vulgaris $L$. (labiades) - Part aèria florida

FORMA FARMACĖUTICA I ÚS. Xarop (ús intern)

EFECTES SECUNDARIS. No consta

DESTINACIO. Medicina humana

DESCRIPCIO DE L'ÚS FETA PER L'INFORMANT. Va molt bé per a reforçar els ossos, sobretot després d'alguna fractura.

PREPARACIO. Preparar en un bol tres ous del dia ben deixatats i una branqueta de farigola cobrir-los de suc de llimona i deixar-ho dos o tres dies, llavors afegir-hi un quilo de sucre i mig litre de vi de missa o moscatell. Deixar-ho tres dies a sol i serena.

MODE D'UTILITZACIÓ/POSOLLGIA. Prendre'n tres cops al dia.

Resolutiu 
Apèndix 2. Catàleg de barreges.

\section{Entrevista 8, barreja II
FONT 853. Camprodon (el Ripollès)}

INGREDIENTS:

Althaea officinalis L. (malvàcies) - Arrel

Allium sativum $L$. (amaril-lidàcies) - Bulb

Bryonia cretica L. subsp. dioica (Jacq.) Tutin (cucurbitàcies) - Arrel

Lilium pyrenaicum Gouan (liliàcies) - Bulb

Petroselinum crispum (Mill.) Hill (umbel'líferes) - Arre

Ruta chalepensis L. (rutàcies) - Part aèria

Sedum dasyphyllum $\mathrm{L}$. (crassulàcies) - Part aèria

Umbilicus rupestris (Salisb.) Dandy (crassulàcies) - Part aèria

FORMA FARMACËUTICA I US. Embrocació (ús extern)

EFECTES SECUNDARIS. No consta

DESTINACIÓ Medicina humana

DESCRIPCIÓ DE L'ÚS FETA PER L'INFORMANT. S'utilitzava per a ferides, infeccions

grans.

PREPARACIÓ. Es posaven totes aquestes plantes en un tupí de terra a bullir en oli bo d'amanir, llavors es colava.

\section{Entrevista 61, barreja III}

FONT 275. Pardines (el Ripollès)

INGREDIENTS:

Linum usitatissimum L. subsp. usitatissimum (linàcies) - Llavor

Rubus caesius L. (rosàcies) - Arrel

FORMA FARMACËUTICA I ÚS. Emplastre (ús extern)

EFECTES SECUNDARIS. No consta

DESTINACIÓ. Medicina humana

DESCRIPCIÓ DE L'ÚS FETA PER L'INFORMANT. Es feien emplastres per a curar els furóncols i els vespers que et surten quan tens la sang bruta i la rel de romegueró és un purificant de la sang.

\section{Entrevista 78, barreja IV}

FONT 291. Planoles (el Ripollès)

INGREDIENTS:

Alkanna tinctoria Tausch (boraginàcies) - Arre

Salvia verbenaca $L$. (labiades) - Fulla

Sempervivum tectorum $L$. (crassulàcies) - Part aèria

Taxus baccata $\mathrm{L}$. (taxàcies) - Parènquima cortical

FORMA FARMACEUTICA I ÚS. Ungüent (ús extern)

EFECTES SECUNDARIS. No consta

DESTINACIO. Medicina humana

DESCRIPCIÓ DE L'ÚS FETA PER L'INFORMANT. Va molt bé per a llagues i cremades.

PREPARACIÓ. Es posen les plantes amb meitat greix i meitat cansalada i es fa coure tot plegat. Queda una pomada de color rosa.

\section{Entrevista 101}

FONT 314. Llanars (el Ripollès)

INGREDIENTS:

Nicotiana tabacum L. (solanàcies) - Fulla

Verbena officinalis $L$. (verbenàcies) - Part aèria florida

FORMA FARMACĖUTICA I ÚS. Emplastre (ús extern)

EFECTES SECUNDARIS. No consta

DESTINACIO. Medicina humana

DESCRIPCIO DE L'US FETA PER L'INFORMANT. Per a estirar els mals cap enfora.

PREPARACIÓ. Es picava la berbena junt amb el tabac negre, es fregia amb oli o greix de la mocada del porc i es preparaven emplastres al mig de draps blancs.

\section{Restauratiu}

\section{Entrevista 47, barreja I}

FONT 265. Sant Joan de les Abadesses (el Ripollès)

INGREDIENTS:

Cucurbita pepo L. var. pepo (cucurbitàcies) - Fruit

Olea europaea L. subsp. europaea (oleàcies) - Suc del fruit

Solanum tuberosum $L$. (solanàcies) - Tubercle

Triticum aestivum L. (gramínies) - Llavor

FORMA FARMACĖUTICA I ÚS. Suspensió (ús intern)

EFECTES SECUNDARIS. No consta

DESTINACIÓ. Medicina veterinària

DESCRIPCIO DE L'US FETA PER L'INFORMANT. Per a les truges quan són malaltes.

PREPARACIÓ. Sopa a base de carbassa, patata, pa, cansalada i un bon raig d'oli.

\section{Salutífer}

\section{Entrevista 7, barreja II}

FONT 849. Camprodon (el Ripollès)

INGREDIENTS:

Ramonda myconi (L.) Reichenb. (gesneriàcies) - Part aèria

Senecio leucophyllus DC. (compostes) - Part aèria florida

Thymus vulgaris $L$. (labiades) - Part aèria florida

FORMA FARMACĖUTICA I ÚS. Tisana (ús intern)

EFECTES SECUNDARIS. No consta

DESTINACIÓ. Medicina humana

DESCRIPCIÓ DE L'ÚS FETA PER L'INFORMANT. Per a la prevenció dels refredats. PREPARACIO. Decocció.

MODE D'UTILITZACIÓ/POSOLOGIA. S'ho prenia durant dos o tres mesos, en dejú. OBSERVACIONS. Així no es refredava de tot l'hivern.

\section{Entrevista 23, barreja III}

FONT 885. Vilallonga de Ter (el Ripollès)

INGREDIENTS: 
Apèndix 2. Catàleg de barreges.

Crataegus monogyna Jacq. subsp. monogyna (rosàcies) - Flor

Lippia triphylla (L'Hér.) O.Kuntze (labiades) - Part aèria

Satureja calamintha (L.) Scheele subsp. ascendens (Jord.) Briq. (labiades) - Part aèria florida

Thymus vulgaris $L$. (labiades) - Part aèria florida

FORMA FARMACĖUTICA I ÚS. Tisana (ús intern)

EFECTES SECUNDARIS. No consta

DESTINACIO. Medicina humana

DESCRIPCIO DE LUUS FETA PER L'INFORMANT. Beu aquesta barreja al matí, en lloc de beure aigua sola, i va canviant les plantes.

PREPARACIO. Decocció.

\section{Entrevista 67, barreja VII}

FONT 480. Sant Joan de les Abadesses (el Ripollès)

INGREDIENTS:

Achillea millefolium L. (compostes) - Inflorescència

Hypericum perforatum $L$. (gutíferes) - Part aèria florida

FORMA FARMACĖUTICA I ÚS. Tisana (ús intern)

EFECTES SECUNDARIS. No consta

DESTINACIÓ. Medicina humana

DESCRIPCIO DE L'ÚS FETA PER L'INFORMANT. Equilibra el cos.

PREPARACIÓ. Decocció.

MODE D'UTILITZACIÓ/POSOLOGIA. Se'n pren un gotet.

\section{Entrevista 72, barreja III}

FONT 285. Planoles (el Ripollès)

INGREDIENTS:

Allium cepa L. (amaril-lidàcies) - Bulb

Citrus limon (L.) Burm. (rutàcies) - Suc del fruit

FORMA FARMACĖUTICA I ÚS. Tisana (ús intern)

EFECTES SECUNDARIS. No consta

DESTINACIÓ Medicina humana

DESCRIPCIÓ DE L'ÚS FETA PER L'INFORMANT. Neteja el cos, és depuratiu, també diuen que és bo per al cor.

PREPARACIÓ. Fer bullir una ceba i llavors agafar l'aigua que fa i afegir-hi el suc d'una llimona.

MODE D'UTILITZACIÓ/POSOLOGIA. Prendre-s'ho en dejú.

Entrevista 78, barreja V

FONT 291. Planoles (el Ripollès)

INGREDIENTS:

Matricaria chamomilla L. (compostes) - Inflorescència

Polygala calcarea F.W.Schultz (poligalàcies) - Part aèria florida

Sambucus nigra L. (adoxàcies) - Inflorescència

FORMA FARMACEUUTICA I ÚS. Tisana (ús intern)

EFECTES SECUNDARIS. No consta
DESTINACIÓ. Medicina humana

DESCRIPCIÓ DE L'ÚS FETA PER L'INFORMANT. Per a beure cada dia.

PREPARACIÓ. Decocció.

\section{Tranquil·litzant}

\section{Entrevista 5, barreja IV}

FONT 873. Camprodon (el Ripollès)

INGREDIENTS:

Hypericum perforatum L. (gutíferes) - Part aèria florida

Melissa officinalis L. (labiades) - Part aèria

Tilia platyphyllos Scop. (tiliàcies) - Bràctea i inflorescència

Valeriana officinalis L. (caprifoliàcies) - Arrel

FORMA FARMACĖUTICA I ÚS. Tisana (ús intern)

EFECTES SECUNDARIS. No consta

DESTINACIÓ Medicina humana

DESCRIPCIÓ DE L'ÚS FETA PER L'INFORMANT. Per als nervis.

PREPARACIÓ. En infusió.

Entrevista 6, barreja II

FONT 847. Camprodon (el Ripollès)

INGREDIENTS:

Lippia triphylla (L'Hér.) O.Kuntze (labiades) - Part aèria

Salvia officinalis $L$. (labiades) - Part aèria

Santolina chamaecyparissus L. (compostes) - Inflorescència

FORMA FARMACEUTICA I ÚS. Tisana (ús intern)

EFECTES SECUNDARIS. No consta

DESTINACIO. Medicina humana

DESCRIPCIÓ DE L'ÚS FETA PER L'INFORMANT. Diu que tranquil.litza i deixa el cos content.

Entrevista 32, barreja V

FONT 877. Vilallonga de Ter (el Ripollès)

INGREDIENTS:

Achillea ptarmica L. subsp. pyrenaica (Sibth. ex Godr. in Gren. et Godr.)

Rouy (compostes) - Inflorescència

Mentha spicata L. (labiades) - Part aèria

Tilia platyphyllos Scop. (tiliàcies) - Bràctea i inflorescència

Verbena officinalis $L$. (verbenàcies) - Part aèria florida

FORMA FARMACEUTICA I US. Tisana (ús intern)

EFECTES SECUNDARIS. No consta

DESTINACIO. Medicina humana

DESCRIPCIO DE L'US FETA PER L'INFORMANT. Quan estàs nerviós.

PREPARACIÓ. En infusió.

OBSERVACIONS. En diuen infusió de la felicitat. 
Apèndix 2. Catàleg de barreges.

Entrevista 67, barreja VIII

FONT 480. Sant Joan de les Abadesses (el Ripollès)

INGREDIENTS:

Antennaria dioica (L.) Gaertn. (compostes) - No consta

Satureja calamintha (L.) Scheele subsp. ascendens (Jord.) Briq. (labiades) - Part aèria

FORMA FARMACĖUTICA I ÚS. Tisana (ús intern)

EFECTES SECUNDARIS. No consta

DESTINACIÓ. Medicina humana

DESCRIPCIÓ DE L'ÚS FETA PER L'INFORMANT. Aigua per als nervis, per a tranquil-litzar. PREPARACIO. Decocció.

\section{Entrevista 84, barreja II}

FONT 297. Camprodon (el Ripollès)

INGREDIENTS:

Melissa officinalis L. (labiades) - Part aèria

Tilia platyphyllos Scop. (tiliàcies) - Bràctea i inflorescència

Valeriana officinalis L. (caprifoliàcies) - Arre

FORMA FARMACEUTICA I ÚS. Tisana (ús intern)

EFECTES SECUNDARIS. No cons

DESTINACIO. Medicina humana

DESCRIPCIO DE L'US FETA PER L'INFORMANT. És una aigua molt relaxant.

PREPARACIÓ. Decocció.

Vasotònic

Entrevista 5, barreja III

FONT 873. Camprodon (el Ripollès)

INGREDIENTS:

Arctium minus Bernh. (compostes) - Arrel

Melissa officinalis L. (labiades) - Part aèria

Urtica dioica L. (urticàcies) - Part aèria

FORMA FARMACĖUTICA I ÚS. Tisana (ús intern)

EFECTES SECUNDARIS. No consta

DESTINACIO. Medicina humana

DESCRIPCIO DE L'US FETA PER L'INFORMANT. Per a la circulació.

PREPARACIÓ. En infusió.

MODE D'UTILITZACIÓ/POSOLOGIA. En cicles de 15 dies.

Entrevista 77, barreja III

FONT 290. Pardines (el Ripollès)

INGREDIENTS:

Plantago lanceolata L. (plantaginàcies) - Fulla

Prunus avium (L.) L. (rosàcies) - Parènquima cortical

Sambucus nigra L. (adoxàcies) - Parènquima cortical

Sedum album $\mathrm{L}$. (crassulàcies) - Part aèria
Vitis vinifera L. (vitàcies) - Suc del fruit

FORMA FARMACĖUTICA I ÚS. Liniment (ús extern)

EFECTES SECUNDARIS. No consta

DESTINACIÓ. Medicina humana

DESCRIPCIÓ DE L'ÚS FETA PER L'INFORMANT. Per a la circulació de la sang, la gangrena [dit "cangrena"] i els fongs dels peus.

PREPARACIÓ. Es bullen totes les herbes en dos gots d'oli, en una cassola de terra fins que es redueix a la meitat, es cola $\mathrm{i}$ ja ho tens a punt.

\section{Vulnerari}

Entrevista 2, barreja I

FONT 846. Camprodon (el Ripollès)

INGREDIENTS:

Cucurbita pepo L. var. pepo (cucurbitàcies) - Flor

Ruta chalepensis L. (rutàcies) - Part aèria

FORMA FARMACĖUTICA I ÚS. Pomada (ús extern)

EFECTES SECUNDARIS. No consta

DESTINACIÓ. Medicina humana

DESCRIPCIÓ DE L'ÚS FETA PER L'INFORMANT. La fa servir per a ferides, morenes, i diu

que va bé per a moltes coses. PREPARACIO. Es fa una pomada amb la flor de carabassa i la ruda picades i fregides amb greix de porc i llavors es cola.

Entrevista 8, barreja II

FONT 853. Camprodon (el Ripollès)

INGREDIENTS:

Althaea officinalis L. (malvàcies) - Arrel

Allium sativum L (amaril.lidàcies) - Bulb

Bryonia cretica L. subsp. dioica (Jacq.) Tutin (cucurbitàcies) - Arrel

Petroselinum crispum (Mill.) Hill (umbel-liferes) - Arrel

Ruta chalepensis L. (rutàcies) - Part aèria

Sedum dasyphyllum $L$. (crassulàcies) - Part aèria

Umbilicus rupestris (Salisb.) Dandy (crassulàcies) - Part aèria

FORMA FARMACEUTICA I US. Embrocació (ús extern)

EFECTES SECUNDARIS. No consta

DESTINACIO. Medicina humana

DESCRIPCIO DE L'US FETA PER L'INFORMANT. S'utilitzava per a ferides, infeccions grans.

PREPARACIÓ. Es posaven totes aquestes plantes en un tupí de terra a bullir en oli bo d'amanir, llavors es colava.

Entrevista 21, barreja III

FONT 865. Setcases (el Ripollès)

INGREDIENTS: 
Apèndix 2. Catàleg de barreges.

Fraxinus excelsior $\mathrm{L}$. (oleàcies) - Parènquima cortical

Quercus petraea (Matt.) Liebl. (fagàcies) - Parènquima cortical

FORMA FARMACEUTICA I ÚS. Bany (ús extern)

EFECTES SECUNDARIS. No consta

DESTINACIÓ. Medicina veterinària

DESCRIPCIÓ DE L'ÚS FETA PER L'INFORMANT. Per als talls del bestiar o els punts de les

vaques quan els havien fet cesària.

\section{Entrevista 31, barreja IV}

FONT 866. Vilallonga de Ter (el Ripollès)

INGREDIENTS:

Allium sativum L. (amaril·lidàcies) - Bulb

Bryonia cretica L. subsp. dioica (Jacq.) Tutin (cucurbitàcies) - Arrel

Fraxinus excelsior L. (oleàcies) - Parènquima cortical

Petroselinum crispum (Mill.) Hill (umbel-liferes) - Arrel

Ruta chalepensis L. (rutàcies) - Part aèria

FORMA FARMACE்UTICA I ÚS. Embrocació (ús extern)

FORMA FARMACEUTICA ÚS. EmbToct

DESTINACIÓ. Medicina humana

DESCRIPCIÓ DE L'ÚS FETA PER L'INFORMANT. S'utilitzava per a ferides, infeccions i per a curar mals externs.

PREPARACIÓ. En un tupí de terra es fan bullir aquestes herbes en oli.

Entrevista 89, barreja III

FONT 302. Toses (el Ripollès)

INGREDIENTS:

Allium sativum L. (amaril-lidàcies) - Bulb

Geranium robertianum $\mathrm{L}$. (geraniàcies) - Part aèria

Valeriana officinalis L. (caprifoliàcies) - Arrel

FORMA FARMACĖUTICA I ÚS. Embrocació (ús extern)

EFECTES SECUNDARIS. No consta

DESTINACIÓ. Medicina humana

DESCRIPCIÓ DE L'ÚS FETA PER L'INFORMANT. Servia per a curar mals, talls i ferides.

PREPARACIÓ. Es bullien en oli.

\section{Entrevista 94, barreja II}

FONT 307. Campdevànol (el Ripollès)

INGREDIENTS:

Allium sativum L. (amaril-lidàcies) - Bulb

Olea europaea L. subsp. europaea (oleàcies) - Suc del fruit

FORMA FARMACĖUTICA I ÚS. Emplastre (ús extern)

EFECTES SECUNDARIS. No consta

DESTINACIO Medicina veterinària

DESCRIPCIÓ DE L'ÚS FETA PER L'INFORMANT. Per a les fístules del bestiar, de seguida

fa rebentar el mal i fa sortir la porqueria.

PREPARACIÓ. Fer un allioli negat amb cabeça d'alls i anar-hi afegint oli. 
Apèndix 3. Nombres de reports d'ús i tàxons de les famílies botàniques.

\begin{tabular}{|c|c|c|}
\hline Família & Nombre de reports d'ús & Nombre de tàxons \\
\hline ACERÀCIES & 6 & 3 \\
\hline ADOXÀCIES & 139 & 2 \\
\hline AGARICÀCIES & 11 & 1 \\
\hline AMARANTÀCIES & 8 & 1 \\
\hline AMARIL·LIDÀCIES & 102 & 6 \\
\hline ANACARDIÀCIES & 7 & 1 \\
\hline APOCINÀCIES & 15 & 2 \\
\hline AQUIFOLIÀCIES & 4 & 1 \\
\hline ARÀCIES & 13 & 2 \\
\hline ARALIÀCIES & 18 & 1 \\
\hline ARISTOLOQUIÀCIES & 1 & 1 \\
\hline ASCLEPIADÀCIES & 1 & 1 \\
\hline ASPARAGÀCIES & 9 & 3 \\
\hline BERBERIDÀCIES & 1 & 1 \\
\hline BETULÀCIES & 28 & 3 \\
\hline BORAGINÀCIES & 66 & 7 \\
\hline BUXÀCIES & 41 & 1 \\
\hline CACTÀCIES & 1 & 1 \\
\hline CAMPANULÀCIES & 3 & 2 \\
\hline CANNABÀCIES & 28 & 2 \\
\hline CAPPARÀCIES & 1 & 1 \\
\hline CAPRIFOLIÀCIES & 63 & 6 \\
\hline CARIOFIL·LÀCIES & 123 & 14 \\
\hline CISTÀCIES & 7 & 2 \\
\hline COMPOSTES & 1176 & 52 \\
\hline CONVOLVULÀCIES & 17 & 2 \\
\hline CORIARIÀCIES & 6 & 1 \\
\hline CRASSULÀCIES & 84 & 8 \\
\hline CRUCÍFERES & 82 & 13 \\
\hline CUCURBITÀCIES & 62 & 5 \\
\hline CUPRESSÀCIES & 36 & 3 \\
\hline DIOSCOREÀCIES & 1 & 1 \\
\hline DIPSACÀCIES & 46 & 2 \\
\hline EQUISETÀCIES & 74 & 1 \\
\hline ERICÀCIES & 39 & 6 \\
\hline ESCROFULARIÀCIES & 57 & 7 \\
\hline EUFORBIÀCIES & 27 & 5 \\
\hline FAGÀCIES & 56 & 4 \\
\hline GENCIANÀCIES & 149 & 3 \\
\hline GERANIÀCIES & 28 & 1 \\
\hline GESNERIÀCIES & 74 & 1 \\
\hline GINKGOÀCIES & 2 & 1 \\
\hline
\end{tabular}




\begin{tabular}{|c|c|c|}
\hline GLOBULARIÀCIES & 7 & 3 \\
\hline GRAMÍNIES & 135 & 15 \\
\hline GUTÍFERES & 155 & 2 \\
\hline HIDRANGEÀCIES & 6 & 2 \\
\hline HIPOCASTANÀCIES & 6 & 1 \\
\hline IRIDÀCIES & 15 & 3 \\
\hline JUGLANDÀCIES & 49 & 1 \\
\hline JUNCÀCIES & 3 & 1 \\
\hline LABIADES & 819 & 32 \\
\hline LAURÀCIES & 51 & 2 \\
\hline LILIÀCIES & 157 & 10 \\
\hline LINÀCIES & 30 & 3 \\
\hline LITRÀCIES & 8 & 1 \\
\hline MALVÀCIES & 114 & 4 \\
\hline MIRISTICÀCIES & 3 & 1 \\
\hline MIRTÀCIES & 26 & 2 \\
\hline MONIMIÀCIES & 2 & 1 \\
\hline MORÀCIES & 14 & 2 \\
\hline NICTAGINÀCIES & 2 & 1 \\
\hline OFIOGLOSSÀCIES & 4 & 1 \\
\hline OLEÀCIES & 120 & 5 \\
\hline OXALIDÀCIES & 2 & 1 \\
\hline PAPAVERÀCIES & 82 & 5 \\
\hline PAPILIONÀCIES & 250 & 26 \\
\hline PINÀCIES & 96 & 4 \\
\hline PIPERÀCIES & 10 & 1 \\
\hline PIROLÀCIES & 1 & 1 \\
\hline PLANTAGINÀCIES & 73 & 7 \\
\hline PLATANÀCIES & 4 & 1 \\
\hline POLIGALÀCIES & 82 & 2 \\
\hline POLIGONÀCIES & 54 & 6 \\
\hline POLIPODIÀCIES & 42 & 6 \\
\hline PORTULACÀCIES & 10 & 1 \\
\hline PRIMULÀCIES & 11 & 1 \\
\hline QUENOPODIÀCIES & 34 & 5 \\
\hline RAMNÀCIES & 2 & 2 \\
\hline RANUNCULÀCIES & 260 & 14 \\
\hline ROSÀCIES & 480 & 35 \\
\hline RUBIÀCIES & 93 & 5 \\
\hline RUTÀCIES & 142 & 3 \\
\hline SALICÀCIES & 14 & 5 \\
\hline SANTALÀCIES & 17 & 1 \\
\hline SAXIFRAGÀCIES & 58 & 5 \\
\hline SOLANÀCIES & 66 & 11 \\
\hline TAXÀCIES & 16 & 1 \\
\hline
\end{tabular}




\begin{tabular}{|l|c|c|}
\hline TIFÀCIES & 1 & 1 \\
\hline TILIÀCIES & 123 & 1 \\
\hline TIMELEÀCIES & 8 & 2 \\
\hline TROPEOLÀCIES & 2 & 1 \\
\hline ULMÀCIES & 13 & 1 \\
\hline UMBEL·LÍFERES & 425 & 18 \\
\hline UROCISTIDÀCIES & 1 & 4 \\
\hline URTICÀCIES & 171 & 1 \\
\hline VERBENÀCIES & 50 & 2 \\
\hline VIOLÀCIES & 7 & 1 \\
\hline VITÀCIES & 51 & 1 \\
\hline XANTORREÀCIES & 3 & \\
\hline
\end{tabular}

